\title{
Le droit maritime international et le transport des hydrocarbures
}

Citation for published version (APA):

Dakouri, J-C. (2011). Le droit maritime international et le transport des hydrocarbures. [Doctoral Thesis, Maastricht University]. Universitaire Pers Maastricht. https://doi.org/10.26481/dis.20111219jd

Document status and date:

Published: 01/01/2011

DOI:

10.26481/dis.20111219jd

Document Version:

Publisher's PDF, also known as Version of record

\section{Please check the document version of this publication:}

- A submitted manuscript is the version of the article upon submission and before peer-review. There can be important differences between the submitted version and the official published version of record.

People interested in the research are advised to contact the author for the final version of the publication, or visit the DOI to the publisher's website.

- The final author version and the galley proof are versions of the publication after peer review.

- The final published version features the final layout of the paper including the volume, issue and page numbers.

Link to publication

\footnotetext{
General rights rights.

- You may freely distribute the URL identifying the publication in the public portal. please follow below link for the End User Agreement:

www.umlib.nl/taverne-license

Take down policy

If you believe that this document breaches copyright please contact us at:

repository@maastrichtuniversity.nl

providing details and we will investigate your claim.
}

Copyright and moral rights for the publications made accessible in the public portal are retained by the authors and/or other copyright owners and it is a condition of accessing publications that users recognise and abide by the legal requirements associated with these

- Users may download and print one copy of any publication from the public portal for the purpose of private study or research.

- You may not further distribute the material or use it for any profit-making activity or commercial gain

If the publication is distributed under the terms of Article $25 \mathrm{fa}$ of the Dutch Copyright Act, indicated by the "Taverne" license above, 


\section{LE DROIT MARITIME INTERNATIONAL ET LE TRANSPORT DES HYDROCARBURES}


(c) Copyright Jean-Claude Dakouri, Maastricht 2011 ISBN 978-94-6159-115-9

Production: Datawyse bv | Universitaire Pers Maastricht 


\section{LE DROIT MARITIME INTERNATIONAL ET LE TRANSPORT DES HYDROCARBURES}

\section{DISSERTATION}

To obtain the degree of Doctor at Maastricht University, on the authority of the Rector Magnificus, Prof. dr. G.P.M.F Mols in accordance with the decision of the Board of Deans, to be defended in public on Monday 19th December 2011 at 10.00 hours

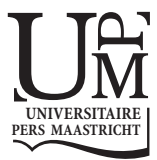




\section{Supervisor}

Prof. dr. Michael G. Faure LL.M.

\section{Assessment Committee}

Prof. mr. C.A. Schwarz (chairman)

Prof. dr. M.G.W.M. Peeters

Prof. mr. F.A.M. Stroink

Dr. Yves-Didier Tiebley 


\section{SOMMAIRE}

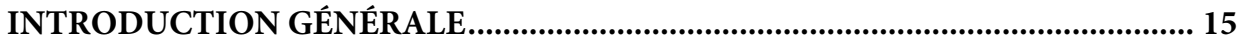

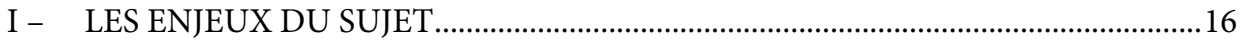

A - Le cadre socio-économique du transport maritime .......................................................16

B - Un aperçu des risques liés au transport maritime des hydrocarbures ........................18

1. Les effets des marées noires sur l'atmosphère et les écosystèmes locaux...................18

2. Un aperçu des conséquences des marées noires sur l'homme ..................................19

II - LA DÉFINITION DES CONCEPTS CLÉS DE L'ETUDE …......................................20

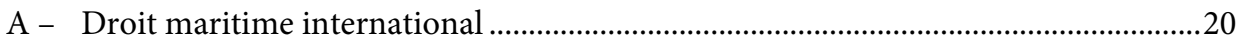

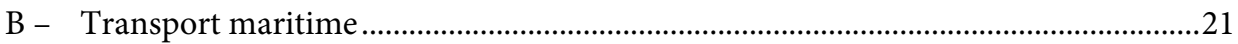

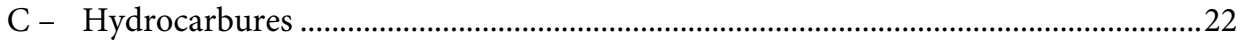

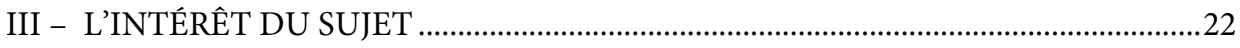

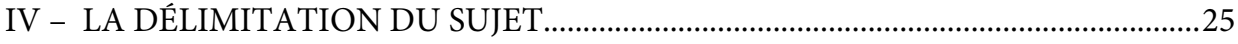

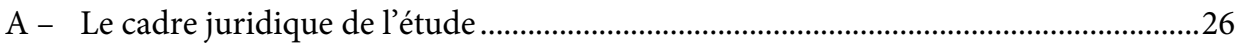

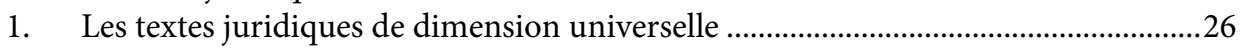

2. Les textes juridiques de portée régionale africaine ......................................................27

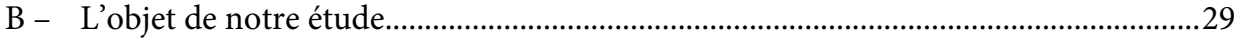

1. Les événements de pollution non couverts par la présente étude................................29

2. Les événements de pollution par hydrocarbures couverts par notre étude...............31

V - LA PROBLÉMATIQUE DU SUJET ………….................................................................

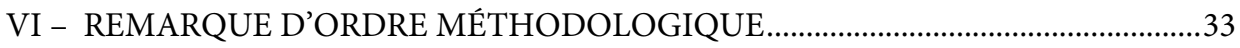

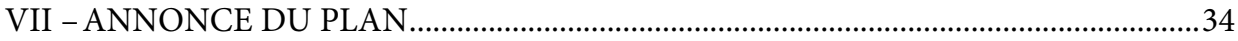

PREMIÈRE PARTIE : L'EXISTENCE AVÉRÉE DES NORMES

INTERNATIONALES RÉGISSANT LE TRANSPORT MARITIME DES

HYDROCARBURES …............................................................................. 37

TITRE I : L'ÉLABORATION D'UN SYSTĖME DE PRÉVENTION DES

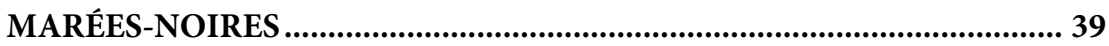

CHAPITRE I : LES RẼGLES RELATIVES À LA CONSTRUCTION DES NAVIRES PÉTROLIERS ..................................................................... 41

Section 1: Les normes universelles élaborées dans le cadre de l'Organisation

Maritime Internationale (OMI)

Paragraphe $1:$ Les techniques initiales appliquées à l'échelle universelle ...........................41

A - Citernes à ballast propre spécialisées .............................................................................

B - Le système de lavage au pétrole brut ou Crude Oil Washing (COW) ........................42

Paragraphe 2 : L'instauration de nouvelles techniques préventives.....................................43

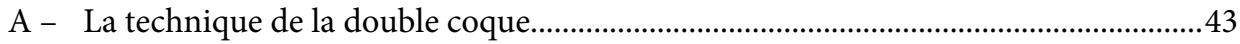


1. La Présentation de la technique

2. La mise en œuvre de la technique de la double coque...............................................4

$\mathrm{B}$ - Les citernes à ballast séparés et les installations de réception à terre ...........................45

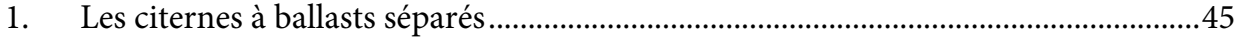

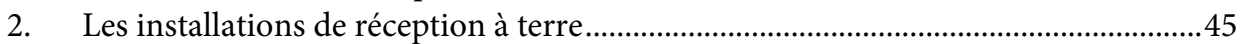

Section 2 : Les normes spécifiques élaborées par l'Union Européenne et les États-

Unis d'Amérique

Paragraphe 1: La lutte contre les navires sous-normes dans le cadre de l'Union Européenne

A - Les compétences de l'État du port dans l'espace communautaire ..............................47

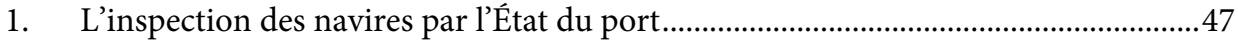

2. Le système de notification des mouvements de navires pétroliers ..............................49

B - La définition d'un cadre juridique relatif aux acteurs privés du transport

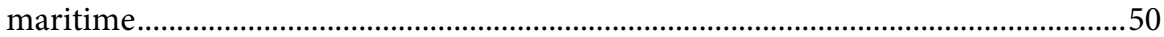

1. La réglementation relative aux sociétés de classification ...........................................50

2. L'édiction de normes relatives aux navires à coque simple ........................................51

Paragraphe 2 : La « Oil Pollution Act » (OPA) 1990 ............................................................52

A - Les accidents de pollution marine et l'adoption de la Oil Pollution Act 1990..........52

1. La série de pollutions accidentelles provenant des pétroliers.......................................52

2. Le processus d'adoption de la Oil Pollution Act 1990 au Congrès..............................52

B - Les spécificités de la Oil Polluction Act 1990......................................................................54

1. L'instauration diligente de la double coque ....................................................................54

2. Les mesures correctrices applicables à tout navire navigant dans les eaux intérieures des États-Unis

\section{CHAPITRE II : LA RÉGLEMENTATION DES REJETS POLLUANTS} D'HYDROCARBURES

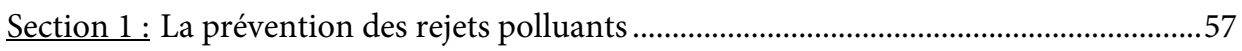

Paragraphe 1: Le principe de l'interdiction des rejets polluants ........................................57

A - Au niveau des zones marines ordinaires ....................................................................57

B - Au niveau des zones marines spéciales..........................................................................

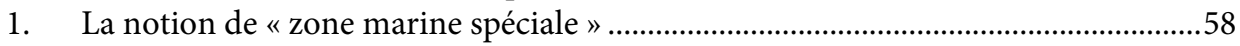

2. Le régime juridique applicable aux zones spéciales .................................................59

Paragraphe 2 : La sécurité du navire en matière de contrôle et de formation

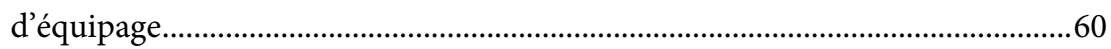

A - Les normes de contrôle du navire ...................................................................................6

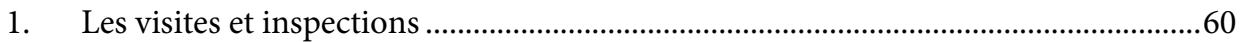

2. Le Certificat international de prévention de la pollution par les hydrocarbures.....61

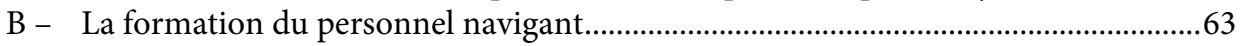

1. Le contrôle de la sécurité de la navigation maritime ...................................................64

A - Le contrôle de la sécurité maritime au moyen de la Convention STCW de 1978 
B - Le contrôle de la sécurité maritime au moyen de la Convention du travail maritime de l'OIT de 2006 .

2. L'application des Conventions STCW et du travail maritime en droit ivoirien......68

Section 2: La répression pénale des infractions aux normes préventives des pollutions marines.

Paragraphe 1 : La recherche des infractions à la législation environnementale. .69

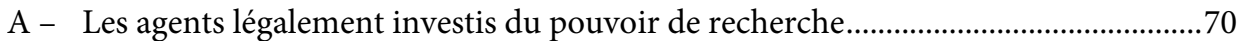

B - Les compétences des agents investis du pouvoir de recherche .....................................71

Paragraphe 2 : Les sanctions pénales applicables en cas de pollution des eaux marines

A - Les sanctions pénales applicables en cas de pollution des eaux marines en République de Côte d'Ivoire.

1. Les sanctions pénales applicables en cas de pollution des eaux intérieures et la mer territoriale

2. Les sanctions pénales applicables en cas de pollution de la Zone économique exclusive (ZEE)

B - Les sanctions pénales applicables en cas de pollution des eaux marines en république Française

1. L'élargissement du cercle des personnes responsables

a. L'adaptation des règles quant aux sujets responsables dans l'affaire de la catastrophe de l'Erika

b. L'adaptation des règles relatives à l'élément moral de l'infraction.

2. Le renforcement de la répression pénale à l'égard des auteurs potentiels des faits en droit français

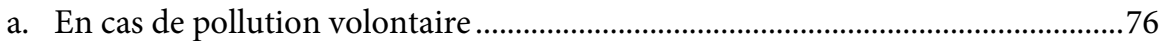

b. En cas de pollution involontaire ou accidentelle .......................................................

\section{TITRE 2: LA LUTTE CURATIVE CONTRE LE PHÉNOMẼNE DES MARÉES}

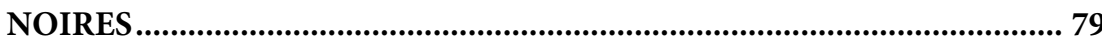

CHAPITRE 1 : LA LUTTE OPERATIONNELLE CONTRE LE PHENOMENE DES MAREES NOIRES

Section 1 : Les normes universelles contenues dans la Convention de Montego Bay et la Convention OPRC 1990.

Paragraphe 1 : La lutte contre les pollutions marines au moyen de la Convention de Montego Bay

A - Les compétences reconnues à l'État côtier

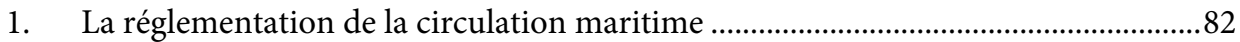

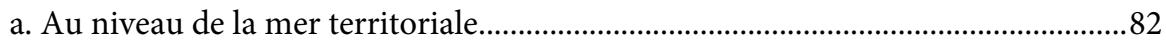

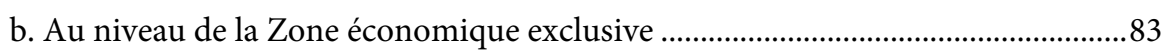

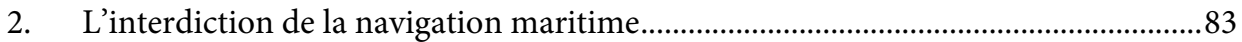

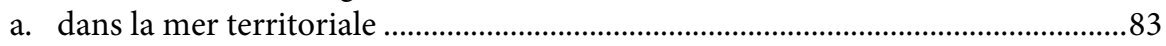

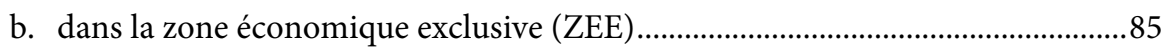


B - Les compétences dévolues à l'État du port et l'État du pavillon.

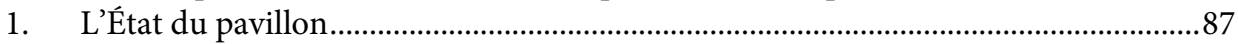

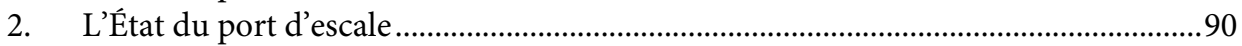

Paragraphe 2: La lutte contre les marées noires au moyen de la Convention OPRC 199092

A - La délimitation des compétences respectives de l'État du pavillon et de l'État

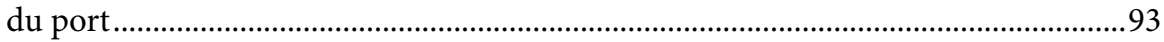

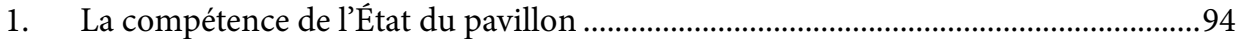

2. La compétence territoriale de l'État du port .............................................................94

B - Le contenu des mesures opérationnelles de lutte contre les marées noires...............95

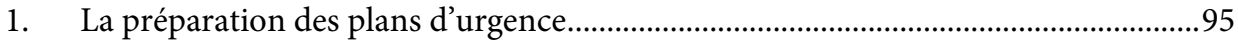

2. L'application des plans d'urgence ........................................................................96

Section 2: Les normes d'intervention définies à l'échelle régionale africaine et

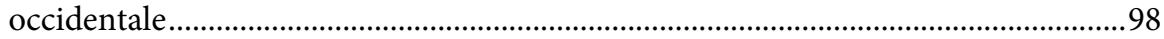

Paragraphe 1: A l'échelle régionale africaine .........................................................................99

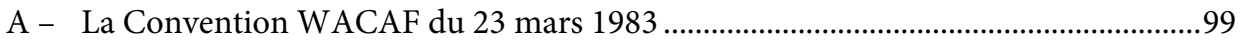

1. De réelles avancées dans la lutte contre les pollutions par les navires .......................99

2. Le mécanisme de lutte dans le cadre du protocole relatif à la convention

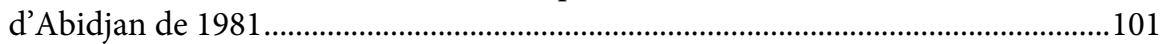

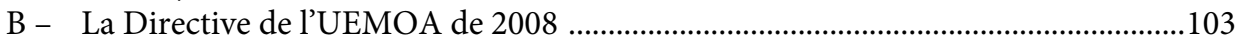

Paragraphe 2 : Le contrôle de la navigation maritime au niveau des pays

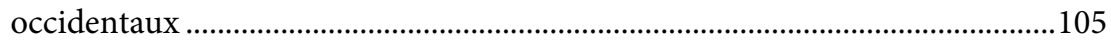

A - Au niveau de l'espace communautaire européen........................................................105

1. La lutte opérationnelle dans le cadre communautaire : l'Agence européenne

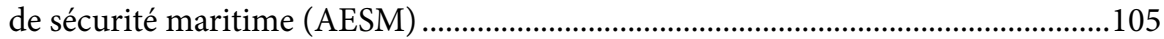

2. La lutte opérationnelle dans une approche bilatérale : le Manche Plan et le Plan Biscaye ................................................................................................................... 107

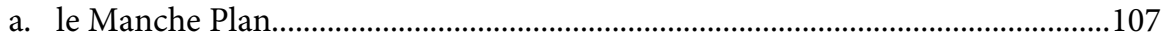

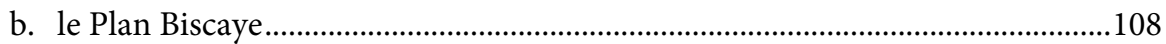

3. Le système préventif de Barcelone et la SASEMAR ....................................................109

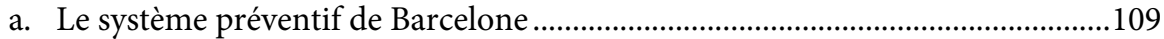

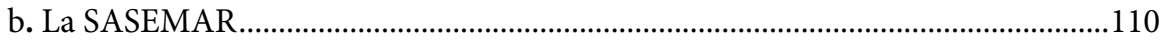

B - Exemples nationaux de lutte opérationnelle contre les marées noires .....................110

1. Les cas français et britannique .....................................................................................111

2. Aperçu de la pratique nord-américaine en matière de lutte opérationnelle contre les marées noires 


\section{CHAPITRE 2 : L'ADOPTION DE REGLES DISSUASIVES EN MATIERE D'INDEMNISATION DES VICTIMES DE MAREES NOIRES}

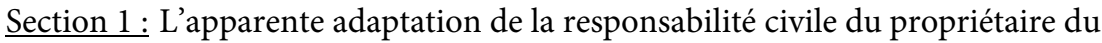
navire

Paragraphe 1 : L'évolution chronologique du processus d'indemnisation des victimes

A - Une indemnisation initialement limitée aux préjudices monétairement évaluables

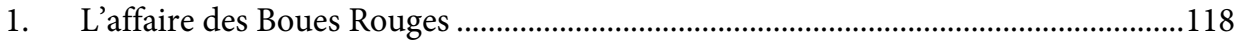

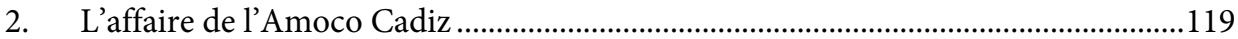

B - Une indemnisation actuellement étendue aux dommages écologiques ..................120

1. Aux États-Unis : affaire Commonwealth of Puerto Rico c. S.S. Zoe Colocotroni

2. En République Française : affaire Erika.

Paragraphe 2: Le nouveau régime spécial d'indemnisation en droit maritime international et en droit comparé

A - Les relèvements successifs des montants d'indemnisation en droit maritime international

1. Les innovations indemnitaires issues des Protocole 1992 aux Conventions CLC 1969 et FIPOL 1971

2. L'indemnisation substantielle issue de la Convention complémentaire de 2003 modifiant la Convention FIPOL 1992

B - La responsabilité civile en droit français et américain...............................................126

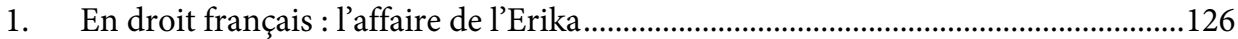

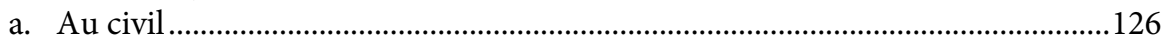

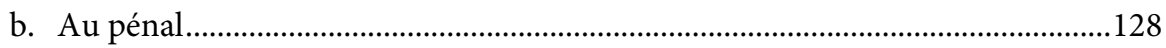

2. En droit états-unien : affaire de l'Amoco Cadiz ......................................................130

Section 2: Le contenu de la responsabilité civile du propriétaire du navire pollueur ...131

Paragraphe 1: Les garanties d'indemnisation des victimes de marées noires et l'institution d'une assurance obligatoire

A - Les garanties d'indemnisation des victimes de marées noires

1. La canalisation de responsabilité du propriétaire du navire pollueur.

2. Le plafonnement de la responsabilité civile du propriétaire du navire pollueur...132

a. Les raisons de la limitation de responsabilité civile.

b. Critique de la limitation de responsabilité 134

B - L'institution d'une assurance obligatoire au profit des victimes................................136

1. Le débat sur la pertinence de l'assurance obligatoire ..................................................136

a. Les positions en présence ...........................................................................................136

b. Les arguments en faveur de l'adoption de l'assurance obligatoire ......................137

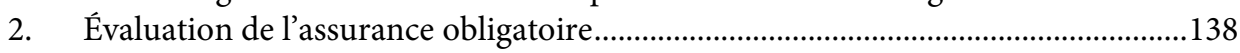

Paragraphe 2: La déchéance du droit à la limitation financière et à l'exonération de la responsabilité civile du propriétaire du navire 
A - La déchéance relative à la limitation financière de responsabilité civile. 140

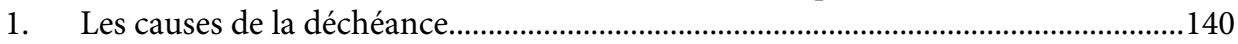

a. La faute personnelle du propriétaire de navire .....................................................140

b. Le défaut de souscription d'un fonds de limitation ou d'une assurance obligatoire.

2. Les effets de la déchéance du droit à la limitation de responsabilité ..........................143

a. La perte du droit au plafonnement de l'indemnité..................................................143

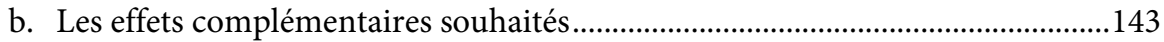

$\mathrm{B}$ - La déchéance du droit à l'exonération de responsabilité civile ..................................144

1. Les causes de la déchéance du droit à l'exonération ................................................145

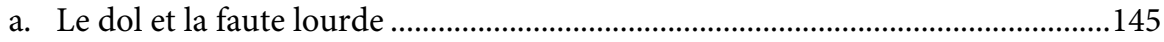

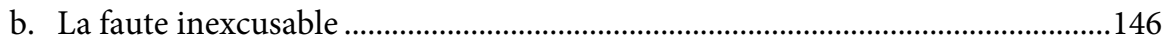

2. Les effets de la déchéance du droit à l'exonération à l'encontre du

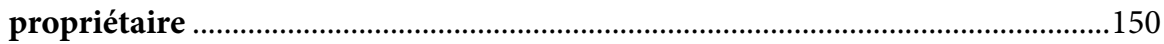

a. Le maintien de la responsabilité civile du propriétaire ........................................150

b. La date concrète de la naissance de la créance d'indemnité des victimes des marées noires

CONCLUSION DE LA PREMIERE PARTIE

DEUXIÈME PARTIE : LE DROIT MARITIME INTERNATIONAL CONTRARIÉ PAR LA PERSISTANCE DES ENTRAVES À SON EFFICACITÉ.

TITRE 1 : LES INSUFFISANCES DU MÉCANISME JURIDIQUE INTERNATIONAL DE LUTTE CONTRE LES MARÉES NOIRES 159

CHAPITRE 1: LES LIMITES DES NORMES INTERNATIONALES DE LUTTE PRÉVENTIVE ET OPÉRATIONNELLE RELATIVES AUX MARÉES NOIRES 161

Section 1: Le caractère inachevé des règles préventives élaborées dans le cadre de l'OMI 161

Paragraphe 1: Le domaine d'application limité de la Convention MARPOL 73/78....161

A - Les navires visés par la Convention MARPOL et leurs obligations ...........................162

1. Les navires visés par l'Annexe I à la Convention MARPOL.......................................162

2. Les obligations incombant aux navires lors de la navigation .....................................163

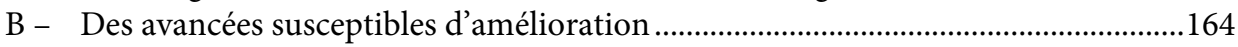

Paragraphe 2: L'application laxiste des mesures préventives de pollutions marines...165

A - Les difficultés découlant du phénomène des pavillons de complaisance ................165

1. L’incapacité de certains Etats du pavillon à appliquer les normes préventives.......165

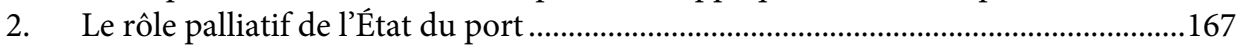

B - Les nombreuses exonérations d'infractions à la Convention MARPOL 73/78 .....168

1. Les aménagements au principe d'interdiction...............................................................168

2. Les exceptions prévues par la Règle 11 de l'Annexe I à la Convention MARPOL 73/78 169 
Section 2: Les insuffisances constatées en matière de lutte opérationnelle contre les marées noires

Paragraphe 1: Les insuffisances des instruments internationaux de lutte opérationnelles contre les marées noires : cas de la Convention OPRC 1990170

A - Les difficultés de mise en œuvre de la Convention OPRC 1990

B - Tentative d'explication peu convaincante des difficultés constatées

Paragraphe 2: Les insuffisances des instruments de lutte opérationnelle contre les marées noires définis dans le cadre régional africain: cas des zones WACAF et l'UEMOA

A - La quasi-absence de plans d'intervention d'urgence (PIU) .........................................174

1. La lenteur des États en matière d'adoption des PIU nationaux ................................174

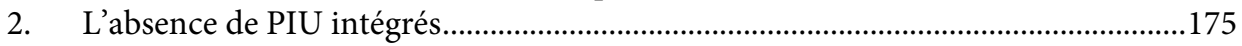

B - L'absence de clarification de l'épineuse question des coûts d'intervention en cas de lutte opérationnelle contre les marées noires.

\section{CHAPITRE 2 : LES INCOHERENCES RELEVEES AU NIVEAU DES INSTRUMENTS DE LUTTE CONTRE LES MAREES NOIRES EN DROIT IVOIRIEN}

Section 1: Les incohérences décelées au niveau du plan POLLUMAR ivoirien 179

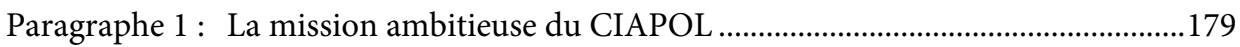

A - Une compétence d'attribution étendue .......................................................................179

B - Une compétence territoriale très étendue ....................................................................182

Paragraphe 2: Les ressources limitées du CIAPOL.............................................................183

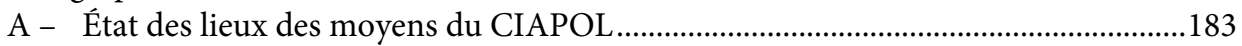

B - Nécessité d'impliquer les opérateurs privés intéressés ...............................................185

Section 2: Les insuffisances au niveau des normes répressives ivoiriennes .....................186

Paragraphe 1: Des règles pénales théoriquement dissuasives .........................................188

A - La pollution des espaces marins sous souveraineté ivoirienne : les eaux intérieures et la mer territoriale

B - La pollution des espaces marins sous juridiction ivoirienne : la zone économique exclusive

Paragraphe $2:$ La rigueur mitigée de la répression des actes de pollution.........................190

A - Les entraves au pouvoir des agents de recherche des infractions ..............................190

1. Les titulaires du pouvoir de recherche des infractions.............................................191

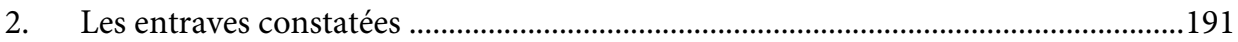

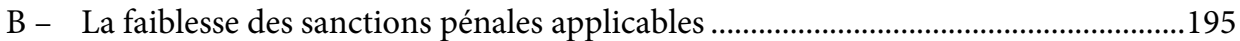

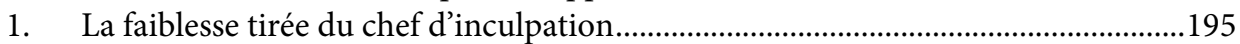

2. La faiblesse tirée du particularisme des règles de droit pénal....................................198 


\section{TITRE 2: L'INADAPTATION DES RÈGLES D'INDEMNISATION DES}

VICTIMES DE MARÉES NOIRES.

\section{CHAPITRE 1 : LES LIMITES DES REGLES PROCEDURALES RELATIVES A} L'ACTION EN RESPONSABILITE CIVILE

Section 1: Le recours exclusif à la procédure judiciaire contentieuse................................203

Paragraphe 1: Le risque de saisine concomitante de plus d'une juridiction ..................203

A - Les conditions de la jonction des instances.................................................................204

B - La loi applicable par la juridiction compétente ............................................................206

Paragraphe 2: Le risque d'inefficacité de l'autorité du jugement rendu ........................208

A - La reconnaissance préalable du jugement rendu .......................................................208

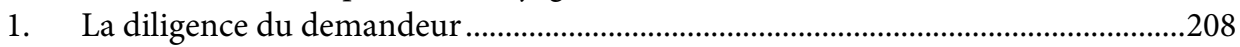

2. Le défaut de recours judiciaire du défendeur à l'action ............................................211

B - L'exécution du jugement menacée d'impasse au préjudice des victimes..................212

1. La subordination de l'exécution du jugement au bon vouloir des États parties....212

2. L'exécution incertaine du jugement par le débiteur de l'indemnisation .................215

Section 2: Le caractère peu dissuasif des règles classiques de l'établissement de la responsabilité civile des pollueurs.

Paragraphe 1: Les entraves à l'indemnisation rapide des victimes de pollution marine

A - Les difficultés liées à l'établissement de la preuve des préjudices imputables au propriétaire du navire ……………………………………………………………...217

1. Les préjudices matériels et économiques …………………………………………....217

2. Les dommages écologiques ...................................................................................218

B - Les difficultés relatives au lien de causalité entre les dommages et l'activité des

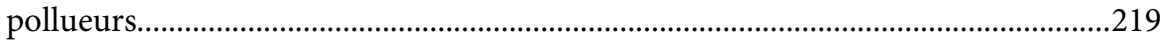

Paragraphe 2: Les modalités de détection des pollutions marines par hydrocarbures et leur force probante

A - Les méthodes manuelles fondées sur la comparaison des échantillons

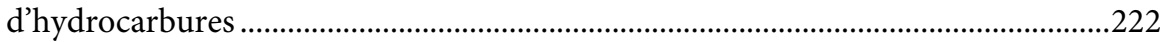

1. Le procès-verbal de constat ...........................................................................................222

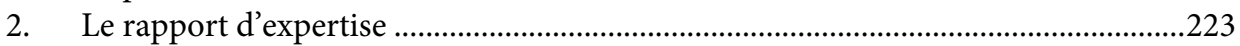

B - Les méthodes non manuelles de détection des échantillons d'hydrocarbures.......225

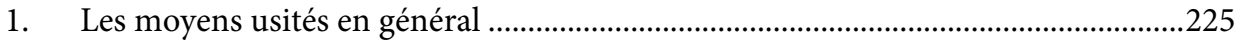

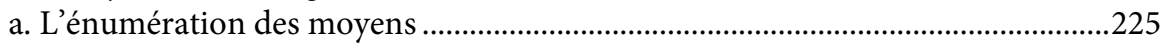

i. Les méthodes scientifiques de détection d'hydrocarbures..........................225

ii. L'observation aéromaritime des hydrocarbures..........................................226

2. Le cas spécifique du CIAPOL en Côte d'Ivoire ………………………………….....229 


\section{CHAPITRE 2: LES FAIBLESSES DU SYSTEME INTERNATIONAL D'INDEMNISATION DECOULANT DE L'ETENDUE DE LA RESPONSABILITE CIVILE DU PROPRIETAIRE DU NAVIRE}

Section 1: La promotion implicite des actes de pollution due à l'institution du "plafonnement» de responsabilité civile.....

Paragraphe 1: Les insuffisances de la Convention CLC 1992

A - La limitation financière de la responsabilité civile du propriétaire du navire ........235

1. L'encouragement implicite des actes de pollution .....................................................235

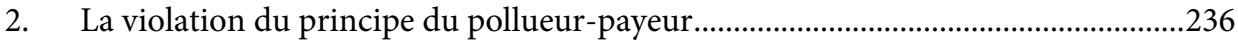

B - La privation des victimes de leur droit de poursuite judiciaire par d'autres voies contre le propriétaire.................................................................................237

1. Le recours implicite à l'institution de la « fortune de mer » ......................................238

2. Une faveur accordée à l'industrie pétrolière ................................................................239

Paragraphe 2: Les limites de la Convention FIPOL 1992 et de la Convention complémentaire de 2003 modifiant le protocole de 1992

A - Les faiblesses des dispositions de la Convention FIPOL 1992 tirées des délais de prescription aux cas de dommages diffus et différés

B - Des faiblesses persistantes de la Convention complémentaire de 2003 modifiant le protocole de 1992

1. La persistante idée du plafonnement de responsabilité .............................................241

2. La problématique de la ratification des Conventions internationales par les pays africains

Section 2: Les entraves à l'indemnisation effective des victimes découlant des exonérations légales de responsabilité civile.

Paragraphe 1: Les causes générales d'exonération de responsabilité civile du propriétaire

A - Les cas alternatifs du fait du tiers, des actes de guerre ou assimilés

1. Le fait du tiers ou assimilé

2. Les situations voisines

B - La force majeure.

1. La conception restreinte du juge de la notion de force majeure ...............................248

2. Les effets de la conception restreinte donnée par le juge ...........................................249

Paragraphe 2: Les causes spéciales d'exonération de responsabilité civile du propriétaire

A - Action ou négligence d'un gouvernement 251

1. La responsabilisation des pays en développement à investir dans la lutte contre les pollutions marines

2. La nécessité d'impliquer toutes les structures publiques et privées dans la politique de lutte contre les pollutions marines ......................................................253

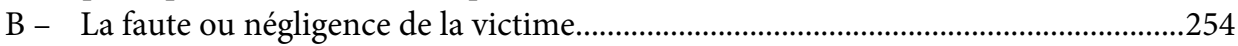

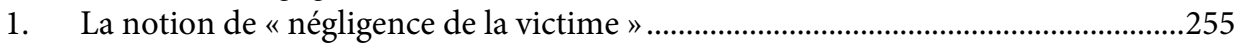

2. Les effets préjudiciables de la négligence à la victime............................................256 
Convention internationale de 1973 pour la prévention de la pollution par les navires (Conclue à Londres le 2 novembre 1973)

Protocole de 1978 relatif à la Convention internationale de 1973 pour la prévention

de la pollution par les navires

Convention internationale de 1978 sur les normes de formation des gens de mer, de délivrance de brevets et de veille.

Convention relative à la coopération en matière de protection et de mise en valeur du milieu marin et des zones côtières de la région de l'Afrique de l'ouest et du centre.285 Convention de 2006 du travail maritime .295

Loi n96-766 du 03 octobre portant code de l'environnement en Côte d'Ivoire 358

SUMMARY 375 


\section{INTRODUCTION GÉNÉRALE}

"L'homme doit constamment faire le point de son expérience et continuer à découvrir, à inventer, à créer et à avancer. Aujourd'hui, ce pouvoir qu'a l'homme de transformer le milieu dans lequel il vit, s'il est utilisé avec discernement, peut apporter à tous les peuples les bienfaits du développement et la possibilité d'améliorer la qualité de la vie. Utilisé abusivement, ce même pouvoir peut causer un mal incalculable aux êtres humains et à l'environnement $»^{1}$.

Ce constat dressé par l'article 1 alinéa 3 de la Déclaration de Stockholm sur l'environnement du 16 juin 1972 révèle combien de fois l'homme est à la fois coupable et victime de la dégradation de l'environnement. Les conséquences néfastes de ses activités se répercutent sur son propre bien-être.

Dans le cas particulier des hydrocarbures, le transport maritime de cette substance peut parfois s'avérer désastreux pour le milieu marin, pour les activités économiques ainsi que la santé des populations côtières à cause du phénomène des marées noires ${ }^{2}$. Le premier transport de pétrole vers l'Europe a eu lieu en novembre 1861 par le brick américain "Elizabeth Watts» (224 tonneaux de jauge brute), effectué entre Philadelphie et Londres ${ }^{3}$. La liste des accidents de navires ayant provoqué des marées noires ces dernières décennies ne cesse de s'allonger: le Torrey Canyon, l'Amoco Cadiz, le Tanio, l'Exxon Valdez, l'Erika, le Prestige, etc...La pollution par les hydrocarbures est la plus spectaculaire des pollutions marines ${ }^{4}$. C'est une pollution d'origine tantôt accidentelle, tantôt volontaire. Elle est accidentelle lorsqu'elle survient à la suite de naufrages de navires. Elle est le fait du transport maritime de produits pétroliers qui constitue la plus vieille activité entraînant directement une pollution marine.

Le continent africain est loin d'être à l'abri de cette forme de pollution. L'Afrique est insulaire : toutes ses façades constituent des voies de navigation maritime. Sur ce dernier point, on dénombrerait entre 1975 et 1980 une dizaine de cas de pollution par les hydrocarbures sur les côtes ouest africaines du fait d'accidents de navigation: l'Ionnis

\footnotetext{
${ }^{1}$ Article 1 alinéa 3 de la Déclaration de Stockholm sur l'environnement du 16 juin 1972.

2 C'est dans cette optique que le Pr. DESPAX affirmait qu' "il tombe en effet sous le sens que la mer ne peut être à la fois la poubelle de l'humanité et son garde-manger». Cf. DESPAX (Michel), Droit de l'environnement, LITEC, Paris 1980, n470, p.667. Cité par LITTMANN-MARTIN (Marie-José), « La répression de la pollution marine en droit interne ", in Droit de l'environnement marin, Développements récents, et rapporté par ASSEMBONI OGUNJIMI (Alida Nabobuè), Le droit de l'environnement marin et côtier en Afrique occidentale, cas de cinq pays francophones, Thèse unique, Droit public, soutenue le 15 septembre 2006, Université de Limoges/Université de Lomé, p.312.

3 BERTRAND (Alain), Transport maritime et pollution accidentelle par le pétrole, Faits et chiffres (1951-1999), Editions TECHNIP, Paris 2000, p.19. Rapporté par ASSEMBONI OGUNJIMI (Alida Nabobuè), Le droit de l'environnement marin et côtier en Afrique occidentale, cas de cinq pays francophones, Thèse unique, Droit public, soutenue le 15 septembre 2006, Université de Limoges/Université de Lomé, p.16.

4 La liste des catastrophes est esquissée par ASSEMBONI OGUNJIMI (Alida Nabobuè), Le droit de l'environnement marin et côtier en Afrique occidentale, cas de cinq pays francophones, op. cit., p.16.
} 
Angeli coussis, échoué le 16 août 1979 au large des côtes sénégalaises, le SALEM, qui a coulé le 16 janvier 1980 dans la même zone alors qu'il transportait 200000 tonnes de brut, le MARIA ALEJANDRA, échoué le 11 mars 1980 au large de la Mauritanie, le MYCENE, échoué le 3 avril 1980 au large de la Côte d'Ivoire, etc.

C'est pour mettre en évidence cette situation que nous nous sommes intéressés au thème: "Le droit maritime international et le transport des hydrocarbures".

En vue d'une bonne compréhension du thème, il apparaît nécessaire de présenter les enjeux du sujet (I). Puis, un aperçu du cadre juridique sera donné pour monter les textes juridiques qui régissent la matière. Ceux-ci sont dominés par les Conventions internationales du Droit maritime introduites, entre autres, dans le droit positif des États côtiers de l'Afrique de l'Ouest et du Centre (zone WACAF), parties auxdites Conventions (II). En outre, l'intérêt du sujet sera dégagé pour mettre en relief les raisons qui justifient la présente étude (III).

Par ailleurs, nous procéderons à la délimitation du sujet pour définir le cadre précis de notre étude (IV). La problématique sera l'occasion de souligner les interrogations auxquelles nous entendons apporter des réponses (V) conformément aux normes méthodologiques en vigueur (VI). Ce faisant, nous comptons contribuer au rehaussement de l'efficacité des textes juridiques internationaux et nationaux. Enfin, suivra l'annonce du plan (VII).

\section{I - $\quad$ LES ENJEUX DU SUJET}

Le cadre socio économique (A) et les risques liés au transport des hydrocarbures (B) constituent à nos yeux les enjeux de notre sujet.

\section{A - Le cadre socio-économique du transport maritime}

De nos jours, les effets du transport ${ }^{5}$ sur la vie sociale et économique constituent un enjeu. Car le transport commande la croissance des économies, un réseau de transport facilite l'échange des biens dans et entre les nations ${ }^{6}$.

Le Commandant Timité LASSANA, un ex-DG de la Marine nationale ivoirienne, faisait l'éloge du transport maritime en ces termes : "Quant on remonte dans l'histoire de l'humanité, on constate que toutes les grandes puissances sont devenues ce qu'elles sont

\footnotetext{
${ }^{5}$ Par transport maritime international, il faut entendre selon le Professeur COULIBALY Climanlo Jérôme, le déplacement d'une marchandise par mer dont le lieu de chargement et celui de déchargement relèvent de deux États au point de vue du droit international. Voir Guyon (Y.F) «Controverse sur la notion de transport international de marchandise", DMF 1958, p.195. Cité par COULIBALY (Climanlo Jérôme), Les intermédiaires $d u$ transport maritime international de marchandises en droit ivoirien, thèse dactylographiée soutenue publiquement pour l'obtention du doctorat de droit privé, Nice, 3 avril 1987, p.17.

${ }^{6}$ Le transport modifie profondément les modes de vie. Il façonne la cité au moins autant qu'il s'y adapte; la route fait éclater la ville, la voies ferrée étire les banlieues le long de son tracé ( ...) les autoroutes irriguent des régions isolées. Voir BAUCHET (Pierre), Le transport international dans l'économie moderne, Paris,

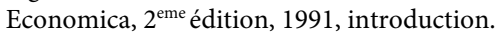


grâce à la mer. La mer est importante pour le développement des nations jeunes comme la Côte d'Ivoire. Puisque $90 \%$ des échanges sont assurés par voie maritime ...»?

Les progrès techniques ont permis l'intensification du commerce mondial et la baisse relative des taux de fret $^{8}$.

Malgré la diversification des sources d'énergies instaurée par les pays non producteurs d'hydrocarbures', le pétrole continue de jouer un rôle capital dans le fonctionnement de l'économie mondiale. Il garde sa première place dans le volume des échanges internationaux ${ }^{10}$. Dans le contexte de croissance de la production et des échanges en raison de nombreux atouts qu'il présente, le trafic maritime assuré par une flotte de quelques 38.000 navires battant pavillon de 150 États, s'est accru considérablement depuis les années 70, passant d'un milliard à plus de 5 milliards de tonnes de marchandises transportées ${ }^{11}$.

Malheureusement, à l'instar des conséquences néfastes de pollution ${ }^{12}$ que cause toute activité anthropique, l'acheminement des hydrocarbures lors de l'expédition se révèle être une opération particulièrement longue et dangereuse pour l'environnement marin ${ }^{13}$.

${ }^{7}$ Voir Jeune Afrique Economie, $\mathrm{n}^{\circ}$ 137, novembre 1990, pp.298 et 304.

8 Voir BAUCHET (Pierre), Le transport international dans l'économie moderne, $2^{\mathrm{eme}}$ édition, Paris, Economica, 1991, p.6. En ce sens, Lamine FADIKA, l'ex-ministre de la marine de Côte d'Ivoire, souligne la nécessité qu'une attention spéciale soit accordée au rôle des transports maritimes sur la croissance des pays pauvres. Voir FADIKA (Lamine), «Système des transports maritimes, développement et industrialisation des pays du tiers monde ", Abidjan, IDREM, 1977, pp.6-9. Voir aussi en ce sens, COULIBALY (Climanlo Jérôme), Les intermédiaires $d u$ transport maritime international de marchandises en droit ivoirien, Thèse dactylographiée, soutenue le vendredi 3 avril 1987, Université de Nice, p.5.

9 Suite aux crises du pétrole instiguées par les pays membres de l'OPEP, les européens vont tout faire pour minimiser leur dépendance énergétique vis-à-vis des grands producteurs d'hydrocarbures en tentant de trouver des substituts au pétrole.

10 En Côte d'Ivoire, l'analyse des trafics par nature des produits permet de relever que sur les 4.025.248 tonnes de marchandises, les hydrocarbures, prédominent à hauteur de $60 \%$ au titre des vracs. Donc, le pétrole brut domine le trafic des produits pétroliers. Le trafic global des produits pétroliers à l'importation a atteint 710.000 tonnes au premier semestre 2004. À l'exportation, les produits pétroliers constituent $37,7 \%$ du trafic total avec 698.244 tonnes. Voir OIC, Bulletin statistique du chargeur, $\mathrm{n}^{\circ} 001,1^{\mathrm{er}}$ semestre 2004 , pp.6-8 et 10-11.

11 Le pétrole représente $40,2 \%$ de la consommation mondiale d'énergie primaire et la principale matière première de la chimie organique. Voir SRITASTAVA (S.P), "Stratégie pour la protection du milieu marin », Grande Bretagne, Manuel OMI, juillet 1988, p.2.

Voir aussi en ce sens, SABRINA (Robert), L'Erika: la responsabilité pour un désastre écologique, Paris, Éditions Pédone, octobre 2003, p.7.

12 La «pollution» est définie par la Commission océanographique intergouvernementale comme l'introduction par l'homme directement ou indirectement de substances ou d'énergies dans le milieu marin et qui a des conséquences néfastes, des dangers pour la santé humaine, une gêne pour les activités maritimes y compris la pêche, une entrave aux diverses utilisations de l'eau de mer et une atteinte à l'intégrité des sites. Definition empruntée à GERLACH SA., in neeresverschmutung, Berlin heidelberg, New York, 1975, p.4. Cette définition est équivalente à celle fournie par l'article $1^{\text {er }}$ paragraphe 4 de la Convention des Nations Unies sur le droit de la mer adoptée la 10 décembre 1982.

13 Les défauts traditionnels des pétroliers conjugués avec la nature de la marchandise transportée ainsi que la durée spécialement longue du voyage résument toute la sensibilité d'un tel voyage. 


\section{B - Un aperçu des risques liés au transport maritime des hydrocarbures}

Si certains accidents graves tels que l'incendie, l'explosion, l'abordage d'un navire avec un pétrolier en cours de dégazage ${ }^{14}$ semblent inévitables, il en est d'autres appelés "marées noires» qui effraient l'opinion publique et met le monde entier en émoi. En effet, les marées noires peuvent s'avérer désastreuses à la fois pour le milieu marin, l'atmosphère et les écosystèmes locaux (1). Leurs conséquences sur l'environnement immédiat peuvent être catastrophiques pour l'homme notamment si le navire en cause a un fort tonnage et si l'accident survient à proximité d'une côte (2).

\section{Les effets des marées noires sur l'atmosphère et les écosystèmes locaux}

Ce ne sont plus seulement nos plages qui sont souillées par les nappes de goudron. Mais la vie entière des océans qui est menacée ${ }^{15}$. La pollution marine est un des aspects importants du phénomène de la pollution. Issue d'une pollution due aux navires pétroliers, la « marée noire » peut être définie comme une arrivée à proximité des côtes d'une importante nappe de pétrole brut ou des produits pétroliers lourds provenant soit de la cargaison soit des soutes d'un navire, ou encore de l'irruption d'un puits sousmarin.

Ce qui retient notre attention dans notre étude est la pollution dite "océanique " venue des bâtiments de mer et engins flottants. Car les hydrocarbures constituent quantitativement le polluant le plus important résultant des opérations de transport maritime ${ }^{16}$. En 1983, l'Académie nationale des sciences des États Unis a estimé que la quantité d'hydrocarbures déversée chaque année dans la mer, toutes sources confondues atteignait 3.000.000 de tonnes dont 1,5 million de tonnes environ provenait des transports maritimes ${ }^{17}$.

Les naufrages du Torrey Canyon en 1967 avec 147.000 tonnes et de l'Amoco Cadiz en 1978 avec 230.000 tonnes, représentent des exemples frappant des conséquences que peuvent entraîner le déversement de 100000 tonnes d'hydrocarbures en peu de temps ${ }^{18}$.

\footnotetext{
${ }^{14}$ Ces accidents sont inhérents aux risques de la mer et aux fautes humaines.

15 Le 12 décembre 1999, le pétrolier Erika battant pavillon maltais et affrété par Total Fina pour le transport de 30000 tonnes de fuel lourd depuis Dunkerque à Livourne a été pris dans une tempête et son naufrage fut inévitable. Il y eu une pollution des côtes françaises par le fuel lourd et visqueux insensible aux produits dispersants habituels.

16 Voir en ce sens, SRTASTAVA (S.P.), «Stratégie pour la protection des milieux marins », op.cit., p.2.

17 Selon SRTASTAVA (S.P.), 400.000 tonnes environ sur ce 1,5 million par an avaient été déversées du fait d'accident maritimes, alors que 700.000 tonnes par an étaient imputables à l'exploitation des navires citernes, 300000 tonnes par an provenaient de l'immersion d'eaux de cales pollués et de l'évacuation de boues d'hydrocarbures et 500000 tonnes par an résultaient de l'exploitation de terminaux ou de mise en cale sèche. Voir SRTASTAVA (S.P.), «Stratégie pour la protection des milieux marins », Op. cit., p.2.

18 Il faut noter que la pollution marine volontaire par hydrocarbure est de deux types. Le premier connu sous le nom de déballastage est produit essentiellement par les pétroliers. Elle est composée d'eau de mer mélangée à du pétrole et provient des cuves de transport. Les autres rejets d'hydrocarbures en mer appelés dégazage correspondent au rejet d'huile de vidange et de résidu de fuel généré par les moteurs de l'ensemble des navires
} 
De même, la pollution consécutive au naufrage de l'Erika en 1999 avec 20.000 tonnes d'hydrocarbures est une pollution accidentelle et chimique. C'est-à-dire une pollution constituée par un déversement en mer de produits nocifs pour le milieu marin. La dégradation d'un élément naturel est d'autant plus grave qu'elle peut se transmettre à d'autres milieux notamment les côtes ${ }^{19}$.

Les événements de mer tels que l'échouement, le naufrage, l'abordage avec un autre navire sont les sources les plus connues de pollution par hydrocarbures.

\section{Un aperçu des conséquences des marées noires sur l'homme}

Le problème posé par les marées noires est spécifique. En ce sens qu'il ne s'agit pas ici d'un dommage causé à la marchandise transportée, mais par la cargaison d'hydrocarbures à des tiers à terre, d'où l'inefficacité des mécanismes juridiques classiques ${ }^{20}$. Car la pollution des mers voit apparaître une nouvelle catégorie de victimes étrangères au jeu du transport maritime. En outre, une seule tonne d'hydrocarbure déversée peut recouvrir des hectares de mer. La caractéristique physique des hydrocarbures en constitue une cause. Car les nappes d'hydrocarbures peuvent en quelques heures s'étaler sur des étendues considérables au gré des vents, des courants et des marées.

Il est donc clair qu'en augmentant sans cesse leur port en lourd, les pétroliers ont progressivement fait courir des risques toujours grands à l'environnement et à l'homme. Tellement les dommages causés par une pollution sont énormes.

Voilà pourquoi le système juridique en la matière est forcément international. Etant donné qu'il n'y a pas d'autre manière de traiter ce phénomène des pollutions par hydrocarbures. Aussi, l'inadéquation des mécanismes juridiques classiques suscitera-telle un effort législatif d'une originalité sans précédent, sous la houlette de l'OMCI ${ }^{21}$, pressée notamment par les gouvernements français et britannique sensibilisés par

utilisés pour le transport des marchandises et des passagers. Voir dans ce sens l'article de ELISA (Noemie) et FREDERIC (Castallemet), « Rapport sur la pollution marine par les hydrocarbures et les dégazages sauvages en méditerranée: 20 Prestiges souilleront la méditerranée cette année », Paris, janvier 2003, in www.lexinter.net, du 25 juillet 2010, p.16.

19 Voir SABRINA (Robert), L'Erika : Responsabilité pour un désastre écologique, op. cit. p.6.

20 A titre d'exemple, la responsabilité civile classique est fondée sur la faute. S'agissant du statut juridique de la mer, il est traditionnellement fondé sur la liberté. La mer échappe à toute emprise étatique. Par essence, la mer est internationale. Depuis toujours le monde maritime a ses propres lois et ses propres techniques en raison des conditions particulières de la vie en mer, le péril, et l'isolement.

${ }^{21}$ Organisation maritime consultative intergouvernementale. Ce nom est devenu OMI organisation maritime internationale en vertu des amendements à la convention portant création de l'organisation entrée en vigueur le 22 mai 1982 avec 131 pays membres. L'OMCI est donc devenue aujourd'hui OMI. C'est le dépositaire de toute convention internationale relative à la préservation du milieu marin des pollutions par les hydrocarbures (Sécurité maritime). C'est la seule institution spécialisée de l'ONU dont l'activité est entièrement consacrée aux questions de la sécurité maritime. Elle regroupe 168 États membres. Elle peut se féliciter d'une production normative considérable malgré la persistance des navires sous normes exploités le plus souvent sous pavillons de complaisance comme l'Amoco Cadiz, l'Erika ou le Prestige. 
l'affaire Torrey Canyon du 18 mars 196722. Aussi, l'OMCI eut-elle la vocation de s'occuper au lendemain du sinistre de Torrey Canyon de tout ce qui concerne la sécurité maritime. L'organisation étudia sous tous les aspects ledit sinistre et reconnut l'ensemble des problèmes techniques et juridiques que soulève la pollution des eaux de mer par les hydrocarbures. Pour les problèmes juridiques, l'OMCI demanda le concours du Comité Maritime International (CIM) pour l'étude juridique du problème de l'indemnisation.

En préalable, il convient de définir brièvement quelques concepts de l'étude.

\section{II - LA DÉFINITION DES CONCEPTS CLÉS DE L'ETUDE}

Le thème de notre étude est un sujet concret, déjà trop ancien mais toujours d'actualité dans lequel les termes tels que le droit maritime international (A), transport maritime (B) ou encore les hydrocarbures (C) prennent toute leur ampleur.

\section{A - Droit maritime international}

Selon le Lexique des termes juridiques, "le droit maritime " est l'ensemble des règles juridiques relatives à la navigation maritime, au transport des voyageurs et des marchandises par mer $^{23}$.

Le droit international maritime est essentiellement un droit du commerce et du transport maritime englobant, le trafic et sa sécurité, la cargaison et sa sûreté, ainsi que le contrat de transport et les problèmes de responsabilitée ${ }^{24}$.

Nous pouvons dire avec Robert Sabrina que le droit maritime international est avant tout le droit de la sécurité maritime. ${ }^{25}$ L'OMI vise justement à inculquer l'esprit de la culture de la sécurité. En effet, son objectif est d'instituer un système de collaboration entre les gouvernants dans le domaine de la réglementation et des usages ayant trait aux questions techniques de toutes sortes qui intéressent la navigation commerciale, d'encourager et de faciliter l'adoption générale des normes aussi élevées que possibles en ce qui concerne la sécurité maritime, l'efficacité de la navigation, la prévention de la pollution des mers par les navires et la lutte contre cette pollution ${ }^{26}$. Les transports maritimes apparaissent comme l'objet du droit maritime.

\footnotetext{
22 Voir REMOND-GOUILLOUD (Martine), « Pollution des mers », Paris, Jurisclasseur, volume 7, 1995, fascicule 1292, 1995, pp.3-4.

23 GUILLIEN (Raymond) et VINCENT (Jean), Lexique des termes juridiques, $14^{\mathrm{ème}}$ édition, Paris, Dalloz, 2003, p.229.

${ }^{24}$ LANGAVANT (E), Droit de la mer, Editions Cujas, 1979, p.8.

25 La sécurité maritime revêt un caractère intuitu personae en protégeant les personnes, un caractère intuitu materiæ en s'assurant de la sécurité des biens et un caractère intuitu loci en assurant la préservation du milieu marin. Voir SABRINA (Robert), L'Erika : responsabilité pour un désastre écologique, Paris, éd. Pédone, octobre 2003, pp.8-9.

${ }^{26}$ Voir l'article I a) de la Convention portant création de l'OMI du 6 mars 1948.
} 


\section{B - Transport maritime}

Le concept de transport maritime s'applique à tous les transports par mer de type commercial et international. Le caractère du transport maritime soulève cependant une question de forme concernant les documents requis pour qu'un transport soit soumis à la Convention de Bruxelles. Celle-ci écarte de son champ d'application non seulement les affrètements, mais aussi les transports par mer qui ne seraient pas constatés par connaissement ${ }^{27}$.

Le transport désigne l'action de porter d'un lieu à un autre. Le transport signifie encore l'ensemble des divers moyens permettant le déplacement des marchandises ou des personnes sur une assez longue distance et par des moyens spéciaux à des fins commerciales et économiques ${ }^{28}$.

Le droit des transports regroupe donc des opérations diverses. Car il y a plusieurs catégories de transport. Ainsi, on a des transports en fonction de leur objet où l'on distingue le transport des marchandises et le transport des personnes. Le transport maritime concerne surtout les marchandises.

On a également le transport en fonction de leur cadre géographique. On distingue, à cet effet, les transports internes et les transports internationaux.

Par "transport maritime international », il faut entendre, selon le professeur Coulibaly Climanlo Jérôme, le déplacement d'une marchandise par mer dont le lieu de chargement et celui de déchargement relèvent de deux États différents au point de vue du droit international ${ }^{29}$.

Le développement des transports internationaux a conduit à un effort d'unification d'où la multitude des conventions internationales en la matière ${ }^{30}$. Le transport maritime fait intervenir deux éléments que tout oppose. Ce sont le navire construit par les hommes et la mer, puissante, insaisissable et imprévisible. La mer est une, ses dangers n'ont ni limites, ni frontières ${ }^{31}$.

\footnotetext{
27 Le connaissement est un acte de reconnaissance fourni par le capitaine d'un navire comme quoi il a effectivement reçu à son bord les marchandises y mentionnées. Il est signé par le capitaine, éventuellement par un agent de l'armateur et contresigné par le chargeur. Cf. NICOLEAU (Patrick), Lexique de droit privé, Paris, Ellipses, 1996, p.90. Voir également l'article 3 alinéa 3 de la Convention de Bruxelles du 25 août 1924.

28 PAUL (Robert), Dictionnaire alphabétique et analogique de la langue française, Tome 6, Paris, 1983, p.634.

${ }^{29}$ Voir GUYON (YF). « Controverse sur la notion de transport international de marchandise », DMF, 1958. p. 195. Cité par COULIBALY (Climanlo Jérôme), Les intermédiaires du transport maritime international de marchandises en droit ivoirien, op.cit, p.17.

30 Les règles de transports maritimes et aériens sont harmonisées, car ces modes de transports sont toujours internationaux. Voir LACASSE (Nicole) et PUTZEY (Jacques), "Droit européen des transports ", European Transport Law, Québec/Bruxelles, 2003, p.680.

${ }^{31}$ Voir SABRINA (Robert), l'Erika : responsabilité pour un désastre écologique, op.cit., p.89.
} 
La cargaison d'hydrocarbures persistants est l'objet du transport maritime qui intéresse notre étude.

\section{C - Hydrocarbures}

Les hydrocarbures sont un groupe de composés organiques constitués par des dérivés hydrogénés [c'est-à-dire combinés avec de l'hydrogène] du carbone. Les hydrocarbures - exception faite du plus léger d'entre eux le méthane qui constitue le gaz naturel - se rencontrent essentiellement dans le pétrole ${ }^{32}$. Autrement dit, il faut distinguer au sein des hydrocarbures le gaz naturel d'un côté et le pétrole et ses dérivés de l'autre.

Dans le cadre de cette étude, le mot "hydrocarbures" désigne tous les hydrocarbures persistants, notamment le pétrole brut, le fuel-oil, l'huile de graissage et l'huile diesel lourde qu'ils soient transportés à bord d'un navire en tant que cargaison ou dans les soutes de ce navire. L'Annexe I à la Convention MARPOL 73/78 établit une liste non exhaustive des hydrocarbures selon huit groupes notamment : le groupe des Asphaltes, les hydrocarbures, les gas-oils atmosphériques, les distillats paraffineux, les bases pour carburants, les Essences, les carburants acteurs et les Naphta.

Pour sa part, la Convention OPRC 1990 définit les hydrocarbures comme le pétrole sous toutes ses formes, y compris le pétrole brut, le fuel-oil, la boue, les résidus d'hydrocarbures et les produits raffinés. C'est dire que les hydrocarbures sont la désignation générique de tous les dérivés et composants du pétrole à savoir tous les sels minéraux persistants notamment le pétrole brut, le fuel oil, l'huile diesel lourde et l'huile de graissage ${ }^{33}$.

Les hydrocarbures non persistants comme l'essence, l'huile diesel légère, le kérosène ne relèvent pas du champ couvert par les Conventions CLC et FIPOL. Il en est de même de la Convention OPRC 1990 qui exclut cette catégorie d'hydrocarbures, en son article 2.

L’intérêt du sujet est indéniable.

\section{III - L'INTÉRÊT DU SUJET}

En choisissant ce thème, nous sommes guidés par un souci : celui de contribuer à la prise de conscience des risques de pollution que crée le transport maritime des hydrocarbures pour en mesurer la gravité et en connaître les origines en particulier pour

\footnotetext{
32 RAMADE (François), Dictionnaire encyclopédique de l'écologie et des sciences de l'environnement, $2^{\text {ème }}$ édition, Paris, DUNOD, 2002, p.391.

${ }^{33}$ Cette définition des hydrocarbures coïncide avec celle de l'article 1 alinéa 5 de la Convention internationale du 29 novembre1969 sur la responsabilité civile pour les dommages dus à la pollution par les hydrocarbures.
} 
les États maritimes africains ${ }^{34}$. En effet, le danger de la pollution accidentelle des mers n'est pas circonscrit aux pays industrialisés ${ }^{35}$.

En outre, nous voulons souligner la nécessité de rehausser l'efficacité des instruments juridiques actuellement en vigueur en matière de protection des milieux marins et côtiers, en particulier ceux de l'Afrique de l'ouest et du centre. Sans oublier la nécessité d'améliorer d'avantage le système international d'indemnisation équitable des personnes qui subissent des dommages du fait des pollutions résultants des fuites ou de rejets d'hydrocarbures provenant des navires. Cette indemnisation se présente comme le corollaire de la responsabilité civile des auteurs des dommages de pollution par hydrocarbures.

Comme on le voit, notre sujet est un aspect spécialisé du droit des transports, particulièrement du droit maritime international. C'est-à-dire un droit qui, par son contenu, contribue à la santé publique ainsi qu'au maintien des équilibres écologiques marins. Mais la mise en œuvre de ce droit finalisé va se heurter à des intérêts économiques $^{36}$. On sait que la rencontre de la mer et de la terre fait naître des sites et des paysages d'une beauté incomparable. L'espace littoral doit donc être protégé pour résister longtemps aux pressions et agressions dont il fait l'objet ${ }^{37}$.

Nos travaux ne manqueront pas d'intéresser le grand public que sont les décideurs, les responsables des collectivités littorales, les compagnies pétrolières, les gérants des activités maritimes, les Universitaires et autres spécialistes des problèmes de domanialité et d'environnement.

Pour les pays en développement, comme la Côte d'Ivoire, notre étude vise à inspirer les décideurs aux fins d'élaborer des plans nationaux de préparation et d'intervention en cas de déversement d'hydrocarbures. En effet, dans les pays côtiers ouest africains, il existe

\footnotetext{
34 A titre d'exemple, nous pensons à l'organisation maritime de l'Afrique de l'ouest et du centre (OMAOC). Elle regroupe l'Angola, le Bénin, le Cameroun, le Cap Vert, le Congo, le Gabon, la Gambie, le Ghana, la Guinée, le Liberia, la Mauritanie, le Nigeria, le Sao Tomé, le Sénégal, la Sierra Leone, le Togo, la RDC, et la Côte d'Ivoire. Concernant les expéditions des chargeurs en provenance ou à destination des pays avec lesquels la Côte d'Ivoire a eu des liaisons maritimes, le Nigeria se situe en tête avec lui seul plus de $90 \%$ du trafic. Voir OIC, bulletin statistique du chargeur $n^{\circ} 1,1^{\text {er }}$ semestre 2004 p.7.

35 C'est ce qui fait dire au Professeur Martin NDENDE que l'Afrique n'a jamais échappé à ces dangers comme l'attestent récemment la catastrophe du déversement des déchets toxiques provenant du navire Probo Koala à Abidjan ou encore le renforcement de la piraterie dans les eaux de l'océan indien et dans le golfe de Guinée. Voir NDENDE (Martin), «L'activité normative des Nations Unies dans le domaine des transports maritimes internationaux ", in Revue Africaine des Affaires Maritimes et des Transports, 2009, p.8.

${ }^{36}$ A ce sujet, Michel DESPAX affirme que le droit de l'environnement a pour finalité de supprimer ou de limiter l'impact des activités humaines sur les éléments ou les milieux naturels. $C f$. DESPAX (Michel), Droit de l'environnement, Litec, 1980, p.9.

37 Voir les journaux : Inter $n^{\circ} 2377$ du lundi 10 et mardi 11 avril 2006 p.12, n²378 du mercredi 12 avril 2006 p.12, Notre Voie ${ }^{\circ} 2362$ du mercredi 12 avril 2006 p.14 et Fraternité Matin, du lundi 3 avril 2006, p.7 : plus de $5000 \mathrm{~m}^{3}$ de pétrole brut ont été déversés au large de Jacqueville, à la suite d'une éruption accidentelle d'un puits de pétrole exploité par la société Canadian Natural Resources (CNR).
} 
également de réels risques de pollution par les navires transportant des hydrocarbures. Ces risques découlent de l'existence des routes maritimes comportant un important trafic pétrolier, de plates-formes pétrolières, d'appontements où s'effectuent des opérations de chargement et de déchargement de pétrole, de soutage, de vidange d'eaux usées ${ }^{38}$.

Malgré le nombre élevé des instruments juridiques sus-exposés, force est de constater que les rejets intentionnels ou dégazages opérationnels, ainsi que les déversements accidentels d'hydrocarbures en mer persistent. En effet, certaines mesures curatives favorisent involontairement les actes de pollutions. Et même, lorsque d'autres sont jugées satisfaisantes, leur application laxiste ne permet pas d'atteindre les objectifs fixés. Par ailleurs, la conciliation entre les exigences de la protection du milieu marin et les impératifs économiques constituent à certains égards, une source d'affaiblissement non négligeable de leur portée.

Or, il serait impérieux que les entreprises du transport maritime soutiennent l'action protectrice de l'environnement ${ }^{39}$.

L'environnement ${ }^{40}$ est la première victime des catastrophes écologiques dues aux pollutions par hydrocarbures. Nombreux sont les navires qui ont prêté leur nom à ces destructions lentes et massives de l'équilibre marin. Outre les navires déjà cités, il en est d'autres qui ont davantage causé l'émoi au sein des populations et ont aussi ravivé l'intérêt des instances de régulation du transport maritime. Celles-ci se sont empressées d'analyser la réglementation internationale pour en discuter la pertinence et l'efficacité. Un peu plus avant, le 12 décembre 1999, une autre catastrophe, celle de l'Erika est venue souiller avec les côtes bretonnes avec 20.000 tonnes de pétrole ${ }^{41}$ souvent meurtries par une succession de marées noires.

Le 31 octobre 2000, le naufrage du chimiquier italien, Ievoli Sun, a tout de suite rappelé celui de l'Erika. Le Jessica, navire équatorien, a déversé plusieurs centaines de tonnes d'hydrocarbures dans le patrimoine naturel des îles de Galápagos en janvier 2001. La réserve sud-africaine de Saint Lucia a, elle aussi, connu l'angoisse de cette peste noire suite à l'échouage du cargo italien le Jolly Rubino le 17 septembre 2002. Sans oublier le Prestige, pétrolier libérien, qui a sombré le 19 septembre 2002 au large des côtes espagnoles laissant s'échapper ses 73.000 tonnes de fioul avec à la clé, des côtes souillées, des ressources halieutiques saccagées, une faune et une flore maritime, des milliers

\footnotetext{
38 À titre d'exemple la Côte d'Ivoire possède une façade maritime longue de $550 \mathrm{~km}$ et un système lagunaire qui s'étend d'Est en Ouest sur plus de 300 km. Voir Jeune Afrique Economie, Novembre 1990, n¹37, mensuel, p.294.

39 C'est le cas des installations portuaires de réception des résidus des hydrocarbures, des programmes de certification des modes de gestion environnementale des entreprises pétrolières et les labels écologiques.

40 Aux termes de l'article $1^{\text {er }}$ de la loi 96-766 du 3 octobre 1996 portant Code de l'environnement en République de Côte d'Ivoire, l'environnement est l'ensemble des éléments physiques, chimiques, biologiques et des facteurs sociaux économiques, moraux et intellectuels susceptibles d'avoir un effet direct ou indirect, immédiat ou à termes sur le développement du milieu, des êtres vivants et des activités humaines.

${ }^{41}$ SABRINA (Robert), L'Erika : Responsabilité pour un désastre écologique, op. cit., pp.1-4.
} 
d'oiseaux détruits, des populations ruinées, des coûts de nettoyage exorbitants, une catastrophe écologique et économique qui s'étend au-delà des frontières d'un État.

En Côte d'Ivoire, au large de Jacqueville, une catastrophe maritime est venue souiller les eaux territoriales ivoiriennes vers la fin du mois de mai $2006^{42}$.

S'il est vrai que l'homme ne peut influer sur le cours de la nature, il n'en demeure pas moins qu'il a l'entière maîtrise de ses activités et le devoir de faire en sorte que son action n'endommage pas davantage l'environnement marin et la terre qui le supporte. La douleur suscitée par ces tristes événements a dû interpeller la conscience de l'homme. Il est conscient qu'il doit et qu'il peut évoluer avec et non contre la nature ${ }^{43}$. Les réglementations environnementales deviennent alors l'instrument de cette conscience. Le droit sert à l'homme, mais aussi aux États et à l'ensemble de la communauté.

Comme on le voit, la pollution des mers doit être traitée globalement et attaquée sur tous les fronts à la fois. Ce problème ne doit pas être ignoré d'aucune administration moderne. Pour celle-ci en effet, la lutte contre cette forme de pollution doit constituer l'une des priorités. Les atteintes portées à l'environnement causent souvent des dommages tellement graves qu'ils ne peuvent faire l'objet d'une réparation équitable. Il convient donc de mettre l'accent sur la prévention, la dénonciation des risques et sur la volonté de combattre non le dommage, mais la menace elle-même.

Pourtant, l'originalité du dommage écologique ${ }^{44}$ est incontestablement attestée notamment par l'importance des préjudices indirectes, la difficulté de trouver les responsables, sans oublier le problème de l'identification de la victime (l'homme ou l'environnement) ou si le dommage est subjectif ou objectif. ${ }^{45}$ Il convient de définir la délimitation du sujet.

\section{IV - LA DÉLIMITATION DU SUJET}

La délimitation de nos développements se subdivise en deux principales catégories à savoir le cadre juridique (A) et l'objet de l'étude (B).

\footnotetext{
${ }^{42}$ Voir Fraternité Matin du 2 avril 2006, n¹2423, p.7.

43 Adhérant à cette opinion, Tor HEYERDAHL disait : "Négliger l'Océan, c'est négliger les deux tiers de notre planète. Détruire l'Océan revient à détruire notre planète. Une planète tuée ne peut servir à aucun pays ". Voir LANGAVANT (Emmanuel), Droit de la mer, Paris, 1979, p.121.

44 Selon Michel PRIEUR, l'écologie est une science transdisciplinaire par nécessité et par objet, qui étudie les relations des êtres vivants avec leur milieu (espèces animales et végétales) à l'exclusion de l'homme. Pour l'auteur, alors que l'environnement prend en considération l'homme dans son milieu naturel ou artificiel, l'écologie ne s'intéresse qu'aux végétaux et aux animaux. Cf. PRIEUR (Michel), Droit de l'environnement, Paris, précis Dalloz, $2^{\text {ème }}$ éd., 1991, pp.2-3.

45 Dans cette optique, la Commission mondiale pour l'environnement et le développement a déclaré dans son rapport intitulé " Notre avenir à tous " être convaincue que le développement rationnel, sinon la survie ellemême dépend des progrès réalisés dans la gestion des océans. Voir SRITASTAVA (C.P), Stratégie pour la protection du milieu marin, Juillet 1988, préface.
} 


\section{A - $\quad$ Le cadre juridique de l'étude}

Le cadre juridique qui intéresse notre étude comporte des textes juridiques de dimension universelle (1) et régionale africaine (2).

\section{Les textes juridiques de dimension universelle}

La nécessité de protéger efficacement la vie animale et végétale du milieu marin ainsi que la population côtière s'est rapidement imposée. Il s'agissait alors de mettre en œuvre une théorie selon laquelle celui qui a le profit d'une activité doit supporter, en contrepartie, la charge des dommages qui en découlent. Plus exactement les victimes estiment que toute responsabilité doit être recherchée auprès des armateurs et des compagnies pétrolières qui bénéficient pleinement de l'expansion commerciale du pétrole. En effet, dès janvier 1969, un projet de convention était mis au point. Ce projet était discuté à Tokyo avec l'aide de l'OMCI et soumis à la conférence juridique internationale réunie à Bruxelles.

Force est donc de reconnaître que la communauté internationale sous la houlette de l'OMI a pris véritablement conscience du danger que représente le phénomène des marées noires dus au transport maritime des hydrocarbures. Aussi, a-t-elle à travers un certain nombre d'instruments juridiques pris des dispositions en termes de prévention et de lutte contre les effets néfastes des marées noires.

Le régime international d'indemnisation pour les dommages dus à la pollution par les hydrocarbures est donc représenté notamment par les Conventions de Bruxelles sur la responsabilité civile pour les dommages dus à la pollution par les hydrocarbures (CLC 69), et la convention de Bruxelles portant création d'un Fonds international d'indemnisation pour les dommages (FIPOL 71) du 18 décembre $1971^{46}$.

Actuellement, le régime repose sur deux Conventions internationales : La Convention de 1992 sur la responsabilité civile ${ }^{47}$ et la Convention de 1992 portant création du Fonds $^{48}$. Un Protocole de 2003 à la Convention de 1992 portant création du Fonds, ou Protocole portant création du Fonds complémentaire, fournit une indemnisation

\footnotetext{
46 Les Fonds internationaux d'indemnisation pour les dommages dus à la pollution par les hydrocarbures (les FIPOL) sont constitués par trois organisations intergouvernementales que sont le Fonds de 1971, le Fonds de 1992 et le Fonds complémentaire mis en place pour indemniser les victimes de dommages par pollution résultants de déversement d'hydrocarbures persistants provenant des navires-citernes. Cf. www.ejustice.fogovbe p.1, du 22/11/ à 14 heures.

47 Elle régit la responsabilité des propriétaires de navires pour les dommages dus à la pollution par les hydrocarbures. En outre, elle pose le principe de la responsabilité objective de ces derniers et instaure un système d'assurance- responsabilité obligatoire.

48 Cette Convention assure un deuxième niveau d'indemnisation financé par les réceptionnaires d'hydrocarbures transportés par mer dans les États parties à la Convention. Créée en 1996, le Fonds compte actuellement 101 États membres. Cf. www.ejustice.fogovbe, p.2 du 22/11/ à 14 heures.
} 
complémentaire supérieure au montant d'indemnisation disponible en vertu de la Convention portant création du Fonds ${ }^{49}$.

Il ne faut pas non plus oublier la Convention MARPOL 73/78 relative à la prévention des pollutions par hydrocarbures. L'adoption, en 1982, d'une nouvelle Convention des Nations Unies sur le droit de la mer parachève cette évolution. Ce système constitue donc, le droit positif en la matière.

\section{Les textes juridiques de portée régionale africaine}

Bien que les problèmes de l'environnement des océans soient de nature universelle, une approche régionale pour les mers régionales a été adoptée pour les résoudre, dans le plan d'action du conseil d'administration du Programme des Nations Unies pour l'environnement (PNUD) ${ }^{50}$. Ainsi, un plan d'action pour la région de l'Afrique de l'ouest et du centre a adopté la Convention relative à la coopération en matière de protection et de mise en valeur du milieu marin et des zones côtières de la région de l'Afrique de l'ouest et du centre ${ }^{51}$.

L'adoption de règles juridiques plus contraignantes et rigoureuses, fait du droit régional un cadre d'action allant au-delà du droit universel. Il existe entre les destinataires des normes juridiques régionales, une communauté d'intérêts plus marquée, un réseau de solidarités plus étroit de nature à les conduire à l'adoption de règles de comportement plus strictes ${ }^{52}$. Il apparaît donc clairement que le cadre régional constitue le "domaine privilégié d'action contre la pollution ${ }^{53}$

49 Ce troisième niveau d'indemnisation a été mis en place en 2005. Le Fonds complémentaire compte actuellement 21 États membres. $C f$. www.ejustice.fogovbe, p.3du 22/11/ à 14 heures.

50 L'OMI a mis au point une stratégie coordonnée. Les éléments fondamentaux de cette stratégie consistent à instituer un système efficace de collaboration technique, juridique et scientifique entre les gouvernements dans le domaine de protection du milieu marin contre la pollution causée par les navires et les activités annexes, à adopter des normes concernant la sécurité maritime, la prévention de la pollution des mers par les navires ainsi que la lutte contre cette pollution, à encourager l'acceptation la plus large possible et l'application efficace de ces normes dans le monde entier, la possibilité de prendre des mesures visant à prévenir, contrôler et atténuer la pollution des mers, à lutter contre celle-ci et à promouvoir la coopération technique nécessaire à cet effet. Voir l'article de SRIVASTANA (S.P.), «Stratégie pour la protection du milieu marin », juillet 1988, op. cit., Préface.

51 Conformément à la Résolution 2997 de l'Assemblée Générale des Nations Unies, le PNUE a été créé pour centraliser l'action en matière d'environnement et réaliser la coordination dans ce domaine entre les organisations des Nations-Unies. Le conseil d'administration du PNUE a défini qu'il existe actuellement dix zones maritimes régionales pour lesquelles des plans d'action ont été déjà adoptés ou sont à l'élaboration. Voir dans ce sens, PNUE convention relative à la coopération en matière de protection et de mise en valeur du milieu marin et des zones côtières. Nations Unies $1981, \mathrm{n}^{\circ} 7, \mathrm{p} .3$.

${ }^{52}$ Le PNUE a réuni à Abidjan (côte d'Ivoire) du 16 au 23 mars 1981, une conférence des plénipotentiaires sur la coopération en matière de protection et la mise en valeur du milieu marin et des zones côtières de la région de l'Afrique de l'ouest et du centre.

53 LUCCHINI (Laurent) et VOELCKEL (Michel), " Les États et la Mer " Documentation française, 1978, p.402. Cités par FALICON (Michel), La protection de l'environnement marin par les Nations Unies: Programme d'Activités pour les mers régionales, Publications du CNEXO, Rapports économiques et juridiques, 
La Conférence des Plénipotentiaires sur la Coopération en matière de protection et de mise en valeur du milieu marin et des zones côtières de l'Afrique de l'Ouest et du Centre a été convoquée à Abidjan en république de Côte d'Ivoire par le Directeur Exécutif du PNUE du 16 au 23 mars 1981. A l'issue de leurs travaux il a été adopté un plan d'action et deux instruments juridiques. Il s'agit du Plan d'Action d'Abidjan pour la protection et la mise en valeur du milieu marin et des zones côtières de la région de l'Afrique de l'Ouest et du Centre. Les instruments juridiques adoptés sont d'une part la Convention relative à la coopération en matière de protection et de mise en valeur du milieu marin et des zones côtières, d'autre part le Protocole relatif à la coopération en matière de lutte contre la pollution en cas de situation critique. Ils ont été adoptés le 23 mars 1981, alors même qu'étaient encore en cours les négociations de la Troisième Conférence des Nations Unies sur le Droit de la Mer qui devaient aboutir à l'adoption de la Convention sur le droit de la mer en décembre 1982.

Cette anticipation n'est que la résultante de la détermination des États de l'Afrique de l'Ouest et du Centre, à évoluer dans un cadre régional où des actions appropriées de gestion et de protection de l'environnement marin et côtier sont susceptibles de voir le jour. La Convention et le Protocole sont entrés en vigueur en le 5 août 1984.

La Convention d'Abidjan est un corps juridique composé de 31 articles. Elle constitue le cadre légal pour toute action nationale et/ou régionale menée en coopération tendant à la protection et au développement du milieu marin et des zones côtières de la région.

C'est un accord-cadre qui, au même titre que toute convention internationale relative à l'environnement marin, énumère les sources de pollution marine susceptibles d'être maîtrisées : pollution par les navires, pollution due aux opérations d'immersion, pollution tellurique, pollution résultant d'activités liées à l'exploration et à l'exploitation du fond de la mer et pollution d'origine atmosphérique et transatmosphérique.

Elle définit également les aspects de gestion de l'environnement marin qui appellent des efforts de coopération : lutte contre l'érosion côtière, création de zones marines spécialement protégées, lutte contre la pollution marine en cas de situation critique, évaluation des incidences des activités sur l'environnement marin et côtier, développement durable et gestion intégrée des zones côtières.

Quant au Protocole, il vise spécifiquement à combattre ou à répondre de façon opérationnelle aux situations critiques en mer, de même qu'à coordonner les activités y relatives, dans chacun des gouvernements des États qui sont Parties contractantes. Il définit les situations critiques pour le milieu marin comme étant tout incident ou événement dont la conséquence est une pollution importante ou une simple menace imminente de pollution importante du milieu marin et des zones côtières par les hydrocarbures.

$\mathrm{n}^{\circ} 9$, 1981, p.10. Cité par ASSEMBONI OGUNJIMI (Alida Nabobuè), Le droit de l'environnement marin et côtier en Afrique occidentale, cas de cinq pays francophones, Thèse unique, Droit public, soutenue le 15 septembre 2006, Université de Limoges/Université de Lomé, p.31. 
La Convention et le Protocole d'Abidjan constituent la composante juridique du Plan d'Action d'Abidjan encore appelé Plan d'Action WACAF. Ils expriment l'engagement des gouvernements de la région, leur volonté politique d'envisager, soit individuellement, soit conjointement leurs problèmes communs concernant l'environnement marin et côtier.

L’objet de notre étude mérite aussi d'être présenté.

\section{B - L'objet de notre étude}

En préalable, il convient de relever que notre étude se veut essentiellement d'inspiration privatiste du Droit. Il s'ensuit que même si notre matière intéresse certains aspects du Droit public, notamment le droit de la mer, le droit administratif des biens ou encore le droit international public, nous les aborderons de manière incidente dans notre exposé. En outre, nos développements ne porteront essentiellement que sur le droit maritime international ${ }^{54}$ applicable au déversement accidentel d'hydrocarbures en mer tel qu'il est introduit ou non dans les pays membres de l'OMAOC ${ }^{55}$, dont la Côte d'Ivoire est membre.

En ce qui concerne l'objet de notre exposé proprement dit, il prend en compte les événements de pollution dus aux hydrocarbures. C'est-à-dire spécifiquement, les déversements accidentels d'hydrocarbures dans le milieu marin de la période des années 1970 à nos jours. Dans nos développements, il est les événements de pollution non couverts par la présente étude (1) et les événements de pollution par hydrocarbures qui le sont (2).

\section{Les événements de pollution non couverts par la présente étude}

Nous écartons de notre exposé, le transport maritime de cargaisons telles que les substances nocives et potentiellement dangereuses soumis à la Convention SNPD de

\footnotetext{
54 Le droit maritime est une branche du droit privé. C'est essentiellement un droit du commerce, englobant notamment le trafic maritime et sa sécurité, la cargaison et sa sûreté, le contrat de transport et les problèmes de responsabilité.

55 L'OMAOC est l'acronyme de l'Organisation Maritime de l'Afrique de l'Ouest et du Centre. Elle a vocation à servir de cadre de coopération pour le traitement de toutes les questions notamment en matière de la sécurité maritime, de la protection de l'environnement marin, ainsi que la mise en oeuvre des conventions pertinentes et du transport en transit en provenance ou à destination des pays membres sans littoral. L'organisme a fonctionné de 1975 à 1999 sous la dénomination «Conférence Ministérielle des États de l'Afrique de l'Ouest et de Centre sur les Transports Maritimes». Créée le 7 mai 1975 et basée à Abidjan, l'OMAOC compte aujourd'hui 25 pays membres et change ainsi de nom pour prendre en compte l'extension du champ d'activité de l'institution. Elle entend promouvoir la coopération et la solidarité entre les États membres, tant au plan international qu'au plan sous-régional autour des questions du secteur maritime et des problèmes spécifiques des pays membres sans littoral. Les fondements et les objectifs de la coopération sont définis par la Charte Maritime d'Abidjan et de la convention portant institution de l'organisme. Voir info@mowca.org du 09-avril 2009.
} 
$1996^{56}$ qui édictent les règles relatives au transport de marchandises dangereuses, ainsi que l'Annexe II de la Convention MARPOL 73/78. Il y a aussi la Convention de Bâle sur le contrôle des mouvements transfrontières de déchets dangereux et leur élimination adoptée par la conférence de plénipotentiaires le 22 mars 1989, entrée en vigueur le 5 mai $1992^{57}$.

Sont également exclus du champ de notre étude, les dommages dus aux opérations d'immersion visées par la Convention de Londres de 1972 sur la prévention de la pollution des mers résultant de l'immersion des déchets et par le protocole de 1996. Il en va de même pour les dommages dus à la pollution par hydrocarbures de soute régie par une convention très récente de 2001 de Londres sur la responsabilité civile pour les dommages dus à la pollution par les hydrocarbures de soute. C'est aussi le cas des pollutions maritimes chimiques ${ }^{58}$. Pas plus que le transport maritime des marchandises soumis à la convention internationale de Bruxelles $^{59}$ de 1924 relatives à l'unification de certaines règles en matière de connaissement ${ }^{60}$.

On citera aussi le transport de passagers appelés bateaux de croisière ou ferry et non de cargaison (tankers, vraquiers porte-conteneurs ...) soumis à la convention de 1960 pour la sauvegarde de la vie en mer et la convention internationale de 1966 sur les lignes de charge et la convention de 1974 pour la sauvegarde de la vie humaine en mer et son protocole de 1978. Sont également exclus, le transport de substances nucléaires ou fissibles soumis à la convention de Paris du 29 juillet 1960 complétée par la convention de Bruxelles le 31 janvier 1963 et la convention de Viennes du 21 mai 1963 suivie d'un protocole du même jour, ainsi que le transport des navires à propulsion nucléaire soumis à la convention de Bruxelles du 25 mai 1962. L'exploitation et l'exploration offshore des hydrocarbures ne concernent pas non plus notre étude ${ }^{61}$.

Hormis les événements de pollutions précités, ceux à indiquer sont couverts par notre étude.

\footnotetext{
${ }^{56}$ En anglais Hazardous and Noxious Substances (HNS).

57 Dans cette optique, il est possible de citer la Convention de Bamako du 30 janvier 1991 sur l'interdiction d'importer en Afrique des déchets dangereux.

${ }^{58}$ Le lindave, l'ammoniaque, le cyanure, la nitrocellulose, le pesticide et le détonateur.

59 Le contrat des transports effectués par voie maritime pose aujourd'hui le problème de la bipolarisation juridique. Car la Convention de Bruxelles de 1924 semble cohabiter avec la Convention de Hambourg de 1978, entrée en vigeur le $1^{\text {er }}$ juillet 1992 et ratifiée par une trentaine d'États. Voir NDENDE (Martin), «L'activité normative des Nations Unies dans le domaine des transports maritimes internationaux », in Revue Africaine des Affaires Maritimes et des Transports, 2009, pp.16-17.

${ }^{60}$ Ce sont tous les transports maritimes commerciaux et internationaux, mais le caractère du transport soulève surtout une question de forme, concernant les documents requis pour qu'un transport soit soumis à la Convention de Bruxelles. Celle-ci écarte de son champ d'application non seulement les affrètements, mais aussi les transports par mer qui ne seraient pas constatés par connaissement.

${ }^{61}$ Depuis le 20 avril 2010, la pire marée noire connue par les États Unis d'Amérique dans leur histoire est due à l'explosion d'une plate forme pétrolière dans le golfe du Mexique exploitée par la Compagnie pétrolière BP. Voir MAGDELEINE (Christophe), «Les États-Unis connaissent la pire des marées noires de leur histoire », in http:// www. Notre planète.Infoactualités du 28/ 05/ 2010.
} 


\section{Les événements de pollution par hydrocarbures couverts par notre étude}

Les hydrocarbures, au sens de notre étude ne se présentent pas comme des produits dangereux. En fait, ce qui nous intéresse c'est bien les hydrocarbures ordinaires. Ceux dont le transport n'est pas prohibé ${ }^{62}$ au regard de leur importance énergétique et stratégique à l'échelle mondiale, notamment pour les transports eux-mêmes, l'électricité, le chauffage, ainsi que le fonctionnement des usines.

En effet, la part du transport d'hydrocarbures représente entre le tiers et la moitié des 90\% de l'ensemble du commerce maritime mondial, des échanges mondiaux. C'est ainsi que paraphrasant Francis Vallat, Christian Scapel n'a pas manqué de faire observer que le transport maritime du pétrole est l'élément de très loin le plus important du transport maritime mondial ${ }^{63}$.

Pour souligner l'influence du pétrole sur la consommation mondiale d'énergie, Yves Carpentier indique que la consommation mondiale d'énergie s'élève à 8,5 milliards de tonnes équivalents au pétrole, les énergies renouvelables (solaires, éoliennes, biomasse, etc.) n'étant pas assez significatives. Il ne faut pas manquer de préciser que les réserves de pétrole sont concentrées pour les $2 / 3$ au Moyen Orient. Tandis que la moitié est consommée par les deux continents nord américain et européen ${ }^{64}$. En tout état de cause, les dommages consécutifs au déversement d'hydrocarbures ne sont pas considérés comme provoqués par des produits dangereux ${ }^{65}$.

Par ailleurs, les réflexions exprimées dans ces travaux de thèse devraient être considérées comme circonscrites aux pays en développement comme la Côte d'Ivoire. Ces pays

\footnotetext{
62 Voilà pourquoi à notre sens, à titre d'exemple, la catastrophe écologique et humaine consécutive au navire Probo Koala en Côte d'Ivoire, relève plus de la volonté humaine de nuire à autrui qu'un fait banal d'événement de mer. En effet, au regard de la nature très toxique de la cargaison, le navire en cause était interdit de sortie du lieu de production des déchets hautement toxiques conformément aux Conventions de Bâle du 22 mars 1989 sur le contrôle des mouvements transfrontières des déchets dangereux et leur élimination, celle de Bamako du 30 janvier 1991 sur l'interdiction d'importer en Afrique des déchets dangereux et par la convention d'Oslo du 15 février 1972 sur la prévention de la pollution marine par les navires et aéronef ou dumping. En aval, après déchargement du produit, cette cargaison mortelle aurait dû être traitée dans des centres spécialisés. Ce qui ne fut pas le cas, d'où les conséquences désastreuses pour l'écologie et des pertes en vie humaine.

63 SCAPEL (Christian), "Présentation », in Centre de droit maritime et des transport, Institut Méditerranéen des transports maritimes, Le transport des produits pétroliers par mer, Colloque Marseille du 9 décembre 1999, Aix-en-Provence, 1999, p.11.

64 CARPENTIER (Yves), «La géographie des échanges énergétiques mondiaux », in Centre de droit maritime et des transports, Institut Méditerranéen des transports maritimes, Le transport des produits pétroliers par mer, op. cit., pp.17-18.

Christian GARIN, estime la consommation de pétrole à 2737 millions de tonnes par an, comprenant 959 millions de tonnes (35\%) de produits moyennement distillés et 512 millions de tonnes(19\%) de produits dits lourds. Voir GARIN (Christian), "Le soutage ", in Centre de droit maritime et des transports, Institut Méditerranéen des transports maritimes, op. cit., pp.29-30.

65 Voir Harrel Courtes G., Prévention et indemnisation des pollutions, Mémoire, Paris, 1999, p 21. Seuls les hydrocarbures au sens de l'Annexe I de la convention MARPOL 73/78 sont visés.
} 
présentent particulièrement un degré de vulnérabilité très préoccupante en matière des catastrophes dues aux marées noires ${ }^{66}$.

Le système juridique maritime international, nous inspire quelques interrogations au regard des événements de pollutions accidentelles par hydrocarbures (les marées noires).

\section{V - LA PROBLÉMATIQUE DU SUJET}

Le problème des marées noires se pose toujours avec acuité. En dépit de l'existence d'un certain nombre de textes juridiques internationaux consacrés au problème de pollutions accidentelles des mers par les navires pétroliers, la situation reste toujours préoccupante.

Face à une telle situation, c'est à juste titre que l'on est amené à se poser un certain nombre de questions :

Le système juridique maritime international relatif au transport d'hydrocarbures garantit-il la protection de l'environnement marin et des zones côtières contre les effets néfastes des marées noires ? Ne comporte-il pas des lacunes préjudiciables à la sécurité maritime ${ }^{67}$ ? Le régime juridique international de responsabilité civile ne comporte-t-il pas des insuffisances favorables aux propriétaires des navires-citernes et à l'industrie pétrolière, au détriment des victimes de marées noires?

En outre, le droit maritime international permet-il de réfréner l'ardeur des pollueurs à se livrer à des actes portant atteinte à l'environnement marin, surtout lorsque des dommages de nature écologique sont difficilement évaluables en termes monétaires ${ }^{68}$ ?

Cette dernière interrogation n'est pas fortuite. Elle se justifie au regard de la réticence des juges à indemniser les dommages causés aux éléments de la nature, dès lors qu'ils ne font pas l'objet d'appropriation.

\footnotetext{
66 Les États parties à l'OMAOC affirment à cet effet qu'en dépit des progrès réalisés, les Conventions internationales relatives à la pollution des mers ne couvrent pas toutes les sources de pollution des mers ni tous les aspects de cette pollution. Pas plus qu'elles ne répondent pas pleinement aux besoins particuliers de la région de l'Afrique de l'Ouest et du Centre. Voir le Préambule de la Convention d'Abidjan de 1981 relative à la coopération en matière de protection et de mise en valeur du milieu marin et des zones côtières de la région de l'Afrique de l'Ouest et de Centre.

${ }^{67}$ L'on peut citer un auteur pour définir la sécurité maritime comme : « La situation dans laquelle le navire, les biens et les personnes qu'il transporte sans oublier le milieu marin, sont placés à l'abri de tout risque. Il s'agit d'éviter tout dommage corporel, matériel et environnemental. Cela englobe également les mécanismes juridiques et techniques de prévention des dommages pouvant toucher les navires les biens et les personnes transportées ainsi que le milieu marin.» Cf. ZINSOU (A. Christian), "Le MOU d'Abuja: un accord administratif pertinent difficilement appliqué dans la région de l'Afrique de l'ouest et du centre ", in Revue Africaine des Affaires Maritime et des Transports, $n^{\circ} 1$, juillet 2006, p.25

68 "Comment chiffrer le juste prix?" s'est interrogé le professeur Martine REMOND-GOUILLOUD, dans sa note à propos de l'affaire Zoé Colocotroni, in Dalloz Sirey, chapitre V, 1982, p 33.
} 
L'ensemble de ces interrogations pourrait se résumer en une question principale, à savoir :

Les instruments juridiques maritimes internationaux relatifs au transport d'hydrocarbures sont-ils appropriés pour assurer une véritable protection de l'environnement marin et en particulier celui des pays de l'Afrique de l'ouest et du centre, ainsi que l'indemnisation adéquate des dommages de pollution accidentelle par hydrocarbures? Leur efficacité n'est-elle pas contrariée par des entraves?

Autant de questions auxquelles nous aurons la tâche de répondre tout au long de cette étude. L'élucidation des questions ci-dessus posées suppose, en règles générales, le recours à une documentation préalable à travers une rigoureuse méthodologie documentaire. Une démarche qui, à coup sûr, devrait permettre de trouver les réponses adéquates à toutes ces interrogations.

\section{VI - REMARQUE D’ORDRE MÉTHODOLOGIQUE}

Pour vérifier la pertinence de notre hypothèse de travail, nous aurons recours à la méthode dialectique. Au moyen de cette méthode, nous voulons mettre en relief les contradictions entre la volonté affichée par les structures internationales et nationales en charge de la gestion des pollutions accidentelles des mers par les navires pétroliers.

Cette méthode nous permettra de souligner deux contradictions. Il s'agit du décalage entre les objectifs définis par l'OMI et les moyens disponibles en particulier dans les pays membres de l'OMAOC. En outre, il s'agit de souligner la contradiction entre la nécessité de soustraire la santé des populations côtières, le milieu marin et l'économie de mer à la persistance du phénomène des marées noires. Ce choix n'emporte pas la mise à l'écart des autres méthodes d'analyse. Il en résulte que les méthodes telles que la méthode comparative à travers le droit comparé, ainsi que la méthode historique seront utilisées.

Le recours au droit comparé s'explique par notre volonté de nous inspirer des expériences bénéfiques en vigueur dans certains pays étrangers. Ces expériences permettront de formuler des propositions nécessaires à l'accroissement de l'efficacité des mesures de lutte en vigueur en Côte d'Ivoire. Nous ferons des propositions tirées de quelques expériences de certaines entités et pays occidentaux (Union Européenne et États-Unis d'Amérique) et particulièrement à la jurisprudence européenne notamment française relative au contentieux des pollutions accidentelles des mers par hydrocarbures, pour étayer notre exposé. 
Cela s'explique par la quasi-absence de décisions de justice rendues par les tribunaux africains et singulièrement ivoiriens en matière de marées noires ${ }^{69}$. Ce phénomène de pollution est vraiment nouveau en Côte d'Ivoire. De plus, en la matière, le législateur ivoirien semble largement s'inspirer du droit français pour élaborer des textes de loi.

L'ensemble de ce travail vise à rehausser l'efficacité des instruments et techniques juridiques internationaux actuellement en vigueur et introduits dans l'ordre juridique de certains pays en développement comme la Côte d'Ivoire.

Dans cette optique, les résultats de nos recherches comporteront principalement deux volets : un volet institutionnel et un volet normatif. Au plan institutionnel, il s'agira pour nous de formuler des propositions visant à inspirer une gestion efficace des structures internationales et à l'administration ivoirienne en charge de la gestion durable de la sécurité maritime. Au plan normatif, nos travaux auront pour objectif de parvenir à une législation maritime internationale plus efficace et plus intégrée au plan régional africain en matière de la protection efficace de l'environnement marin et de la santé des populations contre les dangers des marées noires.

Le contenu de l'étude sera présenté selon le plan qui suit.

\section{VII - ANNONCE DU PLAN}

L'hypothèse de travail de la présente étude est bâtie autour de l'idée selon laquelle le droit maritime international, au regard du transport des hydrocarbures présente un bilan mitigé.

Dans nos développements, nous tiendrons compte de l'esprit des grandes étapes qui ont marqué la gestion juridique des problèmes des marées noires. Il apparaît que la lutte dans un premier temps a privilégié les mesures curatives ou de réparation financière des dommages de pollution par hydrocarbures. Mais face aux limites des mesures de réparations à minimiser l'ampleur des dégâts, la lutte est réarticulée autour de l'approche préventive. Ce qui ne s'est pas traduit par l'abandon des mesures curatives.

A cet effet, la démonstration de notre hypothèse de travail se fera en deux parties :

Dans une première partie, nous mettrons en relief l'existence avérée des normes internationales régissant le transport maritime des hydrocarbures. Cet effort législatif est

\footnotetext{
69 Nos recherches effectuées notamment à la Présidence de la cour d'appel d'Abidjan en vue d'obtenir des décisions de justice en droit ivoirien et particulièrement dans l'affaire du Probo Koala et de la CNR se sont révélées infructueuses. Car, la Présidence de la Cour d'Appel n'a pas fait droit à notre demande d'une copie de l'arrêt rendu surtout dans l'affaire "Probo Koala ». Il ressort de nos enquêtes notamment celles effectuées les 17 et 21 mai 2010 au Cabinet du Maître Menthenon, le bâtonnier de l'Ordre des avocats ivoirien, que non seulement les décisions rendues en matière correctionnelle et civile comporteraient des lacunes, mais elles n'auraient pas été rédigées.
} 
perceptible à travers la législation orientée vers l'élaboration d'un système de prévention des marées noires d'une part, et de lutte curative contre les pollutions marines d'autre part. De la sorte, nous serons situés sur le plan universel et dans des cadres régionaux non seulement sur l'étendue de la protection directe du milieu marin, des zones côtières et des populations côtières victimes, mais aussi des mesures opérationnelles contre les marées noires.

La deuxième partie de ce travail sera consacrée à la persistance des entraves qui contrarient l'efficacité du droit maritime international en vigueur. Les obstacles sont décelables aussi bien en matière des insuffisances du mécanisme juridique de prévention des dégradations de l'environnement marin et de lutte opérationnelle contre les marées noires, qu'en ce qui concerne l'inadaptation des règles d'indemnisation des victimes des dommages de pollutions par hydrocarbures. Nous distinguerons de la sorte, les lacunes $\mathrm{du}$ droit maritime international incorporé au droit national ivoirien et les lacunes décelables au sein du droit interne ivoirien, proprement dit. 



\section{PREMIẼRE PARTIE : L'EXISTENCE AVÉRÉE DES NORMES INTERNATIONALES RÉGISSANT LE TRANSPORT MARITIME DES HYDROCARBURES}

L'importance vitale du milieu marin dans le maintien de toutes formes de vie est, de nos jours, une réalité incontestable. En témoignent d'ailleurs la profusion des mesures juridiques de portée universelle, régionale et sub-régionale qui s'attellent à minimiser, à défaut de les éradiquer, les atteintes portées contre la consistance de l'environnement marin. Il est donc avéré l'existence des normes internationales régissant le transport maritime des hydrocarbures.

Parmi ces normes, nous nous appesantirons sur celles qui visent à prévenir l'altération significative du milieu marin au moyen de substances polluantes de natures diverses. Les mesures de lutte les plus significatives ont été élaborées dans le cadre d'organismes intergouvernementaux tels que les Nations unies, l'Organisation maritime internationale (OMI), le Programme des nations unies pour l'environnement (PNUE) ${ }^{70}$.

Dans l'ensemble, les textes juridiques adoptés en la matière portent sur la protection du milieu marin, les normes de construction des navires, les installations de réception des résidus de substances polluantes, la formation du personnel navigant, la fixation des seuils autorisés de rejets de substances polluantes ...

L'éventail des mesures préventives ci-dessus se justifie au regard de l'article 192 de la Convention des Nations unies sur le droit de la mer (CNUDM) du 10 décembre 1982 (ci-après Convention de Montego Bay ou CMB). La CMB dispose : "les États ont l'obligation de protéger et préserver le milieu marin ».

\footnotetext{
70 La CMB du 10 décembre 1982 a été conclue sous les auspices de l'ONU; l'activité intense de l’OMI a permis de conclure, entre autres, la Convention MARPOL 73/78; le PNUE a initié les programmes régionaux de protection de l'environnement marin qui ont permis la conclusion, entre autres, de la Convention WACAF et son Protocole adoptés à Abidjan le 23 mars 1981.
} 
La lutte préventive contre les pollutions marines comportera de ce fait deux modalités : d'une part, les mesures de lutte dirigées contre les risques certains provoqués par les rejets ou les déversements accidentels de substances polluantes; et d'autre part, les mesures destinées à s'appliquer aux risques potentiels liés à ces pollutions. La première catégorie de mesures correspond à l'élaboration d'un système de prévention stricto sensu des marées noires (Titre I), tandis que les secondes s'analysent en la lutte curative contre le phénomène des marées noires ${ }^{71}$ (Titre II).

71 La distinction entre mesures préventives et mesures anticipatives a été remarquablement abordée par le Professeur Nicolas de SADELEER. Cf. SADELEER (Nicolas de) Le principe pollueur-payeur, le principe de prévention, le principe de précaution : essai sur la genèse et la portée juridique de quelques principes juridiques $d u$ droit de l'environnement, Bruxelles, Bruylant/AUF, 1999. Cité par TIEBLEY (Yves Didier), La Côte d'Ivoire et la gestion durable des ressources naturelles marines, Thèse unique, Droit public, Datawyse/Universiteit pers Maastricht, 2010, p.135. 


\section{TITRE I :}

\section{L'ÉLABORATION D'UN SYSTÈME DE PRÉVENTION DES MARÉES-NOIRES}

La particularité de notre étude est qu'il porte sur un système préventif des pollutions générée par les navires. Celles-ci sont consécutives aux déversements accidentels de substances polluantes appelées hydrocarbures, dans le milieu marin.

Les dangers que présentent ceux-ci, ainsi que les dégâts importants de tous ordres ont déterminé les États et certaines organisations intergouvernementales telle que l'OMI à élaborer des instruments juridiques comme moyen de lutte contre le phénomène des marées noires.

Ces textes juridiques relèvent aussi bien du droit international que du droit régional et interne. Aussi, distinguerons-nous dans notre étude d'une part les règles de prévention de la pollution marine relatives à la construction des navires pétroliers (Chapitre I) et d'autre part, celles touchant à la réglementation des rejets polluants d'hydrocarbures (Chapitre II). 



\section{CHAPITRE I : LES RÈGLES RELATIVES À LA CONSTRUCTION DES NAVIRES PÉTROLIERS}

Les pollutions accidentelles sont source de perturbations majeures du milieu marin ${ }^{72}$, qualifiées de " catastrophes écologiques ", au regard de l'ampleur des dégâts générés par ledit phénomène.

Pour prévenir les dangers liés à la pollution des mers, des mesures de sécurité ont été adoptées. Ces mesures de lutte contre les pollutions marines accidentelles s'intéressent à la construction des navires pétroliers. Elles revêtent deux modalités. Car les unes sont universelles, élaborées dans le cadre de l'Organisation Maritime Internationale (OMI) (Section I). Les autres normes s'attellent particulièrement à lutter contre les navires sous-normes. ${ }^{73}$ Ces dernières sont élaborées par l'Union européenne et par les États-Unis d'Amérique (Section 2).

\section{Section 1: Les normes universelles élaborées dans le cadre de l'Organisation Maritime Internationale (OMI)}

Les normes de construction des pétroliers, de portée universelle, ont été élaborées au sein de l'OMI en vue de prévenir les pollutions par hydrocarbures (Paragraphe 1). Ces normes ont, par la suite, subi des modifications à la suite de l'instauration de nouvelles techniques préventives des marées noires (Paragraphe 2).

\section{Paragraphe 1 : Les techniques initiales appliquées à l'échelle universelle}

Les techniques initiales appliquées à l'échelle universelle sont constituées des systèmes de Citernes à ballast propre spécialisées (A) et celui du lavage au pétrole brut ou Crude Oil Washing (COW) (B).

\section{A - Citernes à ballast propre spécialisées}

Les citernes à ballast propre ${ }^{74}$ sont des citernes de pétroliers prévues à l'origine pour recevoir des cargaisons de pétrole. Mais elles ont été par la suite destinées à recevoir

\footnotetext{
72 Jean-Philippe LARTIGOU a fait dans une étude la distinction entre les pollutions accidentelles et opérationnelles. En effet, dans l'ouvrage "droit maritime" cité par l'auteur, M. Beurrier oppose les pollutions opérationnelles (c'est-à-dire volontaire) aux pollutions accidentelles, toutes deux classées selon la cargaison ou les résidus. Cf. LARTIGOU (Jean-Philippe), «Les pollutions opérationnels et le droit », in Neptumus, Revue électronique, Vol. 13 2007/7, Centre de Droit Maritime et Océanique, Université de Nantes, 2006/2007, pp.2-3

73 Cette expression désigne les navires qui ne respectent pas les normes de sécurité avec le plus souvent un équipage non formé. L'expression «sous-norme " a été employée par certains auteurs dont Patrick DAILLIER, Martin NDENDÉ et Catherine ROCHE. Cf. DAILLIER (Patrick), " Droit communautaire et protection de l'environnement marin », ADMA, 1982, p.289; NDENDÉ (Martin), « Police de la mer », Editions Techniques, Jurisclasseur, Fascicule 209, 1993, p.9 et ROCHE (Catherine), « Après l'Erika : la prévention de la pollution des mers par le renforcement de la sécurité maritime en Europe (Erika I) », RJE, n³, 2002, p.377 et suivants. Cité par TIEBLEY (Yves Didier), La Côte d'Ivoire et la gestion durable des ressources naturelles marines, op.cit, p.14.

${ }^{74}$ En anglais, Clean Ballast Tanks ou CBT.
} 
uniquement de l'eau de mer comme ballast. En effet, la Règle $13 \$ 11$ prévoit, à titre transitoire, la possibilité pour les pétroliers construits avant l'entrée en vigueur de la Convention MARPOL 73/78 de convertir certaines citernes à cargaison en citernes à ballast propre. Ces pétroliers ${ }^{75}$ ne sont pas dotés de citernes à ballasts séparés ${ }^{76}$. En vertu de la Règle $13 \$ 9 a$ ) et $b$ ), ce régime transitoire était prévu prendre fin deux à quatre ans après l'entrée en vigueur de la Convention MARPOL 73/78 ${ }^{77}$.

Cependant, le naufrage de l'Erika, le 12 décembre 1999, à la pointe du Finistère (en France), permet de tempérer fortement la portée de cette disposition.

Il importe de souligner que l'exigence des citernes à ballast propre spécialisées ne s'applique pas aux pétroliers utilisés comme unité flottante de stockage (FSU) ou installation flottante de production, de stockage et de déchargement (FPSO). Pour ce faire, il faudrait que le pétrolier soit amarré à un emplacement fixe sauf dans des conditions ambiantes rigoureuses ou en cas de situation critique ${ }^{78}$.

La deuxième technique classique est représentée par le système de lavage au pétrole brut.

\section{B - Le système de lavage au pétrole brut ou Crude Oil Washing (COW)}

La méthode de lavage au pétrole brut ${ }^{79}$ consiste à laver les citernes à cargaison non pas avec de l'eau, mais avec du pétrole brut en utilisant la cargaison proprement dite. Le lavage au pétrole brut se fait habituellement pendant le déchargement de la cargaison et parfois pendant un voyage en mer après un déchargement partiel de la cargaison. Le pétrole brut utilisé pour le lavage dissout les résidus d'hydrocarbures qui adhèrent aux parois des citernes à cargaison et permet de la décharger avec la cargaison.

Ainsi que le prévoit la Règle $13 \$ 6$, «tout transporteur de pétrole brut d'un port en lourd égal ou supérieur à $20.000 t$ doit être équipé d'un système de nettoyage des citernes à cargaison utilisant le lavage au pétrole brut ...».

Cette méthode a été acceptée comme pouvant remplacer le système des citernes à ballast séparé à bord des navires-citernes existants et constituant une prescription supplémentaire à bord des navires citernes neufs. Ainsi, un transporteur de pétrole brut pourvu de dispositifs permanents de lavage des citernes, directement raccordés aux installations de pompage de la cargaison, peut utiliser du pétrole brut plutôt que l'eau

75 Communément appelés tankers pré-MARPOL.

${ }^{76}$ En anglais, Segregated Ballast Tanks ou SBT.

77 La Convention MARPOL 73/78 et son Annexe I sont entrées en vigueur le 2 octobre 1983. Le régime transitoire des CBT a donc théoriquement cessé d'exister depuis le $1^{\text {er }}$ octobre 1987. Cf. TIEBLEY (Yves Didier), La Côte et la gestion durable des ressources naturelles marines, Thèse unique, Droit public, Datawyse/Universiteit pers Maastricht, 2010, pp.146-147.

78 OMI, Marpol 73/78 : Édition récapitulative de 1997 (Interprétations uniformes), Londres, 1998, p.156.

79 En anglais Crude Oil Washing ou COW. 
pour le lavage de ses citernes. Ce système participe de la diminution nette de la pollution marine.

En outre, dans le cas où il serait nécessaire de procéder en mer à un transbordement d'une cargaison d'hydrocarbures d'un navire à un autre, il faudrait prendre toutes les précautions pour s'assurer qu'il n'y a pas de fuite d'hydrocarbures. À cet effet, il conviendrait de bien fermer toutes les vannes qui ne sont pas utilisées et fermer les issues. Tous les dalots situés sur le pont devraient être efficacement bouchés pour empêcher les fuites d'hydrocarbures de se déverser par-dessus bord ${ }^{80}$.

Le protocole du 17 février 1978 apportera des modifications à l'Annexe I du texte initial. Ces aménagements consistent à instaurer de nouvelles techniques préventives.

\section{Paragraphe 2 : L'instauration de nouvelles techniques préventives}

Les nouvelles techniques instaurées sont constituées de la technique de la double coque (A) et les techniques des citernes à ballasts séparées et des installations de réception à terre (B).

\section{A - La technique de la double coque}

Il convient de présenter dans un premier temps la technique de la double coque (1) avant d'exposer comment ladite technique est mise en œuvre (2).

\section{La Présentation de la technique}

La double coque constitue une double enveloppe de deux mètres d'épaisseur qui protège le navire en cas d'échouement ou de collision ${ }^{81}$.

Le système consiste à installer une épaisseur substantielle de ballast entre le bordé des murailles et les fonds du navire exposés aux abordages et échouements et la cargaison d'hydrocarbures ${ }^{82}$.

L'exigence de la double coque a été posée par la Règle $13 \mathrm{~F}$ de l'Annexe I telle qu'amendée le 6 mars $1992^{83}$. En vertu de la Règle $13 \mathrm{~F}$, les nouveaux pétroliers de plus

80 Cf. OMI, Manuel sur la pollution par les hydrocarbures, $1^{\text {ère }}$ partie : prévention, Édition révisée, Londres, $1983, n^{\circ} 3$ et suivants pp.30-32 et p.55 et suivants.

81 HAGRY (Alexandre), Les navires inférieurs aux normes, Mémoire, DESS, Droit maritime et des transports, Université de droit, d'économie et des sciences d'Aix-Marseille, année 2002-2003, p.17. La définition ci-dessus concorde avec celle du Conseil général des Ponts et Chaussées (CGPC) et l'Inspection générale de l'environnement (IGE), en France, qui définissent la double coque comme "une double enveloppe de deux mètres d'épaisseur dont le but est de protéger les citernes placées à l'intérieur en cas d'échouement ou de pollution ». Cf. CGPC/IGE, Mission d'inspection sur les installations de réception portuaires pour les déchets d'exploitation des navires et les résidus de cargaison, 2000, p.43.

82 Cf. Bureau Veritas, "Pétroliers à double coque, effets sur la pollution des mers par les hydrocarbures ", Paris, Décembre 1991. Cité par HARREL (Courtes Guillaume), Prévention et indemnisation des pollutions marines : évolution et adaptation d'un droit naissant, Mémoire, DEA, Droit privé, Paris, 1999, p.31 et suivants. 
de 5000 tpl doivent être pourvus d'une double coque ${ }^{84}$. Cette exigence s'applique aux pétroliers dont les commandes ont été passées après le 6 juillet 1993, ceux dont la livraison est prévue à partir du 6 juillet $1996^{85}$. La double coque possède un avantage indéniable sur les citernes à ballast séparé. En effet, les citernes à ballast séparé protègent environ le $1 / 3$ de la cargaison alors que la double coque protège la totalité de la cargaison $^{86}$.

La mise en œuvre de la technique de la double coque permet d'apprécier son efficacité.

\section{La mise en cuvre de la technique de la double coque}

La Règle $13 \mathrm{~F}$ de l'Annexe I a été révisée par les parties contractantes à la Convention MARPOL 73/78. Cette modification est intervenue à la suite d'une proposition émanant du Comité de protection de l'environnement marin (CPEM) de l'OMI.

En vertu de cette révision, entrée en vigueur le $1^{\text {er }}$ septembre 2002, les pétroliers à simple coque de plus de vingt-cinq ans et de fort tonnage ne pourront plus naviguer à partir de 2005. En ce qui concerne les pétroliers à simple coque âgés de moins de vingtcinq en 2005, la date limite est fixée à $2015^{87}$.

La Règle 13 G de l'Annexe I telle que révisée le 4 décembre 2003 a réduit les délais précités de retrait de navires pétroliers à simple coque. Ces amendements étaient prévus entrer en vigueur le 5 avril 2005 au moyen de la procédure de l'acceptation tacite. En vertu de ces amendements, les pétroliers de la catégorie 1 (catégorie pré-MARPOL) ${ }^{88}$ doivent être retirés en 2005 (au lieu de 2007). Pour les pétroliers des catégories 2 et 3 (pétroliers MARPOL et petits pétroliers) $^{89}$, la date limite de retrait est ramenée à 2010

\footnotetext{
${ }^{83}$ Les amendements à la Règle $13 \mathrm{~F}$ de l'Annexe I sont entrés en vigueur le 6 juillet 1993.

84 Cf. www.imo.org/HOME.html.

85 ROCHE (Catherine), "Après l'Erika : la prévention de la pollution des mers par le renforcement de la sécurité maritime en Europe (Erika I) », RJE, n³, 2002, p.391.

86 Cf. Bureau Veritas, "Pétroliers à double coque, effets sur la pollution des mers par les hydrocarbures ", Paris, Décembre 1991. Cité par HARREL (Courtes Guillaume), Prévention et indemnisation des pollutions marines : évolution et adaptation d'un droit naissant, Mémoire, DEA, Droit privé, Paris, 1999, p.31 et suivants. ${ }^{87}$ Cf. www.imo.org/HOME.html.

88 La catégorie 1 (catégorie pré-MARPOL) comprend les pétroliers de $20.000 \mathrm{tpl}$ ou plus qui transportent du pétrole brut, du fuel lourd, du bitume. Sont également inclus dans cette catégorie, les pétroliers de $30.000 \mathrm{tpl}$ ou plus qui transportent d'autres produits pétroliers. La particularité des navires pré-MARPOL est qu'ils ne sont pas dotés de ballasts séparés. Cf. TIEBLEY (Yves Didier), Réflexions sur les instruments et techniques juridiques de lutte contre les pollutions marines dues à l'exploitation off-shore et au transport maritime des hydrocarbures, Mémoire, DEA en droit et politique de l'environnement, Université de Lomé, Faculté de Droit, 11 juin 2004, p.50, note 154 .

89 La catégorie 2 (navires MARPOL) est constituée des pétroliers de même tonnage et transportant les mêmes produits mais qui sont dotés de ballasts séparés. La catégorie 3 est une catégorie résiduelle dans laquelle on range les pétroliers dotés ou non de ballasts séparés mais dont le tonnage est compris entre 5000 tpl et les tonnages minima des catégories 1 et 2. Cf. TIEBLEY (Yves Didier), Réflexions sur les instruments et techniques juridiques de lutte contre les pollutions marines dues à l'exploitation off-shore et au transport maritime des hydrocarbures, Mémoire, DEA en droit et politique de l'environnement, Université de Lomé, Faculté de Droit, 11 juin 2004, p.50, note 134 .
} 
(au lieu de 2015) ${ }^{90}$. En sus de la double coque, la Convention MARPOL de 1973 avait prévu que les navires pétroliers de 70.000 tpl et plus devaient être dotés de ballasts séparés. En outre, les ports pétroliers doivent être dotés d'installations de réception.

\section{B - Les citernes à ballast séparés et les installations de réception à terre}

Dans un souci de clarté, notre démarche consistera à analyser au cas par cas les citernes à ballasts séparées (1) et les installations de réception à terre (2).

\section{Les citernes à ballasts séparés}

Conformément à la Règle 13 E de l'Annexe I de la Convention MARPOL, les citernes à ballasts séparés sont exigées à bord de tous les navires-citernes neufs d'un port en lourd (tpl) supérieur ou égal à 20.000 tonnes.

En outre, les navires-citernes transportant du pétrole brut d'un port en lourd supérieur ou égal à 30.000 tonnes doivent être équipés de citernes à ballasts séparés (en anglais Segregated Ballast Tanks ou SBT) disposés de manière à assurer une certaine protection contre les fuites d'hydrocarbures en cas d'échouement ou d'abordage. En effet, les citernes à ballasts séparés doivent faire l'objet d'une localisation défensive. C'est-à-dire que ces citernes doivent être placées de manière à contribuer à la protection des citernes à cargaison.

Le système des ballasts séparés constitue une évolution par rapport à la Convention de 1973 qui ne prenait en compte que les navires-citernes d'un port en lourd de 7.000 tonnes $^{91}$. Ramenant la capacité à 20.000 tonnes, la Convention affiche la volonté de limiter les dangers de pollution des navires à fort tonnage.

La technique des citernes à ballasts séparés est complétée par celle des installations de réception à terre.

\section{Les installations de réception à terre}

L'exigence des installations de réception à terre découle de la Règle 12 de l'Annexe I à la Convention MARPOL 73/78. La Règle $12 \$ 1$ dispose :

"Sous réserve des dispositions de la Règle 10 de la présente Annexe, les Gouvernements des Parties s'engagent à faire assurer la mise en place, dans les terminaux de chargement d'hydrocarbures, dans les ports de réparation et autres ports dans lesquels les navires ont à décharger des résidus d'hydrocarbures, d'installations capables de recevoir les résidus et les mélanges d'hydrocarbures que les pétroliers et les autres navires auraient encore à

\footnotetext{
90 Cf. www.imo.org/HOME.html.

91 En ce qui concerne la conception des pétroliers neufs, la convention de 1973 visait les pétroliers dont le contrat de construction est passé après le 31 décembre 1975 ou dont la livraison s'effectue après le 31 décembre 1979.
} 
décharger et adaptées aux besoins des navires qui les utilisent, sans leur imposer de retards anormaux».

Les $₫ \$ 2$ et 3 de la Règle 12 définissent les spécifications techniques auxquelles doivent satisfaire les installations de réception des résidus d'hydrocarbures.

Cependant, l'application de la Règle 12 de l'Annexe I à la Convention MARPOL $73 / 78$ est mitigée. En effet, le $\$ 4$ a fixé la date limite de la mise en œuvre des installations de réception au $1^{\text {er }}$ janvier $1977^{92}$. Cette échéance n'a, malheureusement, pas pu être respectée par presque tous les États parties à la Convention WACAF ${ }^{93}$.

Les normes relatives à la construction des navires pétroliers ne sont pas exclusivement le fait de l'Organisation maritime internationale. Il y en a qui sont aussi élaborées dans le cadre de l’Union européenne et des États-Unis d'Amérique.

\section{Section 2: $\quad$ Les normes spécifiques élaborées par l'Union Européenne et les États-Unis d'Amérique}

Au niveau de l'ensemble des pays il est tout aussi apparu nécessaire de prendre des mesures pour harmoniser les structures de préparation et de lutte contre les pollutions marines accidentelles ${ }^{94}$. C'est à propos de ces mesures novatrices européennes que le Professeur Martin Ndende constate que depuis les catastrophes pétrolières de l'Erika et de Prestige, l'Europe a affirmé sa volonté de se prendre en charge directement à travers la création entre autre d'une Agence Européenne de la sécurité Maritime (paragraphe $1)^{95}$. De même, aux États-Unis d'Amérique, la lutte contre les navires sous-normes s'effectue au moyen de la "Oil Pollution Act» (OPA 1990) (paragraphe 2).

\section{Paragraphe 1: La lutte contre les navires sous-normes dans le cadre de l'Union Européenne}

La lutte contre les navires sous-normes dans le cadre de l'Union Européenne se traduit par la définition des compétences de l'État du port dans l'espace communautaire (A) ainsi qu'un cadre juridique relatif aux acteurs privés du transport maritime (B).

\footnotetext{
92 Selon la Règle $12 \$ 4$, "les installations de réception ...doivent être en place un an au plus tard après l'entrée

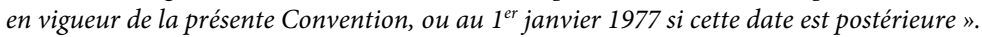

93 À notre connaissance, seule l'Afrique du Sud est, en Afrique subsaharienne, le seul pays à être doté actuellement d'une installation de réception adéquate.

${ }^{94}$ Voir dans ce sens OMI, Rapport de mission antipollution en Guinée, du 16 au 18 janvier 1983, nº et 7, pp.56.

95 NDENDE (Martin), «L'activité normative des Nations Unies dans le domaine des transports maritimes internationaux ", Revue Africaine des Affaires Maritimes et des Transports, $\mathrm{n}^{\circ}$ 1, Nantes, juillet 2009, p.10.
} 


\section{A - Les compétences de l'État du port dans l'espace communautaire}

Les compétences de l'État du port dans l'espace communautaire se résument à la délimitation desdites compétences en l'inspection des navires par l'État du port (1) et au système de notification des mouvements de navires pétroliers (2).

\section{L'inspection des navires par l'État du port}

En vue de lutter contre les pétroliers sous-normes, la Communauté Européenne (CE) a adopté la Directive 95/21/CE du 19 juin 1995 sur le contrôle par l'État du port. L'article 6 intitulé Procédure d'inspection dispose :

«1. L'autorité compétente veille à ce que l'inspecteur procède au moins aux opérations ciaprès :

a) contrôler les certificats et documents pertinents énumérés à l'annexe II;

b) s'assurer de l'état général du navire, et notamment de la salle des machines, du logement de l'équipage, y compris les conditions d'hygiène.

2. L'inspecteur peut examiner tous les certificats et documents pertinents, autres que ceux énumérés à l'annexe II, qui doivent se trouver à bord du navire en vertu des conventions.

3. Lorsque, à l'issue de l'inspection visée aux paragraphes 1 et 2, il existe des motifs évidents de croire que l'état du navire ou de son équipement, ou son équipage, ne répond pas en substance aux prescriptions pertinentes d'une convention, une visite détaillée est effectuée, comprenant un contrôle approfondi de la conformité aux prescriptions relatives aux procédures opérationnelles à bord du navire ...».

En substance, l'article 6 de cette directive énumère les règles minima de contrôle qui doivent être respectées par l'État du port dans le cadre d'une inspection "normale ». La Directive 95/21/CE a été amendée par la Directive 2001/106/CE du Parlement européen et du Conseil du 19 décembre 2001.

La nouvelle directive vise à modifier les dispositions de la Directive de 1995 relatives à l'interdiction d'accès de certains navires, sur les contrôles effectuées et sur la transparence des contrôles et le suivi de l'information au niveau communautaire ${ }^{96}$. En matière d'inspection des navires, l'article 5 tel que modifié par la Directive 2001/106/CE oblige chaque État membre de la Communauté Européenne (CE) à contrôler, au moins, $25 \%$ des navires entrés dans ses ports durant l'année civile écoulée ${ }^{97}$.

96 ROCHE (Catherine), «Après l'Erika: la prévention de la pollution des mers par le renforcement de la sécurité maritime en Europe (Erika I)», RJE, n³, 2002, p.377.

97 L'article 5 tel que modifié par la Directive 2001/106/CE dispose : "1. L'autorité compétente de chaque État membre effectue chaque année un nombre total d'inspections des navires visés au paragraphe 2 et à l'article 7 , correspondant à au moins $25 \%$ du nombre annuel moyen de navires distincts entrés dans les ports dudit État membre calculé sur la base des trois années civiles les plus récentes pour lesquelles des statistiques sont disponibles». 
En vertu de l'article 4 tel que modifié par la Directive de 2001, les États membres de la $\mathrm{CE}$ doivent veiller à ce que les autorités compétentes pour effectuer les inspections soient en nombre suffisant ${ }^{98}$.

L'article 7 bis inséré par la Directive 2001/106/CE définit la procédure à suivre lorsque certains navires ne peuvent pas être inspectés. Cet article dispose :

«1. Lorsque, pour des raisons d'ordre opérationnel, un État membre n'est pas en mesure d'effectuer soit une inspection d'un navire dont le coefficient de ciblage est supérieur à 50, conformément à l'article 5, paragraphe 2, point a), soit une inspection renforcée obligatoire, conformément à l'article 7, paragraphe 4, cet État membre informe sans tarder le système Sirenac que l'inspection n'a pas eu lieu.

2. De tels cas sont notifiés tous les six mois, à la Commission, ainsi que les motifs expliquant pourquoi l'inspection des navires concernés n'a pas été effectuée.

3. Au cours d'une année civile, ces absences d'inspection n'excèdent pas 5\% du nombre annuel moyen de navires distincts susceptibles d'être inspectés visés au paragraphe 1 et qui ont fait escale dans des ports de l'État membre concerné, calculé sur la base des trois années civiles les plus récentes pour lesquelles des statistiques sont disponibles.

4. Les navires visés au paragraphe 1 sont soumis à une inspection, conformément aux dispositions de l'article 5, paragraphe 2, point a), ou à une inspection renforcée obligatoire, conformément à l'article 7, paragraphe 4, selon le cas, à leur prochain port d'escale situé dans la Communauté.

5. Au plus tard le 22 juillet 2008, le pourcentage de 5\% visé au paragraphe 3 est modifié, s'il y a lieu, sur la base d'une évaluation réalisée par la Commission, conformément à la procédure prévue à l'article $19 »$.

L'article 7 ter inséré par la Directive 2001/106/CE oblige les États membres à interdire l'accès aux ports de la Communauté à certains navires. Sont concernés, les navires classés à l'annexe XI, section A. Il s'agit précisément de trois catégories de navires : d'abord, les navires immobilisés plus de deux fois au cours des derniers vingt-quatre mois dans un État signataire du Mémorandum; ensuite, les navires battant pavillon d'un État classé dans la liste noire du rapport annuel du mémorandum; et enfin, les navires immobilisés plus d'une fois au cours des derniers trente-six mois dans un État signataire du mémorandum.

La mesure d'interdiction s'applique dès que le navire quitte le port où il a fait l'objet de la deuxième ou troisième immobilisation. En sont exceptés, les navires confrontés à des cas de force majeure, de nécessité impérative de sécurité. Dans ces cas, les navires concernés sont autorisés à entrer dans un port de la Communauté afin de supprimer ou

\footnotetext{
98 En vertu de l'article 4 intitulé Organisme chargé de l'inspection, "les États membres maintiennent en place des administrations maritimes nationales appropriées disposant $d u$ personnel requis, notamment d'inspecteurs qualifiés, ci-après dénommées 'autorités compétentes', en vue de l'inspection des navires et prennent toutes mesures appropriées pour faire en sorte que leurs autorités compétentes s'acquittent de leurs tâches telles que prévues par la présente directive ».
} 
réduire les risques de pollution ou pour remédier aux anomalies graves affectant le navire ${ }^{99}$.

La compétence de l'Etat côtier est aussi mise en évidence à travers le système de notification des mouvements des navires pétroliers.

\section{Le système de notification des mouvements de navires pétroliers}

L'article 14 de la Directive 95/21/CE tel que modifié par l'article premier $₫ 11$ de la Directive 2001/106/CE dispose :

"Les États membres maintiennent les dispositions nécessaires pour assurer un échange d'informations et une coopération entre leur autorité compétente et les autorités compétentes de tous les autres États membres et maintenir la liaison opérationnelle établie entre leur autorité compétente, la Commission et le système d'information Sirenac créé à Saint-Malo, France».

Cette disposition définit le cadre de la coopération entre les autorités étatiques, portuaires ou commerciales des États membres. Cette coopération consiste en des échanges d'informations disponibles dans le système d'information Sirenac. Ces informations sont rendues publiques par le système d'information Equasis. Ainsi que le prévoit l'article 15 de la Directive de 1995 telle que modifiée par l'article premier $\$ 12$ de la Directive de 2001 :

"Les informations énumérées à l'annexe VIII, parties I et II, ainsi que les informations sur les changements, suspensions et retraits de classe visés à l'article 15, paragraphe 3, de la directive 94/57/CE doivent être disponibles dans le système d'information Sirenac. Elles sont rendues publiques dans le cadre du système d'informations EQUASIS dès que possible après l'inspection ou après la levée de l'immobilisation ".

En vue de mettre en œuvre les dispositions ci-dessus, chaque État membre de la CE transmet à la Commission et au secrétariat du Mémorandum d'entente de Paris, le nombre d'inspecteurs habilités à contrôler les navires ainsi que le nombre total des navires entrés dans ses ports. En outre, il doit fournir, tous les trimestres, à la Commission européenne la liste détaillée des mouvements des navires qui fréquentent ses ports et terminaux ${ }^{100}$.

\footnotetext{
99 Ainsi que le dispose l'article $11 \$ 6$ de la Directive 95/21/CE : « Nonobstant le paragraphe 4, l'accès à un port déterminé peut être autorisé par l'autorité compétente de l'État du port en cas de force majeure, pour raison de sécurité impérative ou pour supprimer ou réduire le risque de pollution ou pour réparer les anomalies, à condition que des mesures appropriées, à la satisfaction de l'autorité compétente de cet État membre, aient été prises par le propriétaire, l'exploitant ou le capitaine du navire en question pour assurer que le navire puisse entrer dans le port en toute sécurité ".

100 Article 17 de la Directive 95/21/CE du 19 juin 1995.
} 
La définition d'un cadre juridique relatif aux acteurs privés du transport maritime est l'autre stratégie au moyen de laquelle l'Union européenne entent lutter contre les navires sous-normes.

\section{B - La définition d'un cadre juridique relatif aux acteurs privés du transport maritime}

La définition de ce cadre juridique consiste à réglementer les sociétés de classification (1) et à édicter des normes relatives aux navires à coque simple (2).

\section{La réglementation relative aux sociétés de classification}

Le régime juridique des sociétés de classification, au sein de la Communauté européenne, est fixée par la Directive 94/57/CE du Conseil du 22 novembre $1994^{101}$.

Cette directive définit les mesures qui doivent être observées par les États membres et par les organismes concernés par l'inspection, la visite et la certification des navires en vue d'assurer la conformité avec les conventions internationales sur la sécurité maritime et la prévention de la pollution marine, tout en favorisant l'objectif de la libre prestation des services. Ce processus couvre notamment l'élaboration et la mise en œuvre de prescriptions de sécurité relatives à la coque, aux machines, aux installations électriques et aux dispositifs de commande des navires relevant du champ d'application des conventions internationales ${ }^{102}$.

Pour ce faire, l'Annexe de la Directive définit les critères minimaux auxquels doit satisfaire toute société de classification avant qu'elle ne soit agréée par un État membre. Ces critères sont multiples. Il est possible d'en souligner quelques-uns. Ainsi, la société de classification doit jouir d'une expérience étendue dans le domaine de l'évaluation de la conception et de la construction des navires de commerce. Elle doit avoir classé au moins 1.000 navires océaniques de plus de 100 tonneaux de jauge brute (tjb), représentant au moins cinq millions de tjb au total.

En outre, la société de classification doit employer un effectif technique proportionné au nombre de navires classés. Cet effectif équivaut, au moins, à 100 inspecteurs exclusifs ayant, au préalable, inspecté, 1.000 navires océaniques de plus de 100 tonneaux de jauge brute (tjb), au minimum. Le registre des navires inspectés par la société de classification

In extenso, la Directive s'intitule: Directive 95/21/CE du 19 juin 1995, concernant l'application aux navires faisant escale dans les ports de la Communauté ou dans les eaux relevant de la juridiction des États membres, des normes internationales relatives à la sécurité maritime, à la prévention de la pollution et aux conditions de vie et de travail à bord des navires (contrôle par l'État du port). Cette Directive a été publiée au Journal officiel $\mathrm{n}^{\circ} \mathrm{L} 157$ du 07/07/1995 p.0001-0019.

101 Directive 94/57/CE du Conseil du 22 novembre 1994 établissant des règles et normes communes concernant les organismes habilités à effectuer l'inspection et la visite des navires et les activités pertinentes des administrations maritimes, JO L 319 du 12.12.1994, p.20.

102 Article premier de la Directive 94/57/CE du 22 novembre 1994. 
doit être publié annuellement ou conservé dans une base de données électroniques accessible au public.

En vue d'éviter les conflits d'intérêt, le critère $\mathrm{n}^{\circ} 6$ des critères minimaux généraux exige que la société de classification ne doit pas être sous le contrôle de propriétaires ou de constructeurs de navires, ou d'autres personnes exerçant des activités commerciales dans le domaine de la fabrication, de l'équipement, de la réparation ou de l'exploitation des navires. Les recettes de l'organisme ne doivent pas dépendre de manière significative d'une seule entreprise commerciale. L'organisme agréé ne doit pas effectuer de tâches réglementaires s'il est lui-même le propriétaire ou l'exploitant du navire ou s'il a des liens professionnels, personnels ou familiaux avec ce propriétaire ou cet exploitant. Cette incompatibilité s'applique également aux inspecteurs employés par l'organisme agréé.

Les normes relatives aux navires à coque simple ne sont oubliées.

\section{L'édiction de normes relatives aux navires à coque simple}

En vue de lutter contre le phénomène des navires à coque simple, la Communauté européenne a adopté un règlement communautaire, en l'occurrence le règlement 2002/417/CE du Parlement européen et du Conseil du 18 février 2002 ${ }^{103}$. Ainsi que le prévoit son article premier, le règlement précité :

«a pour objectif d'établir un plan d'introduction accélérée pour l'application aux pétroliers à simple coque des prescriptions en matière de double coque ou de normes de conception équivalentes de la convention MARPOL 73/78, et d'interdire le transport à destination ou au départ de ports des États membres de produits pétroliers lourds dans des pétroliers à simple coque».

Sont visés par cette disposition, les pétroliers d'un port en lourd égal ou supérieur à 5.000 tonnes entrant, dans un port ou dans un terminal en mer relevant de la juridiction d'un État membre, quittant ces sites ou jetant l'ancre dans une zone relevant de la juridiction d'un État membre, quel que soit le pavillon sous lequel ils naviguent, battant le pavillon d'un État membre ${ }^{104}$. Cette disposition ne s'applique aux navires de guerre et les navires auxiliaires, ni aux autres navires appartenant à un État ou exploités par un État tant que celui-ci les utilise exclusivement à des fins gouvernementales et non commerciales ${ }^{105}$.

À l'analyse de l'article 4, il apparaît que les navires à simple coque de plus de vingt-cinq ans se verront interdire l'entrée dans les ports ou eaux intérieures des États membres de

103 Règlement 2002/417/CE du Parlement européen et du Conseil du 18 février 2002 relatif à l'introduction accélérée des prescriptions en matière de double coque ou de normes de conception équivalentes pour les pétroliers à simple coque, et abrogeant le règlement (CE) n²978/94 du Conseil.

104 Art. $2 \$ 1$.

105 Art. $2 \$ 2$. 
la Communauté à partir de 2003. Cette date a été fixée pour 2007 en ce qui concerne les pétroliers plus jeunes à coque simple qui ne respectent pas les prescriptions applicables aux pétroliers neufs et 2015 pour les pétroliers à simple coque conformes à ces prescriptions.

La «Oil Pollution Act» (OPA) 1990 n'est pas non plus en reste dans la lutte préventive engagée contre les pollutions marines par les navires.

\section{Paragraphe 2 : La " Oil Pollution Act" (OPA) 1990}

L'adoption de la OPA 1990 a été déterminée par une série d'accidents ayant causé des pollutions marines (A). Cette loi présente des spécificités par rapport au droit maritime international applicable aux navires pétroliers (B).

\section{A - $\quad$ Les accidents de pollution marine et l'adoption de la Oil Pollution Act 1990}

L'analyse des accidents de pollution marine (1) précédera le processus d'adoption de la Oil Pollution Act 1990 par le Congrès des États-Unis (2).

\section{La série de pollutions accidentelles provenant des pétroliers}

Les côtes maritimes et les eaux intérieures des États-Unis ont été le théâtre de plusieurs accidents survenus à des navires pétroliers. On mentionnera, entre autres, l'échouement de l'Exxon Valdez dans le détroit de Prince William, en Alaska. Ce naufrage survenu le 24 mars 1989 a provoqué le déversement de 38.500 tonnes de pétrole brut en mer. Avant l'accident du Deepwater Horizon survenu en avril 2010, le naufrage de l'Exxon Valdez constitue la marée noire la plus importante et la plus coûteuse qui soit survenue aux États-Unis.

Cette marée noire fut suivie, dans la même période, par d'autres marées noires de grande ampleur. Il est possible de mentionner, entre autres, le déversement d'hydrocarbures par le World Prodigy au large des côtes de Rhode Island en juin 1989 et celui de l'American Trader au large des côtes californiennes ${ }^{106}$.

Cette série d'accidents maritimes a accéléré le processus d'adoption de la Oil Pollution Act 1990 au Congrès.

\section{Le processus d'adoption de la Oil Pollution Act 1990 au Congrès}

Les deux Chambres du Congrès des États-Unis - à savoir le Sénat et la Chambre des Représentants - ont promptement réagi à cette série de marées noires en adoptant de nouvelles propositions de loi.

\footnotetext{
106 WANG (Hui), Civil Liability for Marine Oil Pollution - A comparative and economic study of international, US and Chinese compensation regime, Thesis, Erasmus University Rotterdam, 27 January 2011, p.180 ; RANDLE (R.), 'The Oil Pollution Act of 1990: Its Provisions, Intent, and Effects', Environmental Law Reporter, 1991, vol.21, pp.10119-10120.
} 
Le Sénat des États-Unis, après d'intenses débats, a adopté une proposition de loi, le 4 août 1989. Celle-ci avait pour objectif d'instituer un Code fédéral unique fixant des plafonds élevés d'indemnisation. En outre, la proposition de loi du 4 août 1989 prévoyait, d'une part, d'accroître le pouvoir des organismes fédéraux chargés d'appliquer les plans d'intervention d'urgence et, d'autre part, de rehausser le montant des indemnisations que doivent verser les auteurs de marées noires. Ce mécanisme juridique devait être complété par un fonds d'indemnisation financé par l'industrie pétrolière. Le montant maximum que pourrait verser le fonds d'indemnisation, au titre des dédommagements, est fixé à un milliard de dollar US par accident. Ce fonds d'indemnisation aura pour tâche de dédommager aussi bien l'État fédéral que les personnes privées au prorata des coûts de nettoyage et d'indemnisation qu'ils ont supportés ${ }^{107}$.

Cependant, le Sénat a refusé que la loi fédérale prévale sur la loi étatique lorsqu'un État fédéré choisirait de fixer un plafond d'indemnisation supérieur à celui prévu par la loi fédérale ${ }^{108}$.

Le 09 novembre 1989, la Chambre des Représentants a, elle aussi, adopté une proposition de loi dénommée H.R.1465. La mouture finale de cette proposition de loi élague pratiquement toutes les dispositions qui consacrent, en matière d'indemnisation et de lutte contre les marées noires, la prééminence des normes fédérales sur les normes étatiques.

La proposition de loi H.R.1465 prévoit également un deuxième palier d'indemnisation qui serait supporté par le propriétaire de la cargaison source de pollution ${ }^{109}$.

Finalement, la Chambre des Représentants et le Sénat des États-Unis ont adopté à l'unanimité, respectivement, les 2 et 4 août 1990, la Oil Pollution Act 1990. Le texte final ne retient pas la disposition relative à l'institution d'un deuxième pallier de responsabilité à la charge du propriétaire de la cargaison, tel que cela était prévu par la proposition de loi H.R.1465. En revanche, le texte final retient une disposition de la proposition de loi H.R.1465 qui prévoit un plafond de responsabilité plus élevé.

La Oil Pollution Act (OPA) 1990 comporte des spécificités par rapport aux normes internationales pertinentes, alors en vigueur.

\footnotetext{
107 WANG (Hui), Civil Liability for Marine Oil Pollution - A comparative and economic study of international, US and Chinese compensation regime, Thesis, Erasmus University Rotterdam, 27 January 2011, p.180.

108 Il est possible de suivre l'évolution des travaux préparatoires de la Oil Pollution Act 1990 en consultant les Auditions S.686, S.687, S.1066 et S.1223 du Sous-comité chargé de la protection de l'environnement, lors de la $1^{\text {ère }}$ session de la $101^{\text {ème }}$ Législature du Congrès des États-Unis, 1989, p.3. Ce sous-comité est un démembrement de la Commission sénatoriale sur l'environnement et les travaux publics.

109 Certains travaux retranscrivent les débats houleux sur la question de la prévalence de la norme fédérale sur la norme étatique. Cf. notamment CORBETT (C.) and BOVET (D.), Comprehensive Oil Spill Liability and Compensation Legislation, Proceedings 1989 Oil Spill Conference, 13-16 February, 1989, San Antonio, Texas, p.513-514. Cité par WANG (Hui), Civil Liability for Marine Oil Pollution - A comparative and economic study of international, US and Chinese compensation regime, op.cit, pp.182-183.
} 
La Oil Pollution Act (OPA) 1990 comportait des dispositions qui, lors de son adoption, constituaient des innovations en droit maritime. Ces innovations étaient nombreuses. Il est cependant possible de les regrouper en deux groupes : d'une part, l'instauration de la double coque (1) et, d'autre part, les mesures correctrices applicables à tout navire navigant dans les eaux intérieures des États-Unis (2).

\section{L'instauration diligente de la double coque}

La Section 4115 de la OPA 1990 est la première disposition juridique à instaurer l'obligation pour les navires pétroliers d'être munis d'une double coque ${ }^{110}$. Cette exigence s'applique aux navires d'un tonneau de jauge brute (tjb) supérieur à $5.000^{111}$. La mise en œuvre de cette exigence incombe au Ministre du transport ${ }^{112}$. Celui-ci devrait édicter, dans le délai de 12 mois à compter de l'entrée en vigueur de la OPA 1990, une réglementation qui oblige les navires pétroliers de $5.000 \mathrm{tjb}$ à se doter de structures et d'équipements protégeant de manière substantielle l'environnement.

La Section 4115 précitée fixe au $1^{\text {er }}$ janvier 2015, la date limite à laquelle tous les navires pétroliers doivent être munis d'une double coque. À l'expiration de cette date, aucun navire à coque simple ne devrait être autorisé à naviguer dans les espaces marins ou les eaux intérieures des États-Unis.

L'instauration de la double coque s'est avérée profitable pour la protection des eaux marines et des eaux intérieures des États-Unis. En effet, une récente étude du Congressional Research Service, un démembrement du Congrès des États-Unis, montre que les importations et la consommation états-unienne de pétrole ont fortement augmenté durant les deux décennies qui ont suivi l'adoption de la OPA 1990. Cependant, la quantité de pétrole déversée de manière accidentelle n’a pas suivie la même courbe ascendante ${ }^{113}$. Au contraire, elle a baissé.

Hormis les navires à double coque, la OPA 1990 prévoit des mesures correctrices applicables aux navires navigant dans les eaux intérieures des États-Unis.

\footnotetext{
110 La Section 4115 intitulée 'Establishment of double hull requirement for tank vessels' dispose : “ ...RULEMAKING. - The Secretary shall, within 12 months after the date of the enactment of this Act, complete a rulemaking proceeding and issue a final rule to require that tank vessels over 5,000 gross tons affected by section 3703 a of title 46, United States Code, as added by this section, comply until January 1, 2015, with structural and operational requirements that the Secretary determines will provide as substantial protection to the environment as is economically and technologically feasible". Cf. Oil Pollution Act of 1990 As Amended Through P.L. 106580, Dec. 29, 2000, 46 U.S.C. 3703 note.

111 Cette exigence s'applique aussi bien aux navires en construction qu'à ceux qui naviguent déjà mais dont l'âge oscillerait de 23 à 30 ans à l'horizon 2005. Les dates limites de retrait de ces navires sont respectivement fixées en 2010 et 2015. Cf. WANG (Hui), 'Recent Developments in the EU Marine Oil Pollution Regime', in FAURE (Michael) and HU (James) (eds), Prevention and Compensation of Marine Pollution Damage - Recent Developments in Europe, China and the US, The Hague, Kluwer Law International, 2006, p.14.

112 En américain, il est désigné sous le nom de 'The Secretary of Transportation'.

113 WANG (Hui), Civil Liability for Marine Oil Pollution - A comparative and economic study of international, US and Chinese compensation regime, op.cit, p.196.
} 
2. Les mesures correctrices applicables à tout navire navigant dans les eaux intérieures des États-Unis

Ces mesures correctrices sont contenues dans la Section 4107 et la Section 4109 de la OPA 1990.

La Section 4109 de la OPA 1990 prévoit l'examen périodique de l'épaisseur des coques des navires de commerce. À cet effet, le Ministre des Transports dispose d'un délai légal d'un (1) an à compter de l'entrée en vigueur de la OPA 1990 pour édicter une réglementation relative aux standards minimum applicables aux navires construits ou aménagés pour le transport de pétrole ${ }^{114}$. L'examen périodique de l'épaisseur des navires pétroliers vise essentiellement les navires âgés de plus de trente (30) ans qui opèrent dans les eaux intérieures et la Zone économique exclusive (ZEE) des États-Unis ${ }^{115}$.

Hormis l'examen périodique de l'épaisseur des coques de navire, la Section 4107 de la OPA 1990 confère au Ministre des transports (The Secretary of Transportation) la compétence pour mener une étude en vue de déterminer les pouvoirs supplémentaires qu'il pourrait exercer en matière de fixation de l'itinéraire des navires ${ }^{116}$. Cette disposition s'explique par la volonté de prévenir tout risque de collision, de déversements accidentels et de dommages causés par le trafic maritime ${ }^{117}$.

En sus des règles relatives à la construction des navires pétroliers, la prévention de la pollution massive du milieu marin s'opère au moyen de la réglementation des rejets polluants d'hydrocarbures.

\footnotetext{
114 La Section 4109 dispose: 'Not later than 1 year after the date of the enactment of this Act, the Secretary shall issue regulations for vessels constructed or adapted to carry, or that carry, oil in bulk as cargo or cargo residue establishing minimum standards for plating thickness'.

115 'Not later than 1 year after the date of the enactment of this Act, the Secretary shall issue regulations for vessels constructed or adapted to carry, or that carry, oil in bulk as cargo or cargo residue ...requiring, consistent with generally recognized principles of international law, periodic gauging of the plating thickness of all such vessels over 30 years old operating on the navigable waters or the waters of the exclusive economic zone'. Cf. Section $4109 \$ 2$ de la OPA 1990.

116 Selon la Section 4107 b 1) A): 'The Secretary shall conduct a study of whether the Secretary should be given additional authority to direct the movement of vessels on navigable waters and should exercise such authority...' 117 'The Secretary shall conduct a study ...to determine and prioritize the United States ports and channels that are in need of new, expanded, or improved vessel traffic service systems, by evaluating ...the risks of collisions, spills, and damages associated with that traffic ...'. Cf. Section 4107 b 1) B) ii).
} 


\section{CHAPITRE II : LA RÉGLEMENTATION DES REJETS POLLUANTS D'HYDROCARBURES}

La pollution pélagique résulte certes d'un accident maritime (en l'occurrence le naufrage d'un pétrolier ou celui d'un navire servant au transport de produits chimiques). Mais, elle peut aussi avoir pour cause un acte délibéré du transporteur de la substance polluante. En effet, les règles analysées précédemment ont pour objet d'éviter autant que faire se peut, les rejets de substances nuisibles par les navires. D'autres règles visent à limiter ou à interdire lors de l'exploitation du navire, les rejets de substance nuisibles.

La lutte contre cette forme de pollutions délibérées du milieu marin est principalement régie par la Convention MARPOL 73/78. La réglementation des rejets polluants d'hydrocarbures tient à la prévention des rejets polluants (Section 1) et la répression pénale des infractions aux normes préventives des pollutions marines (Section 2).

\section{Section 1: La prévention des rejets polluants}

La Convention MARPOL 73/78 pose le principe de l'interdiction des rejets polluants (paragraphe 1). Elle définit en sus des mesures d'application de ce principe en termes surtout de la sécurité du navire en matière de contrôle et de formation d'équipage (paragraphe 2).

\section{Paragraphe 1: Le principe de l'interdiction des rejets polluants}

Le régime juridique des rejets polluants est dualiste. En effet, les Annexes I et II à la Convention MARPOL 73/78 distinguent deux catégories de zones marines ou écosystème marins, dont les degrés de la vulnérabilité sont inégaux. Les unes, jugées moins vulnérables, ont été qualifiées de "zones ordinaires » (A) tandis que les autres, du fait de leur fragilité avérée, ont été considérées comme "zones spéciales » $(B)$.

\section{A - Au niveau des zones marines ordinaires}

La Convention MARPOL procède à la fixation des seuils de rejets autorisés au niveau des zones ordinaires.

La fixation de seuils de rejets autorisés est prévue par la Règle 9 de l'Annexe I à la Convention MARPOL 73/78.

Le texte interdit les rejets d'hydrocarbures dans le milieu marin. Le $\$ 1$ de la Règle 9 à l'Annexe I dispose :

«...il est interdit à tout navire auquel la présente Annexe s'applique de rejeter à la mer des hydrocarbures ou des mélanges d'hydrocarbures ...».

Ce principe d'interdiction n'est cependant pas absolu. La Règle $9 \$ 1$ alinéa a) prévoit des conditions à cette interdiction. Celles-ci sont relatives aux propriétés physiques et 
aux quantités d'hydrocarbures autorisées. Au regard de la Règle $9 \$ 1$ alinéa $a$ ), il est possible pour les pétroliers de procéder à des rejets en observant les conditions suivantes :

i) le pétrolier n'est pas dans une zone spéciale;

ii) le pétrolier est à plus de 50 milles marins de la terre la plus proche ;

iii) le pétrolier fait route ;

iv) le taux instantané de rejet des hydrocarbures ne dépasse pas 30 litres par mille marin ;

v) la quantité totale d'hydrocarbures rejetée à la mer ne dépasse pas, pour les pétroliers existants, 1/15.000 de la quantité totale de la cargaison particulière dont les résidus proviennent, et pour les pétroliers neufs, $1 / 30.000$ de la quantité totale de la cargaison particulière dont les résidus proviennent; et

vi) le pétrolier utilise un dispositif de surveillance continue et de contrôle des rejets d'hydrocarbures et un ensemble de citernes de décantation tels que prescrits à la Règle 15 de la présente Annexe.

Contrairement aux zones maritimes ordinaires, l'interdiction des rejets d'hydrocarbures en mer est rigoureusement affirmée en ce qui concerne les zones spéciales.

\section{B - Au niveau des zones marines spéciales}

Les zones marines spéciales, sont soumises à une application rigide du principe. Cela se ressent au titre de la notion de «zone spéciale » (1) et du régime juridique applicable (2).

\section{La notion de "zone marine spéciale»}

Une particularité nouvelle est apparue dans la Convention MARPOL de 1973. C'est le concept de «zones spéciales». Celles-ci sont considérées comme des zones si vulnérables aux pollutions par les hydrocarbures que les rejets y sont strictement interdits à quelques exceptions près.

Selon la Règle $10 \$ 1$ de l'Annexe I, les zones spéciales sont la zone de la mer Méditerranée, la zone de la mer Baltique, la zone de la mer Noire, la zone de la mer Rouge, la «zone des golfes », la zone du golfe d'Aden, la zone de l'Antarctique.

À cette liste s'ajoute, depuis l'entrée en vigueur le ler février 1999 des amendements du 23 septembre 1997, la zone nord-ouest de l'Europe. Cette zone comprend : la mer du Nord, la mer d'Irlande, la mer celtique, la Manche et une partie de l'Atlantique nordest $^{118}$.

L'application rigide du principe de l'interdiction est surtout illustrée par le régime applicable.

${ }^{118} C f$. www.imo.org/HOME.html. 


\section{Le régime juridique applicable aux zones spéciales}

Les navires pétroliers se trouvant dans une "zone spéciale » sont strictement interdits de procéder à des rejets d'hydrocarbures. Dans cette zone, seuls les navires d'une jauge brute inférieure à 400 tonnes peuvent, à des conditions très strictes, rejeter légalement des hydrocarbures ${ }^{119}$.

Concernant l'Antarctique, le principe de l'interdiction des rejets est plus strict. En effet, la Règle $10 \$ 8$ a) fait obligation aux Parties à la Convention MARPOL 73/78 de mettre en place (dans leurs pays) des installations de réception des résidus d'hydrocarbures pour leurs navires en partance ou en provenance de la zone de l'Antarctique. Le $\$ 8 b$ ), pour sa part, met à la charge des Parties à la Convention MARPOL 73/78 l'obligation de veiller à ce que les navires battant leur pavillon soient équipés d'une ou plusieurs citernes suffisantes qui leur permettent de conserver à bord toutes les boues, tout le ballast pollué, toutes les eaux de nettoyage des citernes et tous les autres résidus et mélanges d'hydrocarbures pendant qu'ils naviguent dans la zone de l'Antarctique. Ces boues et autres résidus doivent être traités dans des installations portuaires situées en dehors de cette zone.

Des interrogations relatives au concept de "zones spéciales » pourraient être formulées : Qu'est ce qu'une zone maritime particulièrement vulnérable? Quels sont les critères et les procédures de désignation d'une zone maritime particulièrement vulnérable?

Il s'agit d'une zone qui en raison de l'importance reconnue de leurs caractéristiques écologiques, socio-économiques ou scientifiques et son éventuelle vulnérabilité aux dommages causés par les activités des transports maritimes internationaux devrait faire l'objet d'une protection particulière, conférée par des mesures prises par l'OMI ${ }^{120 .}$

L'Organisation maritime internationale (OMI) est le seul organisme international habilité à désigner les zones maritimes particulièrement vulnérables et à adopter des mesures de protection appropriées. Quant à la procédure, seul un gouvernement membre de l'OMI est habilité à présenter à l'OMI une demande de désignation de zones maritimes particulièrement vulnérables et l'adoption des mesures de protections adéquates $^{121}$.

Quant aux critères de désignation (identification) d'une zone maritime particulièrement vulnérable, ils sont au nombre de trois. Ce sont le critère écologique, le critère socio-

\footnotetext{
119 Voir Règle 10 de l'Annexe I de la Convention MARPOL 73/78.

120 Cf. OMI., Comité de protection du milieu marin, identification et protection des zones spéciales et des zones maritimes particulièrement vulnérables, Rapport du groupe de travail par correspondance, MEPC 5/8/2, 15 avril 2005, p.3.

121 Cf. OMI., Comité de protection du milieu marin, identification et protection des zones spéciales et des zones maritimes particulièrement vulnérables, Rapport du groupe de travail par correspondance, MEPC 5/8/2, 15 avril 2005, p.7.
} 
économique et le critère scientifique. Ces critères ne s'appliquent uniquement qu'en ce qui concerne l'adoption des mesures destinées à protéger ces zones contre les dommages ou la menace identifiée de dommages dus aux activités des transports maritimes internationaux. Ce qui exclut notamment les opérations d'immersion visée par la Convention de Londres de 1972 sur la prévention de la pollution résultant de l'immersion des déchets ${ }^{122}$.

La prévention des rejets polluants est aussi obtenue au moyen de la sécurité du navire en matière de contrôle et de formation d'équipage.

\section{Paragraphe 2 : La sécurité du navire en matière de contrôle et de formation d'équipage}

En vue de prévenir de telles catastrophes écologiques, des mesures de sécurité ont été adoptées. Ces mesures, dans l'ensemble, s'attellent à lutter contre les navires sousnormes ${ }^{123}$. La lutte contre les pollutions accidentelles se fait aussi au moyen de la police de la mer. En matière de lutte contre les pollutions marines accidentelles, la police de la mer revêt entre autres aspects, la police de la sécurité du navire. Celle-ci se compose de normes de contrôle du navire (A) et de la formation du personnel navigant (B).

\section{A - Les normes de contrôle du navire}

Ces normes se composent des mesures relatives aux visites et inspections (1) et de celles ayant trait au Certificat international de prévention de la pollution par les hydrocarbures (2).

\section{Les visites et inspections}

En vertu de l'article 8 de la Convention MARPOL 73/78, tout évènement entraînant ou pouvant entraîner le rejet en mer de substances nuisibles doit faire l'objet d'un rapport. Celui-ci sera, le cas échéant, transmis à l'État côtier le plus proche susceptible d'être touché par l'évènement.

La Convention MARPOL 73/78 laisse aux États parties la latitude de désigner le fonctionnaire ou l'organisme compétent pour recevoir et analyser les rapports sur les

\footnotetext{
122 Voir OMI, Comité de protection du milieu marin, identification et protection des zones spéciales et des zones maritimes particulièrement vulnérables, $\mathrm{n}^{\circ} 4$, Paris, 15 avril 2005, p.8.

123 Cette expression désigne les navires qui ne respectent pas les normes de sécurité avec le plus souvent un équipage non formé. L'expression "sous-norme " a été employée par certains auteurs dont Patrick DAILLIER, Martin NDENDÉ et Catherine ROCHE. Cf. DAILLIER (Patrick), " Droit communautaire et protection de l'environnement marin », ADMA, 1982, p.289 ; NDENDÉ (Martin), " Police de la mer », Editions Techniques, Jurisclasseur, Fascicule 209, 1993, p.9 et ROCHE (Catherine), « Après l'Erika : la prévention de la pollution des mers par le renforcement de la sécurité maritime en Europe (Erika I) », RJE, n³, 2002, p.377 et suivants, Cité par TIEBLEY, La Côte d'Ivoire et la gestion durable des ressources naturelles marines, op. cit, p148.
} 
évènements sources de pollution marine $\mathrm{e}^{124}$. Si le navire est au port, la connaissance des dangers pour le milieu marin résulte des différentes visites obligatoires effectuées à bord par les autorités compétentes. Ces visites ont pour vocation d'associer sécurité et prévention de la pollution.

Ainsi en République de Côte d'Ivoire, le décret nº8-42 du 28 janvier 1998 portant organisation du Plan d'urgence de lutte contre les pollutions accidentelles en mer, en lagune et dans les zones côtières prévoit des mesures exorbitantes dans le cadre de la lutte et la maîtrise des déversements d'hydrocarbures. En effet, le ministre chargé de l'environnement est habilité à prendre toutes les dispositions utiles en vue d'assurer l'efficacité des interventions notamment par le recours au droit de réquisition. Il met en demeure le propriétaire, l'affréteur, le commandant, l'armateur ou le gérant du navire ou de l'aéronef de prendre des mesures nécessaires pour y mettre fin. Il en informe le ministre des transports. Si les mises en demeure restent sans effet, ou ne produisent pas les résultats escomptés dans le délai imparti, et en cas d'urgence, le ministre chargé de l'environnement prend les mesures nécessaires pour prévenir, atténuer ou éliminer les risques de pollution. Les frais occasionnés par cette intervention seront supportés par le responsable de la pollution ${ }^{125}$.

Les normes de contrôle des navires exigent également le certificat international de prévention de la pollution par les hydrocarbures.

\section{Le Certificat international de prévention de la pollution par les hydrocarbures}

Les titres de navigation pour la prévention de la pollution sont essentiellement ceux déterminés par la Convention MARPOL 73/78 ${ }^{126}$. L'article $5 \$ 2$ de cette convention prévoit que " tout navire ...est tenu de posséder un Certificat délivré conformément aux dispositions des règles ...». À cet effet, il est soumis, dans les ports et terminaux au large relevant de la juridiction d'une autre Partie, à une inspection effectuée par des fonctionnaires dûment autorisés à cet effet par ladite Partie.

Concernant particulièrement les navires pétroliers, la Règle $4 \$ 1$ de l'Annexe I précise que l'inspection obligatoire s'applique à tout pétrolier d'une jauge brute égale ou supérieure à 150 tonneaux, ainsi que tout autre navire d'une jauge brute égale ou supérieure à 400 tonneaux. Un tel navire est soumis à une visite initiale, avant sa mise en service ou avant que le certificat ne lui soit délivré pour la première fois, à des visites

\footnotetext{
124 En France, le décret $n^{\circ} 78-421$ du 24 mars 1978 relatif à la lutte contre la pollution marine accidentelle oblige le capitaine du navire transportant des hydrocarbures, dès l'entrée dans les eaux territoriales françaises, d'adresser au préfet maritime, un message indiquant la date et l'heure d'entrée dans les eaux, sa position, la route et la vitesse du navire, la nature du chargement.

${ }^{125}$ Voir les articles 11, 12 alinéas 1 et 3 du décret $n^{\circ} 98-42$ du 28 janvier 1998.

126 Dans ce cas d'espèce, il s'agit du certificat international de prévention de la pollution par les hydrocarbures. Sa validité est de 5 ans et ne peut être renouvelé qu'après une nouvelle inspection. En France, par exemple, le bureau Veritas est l'autorité compétente pour mener ces visites.
} 
périodiques, à une visite intermédiaire au minimum pendant la période de validité du certificat $^{127}$.

Un certificat international de prévention de la pollution par les hydrocarbures est délivré à tout pétrolier, après visite effectuée conformément aux dispositions de la Règle 4 de l'Annexe I. Le certificat international d'hydrocarbures est prévu par l'article VII $\$ 2$ de la Convention CLC 1992. Ce certificat est délivré soit par l'autorité soit par un agent ou un organisme dûment autorisé par elle ${ }^{128}$.

En outre, le Code de la marine marchande prévoit que tout navire ainsi que tout engin flottant effectuant une navigation maritime soit par ses propres moyens soit à la remorque d'un autre navire soit munis des titres de sécurité129. L'article 13 dudit Code exige qu'avant de quitter un port ivoirien, tout navire est soumis à une visite de partance. De même, tous les navires étrangers touchant un port ivoirien sont soumis aux obligations liées à la sécurité maritime ${ }^{130}$.

La Convention MARPOL 73/78, afin de prévenir tout risque de pollution, prescrit des visites obligatoires par des experts agrées ainsi qu'un système de certificat délivré aux navires après chaque visite de vérification ${ }^{131}$.

Le principe repose sur l'obligation pour l'État partie d'inspecter les navires battant son pavillon pour contraindre le navire à posséder un certificat international prouvant qu'il a été valablement visité et qu'il est conforme aux normes de prévention de la pollution ${ }^{132}$.

L'inspecteur peut interdire ou ajourner le départ du navire qui ne lui semblerait ne pouvoir prendre la $\operatorname{mer}^{133}$ sans danger pour le milieu marin ${ }^{134}$. Car, les navires étrangers

\footnotetext{
127 Voir Règle 4 de l'Annexe I de la Convention MARPOL 73/78.

128 Voir les Règles 4, 6, 7 et 8 de l'Annexe I de la Convention MARPOL 73/78, à propos de la délivrance des certificats, forme et durée de validité.

${ }^{129} C f$. articles 8 et 9 du Code de la marine marchande de la République de Côte d'Ivoire.

130 Selon l'article 10 du Code de la marine marchande, par sécurité maritime, il faut entendre l'ensemble des moyens matériels qui donnent au navire: coque, appareils propulseurs, apparaux divers, instruments et documents nautiques ;

- La possibilité d'effectuer normalement et sans danger, dans les parages autorisés, la mission à laquelle il est destiné dans les conditions prévisibles d'exploitation ;

- L'ensemble des moyens de lutte contre l'incendie et les voies d'eaux;

- Le bon état du matériel de sauvetage collectif et individuel pour l'équipage et les passagers ainsi que les mesures en cas d'alarme et d'évacuation du navire;

- L'arrimage satisfaisant des marchandises et la stabilité du navire; l'observation des règles de franc bord et de la réglementation concernant les marchandises dangereuses ;

- Les dispositions relatives à l'hygiène et à l'habitabilité, au matériel médical et pharmaceutique.

131 Article 5 de la Convention MARPOL 73/78.

132 Étant entendu que cette disposition concerne également les navires des États non parties à la convention, ainsi que nous l'avons déjà indiqué plus haut.

133 Conformément à l'article $5 \S 3$ de la Convention MARPOL, les autorités maritimes des États parties peuvent refuser à un navire l'accès d'un port ou d'un terminal relevant de sa juridiction.

${ }_{134}$ Cf. (BECET) Jean Marie et Le MORVAN (Didier), Droit du littoral et de la mer côtière, Paris, Economica, 1991, p.191.
} 
doivent également être soumis à une visite de partance. Le navire ne sera réputé avoir satisfait aux dispositions relatives à la prévention de la pollution que si le capitaine présente les titres prévus par la convention MARPOL 73/78.

L'autre modalité de la police de la mer s'analyse en la formation du personnel navigant.

\section{B - $\quad$ La formation du personnel navigant}

Ainsi que le soulignait le professeur Martin NDENDÉ, le facteur humain est devenu "un élément clé du système actuel de contrôle de la sécurité de la navigation maritime $»^{135}$. Il est en effet très important pour un État qui reçoit un navire dans ses eaux, de savoir que l'équipage qui le compose présente toutes les garanties de formation, de qualification et d'expérience. Car la formation des gens de mer joue un rôle capital dans la sécurité maritime et dans la protection de l'environnement marin. D'autant plus qu'à l'heure actuelle, foisonnent des entreprises maritimes spécialisées dans le marchandage des équipages sous qualifiés recrutés dans les pays du tiers-monde et employés sous pavillon de complaisance ${ }^{136}$.

Ainsi, le droit maritime international a arrêté au plan international un niveau minimal de formation des gens de mer. A ce titre, l'article $1^{\text {er }}$ alinéa 2 de la Convention internationale de 1978 sur les normes de formation des gens de mer, de délivrance des brevets et de veille déclare :

"Les Parties s'engagent à promulguer toutes lois et tous décrets, ordres et règlements et à prendre toutes autres mesures nécessaires pour donner à la Convention son plein et entier effet, afin de garantir que, du point de vue de la sauvegarde de la vie humaine et des biens en mer ainsi que de la protection du milieu marin, les gens de mer à bord des navires ont les qualifications et l'aptitude correspondant à leurs fonctions.»

L'article $94 \$ 4 b$ ) de la CMB institue l'obligation pour tout navire d'être piloté par un capitaine et des officiers "possédant les qualifications voulues ${ }^{137}$. Cette exigence vise à minimiser autant que possible les risques élevés d'accidents de mer que constituent les équipages sous qualifiés.

La politique du contrôle de la sécurité de la navigation maritime au titre de la qualification du personnel navigant est assurée notamment au moyen de deux Conventions. Il s'agit de la Convention STCW de 1978 et de la Convention du travail

\footnotetext{
135 NDENDÉ (Martin), « La police de la mer », Editions Techniques, Jurisclasseurs, Fascicule 209, 1993, p.8.

136 Ibidem.

137 Selon l'article $94 \$ 4$ b) de la CMB, "tout navire est confié à un capitaine et à des officiers possédant les qualifications voulues, en particulier en ce qui concerne la manouvre, la navigation, les communications et la conduite des machines, et que l'équipage possède les qualifications voulues et est suffisamment nombreux eu égard au type, à la dimension, à la machinerie et à l'équipement du navire ».
} 
maritime du 23 février 2006 (1). Celles-ci semblent recevoir application en droit ivoirien à l'instar d'autres Etats ${ }^{138}$ soucieux de la protection du milieu marin (2).

\section{Le contrôle de la sécurité de la navigation maritime}

Nous exposerons d'abord le contrôle de la sécurité maritime au moyen de la Convention STCW (a), ensuite celui de la Convention du travail maritime (b).

\section{A - Le contrôle de la sécurité maritime au moyen de la Convention STCW de 1978}

Depuis sa création, en 1959, l'Organisation maritime internationale (OMI) s'est efforcée non seulement d'améliorer la sécurité des navires, mais aussi d'élever les normes qui régissent les équipages ${ }^{139}$.

Parmi les résolutions adoptées, il en est une qui invite les gouvernements à prendre toutes les mesures relatives à la formation des capitaines, officiers et marins pour l'utilisation des aides à la navigation, ainsi que d'autres équipements participant à la sécurité en mer, le sauvetage, les systèmes de prévention de détection et d'extinction des incendies ${ }^{140}$.

La Convention internationale sur la formation des gens de mer, la délivrance des brevets et la veille définit les règles relatives à la formation du personnel navigant ${ }^{141}$.

Révisée en $1995^{142}$, la Convention STCW réglemente notamment les titres étrangers telles que la délivrance des visas, les obligations des écoles maritimes et celles de l'Etat du port $^{143}$.

\footnotetext{
138 Au plan européen, la Communauté européenne a définit des normes de formation des gens de mer à travers la Directive 2008/106/CE du Parlement européen et du Conseil du 3 décembre 2008 concernant le niveau minimal de formation des gens de mer en application de la Convention STCW de 1978.

139 La Convention STCW de 1978 est entrée en vigueur le 28 avril 1984. Cf. BLAVEC (André), "Les conventions STCW et STCW-F, Dossier : La formation aux métiers de la mer », Revue maritime n467, janvier 2004, p.2

140 Cf. BLAVEC (André), "Les conventions STCW et STCW-F, Dossier : La formation aux métiers de la mer », Op., cit., p.3

${ }^{141}$ En anglais cette Convention s'intitule International Convention on Standards of Training, Certification and Watchkeeping for Seafarers ou Convention sur les normes de formation des gens de mer, de la délivrance des brevets et de veille. Elle a été adoptée sous les auspices de l'OMCI (actuelle OMI) en 1978. La Convention STCW 1978 a été profondément amendée en 1995 par la Conférence des Parties de l'OMI. Ces amendements portent sur les chapitres II, III, IV, VII et VIII de l'Annexe à la Convention. L'ampleur des amendements est telle que d'aucuns n'hésitent pas à l'appeler Convention STCW 1995. Cf. www.imo.org/Home.html.

142 Il fut admis, vers la fin des années 80 , que la Convention STCW 78 n'avait pas entièrement atteint ses objectifs. Les principales causes étaient:

- le manque de précision des normes

- l'interprétation que chacun pouvait donner à des phrases du type "...à la satisfaction de l'administration » ce qui conduisait à une très large disparité dans l'application des normes.

- de plus, la convention STCW 78 avait été conçue pour des navires traditionnels avec une séparation nette entre le pont et la machine.
} 
En ce qui concerne la délivrance des visas (titres étrangers), pour reconnaître et valider un titre étranger, elle ne peut être déléguée par l'administration. Les originaux des brevets doivent être présentés. Avant de délivrer un visa, l'administration doit s'assurer de l'authenticité du titre présenté ainsi que de sa validité (date d'échéance, suspendu, retiré ...). Pour ce faire, il est essentiel qu'un dispositif d'enregistrement centralisé, conserve la trace de tous les titres émis ou remplacés. Seul, un système de contrôle et d'enregistrement centralisé permet une information sûre et rapide pour répondre aux questions formulées par l'administration elle-même, mais aussi par les officiers chargés du contrôle par l'État du port (Port State Control - PSC) dans les autres pays.

Quant aux obligations des écoles maritimes et des compagnies, la Convention STCW révisée exige une nouvelle approche dans la démonstration de l'aptitude du marin pour exercer telle ou telle fonction: c'est la méthode dite de «la preuve par la compétence ». Le concept de compétence implique l'évaluation de l'aptitude à réaliser des connaissances et de la compréhension; de la capacité à utiliser les savoir-faire et appliquer ses connaissances et sa compréhension pour réaliser la performance lors d'une épreuve pertinente.

En outre, chaque compagnie porte en particulier la responsabilité en matière de sécurité et de prévention contre les pollutions pour les navires qu'elle possède, gère ou exploite. Elle doit s'assurer que tous les marins affectés sur un navire sont titulaires d'un brevet approprié conformément aux dispositions de la convention ou de l'État du pavillon ; que l'effectif est conforme à la décision d'effectifs; que les documents et renseignements concernant les marins sont conservés à bord et tenus à jour ; que les marins nouvellement affectés sont familiarisés (dans une langue qu'ils comprennent) avec leurs tâches, les installations, les procédures de routine ou d'urgence; que les effectifs du navire sont capables de coordonner leurs activités en cas d'urgence ou de risque de pollution $^{144}$.

Enfin, s'agissant du contrôle effectué par l'Etat du port, il renforce les obligations des compagnies au moyen des inspecteurs chargés entre autres de vérifier les qualifications et les compétences des gens de mer. Les inspecteurs sont habilités à contrôler que les marins sont titulaires des certificats requis ou de dispenses ${ }^{145}$; que des visas sont délivrés dans le cas de marins de nationalité différente de celle du pavillon; que le nombre de marins est en rapport avec la liste type d'équipage imposée par l'État du pavillon ${ }^{146}$.

Les principales modifications apportées par STCW-1995mises en œuvre en février 2002 peuvent être résumées selon les rubriques comme suit:

\footnotetext{
${ }^{143}$ Cf. article $1^{\text {er }}$ alinéa 2 de la Convention STCW de 1978

144 Cf. BLAVEC (André), "Les conventions STCW et STCW-F, Dossier : La formation aux métiers de la mer », Op., cit., p.4

145 Conformément à l'article VIII de la Convention STCW de 1978

146 Cf. article X de la Convention STCW de 1978
} 
- Brevets et visas : Les titres étrangers doivent être reconnus et visés par l'État du pavillon.

- Procédures de contrôles : Le respect de la décision d'effectif et la capacité à maintenir les normes de veille peuvent être contrôlées par l'État du port.

- Dispositions nationales : Une enquête est prévue dans le cas d'incompétences avérées. Des amendes doivent aussi être prévues pour des infractions relatives à l'application de la convention.

- Formation et évaluation : Les règles exigent que les formateurs et les évaluateurs, que ce soit à bord ou à terre, soient qualifiés.

- Normes de qualité : Un système de normes de qualité doit être mis en place pour la formation et la certification, une évaluation externe tous les 5 ans.

- Normes médicales, Délivrance et enregistrement des titres maritimes : La règle exige que des normes médicales soient mises en place. Un registre des titres maritimes accessible en permanence par tout pays, doit être mis en place et tenu à jour.

- Reconnaissance des titres : La règle exige de l'État du pavillon qu'il confirme que les normes ont bien été respectées avant la délivrance d'un visa.

- Revalidation des titres : Les besoins de mise à niveau doivent être identifiés et les cours de formation instaurés

- Responsabilités des compagnies: Les compagnies sont tenues responsables de la certification des équipages, de la familiarisation à bord et du respect de la décision d'effectif ${ }^{147}$.

La Convention du travail maritime de 2006 en ce qu'elle apparait comme un pilier de l'élimination des navires sous-normes, complète la STCW ci-dessus examinée.

\section{B - Le contrôle de la sécurité maritime au moyen de la Convention du travail maritime de l'OIT $^{148}$ de 2006}

De façon générale, la Convention du travail maritime de $2006^{149}$ a deux objectifs fondamentaux. Il s'agit dans l'optique du travail décent, de rendre le système de

\footnotetext{
147 Cf. BLAVEC (André), "Les conventions STCW et STCW-F, Dossier : La formation aux métiers de la mer», Op., cit, p.2, l'auteur dresse un tableau récapitulatif des principales modifications apportées par la STCW-95.

148 Créée au lendemain de la première guerre mondiale par le Traité de Versailles, l'OIT a pour mission "l'amélioration du sort des travailleurs et l'instauration d'un régime de travail plus humain, seules garanties d'une paix solidement établie». Cf. VALTICOS, (N.) "Cinquante année d'activité de l'Organisation internationale du travail », R.I.T. 1996, pp.431et s., cité par NDENDE (Martin), "L'activité normative des Nations -Unies dans le domaine des transports maritimes internationaux ", in Revue Africaine des Affaires Maritimes et des Transports, $\mathrm{n}^{\circ} 1$, juillet 2009 , p. 10

149 La Convention du travail maritime a été adoptée le 23 février 2006, à Genève, lors de la 94è session de la Conférence internationale du travail, qui correspondait à sa 10è session maritime, par l'Organisation Internationale du Travail.

Elle constitue le 4è pilier du droit international du transport maritime avec les 3 conventions de l'Organisation Maritime Internationale (OMI), la convention SOLAS sur la sécurité et la sauvegarde de la vie humaine en mer, la Convention MARPOL sur la prévention de la pollution en mer, la Convention STCW révisée en 1995,
} 
protection des normes internationales de travail plus proches des travailleurs concernés, sous une forme mieux adaptée à ce secteur d'activité internationale $\mathrm{e}^{150}$.

En outre, elle vise à atteindre une meilleure application de ces normes internationales par les gouvernements et les armateurs, afin d'éviter un fardeau inégal en cas de conditions de travail décentes ${ }^{151}$. En ce sens que le défaut de celles-ci se trouve très souvent à l'origine des accidents en mer.

Dans cette optique un auteur a dû affirmer que: "Les travailleurs des transports constituent, par excellence la catégorie des travailleurs appelés à franchir les frontières nationales dans l'exercice de leur activité et nécessitent de ce fait une protection adaptée, cohérente et universellement respectée.» ${ }^{152}$

Ainsi la Convention notamment en son article IV définit-elle des conditions minimales de travail des gens de mer en posant que:

"Tous les gens de mer ont droit à un lieu de travail sûr et sans danger où les normes de sécurité sont respectées.

Tous les gens de mer ont droit à des conditions d'emploi équitables.

Tous les gens de mer ont droit à des conditions de travail et de vie décentes à bord des navires.

Tous les gens de mer ont droit à la protection de la santé, aux soins médicaux, à des mesures de bien-être et aux autres formes de protection sociale.

Tout Membre veille, dans les limites de sa juridiction, à ce que les droits en matière d'emploi et les droits sociaux des gens de mer, soient pleinement respectés conformément aux prescriptions de la présente convention. Sauf disposition contraire de celle-ci, le respect de ces droits peut être assuré par la législation nationale, les conventions collectives applicables, la pratique ou d'autres mesures. "

relative aux brevets maritimes et à la veille à la passerelle. Ces quatre piliers participent à l'élimination des navires sous normes. Cf. CHAUMETTE(Patrick), La Convention du travail maritime, OIT, 2006, Neptunus, revue électronique, Centre de Droit Maritime et Océanique, Université de Nantes, Vol. 13 2007/1, p.1, consulté sur le site http://www.cdmo.univ-nantes.fr/centre-droit-maritime-oceanique/cdmo, le 23 mai 2011

150 Selon la Règle 1.3, la Convention du travail maritime a entre autres, pour objet d'assurer que les gens de mer sont formés ou qualifiés pour exercer leurs fonctions à bord des navires :

- pour travailler à bord d'un navire, un marin doit avoir suivi une formation, être titulaire d'un certificat de capacité ou être qualifié à un autre titre pour exercer ses fonctions.

- Les gens de mer ne doivent être autorisés à travailler à bord d'un navire que s'ils ont suivi avec succès une formation à la sécurité individuelle à bord des navires.

- Les formations et brevets conformes aux instruments ayant force obligatoire adoptés par l'Organisation maritime internationale sont considérés comme répondant aux prescriptions des paragraphes 1 et 2 de la présente règle.

151 Cf. CHAUMETTE (Patrick), « La Convention du travail maritime, OIT, 2006, » Op.cit., pp.1 et 3

152 Cf. MORGENSTERN (Félice), "Aspects actuels du Droit social international dans le domaine des transports », Colloque SFDI sur les "Aspects actuels du Droit international des transports », pp228 et s., cité par NDENDE (Martin), op. cit.,p.10 
Pour le suivi des recommandations sur les conditions de travail décent du personnel marin, la Convention sur le travail maritime met des obligations à la charge des Etats parties. A ce titre, elle déclare que :

"Tout Membre vérifie que les dispositions de sa législation respectent, dans le contexte de la présente convention, les droits fondamentaux suivants:

- la liberté d'association et la reconnaissance effective du droit de négociation collective;

- l'élimination de toute forme de travail forcé ou obligatoire;

- l'abolition effective du travail des enfants;

- l'élimination de la discrimination en matière d'emploi et de profession..$^{153}$

Les deux Conventions sus visées semblent avoir reçu application en droit ivoirien.

\section{L'application des Conventions STCW et du travail maritime en droit ivoirien}

En République de Côte d'Ivoire, les dispositions pertinentes de la Convention STCW et des instruments de travail de l'Organisation internationale du travail (OIT) sont rendues applicables par l'arrêté n²07 MT.CAB. du 17 juillet 2002 portant attributions et organisation de la direction de la Navigation maritime et des Gens de $\mathrm{Mer}^{154}$. Selon l'article 12.3 de cet arrêté, l'Inspection de l'Enseignement maritime est chargée de :

- assurer et de contrôler la qualité de l'Enseignement maritime, notamment par :

- L'organisation du recrutement des enseignants de l'Académie régionale des Sciences et Techniques de la Mer (ARSTM);

- Le suivi du perfectionnement des enseignants ;

- L'inspection des enseignants.

- $\quad$ superviser et contrôler le concours d'entrée et les examens de sortie de l'Académie régionale des Sciences et Techniques de la Mer; à cet effet, elle établit les sujets d'examen à partir des propositions faites par les enseignants ...

De même, le Bureau des Normes du Travail maritime (ci-après le Bureau), en vertu de l'article 12.2.2 de l'arrêté précité ...applique les Conventions internationales et recommandations de l'Organisation internationale du Travail ainsi que les Conventions collectives nationales régissant les activités des marins.

Le Bureau assure le contrôle des normes de travail à bord des navires et la qualification des marins conformément à la Convention STCW et aux instruments de travail de l'Organisation internationale du Travail. Il instruit les propositions d'effectifs des armements dans le cadre du respect de l'équipage minimum de sécurité (safe maning).

La répression pénale des infractions aux normes préventives des pollutions marines est la deuxième forme que prend la réglementation des rejets polluants d'hydrocarbures.

\footnotetext{
153 Cf. article III de la Convention du travail maritime de 2006. En ce sens, voir aussi l'article V et les titres I à IV de ladite Convention.

154 Arrêté $\mathrm{n}^{\circ} 207$ MT.CAB. du 17 juillet 2002 portant attributions et organisation de la direction de la Navigation maritime et des Gens de Mer, JORCI nº32, du jeudi 8 août 2002, pp.562-569.
} 


\section{Section 2: La répression pénale des infractions aux normes préventives des} pollutions marines

La police de la navigation maritime se compose d'une multitude de règles juridiques qui visent, en plus de la prévention de la pollution marine, à réprimer les auteurs de cette pollution. Dans ce dernier cas, il s'agit d'une police répressive de la mer $^{155}$.

En Côte d'Ivoire, la répression des actes de pollution du milieu marin trouve son fondement dans plusieurs textes juridiques. En effet, la Côte d'Ivoire a réagi en faisant de la lutte contre la dégradation de l'environnement une de ces préoccupations. Cette lutte contre la dégradation de l'écosystème marin se manifeste entre autres, sous la forme de répression pénale des pollutions par les hydrocarbures. A cet effet, il faut noter les instruments juridiques tels que la loi n81-640 du 31 juillet 1981 portant code pénal ; la loi $\mathrm{n}^{\circ} 96-766$ du 3 octobre 1996 portant code de l'environnement ; le décret n97-678 du 3 décembre 1997 portant protection de l'environnement marin et lagunaire contre la pollution, la loi n ${ }^{\circ} 98-755$ du 23 décembre 1998 portant code de l'eau. A ces lois, il faut ajouter la loi $n^{\circ} 88-651$ du 7 juillet 1988 portant protection de la santé publique et de l'environnement contre les effets des déchets industriels toxiques et nucléaires et des substances nocives. Le rôle de ces instruments juridiques sera à la fois préventif et répressif ${ }^{156}$.

La répression pénale des infractions aux normes préventives des pollutions marines se matérialise par la recherche des infractions à la législation environnementale (Paragraphe 1) et les sanctions pénales applicables en cas de pollution des eaux marines (Paragraphe).

\section{Paragraphe 1: La recherche des infractions à la législation environnementale}

Selon le code de l'environnement ivoirien en son article 109, la poursuite des infractions relevant du présent code obéit aux règles définies par le code de procédure pénale. La recherche des infractions à la législation environnementale repose sur les agents légalement investis du pouvoir de recherche $(\mathrm{A})$ et les compétences à eux dévolues $(\mathrm{B})$.

\footnotetext{
${ }^{155}$ TIEBLEY (Yves Didier), La Côte d'Ivoire et la gestion durable des ressources naturelles marines, Thèse de doctorat, Université de Maastricht, Datawyse/Universitaire Pers Maastricht, 2010 p. 151

156 Le Droit pénal peut contribuer à protéger l'environnement en incriminant certaines infractions, en déterminant la responsabilité pénale et les peines applicables à certains comportements constitutifs d'infraction pour l'environnement.
} 


\section{A - $\quad$ Les agents légalement investis du pouvoir de recherche ${ }^{157}$}

L'article $107 \mathrm{du}$ Code de l'environnement ivoirien dispose que les infractions sont constatées sur procès-verbal par les agents assermentés par l'autorité nationale compétente.

L'article 21 du décret $n^{\circ} 97-678$ du 3 décembre 1997 portant protection de l'environnement marin et lagunaire contre la pollution, complète l'article $15 \mathrm{du}$ code de procédure pénale, ainsi que l'article 107 du code de l'environnement ivoirien, en énumérant limitativement les agents assermentés par l'autorité nationale compétente pour constater les infractions. Il s'agit des officiers de marine, les officiers mariniers, les administrateurs, les officiers et les contrôleurs des affaires maritimes et portuaires, les agents de police de la navigation et des pêches maritimes, les fonctionnaires et les agents assermentés du ministère chargé de l'environnement et du ministère chargé des mines et des hydrocarbures, et les officiers de la police judiciaire. En ce qui concerne l'exercice de l'action publique, il ressort de l'article 109 du Code de l'environnement que l'exercice de l'action publique ${ }^{158}$ ressortit de la compétence du ministère public ${ }^{159}$.

L'action publique est-elle exercée exclusivement par le ministère public ? L'action civile peut-elle être exercée individuellement ou collectivement, notamment par la société civile devant les juridictions répressives?

À ces différentes préoccupations, le Code de procédure pénale (CPP) y apporte des solutions satisfaisantes ${ }^{160}$. En effet, l'article $1^{\text {er }}$ alinéa 2 du CPP dispose que l'action publique peut aussi être mise en mouvement par la partie lésée. En d'autres termes, l'exercice de l'action publique n'est pas fermée aux particuliers ayant subi des dommages suite à la pollution par hydrocarbures. L'article $3 \mathrm{du}$ CPP ajoute, en outre, que l'action civile peut être exercée en même temps que l'action publique et devant la même juridiction. Elle est recevable pour tous les chefs de dommages aussi bien matériels que corporels ou moraux qui découleront des faits, objets de la poursuite.

En outre, le Code de l'environnement ivoirien reconnait l'action civile des associations devant le juge répressif ${ }^{161}$.

157 Conformément à l'article 15 du Code de procédure pénale (ivoirien), le terme " agent de recherche " doit, en la matière, s'entendre au sens large. Sous ce vocable sont inclus aussi bien les officiers, les agents de police judiciaire que les fonctionnaires assermentés du ministère chargé de l'environnement et du ministère chargé des mines et des hydrocarbures.

158 Selon l'article $1^{\text {er }}$ alinéa 1 CPP ivoirien, l'action publique pour l'application des peines est mise en mouvement et exercée par les magistrats ou fonctionnaires auxquels elle est confiée par la loi.

159 Voir l'article 31 du code de procédure pénale ivoirien.

160 Article 109 du Code de l'environnement.

161 A cet effet, l'article 33 du code de procédure pénale dispose : "Toute personne a le droit fondamental de vivre dans un environnement sain et équilibré. Elle a aussi le devoir de contribuer individuellement ou collectivement à la sauvegarde du patrimoine naturel.

A cette fin, lorsqu'un tribunal statue sur une demande, il prend notamment en considération, l'état des connaissances scientifiques, les solutions adoptées par les autres pays et les dispositions des instruments internationaux. » 
Les agents investis du pouvoir de recherche ont une compétence définie en droit répressif ivoirien.

\section{B - Les compétences des agents investis du pouvoir de recherche}

Le Code de procédure pénale (ivoirien) confère des compétences multiples aux agents investis du pouvoir de police. Au regard de l'article 14 du Code de procédure pénale (CPP), ces agents - particulièrement les officiers de la police judiciaire - constatent les infractions à la loi pénale, en rassemblent les preuves, en recherchent les auteurs quand une information n'est pas ouverte. Lorsqu'une infraction est ouverte, la police judiciaire exécute les délégations des juridictions d’instruction et défère à leurs réquisitions.

Les officiers de police judiciaire, dans l'exercice des pouvoirs définis ci-dessus, reçoivent les plaintes et dénonciations. Ils procèdent à des enquêtes préliminaires. Celles-ci sont entreprises soit sur instruction du Procureur de la République, soit d'office ${ }^{162}$.

Les agents de police judiciaire ont pour mission d'épauler les officiers de police judiciaire dans l'exercice de leurs fonctions en matière d'enquête préliminaire. Ainsi que le prévoit l'article $21 \mathrm{du}$ CPP, les agents de police judiciaire ont pour mission :

- de seconder, dans l'exercice de leurs fonctions, les officiers de police judiciaire ;

- de rendre compte, à leurs chefs hiérarchiques, de tous crimes ou délits dont ils ont connaissance ;

- de constater en se conformant aux ordres de leurs chefs, les infractions à la loi pénale et de recueillir tous les renseignements en vue de découvrir les auteurs de ces infractions, le tout dans le cadre et dans les formes prévues par les lois organiques ou spéciales qui leur sont propres.

Les sanctions pénales applicables en cas de pollution des eaux marines constituent le point culminent de la répression pénale des infractions aux normes préventives.

\section{Paragraphe 2 : Les sanctions pénales applicables en cas de pollution des eaux marines}

L'analyse des sanctions pénales applicables en cas de pollution des eaux marines sera l'occasion de comparer en la matière, les droits répressifs ivoirien et français. Il semble transparaître des dispositions des codes pénal et de l'environnement ivoiriens que malgré la multiplication des incriminations pénales, ${ }^{163}$ les peines sont peu dissuasives (A). Tandis qu'en France, le législateur a considérablement renforcé les pénalités applicables aux pollutions des eaux marines (B).

\footnotetext{
162 Article $74 \mathrm{du}$ CPP.

163 Michel PRIEUR reconnaît qu'en France, la plupart des textes n'on jamais fait l'objet d'application pénale. Voir Michel PRIEUR, Droit de l'environnement, Op.cit. P. 707.
} 


\section{A - Les sanctions pénales applicables en cas de pollution des eaux marines en République de Côte d'Ivoire}

Les sanctions prévues par le Code de l'environnement ivoirien diffèrent selon la nature de la zone marine polluée. On distingue d'une part, celles qui s'appliquent en cas de pollution des eaux sous souveraineté nationale. C'est à dire des eaux intérieures et la mer territoriale (1) de celles qui visent les pollutions des eaux sous juridiction nationale à savoir la Zone économique exclusive (ZEE) (2).

1. Les sanctions pénales applicables en cas de pollution des eaux intérieures et la mer territoriale $^{164}$

La pollution des eaux intérieures et de la mer intérieure s'opère par les déversements, les écoulements, des rejets et les dépôts de substances de toute nature. Ces substances doivent être de nature à provoquer ou à accroître la pollution des eaux maritimes. Les sanctions à la pollution des eaux intérieures et la mer territoriale sont déterminées par l'article 97 du Code de l'environnement. Selon cette disposition :

" Est puni d'une amende de 2.000.000de francs à 50.000 .000 de francs et d'un emprisonnement de deux mois à deux ans ou de l'une de ces deux peines seulement, toute personne ayant pollué les eaux continentales par des déversements, écoulements, rejets et dépôts de substances de toute nature susceptible de provoquer ou d'accroître la pollution des eaux continentales et/ou des eaux maritimes dans les limites territoriales ...».

En cas de récidive, la peine est portée au double. Le coupable est, en outre, condamné à curer les lieux pollués. Le texte montre cependant des insuffisances : il ne prend pas le soin de préciser les conditions de la récidive ni de rendre obligatoire le nettoyage des lieux en dehors de la récidive.

Faut-il alors se référer au Code pénal de $1981^{165}$ ?

Quand bien même il serait possible d'appliquer le Code pénal pour régler la question, il importe tout de même de souligner la contradiction entre celui-ci et le Code de l'environnement. En effet, le Code de l'environnement dispose qu'en cas de récidive, la peine est portée au double. Le Code pénal, en revanche, se montre moins sévère. En effet, le doublement de la sanction pénale, au regard du Code pénal, est une faculté

\footnotetext{
164 Au regard de l'article $8 \$ 1$ de la Convention de Montego Bay (CMB), les eaux intérieures sont celles situées en deçà des lignes de base de la mer territoriale. Au-delà des eaux intérieures se trouve la mer territoriale. En vertu de l'article 3 de la CMB, la largeur de la mer territoriale ne dépasse pas 12 milles marins mesurés à partir de lignes de base établies conformément à la Convention. Les articles 4, 5 et 7 de la CMB déterminent les différents tracés des lignes de base.

165 Voir les articles 125 et 132 du code pénal relativement à la récidive. Selon l'article 126 alinéa 3, il n’y a récidive que si le délit est commis entre le jour où la première condamnation est devenue définitive et celui marquant le terme d'un délai de cinq ans après l'expiration ou la prescription de la première peine.
} 
lorsqu'il affirme que "le récidiviste peut être condamné au maximum de la peine encourue, laquelle peut être portée jusqu'au double dudit maximum $»^{166}$.

Cependant, le conflit entre le Code de l'environnement et le Code pénal pourrait être résolu par application de l'adage specialia generalibus derogant, en vertu de laquelle la norme particulière l'emporte sur la norme générale. Il en résulte qu'en cas de conflit entre le Code de l'environnement et le Code pénal, le premier l'emportera sur le second.

Les pollutions de la Zone économique exclusive (ZEE) obéissent à un régime distinct que nous analyserons ci-dessous.

2. Les sanctions pénales applicables en cas de pollution de la Zone économique exclusive (ZEE)

L'article $98 \mathrm{du}$ Code l'environnement prévoit des sanctions pénales à l'encontre des pollueurs de la ZEE. Ainsi, une personne qui pollue la ZEE encourt une peine d'amende de 100.000.000 de francs à 1.000.000.000 de francs et une peine d'emprisonnement de un à cinq ans ou l'une de ces deux peines seulement. Ces sanctions s'appliquent en cas d'infraction à l'article $80 \mathrm{du}$ Code de l'environnement ${ }^{167}$. Ces peines d'amende peuvent être portées au double en cas de récidive.

En outre, l'article $98 \$ 2$ du Code de l'environnement confère la compétence à l'Administration pour procéder à l'arraisonnement du navire ayant causé la pollution ${ }^{168}$. L'article 110 de la CMB consacre le droit de l'État côtier à procéder à l'arraisonnement des navires, même de ceux battant pavillon étranger. En droit interne ivoirien, l'article $98 \$ 3$ du Code de l'environnement reconnaît à l'Administration de procéder à la saisie du navire.

L'ampleur des sanctions pénales applicables en cas de pollution des eaux marines en droit Français est différente.

\footnotetext{
166 Voir, à cet effet, les articles 126 et 127 du Code pénal.

167 L'article 80 du Code de l'environnement dispose: "Conformément aux dispositions spéciales des Conventions internationales ratifiées par la Côte d'Ivoire, sont interdits les déversements, les immersions et les incinérations dans les eaux maritimes sous juridiction ivoirienne de substances de toutes natures susceptibles de: - porter atteinte à la santé publique et aux ressources maritimes biologiques;

- nuire aux activités maritimes y compris la navigation et la pêche;

- altérer la qualité des eaux maritimes;

- dégrader les valeurs d'agrément et le potentiel touristique de la mer et du littoral ».

168 L'article $98 \$ 2$ dispose à cet effet: «L'Administration maritime peut arraisonner tout navire surpris en flagrant délit de déversement de contaminants, $y$ compris les hydrocarbures en mer».
} 


\section{B - $\quad$ Les sanctions pénales applicables en cas de pollution des eaux marines en république Française}

Après le naufrage de l'Erika et du Prestige, les dispositions répressives concernant les rejets illicites d'hydrocarbures à partir des navires ont été modifiées à trois reprises ${ }^{169}$. Afin de responsabiliser les différents acteurs du transport maritime, le législateur français au fil des dernières réformes a élargi le cercle des personnes responsables (1) tout en renforçant considérablement les pénalités applicables ${ }^{170}(2)$.

\section{L'élargissement du cercle des personnes responsables}

L'article L.218-18 du Code de l'environnement français dispose désormais que :

«Les peines prévues à la présente sous-section sont applicables soit au propriétaire, soit à l'exploitant ou à leur représentant légal ou dirigeant de fait s'il s'agit d'une personne morale, soit à toute autre personne que le capitaine ou le responsable de bord exerçant, en droit ou en fait, un pouvoir de contrôle ou de direction dans la gestion ou la marche du navire ou de la plate-forme, lorsque ce propriétaire, cet exploitant ou cette personne a été à l'origine d'un rejet effectué en infraction aux articles L.218-11 à L.218-17 et L.218-19 ou n'a pas pris les mesures nécessaires pour l'éviter $»^{171}$.

L'extension du nombre des personnes responsables a été obtenue au moyen de deux ajustements. Il s'agit d'une part, de l'adaptation des règles quant aux sujets responsables (a) et d'autre part, de l'élément moral de l'infraction (b).

\section{a. L'adaptation des règles quant aux sujets responsables dans l'affaire de la catastrophe de l'Erika}

Lors de la catastrophe de l'Erika, le Bureau d'enquête des accidents de mer avait dénombré plus d'une quinzaine d'intervenants potentiels dans la gestion du navire, indépendamment de tiers tels que la société de classification ou les chantiers navals. Le tribunal correctionnel de Paris dans son jugement du 16 janvier 2008 (a décidé de relaxer le capitaine du navire), s'est livré à une analyse très subtile, remontant tous les maillons de la chaîne du transport maritime pour identifier ceux dont les défaillances étaient à l'origine du naufrage. Finalement, ont été reconnus responsables du délit de pollution des mers, le propriétaire de l'Erika, son gestionnaire, la société de classification

\footnotetext{
169 Ce sont successivement les lois du 3 mai 2001, du 9 mars 2004 et du 1er août 2008. En effet, depuis le naufrage de l'Erika et du Prestige, le dispositif pénal applicable aux pollutions des mers a été modifié à trois reprises dans le sens d'un renforcement de la répression : par la loi ${ }^{\circ} 2001-380 \mathrm{du} 3$ mai 2001, par la loi $\mathrm{n}^{\circ}$ 2004-204 du 9 mars 2004, dite loi Perben II, et enfin par la loi $n^{\circ} 2008-757$ du ler août 2008 relative à la responsabilité environnementale.

${ }^{170}$ Voir aussi, DESFOUGERE (Eric), L'arret d'Appel du 30 mars 2010 relatif au naufrage de l'Erika : Total pénalement coupable, mais civilement irresponsable, in JAC, $\mathrm{n}^{\circ} 103,2010$, pp.1-3

171 Depuis la loi du ler août 2008, le système répressif français vise de façon générale différentes personnes physiques et morales sans distinguer entre les rejets volontaires et involontaires d'hydrocarbures.
} 
Rina et la compagnie pétrolière Total SA ${ }^{172}$. C'est-à-dire la maison-mère dont dépendait le service vetting ${ }^{173}$.

Le raisonnement qui a conduit le Tribunal correctionnel de Paris à retenir la responsabilité pénale de la société Total SA est assez subtil. Il interprète de façon extensive la notion de "personne intervenue dans la gestion du navire». En effet, la maison-mère avait fait procéder à l'inspection du pétrolier avant la conclusion du contrat d'affrètement et donc participé à la gestion du navire dont elle ne pouvait ignorer les défauts. Le navire avait été inspecté sur la base d'un document comportant quatorze rubriques et plusieurs centaines de questions. Ainsi, la faute du professionnel concerné du service vetting, a pu engager la responsabilité pénale de la société Total SA.

L'un des apports essentiels de la loi du 1er août 2008 réside dans le fait que l'article L.218-19. IV du Code de l'environnement semble élargir le cercle des pénalement responsables à « un ensemble de personnes physiques étrangères à la marche du navire, sa gestion, son contrôle ou sa direction ${ }^{174}$.

L'analyse du code de l'environnement précité révèle une autre adaptation des règles, celles relatives à l'élément moral de l'infraction.

\section{b. L'adaptation des règles relatives à l'élément moral de l'infraction}

L'article L.218-19. I du Code de l'environnement réprime le fait d'avoir provoqué un accident de mer entraînant une pollution par hydrocarbures par imprudence, négligence ou inobservation des lois et règlements ou de ne pas avoir pris les mesures nécessaires pour l'éviter ${ }^{175}$. Selon Evelyne MONTEIRO, il faut soit la violation manifestement délibérée d'une obligation particulière de sécurité et de prudence prévue

\footnotetext{
${ }^{172}$ Et non pas la filiale de Total qui avait conclu le contrat d'affrètement car, d'après le tribunal, la Convention CLC (convention sur la responsabilité civile pour les dommages dus à la pollution par les hydrocarbures) du 29 novembre 1969 s'oppose à ce que la responsabilité de l'affréteur soit recherchée ès qualité.

173 Le vetting est une pratique des groupes pétroliers qui s'est développée à la suite du naufrage de l'AmocoCadiz. Afin d'échapper au système de responsabilité internationale mis en place au niveau du transport maritime d'hydrocarbures, les compagnies pétrolières se sont petit à petit démunies de leur flotte tout en conservant un droit de regard sur les navires qu'elles affrètent. Le vetting consiste en une inspection externe du navire avant le contrat d'affrètement qui vient se superposer aux contrôles effectués par les sociétés de classification.

174 RABUTEAU (Y.), « Marées noires: le dispositif pénal issu de la loi sur la responsabilité environnementale ", DMF 2009, n703, p. 481, cité par MONTEIRO (Evelyne), «Le renforcement de la responsabilité pénale en matière de pollution maritime ", in VertigO - La revue en sciences de l'environnement, Hors-Série 8 , octobre 2010, Cf.http :vertigo.revues.org/10184, p.3, du 15/O5/20011 à 19heures.

175 En droit français, la définition de la faute pénale d'imprudence a été profondément modifiée par la loi $\mathrm{n}^{\circ}$ 2000-647 du 10 juillet 2000, dite Loi Fauchon, afin de mieux délimiter la responsabilité pénale des décideurs publics ou privés. Lorsque l'auteur d'une infraction par imprudence, personne physique, n'a pas causé directement le dommage mais a créé ou contribué à créer la situation qui a permis la réalisation du dommage, l'alinéa 4 de l'article 121-3 du Code pénal exige désormais une faute d'imprudence qualifiée, c'est-à-dire plus grave puisque répondant à des strictes exigences légales.
} 
par la loi ou le règlement, soit une faute caractérisée exposant autrui à un risque d'une particulière gravité qui ne pouvait être ignorée ${ }^{176}$.

L'article L.218-19. IV du Code de l'environnement du $1^{\text {er }}$ août 2008 a tenu compte de la nouvelle définition en disposant ainsi qu'il suit :

"Nonobstant les dispositions du quatrième alinéa de l'article 121-3 du Code pénal, les personnes physiques qui n'ont pas causé directement le dommage, mais qui ont créé ou contribué à créer la situation qui a permis la réalisation du dommage ou qui n'ont pas pris les mesures permettant de l'éviter, sont responsables pénalement s'il est établi qu'elles ont soit violé de façon manifestement délibérée une obligation particulière de prudence ou de sécurité prévue par la loi ou le règlement, soit commis une faute caractérisée qui exposait l'environnement à un risque d'une particulière gravité qu'elles ne pouvaient ignorer $»^{177}$.

La répression pénale s'est considérablement durcie à l'égard des auteurs potentiels des faits.

\section{Le renforcement de la répression pénale à l'égard des auteurs potentiels des faits en droit français.}

Les peines diffèrent selon qu'il s'agit de pollution volontaire (a) ou involontaire (b).

\section{a. En cas de pollution volontaire ${ }^{178}$}

La répression pénale s'est considérablement durcie à l'égard des auteurs potentiels des faits en droit français. Les peines se sont durcies avec la loi du $1^{\text {er }}$ août 2008. Ainsi, s'il s'agit d'un navire-citerne (pétrolier) dont la jauge brute est supérieure ou égale à 150 tonneaux, ou bien supérieure ou égale à 400 tonneaux dans le cas des autres navires ou

176 Cf. MONTEIRO (Evelyne), « Le renforcement de la responsabilité pénale en matière de pollution maritime ", in VertigO - La revue en sciences de l'environnement, Hors-Série 8, octobre 2010, Cf.http :vertigo.revues.org/10184, Op., cit., p. 3

177 Ce faisant, le système répressif français semble fortement s'attacher à la directive 2009/35/CE du Parlement et du Conseil du 21 octobre 2009 qui impose aux États d'incriminer les rejets illicites de substances polluantes par les navires lorsqu'ils ont été commis intentionnellement, témérairement ou à la suite d'une négligence grave et entraînant une détérioration de la qualité des eaux.

${ }^{178}$ Les articles L.218-11 à L.218-13 du Code de l'environnement de 2008 incriminent les pollutions par hydrocarbures intentionnelles, c'est-à-dire celles qui contreviennent aux interdictions posées par l'annexe I de la convention MARPOL relative aux contrôle des rejets d'hydrocarbures.

En effet, la convention MARPOL envisage des zones spéciales MARPOL correspondant à des mers particulièrement vulnérables telles que la Méditerranée, la Manche, la mer Baltique ou la mer Noire, et des zones de droit commun. Par exemple, dans le cadre du droit commun, les rejets en provenance des espaces à cargaison des pétroliers (navire-citerne) sont interdits, sauf s'ils respectent certaines conditions très strictes, notamment d'éloignement des côtes. De même les rejets des cales de la tranche des machines de ces naviresciternes sont interdits, sauf si le navire fait route, qu'il utilise un matériel de filtrage des hydrocarbures et que la teneur en hydrocarbure ne dépasse pas un seuil déterminé. 
d'une plate-forme, la peine est portée à 10 ans d'emprisonnement et 15 millions d'euros d'amende. ${ }^{179}$

Les mêmes peines sont prévues pour les navires-citernes inférieurs à 150 tonneaux et les autres navires inférieurs à 400 tonneaux mais d'une puissance supérieure à 150 kilowatts. ${ }^{180}$

Pour les pollutions volontaires par hydrocarbures provenant des navires autres que ceux précédemment cités, l'article L.218-11 du Code de l'environnement prévoit actuellement 50000 euros d'amende. En cas de récidive, ces peines peuvent aller jusqu'à 1 an d'emprisonnement et 100000 euros d'amende.

Le durcissement des peines semble être plus nuancé en cas d'accident de mer.

\section{b. En cas de pollution involontaire ou accidentelle}

Conformément à la loi du $1^{\text {er }}$ août 2008, la peine maximale applicable est désormais de 7 ans d'emprisonnement et de 10,5 millions d'euros d'amende ${ }^{181}$. Lorsque le rejet polluant provient d'un navire de gros tonnage par référence à l'article L.218-13 du Code de l'environnement ${ }^{182}$, ou d'une plate-forme, et lorsque deux autres circonstances aggravantes sont vérifiées. C'est-à-dire, un dommage irréversible ou d'une particulière gravité a été causé à l'environnement et le rejet résulte directement ou indirectement d'une faute d'imprudence qualifiée ${ }^{183}$.

Le dispositif actuel distingue entre l'accident de mer provoqué par une faute simple d'imprudence sans répercussion notable sur l'environnement ${ }^{184}$, et l'accident de mer provoqué par une faute simple d'imprudence ayant causé directement ou indirectement un dommage irréversible ou d'une particulière gravité à l'environnement ${ }^{185}$. Ces faits sont punis uniquement de peines d'amende, qui varient selon la taille du navire, dont le montant a été considérablement augmenté. On notera cependant que la peine d'emprisonnement a disparu ici. La loi du ler août 2008 a surtout augmenté les peines d'amendes sans toucher aux peines.

Ainsi, en cas de faute d'imprudence qualifiée ayant causé directement ou indirectement une pollution accidentelle sans répercussion notable sur l'environnement, les sanctions

\footnotetext{
179 Cf. art. L.218-13 du Code de l'environnement précité.

180 Cf. art. L.218-12 du Code de l'environnement précité.

${ }^{181}$ Cf. art. L.218-19. III du Code de l'environnement.

182 C'est-à-dire les navires-citernes dont la jauge brute est supérieure ou égale à 150 tonneaux ou supérieure ou égale à 400 tonneaux pour les autres navires.

183 Cf. MONTEIRO (Evelyne), « Le renforcement de la responsabilité pénale en matière de pollution maritime

", in VertigO - La revue en sciences de l'environnement, Hors-Série 8, octobre 2010, Cf.http :vertigo.revues.org/10184, Op., cit., pp. 5-6

${ }^{184}$ Cf. art. L.218-19. I et art. L.218- 19.I, $1^{\circ}$ et $2^{\circ}$ du Code de l'environnement.

185 Cf. art. L.218-19. I, $3^{\circ}$ et $4^{\circ}$ du Code de l'environnement.
} 
vont d'une simple amende de 6000 euros pour les navires n'entrant pas dans les catégories des articles L.218-12 et L.218-13 du Code de l'environnement à 5 ans d'emprisonnement et 7,5 millions d'euros pour les navires de gros tonnage ou une plateforme ${ }^{186}$.

Les peines les plus graves sont encourues lorsque la faute d'imprudence qualifiée à l'origine de l'accident de mer a eu pour conséquence directe ou indirecte un dommage irréversible ou d'une particulière gravité à l'environnement.

L'article L.218-19.III du Code de l'environnement prévoit 7 ans d'emprisonnement et 10,5 millions d'euros d'amende pour les navires de gros tonnage et les plates-formes et 5 ans d'emprisonnement et 7,5 millions d'amende pour les navires visés à l'article L.21812 du Code de l'environnement.

La lutte curative contre les pollutions marines se manifeste certes par les règles de répression des actes de pollution. Mais il ne faut pas perdre de vue les autres mesures réglementant les rejets polluants d'hydrocarbures, à savoir les règles de réparation civile, et les règles de réduction des conséquences néfastes des pollutions marines ou plans d'intervention d'urgence (PIU).

186 Cf. Art. L.218-19. II, $1^{\circ}, 2^{\circ}$ et $3^{\circ}$ du Code de l'environnement. 


\section{TITRE 2 :}

\section{LA LUTTE CURATIVE CONTRE LE PHÉNOMÈNE DES MARÉES NOIRES}

Le terme "réparation», est l'action de réparer qui, lui-même, signifie «remettre en bon état, en état de fonctionnement». Il peut être aussi défini comme le fait de "faire disparaître les effets d'une faute, d'un dommage $»{ }^{187}$

Ainsi définie, la réparation, dans son premier sens, consistera à prendre les mesures utiles en vue de résorber du milieu marin la présence d'une substance polluante donnée. De telles mesures sont désignées sous l'appellation de mesures opérationnelles dont les plans d'interventions d'urgence (PIU) constituent la manifestation la plus éclatante.

Dans son second sens, la réparation recouvre le sens d'indemnisation. On peut même affirmer que réparation et indemnisation recouvrent la même réalité : celle de désintéresser une personne ayant subi des préjudices que lui cause une tierce personne. On parle alors de réparation civile.

Les deux sens ci-dessus du mot réparation nous conduisent à analyser la lutte curative contre le phénomène des marées noires au moyen d'une part de la lutte opérationnelle contre le phénomène des marées noires (les PIU) (Chapitre I) et d'autre part, au moyen de l'adoption de règles dissuasives en matière d'indemnisation des victimes de marées noires (Chapitre II).

187 Dictionnaire universel de poche, Éd. Hachette, 1993, p.469, cité par TIEBLEY, La Côte d'Ivoire et la gestion durable des ressources naturelles marines, Thèse de doctorat, Université de Maastricht, Datawyse/Universitaire Pers Maastricht, 2010, p.98. 



\section{CHAPITRE 1: LA LUTTE OPERATIONNELLE CONTRE LE PHENOMENE DES MAREES NOIRES}

Il existe aussi bien sur le plan international que régional des instruments de prévention et de lutte contre les pollutions accidentelles par les hydrocarbures. Il convient donc d'aborder d'une part, les mécanismes juridiques internationaux de lutte opérationnelle contre les pollutions accidentelles à savoir, les normes d'intervention définies à l'échelle universelle par la Convention de Montego Bay et la Convention OPRC 1990 (Section I), et d'autre part, les normes d'intervention définies à l'échelle régionale africaine, européenne et états-unienne (Section).

\section{Section 1: Les normes universelles contenues dans la Convention de Montego Bay et la Convention OPRC 1990}

Pour la clarté de notre exposé, il convient de tenir compte de l'esprit de cette rubrique. En fait, nous analyserons d'abord la lutte contre les pollutions marines au moyen de la Convention de Montego Bay (Paragraphe I) avant de nous intéresser à la lutte contre les marées noires au moyen de la Convention sur la préparation, la lutte et la coopération en matière de pollution par les hydrocarbures (OPRC) 1990 (Paragraphe II).

\section{Paragraphe 1: La lutte contre les pollutions marines au moyen de la Convention de Montego Bay}

Signée à Montego Bay le 10 décembre 1982 (en vigueur depuis le 16 novembre 1994), la Convention fut élaborée lors de la 3ème Conférence des Nations Unies sur le droit de la mer, qui débuta à Caracas, Vénézuéla, le 20 juin 1974.

Bien que cette Convention ne traite pas directement de la pollution par les hydrocarbures, elle pose des règles essentielles en matière de compétence des États, lorsqu'il s'agit de l'exécution des règles et standards internationaux, que ce soit à l'intérieur de leur mer territoriale, de leur zone économique exclusive (ZEE) ou en haute $\operatorname{mer}^{188}$.

L'application des nombreuses normes de sécurité édictées dans le domaine du transport maritime donne lieu à de multiples contrôles concernant des aspects différents par différents intervenants dont notamment l'État côtier (A), l'État du pavillon et l'États du port $(B)^{189}$.

\footnotetext{
188 LAUSANNE (Axelle Prior), «La pollution accidentelle par hydrocarbures, Travail de licence », le 26 mars 2001, pp.11-12, in http://www.bernaddeflesselbs.com/fr/environnement/theme-maritime/d-lutter-contre-les pollutions-marines-et-la-sécurité-marine, du 15 /05 / 2011.

${ }^{189}$ Voire les sociétés de classification, les assureurs, affréteurs ; chacun semble rivaliser de précautions.
} 


\section{A - Les compétences reconnues à l'État côtier}

Ces compétences transparaissent essentiellement des dispositions pertinentes de la Convention de Montego Bay (CMB). Elles consistent en la réglementation de la circulation maritime (1) et l'interdiction de la navigation maritime (2).

\section{La réglementation de la circulation maritime}

Les conventions internationales qui traitent de la question du transport maritime reconnaissent à l'État côtier la compétence pour prendre toutes mesures utiles pour lutter contre les pollutions dans les eaux sous sa juridiction ${ }^{190}$. Cette habilitation se fonde notamment sur la compétence territoriale (mer territoriale) et sur les droits souverains (ressources biologiques, ressources minérales de la ZEE et du plateau continental) de l'État côtier.

Ainsi donc, la Convention de Montego Bay réserve à l'État côtier d'importants droits de protection. Ce pouvoir de réglementation s'exerce tant dans la mer territoriale (a) que dans la Zone économique exclusive (b).

\section{a. Au niveau de la mer territoriale}

$\mathrm{Au}$ niveau de la mer territoriale, ce pouvoir de réglementation a été reconnu par la $\mathrm{CMB}$, en son article $21 \$ 1 f$ ) qui dispose :

«L'État côtier peut adopter, en conformité avec les dispositions de la Convention et les autres règles $d u$ droit international, des lois et règlements relatifs au passage inoffensif dans sa mer territoriale, qui peuvent porter sur les questions suivantes ...préservation de l'environnement de l'État côtier et prévention, réduction et maîtrise de sa pollution ».

L'article $22 \S \$ 1$ et 2 de la CMB précise le contenu du pouvoir de réglementation. Ainsi, l'État côtier est compétent pour déterminer des voies de circulation et des dispositifs de séparation de trafic à l'attention de tout navire qui se trouve dans sa mer territoriale en vertu du $₫ 1$ de la disposition précitée. Le $₫ 2$ de la même disposition étend ce pouvoir de réglementation aux navires-citernes et autres navires transportant des cargaisons dangereuses pour l'écosystème marin.

Le $\$ 3$ de l'article 22 précité balise l'exercice du pouvoir de réglementation. Ainsi, l'État côtier doit satisfaire à certaines exigences lorsqu'il définit des voies de circulation et des dispositifs de séparation de trafic. Il doit notamment tenir compte des recommandations de l'organisation internationale compétente ; de tous chenaux utilisés habituelle-

\footnotetext{
190 En plus du texte précité de la Convention de Montego Bay, il ya aussi l'article $221 \S 1$, la Convention sur la préparation, la lutte et la coopération en matière de pollution par les hydrocarbures (article $6 \$ 1$ ), la convention internationale du 29 novembre 1969 portant sur l'intervention en haute mer (articles I et VII), la convention d'Abidjan du 23 mars 1981 (articles 5 et 8 et son protocole article 9).
} 
ment pour la navigation maritime internationale; des caractéristiques particulières de certains navires et chenaux; et de la densité du trafic.

En outre, il devra, conformément au $\$ 4$, indiquer clairement ces voies de circulation et ces dispositifs de séparation du trafic sur des cartes marines auxquelles il donne la publicité voulue.

Le pouvoir de réglementation de l'Etat côtier s'étend également à la zone économique exclusive.

\section{b. Au niveau de la Zone économique exclusive}

L'exercice du pouvoir de réglementation du trafic maritime dans la ZEE ressort de l'article $221 \S 1$ de la CMB. Il est vrai que le terme « $Z E E$ » ne transparaît pas explicitement de la disposition susvisée. Il n'empêche que cette disposition en fait implicitement mention lorsqu'elle dispose :

"Aucune disposition de la présente partie ne porte atteinte au droit qu'ont les États, en vertu $d u$ droit international, tant coutumier que conventionnel, de prendre et faire appliquer au-delà de la mer territoriale des mesures proportionnées aux dommages qu'ils ont effectivement subis ou dont ils sont menacés afin de protéger leur littoral ou les intérêts connexes, y compris la pêche, contre la pollution ou une menace de pollution résultant d'un accident de mer, ou d'actes liés à un tel accident, dont on peut raisonnablement attendre des conséquences préjudiciables ».

Le groupe de mots "au-delà de la mer territoriale» renvoie inévitablement à la ZEE surtout que la zone contiguë est actuellement un espace marin peu prisé de la majorité des États côtiers, surtout ceux du tiers-monde. Ceux-ci préfèrent de loin la ZEE, immédiatement situé après la mer territoriale, et qui est le réceptacle de ressources naturelles (biologiques ou minérales) sur lesquelles ils exercent des droits souverains.

L'interdiction de la navigation maritime est la deuxième catégorie de compétence de l'État côtier.

\section{L'interdiction de la navigation maritime}

Ce pouvoir s'exerce tant dans la mer territoriale (a) que dans la ZEE (b).

a. dans la mer territoriale

L'État côtier peut prendre, dans sa mer territoriale, les mesures nécessaires pour empêcher tout passage qui n'est pas inoffensif.

En effet, lorsqu'un État a de sérieuses raisons de penser qu'un navire naviguant dans sa mer territoriale a enfreint, lors de son passage, des lois et règlements qu'il a adoptés en conformité de la Convention ou des règles et normes internationales applicables 
visant à prévenir, réduire et maîtriser la pollution par les navires, il peut procéder, à l'inspection matérielle du navire pour établir l'infraction et, lorsque les éléments de preuve le justifient, intenter une action et notamment ordonner l'immobilisation du navire conformément à son droit interne. ${ }^{191}$

En ce qui concerne les navires qui se rendent dans les eaux intérieures ou dans une installation portuaire située en dehors de ces eaux, l'État côtier a également le droit de prendre les mesures nécessaires pour prévenir toute violation des conditions auxquelles est subordonnée l'admission de ces navires dans ces eaux ou cette installation portuaire. L'État côtier peut, sans établir aucune discrimination de droit ou de fait entre les navires étrangers, suspendre temporairement, dans des zones déterminées de sa mer territoriale, l'exercice du droit de passage inoffensif des navires étrangers, si cette mesure est indispensable pour assurer sa sécurité, entre autres pour lui permettre de procéder à des exercices d'armes. La suspension ne prend effet qu'après avoir été dûment publiée $e^{192}$.

Selon une certaine doctrine, ce pouvoir d'interdiction sélective du droit de passage inoffensif constitue un droit de protection reconnu à l'État côtier en vertu de l'article $25 \$ 1$ de la CMB qui dispose: "L'État côtier peut prendre, dans sa mer territoriale, les mesures nécessaires pour empêcher tout passage qui n'est pas inoffensif ${ }^{193}$.

Monsieur Tiebley souligne le caractère logique du pouvoir de réglementation et d'interdiction ainsi reconnus à l'État côtier. En effet, selon lui, le droit international, singulièrement la $\mathrm{CMB}$, assimile la mer territoriale à une zone de souveraineté de l'État côtier. Hormis le droit de passage inoffensif, un droit étroitement contrôlé d'ailleurs, l'État côtier exerce sur sa mer territoriale et sur l'espace aérien surjacent des compétences analogues à celles qu'il exerce sur son espace terrestre et l'espace aérien surjacent. De même, l'obligation de «protéger et préserver le milieu marin » incombant à

191 Cf.LAUSANNE ((Axelle Prior), «La pollution accidentelle par les hydrocarbures, Travail de licence », le 26 mars 2001,in http://www.bernaddeflesselbs.com/fr/environnement/theme-maritime/d-lutter-contre-les pollutions-marines-et-la-sécurité-marine, pp.11-12.

192 Cf. article 25.3 CMB.

193 Cf. TIEBLEY (Yves Didier), La Côte d'Ivoire et la gestion durable des ressources naturelles marines, Thèse de doctorat, Université de Maastricht, Datawyse/Universitaire Pers Maastricht, 2010, p.152; cf. également NDENDE (Martin), « L'évolution du régime de l'assistance : l'assistance imposée. Vers un droit d'autoprotection de l'État côtier? ", Annuaire de Droit maritime et océanique, Tome XVIII, 2000, p.239.

Le professeur Martin NDENDE rapporte d'ailleurs une série d'actions posées par certains États côtiers en vue de se prémunir contre une menace de pollution maritime au large de leurs côtes respectives. L'interdiction de navigation a été mise en œuvre à certaines occasions :

- le pétrolier Kharg $V$ en feu et abandonné par une partie de son équipage en décembre 1989 au large du Maroc s'était vu refuser l'entrée dans les eaux territoriales marocaines et espagnoles ;

- l'Andros Patria, autre pétrolier en déperdition avait été repoussé en 1979 par les britanniques, les français et les portugais et fut contraint à naviguer des semaines durant dans les tempêtes atlantiques, citernes ouvertes et vomissant sa cargaison;

- la même année, l'Aelian Sky, interdit d'accès dans tous les ports britanniques, finit par sombrer en Manche, et par un retour extraordinaire et cruel des choses, sa cargaison de fûts toxiques revint échouer sur les plages du Royaume Uni ... 
l'État côtier en vertu de l'article 192 de la CMB ne saurait raisonnablement être remplie si ce dernier ne se voyait pas reconnaître les moyens juridiques nécessaires ${ }^{194}$.

\section{b. dans la zone économique exclusive (ZEE)}

Une tendance accentuée dans la Convention de Montego Bay du 10 décembre 1982 est mise en évidence par TIEBLEY Yves-Didier. En effet, l'auteur observe que la 3ème Conférence des Nations unies sur le droit de la mer (CNUDM) a été marquée par la volonté des États côtiers en développement de contrôler et, corrélativement, de limiter les captures de ressources halieutiques pratiquées au large de leurs côtes par les armements des États à grande activité de pêche ${ }^{195}$.

Aux termes de l'article 56 la Convention de Montego Bay du 10 décembre 1982, l'État côtier a dans la zone économique exclusive :

- des droits souverains aux fins d'exploration et d'exploitation, de conservation et de gestion des ressources naturelles, biologiques ou non biologiques, des eaux surjacentes aux fonds marins, des fonds marins et de leur sous-sol, ainsi qu'en ce qui concerne d'autres activités tendant à l'exploration et à l'exploitation de la zone à des fins économiques, telles que la production d'énergie à partir de l'eau, des courants et des vents;

- une juridiction, en ce qui concerne, la mise en place et l'utilisation d'îles artificielles, d'installations et d'ouvrages; la recherche scientifique marine et la protection et la préservation du milieu marin.

En outre, le droit international reconnaît à l'État côtier des droits face à un navire qui ne bat pas son pavillon mais qui traverse les zones sous sa juridiction ${ }^{196}$. Et qui manquerait aux obligations issues de la Convention à laquelle l'État côtier serait partie.

Ainsi, lorsqu'un navire se trouve volontairement dans un port ou à une installation terminale au large, l'État du port peut, intenter une action pour toute infraction aux lois et règlements qu'il a adoptés conformément à la Convention ou aux règles et normes internationales applicables visant à prévenir, réduire et maîtriser la pollution par les navires, si l'infraction a été commise dans sa mer territoriale ou sa zone économique exclusive.

Lorsqu'un État a de sérieuses raisons de penser qu'un navire naviguant dans sa zone économique exclusive ou sa mer territoriale a commis, dans la zone économique exclusive, une infraction aux règles et normes internationales applicables visant à prévenir, réduire et maîtriser la pollution par les navires ou aux lois et règlements qu'il a adoptés conformément à ces règles et normes internationales et leur donnant effet, cet

\footnotetext{
194 TIEBLEY (Yves Didier), La Côte d'Ivoire et la gestion durable des ressources naturelles marines, Thèse de doctorat, Université de Maastricht, Datawyse/Universitaire Pers Maastricht, 2010, p.152.

195 LAUSANNE ((Axelle Prior), La pollution accidentelle par les hydrocarbures, Travail de licence, le 26 mars 2001, in http://www.bernaddeflesselbs.com/fr/environnement/theme-maritime/d-lutter-contre-les pollutionsmarines-et-la-sécurité-marine, pp.11-12, du 15/05/2011. Voir aussi TIEBLEY TIEBLEY (Yves Didier), La Côte d'Ivoire et la gestion durable des ressources naturelles marines, Thèse de doctorat, Université de Maastricht, Datawyse/Universitaire Pers Maastricht, 2010, p.183).

${ }^{196}$ Il s'agit des Eaux Intérieures, de la Mer Territoriale et de la Zone Economique Exclusive.
} 
État peut demander au navire de fournir des renseignements concernant son identité et son port d'immatriculation, son dernier et son prochain port d'escale et autres renseignements pertinents requis pour établir si une infraction a été commise.

Les États adoptent les lois et règlements et prennent les mesures nécessaires pour que les navires battant leur pavillon fassent droit aux demandes de renseignement. Lorsqu'un État a de sérieuses raisons de penser qu'un navire naviguant dans sa zone économique exclusive ou sa mer territoriale a commis, dans la zone économique exclusive, une infraction (visée au paragraphe 3) entraînant des rejets importants dans le milieu marin qui ont causé ou risquent d'y causer une pollution notable, il peut procéder à l'inspection matérielle du navire pour déterminer s'il y a eu infraction, si le navire a refusé de donner des renseignements ou si les renseignements fournis sont en contradiction flagrante avec les faits, et si les circonstances de l'affaire justifient cette inspection.

Lorsqu'il y a preuve manifeste qu'un navire naviguant dans la zone économique exclusive ou la mer territoriale d'un État a commis, dans la zone économique exclusive, une infraction (visée au paragraphe 3 )ayant entraîné des rejets qui ont causé ou risquent de causer des dommages importants au littoral ou aux intérêts connexes de l'État côtier ou à toutes ressources de sa mer territoriale ou de sa zone économique exclusive, cet État peut, si les éléments de preuve le justifient, intenter une action, notamment ordonner l'immobilisation du navire conformément à son droit interne.

Dans tous les cas où des procédures appropriées ont été soit établies par l'intermédiaire de l'organisation internationale compétente, soit convenues de toute autre manière pour garantir le respect des obligations concernant le versement d'une caution ou le dépôt d'une autre garantie financière appropriée, l'État côtier, s'il est lié par ces procédures, autorise le navire à poursuivre sa route ${ }^{197}$.

Par ailleurs en ce qui concerne les mesures visant à empêcher la pollution à la suite d'un accident de mer, la Convention de Montégo Bay indique qu'il ne doit être porté atteinte au droit qu'ont les États, en vertu du droit international, tant coutumier que conventionnel, de prendre et faire appliquer au-delà de la mer territoriale des mesures proportionnées aux dommages qu'ils ont effectivement subis ou dont ils sont menacés afin de protéger leur littoral ou les intérêts connexes, y compris la pêche, contre la pollution ou une menace de pollution résultant d'un accident de mer, ou d'actes liés à un tel accident, dont on peut raisonnablement attendre des conséquences préjudiciables ${ }^{198}$.

En vertu de l'article $211 \S 5$ de la CMB, les États côtiers sont compétents pour adopter "pour leur zone économique exclusive des lois et règlements visant à prévenir, réduire et maîtriser la pollution par les navires qui soient conformes et donnent effet aux règles et normes internationales généralement établies par l'intermédiaire de l'organisation internationale compétente ou d'une conférence diplomatique générale ${ }^{199}$.

\footnotetext{
197 Cf Article 220

198 Cf Article 221

199 L'article $211 \$ 5$ de la CMB confirme la pratique étatique et particulièrement le droit interne ivoirien. En effet, l'article 6 de la loi nº77-926 du 17 novembre 1977 portant délimitation des zones marines placées sous la juridiction nationale de la République de Côte d'Ivoire dispose : «Dans toute la zone délimitée à l'article 2 (en
} 
Cette disposition habilite l'État côtier à règlementer le passage dans sa ZEE de tout navire marchand quel qu'il soit. La CMB lui reconnaît en sus le pouvoir de recourir à des mesures opérationnelles ${ }^{200}$. Cette compétence particulière de l'État à l'égard des navires étrangers vient en complément du rôle (monopolistique) joué naguère par l'État du pavillon.

Cependant, certains États se montrent souvent peu soucieux de leur obligation en matière de sécurité des navires. À ce sujet, Sabrina Robert révèle que l'Erika était soumis à la juridiction de l'État maltais de même qu'aux contrôles diligentés par les autorités des ports fréquentés. Et pourtant, le navire a échappé aussi bien à la vigilance de son État de pavillon qu'à celle des ports fréquentés.

\section{B - Les compétences dévolues à l'État du port et l'État du pavillon}

Face à l'ampleur qu'a pris la pollution des mers dans les années 1970, la Communauté Internationale a cherché une réponse juridique globale au moyen notamment dans la Convention de Montego Bay de 1982 (CBM) au titre de la Partie XII portant sur la protection et la préservation du milieu marin.

La CMB va codifier certains principes déjà existants. Mais dans ce cadre-ci, les réserves seront interdites, ce qui garantit une meilleure application de ces principes. Elle va poser comme principes, la prévention, la réduction et la maîtrise de la pollution. Afin de faire face aux États trop laxistes, elle va créer des droits pour deux types d'États à savoir l'État côtier (A travers l'article $220 \mathrm{CMB}$ précité), mais aussi à l'État du pavillon (1) et l'État du port d'escale (2).

\section{L'État du pavillon ${ }^{201}$}

La CMB a posé comme principes, la prévention, la réduction et la maîtrise de la pollution. Elle permet également à l'État du pavillon de décider des règles de délivrance de sa nationalité à un navire ${ }^{202}$.

L'État du pavillon bénéficie de compétences étendues. Car il lui est confié en premier lieu la responsabilité de la mise en oeuvre d'un certains nombres d'obligations.

l'occurrence la ZEE), la République de Côte d'Ivoire se réserve également le droit de prendre toutes les mesures et d'entreprendre toute action afin de prévenir, réduire ou maîtriser la pollution du milieu marin, quelle qu'en soit la source ". Cf. TIEBLEY (Yves Didier), La Côte d'Ivoire et la gestion durable des ressources naturelles marines op.cit, p.153.

200 Celles-ci consistent en des mesures opérationnelles telles que l'approche, la reconnaissance et l'enquête de pavillon.

201 La loi du pavillon est l'expression de la souveraineté d'un État sur un navire. C'est-à-dire celui auprès duquel est immatriculé le navire.

${ }^{202}$ LE DRIAN (Jean-Yves), «Rapport sur la sécurité du transport maritime des produits dangereux ou polluants faits au nom de la Commission d'enquête ", le 5 juillet 2000, in htpp://www.ifremer.fr/dlpc/doc_reference/CNAM_pollution, du 15/05/2011 à 19 heures. 
Il ressort en effet de la Convention de Montégo Bay ${ }^{203}$ que les États veillent à ce que les navires battant leur pavillon ou immatriculés par eux respectent les règles et normes internationales applicables établies par l'intermédiaire de l'organisation internationale compétente ou d'une conférence diplomatique générale, ainsi que les lois et règlements qu'ils ont adoptés conformément à la Convention afin de prévenir, réduire et maîtriser la pollution du milieu marin par les navires et ils adoptent les lois et règlements et prennent les mesures nécessaires pour leur donner effet. L'État du pavillon veille à ce que ces règles, normes, lois et règlements soient effectivement appliqués, quel que soit le lieu de l'infraction.

Les États prennent en particulier les mesures appropriées pour interdire aux navires battant leur pavillon ou immatriculés par eux d'appareiller tant qu'ils ne se sont pas conformés aux règles et normes internationales visées au paragraphe 1 , y compris les dispositions concernant la conception, la construction et l'armement des navires.

Les États veillent à ce que les navires battant leur pavillon ou immatriculés par eux soient munis des certificats requis et délivrés en application des règles et normes internationales visées au paragraphe 1, les États veillent à ce que les navires battant leur pavillon soient inspectés périodiquement pour vérifier que les mentions portées sur les certificats sont conformes à l'État effectif du navire. Les autres États acceptent ces certificats comme preuve de l'état du navire et leur reconnaissent la même force qu'à ceux qu'ils délivrent, à moins qu'il n'y ait de sérieuses raisons de penser que l'état du navire ne correspond pas, dans une mesure importante, aux mentions portées sur les certificats.

Si un navire commet une infraction aux règles et normes établies par l'intermédiaire de l'organisation internationale compétente ou d'une conférence diplomatique générale, l'État du pavillon, fait immédiatement procéder à une enquête et, le cas échéant, intente une action pour l'infraction présumée, quel que soit le lieu de cette infraction ou l'endroit où la pollution en résultant s'est produite ou a été constatée.

Lorsqu'il enquête sur l'infraction, l'État du pavillon peut demander l'assistance de tout autre État dont la coopération pourrait être utile pour élucider les circonstances de l'affaire. Les États s'efforcent de répondre aux demandes appropriées de l'État du pavillon.

Les États, sur demande écrite d'un État, enquêtent sur toute infraction qui aurait été commise par les navires battant leur pavillon. L'État du pavillon engage sans retard, conformément à son droit interne, des poursuites du chef de l'infraction présumée s'il est convaincu de disposer de preuves suffisantes pour ce faire.

L'État du pavillon informe sans délai l'État demandeur et l'organisation internationale compétente de l'action engagée et de ses résultats. Tous les États ont accès aux renseignements ainsi communiqués.

${ }^{203}$ Cf. article 217 de la CMB. 
Les sanctions prévues par les lois et règlements des États à l'encontre des navires battant leur pavillon doivent être suffisamment rigoureuses pour décourager les infractions en quelque lieu que ce soit ${ }^{204}$.

L'article 217 de la CMB investit l'État de pavillon de l'obligation de veiller à ce que le navire qu'il a immatriculé respecte les normes internationales en vigueur destinées à réduire, maîtriser, prévenir les pollutions en application des lois ${ }^{205}$.

Pour ce faire, l'État du pavillon est compétent pour déterminer et infliger aux délinquants les sanctions disciplinaires et les poursuites pénales qu'il estime appropriées. Les pouvoirs ainsi reconnus à l'État du pavillon sont la résultante de la compétence fonctionnelle voire personnelle qu'il exerce sur le navire pollueur et/ou sur son équipage.

En vue de combattre le phénomène des pavillons de complaisance, le $\$ 3$ de l'article 217 précité fait obligation à l'État du pavillon de veiller à ce que les navires battant son pavillon possèdent des certificats dont la validité est vérifiée par des inspections périodiques. Le corollaire de cette obligation est l'acceptation par les autres États des certificats à moins qu'ils n'aient de sérieuses raisons de penser que ces certificats ne reflètent pas la réalité ${ }^{206}$.

L'article $217 \$ 4$ de la CMB précise que l'État du pavillon est toujours compétent pour mener une enquête et une action pour l'infraction présumée en cas d'accident; peu importe le lieu de cet accident. De même, il a la possibilité de demander la coopération de tout autre État pour mener l'affaire à bien ${ }^{207}$.

Les pouvoirs de l'Etat du port complètent ceux de l'Etat du pavillon.

\footnotetext{
204 Cf LE DRIAN (Jean-Yves), « Rapport sur la sécurité du transport maritime des produits dangereux ou polluants faits au nom de la Commission d'enquête", le 5 juillet 2000, in htpp://www.ifremer.fr/dlpc/doc_reference/CNAM_pollution, du 15/05/2011 à 19 heures.

${ }^{205}$ L'article $217 \$ 1$ de la CMB dispose: «Les États veillent à ce que les navires battant leur pavillon ou immatriculés par eux respectent les règles et normes internationales applicables établies par l'intermédiaire de l'organisation internationale compétente ou d'une conférence diplomatique générale, ainsi que les lois et règlements qu'ils ont adoptés conformément à la Convention afin de prévenir, réduire et maîtriser la pollution du milieu marin par les navires et ils adoptent les lois et règlements et prennent les mesures nécessaires pour leur donner effet. L'État du pavillon veille à ce que ces règles, normes, lois et règlements soient effectivement appliqués, quel que soit le lieu de l'infraction ".

206 BOISSON DE CHAZOURNES (Laurence), La protection de l'environnement marin dans le cadre de la Convention des Nations Unies sur le droit de la mer, Séminaire de Droit international public, Année 1999-2000, Université de Genève, Faculté de Droit, p.14.

Article publié en ligne sur : www.jurawelt.com/sunrise/media/mediafiles/14149/protectionmer.pdf. Consulté le 19 mai 2011.

207 Ibidem.
} 


\section{L'État du port d'escale}

L'expérience montre que les contrôles exercés par les États du port sont les plus efficaces, non pas en raison de leur technicité, mais plutôt à cause de leur caractère dissuasif à l'égard de l'exploitation de navires non conformes.

Les navires de commerce étrangers sont soumis à la juridiction de tout État côtier lorsqu'ils se trouvent dans ses eaux intérieures, et à plus forte raison dans ses ports. L'intervention des États du port répond à deux exigences :

- protéger les citoyens et leur environnement contre les dangers induits par les navires sous-normes ;

- veiller à l'application des Conventions internationales sur la sécurité et empêcher qu'un navire en mauvais état ne quitte le port dans lequel il se trouve immobilisé.

Dans la mesure où l'inspection et la détention des navires dans les ports affectent de manière sensible le commerce maritime et la liberté de la navigation, la convention sur le droit de la mer de 1982 (partie XII) a cherché à limiter l'étendue des pouvoirs des États du port à l'égard des navires étrangers et à fixer des procédures très précises pour l'exercice de ces droits.

Ainsi, l'inspection matérielle d'un navire doit être limitée à l'examen des certificats, registres ou autres documents dont le navire est tenu d'être muni. Une inspection plus poussée peut être diligentée dans trois cas de figure seulement: s'il y a de sérieuses raisons de penser que l'état du navire ne correspond pas aux mentions portées sur les documents ; si la teneur des documents ne suffit pas pour vérifier l'infraction présumée ; si le navire ne dispose pas des documents exigibles. Un bateau ne doit pas être retenu plus que nécessaire, de sorte que si des réparations sont préconisées, il peut être autorisé à repartir pour se rendre dans le chantier naval de son choix ${ }^{208}$.

Devant le caractère aléatoire des contrôles effectués par les États du pavillon ou pour leur compte, les États côtiers les plus exposés ont cherché à lutter contre les navires sous-normes en exerçant une véritable police de la navigation maritime dans leurs ports. L'escale des navires est en effet le moment privilégié pour effectuer des visites d'inspection visant à prévenir les risques. Seuls des fonctionnaires dûment autorisés par les États du port peuvent intervenir à bord des bateaux. Outre une bonne connaissance des normes internationales en vigueur, ils doivent maîtriser l'anglais, être titulaires d'un brevet de capitaine ou de chef mécanicien, avoir une expérience suffisante du service en mer ou être diplômés d'un établissement maritime, et avoir reçu une formation spécialisée pour ce type d'inspections ${ }^{209}$.

\footnotetext{
208 LAUSANNE ((Axelle Prior), «La pollution accidentelle par les hydrocarbures », Travail de licence, le 26 mars 2001, p .12 in http://www.bernaddeflesselbs.com/fr/environnement/theme-maritime/d-lutter-contre-les pollutions-marines-et-la-sécurité-marine, pp.19-20 du 11/05/011

209 GOURET( Patricia) et CHARPENTIER (David), « La lutte contre la pollution venue de la mer », pp. 5-6 in http://www.bernarddeflesselbs.com/fr/environnement/theme-13-securite-maritime/d-5lutter-contre-les pollutions-marines-et-la-securite-marine, du 11/05/2011 à 8hheures 35 .
} 
En ce qui concerne l'État du port d'escale, le droit international prévoit que si le navire se trouve dans un port qui n'est pas celui de son pavillon et qu'il ne vient ni livrer ni prendre dans ce port et qu'il a pollué la ZEE d'un État à $3000 \mathrm{~km}$ alors, l'État du port d'escale qui n'est pas concerné peut toutefois intervenir, car il est partie à la Convention de l'État qui se trouve à $3.000 \mathrm{~km}$ de là. L'État du port d'escale peut mener une enquête à bord de ce navire et peut, au nom de l'État concerné, engager une action contre ce navire coupable ${ }^{210}$.

Par ailleurs, en ce qui concerne les mesures de contrôle de la navigabilité visant à éviter la pollution, cet État est également compétent pour empêcher l'appareillage de navire tiers en infraction. En effet, les États, lorsqu'ils ont déterminé, sur demande ou de leur propre initiative, qu'un navire se trouvant dans un de leurs ports ou à une de leurs installations terminales au large a enfreint les règles et normes internationales applicables concernant la navigabilité des navires et risque de ce fait de causer des dommages au milieu marin, prennent, autant que faire se peut, des mesures administratives pour empêcher ce navire d'appareiller. Ils ne l'autorisent qu'à se rendre au chantier de réparation approprié le plus proche et, une fois éliminées les causes de l'infraction, ils lui permettent de poursuivre sa route sans délai ${ }^{211}$.

Au regard de l'article $218 \$ 1$ de la CMB précité, l'État du port enquête et intente une action contre tout navire suspecté de rejet illicite effectué au-delà de ses eaux intérieures, de sa mer territoriale ou de sa Zone économique exclusive ${ }^{212}$.

210 L'article 218 de la CMB dispose : «Lorsqu'un navire se trouve volontairement dans un port ou à une installation terminale au large, l'État $d u$ port peut ouvrir une enquête et, lorsque les éléments de preuve le justifient, intenter une action pour tout rejet effectué au-delà de ses eaux intérieures, de sa mer territoriale ou de sa Zone économique exclusive par le navire en infraction aux règles et normes internationales applicables établies par l'intermédiaire de l'organisation internationale compétente ou d'une conférence diplomatique générale.

L'État du port n'intente pas d'action en vertu du paragraphe 1 pour une infraction du fait de rejets effectués dans les eaux intérieures, la mer territoriale ou la Zone économique exclusive d'un autre État, sauf si ces rejets ont entraîné ou risquent d'entraîner la pollution de ses eaux intérieures, de sa mer territoriale ou de sa Zone économique exclusive, ou si l'autre État, l'État du pavillon ou un État qui a subi ou risque de subir des dommages du fait de ces rejets, le demande.

Lorsqu'un navire se trouve volontairement dans un port ou à une installation terminale au large, l'État du port s'efforce de faire droit aux demandes d'enquête de tout autre État au sujet de rejets susceptibles de constituer l'infraction visée au paragraphe 1 qui auraient été effectués dans les eaux intérieures, la mer territoriale ou la zone économique exclusive de l'État demandeur, et qui auraient pollué ou risqueraient de polluer ces zones. L'État du port s'efforce également de faire droit aux demandes d'enquête de l'État du pavillon au sujet de telles infractions, où que celles-ci puissent avoir été commises.

Le dossier de l'enquête effectuée par l'État du port en application du présent article est transmis, sur leur demande, à l'État du pavillon ou à l'État côtier. Toute action engagée par l'État du port sur la base de cette enquête peut, sous réserve de la section 7 , être suspendue à la demande de l'État côtier, lorsque l'infraction a été commise dans les eaux intérieures, la mer territoriale ou la zone économique exclusive de ce dernier. Les éléments de preuve, le dossier de l'affaire, ainsi que toute caution ou autre garantie financière déposée auprès des autorités de l'État du port, sont alors transmis à l'État côtier. Cette transmission exclut que l'action soit poursuivie dans l'État du port."

211 Cf.Art.219

212 "Lorsqu'un navire se trouve volontairement dans un port ou à une installation terminale au large, l'État du port peut ouvrir une enquête et, lorsque les éléments de preuve le justifient, intenter une action pour tout rejet 
Au regard de cette disposition, il apparaît que si l'ouverture de l'enquête est facultative ${ }^{213}$, en revanche, la décision de recourir à l'action répressive à l'encontre du navire en infraction s'impose à l'État du port ${ }^{214}$. Cette assertion n'est nullement exagérée si l'on garde à l'esprit la reconnaissance, en la matière, de compétences au profit de l'État du port s'inscrit dans la perspective de pallier les défaillances (multiples et répétées) constatées au niveau des États s'adonnant à la pratique du pavillon de complaisance.

Cette compétence lui est encore reconnue lorsque le rejet illicite, bien qu'ayant été effectué dans les espaces marins d'un autre État, entraine ou menace d'entraîner la pollution de ses eaux intérieures, de sa mer territoriale ou de sa Zone économique exclusive. Il peut également le faire si un État tiers victime de cette pollution le lui demande ${ }^{215}$.

La Convention OPRC 1990 prévoit, elle aussi, des mesures opérationnelles de lutte contre les pollutions marines par hydrocarbures.

\section{Paragraphe 2: La lutte contre les marées noires au moyen de la Convention OPRC 1990}

C’est le désastre causé par l'Exxon-Valdez en mars 1989 qui a amené à la conclusion de la Convention sur la préparation, la lutte et la coopération en matière de pollution par les hydrocarbures le 30 novembre $1990^{216}$.

La Convention sur la préparation, la lutte et la coopération en matière de pollution par les hydrocarbures ${ }^{217}$ (OPRC), a pour objet de servir de cadre mondial à la coopération internationale pour la lutte contre les événements ou les menaces graves de pollutions

effectué au-delà de ses eaux intérieures, de sa mer territoriale ou de sa Zone économique exclusive par le navire en infraction aux règles et normes internationales applicables établies par l'intermédiaire de l'organisation internationale compétente ou d'une conférence diplomatique générale » (article $218 \$ 1$ de la CMB).

213 "...l'État du port peut ouvrir une enquête" (formule permissive).

214 "...et intenter une action ...».

215 "L'État du port n'intente pas d'action en vertu du paragraphe 1 pour une infraction du fait de rejets effectués dans les eaux intérieures, la mer territoriale ou la Zone économique exclusive d'un autre État, sauf si ces rejets ont entraîné ou risquent d'entraîner la pollution de ses eaux intérieures, de sa mer territoriale ou de sa Zone économique exclusive, ou si l'autre État, l'État du pavillon ou un État qui a subi ou risque de subir des dommages du fait de ces rejets, le demande " (article $218 \$ 2$ de la CMB).

216 LAUSANNE ((Axelle Prior), "La pollution accidentelle par les hydrocarbures », Travail de licence, le 26 mars 2001, in http://www.bernaddeflesselbs.com/fr/environnement/theme-maritime/d-lutter-contre-les pollutions-marines-et-la-sécurité-marine, pp.19-20 du 11/05/011

217 Cette Convention a été adoptée le 30 novembre 1990 et entrée en vigueur le 13 mai 1995 après une Conférence des principaux États industriels qui s'est tenue à Paris à la suite de la catastrophe de l'Exxon Valdez. Le protocole additionnel du 15 mars 2000 a été adopté pour la préparation, la lutte et la coopération contre les événements de pollution par substances nocives et potentiellement dangereuses. Celui-ci est entré en vigueur le 17 juin 2007. 
de mers. Elle fait référence dans son préambule au principe du " pollueur-payeur ». ${ }^{218}$ Elle prévoit également que les États doivent mettre en place un dispositif de réponse aux accidents pétroliers ${ }^{219}$.

Les dommages causés par les marées noires sont gigantesques et les coûts qu'ils engendrent lorsqu'il faut les réparer le sont tout autant. C’est pourquoi une coopération internationale est indispensable pour une plus grande efficacité dans la lutte contre la pollution : elle permet à un État de mettre en oeuvre des moyens plus importants que s'il ne devait compter que sur les siens propres ${ }^{220}$.

Instituée pour commencer à l'échelon régional ${ }^{221}$, cette coopération interétatique revêt plusieurs formes, à savoir une obligation d'échange d'informations sur leur organisation administrative et sur l'identité des services chargés de recevoir les renseignements sur les événements de pollution, celle qui consiste à mettre en oeuvre les moyens de lutte, ainsi qu'une obligation d'assistance mutuelle face à ces événements ${ }^{222}$.

Concrètement la réponse aux pollutions accidentelles des mers au moyen de la Convention OPRC repose principalement sur la délimitation des compétences respectives des États du pavillon et côtier (A), ainsi que le contenu des mesures opérationnelles de lutte contre les marées noires celles-ci (B).

\section{A - La délimitation des compétences respectives de l'État du pavillon et de l'État du port}

Nous verrons au cas par cas la compétence de l'État du pavillon (1) et celle de l'État du port (2).

\footnotetext{
218 Tenant compte du principe "pollueur-payeur» en tant que principe général du droit international de l'environnement ...

219 AKOHOU (Dossou Rodrigue), «Exploitation pétrolière en mer et le droit international : Aspects juridiques et environnementaux pour les États côtiers du Golfe de Guinée », Programme de Bourses de Recherche Nations Unies-Fondation Nippone du Japon 2007-2008 pp.129-132 in http://www.bernaddeflesselbs.com/fr/environnement/theme-maritime/d-lutter-contre-les pollutions-marineset-la-sécurité-marine, pp.19-20 du 11/05/011)

${ }^{220}$ LAUSANNE ((Axelle Prior), « La pollution accidentelle par les hydrocarbures, Travail de licence, le 26 mars $2001 », \quad$ in http://www.bernaddeflesselbs.com/fr/environnement/theme-maritime/d-lutter-contre-les pollutions-marines-et-la-sécurité-marine, pp.19-20 du 11/05/011

221 Cf. notamment l'Accord de Bonn du 20 décembre 1989 entre les pays riverains de la Manche et de la Mer du Nord ou l'Accord de Lisbonne du 17 octobre 1990 entre l'Espagne, la France, le Portugal, le Maroc et la Communauté européenne.

222 LAUSANNE ((Axelle Prior), " La pollution accidentelle par les hydrocarbures, Travail de licence », le 26 mars 2001, in http://www.bernaddeflesselbs.com/fr/environnement/theme-maritime/d-lutter-contre-les pollutions-marines-et-la-sécurité-marine, pp.19-20 du 11/05/011.
} 


\section{La compétence de l'État du pavillon}

Il convient de noter un progrès dans la logique de prévention de la pollution du milieu marin par les hydrocarbures. Car la Convention OPRC privilégie l'approche coopérative de cette lutte et reconnaît la nécessité d'inclure l'État du pavillon dans la prévention ${ }^{223}$.

Pour sa part, l'État du pavillon doit imposer des plans d'urgence à bord des navires. En effet, il doit aussi adopter des textes imposant aux navires battant leur pavillon de se doter d'un plan d'urgence et aux capitaines de rapporter sans délai à l'État côtier le plus proche, tout événement sur le bateau impliquant un déversement ou un risque de déversement d'hydrocarbures.

De même, les exploitants d'unités au large relevant de la juridiction de Parties à la Convention doivent également avoir des plans d'urgence contre la pollution par les hydrocarbures ou des arrangements analogues qui doivent être coordonnées avec les systèmes nationaux afin de lutter rapidement et efficacement contre les événements de pollution par les hydrocarbures.

A cet effet, l'article 3 alinéal relatif au plans d'urgence contre la pollution par les hydrocarbures dispose que : "Chaque partie doit exiger que les navires autorisés à battre son pavillon aient un plan d'urgence de bord contre la pollution par les hydrocarbures selon l'Organisation.

En outre, un navire tenu d'avoir à bord un plan d'urgence de bord contre la pollution par les hydrocarbures, lorsqu'il se trouve dans un ou un terminal au large relevant de la juridiction d'une Partie, est soumis à une inspection par les agents dûment autorisés de cet État conformément aux pratiques prévues dans les accords internationaux existants ou dans sa législation nationale ».

L'Etat du port se voit aussi reconnaître la compétence sur son territoire, à l'effet de lutter contre les pollutions accidentelles.

\section{La compétence territoriale de l'État du port}

La compétence de l'État du port réside dans sa capacité à contrôler le respect des plans d'urgence contre la pollution par les hydrocarbures, par des acteurs du milieu maritime. Ceux-ci, sont constitués notamment par les exploitants d'unités au large ainsi que ceux ayant la charge des ports maritimes et des installations de manutention d'hydrocarbures.

\footnotetext{
${ }^{223} \mathrm{AKOHOU}$ (Dossou Rodrigue), « Exploitation pétrolière en mer et le droit international : Aspects juridiques et environnementaux pour les États côtiers du Golfe de Guinée », Programme de Bourses de Recherche Nations Unies-Fondation Nippone du Japon 2007-2008, in http://www.bernaddeflesselbs.com/fr/environnement/theme-maritime/d-lutter-contre-les pollutions-marines-et-la-sécurité-marine, pp.19-20 du $11 / 05 / 011$
} 
En ce qui concerne les premiers cités, l'article 3 alinéas 2 et 3 dispose que chaque partie exige que les exploitants d'unités au large relevant de sa juridiction aient des plans d'urgence de bord contre la pollution par les hydrocarbures qui soient coordonnés avec le système national établi ${ }^{224}$. L'article3 alinéa 3 dispose que chaque partie exige que les autorités ou les exploitants ayant la charge des ports maritimes et installations de manutention d'hydrocarbures relevant de sa juridiction, pour lesquels elle le juge approprié, aient des plans d'urgence contre la pollution par les hydrocarbures ou des arrangements analogues qui soient coordonnés avec le système national établi.

Il convient d'analyser à présent le contenu des mesures opérationnelles de lutte contre les marées noires.

\section{B - Le contenu des mesures opérationnelles de lutte contre les marées noires}

Le contenu des mesures opérationnelles de lutte contre les marées noires se résume en la préparation des plans d'urgence (1) et l'application des plans d'urgence (2).

\section{La préparation des plans d'urgence}

En guise de la préparation de pans d'urgences, il est prévu des procédures de notification en cas de pollution par les hydrocarbures.

A cet effet, l'État côtier à l'obligation de prendre des mesures nécessaires pour informer tout État susceptible d'être touché par la pollution, et tous ont ensemble le devoir d'assistance en cas de situation critique.

L'État côtier devra en ce qui le concerne, informer les autres États touchés ou susceptibles d'être touchés des mesures prises pour faire face à la situation. Dans la mesure de ses moyens, chaque État a un devoir d'assistance en cas d'accident particulièrement dangereux.

Le préambule de la convention affirme la volonté des États parties à la convention dans ce sens ${ }^{225}$.

\footnotetext{
224 Conformément à l’art. 6 et approuvés conformément aux procédures prévues par l'autorité nationale compétente.

225 «Conscientes également qu'en cas d'événement de pollution par les hydrocarbures des mesures promptes et efficaces sont essentielles pour limiter les dommages qui pourraient résulter d'un tel événement, Soulignant l'importance d'une préparation efficace pour lutter contre les événements de pollution par les hydrocarbures et le rôle primordial que les industries pétrolière et maritime ont à cet égard, Reconnaissant en outre l'importance d'une assistance mutuelle et d'une coopération internationale en ce qui concerne notamment l'échange d'informations sur les moyens dont disposent les États pour lutter contre des événements de pollution par les hydrocarbures, l'établissement de plans d'urgence contre la pollution par les hydrocarbures, l'échange de rapports sur des événements importants susceptibles de toucher l'environnement marin ou le littoral et les intérêts connexes des États, ainsi que les programmes de recherche-développement portant sur les moyens de combattre la pollution du milieu marin par les hydrocarbures».
} 
En effet, l'article 4 de la Convention indique que : "chaque Partie exige que les capitaines ou autres personnes ayant la charge de navires battant son pavillon ainsi que les personnes ayant la charge d'unités au large relevant de sa juridiction signalent sans retard tout événement survenu à bord de leur navire ou de leur unité au large qui entraîne ou risque d'entraîner un rejet d'hydrocarbures:

- dans le cas d'un navire, à l'État côtier le plus proche;

- dans le cas d'une unité au large, à l'État côtier à la juridiction duquel est soumise l'unité.

En outre il exige que les capitaines ou autres personnes ayant la charge de navires battant son pavillon ainsi que les personnes ayant la charge d'unités au large relevant de sa juridiction signalent sans retard tout événement observé en mer qui entraîne un rejet d'hydrocarbures ou toute présence d'hydrocarbures:

- dans le cas d'un navire, à l'État côtier le plus proche;

- dans le cas d'une unité au large, à l'État côtier à la juridiction duquel est soumise l'unité. Ensuite, chaque État exige que les personnes ayant la charge de ports maritimes et d'installations de manutention d'hydrocarbures relevant de sa juridiction signalent sans retard à l'autorité nationale compétente tout événement qui entraîne ou risque d'entraîner un rejet d'hydrocarbures ou toute présence d'hydrocarbures.

Enfin, chaque État donne à ses navires ou aéronefs chargés de l'inspection des mers et à ses autres services ou agents compétents des instructions les invitant à signaler sans retard à l'autorité nationale compétente ou, selon le cas, à l'État côtier le plus proche, tout événement observé en mer, dans un port maritime ou dans une installation de manutention d'hydrocarbures, qui entraîne un rejet d'hydrocarbures ou toute présence d'hydrocarbures;

Enfin chaque État doit prier les pilotes d'aéronefs civils de signaler sans retard à l'État côtier le plus proche tout événement observé en mer qui entraîne un rejet d'hydrocarbures».

Des mesures d'application des plans d'urgence sont prévues.

\section{L'application des plans d'urgence}

En vue d'appliquer les plans d'urgences et les rendre effectifs, la Convention OPRC a prévu des mesures à prendre à la réception d'un rapport de pollution par les hydrocarbures, des Systèmes nationaux et régionaux de préparation et de lutte, ainsi qu'un système de coopération internationale en matière de lutte contre la pollution.

A propos des mesures à prendre à la réception d'un rapport de pollution par les hydrocarbures, la Convention prévoit que lorsqu'une Partie reçoit un rapport visé à l'art. 4 précité ou des informations sur une pollution fournies par d'autres sources:

- elle évalue la situation pour déterminer s'il s'agit d'un événement de pollution par les hydrocarbures;

- elle évalue la nature, l'importance et les conséquences éventuelles de l'événement de pollution par les hydrocarbures; et

- elle avise ensuite sans retard tous les États dont les intérêts sont concernés par cet événement de pollution par les hydrocarbures ou sont susceptibles de l'être en leur 
communiquant en même temps, les détails de ses évaluations et de toute action entreprise ou prévue pour faire face à l'événement et d'autres informations appropriées, jusqu'à la conclusion de l'action entreprise pour faire face à l'événement ou jusqu'à ce que les États en question aient décidé d'une action commune ${ }^{226}$.

Par ailleurs, la Convention fait la promotion des systèmes nationaux et régionaux de préparation et de lutte contre les pollutions par les hydrocarbures. A cet effet, chaque Partie met en place un système national pour lutter rapidement et efficacement contre les événements de pollution par les hydrocarbures. Ce système comporte au minimum: - la désignation de l'autorité ou des autorités nationales compétentes chargées de la préparation et de la lutte contre la pollution par les hydrocarbures; du point ou des points de contact opérationnels nationaux chargés de recevoir et de transmettre les rapports de pollution par les hydrocarbures visés à l'article 4 précité ; d'une autorité qui est habilitée à agir au nom de l'État pour demander une assistance ou pour décider de fournir l'assistance demandée;

-un plan d'urgence national pour la préparation et la lutte qui comporte le schéma des relations entre les divers organismes concernés, qu'ils soient publics ou privés, en tenant compte des directives élaborées par l'Organisation.

Par ailleurs, chaque Partie, dans la mesure de ses moyens, soit individuellement, soit dans le cadre d'une coopération bilatérale ou multilatérale et, le cas échéant, en coopération avec les industries pétrolière et maritime, les autorités portuaires et les autres entités appropriées, met en place:

- une quantité minimale de matériel de lutte contre les déversements d'hydrocarbures disposée préalablement et appropriée au risque encouru et des programmes relatifs à l'emploi de ce matériel;

- un programme d'exercices à l'intention des organisations de lutte contre la pollution par les hydrocarbures et de formation du personnel concerné;

- des plans détaillés et des moyens de communications pour lutter contre un événement de pollution par les hydrocarbures. Ces moyens devraient être disponibles en permanence; et un mécanisme ou un arrangement pour coordonner les opérations de lutte contre un événement de pollution par les hydrocarbures, qui puisse, le cas échéant, mobiliser les ressources nécessaires.

Chaque Partie veille à ce que des informations à jour soient communiquées à l'Organisation soit directement, soit par l'intermédiaire de l'organisation ou des arrangements régionaux appropriés, en ce qui concerne:

- l'emplacement, les données relatives aux télécommunications et, s'il y a lieu, les zones de responsabilité des autorités et services mentionnés à l’al. $1 \mathrm{a}$ );

- les renseignements sur le matériel de lutte contre la pollution et les services d'experts dans les domaines concernant la lutte contre la pollution par les hydrocarbures et

${ }^{226}$ Cf Art. 5 alinéa 1. 
l'assistance maritime qui pourraient être fournis sur demande à d'autres États; et son plan d'urgence national ${ }^{227}$.

L'assistance mutuelle et une coopération internationale en ce qui concerne notamment l'échange d'informations sur les moyens dont disposent les États pour lutter contre des événements de pollution par les hydrocarbures sont tout aussi une préoccupation de la Convention OPRC. En ce sens que les Parties conviennent de coopérer, en fonction de leurs moyens et de la disponibilité de ressources appropriées, en vue de fournir des services de conseils, un appui technique et du matériel pour faire face à un événement de pollution par les hydrocarbures, lorsque la gravité de l'événement le justifie, à la demande de toute Partie touchée par cet événement ou susceptible de l'être ${ }^{228}$.

Pour surmonter les obstacles liés au défaut de ressources pour la mise en œuvre des plans d'urgences, la convention a prévu des facilités.

En effet, Une Partie qui a demandé une assistance peut solliciter de l'Organisation une aide pour identifier des sources de financement provisoire des frais. En outre, elle prend les mesures juridiques ou administratives nécessaires pour faciliter l'arrivée et l'utilisation sur son territoire ainsi que le départ des navires, des aéronefs et autres moyens de transport participant à la lutte contre un événement de pollution par les hydrocarbures ou transportant le personnel, les cargaisons, les produits et le matériel nécessaires pour faire face à un tel événement, ainsi que l'acheminement rapide du personnel, des cargaisons, des produits et du matériel à destination à l'intérieur et en provenance de son territoire ${ }^{229}$.

Nous ne pouvons nier l'intérêt et le rôle joués par les normes d'intervention contre les marées noires définies à l'échelle régionale africaine, européenne et états-unienne.

\section{Section 2: Les normes d'intervention définies à l'échelle régionale africaine et occidentale}

L'approche régionale de lutte contre les pollutions des mers est apparue dès le début des années1970 comme étant la solution la plus adéquate en matière de préservation des milieux marins. Les États ont été très largement favorables à la conclusion d'accords " locaux ». Ainsi de nombreuses conventions ont été élaborées afin d'organiser une coopération internationale visant d'une part à prévenir les accidents et d'autre part à mettre en place des actions en cas de catastrophes écologiques. Cette politique semble se généraliser à travers des normes d'intervention définies à l'échelle africaine (Paragraphe1), et des normes d'intervention au niveau des pays occidentaux (Paragraphe 2).

\footnotetext{
227 Cf Art. 6

${ }^{228}$ Le financement des frais afférents à cette assistance se fait sur la base des dispositions énoncées à l'Annexe de la présente Convention.

${ }^{229}$ Cf Art. 7.
} 


\section{Paragraphe 1: A l'échelle régionale africaine}

Le Conseil d'administration du PNUE considère les mers et océans comme un milieu naturel sensible qu'il convient de protéger en prioritée ${ }^{230}$. En vue d'aborder l'ensemble des problèmes d'environnement complexes qui se posent aux mers et océans, le Conseil d'administration a adopté une approche régionale dont le programme pour les mers régionales. Ainsi, dans le cadre régional africain des normes sont définies à travers, entre autres, la convention WACAF ${ }^{231}$ du 23 mars 1981 (A). À cela vient s'ajouter, dans un cadre communautaire, la Directive de l'UEMOA de 2008 relative à la recherche et au sauvetage en mer et à la protection de l'environnement marin au sein de l'UEMOA (B).

\section{A - $\quad$ La Convention WACAF du 23 mars 1983}

La Convention WACAF du 23 mars 1983 présente de réelles avancées dans la lutte contre les pollutions par les navires (1) et un mécanisme de lutte en cas de situation critique dans le cadre du protocole relatif à la Convention d'Abidjan de 1981(2).

\section{De réelles avancées dans la lutte contre les pollutions par les navires}

La Convention d'Abidjan est un accord-cadre de coopération entre les États de l'Afrique de l'Ouest et du Centre en matière de protection et de gestion des zones côtières et marines ${ }^{232}$.

\footnotetext{
${ }^{230}$ Voir OMI, Convention relative à la coopération en matière de protection et de mise en valeur du milieu et les zones côtières de l'Afrique de l'ouest et du centre, Introduction à la Convention d'Abidjan et au Protocole y relatif, New York, 1981, p.1.

${ }^{231}$ Il existe d'autres conventions régionales. Hormis la Convention WACAF susmentionnée, il est possible de citer la Convention pour la protection, la gestion et la mise en valeur du milieu marin et des zones côtières de la région de l'Afrique orientale et le Protocole relatif aux zones protégées, à la faune et à la flore sauvages, signés le 21 juin 1983 à Nairobi ; la Convention relative à la Mer Rouge et au Golfe d'Aden, signée le 14 février 1982 à Djeddah ; la Convention de Barcelone du 16 février 1976 sur la Méditerranée et son Protocole du 3 avril 1982 adopté à Genève ; la Convention sur la conservation des ressources biologiques de l'Atlantique du Sudest, signée à Rome le 23 octobre 1969.

${ }^{232}$ AKOHOU (Dossou Rodrigue), "Exploitation pétrolière en mer et le droit international : Aspects juridiques et environnementaux pour les États côtiers du Golfe de Guinée », Programme de Bourses de Recherche Nations Unies-Fondation Nippone du Japon 2007-2008, in

http://www.bernaddeflesselbs.com/fr/environnement/theme-maritime/d-lutter-contre-les pollutions-marineset-la-sécurité-marine, pp.19-20 du 11/05/011.

22 États de la région de l'Afrique de l'Ouest et du Centre ont signé la Convention relative à la coopération en matière de protection et de mise en valeur du milieu marin et des zones côtières et le Protocole y relatif depuis son adoption à Abidjan le 23 mars 1981, mais seulement 12 les ont ratifiés. Elle s'applique à la pollution par les navires, la pollution due aux opérations d'immersion, la pollution tellurique, la pollution résultant d'activités liées à l'exploration et à l'exploitation du fond de la mer et la pollution d'origine atmosphérique et transatmosphérique. Les États Parties considèrent la lutte contre l'érosion côtière, la création des zones marines spécialement protégées, la lutte contre la pollution marine en cas de situation critique, l'évaluation des incidences des activités industrielles sur le milieu marin et côtier, le développement durable et la gestion intégrée des zones côtières comme les aspects prioritaires auxquels il convient de concentrer les efforts de coopération.
} 
La région de l'Afrique de l'Ouest et du Centre est la zone d'application de la Convention d'Abidjan du 23 mars 1981, relative à la coopération en matière de protection et de mise en valeur du milieu marin et des zones côtières (ci-après dénommée Convention WACAF) et à son Protocole relatif aux situations critiques. À l'analyse, il apparaît que l'adoption de la Convention WACAF du 23 mars 1981 est motivée par la volonté des parties contractantes de "préserver leur patrimoine naturel dans l'intérêt des générations présentes et futures $»^{233}$. Pour ce faire, les parties contractantes recourent à la coopération interétatique ${ }^{234}$, et la coopération avec les institutions internationales ${ }^{235}$

La Convention WACAF, à l'image des autres conventions sur les mers régionales conclues sous les auspices du PNUE, s'attelle, d'une part, à lutter contre toutes les formes de pollution marine ${ }^{236}$ et d'autre part, à encourager les parties contractantes à créer des aires marines protégées ${ }^{237}$.

L'objectif assigné à la WACAF est indéniablement ambitieux tant elle embrasse, à une exception près, toutes les activités anthropiques ayant un lien avec la mer. En effet, l'inapplication de la Convention WACAF risquait, à la longue, de se traduire par une catastrophe écologique eu égard au rythme actuel de prélèvement des ressources marines et leurs incidences négatives sur la pérennité du Grand Écosystème Marin du Courant du Golfe de Guinée. C’est d'ailleurs la raison pour laquelle le FEM a décidé de financer le projet GCLME. ${ }^{238}$ Celui-ci sera exécuté par le PNUE, le PNUD, en partenariat avec l'ONUDI. Ce projet renforcera la coopération entre les pays riverains du Grand Écosystème Marin du Courant du Golfe de Guinée, dans le droit fil de la Convention WACAF du 23 mars $1981^{239}$.

Le protocole à la Convention précitée prévoit un mécanisme de lutte en cas de situation critique.

\footnotetext{
233 Alinéa 2 du préambule de la Convention WACAF

234 Alinéa 4 du préambule; article $4 \$ 2$; article $14 \$ 3$; article $14 \$ 1$ de la Convention WACAF

235 Article $4 \$ 4$ de la Convention WACAF.

${ }^{236}$ (Pollution par les navires (article 5) ; pollution par immersion (article 6); pollution d'origine tellurique (article 7) ; pollution résultant d'activités liées à l'exploration et à l'exploitation du fonds de la mer et de son sous-sol (article 8) ; pollution d'origine atmosphérique ou transatmosphérique ; pollution accidentelle et massive (article 12).) et l'érosion côtière (Article 10 de la Convention WACAF)

237 Article 14 de la Convention WACAF).

238 Le Conseil du Fonds pour l'environnement mondial (FEM) a accordé le 21 novembre 2003 un appui financier de 21,45 millions de dollars à 16 pays côtiers d'Afrique de l'Ouest pour les aider à préparer et exécuter un projet visant à protéger une ressource naturelle commune : le grand écosystème marin du Golfe de Guinée. La participation financière du FEM a permis de mobiliser 33,87 millions de dollars de cofinancement provenant, notamment, des 16 pays participant au projet GCLME : l’Angola, le Bénin, le Cameroun, la Côte d’Ivoire, le Gabon, le Ghana, la Guinée, la Guinée-Bissau, la Guinée équatoriale, le Libéria, le Nigeria, la République du Congo, la République démocratique du Congo, Sao Tomé-et-Principe, la Sierra Leone et le Togo. Cf. FONDS POUR L'ENVIRONNEMENT MONDIAL, Le FEM finance la protection des eaux en Afrique de l'Ouest, Communiqué de presse, Washington, 21 novembre 2003, p.1.

${ }^{239}$ Cf. FONDS POUR L'ENVIRONNEMENT MONDIAL, Le FEM finance la protection des eaux en Afrique de l'Ouest, Communiqué de presse, Washington, 21 novembre 2003, p.1, cité par TIEBLEY (Yves Didier), La Côte d'Ivoire et la gestion durable des ressources naturelles marines op.cit, p.62
} 
2. Le mécanisme de lutte dans le cadre du protocole relatif à la convention d'Abidjan de 1981

L'aspect de la situation critique fait particulièrement l'objet d'un Protocole qui vise spécifiquement à combattre ou à répondre de façon opérationnelle aux situations critiques en mer, de même qu'à coordonner les activités y relatives, dans chacun des États parties ${ }^{240}$.

Le Protocole relatif à la Convention définit la situation critique pour le milieu marin comme:

" tout incident, événement ou situation, quelle qu'en soit la cause, ayant pour conséquence une pollution importante ou une menace imminente de pollution importante du milieu marin et des zones côtières par des hydrocarbures ou d'autres substances nuisibles, et en particulier les collisions, échouements et autres incidents survenant à des navires, $y$ compris les navires-citernes, les éruptions sur les sites de production pétrolière et la présence d'hydrocarbures ou d'autres substances nuisibles dues à des défaillances d'installations industrielles $»^{241}$.

Comme l'indique l'intitulé, cette catégorie de mesures opérationnelles interviennent lorsque la pollution a lieu ou lorsqu'elle est imminente. Dans ce cas, le Protocole d'Abidjan énonce un ensemble d'obligations qui incombent à différentes personnes. Ces obligations ont trait d'une part, à l'alerte (1) et d'autre part à la résorption de la pollution (2).

- L'alerte

La question de l'alerte est traitée à l'article 7 du Protocole d'Abidjan. Selon le $\$ 7$ de cette disposition, "chaque Partie s'engage à demander aux capitaines de navires battant son pavillon et aux pilotes des aéronefs immatriculés sur son territoire, ainsi qu'aux personnes responsables d'ouvrages opérant au large des côtes sous sa juridiction, de signaler à toute Partie contractante, par les voies les plus rapides et les plus appropriées compte tenu des circonstances et conformément à l'annexe au présent Protocole:

Tous les accidents causant ou pouvant causer une pollution des eaux de la mer par les hydrocarbures ou d'autres substances nuisibles;

La présence, les caractéristiques et l'étendue des nappes d'hydrocarbures ou d'autres substances nuisibles repérées en mer et de nature à constituer une menace grave et imminente pour le milieu marin, les côtes ou les intérêts connexes d'une ou plusieurs Parties contractantes".

L'analyse de cette disposition permet de cerner :

- les personnes ayant l'obligation de donner l'alerte

\footnotetext{
240 Réseaux d'acteurs Sur l'adaptation au changement climatique en Zone côtière de l'Afrique de l'ouest, Dakar, janvier 2010, in http://www.bernaddeflesselbs.com/fr/environnement/theme-maritime/d-5luttercontre-les pollutions-marines-et-la-sécurité-marine, pp.19-20 du 11/05/011 à 8h35).

241 Cf. Art. 1du Protocole relatif à la coopération en matière de lutte contre la pollution en cas de situation critique.
} 
- les moyens utilisés pour donner l'alerte

- le contenu des renseignements véhiculés par l'alerte.

Trois catégories de personnes ont l'obligation de donner l'alerte : il s'agit des capitaines de navires battant pavillon de la Partie destinataire de l'alerte, des pilotes des aéronefs immatriculés sur le territoire de la Partie alertée et des personnes responsables d'ouvrages off shore soumis à la juridiction de la Partie alertée. La disposition précitée exige que l'alerte soit donnée rapidement et de façon appropriée. C'est d'ailleurs ce qui ressort de la section de phrase «les voies les plus rapides et les plus appropriées".

L'article $7 \$ 1 b$ ) du Protocole d'Abidjan donne d'avance un modèle du contenu que l'alerte doit avoir. Il s'agit des caractéristiques et l'étendue des nappes d'hydrocarbures ou des autres substances nuisibles repérées en mer277. La précision de ces renseignements est très utile vu qu'elle permettra aux équipes d'intervention de se munir dès le départ des moyens de lutte approprié.

L'alerte, une fois donnée, débouchera sur les mesures de résorption de la pollution. Le Protocole d'Abidjan ne donne pas dans le détail les moyens techniques à utiliser en vue de "prévenir, réduire, combattre et maîtriser " la pollution. Toutefois, Monsieur TIEBLEY observe que la pratique observée en matière de nettoyage de nappes de pétrole permet de déceler les techniques du confinement, de la succion, de l'écrémage, de l'absorption, de la gélification, de la précipitation, de l'émulsion et du brûlage ${ }^{242}$.

L'article $8 \$ 1$ préconise la récupération ou le sauvetage des colis, conteneurs, citernes mobiles, camions-citernes ou wagons-citernes immergés. Pour ce faire, la disposition précitée donne la possibilité pour l'État partie à solliciter le concours de toute Partie contractante. La demande d'assistance est adressée en premier lieu aux autres Parties contractantes dont les côtes et les intérêts connexes sont susceptibles d'être touchées par la situation critique en cause $\mathrm{e}^{243}$.

Le deuxième instrument, cette fois, de portée sous-régionale est la Directive de l'UEMOA de 2008 relative à la recherche et au sauvetage en mer et à la protection de l'environnement marin au sein de l'UEMOA.

\footnotetext{
${ }^{242}$ TIEBLEY (Yves Didier), La Côte d'Ivoire et la gestion durable des ressources naturelles marines op.cit, p.62 243 Cf. FOUCHER (B.J), Techniques de contrôle et de lutte contre les pollutions par les hydrocarbures dans le Golfe de Guinée, Communication au symposium international sur ZEE, Abidjan, 18-23 mai 1987, doc. multigr., Annexe 2, p.55. Cité par KAMTO (Maurice), Droit de l'environnement en Afrique, op.cit, p.280. En Côte d'Ivoire, l'exécution des mesures opérationnelles de lutte est confiée au CIAPOL et particulièrement à la CIPOMAR, une des trois sous-directions de la première citée, cité par TIEBLEY (Yves Didier), La Côte d'Ivoire et la gestion durable des ressources naturelles marines op.cit, pp.100-101.
} 
La Directive n²/2008/CM/UEMOA joue un rôle déterminant dans la promotion des PIU en matière de la prévention et la lutte contre les situations critiques dues aux événements de pollution accidentelles des mers ${ }^{245}$.

En effet, les plans d'intervention d'urgence (PIU) sont aujourd'hui des méthodes de lutte incontournables que les États africains qui aspirent à la maîtrise et à la réduction matérielle des conséquences néfastes des marées noires doivent améliorer ${ }^{246}$. La Directive de 2008 de l'UEMOA relative à la recherche et au sauvetage en mer et à la protection de l'environnement marin au sein de l'UEMOA, prône également le renforcement de la politique de coopération intégrée en matière de la protection de l'environnement marin et côtier ${ }^{247}$. En ce sens que le nombre des pétroliers d'anciennes générations aux normes de constructions très peu respectueuses de l'environnement va vraisemblablement augmenter dans les eaux sous juridiction des États africains en général et ceux de l'Afrique de l'ouest et du centre en particulier.

Nous pouvons avec le Professeur Christian SCAPEL préconiser et encourager des initiatives de lutte préventive régionale. En effet, l'auteur reconnaît que les difficultés d'insécurité maritime résultent aussi des limites structurelles du système de prévention en vigueur. Chose que le corpus de droit substantiel international de prévention n'a pu remettre en cause. Or estime- t- il, le contrôle rigoureux par l'État du port est un gage de sécurité maritime et en particulier une solution au problème de navires de complaisance. Phénomène pernicieux, en ce que ces pavillons présentent des équipages sous-payés, formation insuffisante et hétéroclite sans précédent. Au plan technique, le laxisme des contrôles délégués à des sociétés de classification parfois dépourvues de toute exigence est ce que l'État complaisant vend à l'armateur ayant pour seule préoccupation la réduction de ses coûts ${ }^{248}$.

\footnotetext{
${ }^{244} C f$. Directive $\mathrm{n}^{\circ} 2 / 2008 / \mathrm{CM} / \mathrm{UEMOA}$ relative à la recherche et au sauvetage en mer, et à la protection de l'environnement marin au sein de l'UEMOA.

245 Réseaux d'acteurs Sur l'adaptation au changement climatique en Zone côtière de l'Afrique de l'ouest, Dakar, janvier 2010, in http://www.bernaddeflesselbs.com/fr/environnement/theme-maritime/d-5luttercontre-les pollutions-marines-et-la-sécurité-marine, pp.132 et 178 du 11/05/011 à 8h35).

Voir aussi, ASSEMBONI-OGUMJIMI (Alida), « La protection et la mise en valeur de l'environnement marin et côtier en Afrique de l'ouest et du centre à travers le système d'Abidjan ", in Aspects contemporains au droit de l'environnement en Afrique de l'ouest et centrale, UICN, Droit et politique de l'environnement, $n^{\circ} 69$, pp.131-138).

${ }_{246}$ Dans cette optique, l'article 3 de la convention OPRC de 1990 exige que les navires aient à bord un plan d'urgence de bord contre la pollution par les hydrocarbures.

${ }^{247}$ Voir l'article 9 de ladite Directive intitulée «Plans nationaux d'intervention en cas de pollution marine accidentelle».

${ }^{248}$ Selon Christian SCAPEL, les règles de la liberté de la haute mer et de l'exclusivité de la loi du pavillon sur lequel est fondé le transport maritime engendrent des effets pervers au regard de la sécurité maritime. Voir Christian SCAPEL, «L'insécurité maritime : L'exemple de la pollution par les hydrocarbures », in Le droit face à l'exigence contemporaine de sécurité, Colloque de la Faculté de droit et de Sciences politique du 11-12 mai 2000, Marseille, 2000, PP.121-122.
} 
Le PIU apparaît en effet comme le prolongement dans l'espace maritime approprié, des plans nationaux de lutte contre les catastrophes ${ }^{249}$.

A ce titre, il apparaît normal que les États parties au protocole à a Convention WACAF adoptent des plans d'urgence nationaux. Il ne s'agit pas d'un effet de mode, mais plutôt d'une rationalisation des interventions des différentes administrations publiques et des différents acteurs privés concernés. Les PIU s'avèrent également indispensables dans la mesure où la maîtrise efficace et la réduction des conséquences néfastes des marées noires contribuent à préserver les processus écologiques et les activités économiques telles que les activités portuaires, la pêche, le tourisme, la pisciculture, la conchyliculture ${ }^{250}$.

$\mathrm{Au}$ niveau des PIU intégrés, il faudrait remarquer qu'ils viennent en complément aux plans d'urgence nationaux. Leur rôle est en particulier indispensable dans le cadre des États de l'Afrique de l'ouest et du centre. Car les plans d'urgence intégrés permettent de réaliser des économies d'échelle en termes de ressources humaines, matérielles et financières. Etant entendu que la lutte efficace contre les marées noires requièrent de la part des États côtiers des moyens énormes et coûteux de surveillance des larges espaces maritimes placés sous leur juridiction. Il serait également judicieux de la part des États de l'Afrique de l'ouest et du centre d'inciter les compagnies pétrolières exploitant des gisements situés sur leurs plateaux continentaux, à élaborer des PIU intégrés, harmonisés avec ceux mis en place dans un cadre inter étatique, par lesquelles elles participeraient activement à la lutte contre les situations critiques.

Cette Directive ne fait pas expressément allusion, dans son préambule, à la Convention d'Abidjan de 1983. Pourtant, en l'examinant, il est possible de constater qu'elle a aussi vocation à intervenir de façon opérationnelle en matière de lutte contre la pollution des mers par hydrocarbures.

La Directive reconnaît néanmoins que les États membres de l'Union sont à la croisée des grandes routes maritimes avec un intense trafic de pétroliers en pleine charge venant du golfe arabe et des pays africains producteurs de pétrole et allant en Europe ${ }^{251}$. Ce faisant, cette Directive apparait comme un instrument de mise en œuvre de la Convention d'Abidjan du 23 mars 1981. La Directive précitée se distingue de la Convention d'Abidjan par son pragmatisme à l'égard des États membres et des navires fréquentant les eaux maritimes de ceux-ci.

\footnotetext{
${ }^{249}$ ASSEMBONI (Alida) Epse OGUNJIMI, Le droit de l'environnement marin et côtier en Afrique occidentale, cas de cinq pays francophones, Thèse de doctorat en Droit public / Option Droit de l'environnement Présentée et soutenue le 15 septembre 2006, pp. 132 et 178).

${ }^{250}$ Pour une présentation détaillée des conséquences écologiques néfastes des marées noires, voir RAMADE (François), Dictionnaire encyclopédique de l'écologie et de l'environnement, $2^{\mathrm{ème}}$ édition, Paris, DUNOD,.2002, PP. 602-604.

${ }^{251}$ Voir le préambule de la Directive.
} 
À titre d'illustration, la Directive précitée, contrairement à la Convention d'Abidjan, affirme de façon expresse son application à tout navire se trouvant dans les eaux sous juridiction d'un États membre de l'UEMOA quel que soit son pavillon ${ }^{252}$.

Ce faisant, elle se rapproche notamment de par sa fermeté de la politique européenne et d'autres pays occidentaux qui consiste à interdire l'accès des navires sous normes aux ports desdits pays.

\section{Paragraphe 2 : Le contrôle de la navigation maritime au niveau des pays occidentaux}

Face aux risques de pollution maritime que représentent les pétroliers sous-normes, l'Union européenne et les États-Unis d'Amérique, le Canada ou encore le Royaume Uni ont élaboré, chacun en ce qui le concerne, une législation par laquelle ils organisent la lutte opérationnelle contre les marées noires. L'analyse de l'espace communautaire européen (A) précédera celle de certains exemples nationaux de lutte opérationnelle contre les marées noires (B).

\section{A - Au niveau de l'espace communautaire européen}

La lutte opérationnelle contre les marées noires, au sein de l'Union européenne, emprunte de plus en plus la voie de la coopération interétatique. Ainsi, l'Union européenne a créé, à cet effet, une agence dénommée l'Agence européenne de la sécurité maritime (AESM) (1). Cette action de portée communautaire n'exclut pas le recours à l'approche bilatérale, particulièrement par l'adoption du Manche Plan et l'adoption du Plan Biscaye (2), ainsi que le système préventif de Barcelone et la SASEMAR (3).

\section{La lutte opérationnelle dans le cadre communautaire: l'Agence européenne de sécurité maritime (AESM)}

$\mathrm{Au}$ regard de l'évolution des normes communautaires destinées à combattre les pollutions marines dans l'espace européen, le Professeur Martin NDENDE constate que depuis les catastrophes pétrolières de l'Erika et de Prestige l'Europe a affirmé sa volonté de se prendre en charge directement à travers la création, entre autres, d'une Agence européenne de la sécurité maritime (AESM) ${ }^{253}$.

L'Agence européenne pour la sécurité maritime (AESM) est une organisation destinée à être l'instrument opérationnel et technique des décideurs de l'UE. L'AESM a pour fonctions de fournir un soutien et des conseils techniques à la Commission européenne et aux États membres dans certains domaines essentiels pour la sécurité ainsi que de

\footnotetext{
252 Voir l'article 2 de la Directive.

253 NDENDE (Martin), «L'activité normative des Nations Unies dans le domaine des transports maritimes internationaux », in Revue Africaine des Affaires Maritimes et des Transports, n 1 , Nantes, juillet 2009, p.10.
} 
contrôler l'application de la législation de l'UE par les divers États membres et organisations.

De plus, l'Agence a été chargée d'apporter une réponse pratique à la pollution par les hydrocarbures. L'objectif général est d'offrir une contribution significative à l'amélioration progressive de la sécurité dans les eaux communautaires. A cette fin, l'Agence reconnaît l'importance d'une collaboration effective avec des institutions ou organismes représentant des intérêts différents, et notamment, avec les institutions européennes, les autorités des États-membres, les organisations internationales et l'industrie maritime.

Cette tâche est considérable, étant donné l'importance du transport maritime au sein de l'UE. En effet, les 25 États membres comptent plus de 600 ports importants, qui sont répartis sur des milliers de kilomètres de côtes et traitent environ $90 \%$ du commerce extérieur de l'UE et $35 \%$ du commerce intracommunautaire ${ }^{254}$.

L'Agence Européenne pour la Sécurité Maritime (AESM) a été créée par le règlement CE n¹406/2002 du Parlement européen et du Conseil. Cette agence a pour mission de soutenir les États membres de l'Union européenne dans leur lutte contre la pollution maritime accidentelle ${ }^{255}$. L'action de l'AESM vient en appoint aux efforts des États côtiers lorsque le déversement dépasse la capacité de réponse nationale et individuelle de l'État membre.

Elle contribue à renforcer le système global de sécurité maritime dans les eaux communautaires, de manière à réduire les risques d'accident maritime, de pollution par les navires et de décès en mer.

L'Agence peut fournir à la demande des États membres de l'Union une assistance en réponse à une pollution massive. L'assistance consiste notamment en des bateaux de lutte contre la pollution par récupération des hydrocarbures en mer, un service d'imagerie par satellite pour surveiller les déversements, des experts dans le domaine de la lutte contre la pollution pouvant apporter une assistance opérationnelle et technique.

Il n'empêche que la responsabilité principale de réagir à un incident et à la coordination de la réponse incombe à l'État membre sinistré.

\footnotetext{
${ }^{254}$ Cf. PECCIADE, Exercice de Sécurité Civile POLMAR ATLANTIQUE 2009, in Adobe Acrabat Document, du 18/03/2011 18h 52)

${ }^{255}$ Rappelons, à toutes fins utiles, que l'Union européenne n'a compétence en matière de sécurité maritime que depuis le traité de Maastricht du 7 février 1992. L'Agence européenne pour la sécurité maritime est devenue opérationnelle depuis 2003.
} 


\section{La lutte opérationnelle dans une approche bilatérale : le Manche Plan et le Plan Biscaye}

L'approche bilatérale de la lutte opérationnelle contre les marées noires s'est matérialisée, entre autres, par la conclusion de deux plans : à savoir le Manche Plan (a) et le Plan Biscaye (b).

\section{a. le Manche Plan}

Se référant à la politique communautaire européenne qui vise "un niveau élevé de protection de l'environnement ", certains pays comme le Royaume-Uni et la France se réservent le droit de contrôler la navigation, d'imposer des règles de sécurité et d'interdire le passage des navires ${ }^{256}$. Ces deux États ont d'ailleurs conclu un accord - le Manche Plan - au moyen duquel ils organisent d'avance leur réponse face à une pollution maritime ou une menace grave de pollution maritime.

Le Manche plan a été signé par le Royaume-Uni et la France le 15 mai 1978. Il porte sur la lutte contre la pollution et sur les opérations de recherche et de sauvetage (SAR). Les États parties au plan définissent l'autorité responsable de la coordination des opérations communes (ACA), et l'autorité responsable de prévoir l'assistance à l'ALA (Autorité de Liaison des Actions).

Le Manche Plan institue une coopération mutuelle entre les deux pays concernés, en délimitant les frontières en cas d'urgence. Pour les incidents susceptibles de toucher les deux États simultanément, il indique les procédures de maîtrise et de contrôle, les voies de communication, et les ressources à la disposition de chaque État. Le Manche Plan désigne les eaux territoriales des îles anglo-normandes comme une zone spéciale de responsabilité. Il contient des procédures d'assistance, en fonction des besoins, aux autorités des îles anglo-normandes ${ }^{257}$.

Le Manche a été activé à l'occasion de plusieurs accidents maritimes. Il est possible de mentionner parmi les importantes : le Sea Empress - accident survenu au large de Milford Haven en 1996, le Ievoli Sun naufrage en l'an 2000, et plus récemment, le Tricolor, au large de Dunkerque.

\footnotetext{
256 Au sens de l'article 25.5 de la Convention de Montego Bay sur le droit de la mer ou encore de la Convention d'Oslo qui accorde à l'État, en son article 16, les pouvoirs d'intervention prévus à la Convention de Bruxelles de 1969, qui comportent la mise en demeure adressée au propriétaire de prendre toute mesures nécessaires pour mettre fin au danger. Si elle reste sans effet, ou n'a pas produit les effets attendus dans un délai imparti, ou d'office en cas d'urgence, l'État peut faire exécuter les mesures nécessaires aux frais du propriétaire, ou en recouvrer le montant du coût auprès de ce dernier. C $f$. BEURIER (Jean-Pierre) et LANGAVANT (Emmanuel), « La lute contre la pollution accidentelle », in DMF 1976, 520.

${ }^{257}$ Cf. http://www.mcga.gov.uk/c4mca/mcga-contin.pdf.
} 
Le Plan Biscaye, plan d'intervention Franco-Espagnol en cas de sinistre en Atlantique, est un accord opérationnel entre la Préfecture Maritime de l'Atlantique et la Société de Sauvetage et de Sécurité Maritime espagnole (SASEMAR). Il a été signé à Bayonne le 25 novembre 1999. Ce plan prévoit la mise en œuvre conjointe des moyens d'intervention dans le golfe de Gascogne en cas sauvetage maritime et de pollution marine ${ }^{258}$.

L'accord technique de coopération franco-espagnol, en matière de sauvetage et de lutte anti-pollution, le Biscaye Plan a été signé en novembre 1999.

Destiné à mutualiser les moyens des deux pays en cas d'événement maritime grave, il permet l'échange systématique d'informations, l'organisation annuelle d'exercices communs et une direction opérationnelle unique, chargée de coordonner l'action conjointe.

La zone d'application du Biscaye Plan est délimitée par les parallèles $42^{\circ} 30^{\prime}$ Nord et $46^{\circ}$ Nord, le méridien $10^{\circ}$ Ouest et les côtes françaises et espagnoles. Cette zone est divisée par une ligne qui détermine l'autorité nationale qui coordonnera les opérations.

Il prévoit, en outre, le partage des eaux du golfe de Gascogne en deux parties comprises entre les parallèles $42^{\circ} 30$ nord et 46 nord et le méridien $10^{\circ}$ ouest. La division entre les zones de compétence respective de la France et de l'Espagne s'effectue le long d'une bissectrice qui coupe le golfe en deux parties. Toute intervention se déroulant au sud de la ligne de partage relève de l'autorité espagnole compétente. La zone nord reste sous le contrôle des autorités françaises compétentes.

Le «Biscaye Plan» a été déclenché à deux reprises : en décembre 1999 lors du naufrage de l'Erika et le 14 novembre 2002 pour le Prestige. L'intérêt de cet accord réside surtout dans le fait que l'ensemble des moyens de sauvetage français et espagnols sera à la disposition du pays chargé de l'opération ${ }^{259}$.

\footnotetext{
258 "Dans le cas où des opérations de sauvetage ou de lutte contre la pollution doivent être coordonnées, il est indispensable de collaborer afin d'éviter toute sorte de duplicité dans l'action ». Dixit Fernando CASAS, Société de Sauvetage et de Sécurité Maritime espagnole (SASEMAR).

${ }^{259}$ Deux naufrages sur la côte basque ont été à l'origine de la création du Plan Biscaye. Le 20 novembre 1996, un chalutier usine ukrainien, le Franz Halls qui était tracté vers le port de Bilbao pour y être découpé, avait rompu sa remorque avant de s'échouer sur la plage de Biarritz. Le 12 octobre 1997, le Capetan Tzannis, vraquier grec sous pavillon panaméen de $143 \mathrm{~m}$ de long, en provenance des îles du Cap Vert, s'échoue sur une plage d'Anglet à la suite d'un coup de vent. Ces deux navires qui ont été renfloués, auraient pu éviter l'échouage avec une organisation de sauvetage coordonnée. Le Vice-Amiral Naquet-Radiguet, préfet maritime de l'Atlantique, signataire de l'Accord franco-espagnol a estimé que «la coopération internationale permet dans l'urgence, d'ajouter sans préavis, à nos moyens propres, ceux de nos amis espagnols».
} 


\section{Limites de la zone « Biscaye plan »}

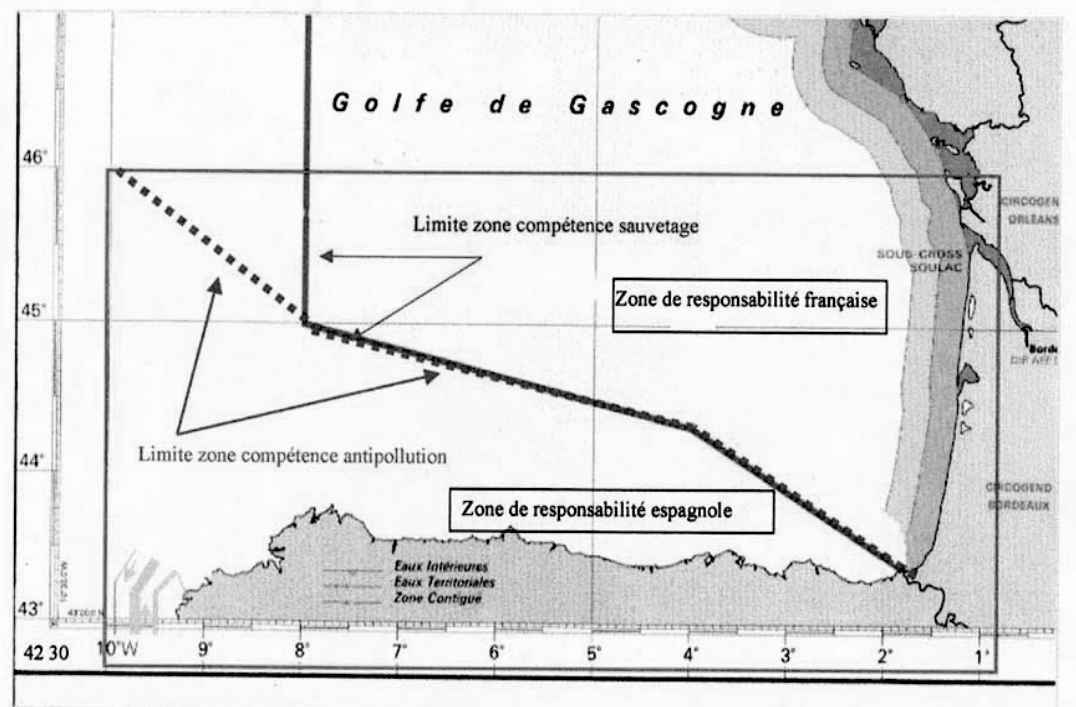

Des succès sont également enregistrés dans d'autres systèmes européens de lutte contre les pollutions marines.

\section{Le système préventif de Barcelone et la SASEMAR}

Le système préventif de Barcelone (a) et celui de la SESEMAR (2) sont les derniers modèles européens de lute opérationnelle contre les marées noires à exposer.

\section{a. Le système préventif de Barcelone}

Le contenu du "Plan Bleu » est un programme d'expertise et d'études prospectives visant l'harmonisation du développement socio-économique et la sauvegarde de l'environnement dans la région Méditerranée. La réalisation de ce programme se fera par étapes successives jusqu'aux horizons 2000 et 2025.

Ce système organise une protection globale du milieu marin et rejette la vision sectorielle de la lutte contre la pollution. Les États s'engagent à prendre les mesures nécessaire pour protéger et améliorer le milieu marin en Méditerranée ainsi que toute mesure pour prévenir réduire et combattre la pollution tant par immersion, que par produits polluants que la pollution tellurique. Le grand intérêt du système de Barcelone est qu'il se matérialise en l'élaboration de mécanismes juridiques de degrés différents. 
Cela se traduit d'une part par l'élaboration d'une convention-cadre contenant les obligations minimales pour tous les riverains, et d'autre part par l'élaboration de protocoles additionnels auxquels les États adhèrent librement. Ces protocoles sont spécifiques ce qui fait qu'ils s'adaptent bien aux particularités locales, géographiques, politiques et économiques.

Ce système de convention-cadre/protocoles rend les États signataires plus volontaires pour signer que si ils s'étaient sentis contraints dans un cadre strict. De plus ces derniers se sentent plus engagés car directement concernés.

En matière de prévention, la convention-cadre prévoit des mesures d'engagements généraux visant à faire prendre aux États les mesures nécessaires pour protéger et améliorer le milieu marin en Méditerranée, ainsi que des mesures pour prévenir, réduire et combattre la pollution. Les protocoles additionnels permettent d'aller plus loin dans la lutte. Aujourd'hui la Convention de Barcelone de 1976 est complétée par 6 protocoles Additionnels ${ }^{260}$. Ce système sera transposé à 12 mers régionales ${ }^{261}$.

\section{b. La SASEMAR}

La «Sociedad de Salvamento y Segurdad Maritima " (SASEMAR) est chargée, au sein de l'organisation espagnole de l'Action de l'État en mer, du sauvetage et de la lutte contre les pollutions en mer.

La SASEMAR est le bras opérationnel de la Direction Générale de la Marine Marchande. Sa mission est de résoudre n'importe quelle situation d'urgence en mer. Pour mener à bien cette mission, la SASEMAR dispose de Centres de Coordination et de Sauvetage (CCS), de nombreux moyens et d'un centre de formation de personnel à la sécurité maritime (Centro Integral Jovellanos). L'aire de responsabilité SAR espagnole est de 1 million de $\mathrm{Km} 2$ (dont $8000 \mathrm{Km}$ de côtes) sur laquelle se déploie un intense trafic maritime. En 2005, on estime que la SASEMAR a dû s'occuper en moyenne de onze (11) urgences par jour.

D’autres États occidentaux ne sont pas en reste dans la politique de lutte opérationnelle contre les marées noires. Ils offrent également des sources d'inspiration appréciables en matière de lutte nationale contre les marées noires.

\section{B - Exemples nationaux de lutte opérationnelle contre les marées noires}

Il est des pays comme le Canada, le Royaume Uni, les États-Unis ou encore la France qui dans le cadre de la lutte contre les pollutions maritimes accidentelles, se réservent le

\footnotetext{
260 Interdiction d'immersion : 1976 ; coopération en cas de situation critique : 1976(inspiré de l'Accord de Bonn de 1969) ; pollution tellurique : 1980 ; plateau continental et plate-forme : 1994 ; diversité biologique : 1995 ; transport transfrontalier de déchets dangereux : 1996

261 On citera à titre d'exemple Koweï : 1978 ; Abidjan :1981; Lima :1981; Djeddah :1982 ; Cartagena de Indias : 1983 ; Nairobi : 1985 ; Nouméa 1986 ; Paipa : 1989 ; Bucarest : 1992).
} 
droit de contrôler la navigation, d'imposer des règles de sécurité et d'interdire le passage des navires ${ }^{262}$. L'analyse des cas français et britannique (1) précédera celle de la pratique nord-américaine (2).

\section{Les cas français et britannique}

Des pays comme la France et le Royaume-Uni imposent des règles d'interdiction de passage à certains navires.

Le Royaume uni a promulgué le 8 avril 1971, une législation permettant à sa marine de guerre d'arraisonner ou de détruire même en haute mer, tout navire susceptible de polluer ses côtes.

En France deux textes donnent aux autorités maritimes le droit d'intervention au-delà des eaux territoriales. Il s'agit de l'instruction ministérielle du 23 décembre 1970 (plan polmar) relative à la lutte contre la pollution accidentelle des côtes par les hydrocarbures et la loi $\mathrm{n}^{\circ} 76-599$ du 7 juillet 1976 relative à la pollution marine par les opérations d'immersion et de la lutte contre la pollution ${ }^{263}$.

Le système nord-américain offre également des exemples non négligeables de lutte opérationnelle contre les marées noires.

\section{Aperçu de la pratique nord-américaine en matière de lutte opérationnelle contre les} marées noires

La loi canadienne du 26 juin 1970 reconnaît le pouvoir d'intervention des autorités maritimes à l'encontre d'un navire en détresse, risquant de ce fait une pollution des eaux arctiques.

Aux Etats Unis d'Amérique, il est des lois telles que la Clean Air Act et la Clean Waters Act de $1972^{264}$. Ces lois obligent entre autre les Etats à présenter à l'EPA des plans de

\footnotetext{
262 Au sens de l'article 25.5 de la convention de Montégo Bay sur le droit de la mer ou encore de la convention d'Oslo qui accorde en son article 16, à l'État les pouvoirs d'intervention. Si elle reste sans effet, ou n'a pas produit les effets attendus dans un délai imparti, ou d'office en cas d'urgence, l'État peut faire exécuter les mesures nécessaires aux frais du propriétaire, ou en recouvrer le montant du coût auprès de ce dernier. Voir en cela, BEURRIER (Jean-Pierre) et LANGAVANT (Emmanuel), " La lute contre la pollution accidentelle ", in DMF 1976, 520.

${ }^{263}$ Voir en cela, BEURRIER (Jean-Pierre) et LANGAVANT (Emmanuel), Op.cit., in DMF 1976, 520

${ }^{264}$ La Loi fédérale relative aux eaux, Federal water Pollution Control Act, populairement connue comme le Clean Water Act, est une loi d'ensemble visant à rétablir et maintenir l'intégrité chimique, physique et biologique des eaux de la nation. Enacted originally in 1948, the Act was amended numerous times until it was reorganized and expanded in 1972. Promulguée à l'origine en 1948, la Loi a été modifiée de nombreuses fois jusqu'à ce qu'elle ait été réorganisée en 1972. It continues to be amended almost every year. Elle continue à être modifiée presque chaque année.

L'autorité principale pour la mise en œuvre et l'application de la Clean Water Act repose sur la US Environmental Protection Agency (EPA). In addition to the measures authorized before 1972, the Act
} 
régulation de la pollution de l'air et de l'eau. Outre la possibilité d'intervenir sur le territoire national, l'EPA se réserve le droit de poursuivre les pollueurs hors des EtatsUnis, si la pollution affecte le bien être des citoyens américains. Modifiés en 1990, ces Actes vont permettre la création des programmes de permis de rejets de polluants ${ }^{265}$.

le législateur fédéral américain a pris des initiatives dans le cadre de l'Environmental Pollution Agency (EPA) tendant à promouvoir une gestion rigoureuse des problèmes environnementaux, en imposant à tout entrepreneur de prouver qu'il dispose de solides garanties financières avant de démarrer une activité présentant un risque pour l'environnement ${ }^{266}$.

Au plan purement national, l'Amendement de 1972 du Federal Water Pollution Control Act autorise l'US Coast Guard à enlever ou à couler par le fond un navire avarié jusqu'à 50 milles de la côte. En outre, l'OPA 90 investit, en ses Sections $4202^{267}$ et $4203^{268}$ le US

authorizes water quality programs, requires federal effluent limitations and state water quality standards, requires permits for the discharge of pollutants into navigable waters, provides enforcement mechanisms, and authorizes funding for wastewater treatment works construction grants and state revolving loan programs, as well as funding to states and tribes for their water quality programs. En plus des mesures autorisées avant 1972, la loi autorise notamment des programmes de qualité de l'eau, exige des permis pour les rejets de polluants dans les eaux navigables, fournit des mécanismes d'application, et autorise le financement des traitements des eaux usées, ainsi que le financement aux États et aux tribus pour leurs programmes de qualité de l'eau. Cf.http://wildlifelaw.unm.edu/fedbook/fwpca.html, consulté le 25-07-011.

265 Voir SPAETER (Sandrine), «Les firmes face à leur responsabilité environnementale», in Problèmes Economiques, 24 novembre 2004, n²863, pp. 58-59. La loi sur la pollution par les hydrocarbures dite OPA 90 dispose notamment ainsi respectivement en ses Sections $\mathbf{4 2 0 2}$ et $\mathbf{4 3 0 1}$ (a) et (c) : la première Section précitée renforce «les activités de planification et de la prévention en prévoyant la création de plans d'urgence pour les déversements rendant obligatoire l'élaboration de plans de réponse pour bateaux-citernes individuelles et certaines installations pour répondre à une décharge ou à une menace substantielle d'un tel rejet et fournir des équipements nécessaires à l'enlèvement des déversements et des inspections périodiques ». \$4301(a) and (c) The fine for failing to notify the appropriate Federal agency of a discharge is increased from a maximum of $\$ 10,000$ to a maximum of $\$ 250,000$ for an individual or $\$ 500,000$ for an organizaLa deuxième Section prévoit « une amende pour n'avoir pas informé l'organisme fédéral compétent d'une décharge. L'amende est augmentée d'un maximum de 10000 \$à un maximum de 250000 \$ pour un individu ou 500000 \$ pour une organisation. The maximum prison term is also increased from one year to five years. La peine maximale d'emprisonnement est également augmentée, passant de un an à cinq ans, avec The penalties for violations have a maximum of $\$ 250,000$ and 15 years in priun maximum de 250000 et de 15 ans de prison». Cf.http://www.epa.gov/oem/content/lawsregs/opaover.htm, consulté le 25-07-011.

${ }^{266}$ Ce sont notamment la loi Ressource Conservation and Recovery Act (loi RCRA) en 1976 et La loi Comprehensive Environmental Response, Compensation, and Liability Act (loi CERCLA).

${ }^{267}$ AREA COMMITTEES AND CONTINGENCY PLANS.-

(A) Not later than 6 months after the date of the enactment of this Act, the President shall designate the areas for which Area Committees are established under section 311(j)(4) of the Federal.Water Pollution Control Act, as amended by this Act. In designating. such areas, the President shall ensure that all navigable waters, adjoining shorelines, and waters of the exclusive economic zone are subject to an Area Contingency Plan under that section.

(B) Not later than 18 months after the date of the enactment of this Act, each Area Committee established under that section shall submit to the President the Area Contingency Plan required under that section.

(C) Not later than 24 months after the date of the enactment of this Act, the President shall-

(i) promptly review each plan; 
Coast Guard de certaines compétences en matière de lutte opérationnelle contre les marées noires ${ }^{269}$.

En effet, le United States Coast Guard est un organisme fédéral américain dévolu au rôle de surveillance, de protection, et de sauvetage des personnes en détresse dans les eaux territoriales américaines. Il est le représentant de l'action de l'état en mer, notamment au plan d'intervention pour les navires citernes et des installations flottantes, conformément à la Section $311 \mathrm{JK}$ de la Federal Water pollution control Act $(\text { FWPCA })^{270}$. C'est à dire une application de la loi en mer et des règlements maritimes,

(ii) require amendments to any plan that does not meet the requirements of section $311(j)(4)$ of the Federal Water Pollution Control Act; and

(iii) approve each plan that meets the requirements of that section.

(2) NATIONAL RESPONSE UNIT.-Not later than one year after the date of the enactment of this Act, the Secretary of the department in which the Coast Guard is operating shall establish a National Response Unit in accordance with section 311(j)(2) of the Federal Water Pollution Control Act, as amended by this Act.)

268 Secretary of the department in which the Coast Guard is operating shall establish Coast Guard District Response Groups in accordance with section 311(j)(3) of the Federal Water Pollution Control Act, as amended by this Act.

(4) TANK VESSEL AND FACILITY RESPONSE PLANS; TRANSITION PROVISION; EFFECTIVE DATE OF PROHIBITION.-(A) Not later

than 24 months after the date of the enactment of this Act, the President shall issue regulations for tank vessel and facility response plans under section $311(\mathrm{j})(5)$ of the Federal Water Pollution Control Act, as amended by this Act.

(B) During the period beginning 30 months after the date of the enactment of this paragraph and ending 36 months after

that date of enactment, a tank vessel or facility for which a response plan is required to be prepared under section 311(j)(5) of the Federal Water Pollution Control Act, as amended by this Act, may not handle, store, or transport oil unless the owner or operator thereof has submitted such a plan to the President.

(C) Subparagraph (E) of section 311(j)(5) of the Federal Water Pollution Control Act, as amended by this Act, shall take effect 36 months after the date of the enactment of this Act. The Secretary shall ensure that vessels designed and constructed to replace Coast Guard buoy tenders are equipped with oil skimming systems that are readily available and operable, and that complement the primary mission of servicing aids to navigation.)

269 Voir en cela, BEURRIER (Jean-Pierre) et LANGAVANT (Emmanuel), «La lutte contre la pollution accidentelle », in DMF 1976, 520.

270 (j) NATIONAL RESPONSE SYSTEM

(1) IN GENERAL_Consistent with the National Contingency Plan required by subsection (c)(2) of this section, as soon as practicable after October 18, 1972, and from time to time thereafter, the President shall issue regulations consistent with maritime safety and with marine and navigation laws (A) establishing methods and procedures for removal of discharged oil and hazardous substances, (B) establishing criteria for the development and implementation of local and regional oil and hazardous substance removal contingency plans, (C) establishing procedures, methods, and equipment and other requirements for equipment to prevent discharges of oil and hazardous substances from vessels and from onshore facilities and offshore facilities, and to contain such discharges, and (D) governing the inspection of vessels carrying cargoes of oil and hazardous substances and the inspection of such cargoes in order to reduce the likelihood of discharges of oil from vessels in violation of this section.

(2) NATIONAL RESPONSE UNIT-The Secretary of the department in which the Coast Guard is operating shall establish a National Response Unit at Elizabeth City, North Carolina. The Secretary, acting through the National Response Unit-

(A) shall compile and maintain a comprehensive computer list of spill removal resources, personnel, and equipment that is available worldwide and within the areas designated by the President pursuant to paragraph (4), and of information regarding previous spills, including data from universities, research institutions, State 
police de la navigation et des pêches, lutte contre les trafics illicites, protection de l'environnement maritime, sauvetage et assistance en mer.... Il dispose entre autres, d'unités armées.

L'USCG est un organisme militaire, placé cependant, depuis 2003, sous l'autorité du département de la Sécurité intérieure, après l'avoir été sous celle du département des Transports des États-Unis. En cas de conflit, il est susceptible de passer sous la direction de l'U.S. Navy. Les garde-côtes américains forment l'une des cinq branches des forces armées des États-Unis d'Amérique

governments, and other nations, as appropriate, which shall be disseminated as appropriate to response groups and area committees, and which shall be available to Federal and State agencies and the public;

(B) shall provide technical assistance, equipment, and other resources requested by a Federal On-Scene Coordinator;

(C) shall coordinate use of private and public personnel and equipment to remove a worst case discharge, and to mitigate or prevent a substantial threat of such a discharge, from a vessel, offshore facility, or onshore facility operating in or near an area designated by the President pursuant to paragraph (4);

(D) may provide technical assistance in the preparation of Area Contingency Plans required under paragraph (4);

(E) shall administer Coast Guard strike teams established under the National Contingency Plan;

(F) shall maintain on file all Area Contingency Plans approved by the President under this subsection; and

(G) shall review each of those plans that affects its responsibilities under this subsection.

(3) COAST GUARD DISTRICT RESPONSE GROUPS

(A) The Secretary of the department in which the Coast Guard is operating shall establish in each Coast Guard district a Coast Guard District Response Group.

(B) Each Coast Guard District Response Group shall consist of-

(i) the Coast Guard personnel and equipment, including firefighting equipment, of each port within the district;

(ii) additional prepositioned equipment; and

(iii) a district response advisory staff.

(C) Coast Guard district response groups-

(i) shall provide technical assistance, equipment, and other resources when required by a Federal On-Scene Coordinator;

(ii) shall maintain all Coast Guard response equipment within its district;

(iii) may provide technical assistance in the preparation of Area Contingency Plans required under paragraph

(4); and

(iv) shall review each of those plans that affect its area of geographic responsibility.

(4) AREA COMMITTEES AND AREA CONTINGENCY PLANS

(A) There is established for each area designated by the President an Area Committee comprised of members appointed by the President from qualified personnel of Federal, State, and local agencies.

(B) Each Area Committee, under the direction of the Federal On-Scene Coordinator for its area, shall-

(i) prepare for its area the Area Contingency Plan required under subparagraph (C);

(ii) work with State and local officials to enhance the contingency planning of those officials and to assure preplanning of joint response efforts, including appropriate procedures for mechanical recovery, dispersal, shoreline cleanup, protection of sensitive environmental areas, and protection, rescue, and rehabilitation of fisheries and wildlife; and

(iii) work with State and local officials to expedite decisions for the use of dispersants and other mitigating substances and devices.

(C) Each Area Committee shall prepare and submit to the President for approval an Area Contingency Plan for its area. The Area Contingency Plan shall-

(i) when implemented in conjunction with the National Contingency Plan, be adequate to remove a worst case discharge, and to mitigate or prevent a substantial threat of such a discharge, from a vessel, offshore facility, or onshore facility operating in or near the area. 
En janvier 2005, l'USCG comptait 39000 hommes et femmes en service actif, 8100 réservistes, 7000 employés civils et 35000 auxiliaires; à la fin de l'année 2009, le personnel en service actif était porté à 43418 personnes $^{271}$. Statutairement, les gardes côtes sont chargés de onze missions différentes allant de la protection de la population contre les risques à la défense des frontières maritimes et le sauvetage en mer, en passant par le commerce maritime et l'environnement.

Les gardes côtes sont rapidement mobilisés lors de catastrophes afin de restaurer les canaux et voies d'eau et de soutenir le système de transport maritime (qui assure $99 \%$ de l'import-export américain) et lorsque la situation l'exige, ils défendent la nation sur son sol comme à l'étranger aux côtés des autres forces armées. Basé à Miami, le 7ème District des gardes côtes américains est l'un des neuf districts nationaux dont la compétence couvre toutes les opérations réalisées par les gardes côtes en Floride, Géorgie, Caroline du Sud, Porto Rico et les îles Vierges américaines ${ }^{272}$.

Il arrive que les pollutions marines, en dépit des Plans d'intervention d'urgence (PIU), causent des dommages aux biens des personnes. Dans ces cas, celles-ci sont en droit d'intenter des actions en réparation civile contre les responsables de la pollution aux fins d'être indemnisées.

\footnotetext{
${ }^{271}$ US Cost guard, in www.//fr.wikipédia.org/wiki/US_Cost_guard du 13/06/ O11.

272 Archive du 31 mars 2011 -Le cyber-Bulletin du consulat $\mathrm{N}^{\circ} 464$,www.consulfrancemiami.org/spip. ?article1780, du 13/06/ 011.
} 



\section{CHAPITRE 2: L'ADOPTION DE REGLES DISSUASIVES EN MATIERE D'INDEMNISATION DES VICTIMES DE MAREES NOIRES}

A l'instar des autres modes de transport, la question de responsabilité de l'entreprise maritime des transports d'hydrocarbures apparaît comme un point sensible dans le droit des régimes de responsabilité. Ce droit se caractérise par la recherche constante d'un équilibre entre les intérêts des victimes et ceux des responsables de la pollution. Tandis que pour ces derniers, à savoir le propriétaire et les affréteurs, la pollution ou le risque de pollution des mers est un élément de leur exploitation, pour les victimes, elle correspond à une activité dont elles ne tirent aucun profit immédiat ${ }^{273}$. Voilà pourquoi la réglementation y relative est un système d'inspiration privatiste. Dès lors, elle ne s’applique qu'aux opérateurs privés.

La responsabilité pour les dommages de pollution par les hydrocarbures répond au mécanisme de la responsabilité objective, sans faute. C'est le corollaire des activités à risques dont l'importance économique est telle que ce risque doit être supporté par la collectivité dans son ensemble. C'est le caractère exceptionnel des dommages qui constitue le fondement de la responsabilité automatique ${ }^{274}$. Ainsi, s'agissant particulièrement des dommages de pollutions par hydrocarbures, le principe de la responsabilité du propriétaire est énoncé par l'article 3 alinéa 1 de la convention CLC 1969.

En effet, cette responsabilité résulte d'une fuite ou de rejets d'hydrocarbures du navire à la suite d'un évènement ayant causé des dommages par pollution. De même, la Convention a adopté une apparente adaptation de la responsabilité civile du propriétaire du navire (Section 1). Elle tend aussi à définir le contenu de la responsabilité du propriétaire du navire pollueur ${ }^{275}$ (Section 2).

\section{Section 1: L'apparente adaptation de la responsabilité civile du propriétaire du navire}

Il semble ressortir de l'analyse des règles de la Convention internationale CLC 1969, deux sortes de régime de responsabilité. L'un est général et l'autre est spécial aux transports « complexes ${ }^{276} »$.

\footnotetext{
273 BOISSON DE CHAZOURNES (L.), DESGAGNE (R.) et ROMACO (C.), Protection internationale de l'environnement: recueil d'instruments juridiques, Paris, Pedone, 1998, P.947. Voir aussi en ce sens, ODIER (F.), L'Erika ou la naissance d'une nouvelle conception de la sécurité maritime, E.R.M., 1999-2000, pp. 35-36.

274 SABRINA (Robert), L'Erika: Responsabilité pour un désastre écologique, op. cit., pp. 12-14. Voir aussi STERN (B.), Responsabilité internationale, Répertoire de droit international, Paris, Encyclopédie juridique Dalloz, tome III, 2002, p.15

${ }^{275}$ Cf. Article 3 alinéas 1 et 4 de la Convention de 1969 sur la responsabilité civile.

276 Terme emprunté à Barthélemy Mercadal, pour désigner le déplacement réalisé par plusieurs transporteurs suivant des combinaisons juridiques différentes, in, Droit des transports maritime et aériens, Paris, Précis Dalloz, n²78, 1973, P. 151.
} 
Par régime général, nous entendons, l'ensemble des règles de la convention CLC qui régit le cadre d'un transport dont l'ensemble de la cargaison d'hydrocarbures déversée dans les eaux de mers est réalisé par un seul transporteur ${ }^{277}$. Ce régime est prévu par l'article 3 de la Convention internationale sur la responsabilité civile pour les dommages dus à la pollution par les hydrocarbures. L'apparente adaptation de la responsabilité civile du propriétaire du navire est mise en évidence par l'évolution chronologique du processus d'indemnisation des victimes (Paragraphe 1) et du nouveau régime spécial d'indemnisation en droit maritime international et en droit comparé (Paragraphe 2).

\section{Paragraphe 1: L'évolution chronologique du processus d'indemnisation des victimes}

L'évolution chronologique du processus d'indemnisation des victimes part d'une indemnisation initialement limitée aux préjudices monétairement évaluables (A) à une indemnisation actuellement étendue aux dommages écologiques (B).

\section{A - Une indemnisation initialement limitée aux préjudices monétairement évaluables}

Les juridictions nationales, tout comme les instruments juridiques internationaux, rechignent à indemniser les dommages de nature écologique. Les affaires des Boues Rouges (1) et de l'Amoco-Cadiz ${ }^{278}$ (2) illustrent ce manque de volonté.

\section{L'affaire des Boues Rouges}

Dans l'affaire des Boues Rouges, des pêcheurs de Bastia, en France, ont intenté une action indemnitaire à l'encontre de la société Montedison. Cette société avait procédé à des déversements de produits toxiques en mer. Le tribunal de grande instance (TGI) de Bastia a partiellement fait droit à la demande des pêcheurs dans son jugement du 4 juillet 1985. En effet, les dommages-intérêts octroyés aux pêcheurs de la prud'homie de Bastia couvraient partiellement le coût des dommages causés au milieu aquatique. En effet, la société Montedison n'a eu à verser aux victimes que des dommages-intérêts calculés sur la base des quantités de poissons habituellement capturés. Le préjudice indemnisable était donc d'ordre patrimonial ou économique.

Visiblement, la nature du préjudice ayant permis le dédommagement des victimes est celle du lucrum cessans. Cette perception est partagée par le Professeur Gilles Martin. D’ailleurs, Marie-José Littmann-Martin et Claude Lambrechts relèvent pertinemment

\footnotetext{
277 Voir dans ce sens, avec quelques différences près, les articles 9 et 16 alinéas 1, 2 et 3 de l'Acte uniforme relatif au contrat de transport de marchandise par route de l'OHADA.

278 Aziz SAHEB-ETTABA écrit en sens : "Elle se cantonne au dédommagement des pertes monétaires dues aux mesures de remise en état et de sauvegarde. Les préjudices portés à l'aspect esthétique ou récréatif de l'environnement marin et les autres dommages écologiques auxquels il est difficile d'attribuer une valeur monétaire, comme la vie des animaux marins, ne sont donc pas indemnisables ». Cf. SAHEB-ETTABA (Aziz), "La protection juridique de l'environnement marin dans le cadre du transport maritime de substances nocives et potentiellement dangereuses ", Montréal, Revue Juridique Thémis, n³2, éd. Thémis, 1998, p.516.
} 
ces propos de Gilles Martin selon lesquels : il est " tout à fait remarquable que la jurisprudence française elle-même accepte de réparer les dommages futurs par manque à gagner ", comme ce fut le cas dans l'affaire des Boues rouges de la société Montedison où les pêcheurs purent obtenir réparation d'une "perte de chance $»^{279}$.

Par contre, les dégâts d'ordre écologique n'ont pas été pris en compte dans le calcul des dommages-intérêts. Aussi, la société Montedison n'eut-elle à verser que des dommagesintérêts calculés sur la base des quantités de poissons habituellement capturés. Seuls les dommages monétairement évaluables ont été indemnisés.

L'affaire de l'Amoco Cadiz illustre également cette approche.

\section{L'affaire de l'Amoco Cadiz}

La décision rendue dans l'affaire de l'Amoco-Cadiz illustre également la réticence du juge américain à admettre l'évaluation des dommages écologiques. À propos de l'affaire de l'Amoco-Cadiz, les professeurs Kiss et Beurier écrivent : "La Cour n'a pas accepté la demande tendant à indemniser la perte qu'a subie la biomasse dans la zone polluée ...En tout cas, estime le juge, la Cour n'avait pas à s'embarrasser de cette demande d'indemnité, puisque le dommage allégué n'a atteint que des res nullius pour lesquelles aucune personne ni aucun organisme n'était fondé à présenter une réclamation $»^{280}$.

La réticence affichée par les juridictions pourrait s'expliquer à un double point de vue.

En premier lieu, il est possible de faire remarquer, à l'instar de certains juristes environnementalistes, qu'il est indécent de donner une valeur monétaire à la nature. Évaluer l'environnement revient à transformer en marchandises des éléments qui relèvent de la vie ${ }^{281}$.

En deuxième lieu, l'évaluation des dommages écologiques se heurte à la difficulté quasiinsurmontable d'attribuer un prix à des composantes de la nature qui ne font pas l'objet de transaction commerciale. Cette seconde raison est, selon nous, beaucoup plus pertinente que la première ${ }^{282}$.

279 Observation de Gilles MARTIN sous la décision du TGI Bastia en date du 4 juillet 1985. Cité par LITTMANN-MARTIN (Marie-José) et LAMBRECHTS (Claude), "Rapport général ", in SFDE, Le dommage écologique en droit interne, communautaire et comparé, Actes du colloque organisé les 21 et 22 mars 1991 à la Faculté de droit, d'économie et de gestion de l'Université de Nice Sophia-Antipolis, Paris, Economica, 1992, p.53.

${ }^{280}$ KISS (Alexandre) et BEURIER (Jean-Pierre), Droit international de l'environnement, Collections Études Internationales, Paris, Éd. Pedone, 2000, p.370.

281 Cf. SAHEB-ETTAHAB (Aziz), "La protection juridique de l'environnement marin dans le cadre du transport maritime de substances nocives et potentiellement dangereuses ", Montréal, Revue Juridique Thémis, n³2, éd. Thémis, 1998, p.533; TIEBLEY (Yves Didier), La Côte d'Ivoire et la gestion durable des ressources naturelles marines, Thèse unique, Droit Public, Université de Maastricht, 20 mai 2010, p.275. 282 Ibidem. 
Cependant, on note actuellement une tendance favorable à l'indemnisation du dommage écologique.

\section{B - Une indemnisation actuellement étendue aux dommages écologiques}

L'idée d'indemnisation des dommages écologiques est de plus en plus admise par les juridictions nationales, notamment aux États-Unis (1) et en République Française (2).

\section{Aux Etats-Unis : affaire Commonwealth of Puerto Rico c. S.S. Zoe Colocotroni}

Aux États-Unis, l'affaire Commonwealth of Puerto Rico c. S.S. Zoe Colocotroni est, en la matière, fort illustrative. En effet, en 1973, un pétrolier, le Zoe Colocotroni, a déversé au large de Porto Rico, une nappe de pétrole qui a pollué une mangrove, une forêt marécageuse déserte. Le Commonwealth de Porto Rico a saisi, en appel, la Cour d'appel de New York aux fins, entre autres, d'obtenir la réparation pécuniaire de l'atteinte portée à la mangrove, une res nullius, sans valeur marchande appréciable.

La Cour d'appel a cependant fait droit à la demande du Commonwealth de Porto Rico en énonçant le principe de l'indemnisation des dommages écologiques. Elle a déterminé, à cet effet, une méthode de calcul du dommage écologique. Ce calcul tient compte des coûts de rétablissement de la zone polluée aux conditions qui préexistaient avant l'incident, à condition que les dépenses ne soient pas disproportionnées. La Cour estime que le montant du dommage causé à un milieu naturel correspond au «cô̂t raisonnable " permettant de le restaurer ou de le ramener à son état initial, ou à un état aussi proche que possible sans dépense grossièrement disproportionnée ${ }^{283}$.

Il convient de souligner que la Cour d'appel de New York ne s'est pas limitée à énoncer le principe de l'indemnisation des dommages écologiques. Elle a fait preuve de hardiesse en s'évertuant à déterminer une méthode de calcul de ce type de dommage. Pour ce faire, la Cour d'appel a tenu compte du coût de remplacement des espèces disparues en utilisant les prix d'un catalogue d'approvisionnement biologique ${ }^{284}$.

En 2008, la justice française a emboîté le pas à son homologue américain dans l'affaire de l'Erika.

283 Cf. Commonwealth of Puerto Rico c. S.S Zoe Colocotroni, [628 F $2^{\mathrm{d}} 6521^{\text {st }}$ circuit 1980], p.40. Cité par MartineREMOND-GOUILLOUD «Le prix de la nature : à propos de l'affaire Zoe Colocotroni », Recueil Dalloz Sirey, Chronique, $5^{\text {ème }}$ cahier, 1982, p.34.

${ }^{284}$ SAHEB-ETTAHAB (Aziz), « La protection juridique de l'environnement marin dans le cadre du transport maritime de substances nocives et potentiellement dangereuses ", Revue Juridique Thémis, $\mathrm{n}^{\circ} 32$, éd. Thémis, Montréal, 1998, p.535. 


\section{En République Française : affaire Erika}

En France, les juridictions civiles tout comme les juridictions pénales statuant en matière civile sont réticentes à allouer des dommages-intérêts consistants aux associations environnementales. La raison de cette réticence tient au fait que le préjudice allégué par ces associations ne leur est pas personnel ${ }^{285}$. Selon elles, la multiplication des actions en justice de ces associations s'apparente à une sorte d'enrichissement sans cause du moment où celles-ci ne justifient pas d'un préjudice personnel mais allèguent plutôt un préjudice s'étendant à l'ensemble de la collectivitée 286 .

Cependant, le jugement du 16 janvier 2008 rendu dans l'affaire de l'Erika par la $11^{\text {ème }}$ Chambre du Tribunal de Grande Instance (TGI) de Paris se distingue, en la matière, des décisions antérieures prises par les juridictions pénales ou civiles françaises. En effet, le TGI a, dans l'affaire Erika, accepté de réparer les dommages non pécuniairement évaluables.

En illustration, on mentionnera le dédommagement que le TGI de Paris a octroyé à certaines associations de protection de l'environnement. Celles-ci ont obtenu réparation pour les préjudices résultant de l'atteinte à l'environnement. Ainsi, la Ligue de Protection des Oiseaux (LPO) s'est vue allouée la somme de 242.040,94€ au titre des frais de fonctionnement (occasionnés par les soins prodigués aux oiseaux mazoutés), $303.167,13 €$ pour le préjudice matériel subi et surtout la somme de $300.000 €$ pour réparer le préjudice résultant de l'atteinte à l'environnement ${ }^{287}$.

Le nouveau régime spécial d'indemnisation en droit maritime international et en droit comparé, participe également de l'apparente adaptation de la responsabilité civile du propriétaire du navire.

\footnotetext{
285 Le Professeur Jean-François NEURAY critique cette réticence en écrivant : "Pourtant, si l'on veut bien se placer dans l'optique d'une protection efficace de l'environnement considéré comme patrimoine commun, n'importe quel citoyen ou groupe de citoyens devrait pouvoir se plaindre d'une nuisance sans être tenu d'administrer la preuve qu'il en fut spécialement la victime".

Cf. NEURAY (Jean-François), "L'amélioration de l'accès à la justice dans une perspective de défense de l'environnement ", in PÂQUES (Michel) et FAURE (Michaël) (dir.), La protection de l'environnement au cœur du système juridique international et du droit interne: Acteurs, valeurs et efficacité, Actes du Colloque des 19 et 20 octobre 2001, Université de Liège, Bruxelles, Bruylant, 2003, pp.410-411.

286 Cf. LITTMANN-MARTIN (Marie-José) et LAMBRECHTS (Claude), " Rapport général ", in SFDE, Le dommage écologique en droit interne, communautaire et comparé, op.cit, p.72.

287 En outre, le TGI de Paris a accepté de condamner la société TOTAL - propriétaire de la cargaison polluante - à réparer le préjudice moral subi par d'autres associations de protection de l'environnement. Ainsi, la somme de $30.000 €$ a respectivement été allouée aux associations Greenpeace France et WWF France. L'association Mouvement national de lutte pour l'Environnement (MNLE) a obtenu la somme de $18.773 €$ au titre du préjudice matériel subi, et la somme de $5.000 €$ au titre du préjudice moral. Le TGI de Paris a également accepté d'allouer la somme de $15.000 €$ à l'Association pour la sauvegarde des animaux sauvages (ASPAS) en vue de réparer le préjudice moral subi par celle-ci. Enfin, l'association "Environnement 56" a obtenu du TGI de Paris que le préjudice moral subi par elle soit réparé à hauteur de 10.000 somme de 15.000 $€$. Cf. TGI de Paris, $11^{\text {ème }}$ Ch., $4^{\text {ème }}$ section, Paris, 16 janvier 2008, Jugement $\mathrm{n}^{\circ} 1$, pp.251-254 et 257.
} 


\section{Paragraphe 2: Le nouveau régime spécial d'indemnisation en droit maritime international et en droit comparé}

C'est au prix du relèvement et de la modulation des plafonds que les armateurs seront responsabilisés ${ }^{288}$. Les amendements aux règles de réparation des dommages de pollution découlent successivement de deux protocoles. L'un a été adopté en 1992 et l'autre en 2003. Pour un souci de clarté de notre analyse, il convient d'examiner les relèvements successifs des montants d'indemnisation en droit maritime international (A) et la responsabilité civile en droit français et américain (B).

\section{A - Les relèvements successifs des montants d'indemnisation en droit maritime international}

Les innovations indemnitaires sont perceptibles au regard du protocole de 1992 aux Convention CLC 69 et FIPOL 1971 (1). Quant à la Convention supplémentaire de 2003 elle viendra corriger l'insuffisance du montant disponible au titre du Protocole de 1992 ${ }^{289}(2)$.

\section{Les innovations indemnitaires issues des Protocole 1992 aux Conventions CLC 1969 et FIPOL 1971}

Sous l'empire de la CLC 1969 telle que modifiée par le Protocole du 24 mai 1984290, les plafonds de responsabilité se présentaient comme suit :

- 3 millions de DTS pour les pétroliers de moins de 5.000 tonneaux de jauge ;

- 3 millions de DTS + 420 DTS par tonneau de jauge supplémentaire ;

- 45 millions de DTS pour les pétroliers de 105.000 tonneaux de jauge ;

- 59,7 millions de DTS pour les pétroliers de 140.000 tonneaux de jauge et plus.

L'article $6 \$ 1$ du protocole de 1992 procède à une légère modification des plafonds de responsabilité définis par la CLC 1969. Désormais, les plafonds d'indemnisation se présentent comme suit :

- une limite de 3 millions de DTS (environ 3,8 millions de dollars US) pour un navire de moins de 5.000 tonneaux de jauge ;

- pour un navire de 5.000 à 140.000 tonneaux de jauge, la limite est de 3 millions de DTS augmentés de 420 DTS (environ 538 dollars US) pour chaque tonneau de jauge supplémentaire ;

\footnotetext{
288 La responsabilité est fondée sur une idée clé à savoir qu'être responsable, c'est l'aptitude à remplir des engagements nés des actes dommageables.

289 Voir le préambule du Protocole de 2003 à la Convention internationale de 1992 portant création du Fonds international d'indemnisation pour les dommages de pollution par hydrocarbures.

290 Cependant, le Protocole du 24 mai 1984 à la Convention CLC 1969 n'a pu entrer en vigueur par suite du refus des États-Unis d'être partie audit Protocole. Le Protocole du 27 novembre 1992 à la Convention CLC 1992 a pu entrer en vigueur le 30 mai 1996 grâce à l'abandon d'une disposition incluse dans le Protocole de 1984 qui subordonnait son entrée en vigueur à l'adhésion des États-Unis, une nation possédant une flotte très importante. Cf. TIEBLEY (Yves Didier), La Côte d'Ivoire et la gestion durable des ressources naturelles marines, Thèse unique, Droit Public, Université de Maastricht, 20 mai 2010, p.121.
} 
- pour un navire de plus de 140.000 tonneaux de jauge, la limite est 59,7 millions de DTS (environ 76,5 millions de dollars US).

Cependant, ces hausses se révèleront insuffisantes au regard des accidents de pétroliers, en l'occurrence celui du Nakhodka (1997) au large du Japon et de l'Erika (1999) à la pointe du Finistère, en France. Le Comité juridique de l'Organisation maritime internationale (OMI), en sa 82 $2^{\text {ème }}$ session tenue du 16 au 20 octobre 2000, procédera à des amendements à l'issue de la Convention CLC 1992.

Ces amendements, entrés en vigueur le $1^{\text {er }}$ novembre 2003, augmentent le plafond d'indemnisation de 50,37\%. Désormais, les plafonds de responsabilité se présentent comme suit :

- pour un navire de moins de 5.000 tonneaux de jauge, la limite est de 4,51 millions de DTS (environ 5,78 millions de dollars US) contre 3 millions de DTS sous le Protocole de 1992 ;

- pour un navire de 5000 à 140.000 tonneaux de jauge, la limite de 4,51 millions de DTS est augmentée de 631 DTS (environ 807 dollars US) pour chaque tonneau de jauge supplémentaire contre 420 DTS sous le régime précédent ;

- pour un navire de plus de 140.000 tonneaux de jauge, la limite est de 89,77 de DTS (environ 115 millions dollars US) contre 59,7 millions sous le régime précédent.

Tableau 1 : Tableau récapitulatif des différents relèvements des plafonds d'indemnisation sous le régime de la CLC (en millions de DTS)

\begin{tabular}{|l|l|l|l|}
\hline Tonneau de jauge brut $(\mathrm{tjb})$ & CLC 1969 & CLC 1992 & Amendements de 2000 \\
\hline$\leq 5000$ & 3 millions & 3 millions de DTS & 4,51 millions de DTS \\
\hline$>5000$ & 3 millions + 420 DTS/tjb & $\begin{array}{l}3 \text { millions de DTS } \\
\text { augmentés de 420 DTS }\end{array}$ & $\begin{array}{l}4,51 \text { millions de DTS est } \\
\text { augmentée de 631 DTS }\end{array}$ \\
\hline$\leq 105.000<$ & 45 millions de DTS & - & - \\
\hline$<140.000$ & 59,7 millions de DTS & 59,7 millions de DTS & 89,77 de DTS \\
\hline
\end{tabular}

Tableau 2: Tableau récapitulatif des différents relèvements des plafonds d'indemnisation sous le régime de la CLC (en millions \$US)

\begin{tabular}{|l|l|l|l|}
\hline Tonneau de jauge brut (tjb) & CLC 1969 & CLC 1992 & Amendements de 2000 \\
\hline$\leq 5000$ & $203 \$ \mathrm{US} / \mathrm{tjb}$ & 4,5 millions & 7 millions \\
\hline$>5000$ & $203 \$ \mathrm{US} / \mathrm{tjb}$ & 4,5 millions + 636 \$US/tjb & 7 millions + 963 \$US/tjb \\
\hline Limite du montant d'indemnisation & 21 millions & 90 millions & 136 millions \\
\hline
\end{tabular}

Source : FAURE (Michael) et WANG (Hui), "Financial Caps for Oil Pollution : A Historical Mistake? », Marine Policy, n³2, 2008, p.594 ${ }^{291}$.

\footnotetext{
${ }^{291}$ Les montants ci-dessus ont été obtenus en convertissant les droits de tirage spéciaux (DTS) en \$US selon le cours du dollar défini à la date du $1^{\text {er }}$ juin 2007 par le Fonds monétaire international (FMI). Les présentes informations ont été recueillies sur le site du Fonds FIPOL : www.iopc.fund.org/SDR.htm à la date du 31 août 2007.
} 
Le Protocole 1992 à la Convention FIPOL 1971 a décidé d'une majoration de 50,37\% le plafond d'indemnisation. Ainsi, le plafond sera porté à 203 millions de DTS à compter du $1^{\text {er }}$ novembre 2003. Cette augmentation ne s'applique qu'aux sinistres survenus après cette date.

Les indemnités payables par le FIPOL 1992 sont limitées à certain montant pour un évènement donné. Le plafonnement de l'indemnité résulte de l'article 6 alinéa $3 a$ ) à $e$ ). Ainsi, le montant total des indemnités que le Fonds doit verser pour un évènement déterminé est limité à 135 millions d'unités de compte (UC) $)^{292}$.

Ce maximum a été porté à 200 millions d'UC pour les accidents de la pollution qui se produiraient pendant une période suivant une année de calendrier, durant laquelle trois États parties ont reçu dans leurs ports 600 millions de tonnes d'hydrocarbures ou plus (article $4 \$ 4 c$ de la Convention FIPOL 1992). Le plafond de 135 millions d’UC a été porté à 203 millions d'UC par une résolution du Comité juridique de l'Organisation maritime internationale $(\mathrm{OMI})^{293}$.

Il est important de préciser que le caractère complémentaire de l'indemnisation accordée par le Fonds implique que les dommages intérêts alloués aux victimes par le propriétaire du navire seront déduits du montant alloué par le Fonds. Par exemple, si la réparation pécuniaire s'élève à 203 millions d'UC377 le propriétaire devra payer au maximum la somme de 89,77 millions d'UC sous le régime du Protocole de 1992 à la CLC tel que modifié par les amendements d'octobre 2000 du Comité juridique. Il en résulte que le Fonds interviendra au maximum à hauteur de 113,23 millions d'UC (203 $-89,77=113,23)^{294}$.

La Convention complémentaire instaure une indemnisation substantielle.

\footnotetext{
292 1'unité de compte (UC) équivaut à 1 droit de tirage spécial (DTS) du Fonds monétaire international (FMI).

293 L'amendement a été adopté par le Comité juridique lors de sa $82^{\text {ème }}$ session qui s'est déroulée du 16 au 20 octobre 2000. L'amendement est entré en vigueur le ler novembre 2003. Cf. www.imo.org/liability and compensation. Site consulté le 14 janvier 2006.

294 TIEBLEY (Yves Didier), La Côte d'Ivoire et la gestion durable des ressources naturelles marines, Thèse unique, Droit Public, Université de Maastricht, 20 mai 2010, p.123.
} 
Tableau 4 : Tableau récapitulatif des différents relèvements des plafonds d'indemnisation sous le régime complémentaire du FIPOL (en millions \$US)

\begin{tabular}{|l|l|l|l|l|}
\hline & FIPOL 1971 & FIPOL 1992 & $\begin{array}{l}\text { Amendement de } \\
\mathbf{2 0 0 0}\end{array}$ & $\begin{array}{l}\text { Protocole FIPOL } \\
\text { de 2003 }\end{array}$ \\
\hline $\begin{array}{l}\text { Plafond d'indemnisation } \\
\text { octroyé par le FIPOL }\end{array}$ & 91 millions & 204 millions & 307 millions & 1.134 millions \\
\hline
\end{tabular}

Source : FAURE (Michael) et WANG (Hui), "Financial caps for oil pollution : A historical mistake ?", Marine Policy, $\mathrm{n}^{\circ} 32,2008$, p.594 ${ }^{295}$.

\section{L'indemnisation substantielle issue de la Convention complémentaire de 2003 modifiant la Convention FIPOL 1992}

Il ressort du préambule du Protocole de 2003 à la Convention de 1992 portant création du Fonds d'indemnisation, une prise de conscience de la part des États contractants au Protocole de 2003. Ils ont tous affirmé la nécessité de préserver la viabilité du système international de responsabilité et d'indemnisation pour les dommages de pollutions par hydrocarbures.

En outre, ils ont tous reconnu que le montant maximal de l'indemnisation disponible en vertu de la convention de 1992 portant création du Fonds pourrait dans certaines circonstances ne pas suffire pour répondre aux besoins d'indemnisation dans certains États contractants. Aussi, ont-ils décidé à des fins d'indemnisation suffisante, de disposer de fonds additionnels grâce à la création d'un mécanisme complémentaire à même de garantir aux victimes d'une pollution par hydrocarbures, une réparation intégrale pour les préjudices ou dommages subis.

La Conférence diplomatique de l'OMI a décidé de la création d'un Fonds complémentaire à l'effet d'augmenter de façon significative l'indemnisation maximale pour un sinistre. Ainsi en mai 2003, il a été décidé de porter à 750 millions de DTS où sont inclus les montants actuels soit près de 920 millions $€$ pour un évènement déterminé. En effet, aux termes de l'article 4 dudit Protocole, le Fonds doit indemniser toute personne ayant subi un dommage par pollution, si cette personne n'a pas été en mesure d'obtenir une réparation intégrale et adéquate des dommages au titre d'une demande ( ...) le montant total des indemnités que le Fonds complémentaire doit verser pour un événement déterminé n'excède pas 750 millions d’UC.

Ainsi, la Convention supplémentaire de 2003 a augmenté considérablement le dédommagement des victimes par rapport à la Convention de 19992. Aujourd'hui, conformément à la Convention complémentaire de 2003, le montant disponible pour les

\footnotetext{
295 Les montants ci-dessus ont été obtenus en convertissant les droits de tirage spéciaux (DTS) en \$US selon le cours du dollar défini à la date du $1^{\text {er }}$ juin 2007 par le Fonds monétaire international (FMI). Les présentes informations ont été recueillies sur le site du Fonds FIPOL : www.iopc.fund.org/SDR.htm à la date du 31 août 2007.
} 
victimes est presque d'un (1) milliard $€$. Mieux, depuis avril 2003, le niveau des paiements a été porté à $100 \%{ }^{296}$.

L'autre pan du nouveau régime spécial d'indemnisation en droit maritime international et en droit comparé est perceptible dans la responsabilité civile en droit français et américain.

\section{B - $\quad$ La responsabilité civile en droit français et américain}

En Côte d'Ivoire, l'indemnisation des victimes de dommages quelles qu'elles soient, se fait, sauf intervention de textes juridiques particuliers, sur la base des articles 1382 et suivants du Code civil napoléonien de $1804^{297}$.

Cependant, la jurisprudence relative au désintéressement des victimes de pollutions marines de grande ampleur est quasi-inexistante. Une telle situation est due à l'absence de décisions de justices rendues à la suite d'une action indemnitaire intentée par les victimes de pollutions marines accidentelles. ${ }^{298}$ C'est pourquoi l'étude de l'indemnisation des victimes de pollutions marines accidentelles, précisément des marées noires, se fera sur la base du droit comparé. Elle portera sur le droit français ainsi que sur le droit étatsunien à travers deux affaires célèbres de pollution marine : l'affaire de l'Erika et l'affaire de l'Amoco Cadiz. Aussi, procéderons-nous à une distinction entre l'indemnisation des victimes en droit français, singulièrement dans l'affaire de l'Erika d'une part (1) et l'apport de la législation étatsunienne dans l'affaire de l'Amoco Cadiz (2).

\section{En droit français : l'affaire de l'Erika}

L'affaire de l'Erika a fait l'objet de plusieurs décisions de justice tant au civil (a)qu'au pénal (b) ${ }^{299}$.

\section{a. Au civil}

Au civil, la première décision rendue dans l'affaire Erika, le 6 décembre 2000, émane du Tribunal de commerce de Saint-Nazaire. Cette juridiction a débouté la commune de

\footnotetext{
296 Voir en ce sens, le Manuel du FIPOL « Sinistre dont les FIPOL ont à connaître », octobre 2009, p.3.

297 TIEBLEY (Yves Didier), La Côte d'Ivoire et la gestion durable des ressources naturelles marines, op.cit, p.102.

298 Un accident survenu le mardi 28 mars 2006, sur une plate-forme au large de Jacqueville, a entraîné le déversement de $26.000 \mathrm{~m} 3$ de pétrole brut dans la mer. Les mesures opérationnelles de lutte contre cette marée noire ont été mises en oeuvre par la CNR International (l'opérateur pétrolier exploitant le puits pétrolier source de la pollution marine accidentelle) et le CIAPOL. La pollution marine a entraîné l'empoisonnement des organismes marins notamment les poissons. Il en a résulté la réduction des activités économiques, l'intoxication des populations riveraines, des maladies oculaires.

299 Au pénal, le Tribunal de Grande instance de Paris (TGI) s'est prononcée le 16 janvier 2008 sur l'action intentée par les parties civiles, victimes de la marée noire provoquée par le naufrage de l'Erika.
} 
Mesquer de son action en responsabilité300. La seconde décision a été rendue le 13 février 2002 par la Cour d'appel de Rennes. L'arrêt de cette cour d'appel confirme le jugement précité du 6 décembre 2000, en tous ses points.

La commune de Mesquer a interjeté appel auprès de la Cour d'appel de Rennes aux fins de voir la responsabilité civile des sociétés Total être retenue. L'appelante a, entre autres, fondé son action indemnitaire sur le fait que le fioul lourd $\mathrm{n}^{\circ} 2$ transporté par l'Erika constitue un déchet au regard des articles L.541-1 et suivants du Code de l'environnement français.

La Cour d'appel a eu une perception différente de la nature du fioul lourd $n^{\circ} 2$. Des motifs de l'arrêt, il ressort que la Cour considère comme déchet une substance qui fait ou doit "faire l'objet d'abandon ». Aussi, la qualification de déchet doit-elle être écartée aussi longtemps que la substance se révèle utile à un usage quelconque ${ }^{301}$.

La conséquence logique de cette conception (restrictive) de la notion de déchet est la confirmation du jugement rendu en première instance par le tribunal de commerce de Saint-Nazaire. Ce jugement, rappelons-le, déboutait la commune de Mesquer de son action indemnitaire.

Il importe cependant de noter que la Cour de cassation (française) a partiellement cassé l'arrêt de la Cour d'appel de Rennes. Pour ce faire, la haute juridiction a saisi la Cour de justice des communautés européennes (CJCE), sur renvoi préjudiciel, aux fins de statuer sur la nature du fioul lourd $\mathrm{n}^{\circ} 2$ transporté par l'Erika.

De manière constante, la CJCE considère que la notion de déchet ne doit pas être interprétée de manière restrictive parce que la Communauté vise un niveau élevé de protection de l'environnement ${ }^{302}$. Selon la CJCE, l'intention du détenteur d'éliminer ou

\footnotetext{
300 Rappelons que la commune de Mesquer est l'une des nombreuses collectivités territoriales victimes de la marée causée par le naufrage de l'Erika.

301 Selon la Cour d'appel de Rennes, le fioul lourd n 2 ne constituait pas un déchet dans la mesure où "la destination recherchée dès l'origine était l'utilisation directe comme combustible pour les besoins de production électrique; qu'il s'agissait donc d'une matière combustible constituant un produit énergétique élaboré pour un usage déterminé non d'un déchet devant être éliminé, c'est-à-dire devant faire l'objet d'un abandon ou dont il y a lieu de se défaire ». Cf. Cour d'appel de Rennes, 13 février 2002, Commune de Mesquer c/ SA Total Raffinage Distribution, Société Total International Ltd, RJE, $\mathrm{n}^{\circ} 1,2003$, p. 54 .

$C f$. également ROBIN (Cécile), "La réparation des dommages causés par le naufrage de l'Erika ", RJE, ${ }^{\circ} 1$, 2003; TIEBLEY (Yves Didier), La Côte d'Ivoire et la gestion durable des ressources naturelles marines, op.cit, p.103.

${ }_{302}$ CJCE, 15 juin 2000, ARCO Chemie Nederland Ltd, aff. C-418/97 et C-419/97, obs. F. Kauff-Gazin, Europe, août-sept. 2000, n²73. Rapporté par ROBIN Cécile, op.cit, p.44.

La CJCE a d'ailleurs rappelé que, selon le troisième considérant de la directive 75/442, l'objectif de ladite directive consiste en la protection de la santé de l'homme et de l'environnement contre les effets préjudiciables causés par le ramassage, le transport, le traitement, le stockage et le dépôt des déchets, compte tenu de l'article $174 \S 2$ du traité CE. Cet article dispose que la politique de la Communauté dans le domaine de l'environnement vise un niveau de protection élevé et est fondée, notamment, sur les principes de précaution et d'action préventive.
}

Cf. CJCE, 11 novembre 2004, Niselli, aff. C-457/02, Rec. p. I-10853, point 33. 
de réutiliser la substance (de la valoriser dans l'avenir) par lui-même ou par un tiers est sans incidence sur sa qualification de déchet $^{303}$...Et elle ajoute que l'utilisation d'une substance comme combustible est un mode courant de valorisation des déchets ${ }^{304}$. Il en découle que le fioul lourd $\mathrm{n}^{\circ} 2$, nonobstant la destination de combustible qui lui est assignée, est bel et bien un déchet ${ }^{305}$.

Précisément dans l'affaire Erika, la CJCE a estimé que le fioul lourd $\mathrm{n}^{\circ} 2$ mélangé à de l'eau et à des sédiments était un déchet ${ }^{306}$. La Cour de cassation (française) s'est fondée sur la décision de la CJCE pour casser partiellement l'arrêt de la Cour d'appel de Rennes $^{307}$.

Quoique mitige, la décision du juge français au pénal n’a pas vraiment varié.

\section{b. Aupénal}

Au pénal, deux juridictions ont statué dans l'affaire Erika, le 16 janvier 2008 et le 30 mars 2010. Il s'agit respectivement du Tribunal de Grande Instance (TGI) de Paris et de la Cour d'appel de Paris.

\footnotetext{
303 La Cour note à cet effet qu'eu égard à l'objectif poursuivi par la directive 75/442, la notion de déchet ne peut être interprétée de manière restrictive. Cf. CJCE, 15 juin 2000, ARCO Chemie Nederland Ltd, aff. C$418 / 97$ et C-419/97, point 40.

${ }^{304}$ CJCE, 15 juin 2000, ARCO Chemie Nederland Ltd, points 65 et suivants.

${ }^{305}$ Cf. TIEBLEY (Yves Didier), La Côte d'Ivoire et la gestion durable des ressources naturelles marines, op.cit, p.105.

306 La CJCE soulignait : "Des hydrocarbures accidentellement déversés en mer à la suite d'un naufrage, se retrouvant mélangés à l'eau ainsi qu'à des sédiments et dérivant le long des côtes d'un État membre jusqu'à s'échouer sur celles-ci, constituent des déchets au sens de l'article ${ }^{\text {er }}$, sous a), de la directive 75/442, dès lors que ceux-ci ne sont plus susceptibles d'être exploités ou commercialisés sans opération de transformation préalable ». Cf. CJCE, 24 juin 2008, Commune de Mesquer c/ Total France SA, Total International Ltd, aff. C-188/07, point 63 (repris à l'al. 2 du dispositif), JOCE, C209/10 du 15 août 2008.

307 «Attendu que pour dire que la commune de Mesquer n'était pas fondée à invoquer les dispositions de la loi du 15 juillet 1975 sur l'élimination des déchets et la débouter de sa demande de condamnation in solidum des sociétés Total international Ltd et Total raffinage distribution à lui payer une somme, l'arrêt retient que les sociétés Total ne peuvent être considérées, au sens de l'article L. 541-2 du code de l'environnement, comme productrices ou détentrices des déchets retrouvés sur les plages après le naufrage du navire Erika, alors qu'elles ont en réalité fabriqué un produit pétrolier devenu déchet uniquement par le fait du transport.

Qu'en statuant ainsi, alors que le vendeur des hydrocarbures et affréteur du navire les transportant peut être considéré comme détenteur antérieur des déchets s'il est établi qu'il a contribué au risque de survenance de la pollution occasionnée par le naufrage et que le producteur du produit générateur des déchets peut être tenu de supporter les coûts liés à l'élimination des déchets si, par son activité, il a contribué au risque de survenance de la pollution occasionnée par le naufrage, la cour d'appel, qui a constaté que la société Total raffinage distribution avait produit le fioul lourd et que la société Total international Ltd l'avait acquis puis vendu à la société Enel et affrété le navire Erika pour le transporter, n'a pas tiré les conséquences légales de ses propres constatations et a violé le texte susvisé ".

La Cour de cassation a renvoyé les parties devant la Cour d'appel de Bordeaux.

Cf. Cass. Civ, $3^{\text {ème }}$ chambre, 17 décembre 2008, Commune de Mesquer c/ Société Total Raffinage et al., ${ }^{\circ} 04-$ 1235, arrêt $\mathrm{n}^{\circ} 1317$ du 17 décembre 2008. L'intégralité de cet arrêt peut être consulté en ligne sur le site http://www.courdecassation.fr/jurisprudence_2/troisième_chambre_civile_572/arrêt_no_12028.html.
} 
En première instance, le TGI de Paris a connu à la fois de l'action pénale et de l'action civile intentées par les victimes de la marée noire provoquée par le naufrage de l'Erika. L'action pénale a abouti à la condamnation des sociétés RINA ${ }^{308}$, TOTAL S.A ${ }^{309}$ et de Messieurs Savarese ${ }^{310}$ et Pollara ${ }^{311}$. Ainsi, messieurs Giuseppe Savarese et Antonio Pollara ont été condamnés, chacun, à une amende délictuelle de $75.000 €$. La société TOTAL S.A. $\mathrm{A}^{312}$ et la société RINA (SpA) ont écopé, chacune, d'une amende délictuelle de 375.000 $€^{313}$.

L'affirmation de la responsabilité pénale de ces prévenus a facilité l'indemnisation des victimes du naufrage de l'Erika ${ }^{314}$. Parmi ces victimes figurent particulièrement la commune de Mesquer qui a obtenu "réparation de l'atteinte portée à sa réputation et à son image de marque $\aleph^{315}$. Le montant alloué à cette dernière s'élève à $500.000 €$. En la matière, la décision rendue par le TGI de Paris contraste fortement avec la fin de nonrecevoir opposée à l'action indemnitaire intentée par la commune de Mesquer successivement devant le Tribunal de commerce de Saint-Nazaire et la Cour d'appel de Rennes qui n'avait pas abouti.

308 Le REGISTRO ITALIANO NAVALE (RINA) était initialement une fondation de droit privé italien. Elle est une société de classification. Par la suite, il a été créé, le 25 mars 1999, la société RINA qui est une société par actions (SpA) dans laquelle la fondation RINA détenait 99\% des actions. La nouvelle RINA avait pour activités de procéder à la certification dans les domaines maritimes et industriels. À ce titre, la nouvelle RINA est la société de classification qui a repris les activités de la fondation RINA et qui a certifié que le navire Erika était en état de naviguer. $C f$. TGI Paris, 16 janvier 2008, $11^{\text {ème }}$ chambre, $4^{\text {ème }}$ section, p.110 ; pp.117-120.

309 Au moment du naufrage de l'Erika, la société TOTAL FINA S.A (devenue par la suite TOTAL FINA ELF puis TOTAL S.A) était le propriétaire de la cargaison transportée par ce navire en vertu de la charte-partie du 26 novembre 1999 par laquelle le Groupe TOTAL affrète l'Erika pour transporter sa cargaison de fuel oil n 2 .

Cf. TGI Paris, 16 janvier 2008, $11^{\text {ème }}$ chambre, $4^{\text {ème }}$ section, pp.137-138.

310 Monsieur Giuseppe SAVARESE est le porteur de la totalité des actions de huit (8) sociétés libériennes. Celles-ci sont actionnaires et administrateurs de quatre sociétés maltaises qui sont : la Tevere Shipping Company Limited, la Palm Maritime Limited, la Daisy Shipping Limited, et la Hive Maritime Limited. Ces quatre (4) sociétés sont respectivement armateurs propriétaires des navires Erika, Zagara, Maria S. et Luigi S. Chaque société est propriétaire d'un seul navire. Cf. TGI Paris, 16 janvier 2008, $11^{\text {ème }}$ chambre, 4ème section, pp.104-105.

311 Monsieur Antonio POLLARA est le Président du Conseil d'administration de la société PANSHIP srl. Cette société a été créée le 21 mars 1997 par Messieurs Antonio Pollara, Luca Vittiello et la société EUROMAR représentée par Monsieur Savarese. Un contrat d'assistance technique a été signé entre les sociétés TEVERE SHIPPING et la société PANSHIP pour la gestion technique de l'Erika. De manière simplifiée, on retiendra que la société PANSHIP était responsable de l'entretien et du maintien en bon état de navigabilité du navire Erika. Le Président de la PANSHIP avait, quant à lui, le rôle de veiller à ce que le pétrolier fût accepté par les principales compagnies et devait, en conséquence, s'assurer du bon déroulement des visites d'inspection de la société de classification. Cf. TGI Paris, 16 janvier 2008, $11^{\text {ème }}$ chambre, $4^{\text {ème }}$ section, pp.106-107 et 108.

312 L'actuelle société dénommée TOTAL S.A était initialement TOTALFINA. Elle est, par la suite, devenue la TOTALFINAELF.

313 Cf. TGI Paris, 16 janvier 2008, $11^{\text {ème }}$ chambre, $4^{\text {ème }}$ section, p.270.

314 Les victimes de la marée noire provoquée par le naufrage de l'Erika sont : l'État français ; les collectivités territoriales (régions, départements, communes); les personnes morales de droit privé (associations de protection de l'environnement, sociétés commerciales) et les personnes physiques.

${ }^{315}$ Cf. TGI Paris, 16 janvier 2008, $11^{\text {ème }}$ chambre, $4^{\text {ème }}$ section, p. 274. 
En appel, en revanche, l'arrêt du 30 avril 2010 rendu par la Cour d'appel de Paris a partiellement infirmé le jugement du TGI de Paris. Cet arrêt a infirmé la condamnation de la société TOTAL S.A à verser des dommages-intérêts aux victimes de la marée noire provoquée par l'Erika. Rappelons que le TGI de Paris avait très subtilement considéré que la société TOTAL S.A n'était pas l'affréteur de l'Erika. Selon le TGI, ce rôle revenait à ses filiales. Cette interprétation de la loi avait alors permis au tribunal d'écarter la canalisation de responsabilité prévue par l'article III $\$ 1$ la Convention CLC 1992.

La Cour d'appel de Paris a estimé que la société TOTAL S.A doit être considérée comme l'affréteur au voyage. Cette interprétation permet à la société TOTAL S.A de bénéficier à ce titre de la canalisation de responsabilité édictée par la Convention CLC, tout comme deux de ses filiales TOTAL Transport Corporation (TTC), qui était son mandataire pour passer le contrat d'affrètement, et TOTAL Petroleum Service (TPS) qui, elle, était le mandataire de $\mathrm{TTC}^{316}$.

L'évolution de la situation indemnitaire des victimes des marées noires se constate également en droit américain.

\section{En droit états-unien : affaire de l'Amoco Cadiz}

Le procès intenté par les victimes françaises de l'Amoco Cadiz devant les juridictions états-uniennes a permis de saisir la hardiesse du juge états-unien dans la fixation des dommages-intérêts à attribuer auxdites victimes ${ }^{317}$. En effet, le montant total de la facture présentée par les victimes françaises s'élevait à 2,270 milliards de FF alors que le plafond de responsabilité prévu par l'article V de la Convention CLC de 1969 était de 210 millions de FF.

Par application de la Convention CLC 1969 et au regard du tonneau de jauge brute de l'Amoco Cadiz, le propriétaire n'aurait eu à s'acquitter que de la somme de 77 millions de FF. Cette somme est largement inférieure à la facture de 2,270 milliards de FF présentées par les victimes de la marée noire de l'Amoco Cadiz.

Heureusement, l'arrêt rendu par la Cour d'appel de Chicago le 24 janvier 1992 a permis aux victimes françaises d'obtenir une indemnisation beaucoup plus consistante. Il est vrai que cette indemnisation s'élevant à 1,25 milliard de FF semble largement

\footnotetext{
316 DESFOUGÈRE (Eric), «L'arrêt d'appel du 30 mars 2010 relatif au naufrage de l'Erika: Total pénalement coupable, mais civilement irresponsable », JAC, Rubrique Actualité catastrophe, nº103, avril 2010.

317 Les juridictions américaines ayant statué sur l'affaire de l'Amoco Cadiz, en simplifiant quelque peu les péripéties judiciaires, sont : le Tribunal de District de New York (assignation de l'Amoco International Oil Company (AIOC), gestionnaire du navire pollueur et de la Standard Oil of Indiana, société-mère du groupe) ; le Tribunal fédéral du District Nord de l'Illinois à Chicago (jugement sur les responsabilités le 18 avril 1984 ; procès d'indemnisation, rectification et jugement final sur les indemnisations (11 janvier 1988 ; 21 février 1989 ; 24 juillet 1990)) et la Cour d'appel de Chicago (appel et audience août 1990 et 12 juin 1991 ; arrêt le 24 janvier 1992). Cf. TIEBLEY (Yves Didier), La Côte d'Ivoire et la gestion durable des ressources naturelles marines, op.cit, p.102, note 282 .
} 
insuffisante au regard de la facture initialement présentée. Il n'empêche que les victimes bretonnes elles-mêmes après quatorze ans de procès l'ont favorablement accueillie ${ }^{318}$.

Le contenu de la responsabilité civile du propriétaire du navire pollueur contribue aussi à la dissuasion en matière d'indemnisation des victimes des marées noires.

\section{Section 2: Le contenu de la responsabilité civile du propriétaire du navire pollueur}

L'étude du contenu de la responsabilité civile du propriétaire du navire nous conduira à exposer successivement les garanties d'indemnisation des victimes de marées noires et l'institution d'une assurance obligatoire (Paragraphe1), ainsi que la déchéance du droit à la limitation financière et à l'exonération de la responsabilité civile du propriétaire du navire (Paragraphe2).

\section{Paragraphe 1: Les garanties d'indemnisation des victimes de marées noires et l'institution d'une assurance obligatoire}

Pour la clarté de notre analyse, nous examinerons au cas par cas les garanties d'indemnisation des victimes de marées noires (A) et ensuite l'institution d'une assurance obligatoire au profit des victimes (B).

\section{A - Les garanties d'indemnisation des victimes de marées noires}

Les garanties d'indemnisation des victimes de marées noires résultent de la canalisation de responsabilité du propriétaire du navire pollueur (1) et du plafonnement de la responsabilité civile du propriétaire du navire pollueur (2)

\section{La canalisation de responsabilité du propriétaire du navire pollueur}

La canalisation de responsabilité trouve son fondement juridique dans l'article III $\$ 4$ in fine de la Convention CLC 1992 ${ }^{319}$. Cette disposition facilite l'identification du

\footnotetext{
${ }^{318}$ Les victimes bretonnes ont accueilli la décision de la Cour d'appel comme une "victoire" tandis que l'État français la considère comme une "réparation significative des préjudices subis". Cf. NDENDÉ (Martin), "L'affaire de l'Amoco-Cadiz ...Quatorze ans de bataille juridique », Paris, Espaces et ressources maritimes, n6, Éditions Pedone, 1992, p.245.

319 Selon l'article III $\$ 4$ de la Convention CLC 1992, " aucune demande de réparation de dommage par pollution ne peut être formée contre le propriétaire autrement que sur la base de la présente Convention. Sous réserve du paragraphe 5 du présent article, aucune demande de réparation de dommage par pollution, qu'elle soit ou non fondée sur la présente Convention, ne peut être introduite contre:

a) les préposés ou mandataires du propriétaire ou les membres de l'équipage;

b) le pilote ou toute autre personne qui, sans être membre de l'équipage, s'acquitte de services pour le navire;

c) tout affréteur (sous quelque appellation que ce soit, y compris un affréteur coque nue), armateur ou armateur-gérant du navire;
} 
civilement responsable dans la mesure où elle institue une responsabilité canalisée sur la personne du propriétaire du navire pollueur.

En effet, la recherche du civilement responsable n'est pas aisée étant donné la pluralité d'acteurs impliqués. Cette pluralité est à l'origine de relations juridiques extrêmement complexes et opaques. Ainsi, en ce qui concerne le navire, trois principaux acteurs doivent être distingués : le propriétaire, l'armateur (armateur-propriétaire, armateur non-propriétaire), l'affréteur (affréteur du navire à coque nue, affréteur au voyage ou affréteur au temps) ${ }^{320}$.

Cependant, au regard de l'article III $\$ 4$ de la Convention CLC 1992, il apparait que la présomption de responsabilité qui pèse sur le propriétaire du navire est une présomption simple.

Aussi, le propriétaire du navire pollueur peut-il s'exonérer de sa responsabilité s'il prouve que le dommage par pollution résulte d'un acte de guerre, d'hostilités, d'une guerre civile, d'une insurrection ou d'un phénomène naturel de caractère exceptionnel, inévitable et irrésistible.

Il en est de même si le dommage résulte en totalité de l'action délibérée d'un tiers ou résulte totalement ou partiellement de la négligence ou d'une action préjudiciable d'un gouvernement ou autre autorité responsable de l'entretien ou autres aides à la navigation dans l'exercice de cette fonction (article III $\$ 2 a, b$ et $c$ ).

La présomption simple de responsabilité qui pèse sur le propriétaire du navire pollueur a pour contrepartie le plafonnement de sa responsabilité civile.

\section{Le plafonnement de la responsabilité civile du propriétaire du navire pollueur}

L'idée du plafonnement de la responsabilité civile du propriétaire du navire pollueur comme garantie d'indemnisation a des raisons (a), malgré les critiques (b).

\section{a. Les raisons de la limitation de responsabilité civile ${ }^{321}$}

Le principe général qui régit le droit de la responsabilité civile est celui de la restitutio in integrum en vertu duquel la victime d'un dommage est en droit de réclamer à l'auteur

d) toute personne accomplissant des opérations de sauvetage avec l'accord du propriétaire ou sur les instructions d'une autorité publique compétente ;

e) toute personne prenant des mesures de sauvegarde;

f) tous préposés ou mandataires des personnes mentionnées aux alinéas c), d) et e) 》.

320 Cf. SOHNLE (Jochen), "Sécurité maritime et marées noires : aspects de droit international public et privé ", Journal des accidents et catastrophes (JAC), n³2, janvier 2003, http : www.iutcolmar.uha.fr, site consulté le 21 janvier 2006.

${ }^{321}$ Ce passage se réfère essentiellement à un article de doctrine des professeurs Michael FAURE et WANG Hui. Cf. FAURE (Michael) et WANG (Hui), 'Financial caps for oil pollution damage: A historical mistake ?', Marine Policy, n³2, Elsevier, 2008, pp.592-606. 
dudit dommage une réparation intégrale dès lors que les conditions du dommage indemnisable sont réunies. Il existe cependant des exceptions à ce principe. C'est notamment le cas lorsque la responsabilité de l'auteur du dommage est limitée à un certain montant. La limitation de responsabilité s'observe particulièrement en droit maritime.

Plusieurs raisons sont couramment avancées pour expliquer le recours à la limitation de responsabilité du propriétaire de navire.

Premièrement, la limitation de responsabilité du propriétaire de navire a été instituée en vue d'encourager le transport maritime qui était considérée comme une activité très risquée.

Deuxièmement, la promotion d'une flotte marchande nationale capable de soutenir la concurrence internationale a conduit plusieurs États à introduire dans leur législation la limitation de responsabilité du propriétaire de navire ${ }^{322}$.

Il est possible de discuter de la pertinence des deux raisons ci-dessus. En effet, si elles s'avéraient pertinentes au XVII ${ }^{\text {ème }}$ siècle, les avancées technologiques observées actuellement dans la navigation maritime ont rendu la navigation maritime beaucoup plus sûre.

Des raisons plus actuelles pourraient expliquer la limitation de responsabilité observée en droit maritime. D'une part, les évolutions technologiques observées dans le transport maritime n'ont pas totalement annihilé les risques inhérents à cette activité. D’autre part, la limitation de responsabilité du propriétaire de navire répond à la volonté de répartir les risques liés au transport maritime entre les différents bénéficiaires de cette activite $^{323}$. Une autre raison qui pourrait actuellement justifier la limitation de responsabilité du propriétaire de navire réside dans la volonté d'éviter au transporteur de la cargaison polluante de supporter l'entièreté des risques et coûts induits par l'absence de limitation de responsabilité. L'absence de limitation de responsabilité pourrait conduire soit les armateurs propriétaires à se retirer de l'activité du transport maritime ${ }^{324}$ soit le propriétaire de navire à payer une prime d'assurance plus élevée en vue de couvrir sa responsabilité civile ${ }^{325}$.

\footnotetext{
322 LORD (M.) 'Ships are different - or are they?', Lloyd's Maritime and Commercial Law Quarterly, 1993, pp.490-501; WETTERSTEIN (P.), 'The principles of limitation and sharing of liability'. In Legislative approaches in maritime law, Proceedings from the European colloquium on maritime law, 7-8 December 2000, Oslo; 2000, pp. 95-100. Rapporté par FAURE (Michael) and WANG (Hui), 'Financial caps for oil pollution damage: A historical mistake?', Marine Policy, nº $^{\circ}$, Elsevier, 2008, p.594.

323 FAURE (Michael) and WANG (Hui), 'Financial caps for oil pollution damage: A historical mistake?', op.cit, p.595.

${ }^{324}$ Avec pour corollaire la réduction de l'éventail de choix des propriétaires de cargaison.

325 Le corollaire de cette seconde hypothèse est la hausse du coût du fret que le propriétaire de la cargaison devrait verser à l'armateur propriétaire.
} 
Troisièmement, la limitation de responsabilité, dans le contexte du commerce moderne actuel, répond aux nécessités de l'assurance. En effet, les capacités du marché de l'assurance ne sont pas illimitées. Une responsabilité illimitée est considérée comme inassurable ou, au moins, entrainerait des coûts d'assurance très élevés ${ }^{326}$. En outre, les coûts d'assurance constituent une très grande partie des coûts générés par le transport maritime. Exposer le propriétaire de navire à une responsabilité illimitée conduirait à une prime d'assurance plus élevée qui pourrait être une lourde charge pour l'industrie du transport maritime.

La canalisation de responsabilité est l'objet de critique.

\section{b. Critique de la limitation de responsabilité}

Le principe de la limitation de responsabilité comporte des faiblesses parmi lesquelles deux retiendront particulièrement notre attention. La première critique relève de l'analyse économique de la règle de droit tandis que la seconde met en relief la rupture du principe pollueur-payeur.

L'analyse économique de la règle de droit a tendance à souligner le rôle dissuasif de la responsabilité civile ${ }^{327}$. En d'autres termes, l'économiste considère que l'indemnisation des victimes d'un accident n'est pas le but principal de la responsabilité civile. Cette institution doit offrir aux parties en cause des incitations à un meilleur comportement. Le professeur André TUNC écrit à ce sujet :

"L'indemnisation de la victime est, elle aussi, une fonction fondamentale de la responsabilité: on ne peut en douter. La responsabilité doit à la fois décourager les comportements antisociaux et assurer l'indemnisation de ceux qui seraient victimes d'un tel comportement $»^{328}$.

Aussi, les analyses économiques de la règle de droit critiquent-elles le principe du plafonnement de la responsabilité civile. À la limite, le plafonnement de responsabilité civile apparaît comme une légitimation des actes de pollution. En effet, le propriétaire qui souscrit à une police d'assurance équivalente au plafond de sa responsabilité civile éventuelle n'éprouve pas le besoin de prendre les mesures préventives en vue d'éviter sinon de minimiser autant que possible les risques d'accidents maritimes sources de marées noires ${ }^{329}$. Celles-ci considèrent que les limites de responsabilité accordées au

\footnotetext{
326 FAURE (Michael) and WANG (Hui), 'Financial caps for oil pollution damage: A historical mistake?', op.cit, p.595.

327 Il est possible de consulter à cet effet : OGUS (Anthony) et FAURE (Michael), Économie du droit: le cas français, Paris, Éditions Panthéon Assas, 2002, 176 p. ; FAURE (Michael), L'analyse économique du droit de l'environnement, Bruxelles, Bruylant, 2007, 362 p.

328 Cf. TUNC (André), La sécurité routière. Esquisse d’une loi sur les accidents de la circulation, Paris, Dalloz, $1966, \mathrm{n}^{\circ} 170$.

329 Les professeurs Michael FAURE et WANG Hui soulignent à cet effet : 'The limits on liability have been critically attacked in economic analyses of law where it has been argued that a financial limit on the exposure to
} 
pollueur diluent l'effet dissuasif recherché à travers la condamnation de celui-ci à payer des dommages-intérêts aux victimes.

L'affaire de l'Erika illustre parfaitement cet état de chose. En effet, le propriétaire du navire pollueur - la société Tevere Shipping - a vu sa responsabilité civile être écartée dès lors qu'il a constitué un fonds de garantie de 84 millions de FF auprès du Tribunal de commerce de Nantes alors que l'étendue des dommages subis par les victimes étaient évalués à 6 milliards de FF par un cabinet d'expertise sollicité par les collectivités locales sinistrées ${ }^{330}$.

Quelle serait alors la motivation du propriétaire d'un navire sous-norme à respecter les prescriptions conventionnelles - en l'occurrence celles de l'Annexe I à la Convention MARPOL 73/78 - s'il sait d'avance les dommages intérêts qui lui seraient imputables?

Surtout lorsque les dommages intérêts sont négligeables au regard des bénéfices escomptés de l'exploitation de ce navire sous-norme ? Visiblement, aucune motivation ne l'inciterait à se mettre en règle vis-à-vis de la Convention MARPOL 73/78 331.

Concernant la deuxième critique, la limitation de responsabilité viole le principe du pollueur-payeur, particulièrement sa fonction curative qui se manifeste à travers la responsabilité civile du pollueur. En effet, les écarts énormes qui existent entre les plafonds de responsabilité civile du propriétaire de navire et les estimations des coûts des dommages affaiblissent considérablement la portée du principe d'indemnisation contenu dans les dispositions pertinentes de la Convention CLC. La limitation de responsabilité ne permet pas de produire un effet dissuasif à l'égard des propriétaires de navire sous-norme.

En vue de juguler les effets pervers de la limitation de responsabilité civile, les professeurs Michael FAURE et WANG Hui suggèrent que l'assurance obligatoire souscrite par le propriétaire du navire (en vue de couvrir sa responsabilité civile) ne devrait couvrir celui-ci qu'à hauteur du plafond conventionnel défini. En revanche, les dommages non couverts par l'assurance seraient supportés par le propriétaire (aussi bien nominal que véritable) du navire pollueur ${ }^{332}$. L'application de ces innovations inciterait beaucoup plus les propriétaires de navire à appliquer de manière rigoureuse les normes de sécurité définies par l'Annexe I à la Convention MARPOL 73/78.

liability of an injurer may dilute the incentives for prevention. According to some scholars, limits on liability lead to a "de-responsibilization" of the industry involved'. FAURE (Michael) et WANG (Hui), "The International Regimes for the Compensation of Oil Pollution Damage: Are they effective?”, RECIEL, Vol.12, n³, Oxford, Blackwell Publishing, 2003, p.249.

330 Cf. TIEBLEY (Yves Didier), La Côte d'Ivoire et la gestion durable des ressources naturelles marines, op.cit, p.269.

331 Ibidem.

332 Cf. FAURE (Michael) et WANG (Hui), « The International Regimes for the Compensation of Oil Pollution Damage : Are they effective ? ", RECIEL, Vol.12, n³, Oxford, Blackwell Publishing, 2003, p.249 ; FAURE (Michael) et WANG (Hui), "Compensation for Oil Pollution Damage: China versus the International Regime ", Asia Pacific Journal of Environmental Law, Vol.9, Issue 1, 2005, p.33. 
L'institution d'une assurance obligatoire au profit des victimes apparaît également comme une garantie supplémentaire d'indemnisation des victimes des marées noires.

\section{B - $\quad$ L'institution d'une assurance obligatoire au profit des victimes}

Le débat sur la pertinence de l'assurance obligatoire (1) et l'évaluation de l'assurance obligatoire (2) sera exposé au cas par cas.

\section{Le débat sur la pertinence de l'assurance obligatoire}

Des positions en présence (1), se sont dégagés les arguments en faveur de l'adoption de l'assurance obligatoire (2).

\section{a. Les positions en présence}

L'institution d'une assurance obligatoire a fait l'objet d'un vif débat entre les délégations présentes aux négociations de Bruxelles ${ }^{333}$.

Certaines délégations présentes à Bruxelles ont exprimé leur crainte de voir l'assurance obligatoire des navires pétroliers excéder les capacités du marché de l'assurance ${ }^{334}$. C'est notamment le cas de Lord Devlin (délégation du Royaume-Uni) qui estimait que l'assurance obligatoire imposerait une charge trop lourde au marché de l'assurance. Celui-ci serait incapable de couvrir tous les risques pour lesquels il serait sollicité ${ }^{335}$.

Les partisans de l'assurance obligatoire (notamment la France et les États-Unis), en revanche, croient en la capacité du marché de l'assurance à supporter les risques générés par le transport maritime des hydrocarbures ${ }^{336}$. Ils se référaient à une enquête menée auprès du marché de l'assurance de Londres. Ils croyaient que les capacités du marché de l'assurance étaient beaucoup plus prometteuses que ne le suggéraient les enquêtes antérieures.

En outre, le fait qu'un marché de l'assurance ait été développé pour couvrir les risques nucléaires leur faisait croire qu'il pouvait en être de même pour les risques de pollution maritime par hydrocarbures ${ }^{337}$.

\footnotetext{
333 Le professeur WANG Hui présente de manière détaillée les débats qui ont eu lieu lors des négociations de la CLC 1969, à Bruxelles. Cf. WANG (Hui), Civil Liability for Marine Oil Pollution Damage - A comparative and economic study of the international, US and the Chinese compensation regime, Thesis, Erasmus University Rotterdam, 27 January 2011, pp.80-87.

${ }^{334}$ Délégations du Royaume-Uni et de la République fédérale d'Allemagne.

335 WANG (Hui), Civil Liability for Marine Oil Pollution Damage ..., op.cit, p.81.

336 États-Unis, Brésil, Suède, France, Irlande, Grèce, Japon, Australie, Roumanie.

337 WANG (Hui), Civil Liability for Marine Oil Pollution Damage ..., op.cit, p.81.
} 


\section{b. Les arguments en faveur de l'adoption de l'assurance obligatoire}

Les partisans de l'assurance obligatoire l'emportèrent cependant au sein du Comité Maritime International (CMI). Les principaux arguments développés en faveur de l'assurance obligatoire étaient au nombre de trois ${ }^{338}$ :

D'abord, l'assurance obligatoire est une mesure essentielle qui complète le système de la responsabilité civile. Sans l'assurance obligatoire, le système de la responsabilité civile ne serait pas viable eu égard aux risques d'insolvabilité du propriétaire du navire pollueur. En outre, l'assurance obligatoire est considérée comme la seule manière de rendre viable l'objectif de la réparation adéquate étant donné le coût élevé des dommages causés par les marées noires. Dans le cas d'une compagnie maritime dotée d'un seul navire, un tel système est nécessaire pour résoudre la difficulté que pose un débiteur insolvable. Particulièrement dans le cas des pavillons de libre immatriculation (ou pavillon de complaisance), l'assurance obligatoire constitue une garantie de solvabilité de celui qui y souscrit.

Ensuite, face à l'argument selon lequel l'assurance obligatoire excéderait les capacités du marché de l'assurance, les États-Unis répliquèrent que ce type d'assurance a été conçu pour protéger les victimes, non pour avantager les petits groupes d'assureurs. Au besoin, les assureurs pourraient répartir entre eux les risques au moyen de la ré-assurance.

Enfin, le Royaume-Uni faisait remarquer que l'assurance obligatoire contribuerait à rendre certaine la réparation des actions indemnitaires intentées par les victimes de marées noires. En revanche, si la souscription à la police d'assurance est laissée au libre choix des propriétaires de navire, ceux-ci pourraient choisir de ne pas s'assurer ou pourraient bénéficier d'exonérations ou dérogations de responsabilité. L'assurance obligatoire règle de telles défaillances.

Après l'adoption de l'assurance obligatoire, le débat porta sur la possibilité pour les victimes d'intenter directement une action indemnitaire contre l'assureur du navire pollueur ou toute autre personne se portant garant du navire pollueur.

Le vote qui sanctionna ce deuxième débat se solda comme suit : trente-trois (33) voix en faveur de l'action directe des victimes, zéro (0) voix contre et huit (8) abstentions. La version finale de la Convention CLC 1969 admit l'action directe des victimes à l'encontre de l'assureur ou autres garants du navire pollueur.

Qu' en est-il de l' évaluation de l' assurance obligatoire?

338 WANG (Hui), Civil Liability for Marine Oil Pollution Damage ..., op.cit, p.82. 


\section{2. Évaluation de l'assurance obligatoire}

Avant 1969, le propriétaire de navire n'était pas obligé de souscrire à une assurance obligatoire qui couvrirait sa responsabilité civile en cas de pollution marine. Même si le juge faisait droit à l'action en responsabilité intentée par la victime, celle-ci n'était pas sûre d'être dédommagée par le pollueur à cause de l'insolvabilité de ce dernier. Cette faille a conduit les différentes délégations présentes au Comité maritime internationale (CMI) à opter pour l'assurance obligatoire en dépit des objections (parfois pertinentes) qui ont été formulées. Le système de l'assurance obligatoire se présente comme le mécanisme indispensable qui procure la garantie financière nécessaire à la mise en œuvre du principe d'indemnisation ${ }^{339}$.

Chaque État partie à la Convention CLC 1969 assume, en matière d'assurance obligatoire, deux sortes d'obligations :

Premièrement en tant qu'État d'immatriculation du navire, il devra délivrer un certificat constatant que l'assurance obligatoire ou toute autre garantie exigée par la Convention CLC a été souscrite. Il ne devrait pas autoriser un navire battant son pavillon à appareiller si celui-ci ne détient pas un tel certificat.

Deuxièmement en tant qu'État côtier, il devra s'assurer que tout navire, en dépit de son lieu d'immatriculation, se trouvant dans son port ou son terminal pétrolier, dispose d'un tel certificat. D’ailleurs, l'article VII $₫ 11$ de la Convention CLC 1969 fait obligation à tout navire qui entre dans le port d'un État contractant d'être muni de ce certificat. Cette disposition est un remède à l'avantage injuste dont pourraient bénéficier les navires des États tiers à la CLC dès lors que ces navires ne seraient pas soumis à l'obligation de présenter un certificat garantissant leur solvabilité ${ }^{340}$.

L'exigence du certificat ne s'applique pas aux navires transportant moins de 2.000 tonnes d'hydrocarbures en vrac en tant que cargaison ${ }^{341}$. Il importe de souligner que l'ampleur des dégâts causés par une marée noire dépend moins de la quantité d'hydrocarbures déversée que de la nature (ou de la nocivité) de celle-ci ${ }^{342}$ ( $C f$. tableau de classification des types de pétrole).

\footnotetext{
339 WANG (Hui), Civil Liability for Marine Oil Pollution Damage ..., op.cit, p.87.

${ }^{340}$ Ibidem.

341 Article VII $\$ 11$ de la Convention CLC 1969.

342 À titre d'illustration, il est possible de comparer les dégâts causés par le naufrage de l'Amoco Cadiz et celui de l'Erika, suite au naufrage de l'Erika en décembre 1999, 200.000 oiseaux de mer avaient déjà péri fin avril 2000 ! Voir RAMADE (François), op.cit, p.60.
} 
Typologie des marées noires établie par l' « International Tanker Owners Pollution Federation (ITOPF) »

\begin{tabular}{|l|l|l|l|l|}
\hline Groupe & I & II & III & IV \\
\hline Densité & $<0,80$ & $0,80-0,85$ & $0,85-0,95$ & $>0,95$ \\
\hline Pétroles bruts & - & Pétroles légers & Pétroles moyens & Pétroles lourds \\
\hline Produits raffinés & $\begin{array}{l}\text { Essence, } \\
\text { kérosène }\end{array}$ & Gas oil & Fuel domestique & Fuel lourd, bitume \\
\hline $\begin{array}{l}\text { Exemples de marées } \\
\text { noires }\end{array}$ & Ekofisk & Amoco Cadiz, Braer & Torrey Canyon & $\begin{array}{l}\text { Bohlen, Tanio, } \\
\text { Erika, Prestige }\end{array}$ \\
\hline $\begin{array}{l}\text { Comportement et } \\
\text { effets }\end{array}$ & $\begin{array}{l}\text { Faible } \\
\text { persistance, } \\
\text { Toxicité à court } \\
\text { terme }\end{array}$ & $\begin{array}{l}\text { Persistance moyenne à forte, } \\
\text { Effets par toxicité et engluement }\end{array}$ & $\begin{array}{l}\text { Très forte } \\
\text { persistance. Effets } \\
\text { principalement par } \\
\text { engluement }\end{array}$ \\
\hline $\begin{array}{l}\text { Lutte antipollution en } \\
\text { mer }\end{array}$ & $\begin{array}{l}\text { Ne rien faire } \\
\text { Indemnisation FIPOL }\end{array}$ & $\begin{array}{l}\text { Confiner, récupérer, disperser } \\
\text { non persistants }\end{array}$ & Hydrocarbures persistants & $\begin{array}{l}\text { Confiner et } \\
\text { récupérer }\end{array}$ \\
\hline
\end{tabular}

Source: MARCHAND (Michel), Les pollutions marines accidentelles. Au-delà du pétrole brut, les produits chimiques et autres déversements en mer, IFREMER, Centre de Nantes, Département Polluants Chimiques,1978, p.13.

Il en résulte que les dommages causés par un navire pétrolier ne correspondent pas toujours avec sa taille encore moins avec le volume de sa cargaison. Dès lors, exclure les petits navires de l'obligation de souscrire à l'assurance obligatoire pourrait ne pas contribuer à la résolution du risque d'insolvabilité que pourrait poser ce type de navire pétrolier $^{343}$.

Au sens de notre étude, la deuxième modalité du contenu de la responsabilité civile du propriétaire du navire est composée de la déchéance du droit à la limitation financière et à l'exonération de la responsabilité civile du propriétaire du navire.

\section{Paragraphe 2: La déchéance du droit à la limitation financière et à l'exonération de la responsabilité civile du propriétaire du navire}

Par déchéance, il faut entendre la perte du bénéfice d'un droit ou encore la privation du bénéfice d'un privilège. En droit civil, la déchéance est définie comme la perte d'un droit, soit à titre de sanction, soit en raison du non respect des conditions d'exercice du droit $^{344}$.

Rapprochée à notre étude, la déchéance intervient à titre de sanction des agissements fautifs et du défaut de diligence du propriétaire. La déchéance des droits à la limitation et à l'exonération de la responsabilité résulte des dispositions des articles 5 alinéa 2 et 3

343 WANG ( Hui), Civil Liability for Marine Oil Pollution Damage ..., op.cit, p.87.

344 Voir le lexique des termes juridiques, 14è Edition.2003, p.183 
de la Convention sur la responsabilité civile de 1969 et du protocole de 1992 modifiant la Convention de 1969 sur la responsabilité civile en ses articles 2 alinéa 4 in fine et 6 alinéas 2,3 et 6 .

En effet, conformément à l'article 5 de la Convention susvisée, si l'évènement est causé par une faute personnelle du propriétaire, ce dernier n'est pas recevable à se prévaloir de limitation de sa responsabilité. A l'analyse, aucune clarté ne transparaît sur cette question au niveau du droit international. A première vue, nous ne pouvons pas déterminer avec exactitude les déchéances qui concernent les limitations financières et celles qui se rapportent à l'exonération de la responsabilité. C’est dire que le droit international entretient le flou à ce sujet. Aussi, convient-il pour la clarté de notre exposé de dégager deux sortes de déchéance susceptibles de frapper le propriétaire. A ce titre donc, nous pouvons dire que les unes concernent le droit à la limitation financière (A) et les autres s'entrevoient à travers l'exonération de la responsabilité (B).

\section{A - La déchéance relative à la limitation financière de responsabilité civile}

L'analyse de la déchéance du droit à la limitation financière de la responsabilité de l'opérateur maritime sera consacrée à l'exposé des causes (1) et des effets (2) qui s'y rattachant.

\section{Les causes de la déchéance}

Deux principales causes de la déchéance des droits à la limitation financière de la responsabilité du propriétaire sont perceptibles à l'analyse des Conventions CLC de 1969 et de son Protocole de 1992. Il résulte de cette analyse que le propriétaire de navire est déchu de son droit à la limitation financière s'il a commis une faute personnelle (a) et s'il ne fait pas preuve de diligence ou s'il est défaillant au titre des obligations à sa charge (b).

\section{a. La faute personnelle du propriétaire de navire}

La cause tirée de la faute personnelle du propriétaire résulte notamment de l'article $\mathrm{V}$ alinéa 2 et de l'article VI alinéa 2 de la Convention CLC 1992.

Au regard de l'article V $\$ 2$ de la Convention CLC 1992, le propriétaire n'est pas recevable à se prévaloir de la limitation de sa responsabilité, si l'évènement, source des dommages est causé par une faute personnelle du propriétaire ${ }^{345}$. A priori, ce mécanisme est bien appréciable, car il n'entend pas alléger la charge financière du propriétaire.

\footnotetext{
345 Article $\mathrm{V} \$ 2:$ : Le propriétaire n'est pas en droit de limiter sa responsabilité aux termes de la présente Convention s'il est prouvé que le dommage par pollution résulte de son fait ou de son omission personnels, commis avec l'intention de provoquer un tel dommage, ou commis témérairement et avec conscience qu'un tel dommage en résulterait probablement ».
} 
Cependant que recouvre concrètement l'expression "faute personnelle» du propriétaire? Quel en est le contenu?

Le droit maritime international n'y apporte pas de réponse précise. Comment le propriétaire qui n'a effectivement pas de pouvoir de direction et de contrôle sur le navire, pouvoir dévolu au capitaine lors de l'expédition, peut-il personnellement commettre une faute personnelle?

Dans cette optique, Sabrina Robert avoue qu'il est rare que le propriétaire commette personnellement une faute inexcusable causant le dommage par pollution. D'autant plus que la gestion du navire lui échappe dans les faits. Abondant dans le même sens, WU Chao voit dans l'exigence d'une faute personnelle du propriétaire, un droit pratiquement non réfutable de limitation de responsabilité ${ }^{346}$. Sa seule qualité de gardien du navire suffit-elle? Qu'adviendra-t-il si la preuve de l'origine du sinistre n'est pas établie?

Force est donc de reconnaître avec le professeur René Rodière qu'en l'espèce, il n'est fait allusion qu'à tout ce qui concerne la faute nautique du navire commise par le propriétaire $^{347}$. Ainsi, commet une faute personnelle, le propriétaire du navire qui cause des dommages par pollution consécutifs au défaut d'équipement, ou équipage incompétent ou encore l'armement défectueux du navire, un équipage maltraité et mal surveillé. Il y a également le cas d'un accident causé par un défaut d'entretien ou de réparation oubliée. Peuvent également constituer une faute personnelle, les défaillances des instruments de bord ou des équipements de sécurité peuvent également témoigner d'une faute de sa part ${ }^{348}$.

C'est dire que la faute personnelle du propriétaire consistera essentiellement à faire naviguer un navire dans un état dangereux de navigabilité. Ce qui est à redouter est notamment la difficulté pratique à déterminer cette faute ${ }^{349}$. Étant donné que cette défaillance du propriétaire n'est pas apparente, mais cachée. Elle requiert de véritables enquêtes des experts.

Ce qui n'est pas le cas du défaut de souscription d'un fonds de limitation ou d'une assurance obligatoire.

\footnotetext{
${ }^{346} \mathrm{WU}$ (Chao), La pollution du fait du transport maritime des hydrocarbures : Responsabilité et indemnisation des dommages, Paris, Pedone, 1994, p.228.

${ }^{347}$ Cf. Voir RODIERE (René), Droit maritime, Paris, Précis Dalloz, 7ème édition, n¹56, 1977, p.121.

${ }_{348}$ Cf. REMOND-GOUILLOUD (Martine), " Pollution des mers », Jurisclasseur 1995, fascicule 1292, $\mathrm{n}^{\circ} 12$, p.6.

349 Selon l'article VI $\$ 2$ de la Convention CLC 1992, «le propriétaire n'est pas en droit de limiter sa responsabilité ...s'il est prouvé que le dommage par pollution résulte de son fait ou de son omission personnels, commis avec l'intention de provoquer un tel dommage ou commis témérairement et avec conscience qu'un tel dommage en résulterait probablement ».
} 


\section{b. Le défaut de souscription d'un fonds de limitation ou d'une assurance obligatoire}

Les obligations relatives à la souscription du fonds de limitation et à l'assurance sont prévues par l'article V $\$ 3$ de la Convention CLC 1992. Conformément à cette disposition, le propriétaire doit constituer un fonds s'élevant à la limite de sa responsabilité auprès d'un tribunal ou de toute autre autorité compétence de l'un quelconque des États contractants où une action est engagée. À défaut d'une telle diligence, il sera déchu du droit à la limitation financière de sa responsabilité.

Quelles sont les règles de procédure de constitution du fonds et les organes $\mathrm{y}$ afférents ${ }^{350}$ ?

La Convention CLC reste muette sur la question. Elle en laisse la latitude à chaque État contractant ${ }^{351}$. C'est dire que les règles de procédures varient d'un État à un autre. Ce qui est à l'évidence regrettable pour les victimes. Qu'adviendra-t-il si le pays dont les côtes et les eaux maritimes sont polluées n'est pas partie à la convention ${ }^{352}$ ?

Aussi, partageons-nous l'avis de Martine Rémond-Gouilloud qui recommande des dispositions d'ordre procédural, détaillées, impératives et de portée universelle à l'effet de fournir aux praticiens, le mode d'emploi des règles.

350 A cette interrogation, le professeur Martine Rémond-Gouilloud répond que «si la Convention comporte quelques règles de procédures, celles-ci visent uniquement à assurer l'harmonisation des lois nationales là où une disparité de solutions risquerait d'engendrer une disparité de traitement entre les victimes : notamment, les conditions de constitution du fonds et de prescription des actions. Voir REMOND-GOUILLOUD (Martine), «Les surprises du Fonds ", in DMF, Février 1986, $38^{\text {ème }}$ année, Paris, 1986, n446, p.99, à propos du commentaire de l'arrêt de la CA de Rennes du 3 octobre 1985, dans l'affaire " Amoco Cadiz ». Ces lacunes ont conduit, le liquidateur nommé par le tribunal de Brest pour gérer le fonds de limitation, à soulever l'irrecevabilité de la demande britannique parce que selon lui, cette demande aurait dû être déposée entre ses mains au sens du droit commun de la liquidation de responsabilité (décret français du 27 octobre 1967). Exception d'incompétence que le tribunal rejeta. Voir BONASSIES (Pierre), "Pollution par le transport d'hydrocarbure ", note sous l'arrêt de la Cour de Cassation chambre commune du 27 juillet 1987, in DMF $1987 \mathrm{n}^{\circ} 12$ p.16. Voir aussi dans ce sens, CA de Rennes ( $1^{\text {ère }}$ chambre) du 8 juillet 1987 et la note qui suit dans l'affaire "Juosas Garialis» consécutive à un abordage pour faute commune, à propos des honoraires du liquidateur du Fonds. Les règles de droit régissant les syndics des procédures collectives de droit commun ne sont pas applicables aux liquidateurs de Fonds de limitation de la responsabilité : les tâches et les émoluments sont différents. La Cour affirme la compétence du tribunal à gérer le fonds de limitation à l'exclusion du liquidateur et du juge commissaire dotés de pouvoir propre. Voir note sous l'arrêt de la CA de Rennes $\left(1^{\text {ère }}\right.$ chambre) du 8 juillet 1987 in DMF nº 469 février 1988, 40 ${ }^{\mathrm{ème}}$ année p.114 et suivant. Voir aussi Bonassies, "Pollution par transport d'hydrocarbures », observations relatives à l'arrêt de la cour de cassation française du 27 juillet 1987, in DMF, Décembre 1988, n¹2 p.16.

351 La Cour d'appel de Rennes, dans l'arrêt du 3 octobre 1985, l'affaire Amoco Cadiz l'a souligné justement. Dans cette affaire, l'on s'aperçoit que le propre des conventions internationales est d'édicter des règles de conflit ou des règles de fond uniformes. Jamais un accord international n'a eu vocation à prévoir les détails de l'application des règles qu'il instaure. Voir aussi en ce sens DAVID (René), Le droit du commerce international, Paris, Economica, ${ }^{\circ} 151$, septembre 1987, p.137.

352 Sur cette question, voir REMOND-GOUILLOUD (Martine), " Pollution des mers ", Jurisclasseur, volume 7, Fascicule $\mathrm{n}^{\circ} 1292,1995$, p.7. À cet effet, l'auteur propose que conformément à la loi française sur la limitation de la responsabilité des propriétaires de navire, le tribunal compétent devrait nommer un liquidateur pour procéder à toutes les vérifications et à la distribution. 
La déchéance du droit du propriétaire à la limitation financière de la responsabilité va entraîner une lourde conséquence financière, à la charge du propriétaire du navire fautif. Elle ouvre droit à une indemnisation sans possibilité pour le propriétaire de prétendre à une limitation de responsable.

\section{Les effets de la déchéance du droit à la limitation de responsabilité}

Les effets de la déchéance du droit à la limitation financière de responsabilité résultent de l'article V de la Convention CLC 1992. Ceux-ci résident dans ceci que la déchéance entraîne la perte du plafonnement de l'indemnité de l'article $6 ₫ 1$ du protocole 1992 sur la responsabilité. Du fait de la déchéance, le propriétaire sera condamné à payer des indemnités au-delà de ce qu'il avait strictement à payer. C'est-à-dire payer des indemnités supérieures au montant du fonds. La déchéance du droit à la limitation de responsabilité entraîne la perte du droit au plafonnement de l'indemnité (a). En sus, il paraît nécessaire d'envisager des effets complémentaires (b).

\section{a. La perte du droit au plafonnement de l'indemnité}

Conformément à l'article 6 alinéa 2 du Protocole de 1992 à la Convention CLC, le propriétaire n'est pas en droit de limiter sa responsabilité s'il est prouvé que le dommage par pollution résulte de son fait ou de son omission personnelle. En outre, il ressort du même texte que si le propriétaire ne constitue pas un fonds, il ne pourra pas bénéficier de la limitation de responsabilité. Les mêmes conséquences s'attachent également au non respect des prescriptions de l'article 7 alinéa 1 de la Convention CLC ${ }^{353}$.

En effet, selon l'article 6 alinéa 6 du Protocole de 1992 à la Convention CLC sur la responsabilité civile, le fonds de limitation peut être constitué même lorsque, en vertu des dispositions de l'article 6 alinéa 2 de la CLC 69, le propriétaire n'est pas en droit de limiter sa responsabilité. Mais la constitution ne porte pas atteinte dans ce cas, aux droits qu'ont les victimes vis à vis du propriétaire. Il est des effets complémentaires qu'il apparaît nécessaire de suggérer.

\section{b. Les effets complémentaires souhaités}

Indépendamment des mécanismes précités prévus par le système international de réparation des dommages de marées noires, nous voudrions suggérer au titre des effets une institution spécifique, à savoir la "déclaration des valeurs ». Cette déclaration est une technique contractuelle que l'on rencontre dans tous les modes de transport en vertu de laquelle l'expéditeur des marchandises échappe aux limitations de l'indemnité pour perte ou avarie. Le but de la déclaration de valeur est d'élever le plafond de l'indemnité pour dommages matériels au prorata du montant déclaré.

353 Voir en cela René RODIERE, Traité général de Droit maritime, Op.cit., P 662. 
Ramenée à notre matière, cette technique consisterait, de la part de tout État côtier, à recenser toutes les espèces marines notamment la faune et la flore aquatiques qui se trouvent sous sa juridiction, ainsi que les activités économiques à savoir les restaurants, les sites touristiques, les hôtels balnéaires et les infrastructures portuaires. Il procédera, par la suite, à l'évaluation financière ainsi que les chiffres d'affaires par activité économique et les consignera dans un document officiel. Celui-ci devra être mis à jour chaque année et rendu public dans le monde du transport maritime.

En cas de dommages générés par une marée noire, le responsable sera condamné à réparer l'intégralité des dommages causés sans prétendre à une quelconque limitation de responsabilité. ${ }^{354}$ De sorte que si la valeur des biens et ressources naturelles est déclarée, le propriétaire fautif devrait être tenu de verser une indemnisation intégrale pour la réparation de tous les dommages justifiés.

En outre, nous suggérons qu'en plus de la perte du plafonnement, l'indemnité allouée produise intérêt si le réclamant justifie d'un préjudice complémentaire du fait de la déclaration de valeur des biens endommagés ${ }^{355}$. De la sorte, les victimes trouveraient l'occasion d'être indemnisées convenablement par les armateurs dont les charges financières se trouveraient par ricochet, alourdies. Etant donné que ceux-ci, peuvent dans certaines circonstances perdre leur droit à l'exonération de leur responsabilité.

\section{B - La déchéance du droit à l'exonération de responsabilité civile}

La déchéance du droit à l'exonération de la responsabilité du propriétaire du navire est prévue par la convention de 1992 sur la responsabilité civile ${ }^{356}$. L'article 4 alinéa 2 dudit protocole déclare qu'aucune demande de réparation des dommages par pollution ne peut être formée contre le propriétaire autrement que sur la base de la présente Convention à moins que le dommage ne résulte de leurs faits ou de leur omission personnels commis avec l'intention de provoquer un tel dommage ou commis témérairement et avec conscience qu'un tel dommage en résulterait probablement. De même, si le propriétaire est ainsi défaillant, le Fonds ne peut se prévaloir du moyen de défense tiré de l'exonération de sa responsabilité.

A l'analyse de ces textes, l'on peut s'apercevoir sans risque de se tromper qu'il est fait allusion au dol, à la faute lourde et inexcusable non seulement du propriétaire du navire mais également des personnes auxquelles il recourt.

\footnotetext{
354 La reforme du système est donc souhaitée dans ce sens. Dès lors, la responsabilité civile du propriétaire ne pourrait être dégagée que s'il prouve que les dommages ont pour origine la force majeure ou la faute grave de la victime ou du tiers. Tout amalgame doit être évité entre la déclaration de valeur et l'assurance. Le but de la déclaration est d'élever le plafond de l'indemnité. Elle ne modifie pas le principe de la responsabilité. L'assurance au contraire a pour objet de couvrir la responsabilité du débiteur.

355 Au sens de l'article 19 alinéa 3 de l'AUCTMR où l'indemnité allouée est productrice d'intérêts au taux de $5 \%$ l'an à compter du jour de la réclamation par écrit ou à défaut de réclamation, le jour de la demande d'arbitrage ou en justice.

356 Voir les articles 4 et 6 .de la convention de 1992 sur la responsabilité civile.
} 
En ce que, ceux-ci sont des intervenants dans le circuit du transport d'hydrocarbures ${ }^{357}$. A ces causes de la perte du droit à l'exonération de la responsabilité (1), s'attachent des effets à l'encontre du propriétaire du navire (2).

\section{Les causes de la déchéance du droit à l'exonération}

Pour la clarté de notre exposé, il convient de distinguer deux catégories de causes de déchéances. Les unes sont constituées de dol et de la faute lourde (a) et les autres se présentent sous la forme de la faute inexcusable du propriétaire du navire pollueur ou celles des personnes auxquelles il recourt lors de la navigation au cours de laquelle les évènements de pollution par hydrocarbures se sont produits (b).

\section{a. Le dol et la faute lourde}

Par dol, il faut, entendre l'attitude psychologique du délinquant consistant de sa part à avoir voulu commettre l'infraction. Le dol peut être éventuel ou indéterminé. Il y a dol éventuel lorsque l'agent n'a pas voulu le résultat dommageable, tout en ayant prévu la possibilité de sa réalisation.

Le dol est indéterminé lorsque l'agent a agi intentionnellement sans se fixer un résultat bien déterminé ${ }^{358}$. Appliqué à notre analyse, le dol impliquerait un acte commis par le propriétaire avec la volonté de nuire à autrui en causant les dommages par pollution ${ }^{359}$. Ainsi à titre d'exemple, perdrait le droit à l'exonération de sa responsabilité, le pétrolier armateur qui laisserait prendre la mer un navire alors que son équipage est incompétent et mal traité. Ou encore, le défaut d'entretien, de réparation, ou d'assurance du navire ${ }^{360}$.

Le code civil fait allusion au dol du débiteur en termes de manquement intentionnel et délibéré des obligations contractuelles. Indifféremment de la matière délictuelle ou contractuelle, le débiteur ne peut plus invoquer ni la force majeure, ni la faute de la victime ou du tiers pour dégager sa responsabilité.

A la simple lecture des textes susvisés, l'on serait tenté de croire que les termes dol et faute lourde à propos du comportement fautif des exploitants du navire sont

\footnotetext{
357 C'est la circonstance de l'article 4 alinéa 2 où l'on retient la responsabilité des autres acteurs du transport d'hydrocarbures notamment, les préposés du propriétaire, le pilote, tout affréteur. Car en régime général, si l'accident est causé par la faute du capitaine ou de l'équipage, préposés sur lesquels il n'avait aucune emprise, la limitation de la responsabilité du propriétaire joue. Voir en cela, Martine. REMOND- GOUILLOUD, Pollution des mers, Jurisclasseur, fascicule 1292, n¹5, 1995. P.6

358 Définition en matière pénale, tirée du lexique des termes juridiques, Paris, DALLOZ, 14ème édition, 2003, P.219.

359 C'est ainsi que l'article 6 alinéa 2 du protocole de 1992 sur la responsabilité précise que le propriétaire n'est pas en droit de limiter sa responsabilité aux termes de la convention s'il est prouvé que le dommage par pollution résulte de son fait ou de son omission personnelle.

360 A propos de la faute nautique : le dol consisterait donc pour le propriétaire à laisser le navire affronter les périples de la mer alors qu'il est en état d'innavigabilité.
} 
équivalents. Nous pensons qu'à la vérité, la faute lourde doit être distinguée du dol. En effet, au contraire du dol, la faute lourde ne comporte pas l'intention de causer un dommage. La faute lourde réside dans la négligence grossière, l'inaptitude du débiteur à accomplir sa mission acceptée par lui-même au sens de l'affaire Dubosc et Landowski contre Chronopost, cassation chambre mixte, 22 avril $2005^{361}$.

La délicatesse du départ entre le dol et la faute lourde s'est manifestée en jurisprudence en matière de transport maritime de marchandises. Il s'agissait d'une affaire dans laquelle un chargeur avait donné des instructions écrites à un entrepreneur de manutention de charger en cale des camions à destination de la Côte d'Ivoire. Les camions avaient été chargés en ponté: la cour de Caen avait considéré qu'il y avait là une faute lourde de l'entrepreneur de manutention, équivalent à un dol lui faisait perdre le bénéfice de la limitation de responsabilité. La cour de cassation française dans un arrêt du 18 juillet 1984 a censuré la décision de la cour de Caen ${ }^{362}$. En effet, dans un arrêt du 4 juillet 1984, la cour de cassation française a précisé que la faute lourde doit consister en des faits précis qu'il appartient à celui qui l'invoque d'établir ${ }^{363}$. Ainsi, a-t-il été jugé par exemple en matière de transport que consiste en une faute lourde, le fait pour le transporteur de n'avoir pas vérifié la hauteur d'un chargement de dimensions exceptionnelles tant au départ qu'avant de s'engager sous un pont dont la hauteur se révéla insuffisante. Ou encore le fait de n'avoir pas donné à son suivant des instructions correctes sur la destination de la marchandise ou le fait d'avoir abandonné son véhicule en cours de route sans se soucier de la cargaison.

En tout état de cause, il ressort de la convention de 1992 sur la responsabilité civile qu'au dol et à la faute lourde du propriétaire du navire ${ }^{364}$, il faut assimiler ceux des personnes auxquelles il recourt au cours des opérations de transport des hydrocarbures. La faute inexcusable est la deuxième cause d'exonération de responsabilité civile du propriétaire.

\section{b. La faute inexcusable 365}

La référence faite à la faute inexcusable procède de l'expression : «...dommage commis témérairement et avec conscience qu'un tel dommage en résulterait probablement ${ }^{366}$ ». La notion de faute inexcusable est une tradition de tout temps connue en matière de transport maritime. Dans ce sens, la CAA a statué dans l'arrêt nº157 du 14 février 2003, que le transporteur n'ignorait nullement la nature et la valeur de la marchandise transportée, qu'avant l'appareillage et au moment du chargement, il n'y a apporté aucun

\footnotetext{
361 Voir Cass. Com. Ch. Mixte, 22 avril 2005, in JCP, mai 2005, PP 270 et suivants.

362 Voir DMF février 1986, 38ème année Paris 1986 - n²8,p.71. A propos des différentes interprétations des deux termes, voir aussi l'article de De JUGLART (Michel) et CHASSERIAUX (Jean), « Droit maritime, droit aérien », in RTDC 1952, P.185.

363 C. Paris 4 juillet 1984, BT, .1985p.158.

364 Voir l'article 6 de la convention de 1992 sur la responsabilité civile.

365 Voir l'article 3 alinéa 4 in fine de la convention de 1992 sur la responsabilité civile.

366 Voir indifféremment les dispositions des articles 4 in fine et 6 alinéa 2 de la Convention de 1992 sur la responsabilité.
} 
soin particulier. A cet égard, il n'y a pas d'exonération de responsabilité, ni pour l'ensemble, ni par colis.

Le tribunal de commerce de Bordeaux a rappelé dans l'affaire du navire Heidberg, que la limitation de responsabilité de l'armateur demeure un privilège et non un droit. Or ditil, le privilège se mérite, en affirmant que la limitation consacre un privilège auquel ne peut prétendre que l'armateur qui prend en permanence les dispositions imposées par les lois et les usages de la mer. Mesures qui permettent à ces navires de naviguer en assurant à tout moment leur sécurité ou celle des tiers, des personnes ou des biens matériels ${ }^{367}$.

En effet, la faute inexcusable consiste en une faute causée témérairement et avec conscience qu'un dommage en résultera probablement. Ainsi par exemple, le fait pour le capitaine ou le commandant de bord du navire qui, agissant dans l'exercice de ses fonctions décide de prendre la mer selon son bon valoir et ce, indépendamment des règles de la sécurité maritime et autres indications indispensables à la navigation maritime qu'il peut recevoir des aides à la navigation. Comment donc interpréter ou apprécier cet "acte commis témérairement et avec conscience qu'un dommage en résulterait probablement»?

A cette question, le doyen René RODIERE cite deux arrêts en parfait désaccord pour la même affaire. Pour la cour de cassation française, c'est «objectivement », c'est-à-dire par rapport à une personne normalement avisée et prudente qu'il faut apprécier si l'auteur de l'acte ou omission avait eu conscience qu'un dommage en résultera probablement. Pour la cour de cassation de Belgique, celui qui demande réparation intégrale du préjudice souffert doit prouver «la conscience effective que le transporteur ou ses préposés ont eu de la probabilité du dommage et non celle qu'ils auraient normalement dû avoir ". Au vu des positions contraires des deux hautes juridictions, René RODIERE a eu un penchant pour la solution de la cour de cassation de Belgique. Car, dit-il, la «conscience ne s'emprunte pas. Elle est toujours relative à l'intéressé lui-même ${ }^{368} \ldots »$.

Aussi, pertinente parait-elle, cette position du doyen RODIERE nous embarrasse. En ce qu'elle est de nature à mettre en difficulté les victimes de pollution par hydrocarbures.

\footnotetext{
367 Voir en ce sens, TASSEL( Y.), «Le dommage élément de la faute », DMF, 2001, p. 773.-En ce sens, BELLABAS Okba fait observer qu' en matière de pollution marine par hydrocarbures, seul le propriétaire du navire supporte la responsabilité pour charge de pollution afin de faciliter les actions en réparation. Donc les autres intervenants au transport sont exonérés. Mais l'immunité ainsi attribuée à tout affréteur sous quelque appellation que ce soit, armateur ou armateur gérant du navire, n'est pas absolue. Car la faute inexcusable personnelle permet de mettre en jeu la responsabilité de l'armateur. Voir, BELLABAS Okba, «La responsabilité du propriétaire du navire sous la nouvelle loi ${ }^{\circ} 2008$ du $1^{\text {er }}$ août 2008 relative à la responsabilité environnementale». Cet article peut être consulté en ligne sur le site: http: villagejustice.com/article/responsabilité-propriétaire-navire, 4725 html. Site consulté le 11 juin 2009.

368 En cela, il reste en phase avec Jean Jacques Rousseau, pour qui la conscience est le sentiment intime, immédiat, constant de l'activité du "moi » dans chacun des phénomènes de sa vie morale. Voir RODIERE (René), « La faute inexcusable du transporteur aérien », in Recueil Dalloz Sirey, 1978 chronique VII, p 32.
} 
Obligées qu'elles seront de prouver la conscience de l'auteur des dommages par elles subis et non celles qu'il aurait normalement pu avoir ${ }^{369}$. Cette question est d'autant plus délicate que les conventions sur la responsabilité civile ne précisent pas la notion de la faute inexcusable. En cela, nous partageons la conception du professeur Pierre BONASSIS. Pour l'auteur, la faute de l'armateur est une faute contre la navigabilité du navire. Elle couvre des domaines aussi variés que la bonne condition matérielle du navire, ses moyens de propulsion et de direction, son équipement ou son armement ${ }^{370}$. Dans cette même optique, la cour d'appel de Hambourg a posé en principe que le fait de prendre un risque consistant à ne pas prendre en considération un autre risque peut être une faute ${ }^{371}$.

Un autre exemple d'un comportement caractéristique d'une faute inexcusable nous est fourni par une jurisprudence de la cour de cassation française. Il ressort des faits de l'espèce que depuis un aéronef, un officier de la marine nationale française a constaté par procès verbal, dans le sillage du navire Hova Hollandia battant pavillon maltais la présence d'une nappe d'hydrocarbures de $18 \mathrm{~km}$ de long et $200 \mathrm{~m}$ de largeur, qu'il a noté la cessation du rejet après le contact radio avec le capitaine du navire Gennadiy X. Poursuivi pour rejet d'hydrocarbures dans la ZEE ou écologique, le capitaine s'est prévalu du fait justificatif prévu la règle 11. b de l'annexe 1 de la convention de Londres du 2 novembre 1973 ou convention MARPOL, en excipant d'une avarie liée à la corrosion d'une canalisation survenue à l'occasion de la mise en œuvre d'une opération régulière de déballastage du peak avant contenant de l'eau de mer propre.

La cour a jugé que le capitaine s'est borné à interdire physiquement l'usage du ballast $\mathrm{n}^{\circ} 3$ tribord qu'il savait pollué. Qu’il a cependant accepté de faire naviguer le navire sans qu'il puisse utiliser toutes ses capacités de déballastage alors que cette recherche nécessaire qui pouvait se faire auprès du propriétaire ou l'armateur du navire ou en consultant des documents de bord lui aurait appris que cette cause résidait dans la rupture d'une canalisation. Qu'en omettant de procéder à la vérification et contrôle, le capitaine a fait preuve de témérité dans la conduite et la surveillance du bon état de fonctionnement de son navire et a contribué à l'exposer à la survenance d'une nouvelle avarie et avec la conscience qu'un dommage en résulterait probablement $t^{372}$.

Aussi recommanderions-nous d'apprécier la «conscience qu'un dommage en résulterait», objectivement, conformément à la position de la cour de cassation

\footnotetext{
369 Voir en ce sens SABRINA (Robert), L'Erika : responsabilité pour un désastre écologique, op. cit., p. 114.

370 BONASSIES (P.), Le droit maritime classique et la sécurité des espaces maritimes, E.R.S., 1986, P.119.

Voir aussi en ce sens, tribunal de commerce de Bordeaux, 23 septembre 1993, affaire du navire Hedberg, DMF, 1993, P. 706 : le fait pour l'armateur de doter un navire d'un équipage insuffisant en nombre et en qualité, constitue une faute susceptible de le priver du bénéfice de la limitation de la responsabilité.

371 Cour d'appel de Hambourg, 15 septembre 1994, Instance en exequatur du jugement français dans l'affaire du navire Hedberg, DMF, 1995, p.670.

372 Voir Cass. Crim., 4 avril 2006, in Lexinter .net, jurisprudence 2005 à 2009, Pollution marine et preuve.

Voir aussi, FAVAREL- (Verdig), "Responsabilité pénale et civile du capitaine en matière de pollution marine », in http://www. African.org/dossiers-juridiques/resp-poll-Cne.html.
} 
française. C'est à dire par rapport à une personne normalement avisée et prudente. Car à la vérité, l'exploitant du pétrolier transportant des hydrocarbures en vrac en tant que cargaison devrait être tenu de faire la preuve de la prudence et ce, en raison des risques graves que présente l'expédition en mer. Faute de quoi, il devrait s'exposer à la réparation intégrale des dommages causés. Car vouloir prescrire le renversement du fardeau de la preuve à la charge de la victime sera très préjudiciable à celle-ci.

A ce propos, l'affaire de l'Amoco Cadiz est fort instructive sur les difficultés que pourraient rencontrer les victimes au sujet de la preuve de la faute du pollueur qu'il a eu "l'attitude d'une personne qui par négligence, imprudence ou malveillance ne respecte pas (...) son devoir de ne causer aucun dommage à autrui ». En effet, l'État français, une des parties demanderesse au procès intenté devant les tribunaux américains dans l'affaire précitée, n'est parvenu à retenir la responsabilité de la société standard oil que par le recours à la procédure du discovery ayant cours en Droit américain. ${ }^{373}$ Cette procédure a eu pour mérite de révéler l'existence d'un document interne qui établissait qu'au plus haut niveau au sein de la standard oil, la décision avait été prise de reporter certaines mesures d'entretien du gouvernail tant que le navire serait en affrètement auprès de la shell. La révélation de ce comportement a été le tournant du procès. ${ }^{374}$

Il est évident que les victimes de marées noires ne pourront pas toujours accéder à des informations capitales internes à l'entreprise gérante ou propriétaire du navire. A moins que cette entreprise n'accepte, d'elle-même, de fournir aux victimes les documents administratifs, techniques ainsi que toute autre information qui établisse sa négligence ou sa malveillance. En somme, il s'agira d'attendre que le pollueur fournisse à ses victimes les informations qu'elles n'auraient pu se procurer par elles-mêmes. Bien entendu, ces informations capitales permettront aux victimes d'obtenir du juge la condamnation du pollueur à leur verser des dommages et intérêts. Avouons qu'un tel scénario est très improbable. Pour ne pas dire impossible à constituer un moyen que la victime peut facilement invoquer pour obtenir la déchéance du droit à l'exonération de la responsabilité du pollueur. En tout état de cause, la déchéance du droit à l'exonération de responsabilité est de nature à produire des effets favorables aux victimes.

\footnotetext{
373 La procédure du discovery est une procédure d'investigation avant tout examen de l'instance au fond, qui a pour objet de soumettre chaque partie à l'obligation rigoureuse de révéler ses sources d'information, de documentation et de témoignage ...qui ont un rapport avec le litige. Cette procédure se déroule sous le contrôle du juge. Chaque élément probatoire du dossier est examiné de manière contradictoire de même qu'il est fait obligation aux témoins et experts de subir une sorte de contre- interrogatoire systématique («cross examination ") ....cette procédure expose tout plaideur qui refuse de communiquer ou de témoigner à des sanctions sévères pouvant entraîner le rejet de sa demande ou l'approbation pure et simple de la demande émanant de l'adversaire. Voir en cela NDENDE (Martin), l'affaire de l'Amoco Cadiz ...14 ans de bataille juridique, Collection Espaces et Ressources Maritimes, nº 6, Edition PEDONE, janvier 1992, pp. 11-12. À en croire un auteur, « la procédure du discovery américaine s'est révélée d'une redoutable efficacité ».

374 Voir FONTAINE «(Emmanuel), Les sinistres de l'Amoco Cadiz et du Tanio » : comparaison de deux expériences, Communication au colloque du CMI à Gênes du 21 au 27 septembre 1992.
} 


\section{Les effets de la déchéance du droit à l'exonération à l'encontre du propriétaire}

Au niveau des effets, les déchéances du droit à la limitation et à l'exonération de la responsabilité sont équivalentes. Au risque de nous répéter, il convient donc de se référer à notre exposé sur ce qui devrait être les effets des déchéances du droit à la limitation de la responsabilité en termes du relèvement des charges financières du propriétaire du navire.

En tout état de cause, le propriétaire et toues les personnes auxquelles il recourt verront leur responsabilité maintenue (a). Par ailleurs, il apparaît nécessaire de savoir la date concrète de naissance des créances d'indemnités des victimes des marées noires (b).

\section{a. Le maintien de la responsabilité civile du propriétaire}

Le propriétaire du navire encore moins ses préposés ou autre mandataire et toutes personnes auxquelles il recourt, surpris de dol, faute lourde ou inexcusable ne peuvent plus se prévaloir des dispositions de l'article 3 alinéa 2 de la convention 1969 sur la responsabilité civile. Dispositions qui excluent la responsabilité du propriétaire ou qui renverse le fardeau de la preuve pour lesquelles il bénéficierait d'une présomption d'irresponsabilité. Et ce, lorsque d'après les circonstances de fait, les dommages dus à la pollution par le déversement d'hydrocarbures ont pu en résulter.

Pour ce genre de pollutions intentionnelles, la condamnation de leurs auteurs à des dommages et intérêts punitifs doit selon nous annuler les économies qu'ils espéraient réaliser à travers l'analyse coûts-bénéfices de leurs rejets intentionnelles. Dans ce cas, la responsabilité que le propriétaire encourt n'est pas une responsabilité objective au sens des conventions internationales mais une responsabilité de droit commun fondé sur la faute qu'il a commise. La condamnation à des dommages et intérêts "punitifs » ne constitue pas une nouveauté en soi.

En réalité, il s'agit d'une méthode de lutte en vigueur déjà aux États-Unis d'Amérique. La loi de l'Alaska sur la pollution par les hydrocarbures (Trans-Alaska Pipeline Autorisation Act 1973) prévoit que lorsqu'une marée noire a été causée par un acte intentionnel ou par une négligence grave ou encore lorsque le pollueur n'a pas pris des mesures raisonnables pour contenir la nappe, le taux de l'amende forfaitaire peut être multiplié par $5 .{ }^{375}$

Par ailleurs, il faut indiquer à toutes fins utiles que dans toutes les circonstances, au titre des mesures de sauvegarde, le Fonds de limitation n'est pas exonéré dans la mesure où le propriétaire n'a pu l'être aux termes de l'article 3 de la convention CLC 1969.

375 De KLEMM (Cyrille), Les apports du Droit comparé, Actes du colloque organisé les 21 et 22 mars 1991 à la faculté de Droit, d'économie et de gestion de Nice Sophia-Antipolis, Paris, Economica, 1992, p.160. 
A propos des effets des déchéances au titre de la réparation intégrale des dommages causés, il peut se poser la question de savoir à quand naît concrètement la créance des indemnités des victimes de pollution.

\section{b. La date concrète de la naissance de la créance d'indemnité des victimes des marées noires}

La créance d'indemnité naît- elle avec les actes dommageables ou au jour de la décision définitive de condamnation? La solution jurisprudentielle tend à distinguer la créance de réparation et le droit à la réparation ${ }^{376}$.

En effet, selon la jurisprudence, le droit de la victime n'est fixé que par le jugement allouant l'indemnité. Cette solution nous semble défavorable aux victimes de pollution $^{377}$. Aussi sommes- nous d'avis avec le professeur Adrienne Honorat lorsqu'elle affirme que la victime est créancière de la réparation dès l'acte dommageable. Sans nier cependant que le juge va jouer un rôle extrêmement important dans la concrétisation de ce droit de créance ${ }^{378}$. En ce sens que jusqu'au jugement, la victime n'est créancière que d'une manière informe. C'est-à-dire que le juge joue un rôle important non seulement dans l'établissement de la responsabilité de l'armateur propriétaire du navire pollueur, mais également dans la fixation du droit à réparation des victimes des dommages de pollution par hydrocarbures.

\section{CONCLUSION DE LA PREMIERE PARTIE}

La première partie de notre étude met en évidence l'existence des normes internationales régissant le transport maritime des hydrocarbures. Celles-ci découlent d'une part du système de prévention du phénomène des marées noires et d'autre part des instruments curatifs contre ledit phénomène.

Le système de prévention du phénomène des marées noires réglemente la construction des navires et les rejets polluants d'hydrocarbures. Les règles des constructions des navires et des rejets polluants d'hydrocarbures sont élaborées tant au plan universel dans le cadre de l'OMI que sur le plan régional notamment par l'Union européenne et les États-Unis d'Amérique. Le système de prévention des marées noires instaure notamment le principe de la double coque et les installations de réception à terre. Au

\footnotetext{
376 Requête. 18 janvier 1898, Dalloz.1898.1.473 - note Taller, S 1899.1.5, note Lyon Caen, 22 octobre 1901, D.1901.1.527.

377 Il y aurait absorption du droit à réparation par la créance de réparation.

378 A ce titre, selon René Savatier cité par Adrienne Honorat, la créance de réparation existe dès le fait dommageable. Mais tant que le jugement n'est pas intervenu, ce n'est pas encore une créance d'indemnité puisque la réparation peut être conçue sous une autre forme. Voir HONORAT (Adrienne), « la situation des créanciers d'indemnités délictuelles et contractuelles dans la faillite où le règlement judiciaire du débiteur ", in RTDC tome XIV, 1961 n $^{\circ} 3$ P.20.
} 
plan régional américain et européen, l'accent est mis sur la lutte tout azimut contre les navires sous- normes, en termes de leur interdiction.

En ce qui concerne les rejets polluants d'hydrocarbures le droit maritime international a prévu des mesures préventives desdits rejets. A cet effet, il pose le principe de l'interdiction des rejets polluants à travers notamment les Conventions MARPOL 73/78. Par ailleurs, le contrôle de la navigation maritime par la formation des gens de mer et leur condition optimale de travail, est assuré au moyen de la Convention STCW 1978 révisée en 1995 et la Convention de travail maritime de 2006.

Les infractions aux normes préventives susmentionnées sont sanctionnées pénalement.

Les instruments juridiques internationaux à caractère curatif contre les marées noires, comprennent deux modalités. Il s'agit de la lutte opérationnelle contre ledit phénomène et l'adoption des règles dissuasives en matière d'indemnisation des victimes de marées noires. La lutte opérationnelle contre les marées noires est menée au moyen des normes d'intervention définies à l'échelle universelle par les Convention de Montego Bay 1982 et OPRC 1990, ainsi que celles définies notamment à l'échelle régionale africain, européen et états-unienne. En matière de lutte opérationnelle contre les marées noires, les Convention de Montego Bay de 1982 et OPRC reconnaissent aux États côtier et du pavillon des compétences d'intervention contre les pollutions marines par les navires selon des zones maritimes. Les normes internationales notamment à l'échelle régionale africaine, européenne et états-unienne ne sont pas non plus en reste dans la lutte opérationnelle contre les marées noires à travers la promotion des plans d'intervention d'urgence intégrés.

Les règles dissuasives en matière d'indemnisation des victimes de marées noires semblent de plus en plus connaître une évolution favorable aux victimes des dommages de pollution par hydrocarbures. Celle-ci découle de l'apparente adaptation de la responsabilité civile du propriétaire du navire et du contenu de celle-ci. L'adaptation de la responsabilité civile du propriétaire du navire est mise en évidence par la nature de la responsabilité civile, ainsi que le nouveau régime spécial d'indemnisation en droit maritime international et en droit comparé.

Le droit maritime international a élaboré un système en faveur des victimes grâce au système de dispense de la preuve de la faute à travers la responsabilité objective, ainsi que l'élargissement de l'assiette des préjudices indemnisables. Le nouveau régime spécial d'indemnisation en droit maritime international est marqué par les relèvements successifs des montants d'indemnité alloués aux victimes qui ont atteints un niveau d'indemnisation substantielle depuis la Convention complémentaire de 2003 modifiant la Convention FIPOL1992.

Par ailleurs, le contenu de la responsabilité civile du propriétaire du navire pollueur est caractérisé par de nombreuses garanties d'indemnisation des victimes des marées noires et par des déchéances. Il s'agit du principe de la canalisation de responsabilité civile et de 
l'institution d'assurance obligatoire. En outre, les victimes des marées noires profitent énormément de la déchéance du droit à la limitation financière et à l'exonération de la responsabilité civile du propriétaire du navire.

Comme on le voit, il est indéniable que le droit maritime international préventif et curatif existe. En effet, des efforts importants pour protéger, préserver les milieux marins et pour lutter et réparer les dommages de pollution dus aux marées noires sont faits.

Cependant, cet effort manifeste est contrarié par des entraves à l'efficacité du droit maritime international. 



\section{DEUXIÈME PARTIE :}

\section{LE DROIT MARITIME INTERNATIONAL CONTRARIÉ PAR LA PERSISTANCE DES ENTRAVES À SON EFFICACITÉ}



Dans l'ordre international, les États et les organisations intergouvernementales ont élaboré et adopté différents instruments juridiques par lesquels ils entendent combattre efficacement les dangers de la mer. La sécurité de la navigation a d'abord cherché à assurer la sauvegarde de la vie humaine en mer et la défense contre les dangers naturels et navals ${ }^{379}$.

Ces instruments couvrent différents aspects de ce type de pollution. Certains s'assignent pour objectif de prévenir la pollution des mers, d'autres ont pour vocation de ne s'appliquer rationnellement et temporairement qu'après la survenance de la pollution. On est alors en présence de mesures curatives qui ont pour objet l'indemnisation des victimes des marées noires, la réduction ou l'élimination des conséquences néfastes des marées noires ${ }^{380}$.

Au plan interne, la lutte contre les marées noires se fait aux moyens des règles classiques de la responsabilité civile, de la responsabilité pénale et du droit administratif. A ces mécanismes juridiques, il convient d'ajouter les plans d'interventions d'urgence (PIU) qui s'analysent en des mesures de maîtrise, de réduction et d'élimination des nappes de pétrole déversées à la surface de la mer ${ }^{381}$.

Deux grandes étapes ont donc marqué l'élaboration des instruments juridiques de lutte contre les marées noires. L'une est caractérisée par les mesures curatives et l'autre, par les mesures d'ordre préventif.

L'approche curative se perçoit à travers l'adoption de la Convention CLC 1969 et de la Convention FIPOL 1971. Ces deux instruments juridiques - portées sur l'indemnisation des victimes de marées noires - ont été amendés en 1992 au moyen, chacun, d'un protocole. On parle alors de CLC 1992 et FIPOL 1992. La Convention CLC de 1992 sera amendée en 2000 par l'OMI. L'année 2003 verra l'adoption d'une Convention portant création d'un fonds complémentaire au FIPOL 1992.

Les mesures préventives sont prévues principalement par la Convention internationale sur la prévention de la pollution par les navires ou Convention MARPOL 73/78 ${ }^{382}$ et, à un degré moindre, par la Convention de Montego Bay de 1982. Elles énoncent des règles juridiques qui sont sensées contribuer à accroître l'efficacité de la lutte contre les marées noires. À l'analyse le droit maritime international présente des entraves à son efficacité.

\footnotetext{
379 La première convention internationale, l'amorce d'un droit maritime plus humaniste, adoptée dans le domaine de la sécurité maritime est la Convention internationale pour la sauvegarde de la vie en mer, ou Convention SOLAS, adoptée lors d'une conférence tenue à Londres en 1914 à la suite du naufrage du Titanic. Voir aussi en ce sens GARIN (Christian), "Le soutage », in Centre de droit maritime et des transports, Institut Méditerranéen des transports maritimes, Le transport des produits pétroliers par mer, Colloque de Marseille, 9 décembre 1999, Aix- en-Provence, 1999, pp.30-50.

380 TIEBLEY (Yves Didier), La Côte d'Ivoire et la gestion durable des ressources naturelles marines, op.cit, p.96.

381 Ibidem.

382 Cette Convention a abrogé la Convention OILPOL 1954 relative à la prévention de la pollution des mers par les hydrocarbures.
} 
Celles-ci résultent des insuffisances du mécanisme juridique international de lutte contre les marées noires, d'une part (Titre 1) et de l'inadaptation des règles d'indemnisation ou de responsabilité des dommages causés par les marées noires, d'autre part (Titre 2). 
TITRE 1 :

\section{LES INSUFFISANCES DU MÉCANISME JURIDIQUE INTERNATIONAL DE LUTTE CONTRE LES MARÉES NOIRES}

En dépit des mesures prises pour prévenir les pollutions par les hydrocarbures, le développement considérable des pratiques industrielles modernes impose la nécessité d'engager une action de grande envergure. L'Assemblée de l'OMI décida en 1969 d'organiser une conférence internationale en vue d'adopter une nouvelle convention. La conférence s'achèvera par la signature de l'un des traités internationaux les plus ambitieux dans le domaine de la pollution des mers à Londres le 2 novembre 1973, appelé convention MARPOL ${ }^{383}$. Dans le cadre de notre étude, seul l'Annexe 1 focalisera notre attention ${ }^{384}$.

Par ailleurs, reconnaissant la gravité des événements récents des pollutions des mers par les hydrocarbures, l'OMI a adopté la Convention internationale de 1990 sur la préparation, la lutte et la coopération en matière de pollution par les hydrocarbures. L'analyse de ces Conventions internationale laisse entrevoir deux sortes de limites. Les unes tiennent au plan international aux normes de lutte préventive et opérationnelle contre les marées noires (Chapitre). Celles-ci sont accentuées au plan strict du droit ivoirien, au titre de l'application des instruments juridiques internationaux consacrés à la lutte contre les marées noires auxquels adhère la Côte d'Ivoire (Chapitre II).

\footnotetext{
${ }^{383}$ La Convention MARPOL est entrée en vigueur le 2 octobre 1983. Soit 10 ans après son adoption en raison notamment de ses caractères très contraignants pour les armateurs comme pour les États d'immatriculation des navires. Assez rapidement la Convention sera complétée par le protocole du 17 février 1978 entrée en vigueur le 2 octobre 1983 et elle ne formera qu'un seul et unique instrument : convention 73/78. Voir, OICNM, Rapport de mission du consultant spécial au Zä̈re, nº9, Londres, 8 juin 1979, P. 100.

384 Elle comprend cinq Annexes qui énoncent les règles relatives à la prévention des diverses formes de pollution. C'est l'Annexe I de cette Convention qui est exclusivement consacrée aux hydrocarbures. Conformément à l'article 3, la Convention ne s'applique pas qu'aux navires battant le pavillon d'une partie ou exploités sous son autorité. Elle ne porte pas atteinte aux droits souverains des parties sur le fonds des mers et le sous-sol marin. Elle exclut les navires de guerre et les navires appartenant à un État utilisés à des fins non commerciales.
} 



\section{CHAPITRE 1: LES LIMITES DES NORMES INTERNATIONALES DE LUTTE PRÉVENTIVE ET OPÉRATIONNELLE RELATIVES AUX MARÉES NOIRES}

Le droit maritime international spécifique à la prévention, à la limitation et à la lutte opérationnelle contre les pollutions marines pétrolière est constitué respectivement de deux Conventions à savoir la Conventions MARPOL 73/78 et la Convention OPRC 1990. Les Conventions ci-dessus indiquées présentent des limites. En ce sens que l'amélioration quelle entendait apporter est inachevée tant en ce qui concerne les règles préventives (Section 1) que des règles de lutte opérationnelle contre les marées noires (Section 2).

\section{Section 1: Le caractère inachevé des règles préventives élaborées dans le cadre de l'OMI}

Les conventions internationales consacrées à la sécurité des navires sont nombreuses. La plupart d'entre elles ont été conclues à l'initiative de l'OMCI (actuelle OMI). Il s'agit notamment de la Convention internationale sur les lignes de charge du 5 avril 1966 ; la Convention internationale pour la prévention de la pollution par les navires du 2 novembre 1973 telle que modifiée par le protocole du 17 février 1978 (Convention MARPOL 73/78) ; la Convention internationale pour la sauvegarde de la vie humaine en mer du 1er novembre 1974 telle que modifiée (Convention SOLAS) ; la Convention des Nations unies sur le Droit de la mer (CNUDM) ou Convention de Montego Bay (CMB) adoptée le 10 décembre1982. Cette dernière convention constitue le droit commun de la mer. Il serait fastidieux d'analyser toutes les dispositions pertinentes de chacune des conventions précitées. Nous nous contenterons de nous appesantir sur celles contenues dans la Convention MARPOL 73/78.

L'analyse de l'Annexe I de la Convention MARPOL 73/78 laisse entrevoir que les apports des règles de prévention, en termes de la sécurité relative à la navigation maritime sont inachevés. En effet, ce caractère inachevé des avancées desdites règles procède du domaine d'application limité de la Convention (Paragraphe 1) mais aussi dans l'application laxiste des mesures préventives des pollutions marines, des difficultés découlent du phénomène des pavillons de complaisance (Paragraphe 2).

\section{Paragraphe 1: Le domaine d'application limité de la Convention MARPOL 73/78}

Il ressort de l'analyse de l'article 3 de la convention MARPOL que le champ d'application de celle-ci est limité. Cette observation est rendue plausible tant qu'en ce qui concerne les navires visés (A) que par les obligations qui pèsent sur les armateurs. Cependant les avancées constatées restent à améliorer (B). 


\section{A - Les navires visés par la Convention MARPOL et leurs obligations}

La Convention MARPOL s'applique à une catégorie déterminée de navires (1). Ceux-ci sont tout aussi tenus de respecter certaines obligations pendant la navigation (2).

\section{Les navires visés par l'Annexe I à la Convention MARPOL}

Les navires visés par l'Annexe I à la Convention MARPOL sont répartis en trois catégories, à savoir les pétroliers de la catégorie 1 (pré-MARPOL), les pétroliers de la catégorie 2 (MARPOL) et ceux de la catégorie 3, une catégorie résiduelle.

Les pétroliers de la catégorie 1 (pré-MARPOL) sont ceux qui vont de 20000 tpl et audelà et qui transportent du pétrole brut, du fuel lourd, du bitume. Sont également compris dans cette catégorie, les pétroliers de 30000 tpl et au-delà qui transportent les autres produits pétroliers. La particularité des navires pré-MARPOL est qu'ils ne sont pas dotés de ballasts séparés.

La catégorie 2 (navires MARPOL) est constituée de navires du même tonnage et transportant les mêmes produits mais qui sont dotés de ballasts séparés.

La catégorie 3 est une catégorie résiduelle dans laquelle on range les navires pétroliers dotés ou non de ballasts séparés mais dont le tonnage est compris entre 5000 tpl et les tonnages minimaux des catégories 1 et 2 .

À l'instar de la Convention OILPOL 1954, la Convention MARPOL exclut les navires de guerre et les navires exploités à des fins non commerciales appartenant à un État. Cette restriction à l'égard de cette catégorie de navires répond visiblement au souci de ménager la souveraineté des États. Il n'empêche qu'au regard de leurs incidences (pollutions) sur le milieu marin, cette dérogation est regrettable. Cette institution, compréhensible à une certaine époque de l'évolution des relations internationales, ne saurait, à notre avis, être valablement invoquée de nos jours. La protection des mers devrait, selon notre perception, conduire les États parties à la Convention MARPOL $73 / 78$ à consentir à l'allègement de cette restriction.

Par ailleurs, de nombreuses dispositions s'appliquent à un certain type de navire avec un tonnage déterminé. En effet, les navires non pétroliers qui transportent plus de $200 \mathrm{~m}^{3}$ d'hydrocarbures en vrac sont traités comme des pétroliers par certaines règles avec un régime particulier en dessous de $1000 \mathrm{~m}^{3}$. Par contre, certaines dispositions exemptent les aéroglisseurs et autres types de navires à condition d'offrir une protection équivalente contre la pollution.

Les transporteurs maritimes sont ténus de connaître le danger d'atteinte à l'environnement que peut présenter leurs engins en mer, mais aussi il leur est défendu des rejets des hydrocarbures dans des zones spéciales en fonction de la nature du 
navire ${ }^{385}$. En effet, la connaissance du danger d'atteinte à l'environnement que peut présenter un navire est plus difficile s'il se trouve en mer que s'il est au port ${ }^{386}$.

Il pèse sur les navires visés des obligations spécifiques qu’exige la sécurité maritime.

\section{Les obligations incombant aux navires lors de la navigation}

Lorsque le navire est en mer, l'Annexe I de la Convention MARPOL 73/78 lui fait obligation d'informer les autorités compétentes en cas de danger. Selon l'article 8 de la Convention précitée, le capitaine de tout navire doit envoyer des rapports sur les évènements entraînant ou pouvant entraîner le rejet de substances nuisibles à l'État côtier le plus proche lors de la survenance de certains évènements pouvant se traduire par une atteinte à l'environnement.

La prescription de la convention est capitale. Nous savons qu'en France, le capitaine du navire transportant des hydrocarbures est tenu dès l'entrée dans les eaux territoriales françaises, d'adresser au préfet maritime, un message indiquant la date et l'heure d'entrée dans les eaux, sa position, la route et la vitesse du navire, la nature du chargement $^{387}$. C'est le lieu d'encourager de telle législation nationale et surtout d'instituer les préfets maritimes dans les États maritimes africains. Car en la matière, la Convention MARPOL s'en remet à la législation nationale de chaque État. Si le navire est au port, la connaissance des dangers pour le milieu marin résulte des différentes visites obligatoires effectuées à bord par les autorités compétentes. Ces visites ont pour objectif de parvenir à la sécurité du navire et de prévenir la pollution marine.

En droit ivoirien, la police de la sécurité du navire est constituée par une diversité de textes juridiques. Ces textes relèvent soit du droit interne ivoirien soit $\mathrm{du}$ droit international.

Ainsi que le relève pertinemment un auteur, le Code de la marine marchande ivoirien occupe une place de choix. En effet, ce code, en son article 9, subordonne la navigation dans les eaux maritimes sous souveraineté ou juridiction ivoirienne à l'obtention des titres de sécurité suivants :

- permis de navigation pour tous les navires ;

- certificat de franc-bord ou certificat d'exemption ;

- le certificat de sécurité pour les navires à passager ;

- le certificat de sécurité pour le matériel d’armement ;

\footnotetext{
385 Le rejet désigne tout déversement provenant d'un navire quelle qu'en soit la cause. Il ne concerne pas l'immersion, les déversements qui résultent directement de l'exploration et du traitement connexe des ressources minérales du fonds de la mer, les déversements effectués à des fins scientifiques.

386 BECET (Jean-Marie) et Le MORVAN (Didier), Droit du littéral et de la mer côtière, Paris, Economica, 1991, p188.

387 Conformément au décret français $n^{\circ} 78-421$ du 24 mars 1978 relatif à la lutte contre la pollution marine accidentelle.
} 
- le certificat de sécurité radio ${ }^{388}$.

Cette énumération est visiblement loin d'être exhaustive dans la mesure où elle n'inclut pas, entre autres, le certificat international d'hydrocarbures prévu par l'article VII de la Convention CLC. Ce certificat est très important ; il donne aux autorités portuaires et maritimes tous les renseignements sur le chargement, l'état, l'entretien et le nettoyage des soutes et citernes des navires de transport des hydrocarbures ${ }^{389}$.

Les avancées relevées peuvent être, tout de même, améliorées.

\section{B - Des avancées susceptibles d'amélioration}

Il est souhaitable que soient adoptées des normes techniques particulières en fonction de chaque type de navire. Ces derniers devront absolument conserver à leur bord un registre d'hydrocarbures. Ainsi, en cas d'évènement de pollution à partir de son navire, le capitaine accomplirait aisément et sans retard les formalités appropriées vis-à-vis de l'État côtier par les voies de communications les plus appropriées.

En outre, les difficultés qu'éprouvent les pays en développement pour appliquer la Convention MARPOL méritent qu'on y prête une attention plus soutenue ${ }^{390}$. En effet, les ressources limitées de ces pays n'exposent-ils pas les navires battant leur pavillon au risque d'être déclarés indésirables dans les eaux maritimes des États développés?

Si l'on n'y prend garde, peu seront les pays en développement - disposant encore d'une flotte maritime - dont les navires pourront accéder aux ports ou aux terminaux des États industrialisés. À défaut de règles exonératoires, on pourrait, tout au moins, suggérer avec C.A. Walder et J.C.S. Horrocks qu'une assistance technique et financière bilatérale ou multilatérale (dans le cadre de l'OMI) soit fournie à tous les pays intéressés ${ }^{391}$.

Dans le même ordre d'idée, il convient de souligner l'importance que revêtent la formation d'équipage, la formation du personnel chargé des inspections, le recrutement du personnel qualifié et des experts nécessaires pour assumer les tâches administratives et de contrôle de la mise en œuvre de la Convention MARPOL. Il est aussi recommandé la coopération régionale ou sous-régionale pour prévenir et limiter les risques de pollution des mers. Car la lutte contre la pollution du milieu marin revêt

\footnotetext{
388 Cf. TIEBLEY (Yves Didier), La Côte d'Ivoire et la gestion durable des ressources naturelles marines, op. cit, p.148.

389 Ibidem.

390 Voir dans ce sens, le point de vue de H. Agate paru dans «Dispositions prises à l'échelon national par un pays en développement, le cas du Nigeria ", in OMI, Rapport du colloque sur la prévention de la pollution des mers par les navires, Acapulco (Mexique), 22-31 mars, 1976, p.19.

391 WALDER (C. A.) et HORROCKS (J.C.S), «Point de vue de milieux maritimes et pétroliers sur la convention MARPOL ", in OMI, Rapport du colloque sur la prévention de la pollution des mers par les navires, Acapulco (Mexique), 22-31 mars 1976, nº16 à 18, p.14.
} 
indéniablement une importance vitale pour toutes les nations quel que soit leur stade de développement.

En raison du nombre croissant des pavillons de complaisance, des navires sous-normes et de la négligence de nombre d'États parties ou non à se conformer aux règles internationales, la politique de sécurité maritime ne devrait plus reposer uniquement sur les seules initiatives de l'OMI. Il convient donc d'impliquer, outre les acteurs nationaux ou internationaux de droit public, certaines ONG écologistes telles que Greenpeace ${ }^{392}$.

Les mesures préventives de pollutions marines font l'objet d'une application laxiste particulièrement de la part des États du pavillon.

\section{Paragraphe 2: L'application laxiste des mesures préventives de pollutions marines}

Le laxisme observé par certains États à flotte marchande importante se traduit par les difficultés croissantes que pose le phénomène des pavillons de complaisance (A). Quant à la Convention MARPOL 73/78, elle assortit le principe d'interdiction des rejets polluants d'hydrocarbures de nombreuses exonérations d'infractions (B).

\section{A - Les difficultés découlant du phénomène des pavillons de complaisance ${ }^{393}$}

Les difficultés envisagées découlent de l'incapacité des Etats du pavillon à appliquer les normes préventives (1), ainsi, la Convention de Montego Bay essaie de combler cette lacune en attribuant, en la matière, un rôle palliatif à l'État du port (2).

\section{L'incapacité de certains Etats du pavillon à appliquer les normes préventives}

L'accentuation du phénomène des pavillons de complaisance résulte de l'incapacité ou, à défaut, de la répugnance de certains États de pavillon ${ }^{394}$ à appliquer les normes préventives en vigueur.

\footnotetext{
392 Greenpeace est une ONG canadienne fondée en 1969. Son objectif était de lutter contre les essais nucléaires. Ensuite, elle s'intéressera à l'ensemble des problèmes environnementaux. Voir SPAETER (Sandrine), "Les firmes face à leur responsabilité environnementale », in Problèmes économiques, mercredi 24 novembre $2004, \mathrm{n}^{\circ} 2863$, p.58.

${ }^{393}$ L'OCDE a dégagé six traits dominants du pavillon de complaisance. Le pavillon de complaisance est arboré par la poupe de navire possédé ou contrôlé par les non résidents, l'accès au registre d'immatriculation est très facile, l'imposition est peu élevée, le pays d'immatriculation a une faible puissance économique, il est possible d'employer un équipage de non ressortissants et enfin, l'État ne dispose pas de moyens suffisants pour exercer son contrôle sur les navires afin de faire respecter les exigences des conventions internationales.

Selon Robert SABRINA, le phénomène de pavillon de complaisance n'est pas près d'être endigué du fait de la démission de certains États face à leur obligation préventive de protection de l'environnement marin. Ainsi, en 1998, 46\% des navires et 62\% du tonnage des 35 plus importants États marins naviguaient sous pavillon de complaisance. Voir SABRINA (Robert), "L’Erika: Responsabilité pour un désastre écologique ", op. cit, pp.166-168.
} 
On assiste de plus en plus à la création de compagnies de navigation dotées d'un seul navire. Il s'agit, en réalité, de sociétés écrans par lesquelles des sociétés plus importantes organisent d'avance leur insolvabilité lorsque leur navire viendrait à être à la base d'importants dommages par pollution ${ }^{395}$.

Dans l'affaire de l'Erika, la commission d'enquête du bureau des enquêtes et des analyses constate que le propriétaire réel est resté inconnu. Quant à son propriétaire inscrit sur le registre d'immatriculation, TEVERE Shipping, il n'a jamais eu de contact avec la société de classification qui, pourtant, est censée effectuer des contrôles pour son compte. La commission révèle que la gestion du navire était compartimentée et éclatée en différentes sociétés. Dès lors, la sécurité du navire se perd dans une nébuleuse de responsabilité confuse.

Toujours dans l'affaire de l'Erika, la commission chargée d'établir un rapport technique sur les conditions du naufrage était dans l'impossibilité d'affirmer avec certitude le rôle exact de chaque intervenant. Selon ledit rapport, la propriété réelle de l'Erika différait de la propriété sur le titre du navire. Sur le registre d'immatriculation, c'est la société maltaise, Tevere shipping qui est le propriétaire l'Erika, et qui engage sa responsabilité au titre de la convention de 1992. À la vérité, c'est une "coquille vide » selon le rapport de la commission d'enquête du bureau d'enquête et d'analyse (B.E.A.). La société ne possédait en fait qu'un seul navire et pour seule surface financière le montant de l'assurance sur le navire. Le seul but de ce montage était d'obscurcir la réalité patrimoniale et de se préserver de toute responsabilité.

Le Professeur Jean-Pierre Beurrier explique que ces pratiques sont d'usage très courant dans le monde maritime. Le droit maritime international a voulu simplifier la tâche des victimes en canalisant les recours intentés par celles-ci sur le propriétaire du navire. Ce dernier, en réponse, organise son patrimoine pour le soustraire à toute mesure de saisie ${ }^{396}$.

A cet égard il paraît nécessaire de noter le rôle palliatif de l’Etat du port.

\footnotetext{
394 Particulièrement des États Panlibhonco (Panama, Liberia, Honduras, Costa Rica) auprès desquels est immatriculée l'écrasante majorité des navires de commerce actuellement en activité.

395 L'organisation de leur insolvabilité par certaines compagnies maritimes a été abordée par FAURE (Michael) et WANG Hui, "The international Regimes for the Compensation of oil Pollution Damage », op., cit., p.24.

396 BEURIER (Jean-Pierre), Propos recueillis par le journal Ouest-France du 12 décembre 2000, in SABRINA (Robert), l'Erika, op. cit., P.29. Il faut en cela saluer la décision du tribunal correctionnel de Paris en date du 16 janvier 2008. Le juge français a entre autres innovations, donné une conception large des responsables au contraire du régime international de responsabilité.
} 


\section{Le rôle palliatif de l'État du port}

La compétence de l'Etat du port consiste à règlementer la circulation maritime et d'interdire la navigation maritime.

La règlementation de la circulation maritime

Les compétences de l'État du port en matière de lutte contre la pollution marine sont prévues par l'art.218 $\$ 1$ de la $\mathrm{CMB}^{397}$.

Ainsi que le note le professeur Boisson de Chazournes, l'État du port est l'hôte de transit des navires étrangers qui s'y trouvent volontairement ${ }^{398}$. Le terme de "volontairement " est primordial dans l'application de la disposition. Ainsi, lorsqu'un navire se trouve volontairement dans le port ou l'installation terminale d'un État et que des éléments de preuves le justifient, l'État a la faculté d'intenter une action pour les rejets effectués audelà de ses eaux intérieures, sa mer territoriale ou de sa zone économique exclusive par le navire en question. Il y a donc un droit de l'État du port d'agir en haute mer, ce qui est tout à fait nouveau. En effet, c'est la première fois qu'un État est garant d'intérêts communs comme celui-ci ${ }^{399}$.

Les compétences exercées, en la matière, par l'État du port consistent en un pouvoir d'inspection et, le cas échéant, d'immobilisation du navire suspecté de pollution. Ainsi, la compétence de l'État du port permettrait un contrôle plus efficace en matière de sécurité ou d'environnement car il suppose une meilleure coopération entre les navires et les autorités ${ }^{400}$. Cette procédure de contrôle devrait théoriquement pallier les insuffisances voire le laxisme des États du pavillon. Cependant, des écueils à l'efficacité du rôle palliatif de l'État du port demeurent.

Différentes raisons viennent éclaircir ce problème d'effectivité. Tout d'abord l'État du pavillon reste le seul compétent pour délivrer les certificats de navigabilité. En outre, chaque État organise librement le contrôle à effectuer sur les navires sous-normes. Il peut de ce fait choisir d'affecter un plus ou moins grand nombre d'inspecteurs pour

\footnotetext{
397 L'art.218 \$ 1 de la CMB dispose: "lorsqu'un navire se trouve volontairement dans un port ou à une installation terminale au large, l'État $d u$ port peut ouvrir une enquête et, lorsque les éléments de preuve le justifient, intenter une action pour tout rejet effectué au-delà de ses eaux intérieures, de sa mer territoriale ou de sa Zone économique exclusive par le navire en infraction aux règles et normes internationales applicables établies par l'intermédiaire de l'organisation internationale compétente ou d'une conférence diplomatique générale».

398 BOISSON DE CHAZOURNES (Laurence), La protection de l'environnement marin dans le cadre de la Convention des Nations Unies sur le droit de la mer, Séminaire de Droit international public, Année 1999-2000, Université de Genève, Faculté de Droit, p.15.

Article publié en ligne sur : www.jurawelt.com/sunrise/media/mediafiles/14149/protectionmer.pdf. Consulté le 19 mai 2011.

399 Idem, p.16.

400 LEFEVRE (Hélène) et COURDE (Pierre-Antoine), «La sécurité maritime et la protection de l'environnement : quelles contradictions ?», p.13. Article en ligne sur www.droit.univ-nantes.fr/labos/cdmo/centre-droit-maritimeoceanique/cdmo/neptunus/nept/nep30/nep30_3.pdf. Texte consulté le 19 mai 2011.
} 
assurer cette tâche. Dans ces conditions les navires à risque continuent nécessairement à circuler ${ }^{401}$.

Par Ailleurs, la Convention MARPOL souffre de nombreuses exonérations d'infractions.

\section{B - $\quad$ Les nombreuses exonérations d'infractions à la Convention MARPOL 73/78}

A l'analyse, la Convention MARPOL 73/78 est assortie de nombreux aménagements(1) et des exceptions(2).

\section{Les aménagements au principe d'interdiction}

Les aménagements sont prévus par la Règle 9 de la Convention. Sous certaines conditions, les pétroliers peuvent procéder à des rejets.

Au regard de l'ampleur des aménagements accordés aux navires pétroliers et autres navires, nous nous interrogeons sur la consistance du principe de l'interdiction. En d'autres termes, les dérogations n'ont-elles pas vidé le principe de sa substance? Le principe n'est-il pas, au contraire, la possibilité de procéder à des rejets ? Et l'interdiction de tels rejets, l'exception ${ }^{402}$ ?

Nos interrogations s'expliquent par le fait que la lutte contre les pollutions du milieu marin par les hydrocarbures doit être exempte de toute complaisance à l'égard des pollueurs. Or, les dérogations telles que prévues par les Règles analysées ci-dessus, à notre avis, contribuent à annihiler les effets bénéfiques attendus de l'application rigoureuse des mesures de lutte préventive. Même si les aménagements sont assortis de conditions, de quels moyens disposent les pays en développement pour prouver, par exemple, que le navire pollueur a effectué un dégazage illicite à moins de 50 milles de ses côtes? Ou que la quantité totale d'hydrocarbures rejetée est inférieure à 1/15.000 de sa dernière cargaison?

Notre réserve s'appuie, entre autres, sur le volume autorisé des rejets que peuvent effectuer les navires sous l'empire de la Règle $9 \$ 1$ a $v$ ). Selon cette Règle, les pétroliers sont autorisés à rejeter $1 / 15.000$ (pétroliers existants) ou $1 / 30.000$ (pétroliers neufs) de leur cargaison totale à la mer. On se rendra compte qu'un pétrolier de 630.000 tonnes dont 540.000 tonnes de pétrole (cargaison) ${ }^{403}$ pourra procéder à un dégazage opérationnel licite de 36 tonnes (pétrolier ancien) ou de 18 tonnes (pétrolier neuf) ${ }^{404}$.

\footnotetext{
401 Ibidem.

402 Cf. TIEBLEY (Yves Didier), Réflexions sur les instruments et techniques juridiques de lutte contre les pollutions marines dues à l'exploitation off-shore et au transport maritime des hydrocarbures, Mémoire, DEA en droit et politique de l'environnement, Université de Lomé, Faculté de Droit, 11 juin 2004, p.45.

403 Déjà dans les années 1976 et 1977, la revue Notre monde faisait état d'un pétrolier de $414 \mathrm{~m}$ de long, $63 \mathrm{~m}$ de large, $72 \mathrm{~m}$ de haut, un pont de près de trois hectares ...630.000 $\mathrm{t}$ dont $540.000 \mathrm{t}$ de pétrole. Elle faisait aussi
} 
Lorsqu'on sait qu'une (1) tonne de pétrole s'étale sur $12 \mathrm{~km}^{2}$ à la surface de la mer ${ }^{405}$, on se rend compte que c'est une surface comprise entre 216 et $432 \mathrm{~km}^{2}$ qui est polluée après le dégazage opérationnel licite effectué par un seul pétrolier. Ce phénomène est, à l'heure actuelle, amplifié par le volume énorme d'hydrocarbures transporté annuellement par les pétroliers et autres navires utilisés pour le transport de produits pétroliers $^{406}$ et par les rejets illicites auxquels se livrent les navires, toutes catégories confondues. Il en résulte qu'une surface importante des océans et mers du globe terrestre est en permanence souillée par les hydrocarbures avec toutes les perturbations de l'écosystème marin que cela comporte.

Hormis les aménagements au principe d'interdiction, la Règle 11 de l'Annexe I à la Convention MARPOL 73/78 instaure des exceptions.

\section{Les exceptions prévues par la Règle 11 de l'Annexe I à la Convention MARPOL $73 / 78$}

La Règle 11 (Exceptions) traite des cas où, exceptionnellement, la cargaison d'hydrocarbures peut être massivement déversée dans le milieu marin. Au regard de cette Règle, tout navire est autorisé à rejeter à la mer sa cargaison d'hydrocarbures lorsque cela est nécessaire pour assurer sa propre sécurité ou celle d'un autre navire, ou sauver des vies humaines en mer (Règle 11 alinéa $a$ ).

Il convient de souligner que la Règle 11 ne détermine ni le volume maximum ni les caractéristiques physiques d'hydrocarbures qu'un navire est autorisé à rejeter en mer en cas de force majeure. Cette dérogation au principe d'interdiction s'observe également en cas d'avarie, survenue au navire ou à son équipement sous certaines conditions (Règle 11 alinéa $b)^{407}$. En outre, la dérogation au principe d'interdiction est admise lorsque la

\footnotetext{
état de ce que le Japon envisageait la construction de pétroliers de 1.200 .000 t. Cf. Notre monde, Le pétrole, EDICEF/NEA, 1977, p.24.

404 Cf. TIEBLEY (Yves Didier), Réflexions sur les instruments et techniques juridiques de lutte contre les pollutions marines dues à l'exploitation off-shore et au transport maritime des hydrocarbures, op.cit, p.45.

405 RAMADE (François), Dictionnaire encyclopédique de l'écologie et des sciences de l'environnement, $2^{\text {ème }}$ édition, Paris, DUNOD, 2002, p.602.

406 Le trafic maritime à l'échelle mondiale peut se résumer par quelques chiffres clés. Les hydrocarbures transportés par voie maritime représentent un chiffre annuel compris entre 1.200 et 1.500 millions de tonnes pour le pétrole brut et entre 200 et 350 millions de tonnes pour les produits raffinés (essences, fuels domestiques, fuels lourds, bitume), transport assuré par une flotte d'environ 6.500 navires. Cf. MARCHAND (Michel), Les pollutions marines accidentelles. Au-delà du pétrole brut, les produits chimiques et autres déversements en mer, IFREMER, Centre de Nantes, Département Polluants Chimiques, p.2. (notre pagination).

407 Selon la Règle 11 alinéa $b$, de tels rejets sont possibles :

i) à condition que toutes les précautions raisonnables aient été prises après l'avarie ou la découverte du rejet pour empêcher ou réduire ce rejet, et

ii) sauf si le propriétaire ou le capitaine a agi soit avec l'intention de provoquer un dommage, soit témérairement et avec conscience qu'un dommage en résulterait probablement.
} 
cargaison d'hydrocarbures est rejetée en mer en vue de circonscrire l'ampleur d'une marée noire. C'est d'ailleurs ce qui ressort de la Règle 11 alinéa $c$ ) qui dispose :

"les Règles 9 et 10 ne s'appliquent pas ... au rejet à la mer de substances contenant des hydrocarbures ...ces substances sont utilisées pour lutter contre un cas particulier de pollution afin de réduire les dommages dus à cette pollution. Le gouvernement compétent pour autoriser de tels rejets est celui qui exerce sa juridiction sur l'espace marin prévu pour recevoir les substances polluantes $»$.

Cette hypothèse, à notre avis, pourrait se vérifier lorsque la lutte contre la marée noire s'effectue notamment au moyen de la technique du brûlage $\mathrm{e}^{408}$.

Les insuffisances du mécanisme juridique de lutte contre les marées noires s'observent également au niveau de la lutte opérationnelle contre ce type de pollution.

\section{Section 2: Les insuffisances constatées en matière de lutte opérationnelle contre les marées noires}

En dépit des efforts consentis pour assurer la sécurité maritime, il se produit néanmoins des accidents qui provoquent des pollutions. Celles-ci ont des conséquences socioéconomiques et écologiques graves pour le milieu marin ${ }^{409}$. Dès lors, une intervention contre lesdites pollutions s'imposent. Mais il ressort de l'analyse des insuffisances au niveau des Conventions pertinentes .Dans le cadre de notre étude, nous nous intéresserons particulièrement aux insuffisances des instruments internationaux de lutte opérationnelles contre les marées noires : cas de la Convention OPRC 1990 (Paragraphe 1) et celles ressortant des normes définies dans le cadre régional africain (Paragraphe 2).

\section{Paragraphe 1: Les insuffisances des instruments internationaux de lutte opérationnelles contre les marées noires : cas de la Convention OPRC 1990}

Les difficultés ressortent notamment de la mise en œuvre de la Convention OPRC 1990 (A) dont les explications apparaissent peu convainquantes (B).

\footnotetext{
408 La pratique observée en matière de nettoyage de nappes de pétrole permet de déceler les techniques du confinement, de la succion, de l'écrémage, de l'absorption, de la gélification, de la précipitation, de l'émulsion et du brûlage. Cf. FOUCHER (B.J), Techniques de contrôle et de lutte contre les pollutions par les hydrocarbures dans le Golfe de Guinée, Communication au symposium international sur ZEE, Abidjan, 18-23 mai 1987, doc. multigr., Annexe 2, p.55. Cité par KAMTO (Maurice), Droit de l'environnement en Afrique, Vanves, EDICEF/AUPELF, 1996, p.280.

409 Voir dans ce sens SRITASTAVA (S.P.), Stratégie pour la protection du milieu marin, juillet 1988, p.28.
} 


\section{A - $\quad$ Les difficultés de mise en œuvre de la Convention OPRC 1990}

Le droit maritime international reconnaît aux États côtiers des pouvoirs d'intervention sur les navires en difficulté et présentant des risques pour l'environnement marin en haute mer. A l'analyse, il apparaît une inadéquation entre la volonté affichée par certains acteurs dans la lutte contre les marées noires et leurs actes.

En effet, les Conventions internationales ${ }^{411}$ pertinentes admettent l'intervention des États côtiers pour lutter contre les pollutions marines ${ }^{412}$. Le droit d'intervention perçu comme attentatoire à la liberté de navigation ne peut être utilisé que dans des cas strictement définis. ${ }^{413}$

Par ailleurs, avant le déclenchement des opérations d'intervention, l'État côtier doit, sauf en cas d'urgence qui appelle des mesures immédiates, consulter les autres États mis en cause par l'accident et en particulier celui du pavillon conformément aux articles $4^{414} \mathrm{et}$

410 Voir à titre d'illustration l'article 5 (Mesures à prendre à la réception d'un rapport de pollution par les hydrocarbures) de la Convention OPRC 1990.

411 Ces pouvoirs d'intervention des autorités maritimes de l'État côtier trouvent désormais leur fondement dans la Convention OPRC 1990 en remplacement de la Convention de Bruxelles du 29 novembre 1969 sur l'intervention en haute mer et son protocole d'amendement du 2 novembre 1973 adoptée au lendemain de la catastrophe de Torrey Canyon.

412 Les États contractants peuvent prendre en haute mer toutes les mesures nécessaires pour prévenir, atténuer, éliminer les dangers graves et imminents que présente pour leurs côtes ou intérêts connexes, une pollution ou une menace de pollution des eaux de mer par les hydrocarbures, à la suite d'un accident susceptible selon toute vraisemblance d'avoir des conséquences dommageables très importantes.

413 L'article 110 de la convention sur le droit de la mer cite la piraterie, le transport d'esclaves, la diffusion d'émissions non autorisées, navire sans nationalité, refus d'arborer de pavillon.

414 Aux termes de l'article 4 de la Convention OPRC chaque Partie:

a) exige que les capitaines ou autres personnes ayant la charge de navires battant son pavillon ainsi que les personnes ayant la charge d'unités au large relevant de sa juridiction signalent sans retard tout événement survenu à bord de leur navire ou de leur unité au large qui entraîne ou risque d'entraîner un rejet d'hydrocarbures:

i) dans le cas d'un navire, à l'État côtier le plus proche;

ii) dans le cas d'une unité au large, à l'État côtier à la juridiction duquel est soumise l'unité;

b) exige que les capitaines ou autres personnes ayant la charge de navires battant son pavillon ainsi que les personnes ayant la charge d'unités au large relevant de sa juridiction signalent sans retard tout événement observé en mer qui entraîne un rejet d'hydrocarbures ou toute présence d'hydrocarbures:

i) dans le cas d'un navire, à l'État côtier le plus proche;

ii) dans le cas d'une unité au large, à l'État côtier à la juridiction duquel est soumise l'unité;

c) exige que les personnes ayant la charge de ports maritimes et d'installations de manutention d'hydrocarbures relevant de sa juridiction signalent sans retard à l'autorité nationale compétente tout événement qui entraîne ou risque d'entraîner un rejet d'hydrocarbures ou toute présence d'hydrocarbures;

d) donne à ses navires ou aéronefs chargés de l'inspection des mers et à ses autres services ou agents compétents des instructions les invitant à signaler sans retard à l'autorité nationale compétente ou, selon le cas, à l'État côtier le plus proche, tout événement observé en mer, dans un port maritime ou dans une installation de manutention d'hydrocarbures, qui entraîne un rejet d'hydrocarbures ou toute présence d'hydrocarbures;

e) prie les pilotes d'aéronefs civils de signaler sans retard à l'État côtier le plus proche tout événement observé en mer qui entraîne un rejet d'hydrocarbures ou toute présence d'hydrocarbures.

2) Les rapports visés à l'al. 1 a) i) sont faits conformément aux prescriptions élaborées par l'Organisation et sont fondés sur les directives et principes généraux adoptés par l'Organisation. Les rapports visés aux al. 1) a) 
$5^{415}$ de la Convention OPRC, intitulés respectivement "procédure de notification en cas de pollution par les hydrocarbures » et « Mesures à prendre à la réception d'un rapport de pollution par les hydrocarbures ".

En outre, il est tenu de notifier les mesures qu'il envisage prendre aux personnes physiques et morales qui sont connues de lui ou qui lui ont été signalées aux cours des consultations comme ayant des intérêts qui pourraient être compromis ou affectés par ces measures.

L'intervention contre les événements de pollution par les hydrocarbures telle que prévue la Convention OPRC de 1990 revêt donc un caractère lourd. En effet, lorsqu'une partie reçoit un rapport de l'événement qui risque d'entraîner un rejet d'hydrocarbures, elle doit d'abord évaluer la situation, la nature, l'importance et les conséquences éventuelles de l'événement de pollution par les hydrocarbures. Ensuite elle doit aviser sans retard tous les États dont les intérêts sont concernés par cet événement de pollution par les hydrocarbures ou sont susceptibles de l'être, en leur communiquant les détails de ses évaluations et de toute action entreprise ou prévue pour faire face à l'événement et d'autres informations appropriées ${ }^{416}$.

Si une obligation de préservation de l'environnement marin pèse sur l'État du pavillon déjà défaillant, pourquoi donc conditionner l'intervention de l'État sinistré ? Cette interrogation trouve une certaine explication peu convaincante.

ii), b), c) et d) sont faits conformément aux directives et aux principes généraux adoptés par l'Organisation dans la mesure applicable.

415 Conformement à l'article 5 de la Convention lorsqu'une Partie reçoit un rapport visé à l'art. 4 ou des informations sur une pollution fournies par d'autres sources:

a) elle évalue la situation pour déterminer s'il s'agit d'un événement de pollution par les hydrocarbures;

b) elle évalue la nature, l'importance et les conséquences éventuelles de l'événement de pollution par les hydrocarbures; et

c) elle avise ensuite sans retard tous les États dont les intérêts sont concernés par cet événement de pollution par les hydrocarbures ou sont susceptibles de l'être en leur communiquant en même temps:

i) les détails de ses évaluations et de toute action entreprise ou prévue pour faire face à l'événement, et

ii) d'autres informations appropriées, jusqu'à la conclusion de l'action entreprise pour faire face à l'événement ou jusqu'à ce que les États en question aient décidé d'une action commune.

2) Lorsque la gravité de cet événement de pollution par les hydrocarbures le justifie, cette Partie devrait fournir à l'Organisation les informations visées aux al. 1 b) et c), soit directement, soit par l'intermédiaire de l'organisation ou des arrangements régionaux appropriés.

3) Lorsque la gravité de cet événement de pollution par les hydrocarbures le justifie, les autres États touchés par cet événement sont instamment priés d'informer l'Organisation, soit directement, soit par l'intermédiaire des organisations ou arrangements régionaux appropriés, de leur évaluation de l'importance de la menace pour leurs intérêts et de toute action entreprise ou prévue.

4) Les Parties devraient, dans la mesure du possible, utiliser le système d'établissement de rapports de pollution par les hydrocarbures élaboré par l'Organisation, lorsqu'elles échangent des renseignements et communiquent avec d'autres États et avec l'Organisation.

${ }^{416}$ Tel que disposent les articles 4 et 5 de la convention OPRC de 1990. 


\section{B - $\quad$ Tentative d'explication peu convaincante des difficultés constatées}

Sans doute les formalités d'avant l'intervention de l'État sinistré peuvent trouver une explication. En effet, pendant longtemps, le navire a été considéré comme une partie flottante du territoire de l'État du pavillon ${ }^{417}$.

Il y a cependant une question que la Convention OPRC n'a pu élucider : l'État côtier intervenant est-il lié par les avis des personnes consultées? Répondant à une question similaire en 1979, M. Jacquier le consultant spécial de l'Organisation intergouvernementale consultative de la navigation maritime, disait « qu'il y a obligation pour l'État de consulter, mais non de suivre les avis des personnes consultées ${ }^{418}$.

Nous partageons cet avis. Car qu'adviendrait-il si les avis étaient divergents? Cela pourrait paralyser l'intervention.

En outre, nous estimons que tout accident de navire en termes de naufrage ou d'abordage est suffisamment grave pour justifier des mesures immédiates. Les prérogatives reconnues aux États du port par le droit de la mer ne sont-elles pas le reflet de la défaillance de l'État du pavillon dans ses pouvoirs de contrôle et de surveillance sur les navires qui portent son pavillon ? $^{419}$

À cette interrogation, Robert Sabrina répond par l'affirmative. Selon l'auteur, les pouvoirs qui ont été progressivement accordés à l'État côtier se justifient par le fait que l'État du pavillon se montre parfois défectueux dans l'accomplissement de sa mission ${ }^{420}$.

À propos de l'affaire Olympic Bravery, Langavant et Beurier ont mis en évidence comment, en dehors des moyens techniques employés, le succès des opérations de lutte contre les pollutions accidentelles par hydrocarbures impose à l'État, une intervention rapide. Selon le rapport de mer du commandant du navire précité, la compagnie néerlandaise de sauvetage est intervenue, mais à la demande tardive de l'administration française n'a pu avoir d'action efficace. Ce qui a entraîné la pollution du rivage marin par les hydrocarbures du fait du pompage tardif du contenu des soutes.

\footnotetext{
417 Selon la Cour permanente de justice internationale, la conséquence du principe de la liberté de la haute mer est que le navire en haute mer est assimilé au territoire de l'État dont il porte le pavillon. Ainsi, comme sur son territoire, cet État y fait valoir son autorité, et aucun autre État ne peut y exercer la sienne. Voir en cela, C.P.J.I., 7 septembre 1927, Affaire LOTUS (France c. Turquie), Recueil, série A. nº10, p. 25 .

À ce sujet, la Convention des Nations Unies sur le droit de la mer dispose que les navires possèdent la nationalité de l'État dont ils sont autorisés à battre le pavillon. La Convention précise par ailleurs qu'un navire n'est pas autorisé à battre pavillon de plusieurs États. Ainsi, les Professeurs RODIÊRE et Du PONTAVICE font remarquer qu'un navire a forcément une nationalité. S'il n'en avait pas, il serait considéré comme un navire pirate.

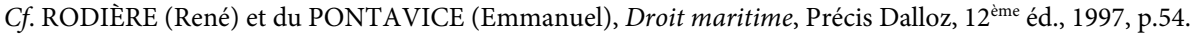

${ }^{418}$ Voir OMCI, Rapport de mission du consultant spécial au Zaïre, du 23 au 27 avril 1979, p.32.

419 Voir en cela notamment, les articles 94, 192, 235 de la Convention des Nations Unies sur le droit de la mer et l'article 21 de la Déclaration de Stockholm.

${ }^{420}$ SABRINA (Robert), «L'Erika : Responsabilité pour un désastre écologique », op. cit., pp.168-172.
} 
Pour éviter une telle pollution, une action vigoureuse antérieure de l'État côtier victime des dommages s'impose, comme l'avait fait le gouvernement anglais en bombardant l'épave disloquée du Torrey Canyon sur les rochers en $1967^{421}$.

Les normes préventives de lutte contre les marées noires sont également définies dans le cadre régional africain, particulièrement dans la zone WACAF. Ces normes présentent, elles aussi, des insuffisances.

\section{Paragraphe 2: Les insuffisances des instruments de lutte opérationnelle contre les marées noires définis dans le cadre régional africain: cas des zones WACAF et l'UEMOA}

La Convention d'Abidjan du 23 mars 1981 et son Protocole, d'une part, et la Directive de l'UEMOA de 2008, d'autre part, constituent les instruments par lesquels les États de la région organisent la lutte opérationnelle contre les marées noires. Les lacunes de ces différents instruments juridiques s'observent à la lueur de la quasi-absence de plans d'intervention d'urgence (A) et la non-clarification de l'épineuse question des coûts d'intervention en cas de lutte opérationnelle contre les marées noires (B).

\section{A - La quasi-absence de plans d'intervention d'urgence (PIU)}

Cette quasi-absence est le produit de la lenteur des États à adopter des PIU nationaux (1) et le peu d'empressement des États à coopérer en vue d'établir des PIU intégrés (2).

\section{La lenteur des États en matière d'adoption des PIU nationaux}

En dépit des dispositions pertinentes de la Convention d'Abidjan et de son Protocole ainsi que de la Directive de l'UEMOA de 2008, les États parties tardent à se doter des moyens d'assistance technique, de recherche et de surveillance que nécessite la mise en œuvre d'un plan d'intervention d'urgence en cas de situation critique pour le milieu marin.

Concernant la zone WACAF, le professeur Maurice Kamto notait d'ailleurs que plus d'une décennie après l'adoption de la Convention d'Abidjan et de son Protocole, très peu de parties contractantes avaient adopté des PIU au niveau national ${ }^{422}$. La situation est loin de s'être améliorée à l'heure actuelle.

Or, force est de reconnaître que les PIU nationaux constituent la pierre angulaire de la lutte opérationnelle contre les marées noires. Ainsi que le souligne Monsieur Yves

${ }^{421}$ Voir LANGAVANT (Emmanuel) et BEURIER (Jean Pierre), in DMF 1976, nº 333, PP. 517- 518.

422 À l'horizon 1995, le Congo et la Côte d'Ivoire étaient les seules parties contractantes à avoir adopté des PIU nationaux. Voir à ce sujet KAMTO (Maurice), Droit de l'environnement en Afrique, Vanves, Edicef/Aupelf, 1996, p.279. 
Didier TIEBLEY, les conventions internationales qui traitent de la question du transport maritime reconnaissent à l'État côtier la compétence pour prendre toutes mesures utiles pour lutter contre ces genres de pollution dans les eaux sous sa juridiction ${ }^{423}$. Cette habilitation se fonde notamment sur la compétence territoriale (mer territoriale) et sur les droits souverains (ressources biologiques, ressources minérales de la ZEE et du plateau continental) de l'État côtier. Le PIU apparaît de ce fait comme le prolongement dans l'espace maritime approprié, des plans nationaux de lutte contre les catastrophes ${ }^{424}$. Les PIU nationaux permettent de définir d'avance les rôles des intervenants dans la lutte matérielle contre les marées noires.

Au plan régional africain, il est regrettable que les Etats tardent à assoire une vraie politique de plans d'intervention d'urgence intégrés.

\section{L'absence de PIU intégrés}

Les PIU intégrés viennent en complément aux plans d'urgence nationaux. Leur rôle est indispensable dans le cadre de la zone WACAF en considération des ressources limitées des États concernés pris individuellement. Les plans d'urgence intégrés permettent, en effet, de réaliser des économies d'échelle en termes de ressources humaines, matérielles et financières ${ }^{425}$.

Le constat est qu'à l'heure actuelle, de tels plans n'existent pas encore. Et pourtant, la côte de l'Afrique de l'ouest et du centre est le théâtre de rejets accidentels ou volontaires répétés d'hydrocarbures ${ }^{426}$.

Cette attitude des parties contractantes contraste fortement avec le préambule de la Convention d'Abidjan du 23 mars 1981 dans lequel elles se disent: conscientes de la valeur que le milieu marin et les zones côtières de la région de l'Afrique de l'ouest et $d u$ centre présentent du point de vue économique et social et du point de vue de la santé. Ainsi que du devoir qui leur incombe de préserver leur patrimoine naturel dans l'intérêt des générations présentes et futures ».

Or, le développement croissant de l'exploitation pétrolière offshore dans le golfe de Guinée aura pour corollaire l'accroissement du nombre de navires pétroliers. Il est

\footnotetext{
423 La Convention de Montego Bay (article $221 \S 1$ ), la Convention sur la préparation, la lutte et la coopération en matière de pollution par les hydrocarbures (article $6 \$ 1$ ), la Convention internationale du 29 novembre 1969 portant sur l'intervention en haute mer (articles I et VII), la Convention d'Abidjan du 23 mars 1981 (articles 5 et 8) et son Protocole (article 9).

424 TIEBLEY (Yves Didier), Réflexions sur les instruments et techniques juridiques de lutte contre les pollutions marines dues à l'exploitation off-shore et au transport maritime des hydrocarbures, Mémoire, DEA en Droit et Politique de l'environnement, Université de Lomé, Faculté de Droit, 11 juin 2004, pp.33-34.

425 TIEBLEY (Yves Didier), Réflexions sur les instruments et techniques juridiques de lutte contre les pollutions marines dues à l'exploitation off-shore et au transport maritime des hydrocarbures, op.cit, p.34

426 L'auteur rapporte plusieurs faits de pollutions accidentelles ou volontaires par les hydrocarbures dans son ouvrage précité à la page 259 .
} 
indéniable que les pétroliers d'anciennes générations, aux coûts d'exploitation très avantageux, recueilleront la faveur des affréteurs opérant dans la zone. Il n'est pas du tout exagéré d'affirmer que la zone WACAF constitue un lieu privilégié pour les navires sous-normes. Cette situation a d'ailleurs été soulignée par O. B. Oluwole, secrétaire général du Mémorandum d'Abuja, qui affirmait : "La sous région de l'Afrique du Centre et de l'Ouest est un havre sûr fréquenté par les boîtes rouillées et de vieux navires " ${ }^{427}$.

Au regard de l'urgence de la situation, il est clair que les États de la zone WACAF et ceux de la zone communautaire UEMOA devraient s'activer pour rendre opérationnelles les dispositions pertinentes du Protocole à la Convention d'Abidjan du 23 mars $1981^{428}$, ainsi que l'esprit de la Directive de l'UEMOA de 2008 relative à la recherche et au sauvetage en mer et à la protection de l'environnement marin au sein de l'UEMOA ${ }^{429}$.

Hormis cette absence de coopération interétatique réelle, les textes juridiques précités n'organisent pas clairement le financement des opérations conjointes de lutte en cas de situation critique.

\section{B - L'absence de clarification de l'épineuse question des coûts d'intervention en cas de lutte opérationnelle contre les marées noires}

La non-clarification de la question du remboursement des frais engagés par un État en cas d'assistance sollicitée par un autre constitue le talon d'Achille de la coopération interétatique en matière de plans d'intervention d'urgence.

Au niveau du remboursement des frais d'assistance sollicités par un État à un autre en cas de situation critique, cette question devrait être clarifiée au plus vite.

Le premier avantage réside dans le fait que l'État sollicité qui met ses moyens à la disposition du sollicitant sera beaucoup plus motivé à le faire dans le cas où le Protocole viendrait à imputer le coût des opérations de lutte dans le chef du sollicitant.

\footnotetext{
${ }^{427}$ Ces propos sont tirés de l'allocution de Monsieur B. O. OLUWOLE, Secrétaire général du Mémorandum d'Abuja, prononcée lors de la réunion du $26^{\text {ème }}$ Conseil Annuel de l'Association de Gestion des Ports de l'Afrique de l'Ouest et du Centre (AGPAOC). Cette rencontre s'est tenue en Angola du 20 au 25 janvier 2003. Cf. ZINSOU (Amour Christian), «Le Mémorandum d'entente (MOU) d'Abuja et sa mise en œuvre au Congo ", in Neptunus, Centre de Droit Maritime et Océanique, Université de Nantes, Vol. 15, n¹, 2009, p.2. Cet article peut également être consulté en ligne sur le site http://www.cdmo.univ-nantes.fr/centre-droitmaritimeoceanique/cdmo.

428 Voir les articles 3 et 5 de la Convention relative à la coopération en matière de protection et de mise en valeur du milieu marin et des zones côtières de l'Afrique de l'Ouest et du Centre de 1981 ou convention d'Abidjan.

${ }^{429}$ Aux termes de l'article 10 de la Directive, "l'Union veille à mettre en place et à prendre en charge le plan POLMAR communautaire ». Mais ce dispositif sous régional reste encore au stade de l'imagination, car l'article 10 alinéa 2 indique que le plan POLMAR est activé par le dispositif sous régional pour assister tout État membre concerné.
} 
Le second avantage de la précision réside dans la dissipation des malentendus éventuels qui pourraient naître entre l'État sollicitant et l'État sollicité au sujet du financement de certaines dépenses liées aux opérations de lutte.

Au plan purement national ivoirien, les instruments de lutte contre les pollutions marines recèlent des incohérences non négligeables. 



\section{CHAPITRE 2: LES INCOHERENCES RELEVEES AU NIVEAU DES INSTRUMENTS DE LUTTE CONTRE LES MAREES NOIRES EN DROIT IVOIRIEN}

La dégradation de la qualité des eaux marines ivoiriennes est accentuée par les insuffisances du mécanisme juridique de lutte contre les pollutions pélagiques dont s'est dotée la République de Côte d'Ivoire. Les incohérences dont il est question sont décelables d'une part au niveau des mesures opérationnelles de réduction des conséquences néfastes des pollutions marines à savoir le plan POLLUMAR - (Section1) et d'autre part, au niveau des mesures répressives (Section 2 ).

\section{Section 1: Les incohérences décelées au niveau du plan POLLUMAR ivoirien}

Le plan POLLUMAR ivoirien est institué par le décret nº98-42 du 28 janvier 1998 relatif à l'organisation du plan d'intervention d'urgence contre les pollutions accidentelles en mer, en lagune et dans les zones côtières.

L'examen des moyens disponibles en vue d'appliquer les dispositions pertinentes dudit décret permet de souligner le caractère limité des ressources dont dispose le CIAPOL. Il apparaît donc nécessaire d'impliquer l'action des opérateurs privés dans la lutte contre les pollutions des eaux ivoiriennes. A vrai dire, la mission assignée au CIAPOL dans le cadre du Plan POLLUMAR ${ }^{430}$ est ambitieuse (Paragraphe1). Malheureusement, la réalisation satisfaisante du Plan POLLUMAR ivoirien est entravée par le caractère limité des moyens alloués au CIAPOL (Paragraphe 2).

\section{Paragraphe 1: La mission ambitieuse du CIAPOL}

Le caractère ambitieux de la mission du CIAPOL transparaît de sa compétence d'attribution du CIAPOL d'une part (A) et de sa compétence territoriale d'autre part (B).

\section{A - Une compétence d'attribution étendue}

Le décret n $91-662$ du 9 octobre $1991^{431}$, en son article 4, détermine les missions du CIAPOL. Celles-ci couvrent une multitude et une diversité de matières. A propos de la compétence d'attribution ou ratione materiæ, nous pouvons noter avec Monsieur TIEBLEY Yves Didier qu'il est possible de relever deux catégories de missions qui

\footnotetext{
430 Le Plan POLLUMAR, est la dénomination du plan d'intervention d'urgence (PIU) ivoirien. La mise en oeuvre de ce plan incombe au CIAPOL.

431 Décret $\mathrm{n}^{\circ} 91-662$ du 9 octobre 1991 portant création d'un établissement public administratif à caractère administratif (EPA) dénommé « Centre ivoirien antipollution » (CIAPOL) et déterminant ses attributions, son organisation et son fonctionnement. Le CIAPOL, comme l'indique l'intitulé qui le crée, est un établissement public à caractère administratif en vertu de l'article premier du décret précité.
} 
ressortissent de la compétence de cet établissement public à caractère administratif ${ }^{432}$. La première catégorie est de nature scientifique et recouvre cinq (5) matières volumineuses. En effet, au titre des missions du CIAPOL, le décret $n^{\circ} 91-662$ du 9 octobre 1991 prévoit en son article 4 que le CIAPOL a pour mission :

- l'analyse systématique des eaux naturelles (marines, lagunaires, fluviales, souterraines) des déchets (solides, liquides et gazeux) et des résidus, l'évaluation des pollutions et nuisances ...

- La surveillance continue du milieu marin et lagunaire ainsi, que des zones côtières par des patrouilles régulières

- La lutte contre les pollutions de ces milieux ...

- La mise en œuvre du plan d'intervention d'urgence contre les pollutions accidentelles en mer, en lagunes ou dans les zones côtières, dénommé «plan POLLUMAR».

L'article 4 dudit décret portant organisation du plan POLLUMAR, à propos de la préparation de la lutte contre les pollutions des eaux, déclare que le ministre chargé de l'environnement est responsable de la coordination des actions de prévention et de lutte contre la pollution des milieux récepteurs marins et lagunaires. Il est chargé d'informer toute personne participant au plan POLLUMAR sur les questions de pollution par les hydrocarbures et autres substances nocives.

A cet effet, il réunit une documentation aussi complète que possible concernant notamment les produits polluants et leurs effets, les matériels et dispositifs techniques et juridiques de prévention et de lutte contre les pollutions ${ }^{433}$.

La réalisation de cette première catégorie de missions est confiée au Laboratoire central de l'environnement (LCE). La seconde catégorie d'actions comprend quatre (4) matières majeures et revêt un caractère opérationnel. Elle vise à prévenir la pollution du milieu aquatique et, le cas échéant, à résorber de manière drastique les conséquences néfastes de la pollution aquatique survenue. Cette catégorie comprend également les pouvoirs de police conférés au CIAPOL en vue de faire respecter les normes juridiques nationales, régionales ou internationales relatives à la protection des milieux aquatiques en général, et du milieu marin en particulier.

La Compagnie d'Intervention contre les Pollutions du Milieu marin et lagunaire (CIPOMAR) est la sous-direction chargée de réaliser la deuxième catégorie de missions. Le nombre total des matières dévolues au CIAPOL et l'ampleur de celles-ci font de ce

\footnotetext{
432 Voir TIEBLEY (Yves Didier), Thèse précitée, p.281

433 Pour la réalisation de ses missions le CIAPOL comprend trois sous directions à savoir : le Laboratoire Central de l'Environnement (LCE), la Compagnie d'Intervention Contre les Pollutions du Milieu Marin et Lagunaire (CIPOMAR) chargée entre autre de la mise en œuvre du plan POLLUMAR et la Sous Direction des Affaires administratives et financières. En cela, la législation ivoirienne en la matière implique les moyens des structures privées dans la lutte contre les pollutions accidentelles des eaux ivoiriennes appelée "plan d'entreprise" prévu aux articles 7,8 et 11 du décret de janvier 1998 portant organisation du plan POLLUMAR.
} 
dernier une structure étatique sous la tutelle de plusieurs ministères ${ }^{434}$. Le CIAPOL se présente dès lors comme une structure chargée de coordonner les actions étatiques et infra-étatiques de lutte contre la pollution des milieux aquatiques de la Côte d'Ivoire.

En Côte d'Ivoire, le décret du 28 janvier 1998 portant organisation du Plan d'urgence de lutte contre les pollutions accidentelles en mer, en lagune et dans les zones côtières prévoit des mesures exorbitantes dans le cadre de la lutte et la maîtrise des déversements d'hydrocarbures. En effet, le ministre chargé de l'environnement est habilité à prendre toutes les dispositions utiles en vue d'assurer l'efficacité des interventions notamment par le recours au droit de réquisition. Il met en demeure le propriétaire, l'affréteur, le commandant, l'armateur ou le gérant du navire ou de l'aéronef de prendre des mesures nécessaires pour y mettre fin. Il informe le ministre des transports. Si les mises en demeure restent sans effet, ou n'ont produit les résultats escomptés dans le délai imparti, et en cas d'urgence, le ministre chargé de l'environnement prend les mesures nécessaires pour prévenir, atténuer ou éliminer les risques de pollution. Les frais occasionnés par cette intervention seront à la charge du responsable de cette pollution ${ }^{435}$.

A cet effet, les titres de la navigation pour la prévention de la pollution sont essentiellement ceux déterminés par la convention MARPOL 73/78. ${ }^{436}$ Celle-ci prévoit en effet, que tout pétrolier d'une jauge brute égale ou supérieure à 150 tonneaux, ainsi que tout autre navire d'une jauge brute égale ou supérieure à 400 tonneaux, est soumis à une visite initiale, avant sa mise en service ou avant que le certificat ne lui soit délivré pour la première fois, à des visites périodiques, à une visite intermédiaire au minimum pendant la période de validité du certificat ${ }^{437}$. Un certificat international de prévention de la pollution par les hydrocarbures est délivré à tout pétrolier, après visite effectuée conformément aux dispositions de la Règle IV. Ce certificat est délivré soit par l'autorité soit par un agent ou un organisme dûment autorisé par elle ${ }^{438}$.

A cet effet, la loi ivoirienne portant institution d'un code de la marine marchande dispose que sont astreints à la possession d'un titre de navigation maritime, les navires et les engins pratiquant la navigation maritime de commerce, de pêche ou de plaisance. En outre, tout navire ainsi que tout engin flottant effectuant une navigation maritime

\footnotetext{
${ }^{434}$ Il s'agit, entre autres, les ministères en charge respectivement de la recherche scientifique et de l'environnement pour la première catégorie de mesures ; les ministères de l'environnement, de l'industrie ainsi que celui du transport qui assure la tutelle de la police maritime. Le contenu de l'article 6 du décret du 9 octobre 1991 traitant de la Commission Consultative de Gestion achève de nous convaincre des compétences transversales du CIAPOL. En vertu de cette disposition, la Commission Consultative de Gestion comprend le ministre intéressé ou son représentant. Ainsi y sont représentés : le ministre de l'environnement, le ministre de la défense ; le ministre de la recherche scientifique ; le ministre de l'industrie ; le ministre de l'agriculture ; le ministre de la santé et le ministre du transport ; soit 8 ministres ou leurs représentants.

${ }^{435}$ Voir les articles 11, 12 alinéa 1 et 13 du décret de 1998 portant organisation du plan POLLUMAR.

${ }_{436}$ Dans ce cas d'espèce, il s'agit du certificat international de prévention de la pollution par les hydrocarbures. Sa validité est de 5 ans et ne peut être renouvelé qu'après une nouvelle inspection. En France par exemple, le bureau Veritas est l'autorité compétente pour mener ces visites.

${ }_{437}$ Voir Règle IV de l'Annexe I de la convention MARPOL 73/78.

${ }_{438}$ Voir les Règles V, VI, VII et VIII de l'Annexe I de la convention MARPOL73/78, à propos de la délivrance des certificats, forme et durée de validité.
} 
soit par ses propres moyens soit à la remorque d'un autre navire doit être munis des titres de sécuritét ${ }^{439}$. Par ailleurs la même loi précitée en son article 13, exige qu'avant de quitter un port ivoirien, tout navire est soumis à une visite de partance. De même tous les navires étrangers touchant un port ivoirien sont soumis aux obligations liées à la sécurité maritime ${ }^{440}$. Ainsi, la convention afin de prévenir au maximum tout risque de pollution, prescrit des visites obligatoires par des experts agrées ainsi qu'un système de certificat délivré aux navires après chaque visite de vérification. Le principe repose sur l'obligation pour l'État partie d'inspecter les navires battant son pavillon. Ce qui permet de contraindre le navire à posséder un certificat international prouvant qu'il a été visité par le représentant d'une autorité compétente et qu'il est conforme aux normes de prévention de la pollution.

L'étendue des missions incombant au CIAPOL se perçoit également au regard de son champ d'action spatiale ou de sa compétence ratione loci.

\section{B - Une compétence territoriale très étendue}

La question se poserait de savoir, jusqu'où peut aller la compétence du CIAPOL ivoirien sur le territoire ivoirien? A cette question Monsieur TIEBLEY Yves Didier nous en esquisse une réponse. Pour se faire, il se fonde sur les dispositions du décret portant création d'un établissement public à caractère administratif dénommé CIAPOL ${ }^{441}$. En effet, l'analyse des dispositions pertinentes du décret n91-622 du 9 octobre 1991précité permet d'affirmer que les missions de nature scientifique confiées au CIAPOL s'étendent à l'ensemble du territoire national. A cet effet, l'article 4 alinéa 1 précise que les missions du CIAPOL consistent, entre autres, en "l'analyse systématique des eaux naturelles (marines, fluviales, souterraines et météoriques) ...».

Il est vrai que les eaux marines et lagunaires se retrouvent seulement dans la zone côtière $\mathrm{du}$ pays. Les eaux fluviales, en revanche, ne se retrouvent pas seulement dans la zone côtière mais traversent plutôt le territoire national du nord au sud. De même, le décret précité ne restreint pas les eaux météoriques devant faire l'objet d'analyses par le CIAPOL à celles prélevées dans la zone côtière. En outre, l'article $4 \$ 5$ du décret $n^{\circ} 91$ -

\footnotetext{
439 Voir les articles 8 et 9 de la loi de novembre 1961 portant institution du code de la marine marchande.

440 Par sécurité maritime, il faut entendre selon l'article $10 \mathrm{du}$ code de la marine marchande ivoirien, l'ensemble des moyens matériels qui donnent au navire: coque, appareils propulseurs, apparaux divers, instruments et documents nautiques ;

-La possibilité d'effectuer normalement et sans danger, dans les parages autorisés, la mission à laquelle il est destiné dans les conditions prévisibles d'exploitation;

-L'ensemble des moyens de lutte contre l'incendie et les voies d'eaux ;

-Le bon état du matériel de sauvetage collectif et individuel pour l'équipage et les passagers ainsi que les mesures en cas d'alarme et d'évacuation du navire ;

-L'arrimage satisfaisant des marchandises et la stabilité du navire ; l'observation des règles de franc bord et de la réglementation concernant les marchandises dangereuse ;

- Les dispositions relatives à l'hygiène et à l'habitabilité, au matériel médical et pharmaceutique.

441 TIEBLEY Yves Didier, Thèse précitée, p.282
} 
622 du 9 octobre 1991 ne limite pas les données environnementales et les résultats du Réseau national d'Observation devant être diffusées par le CIAPOL à celles prélevées dans la zone côtière.

Il est donc évident que les missions scientifiques du CIAPOL couvrent tout le territoire ivoirien. En revanche, les missions de nature opérationnelle sont spatialement circonscrites, en vertu de l'article 4 alinéas 6 à 8, aux milieux marins et lagunaires ainsi qu'aux zones côtières. Même dans cette approche minimaliste, le champ d'intervention spatiale du CIAPOL s'étend sur un espace marin de $12.223,2 \mathrm{~km} 2^{442}$. À cet espace, il convient d'ajouter les aires des milieux lagunaires et des zones côtières relevant de sa compétence territoriale. Il apparaît en définitive que le champ d'intervention matérielle et spatiale du CIAPOL est très vaste et nécessite, pour leur mise en oeuvre, des moyens humains et matériels conséquents. Cependant, la réalité est que les ressources du CIAPOL sont limitées.

\section{Paragraphe 2: Les ressources limitées du CIAPOL}

L'examen de l'État des lieux permet de s'apercevoir du caractère limité des ressources dont dispose le CIAPOL (A). Il apparaît donc nécessaire d'impliquer l'action des opérateurs privés dans la lutte contre les pollutions des eaux ivoiriennes (B).

\section{A - État des lieux des moyens du CIAPOL}

En ce qui concerne le plan POLLUMAR ivoirien institué par le décret 98-42 du 28 janvier 1998 relatif à l'organisation du plan d'intervention d'urgence contre les pollutions accidentelles en mer, en lagune et dans les zones côtières, des inadéquations sont tout aussi à observer. En effet, de quels moyens techniques de recherche et de surveillance, ces pays pour la plupart sous développés ${ }^{433}$ peuvent-ils disposer ${ }^{444}$ ? Pour mettre en évidence la rareté des ressources Monsieur TIEBLEY part d'un constat. Celuici est que le cadre d'exercice de la compétence territoriale du CIAPOL est très étendu. En ce sens que, le champ de compétence du CIAPOL inclut vraisemblablement aussi bien la mer territoriale que la ZEE de la République de Côte d'Ivoire. La mission du

${ }^{442}$ Ce résultat est obtenu après la conversion des 12 milles marins (largeur de la mer territoriale ivoirienne) en kilomètres sachant que 1 mille marin $=1,852 \mathrm{~km}$. Ce qui donne une mer territoriale avec une largeur de : $12 \mathrm{x}$ $1,852=22,224 \mathrm{~km}$. Avec une côte mesurant $550 \mathrm{~km}$ de long, la superficie de l'aire marine théoriquement couverte par le CIAPOL est de : $1 \mathrm{~km} 2$ x 22,224 x $550=12.223,2 \mathrm{~km} 2$.

443 - Selon le Professeur LANGAVANT, dans le trafic maritime, le tiers Monde est dans une situation défavorable. Ne possédant qu'une flotte restreinte à savoir $9 \%$ de la flotte mondiale, son commerce extérieur dépend des grandes puissances maritimes. Voir LANGAVANT ( E.), Droit de la mer, Paris, CUJAS, 1979, pp.9 et 57 .

444 En cela, en tant que le seul organisme spécialisé de l'ONU en charge de sécurité marine et à la prévention de la pollution par les navires, l'OMI doit donc s'inspirer notamment de la disposition de l'article 10 de la Directive de 2008 de l'UEMOA précitée en formalisant la coopération et l'assistance en matière de la protection de l'environnement marin à l'endroit de ses pays membres, et en particulier envers les pays du tiers monde. 
CIAPOL est indéniablement d'une grande ampleur ${ }^{45}$. Malheureusement, l'ampleur de la mission confiée au CIAPOL contraste avec les moyens limités mis à sa disposition.

En effet, en vue de faire appliquer cette disposition, l'État ivoirien a créé une unité de police chargée de constater et de réprimer des infractions à la législation relative à la protection de l'environnement marin, lagunaire et du littoral contre la pollution. Cette unité de police spéciale est rattachée au CIAPOL qui en assure la direction, la gestion et l'organisation. Cependant, la réalisation de celle-ci est sérieusement compromise eu égard à la modicité des moyens matériels mis à la disposition du CIAPOL ${ }^{446}$. En effet, le CIAPOL ne dispose pas des moyens matériels nécessaires à la détection des actes de pollution marine sur un espace de $550 \mathrm{~km}$ de long (longueur du littoral) sur 200 milles marins de large ${ }^{447}$. Pour se rendre compte de l'ampleur de la tâche, il convient de se reporter au constat effectué par un spécialiste qui affirme : "les côtes françaises sont surveillées régulièrement par les avions des douanes (avions Polmar) et communiquent des constats de pollution aux différents CROSS qui établissent des procès-verbaux (POLREP). Chaque année, 200 à 300 POLREP sont établis et environ $80 \%$ d'entre eux concernent le repérage de nappe d'hydrocarbures en mer. $40 \%$ de ces observations identifient le navire pollueur ou suspect ${ }^{448}$.

Il est peu probable que le Centre dispose de moyens conséquents lui permettant d'effectuer des patrouilles (aériennes et navales) fréquentes et régulières en vue de détecter les infractions aux dispositions pertinentes des lois, décrets et conventions nationales, régionales et internationales, relatives aux règles de préventions et de lutte contre la pollution du milieu marin et lagunaire. La réalisation des patrouilles fréquentes et régulières est d'autant plus nécessaire que la probabilité de détection des infractions est inférieure à la moyenne. Dans l'exemple français rapporté ci-dessus, la probabilité de découverte des pollueurs avérés ou potentiels est de $40 \%$ avec des moyens de détection conséquents. Au regard de ce qui précède, il est possible de soutenir que les patrouilles

\footnotetext{
445 selon l'article 4 du décret créant le CIAPOL, les missions dévolues à cette structure sont, entre autres : « ...la surveillance continue du milieu marin et lagunaire ainsi que des zones côtières par des patrouilles régulières ; la lutte contre les pollutions de ces milieux ; le contrôle de l'application des lois, décrets et conventions régionales et internationales, édictées ou ratifiées par la République de Côte d'Ivoire, relatives aux règles de préventions et de lutte contre les pollutions du milieu marin et lagunaire par les entreprises, les navires, les engins de la mer et de la lagune ".

446 La modicité des moyens de police nécessaires à la prévention et à la répression des atteintes au milieu marin a quelquefois des conséquences tragiques pour les agents de police chargés de surveiller le milieu marin de la République de Côte d' Ivoire. C'est le cas du Lieutenant GONKANOU Philibert, des Sergents YAPO Kouassi, KOUAO Yapi et BOTTY Trazié qui ont été tués par des pêcheurs pirates alors qu'ils patrouillaient dans de frêles embarcations dans les eaux maritimes ivoiriennes. Cf. Le Temps, $\mathrm{n}^{\circ} 1774$, dans sa parution du jeudi 26 mars 2009, p. 9

447 Limite de la ZEE en vertu de l'article 2 de la loi nº77-926 du 17 novembre 1977 portant délimitation des zones marines placées sous la juridiction nationale de la République de Côte d'Ivoire.

448 MARCHAND (Michel), «Les pollutions marines accidentelles. Au-delà du pétrole, les produits chimiques et autres déversements en mer », in, IFREMER, Centre de Nantes, Département des Polluants Chimiques, p.5.
} 
du CIAPOL atteindront un taux de détection nettement inférieur étant donné le grand écart entre le champ d'intervention spatial du CIAPOL et les moyens disponibles ${ }^{49}$.

Ajoutons tout simplement qu'au regard des capacités financières actuelles de l'État ivoirien, il ne serait pas prudent pour l'administration de se contenter d'attendre qu'une situation critique survienne pour solliciter l'aide financière du Fonds national de l'environnement( FNDE) sans avoir auparavant trouvé un moyen efficace pour renflouer les caisses de celui-ci. A ce sujet, il est important d'instituer une redevance prélevée sur tous les navires de transport d'hydrocarbures qui bénéficient des prestations des ports autonomes d'Abidjan et de San Pedro. Le montant de cette redevance serait adaptable selon qu'il s'agit d'une plate forme pétrolière ou d'un navire de transport d'hydrocarbures en fonction de la taille de celui-ci.

Par ailleurs, il serait souhaitable que l'action des opérateurs privés soit prise en compte dans la lutte opérationnelle contre les pollutions marines en droit ivoirien.

\section{B - $\quad$ Nécessité d'impliquer les opérateurs privés intéressés}

Nous pensons qu'au niveau de chaque pays, il suffit de faire un minimum d'effort. On n'a pas besoin d'avoir des équipements de pointe, lourds pour prévenir et lutter efficacement contre les risques de pollution par hydrocarbures. Le CIAPOL et les structures privées disposent du minimum qu'il convient d'organiser de rentabiliser et de coordonner ${ }^{450}$. Il faut d'une part mettre sur pied une franche politique de collaboration entre les différentes structures publiques de gestion des accidents marins notamment la DGAMP, le CIAPOL, les ministères du transport et de l'environnement, et la SIR et d'autre part celles-ci avec les entreprises pétrolières privées afin de lutter efficacement contre les sinistres.

A titre d'exemple, lors du naufrage de l'Erika, l'administration française a été la cible de nombreuses critiques quant à sont manque d'efficacité dans le déploiement des plans POLMAR-terre et POLMAR-mer ${ }^{451}$, l'impréparation à terre, le manque de moyen, l’incapacité à encadrer le travail du nettoyage des plages, a laissé développer une

\footnotetext{
449 Pour le seul espace marin, la superficie couverte est de $203.720 \mathrm{~km} 2$. Cette superficie a été obtenue en convertissant 200 milles marins en $\mathrm{Km}(1$ mille $=1,852 \mathrm{~km})$. Donc en faisant l'opération : $200 \times 1,852=370,4$ $\mathrm{km}$. La largeur de la ZEE est donc égale à $370,4 \mathrm{~km}$. La superficie totale de la zone marine sous juridiction de la Côte d'Ivoire sera obtenue en multipliant la longueur totale du littoral (550 km) par la largeur de la ZEE. Dès lors, le calcul suivant donnera : $1 \mathrm{~km} 2$ x 550 x 370,4=203.720 km2.

450 Il ressort de nôtres enquête que le P.A.A et la SIR disposent des moyens de lutte contre les pollutions accidentelles en mer et d'un plan de lutte interne appelé POI. Il est souhaitable que tous ces plans de lutte des entreprises de la communauté portuaire soient intégrés au plan pollunar et les vulgariser auprès des différents partenaires. Voir en ce sens, le compte rendu du consultant de l'OMI en Côte d'Ivoire, précité, avril 2006, p.2. 451 Voir MULLER (M.), "La prévention des risques et les conditions de réparation des dommages dus aux pollutions marines ", in Avis du Conseil Economique et Social, Les causes et conséquences du naufrage de l'Erika, Paris, Journaux officiels, mars 2000, p.17.
} 
impression de manque de maîtrise des évènements ${ }^{452}$. Comme on le voit, il est des cas où l'État du port peut voir sa responsabilité engagée vis-à-vis de l'armateur. En effet, dans une affaire en date du 21 juin 1961, le conseil d'État français a jugé que l'administration est responsable des avaries souffertes par un navire le "Cap Cepet» qui a heurté les enrochements se trouvant à l'extrémité d'un port dans lequel il devrait accoster. Cet événement était consécutif à l'extinction du fanal qui est situé dans le prolongement de la jetée. Dès lors que ce feu servait à guider les navires au cours de leurs manœuvres et que l'administration n'établit pas que cet ouvrage était en bon état d'entretien normal ${ }^{453}$.

En cela, il convient donc de réviser, codifier et vulgariser les textes régissant les rapports entre les différents établissements concernés de l'État ivoirien et les industries pétrolières que sont notamment CHEUVRON, TEXACO, SHELL, CNR en ce qui concerne la protection de l'environnement en matière des pollutions maritimes provenant des déversements d'hydrocarbures. Dans cette même optique, il faut créer ou corriger le circuit de communication afin que l'information arrive au bon endroit à l'effet d'éviter des malentendus préjudiciables à l'environnement.

A côté des incohérences constatées au niveau du plan POLLUMAR, les normes répressives contre les actes de pollution marine présentent tout aussi des insuffisances.

\section{Section 2: Les insuffisances au niveau des normes répressives ivoiriennes}

Le droit pénal est principalement fondé sur la faute, c'est-à-dire la survenance d'un accident écologique plutôt que sur le résultat. C'est à dire les dommages. Il permet donc d'appréhender les comportements négligents des personnes en cause ${ }^{454}$. Le point de départ de la répression pénale est l'existence d'un texte qui incrimine l'infraction. Dans le domaine de la pollution, les textes imputent deux sortes d'infractions de rejet d'hydrocarbures à savoir, les rejets accidentels et les rejets opérationnels. Ces textes se situent au niveau national et international. Et la mise en œuvre de la répression y est

\footnotetext{
452 Dans l'affaire de l'Amoco Cadiz, les défendeurs avaient mis en cause la responsabilité des pouvoirs publics français pour manque de diligence dans l'organisation de la lutte contre la marée noire. Les tribunaux Américains avaient rejeté cette responsabilité.

453 C.E., 21 juin 1961, in DMF 1962, 14-16. Dans ce cas d'espèce, le conseil d'État a rejeté les allégations de l'administration fondée sur la force majeure et la faute du capitaine. Selon la haute juridiction, il y a absence de force majeure dans la mesure où dans les circonstances de l'espèce, l'état de la mer ne présentait pas le caractère d'une tempête d'une violence exceptionnelle constituant un cas de force majeure. Absence de faute du capitaine du navire endommagé, car il n'y avait aucune restriction particulière par gros temps, par les règlements à l'accès de nuit dans le port, et le capitaine à fait appel au pilote qu'il n'a pu prendre à bord à raison de l'état de la mer.

454 Plusieurs actions pénales ont été intentées devant la chambre correctionnelle du tribunal de grande instance de Paris contre notamment le capitaine de l'Erika et contre la société Total Fina et certains de ses membres. La mise en cause de la responsabilité de ceux-ci repose sur les griefs de pollution marine et de complicité de mise en danger délibérée de la vie d'autrui.
} 
fortement subordonnée. L'arsenal répressif des actes de pollution par les hydrocarbures se présente donc comme un assemblage de textes internationaux et nationaux ${ }^{455}$.

C'est à dire que la répression pénale des pollutions par hydrocarbures est aujourd'hui assurée par le Droit interne ${ }^{456}$ de chaque État partie à la convention internationale sur la sécurité maritime. Du point de vue pénal, les Conventions internationales ne sont que des normes imparfaites, incomplètes. Car elles ne fixent pas les peines. Elles se bornent à décrire de manière générale les comportements interdits, sans édicter de sanctions pénales. C'est au législateur national de chaque État contractant qu'il revient de sanctionner ${ }^{457}$. En plus, les enquêtes et les instructions ne sont pas menées de manière uniforme à l'échelle internationale. Le constat est que les poursuites pénales sont relativement rares dans ce domaine, compte tenu des difficultés de constatations des actes de pollution et de preuve.

Le gouvernement ivoirien a réagi en faisant de la lutte contre la dégradation de l'environnement une de ces préoccupations. Cette lutte se manifeste en effet entre autres, sous la forme de répression pénale des pollutions par les hydrocarbures. A cet effet, il faut noter les instruments juridiques tels que la loi $\mathrm{n}^{\circ} 81-640$ du 31 juillet 1981 portant code pénal; la loi $\mathrm{n}^{\circ} 96-766 \mathrm{du} 3$ octobre 1996 portant code de l'environnement; le décret $\mathrm{n}^{\circ} 97-678$ du 3 décembre 1997 portant protection de l'environnement marin et lagunaire contre la pollution, la loi ${ }^{\circ} 98-755$ du 23 décembre 1998 portant code de l'eau.

A ces lois, il faut ajouter la loi $n^{\circ} 88-651$ du 7juillet 1988 portant protection de la santé publique et de l'environnement contre les effets des déchets industriels toxiques et nucléaires et des substances nocives. Le rôle de ces instruments juridiques sera à la fois préventif et répressif $f^{458}$.

Le système répressif ivoirien assure-t-il efficacement la protection de l'environnement marin? À l'analyse, ne consacre-t-il pas l'impunité au regard de la faiblesse de sa capacité de dissuasion?

La résolution de cette préoccupation permettra d'apprécier la contribution réelle du système répressif ivoirien à la protection de l'environnement marin ivoirien. L'analyse

\footnotetext{
455 Le décret ivoirien n97-678 du 3 décembre 1997 portant protection de l'environnement marin et lagunaire contre la pollution se réfère abondamment aux conventions internationales relatives à la pollution par hydrocarbures, notamment la convention CLC 1969, la convention de 1969 portant intervention en haute mer, la convention MARPOL 73 / 78. Voir préambule dudit décret, article 80 du code de l'environnement et les articles $1,7,8$, et 10 du décret portant protection de l'environnement marin.

${ }^{456}$ Voir dans ce sens, BECET (Jean-Marie), Le MORVAN (Didier), Droit du littoral et de la mer côtière, Paris, Economica, 1991, P.200.

457 L'article 4 paragraphe 4 de la convention MARPOL 73/78 se contente de dire que les peines devront par leur rigueur être de nature à décourager les contrevenants éventuels.

458 Le Droit pénal peut contribuer à protéger l'environnement en incriminant certaines infractions, en déterminant la responsabilité pénale et les peines applicables à certains comportements constitutifs d'infraction pour l'environnement.
} 
de ce système révèle que les règles pénales sont théoriquement dissuasives (Paragraphe 1 ) et que la répression des actes de pollution est d'une rigueur mitigée (Paragraphe 2).

\section{Paragraphe 1: Des règles pénales théoriquement dissuasives}

La pollution des eaux est réprimée en droit ivoirien notamment par le code pénal, le code de l'environnement en ses articles 96, 97, 98, 99 et $101^{459}$ et par le code de l'eau de 1988 en ses articles 107 à 127 . Le code pénal fait un traitement général de la matière en son article $328^{460}$. En tout état de cause, cette réglementation détaillée interdit tout rejet de substances nocives dans les eaux, toutes pollutions des eaux continentales, des eaux maritimes sous juridiction ivoirienne, des eaux du domaine public national. Les infractions relatives à la pollution des eaux sont fonction de la nature juridique de ces eaux et se repartissent en trois groupes à savoir les rejets interdits, les rejets sans autorisation et les rejets soumis à autorisation préalable conforment à l'article $96 \mathrm{du}$ code de l'environnement.

Le texte nous renvoie pour la détermination des rejets aux articles 74 à 86 du même code. Sont donc visés tout corps solide, toute substance liquide, gazeuse dans les cours et plan d'eaux et leurs abords, les rejets dans les zones maritimes et lagunaires de toutes substances susceptibles de détruite la faune et la flore. Nous pensons que ce texte présente des limites dans ses dispositions. Cela se constate tant au niveau de la pollution des espaces marins sous souveraineté ivoirienne (A) que de la pollution des espaces marins sous juridiction ivoirienne (B).

\section{A - La pollution des espaces marins sous souveraineté ivoirienne : les eaux intérieures et la mer territoriale}

Les eaux continentales sont constituées de toutes les eaux situées sur le territoire ivoirien à l'exclusion des eaux maritimes et lagunaires. La pollution des eaux continentales est faite par les déversements, les écoulements, des rejets et les dépôts de substances de toutes nature. Ces substances doivent être de nature à provoquer ou à accroître la pollution des eaux continentales et/ou des eaux maritimes dans les limites territoriales.

La peine ne devient aggravée qu'en cas de récidive. Car le texte indique qu'en ce cas, la peine est portée au double et le coupable est condamné à curer les lieux pollués. Le texte montre d'avantage des insuffisances. Car il ne prend pas le soin de préciser les conditions de la récidive ni de rendre obligatoire le nettoyage des lieux en dehors de la

\footnotetext{
459 Selon l'article 20 du décret portant protection de l'environnement marin et lagunaire contre la pollution, toute violation des dispositions du présent décret est punie par les dispositions prévues par la loi $n^{\circ} 96-766$ portant code de l'environnement. Les dispositions pénales concernant notre matière sont notamment les articles 76 à 81 et 98 à 99 . Voir le préambule du décret.

${ }^{460}$ Est puni d'un emprisonnement de 15 jours à 6 mois et d'une amende de 100.000 à 1.000 .000 de francs, ou de l'une de ces deux peines seulement, celui qui souille ou pollue directement ou indirectement par quelques moyens que ce soit, tout produit ou élément naturel, nécessaire à la vie ou à la santé de la population.
} 
récidive. Sur cette question, le décret d'application du code de l'environnement est silencieux.

Faut-il alors se référer au code pénal général de $1981^{461}$ ? Quand bien même qu'il serait possible d'appliquer le code pénal général pour régler la question, reconnaissons tout de même l'existence de contradiction entre celui-ci et le code de l'environnement. En effet, le code de l'environnement dispose qu'en cas de récidive, la peine est portée au double. Tandis que le code de l'environnement se montre plus ferme, le code pénal général se montre moins sévère. Le code pénal parle de la faculté lorsqu'il affirme que "le récidiviste peut être condamné au maximum de la peine encourue, laquelle peut être portée jusqu'au double dudit maximum ${ }^{462}$ ».

Nous souhaiterions que pour une meilleure dissuasion, qu'il soit appliqué aux pollueurs récidivistes des eaux ivoiriennes, les dispositions du code de l'environnement. En ce sens qu'elles sont plus sévères au titre des peines applicables. En revanche, le code de l'environnement ne rend pas obligatoire le nettoyage des lieux pollués. C'est une simple faculté : "peut curer les endroits pollués». Cela est regrettable. Les eaux maritimes sont constituées par la mer territoriale fixée à 12 milles marins à compter de la laisse de base mer. La zone économique exclusive est aussi concernée par la répression.

Le droit pénal ivoirien tend tout aussi à réprimer la pollution de la zone économique exclusive.

\section{B - La pollution des espaces marins sous juridiction ivoirienne : la zone économique exclusive}

La zone économique exclusive (ZEE) s'étend jusqu'à 200 milles marins. La pollution est faite au moyen de déversement de substances de toutes natures susceptible de porter atteinte à la santé publique et aux ressources maritimes biologiques, de nuire aux activités maritimes y compris la navigation et la pêche, d'altérer la qualité des eaux maritimes, de dégrader les valeurs d'agrément et le potentiel touristique de la mer et du littoral.

Le domaine maritime national est constitué par le rivage de la mer, les étangs salés en communication avec la mer, le sol et le sous-sol de la mer territoriale les havres et les rades, les lacs et les relais futurs ainsi que les terrains qui seront artificiellement soustraits à l'action des flots. L'infraction est également constituée par le dépôt des déchets dans le domaine public maritime national, l'importation sans autorisation des

\footnotetext{
461 Voir les articles 125 et 132 du code pénal relativement à la récidive. Selon l'article 126 alinéa 3, il n'y a récidive que si le délit est commis entre le jour où la première condamnation est devenue définitive et celui marquant le terme d'un délai de cinq ans après l'expiration ou la prescription de la première peine.

${ }^{462}$ Voir les articles 126 et 127 du code pénal général.
} 
déchets ${ }^{463}$ sur le territoire national, et par immersion, incinération ou par élimination par quelques procédés que ce soit de déchets dans les eaux continentales, lagunaires ou maritimes sous juridiction ivoirienne.

Cette étude montre l'intensité de la réaction sociale face aux pollutions des eaux ivoiriennes. Ce sont pour la plupart des infractions alternatives. C'est à dire, l'infraction est constituée si un des actes est réalisé. Néanmoins, nous faisons le constat qui est ceci que la plupart des infractions sont qualifiées soit de contravention soit de délits ${ }^{464}$. Nous trouvons que le système juridique ivoirien est souple, au regard du caractère particulièrement dangereux que ce type de pollution présente pour la faune, la flore marine et les activités économiques liées à l'eau et pour la survie de populations côtières ${ }^{465}$.

En outre, nous regrettons que le code n'ait pas pris en compte les eaux aménagées par les particuliers, notamment en ce qui concerne la pisciculture ${ }^{466}$. A la détermination des infractions, le système répressif ivoirien attache une sanction qui nous paraît se caractériser par une rigueur mitigée.

\section{Paragraphe 2 : La rigueur mitigée de la répression des actes de pollution}

A l'analyse des textes répressifs ivoiriens l'on voit apparaître des failles qui révèlent le contraste entre l'objectif poursuivi et le résultat atteint. Cette rigueur mitigée de la répression est mise en évidence par les entraves au pouvoir des agents de recherche des infractions à la législation (A) et la faiblesse des sanctions pénales proprement dites applicables (B).

\section{A - Les entraves au pouvoir des agents de recherche des infractions}

Selon le code de l'environnement ivoirien en son article 109, la poursuite des infractions relevant du présent code obéit aux règles définies par le code de procédure pénale. A l'analyse, les titulaires du pouvoir de recherche des infractions (1) butent sur des entravent (2).

\footnotetext{
463 Selon l'article ler du code de l'environnement, les déchets sont des produits solides, liquides ou gazeux, résultant des activités des ménages, d'un processus de fabrication ou tout bien meuble ou immeuble abandonné ou qui menace ruine.

${ }^{464}$ Voir les dispositions de l'article 328 du code pénal.

465 Voir dans ce sens, LE COUVIOUR (Karine), « Récent développement normatif et judiciaire de la répression des rejets polluants des navires ", in semaine juridique, Paris, édition générale, $\mathrm{n}^{\circ} 4$, du 11 juin 2003 , P.1081.

466 Il s'agit notamment des poissons, des crustacés et mollusques que l'on garde dans des cages flottantes ou dans des enclos ou des parcs près du littoral. Voir OMI, Manuel sur la pollution par les hydrocarbures, Londres, 2005, p.33.
} 


\section{Les titulaires du pouvoir de recherche des infractions}

L'article $107 \mathrm{du}$ code de l'environnement ivoirien, dispose que les infractions sont constatées sur procès verbal par les agents assermentés par l'autorité nationale compétente. L'article 21 du décret d'application du code de l'environnement, complète l'article 107 précité en énumérant limitativement les agents assermentés par l'autorité nationale compétente pour constater les infractions ${ }^{467}$.

En ce qui concerne l'exercice de l'action publique, il ressort de l'article 109 du code de l'environnement ${ }^{468}$ que le pouvoir revient au ministère public ${ }^{469}$ d'exercer l'action publique $^{470}$. L'action publique est-elle exercée exclusivement par le ministère public? L'action civile peut-elle être exercée individuellement ou collectivement, notamment par la société civile devant les juridictions répressives?

En effet, l'article $1^{\text {er }}$ alinéa 2 du code de procédure pénale dispose que l'action publique peut aussi être mise en mouvement par la partie lésée. C'est-à-dire que l'exercice de l'action publique ne devrait être fermée aux particuliers ayant subi des dommages suite à la pollution par hydrocarbures. L'article $3 \mathrm{du}$ CPP ajoute en outre que l'action civile peut être exercée en même temps que l'action publique et devant la même juridiction. Elle est recevable pour tous les chefs de dommages aussi bien matériels que corporels ou moraux qui découleront des faits objets de la poursuite.

La mission de recherche des infractions, rencontre malheureusement des entraves.

\section{Les entraves constatées}

Il ressort de l'article 110 du code de l'environnement ivoirien précité que les collectivités locales, les associations de défense de l'environnement régulièrement déclarées ou toutes personnes doivent saisir l'autorité nationale compétente avant tout recours aux juridictions et/ou exercer les droits reconnus à la partie civile en ce qui concerne les faits constituant une infraction relevant de la présente loi et portant un préjudice direct ou indirect aux intérêts collectifs ou individuels. Ainsi l'action civile des particuliers doit être constituée devant le juge pénal de sorte à mettre obligatoirement en mouvement l'action publique et ouvrir le procès pénal.

\footnotetext{
467 Il ressort de l'article 21 du décret d'application du code de l'environnement que ce sont les officiers de marine, les officiers mariniers, les administrateurs, les officiers et les contrôleurs des affaires maritimes et portuaires, les agents de police de la navigation et des pêches maritimes, les fonctionnaires et les agents assermentés du ministère chargé de l'environnement et du ministère chargé des mines et des hydrocarbures, et les officiers de la police judiciaire.

${ }^{468}$ La poursuite des infractions relevant du présent Code obéit aux règles définies par le Code de Procédure Pénale.

${ }^{469}$ Voir l'article 31 du code de procédure pénale ivoirien.

470 Selon l'article 1er alinéa 1 CPP ivoirien, l'action publique pour l'application des peines est mise en mouvement et exercée par les magistrats ou fonctionnaires auxquels elle est confiée par la loi.
} 
En outre, les règles de délai de prescription des actions de droit commun qui éteignent l'action publique en matière de l'environnement paraissent inadaptées, au regard du caractère souvent continu et insidieux des atteintes à l'environnement. A ce titre, il conviendrait de suggérer que la jurisprudence applicable en droit pénal des affaires soit étendue au droit pénal de l'environnement en reconnaissant que la prescription de l'action ne commence qu'au jour où le délit prend fin. Néanmoins, nous souhaiterions qu'à l'instar du cas des déchets dangereux ${ }^{471}$, les circonstances atténuantes et le sursis ne soient pas applicables aux infractions liées à la pollution par les hydrocarbures ${ }^{472}$.

Par ailleurs, la possibilité de transaction ${ }^{473}$ prévue par l'article 108 du code de l'environnement est préjudiciable à une répression efficace des actes de pollution ${ }^{474}$. A propos de l'extinction de l'action publique, la transaction peut intervenir à tout moment du procès pénal à l'initiative de l'autorité compétente ou du prévenu. Elle aboutit souvent à la fixation d'une amende qui peut être inférieure à l'amende pénalement encourue, accompagnée de prescription de travaux visant à réduire les atteintes à l'environnement et à réparer les dommages causés aux victimes. La transaction malgré ces quelques avantages ${ }^{475}$, ne devrait à notre sens en aucun cas s'ouvrir de façon abusive. Il faut donc instaurer une procédure rigoureuse à l'effet de limiter le jeu de la transaction notamment en subordonnant celle-ci à l'accord du procureur de la république après avis des victimes sur la base du contenu de l'arrangement en question.

Car si l'on ni prend garde, le jeu des transactions risque de se révéler comme la porte ouverte à la complaisance et à tout ce que l'on peut imaginer en termes de malversations de la part des autorités chargées de protéger les milieux marins contre la pollution par les hydrocarbures. A quelle hauteur devrait se réaliser la transaction ? Comment l'on peut édicter des répressions dissuasives contre les contrevenants à la loi et prévoir la possibilité de transaction? Autant d'interrogations qui traduisent notre inquiétude. A l'évidence, la transaction se présente véritablement comme une opportunité pour le pollueur d'échapper à la rigueur de la loi. Cela est de nature à constituer une source des frustrations de la part des populations victimes des contaminations. Ce sentiment s'est vérifié lors de l'audience pénale dans le cadre de l'affaire " des déchets toxiques " à Abidjan. En effet, se fondant sur la transaction entre l'État de Côte d'Ivoire et la multinationale Trafigura, la cour d'assises s'est refusée de faire comparaître les responsables de ladite compagnie pétrolière. Décision que le collectif des avocats des

\footnotetext{
471 L'article 105 du code de l'environnement dispose que les circonstances atténuantes et le sursis n'est pas applicable aux infractions prévues par le présent code relatif aux déchets dangereux.

${ }^{472}$ Il faut aussi se réjouir des dispositions de l'article 106 du code de l'environnement. Lequel texte déclare que la tentative et la complicité des infractions sont punissables des mêmes peines que l'infraction elle-même.

${ }^{473}$ La transaction est un contrat par lequel les contractants terminent une contestation en renonçant chacun à une partie de leur prétention, ou encore une Administration fiscale consent en cas d'infraction à n'exercer aucune poursuite moyennant amendes. Voir REY DEBOVE (Josette) et REY (Alain), le nouveau petit Robert, Paris 2004 P. 2658.

${ }^{474}$ Selon l'article 108 alinéa 1 du code de l'environnement, l'Administration chargée de l'environnement peut transiger en toutes circonstances et en tout moment de la procédure avant toute défense au fond.

475 Selon l'adage populaire, mieux vaut un mauvais arrangement qu'un bon procès.
} 
victimes des déchets toxiques a dénoncé en la qualifiant de suspicion légitime à travers une requête pour bloquer le procès civil de la cour d'assises du mardi 21 octobre 2008. Voici comment peut se poser le problème de la légitimité d'une transaction faite dans la précipitation, à l'insu des concernés. Cela risque de faire entorse à la rigueur de ce qu'exige la loi à savoir le devoir de conscience.

L'administration dispose-t-elle de moyens appropriés pour rendre effectif l'arsenal juridique répressif ? La réponse à cette interrogation est malheureusement négative ${ }^{476}$. En ce sens qu'à l'instar des autres pays de la sous région de l'Afrique de l'ouest et du centre, parties contractantes à la convention d'Abidjan du 23 mars 1981 précitée (Convention WACAF), il ressort de nos investigations qu'en Côte d'Ivoire les structures chargées de la surveillance du territoire et de la lutte contre les pollutions des mers notamment le CIAPOL ne disposent pas véritablement d'équipements nécessaires ${ }^{47}$ à la détection en mer des navires pétroliers ou autres navires effectuant des rejets des déchets volontaires ou accidentels d'hydrocarbures sur un espace de près de $600 \mathrm{~km}$ de long (longueur du littoral) sur 200 milles marins de large $\mathrm{e}^{478}$.

Comme on le voit, la détection des actes de pollution marine par les hydrocarbures nécessite l'utilisation d'aéronefs spécialement équipés à cet effet. Or, il est clair que l'acquisition, l'entretien de ces moyens ainsi que la formation du personnel qualifié nécessaire exige des investissements financiers très importants de la part des autorités nationales compétentes. En l'état actuel, est-il certain que les coûts énormes qu'impliquent les opérations fréquentes et régulières de détection des navires pollueurs soient aisément supportables par l'État ivoirien?

Par ailleurs, l'on renforcerait davantage la lutte contre les pollutions marines effectives par les rejets d'hydrocarbures par la formation des agents de police et d'agents de douane chargés de garder les côtes ivoiriennes rompus aux techniques de détection des rejets illégaux d'hydrocarbures par les navires. Dans cette optique, il est clair que la coopération bilatérale avec des pays tels que la France, la Grande Bretagne ou l'Espagne

\footnotetext{
476 Voir en ce sens, TIEBLEY (Yves Didier), Thèse précitée, p. 286. l'auteur soutient que les autorités de la Côte d'Ivoire ne disposent pas des moyens matériels nécessaires à la détection des navires pétroliers ou autres navires effectuant des rejets volontaires d'hydrocarbures sur un espace de près de 550 kilomètres de long (longueur du littoral) sur 200 milles marins de large.

477 Les moyens modernes de surveillance maritime et de détection des pollutions en mer dont devrait disposer tout pays soucieux de la protection de ses eaux maritimes contre les actes de pollueurs sont notamment l'Argonaute qui est un remorqueur aux équipements antipollution, les avions Falcon 50 VIP pour traquer les voyous des mers effectuant des vols de surveillance, des avions équipés de radar infra rouge spécialisé pour la télédétection nocturne des pollutions.

Voir http://www.ifremer.fr/envlit/documentation/dossiers/pollutionchimique/index.htm.

${ }^{478}$ Limite de la ZEE en vertu de l'article 2 de la loi $n^{\circ} 77-926$ du 17 novembre 1977 portant délimitation des zones maritimes placées sous la juridiction nationale de la république de Côte d'Ivoire.

Voir aussi en ce sens, la reflexion du Professeur MARCHAND, MARCHAND (Michel), Les pollutions marines accidentelles. Au-delà du pétrole, des produits chimiques et autres déversements en mer, Paris, IFREMER, Centre de Nantes, Département des Polluants Chimiques,1978, p.5.
} 
pourrait s'avérer fructueuse au regard de l'expérience qu'ils ont acquise par suite de multiples et gigantesques marées noires survenues au large de leurs côtes.

En plus de la formation, il est important de prévoir l'accroissement de l'effectif des agents de surveillance des côtes. L'étendue de l'espace maritime placé sous la juridiction de l'État ivoirien rend indispensable cette mesure, soit environ $222.360 \mathrm{~km}^{2}$ dont 130.341 de mer territoriale ${ }^{47}$. La conséquence de cette situation est la persistance de rejets opérationnels dans les eaux sous juridiction ivoirienne et en haute mer.

Par ailleurs, l'on constate une impasse de l'administration au regard des défaillances constatées dans l'action de protection des services spécialisés tel que le CIAPOL. Or les officiers de la police judiciaire, les agents de police judiciaire et le parquet mal armés juridiquement, techniquement et matériellement en matière de protection de la nature et de pollution ${ }^{480}$ s'en remettent à ces derniers. En effet, le parquet chargé de poursuivre les suspects n'est pas habitué à la multiplicité des incriminations existant en matière d'environnement et de ce fait à tendance à classer sans suite les affaires de pollutions.

Ainsi nous pouvons conclure avec Monsieur Tiebley qu'il est clair que l'acquisition, l'entretien de des moyens modernes de détection des hydrocarbures ainsi que la formation du personnel qualifié nécessaire exigent des investissements financiers très importants de la part des autorités nationales compétentes. En l'état actuel, il n'est pas certain que les coûts énormes qu'impliquent les opérations fréquentes et régulières de détection des navires pollueurs (formation d'un personnel qualifié, achats d'aéronefs spécialisés, dépenses en carburant, pièces de rechange ...) soient aisément supportables pour l'État ivoirien. La conséquence de cette situation est la persistance des rejets opérationnels dans les eaux sous juridiction ivoirienne.

\footnotetext{
479 Cette superficie a été obtenue en convertissant les 200 milles marins de la ZEE en kilomètres. Soit 200 multiplié par 1,853 (1 mille marin = 1,853kilomètre). Le produit obtenu est de 370,600 kilomètres. En multipliant 370,600 (largeur de la ZEE) par les 600 kilomètres (longueur du littoral ivoirien), on obtient une superficie de $222360 \mathrm{~km} 2$. Le même procédé a été utilisé pour calculer la superficie de la mer territoriale d'une largeur de 12 milles nautiques. La largeur de la ZEE a été étendue à 200 milles marins en vertu de l'article 2 de la loi n77-926 du 17 novembre 1977 portant délimitation des zones maritimes placées sous la juridiction nationale de la république de Côte d'Ivoire.

${ }^{480}$ Il n'y a évidemment aucune preuve incontestable de l'infraction de pollution. Cependant il existe des règles éprouvées au fil des procès. Aujourd'hui, la reine des preuves est la photographie, numérique ou argentique. On utilise pour cela un critère physique des hydrocarbures, que la photographie révèle très bien. En effet en zone économique française dans le Golfe de Gascogne, le débit maximum de rejet autorisé pour un navire en route est de $15 \mathrm{ppm}$. Or des expérimentations faites dans le cadre de l'Accord de Bonn montrent qu'aucun débit inférieur à $100 \mathrm{ppm}$ n'est visible à l'oeil nu ! La constatation visuelle, confirmée par photographies, est donc suffisante pour établir un débit supérieur à la norme autorisée ...Puisque la justice reconnaît la photo comme preuve depuis le jugement du TRAQUAIR par la Cour d'appel de Rennes en 1995, l'essentiel de la preuve repose sur les vues prises par avion, corroborées bien entendu par tout autre élément probant comme les déclarations du capitaine ou de l'équipage, des films vidéo, l'enquête judiciaire ou l'expertise technique des installations ...Cf. LE GOAZIOU (Benoît), Les opérations de répression des infractions à la convention MARPOL 73/78 : L'action du préfet maritime de l'Atlantique, inédit, 2005, p.4, cité par TIEBLEY Yves Didier, Thèse précitée, p.286.
} 
Le manque de rigueur du système répressif ivoirien s'explique aussi par la faiblesse des sanctions pénales proprement dites applicables.

\section{B - $\quad$ La faiblesse des sanctions pénales applicables}

Les textes de loi portant répression des actes de pollution de milieu marin par les hydrocarbures sont multiples. En outre, le quantum des peines tel qu'il se présente à notre avis peut malgré tout contribuer efficacement à inciter les pollueurs éventuels à surseoir à l'exécution de leurs actes de pollution. A titre d'exemple, le montant des amendes pénales notamment 100 millions à 1milliard de francs CFA, conjugué avec le droit que se réserve l'Administration de procéder à la saisie du navire peut être jugé suffisamment élevé pour annuler les avantages financiers que le pollueur escompterait retirer de la violation de la loi ${ }^{481}$. De ce fait, cette disposition peut permettre d'infléchir le comportement illicite du pollueur dans la mesure où il se voit priver du moyen par lequel il s'enrichit.

En revanche il apparaît à l'examen des dispositions des codes pénal et de l'environnement ivoiriens que les peines sont sans utilité. En ce sens qu'elles sont insuffisantes et peu dissuasives malgré la multiplication des incriminations pénales ${ }^{482}$. Ces faiblesses semblent résulter du chef d'inculpation qui en général, est qualifié de contravention de simple police (1) et du particularisme du Droit pénal (2).

\section{La faiblesse tirée du chef d'inculpation}

L"article 96 du code de l'environnement prévoit seulement une amende de 100 millions à 500 millions de francs ${ }^{483}$. Quant à l'article $97 \mathrm{du}$ même code $\mathrm{e}^{484}$, il prévoit une peine d'emprisonnement de 2 mois à 2 ans. Mais nous estimons que cette peine est faible. L'amende exigée est de 2 millions à 50 millions de franc CFA. Ce taux est insuffisant et manque d'uniformité. Il conviendrait donc de prévoir une peine d'emprisonnement suffisamment dissuasive pour sanctionner les pollueurs. Seulement une peine d'amende de 100 millions à 500 millions francs. Cette seule sanction du délinquant dans son

\footnotetext{
481 La lutte répressive contre les marées noires trouve son fondement juridique dans l'article 98 du Code de l'environnement en Côte d'Ivoire.

482 Michel PRIEUR reconnaît qu'en France, la plupart des textes n'on jamais fait l'objet d'application pénale. Voir PRIEUR (Michel), droit de l'environnement, Op.cit. p. 707.

${ }^{483}$ Aux termes de l'article 96, est passible d'une amende de 100.000 .000 de francs à 500.000.000 de francs quiconque effectue des rejets interdits ou, sans autorisation, des rejets soumis à autorisation préalable ainsi que défini aux articles 74 à 86 du présent Code dans les conditions fixées par décret ou ne se conforme pas aux conditions déterminées par son autorisation.

484 Le texte dispose qu'est puni d'une amende de 2.000.000 de francs à 50.000.000 de francs et d'un emprisonnement de deux mois à deux ans ou de l'une de ces deux peines seulement, toute personne ayant pollué les eaux continentales par des déversements, écoulements, rejets et dépôts de substances de toute nature susceptible de provoquer ou d'accroître la pollution des eaux et/ou des eaux maritimes dans les limites territoriales.
} 
patrimoine nous semble très insuffisante. Les articles 97 et suivants prévoient des sanctions différentes de celle de l'article 96 du code de l'environnement.

A l'analyse donc de la loi ivoirienne, il ressort que les sanctions ne sont pas suffisamment lourdes pour dissuader les auteurs de pollution des eaux nationales. Dans cette optique, le Professeur Michel PRIEUR fait observer que l'inefficacité de la répression pénale en matière de pollution ne réside pas seulement dans la difficulté de mettre en œuvre l'action publique mais aussi de la nature et du montant des peines encourues souvent de simples contraventions de police. Ainsi l'auteur s'interroge t-il, compte tenu de l'encombrement des tribunaux : quel est le nombre des classements sans suite, des relaxes et des transactions en matière de pollution marine ${ }^{485}$ ?

Aussi, le législateur français a t-il prévu depuis quelques années des peines plus élevées surtout dans le domaine de la pollution de la mer en correctionnalisant certaines infractions relevant auparavant des contraventions. Cette incrimination en deux temps lui a permis de passer de la contravention au délit en cas de récidive et par une aggravation des peines délictuelles sans préjudice des peines complémentaires telles que la remise en état des lieux, l'interdiction d'exercice d'activités professionnelles, la publication du jugement de condamnation, la confiscation du corps du délit ou des choses produites par le délit ayant servi ou ayant été destinées à le commettre, la procédure de l'amende forfaitaire à paiement immédiat ou différéét

Ce n'est qu'à propos de la pollution des eaux maritimes sous juridiction ivoirienne que la législation ivoirienne prévoit une amende maximale de 1 milliard et de 5 ans d'emprisonnement ou l'une de ses peines ${ }^{487}$ seulement. Ne serait-il pas avantageux pour l'État de Cote d'Ivoire de s'inspirer par exemple de la loi française n²001-380 du 03 mai $2001^{488}$, relative à la répression des rejets polluants des navires?

En effet, le législateur français a considérablement durci le dispositif législatif, en tendant à faire de la lutte contre les pollutions marines une priorité. Dans cette optique, il a accru le rôle des magistrats du Ministère public en renforçant les moyens de l'État pour préserver le patrimoine maritime ${ }^{489}$.

Ainsi que le suggère le Professeur PRIEUR se fondant sur la déclaration d'un ministre français de la justice à savoir le discours de M. LECANUET garde des sceaux, le 23 juin 1976, "l'éthique de l'environnement et la reconnaissance de la valeur d'intérêt général des préoccupations d'environnement devraient conduire à souhaiter la mise en place d'une incrimination générale réprimant la faute écologique. L'enjeu serait de préserver le droit à la qualité du milieu naturel en punissant dans le code pénal toutes les pollutions comme le

\footnotetext{
${ }^{485}$ PRIEUR (Michel), Droit de l'environnement, Op.Cit., pp. 717-718

${ }^{486}$ Voir LANGAVANT (E.), Droit de la mer, op. cit. p. 139.

${ }^{487}$ Article 98 du code de l'environnement ivoirien.

488 Loi sur la responsabilité environnementale, modifiée successivement par la loi nº 2004-204 du 4 mars 2004 et la loi n ${ }^{\circ} 2008-757$ du $1^{\text {er }}$ août 2008 dans le sens du renforcement de la répression.

489 Voir RIVET (Marc), « La lutte contre les pollutions maritimes en Méditerranée : Un enjeu de politique pénale », in DMF n661 juillet août 2005, PP. 579-589.
} 
meurtre et le vol au même titre que le droit à la vie et à la propriété et de faire apparaître le pollueur au même titre que le voleur ou le criminel $»^{490}$.

Mais comme le souligne le Professeur PRIEUR, de telles propositions se heurtent aux difficultés techniques liées au statut juridique des biens-environnement, qui empêchent de mettre sur le même pied des incriminations générales visant à la fois les hommes, les plantes et les animaux. Car le droit pénal a été construit pour régir les relations de "type individualiste". Face à cette difficulté, l'auteur indique que comme il n'est pas possible de modifier la place et le rôle des éléments qui constituent l'équilibre écologique, il faut donc modifier les règles et principes du droit pénal pour les adapter à la demande sociale. Il faut que le droit pénal prenne désormais en compte les comportements sociaux et intègre la globalité du nouvel ordre écologique. Cette nouvelle construction du droit pénal est souhaitée au regard du caractère continu et insidieux des atteintes à la vie humaine et aux milieux marins ${ }^{491}$.

Par ailleurs, l'élément moral de l'infraction pénale a fait l'objet de nombreuses controverses. A titre d'exemple, selon Michel PRIEUR, si la faute intentionnelle n'est plus exigée, la faute d'imprudence ou de négligence est restée longtemps requise. Mais la jurisprudence ${ }^{492}$ admet désormais que l'infraction soit purement matérielle. C'est-à-dire qu'elle résulte du déversement sans qu'il ait besoin d'une faute ou d'une imprudence ${ }^{493}$.

De sorte que les peines pécuniaires et les peines privatives de liberté soient appliquées non de manière alternative mais plutôt concomitante. Car le coût du nettoyage des déversements d'hydrocarbures et les pertes économiques que subissent divers secteurs de l'économie tels que les industries de la pêche, le tourisme etc. peuvent s'élever à plusieurs millions de dollars ${ }^{494}$. En outre, l'on remarque avec regret que la répression vise au premier chef le capitaine du bâtiment ${ }^{495}$. En effet, dans le domaine de l'environnement prévaut rigoureusement, le principe du droit pénal selon lequel nul n'est passible de peine qu'à raison de son fait personnel même si le délit a été commis par et pour l'entreprise. Mais, la jurisprudence tend pour désigner les personnes responsables à écarter le salarié de l'entreprise auteur matériel de la pollution et à

\footnotetext{
490 A la suite de cette proposition, une loi nº 292 du 6 avril 1978, jamais discutée au Parlement avait été proposée au Sénat français et a inspiré les réflexions de la commission interministérielle pour la lutte contre les infractions en matière d'environnement.

491 Voir PRIEUR (Michel), Droit de l'environnement, Op.Cit, pp.719-720.

492 Cass. Crim. 28 avril 1977, D. 1978. 1, L9, note M.L. RASSAT. JCP. 1978. II. 18931, note Delmas-Marty; Cass. Crim. 5 octobre 1982, G.P. 1983, I, Sommaire 97.

${ }^{493}$ Voir en ce sens, PRIEUR (Michel), Droit de l'environnement, Op.Cit. pp. 711-712. En France, la loi de 1990 sur la pollution de la mer par les hydrocarbures précisant la convention de Londres de 1954, qui définit les éléments constitutifs d'une infraction a institué une incrimination nouvelle et autonome de pollution involontaire et accidentelle de la mer.

${ }^{494}$ SRITASTAVA ( S.P.), Stratégie pour la protection du milieu marin, juillet1988, PP6-16.

${ }^{495}$ Cela est d'ailleurs conforme à l'article 95 du code pénal ivoirien qui dispose que la personne physique responsable de ses actes est seule soumise à une sanction pénale. Est responsable de ses actes, celui qui est apte à comprendre et à vouloir.
} 
inculper le patron, auteur intellectuel ou moral. Selon la cour de cassation, la responsabilité doit remonter aux chefs d'entreprise à qui sont imposées les conditions et le mode d'exploitation de leur industrie en terme de la défense de la salubrité ou de sûreté publique. Car dit elle, l'activité industrielle n'a pas uniquement pour but la production des biens, elle doit également assurer l'hygiène, la qualité de l'environnement et la sécurité.

De ce fait, le chef d'entreprise a un devoir de surveillance et de commandement en vue de préserver le milieu dans lequel il exerce ses activités de toute atteinte ou destruction, sauf délégation de pouvoir à un préposé pourvu de la compétence et de l'autorité nécessaire ${ }^{496}$.

Nous proposons qu'il soit facilité la mise en cause d'autres responsables que le capitaine. A cet effet, il serait équitable que les amendes soient supportées par le propriétaire du navire ou l'exploitant du navire compte tenu des circonstances de fait notamment en ce qui concerne les conditions du travail. De même, toutes personnes exerçant en droit ou en fait un pouvoir de contrôle ou de direction dans la gestion ou la marche du navire et qui a été à l'origine d'un rejet illégal ou qui n'a pas pris les mesures nécessaires pour l'éviter pourra encourir les mêmes peines que celui qui fait souvent figure de bouc émissaire. C'est-à-dire le capitaine.

De même, les personnes morales ayant ordonné ou s'étant rendues complices de rejet d'hydrocarbures ou autres substances polluantes devraient être frappées d'une amende plus forte que celle frappant les personnes physiques. Car ce serait injuste que l'entreprise employant le capitaine et n'ayant prévu aucun système de traitement échappe à la sanction pénale. Quitte à elle de se séparer du capitaine après lui avoir ordonné le déversement des substances polluantes. De plus, tenir l'employeur pénalement responsable des pollutions est une faveur pour les victimes. Car celui-ci est en général plus solvable que le préposé salariét97. De même, l'entreprise peut être placée sous surveillance judiciaire ou se voir opposer l'interdiction d'exercer une certaine activité professionnelle ou l'interdiction d'avoir recours à l'épargne publique. Le particularisme du Droit pénal semble influencer négativement son efficacité.

\section{La faiblesse tirée du particularisme des règles de droit pénal}

La répression de la pollution par les hydrocarbures ne se heurte-t-elle pas à des difficultés liées au nécessaire respect des règles du droit pénal notamment en ce qui concerne leur interprétation stricte ou encore celles relatives à la preuve du rejet pour

\footnotetext{
${ }^{496}$ Voir en ce sens, PRIEUR (Michel), Droit de l'environnement, op.cit, P.712.

${ }^{497}$ Aujourd'hui, les principales compagnies pétrolières internationales appelées les majors sont au nombre de cinq à savoir l'américaine Exxon/Mobil, la britannique BP, l'anglo-néerlandaise Shell, la française Total, produit de la fusion d'Elf, Fina et de Total et l'américaine Chevron/Texaco fournissent une idée sur la taille de leur fortune en milliards de dollar américain en 2003. Voir Encyclo, Tout savoir sur les énergies, le marché international du pétrole : les majors, avril 2005, pp.1- 5.
} 
identifier le navire responsable pénal ${ }^{248}$ Encore, les difficultés de preuve de la faute n'incombent-elles pas à chacune des personnes qui interviennent dans la gestion du navire?

Ces interrogations trouvent leur intérêt dans la mesure où ces difficultés sont de nature à paralyser la mise en ouvre des sanctions pénales ${ }^{49}$. En matière de pollution, la répression se heurte toujours à la difficile preuve de l'intention coupable de l'auteur, élément moral en principe indispensable à la caractérisation d'un délit. La preuve du caractère involontaire d'un rejet opérationnel d'hydrocarbures est difficile à rapporter. Comment déduire systématiquement de la concomitance de l'arrêt du rejet et du contact radio avec le caractère volontaire des faits?

Ces difficultés d'interprétation stricte des règles du droit pénal et de la preuve sont respectivement mises en évidence par deux arrêts. Le premier arrêt est celui de la C.A de Poitiers du 14 mars 1975, arrêt ministère public contre Perrin Jacques. Dans cet arrêt, il est jugé que l'infraction des rejets "à la mer» n'est pas constituée lorsque le déversement d'hydrocarbures s'est produit alors que l'eau du bassin à flot pénétrait dans une cale sèche. Le deuxième arrêt met en évidence les difficultés de preuve de l'infraction de pollution. C'est l'arrêt, M. Kniebush contre procureur de la république de Brest $^{500}$ rendu par la CA de Rennes le 22 février 1983.

Le versement d'une importante caution au prorata des dommages par pollutions devrait être exigé pour obtenir la main levée de la saisie du navire. Dès lors, si la justice prononce une décision de condamnation, la caution devrait être acquise à L'État. Si celle-ci n'est pas suffisante pour l'amende, l'auteur des rejets devrait verser le supplément sous peine d'une nouvelle saisie du navire lors de son tout prochain passage dans le port du pays victime de pollution par déversement d'hydrocarbures ${ }^{501}$.

A cet effet, il faut encourager la collaboration des ministères qui ont en charge la prévention et la lutte contre les pollutions des eaux ivoiriennes. De sorte qu'ils puissent mettre en œuvre les lois nationales sur la protection du patrimoine maritime national.

\footnotetext{
${ }^{498}$ En matière pénale, la règle est que le preuve est libre et peut être rapporter par tout moyen concernant l'établissement des infractions et de la matérialité des faits. Voir en cela l'article $10-6$ de la convention MARPOL 13/78.

499 Voir en ce sens BECET (Jean-Marie) et LE MORVAN (Didier), Le droit du littoral et de la mer côtière, Economica, p. 201, et l'article de Karine Le Couviour, Récent développement normatif, Op. cit., p.1082. Robert SABRINA reconnait que pour que l'infraction soit reconnue à l'encontre du mis en cause, il faut que soit prouvée la toxicité du pétrole déversé, le risque immédiat de mort et de blessures. Cela implique la preuve du non respect volontaire des règles de sécurité ou de prudence par l'affréteur ou toute autre personne ayant manqué intentionnellement à ses obligations.

500 Les deux arrêts sont cités par Jean-Marie Becet et Didier le Morvan, in, Le droit du littoral et de la mer côtière, Paris, Economica, 1991 P.201.

${ }^{501}$ A propos des mesures de sûreté souhaitées, l'article 98 (alinéas 2 et 3 ) du code de l'environnement dispose à juste titre que l'Administration marine peut arraisonner tout navire surpris en flagrant délit de déversement de contaminants, y compris les hydrocarbures en mer. En cas de récidive, l'amende est portée au double et l'Administration se réserve le droit de procéder à la saisie du navire. Voir aussi, en ce sens, BAIKEH ( Jonas), "Un navire suspect saisi ", in Soir info n ${ }^{\circ} 3764$ du jeudi 15 mars 2007 où l'auteur met en évidence ce qui devrait être l'attitude normale d'un État souverain soucieux de la sécurité de sa population.
} 
La persistance des entraves à l'efficacité du droit maritime international est également perceptible à travers l'inadaptation des règles d'indemnisation des victimes de marées noires. 
TITRE 2:

\section{L'INADAPTATION DES RÈGLES D'INDEMNISATION DES VICTIMES DE MARÉES NOIRES}

La réparation civile des dommages causés par les pollutions marines est régie au plan international par les règles de responsabilité prévues par les conventions internationales pertinentes.

Au niveau des normes issues du droit maritime international, notre attention se portera sur la Convention de Bruxelles du 29 novembre 1969 portant sur la responsabilité civile pour les dommages dus à la pollution par les hydrocarbures telle que modifiée notamment par le Protocole du 27 novembre 1992 ; sur la Convention de Bruxelles du 18 décembre 1971 portant création d'un Fonds international d'indemnisation pour les dommages dus à la pollution par les hydrocarbures (FIPOL) telle que modifiée par le Protocole du 27 novembre 1992. A l'analyse, le droit maritime international s'avère inadapté à indemniser les victimes des marées noires.

L'inadaptation du droit maritime international est perceptible à travers les limites des règles procédurales relatives à l'action en responsabilité civile (Chapitre 1) et des faiblesses du système international d'indemnisation découlant de l'étendue de la responsabilité civile du propriétaire du navire (Chapitre 2). 


\section{CHAPITRE 1: LES LIMITES DES REGLES PROCEDURALES RELATIVES A L'ACTION EN RESPONSABILITE CIVILE}

L'étude des règles procédurales de l'action en responsabilité consiste à analyser essentiellement les règles de compétence juridictionnelle ${ }^{502}$.Celles-ci sont définies notamment par les articles 9 et 10 de la convention internationale de 1969 relative à la responsabilité civile.

En effet, il apparaît que le demandeur en indemnisation pour dommages de pollution par hydrocarbures ne peut s'adresser à n'importe quelle juridiction (Section I). Par ailleurs, les règles classiques de l'établissement de la responsabilité civile des pollueurs s'avèrent peu dissuasives (Section II).

\section{Section 1: Le recours exclusif à la procédure judiciaire contentieuse}

La détermination du juge compétent pour apprécier et évaluer la responsabilité du propriétaire du navire en cas de pollution présente un enjeu certain pour le bon déroulement de la procédure. Car c'est de celle-ci que dépendent la concrétisation et la formalisation de la créance d'indemnisation des victimes. La question de la compétence juridictionnelle se trouve être réglée par les articles 9 de la Convention CLC 1969 et 7 de la Convention FIPOL 1971. A l'analyse, sur ce point le droit maritime international présente deux types de risques : ce sont d'une part la question d'incident de procédure en termes de jonction en cas de connexité ${ }^{503}$ en cas de saisine concomitante de plus d'une juridiction (paragraphe1), d'autre part il existe un risque d'inefficacité de l'autorité du jugement rendu (paragraphe 2).

\section{Paragraphe 1: Le risque de saisine concomitante ${ }^{504}$ de plus d'une juridiction}

Le requérant ne peut saisir en droit commun qu'une juridiction de l'appareil judiciaire d'un des États parties à la convention CLC 1969.

En effet, aux termes de l'article 9 de la convention CLC1969:

"lorsqu'un événement a causé un dommage par pollution sur le territoire y compris la mer territoriale d'un ou de plusieurs États contractants, ou que des mesures de sauvegarde

\footnotetext{
502 La compétence est le pouvoir octroyé par la loi à une juridiction d'instruire et/ou de juger tel ou tel type d'affaire. Voir NICOLEAU (Patrick), Lexique de droit privé, op. cit. p.83

${ }^{503}$ Lien établissant un rapport étroit entre deux affaires et obligeant de ce fait à, les lier dans une même instance sous peine d'aboutir à une contrariété de décision. Voir Patrick NICOLEAU Lexique de droit privé, p.90

${ }^{504}$ Dans l'affaire de l'Amoco Cadiz, la compagnie défenderesse avait son siège social aux États-Unis, État non partie à la Convention. Ignorant la convention de Bruxelles, les demandeurs français allèrent saisir les tribunaux américains, alors que la France est partie à ladite convention ainsi que le Liberia État du pavillon du navire pollueur. Le tribunal de Lilles accepta de statuer sur la demande formée contre les sociétés exploitantes du navire ainsi que contre leur société mère. Voir REMOND-GOUILLOUD (Martine), " Pollution des mers ", in Jurisclasseur volume 7 , fascicule 1292 , op. cit., , $n^{\circ} 18$, p.7.
} 
ont été prises pour prévenir ou atténuer tout dommage par pollution sur ces territoires y compris la mer territoriale, il ne peut être présenté de demande $e^{505}$ d'indemnisation que devant les tribunaux de ce ou de ces États contractants ${ }^{506}$.

La nécessité de la jonction ${ }^{507}$ des instances est mentionnée tant par la convention CLC de 1969 en son article 9 alinéa 3, que par la convention FIPOL de 1971 en son article 7 alinéa 3.

Le litige relatif à la pollution par hydrocarbures est bien celui qui véritablement peut poser le problème de conflit de la compétence de juridiction à saisir, voire même celui de la loi de fond à appliquer. Car le contentieux des dommages par pollution intéresse à l'évidence les règles de droit international privé soumises en l'espèce à des Conventions internationales du fait du caractère transfrontière que les pollutions des mers par les navires sont réputées avoir. Ainsi que nous l'avons indiqué plus haut, au regard du lieu où s'exerce l'activité, le transport maritime n'a véritablement pas de frontière. En effet, la créance invoquée par le demandeur en l'encontre du défendeur qu'est le transporteur maritime apparaît comme, selon les termes du professeur Pierre JULIEN « un conglomérat de créances multiples ayant chacune sa nature propre mais reliée entre elles par un lien d'indivisibilité qui les unit les unes aux autres ${ }^{508} »$.

Dès lors, il apparaît nécessaire de rechercher les conditions de la jonction des instances (A) ainsi que la loi applicable par le juge saisi (B).

\section{A - Les conditions de la jonction des instances}

L'intérêt de cette problématique de la jonction des instances est mis en évidence notamment dans l'affaire «Amoco Cadiz » par la cour d'appel de Rennes du 3 octobre $1985^{509}$. Il ressort des faits de l'espèce que le gouvernement du Royaume uni avait fait valoir ses prétentions sur le fonds de limitation constitué par l'armateur en France

\footnotetext{
505 En effet, il est de principe qu'en matière civile, c'est bien le tribunal du domicile du défendeur qui est compétent à connaître de l'affaire dans laquelle celui-ci est mis en cause. A ce propos, l'article 11 alinéa 1 du CPCCA ivoirien affirme que le tribunal territorialement compétent en matière civile est celui du domicile réel ou élu du défendeur et en l'absence de domicile, celui de sa résidence.

${ }^{506}$ Aux termes de l'article 5 du CPCCA ivoirien, les tribunaux de première instance et les sections détachées connaissent de toutes les affaires civiles, commerciales, administratives, et fiscales pour lesquelles compétence n'est pas attribuée expressément à une autre juridiction en raison de la nature de l'affaire. Cependant le traité de l'OHADA complète le système judiciaire ivoirien par des dispositions à caractère supranational avec la naissance d'une juridiction spécialisée dans la connaissance des litiges nés de l'application du traité de l'organisation pour l'harmonisation en Afrique du droit des Affaires (l'OHADA). Elle regroupe 16 pays membres dont la Côte d'Ivoire. Elle a pour vocation d'ouvrir son espace à tout État membre ou non de l'Union Africaine.

${ }^{507}$ La jonction d'instance est une mesure d'administration judiciaire par laquelle un tribunal (un juge de mise en état ou un juge rapporteur) décide d'instruire ou de juger en même temps deux ou plusieurs instances unies par un lien étroit de connexité. Voir GUILLIEN (Raymond) et VINCENT (Jean), Lexique des termes juridiques, Précité, p.332.

${ }^{508}$ Voir JULIEN (Pierre), note sous l'arrêt de la cour d'appel de Paris du 2 mai 1983, Dalloz Sirey, 1984, p. 349

${ }^{509}$ DMF février 1986, 38 è année, $n^{\circ} 446$, p.100.
} 
auprès du président du tribunal de commerce de Brest le 10 février 1981 pour les dommages causés. Le 9 juillet 1981, le même gouvernement assigne Geniteau (le liquidateur du fonds de limitation des responsabilités) en intervention à l'instance. Le 15 juillet 1981, la même partie délivra une troisième assignation aux fins de la liquidation du fonds et de la mise à sa disposition de la somme demandée ( $£$ 1.877.207) ainsi que l'exécution provisoire du jugement. Pendant ce temps, la plupart des créanciers ignorant ce fonds préféraient agir devant les tribunaux américains. Devant cet éparpillement des instances, la cour d'appel de Rennes prononça la jonction des instances du 10 février, 9 juillet et 15 juillet 1981 .

La cour d'appel de Rennes à propos de l'affaire « Amoco Cadiz» déclare que : "considérant qu'ils ont joint les procédures puisqu'elles concernent les mêmes parties, et visent à la mise en cuvre d'une seule et même action à savoir la réparation d'un dommage».

Ces propos qui illustrent bien les conditions de la jonction des procédures, cachent en fait selon le professeur Martine REMOND-GOUILLOUD, la faiblesse inhérente à toute convention internationale qui ne lie que les États qui l'on ratifiée.

En effet, selon l'auteur, les mécanismes qu'instaure le système international de responsabilité n'excluent pas le jeu parallèle d'autres procédures engagées sur d'autres fondements dans des États tiers ${ }^{510}$. Étant donné que pour la même affaire, les tribunaux américains avaient été saisis par d'autres créanciers ${ }^{511}$. Comme on le voit, les instruments juridiques internationaux en la matière ont montré leur faiblesse sur le problème d'éparpillement des instances relatives à un même accident entre des juridictions relevant des États différents, dont les uns sont parties à la convention et les autres non parties. Cet état de fait est véritablement de nature à créer des préjudices graves à la bonne marche de la justice. Dans cette optique, l'article 7 alinéa 3 de la convention FIPOL 1971 et l'article 9 de la convention CLC 1969 déclarent l'un et l'autre que si une action en réparation des dommages est intentée devant un tribunal compétent contre le propriétaire d'un navire ou son garant, le tribunal saisi de l'affaire est seul compétent pour connaître de toute demande d'indemnisation introduite contre le Fonds. ${ }^{512}$

La connexité et la litispendance constituent des délicats incidents de procédure qui influent sur le règlement d'un procès ${ }^{513}$. Pour Jean VIATTE, la litispendance oblige la

\footnotetext{
510 Voir REMOND-GOUILLOUD (Marine), « Les surprises du Fonds », in DMF février 1986, n446, p.90.

511 Ce dispersement des instances est favorisé par l'article 2 de la convention CLC 1969, en ce que ce texte déclare que ladite convention s'applique exclusivement aux dommages par pollution survenus sur le territoire d'un État contractant.

512 Voir en ce sens, CAA arrêt $\mathrm{n}^{\circ} 157$ du 14 février 2003, Sté Delmas SA contre Sté SAFARIV-CI. Sur la question de la jonction des procédures, la cour déclare qu'il y a connexité de cause et des parties dans lesdites procédures. Aussi ordonne-t-elle, la jonction des procédures inscrites au rôle général du greffe de la cour, les $n^{\circ} 1140$ et $1141 / 2002$.

${ }^{513}$ Néanmoins, ces deux termes doivent être distingués. Il y a litispendance lorsque deux demandes identiques sur le même litige sont portées devant deux juridictions de mêmes degrés également compétents pour en connaître. Tandis que la connexité suppose deux demandes différentes quant au fond, mais portant sur la
} 
juridiction saisie en second lieu à se dessaisir au profit de l'autre si l'une des parties le demande ${ }^{514}$. Cela exige l'identité des litiges qui doit exister tant en ce qui concerne l'objet de la demande notamment l'indemnisation (dommages et intérêts), que la personnalité des parties. Pour l'auteur, le problème se pose différemment en ce qui concerne la connexité car celle-ci suppose seulement un lien tel qu'il soit de l'intérêt d'une bonne justice de faire instruire et juger ensemble les deux instances ${ }^{515}$.

Saisi régulièrement d'une demande en réparation des dommages subis, le juge doit pouvoir se fonder sur une loi pour trancher l'affaire.

\section{B - La loi applicable par la juridiction compétente}

Poser le problème de la loi applicable revient à rechercher le fondement de l'instance en responsabilité civile engagée devant le juge saisi. A priori, nous estimons que cette question semble plus présenter d'intérêt pour les règles de forme ou processuelles du juge saisi que pour les règles de fond ${ }^{516}$. Etant donné que les Conventions sur le système international de responsabilité et d'indemnisation constituent en la matière, les règles de fond devant régir le jugement.

A notre sens, il serait plus commode de qualifier cette situation non de conflit de lois, mais plutôt de conflit de juridictions. Car l'expression "conflit de juridictions" recouvre l'ensemble des problèmes que soulève le contentieux privé international. C'est en fait le droit judiciaire privé applicable à un litige comportant des éléments internationaux ${ }^{517}$.

Quelle est donc la règle procédurale devant régir l'instance? A cet effet, la convention FIPOL indique en son article 7 que si une action en réparation de dommage par pollution a été intentée devant un tribunal compétent d'un État contractant contre un

même affaire sont portées devant deux tribunaux différents. Voir VINCENT (Jean) et GUINCHARD (Serge), "Procédure civile ", Dalloz, 23è édition, 1994, pp. 300 à 338.

${ }^{514}$ Alors qu'en matière de connexité, la juridiction saisie en second lieu ne peut se dessaisir d'office au profit de l'autre que si la demande de renvoi est exercée par le mis en cause. Voir Cour de cassation 5 juillet 1978, G.P., $1978,624$.

${ }^{515}$ Voir VIATTE (Jean), note sous l'arrêt de la cour de cassation (2è ch civile) du 5 juillet 1978, in G.P., p 624. Voir aussi dans ce sens, l'article du professeur REMOND-GOUILLOUD «Les surprises du fonds » où l'auteur met en évidence non seulement les inconvénients de l'existence de deux instances parallèles l'une aux ÉtatsUnis et l'autre en France, statuant sur des fondements juridiques différents, mais également la jonction des instances dans l'intérêt d'une bonne justice, in DMF 1946, n446 PP 94 et suivants.

516 Par opposition à la forme, le fond concerne la matière fondamentale qui fait l'objet de l'acte juridique ou $\mathrm{du}$ procès. Pour un procès, les prétentions des parties, les faits font parties du fond par opposition à la procédure et à la compétence. Voir NICOLEAU (Patrick), Lexique de droit privé, Op. cit, p. 165

517 Les règles de conflit de juridictions englobent trois types de règles à savoir les règles de compétence directe ou les règles qui permettent au juge par exemple ivoirien de savoir s'il est compétent pour trancher le litige que les parties lui soumettent, les règles de compétence indirecte, c'est-à-dire les règles qui déterminent si et à quelle conditions un jugement étranger peut produire ses effets par exemple en Côte d'Ivoire et surtout les règles de procédure devant être suivies par le juge ivoirien confronté à un litige international. Voir en ce sens, MAYER (Pierre), HEUZE (Vincent), Droit international privé, Paris, Montchrestien, 7è édition, 2001, pp. 247 et suivants. 
propriétaire ou son garant ( ...) la loi nationale de l'État en question doit permettre à toute partie à la procédure de notifier cette action au Fonds ( ...)

La clarté des règles procédurales est déterminante au regard de l'importance de la conséquence qui s'y attache.

En effet, la convention portant création du Fonds dispose que si une telle notification a été faite suivant les modalités prescrites par la loi de l'État où se trouve le tribunal saisi, en laissant au Fonds un délai suffisant pour pouvoir intervenir utilement comme partie à la procédure, tout jugement rendu par le tribunal dans cette procédure et qui est devenu définitif et exécutoire dans l'État où il a été prononcé est opposable au Fonds. Même si celui-ci n'est pas intervenu dans la procédure, en ce sens qu'il n'est pas en droit de contester les motifs et le dispositif du jugement ${ }^{518}$.

Comme on le voit, le système international par cette disposition montre des signes de cohérences grâce au mécanisme qui consiste à donner compétence au tribunal de l'État saisi de statuer conformément aux règles de procédure du juge saisi. Dès lors, nous aurions souhaité que le système détermine le délai nécessaire pour notifier au Fonds l'action en réparation de dommages par pollution intentée devant le tribunal compétent. Cela éviterait des ambiguïtés liées aux interprétations.

En tout état de cause, l'article 34 du code de procédure civile, commerciale et administrative ivoirien dispose au titre du délai de comparution que le délai de huit jours est augmenté d'un délai de quinze jours si le destinataire est domicilié dans un autre ressort et de deux mois s'il demeure hors du territoire de la république de Côte d'Ivoire $^{519}$. Ces délais répondent-ils aux exigences du système international de responsabilité ? Faute de critère suffisant d'appréciation, il serait difficile d'y répondre. Aussi redoutons- nous des incidents de procédures liés au délai de comparution lors du déroulement du procès.

En effet, ces incidents se traduiraient notamment par le dilatoire ${ }^{520}$ du défendeur (armateur pétrolier) ou encore du Fonds d'indemnisation a qui l'on adresse la demande d'indemnisation des dommages de pollution. A la vérité, tout défaut de diligence de la part du demandeur peut se révéler comme un moyen de défense pour le défendeur ${ }^{521}$ et particulièrement pour le Fonds d'indemnisation. Car celui-ci constitue véritablement le dernier recours du demandeur. En ce sens que le Fonds apparaît comme l'ultime garant

\footnotetext{
518 Voir dans ce sens aussi l'article 9 alinéa 1 de la Convention CLC 1969. Dans cette optique, l'article 5 alinéa 1 de la convention CLC 1969 dit que avis doit être donné au défendeur dans un délai raisonnable de l'introduction de telle demande.

519 Etant entendu que les délais sont francs et se calculent de quantième en quantième sans tenir compte de la durée réelle de chaque mois. Selon l'article 104 du CPCCA, la demande en intervention volontaire ou forcée est introduite selon les règles ordinaires applicables devant la juridiction saisie.

${ }^{520}$ Le dilatoire a pour but de retarder une décision de justice ou de prolonger le procès.

521 A ce sujet, l'article 7 alinéa 4 de la convention FIPOL 71, précise que chaque État contractant est tenu de prendre toutes les dispositions nécessaire pour que le Fonds puisse se porter intervenant dans toutes procédures judiciaires introduites devant un tribunal compétent de cet État, contre le propriétaire d'un navire et son garant.
} 
en termes de réparation des dommages subis au cas où le propriétaire du navire serait incapable d'indemniser les créanciers ${ }^{52}$. A notre sens, l'autorité du jugement rendu par le tribunal compétent risque de manquer d'efficacité.

\section{Paragraphe 2: Le risque d'inefficacité de l'autorité du jugement rendu}

La reconnaissance et l'exécution forcée du jugement rendu sont-elles mieux assurées au profit des créanciers de l'indemnisation par pollution? Le jugement rendu par le tribunal compétent conformément à la Convention sur la responsabilité peut donner lieu à deux issues.

En effet, le juge peut soit débouter le demandeur en indemnisation des dommages par pollution soit encore faire droit à sa demande. Dans ce dernier cas de figure, il convient de se demander si la législation internationale assure une exécution forcée à ce jugement. Jugement qui va servir de fondement à l'exécution forcée du droit reconnu au demandeur ${ }^{223}$. Il ressort de nos observations que le jugement rendu doit faire l'objet d'une reconnaissance préalable $(A)$ et les victimes risquent de subir l'impasse de l'exécution effective du jugement rendu (B).

\section{A - La reconnaissance préalable du jugement rendu}

La reconnaissance du jugement est marquée par la coopération judiciaire internationale. C'est ce qui ressort de l'article 10 de la convention internationale portant responsabilité civile pour les dommages dus à la pollution par hydrocarbures. En effet, aux termes du texte susvisé, la coopération judiciaire est subordonnée à deux sortes de conditions à savoir que le demandeur à l'action en indemnisation doit faire preuve de diligence au cours de poursuite engagée (1) et qu'aucun recours de la part du défendeur ne doit être exercé contre le jugement rendu par le tribunal (2)

\section{La diligence du demandeur}

Le système international de responsabilité met à la charge de l'État contractant et surtout du demandeur à l'action un certain nombre d'obligations. De l'observation de celles-ci, dépend la reconnaissance du jugement rendu dans tout autre État partie à ladite convention.

\footnotetext{
522 Selon le doyen René RODIERE, l'avis donné au défendeur dans le délai requis de l'introduction de la demande devrait l'engager à faire son calcul et à se décider à constituer le Fonds de limitation. Voir René RODIERE, Traité général de droit maritime, Op.cit, P.22.

523 Selon l'article 1351 du code civil français, l'autorité de la chose jugée n'a lieu qu'à l'égard de ce qui a fait l'objet du jugement. Il faut que la chose demandée soit la même; que la demande soit fondée sur la même cause, que la demande soit entre les mêmes parties et formée par elles et contre elles en la même qualité.
} 
En effet, aux termes de l'article 10 alinéa 1a et b de la Convention CLC 69, tout jugement d'un tribunal compétent qui est exécutoire dans l'État d'origine est reconnu dans tout autre État contractant sauf si le jugement a été obtenu frauduleusement, si le défendeur n'a pas été averti dans des délais raisonnables et mis en mesure de présenter sa défense ${ }^{524}$.

Quant à l'État dont le tribunal a rendu le jugement, il doit satisfaire aux prescriptions fixées par les articles 9 et 10 de la convention CLC 1969, ainsi qu'à l'article 7 de la convention FIPOL 1971. Il ressort de l'article 9 alinéas 2 et 3 que chaque État contractant veille à ce que ses tribunaux aient compétence pour connaître de telles actions en réparation et que les tribunaux de l'État où le fonds est constitué sont seuls compétents pour statuer sur toutes questions de répartition et de distribution du fonds. L'article 10 alinéa 2 précise également que tout jugement qui est reconnu, est exécutoire dans chaque État contractant dès que les procédures exigées dans ledit État ont été remplies.

Par ailleurs, la convention FIPOL 1971 fait des recommandations à chaque État contractant sous peine de voir le Fonds ne pas être lié par aucun jugement rendu à la suite d'une procédure judiciaire, ni par aucun règlement à l'amiable auquel il n'a pas été partie. C'est ce qui ressort de l'article 7 alinéa 5.

Dans cette même optique, les alinéas 4 et 6 de l'article 7 de la convention FIPOL 1971 déclarent que chaque État contractant est tenu de prendre toutes les dispositions nécessaires pour que le Fonds puisse se porter partie intervenante dans toutes procédures judiciaires introduites conformément à l'article 9 de la convention CLC 1969 devant un tribunal compétent de cet État contre le propriétaire d'un navire ou son garant. A cet effet, la loi nationale de l'État en question doit permettre à toute partie à la procédure de notifier cette action au Fonds. Dès lors, si une notification a été faite en laissant au Fonds un délai suffisant pour intervenir comme partie à la procédure, tout jugement rendu par le tribunal dans cette procédure et qui est devenu définitif et exécutoire dans l'État où il a été prononcé est opposable au Fonds, même si celui-ci n'est pas intervenu dans la procédure.

Toutes les recommandations requises par le système international de responsabilité à l'effet de conférer reconnaissance au jugement rendu semblent pertinentes. Toutefois, des inquiétudes demeurent. En fait, nous redoutons des obstacles au niveau du processus d'indemnisation rapide des victimes de pollution au titre des exceptions susceptibles d'être soulevés par le défendeur tant contre le demandeur pour sa négligence que contre la décision elle-même. Il est possible qu'il se fonde notamment sur l'adage fraus omnia corrumpit ou encore la fraude corrompt tout. La jurisprudence fait appel à cette théorie en indiquant que "la fraude fait exception à toutes les règles".

${ }^{524}$ Voir en ce sens, les articles 41 et 54 du CPCCA. 
Cet adage exprime que la fraude ${ }^{525}$ pourra toujours être sanctionnée même en l'absence de dispositions légales expresses, par une action en nullité de l'acte qui en est entaché. En effet, par fraude il faut entendre un acte accompli par un sujet de droit dans l'intention de détourner la loi ou de porter une atteinte illicite au droit des tiers. Dans quelle mesure, le jugement rendu serait-il donc entaché de fraude?

La Convention n'y apporte pas précisément de réponse. A notre avis, la décision devrait être privée de reconnaissance si elle est fondée par exemple sur la prise à partie ou encore sur le fonctionnement défectueux de la justice. Autrement dit, le jugement ne serait pas reconnu par les autres États par exemple s'il est rendu à la suite d'emploi des moyens contraires à la loi. A ce sujet, Jacques GHESTIN fait observer que le droit n'est pas une mécanique aveugle. Il se contrôle lui- même. En ce sens que si la mise en œuvre des règles juridiques aboutit à des résultats trop choquants, des instruments telle que la théorie de la fraude sont forgée afin de corriger les excès ${ }^{526}$.

Comment donc prouver la fraude que le défendeur à l'action en réparation voudrait imputer au demandeur? Le code civil limite le jeu du moyen de défense tiré de la fraude. En effet, il ressort de l'article 2268 du code civil français que la fraude ne se présume point ${ }^{527}$.

Le code de procédure civile commerciale et administrative ivoirien indique en son article 218 les cas dans lesquelles le plaideur peut agir en responsabilité civile contre un magistrat. Selon ce texte, il y a la prise à partie ${ }^{528}$, s'il y a le dol, la fraude, la concussion ou la faute lourde professionnelle commis soit au cours de l'instruction, soit lors des décisions. Et ce, si la prise à partie est expressément prévue par une disposition législative comme il en est lorsque les juges refusent de juger sous prétexte du silence, de l'obscurité ou de l'insuffisance de la loi. Ainsi, il pèse sur le défendeur qui fait grief au jugement rendu de démontrer la fraude dont serait entachée la décision qui le frappe, autant qu'il doit faire la preuve qu'il n'est pas mis en mesure de présenter sa défense ${ }^{529}$.

\footnotetext{
${ }^{525}$ Pour M. VIDAL, il y a fraude chaque fois que le sujet de droit parvient à se soustraire à l'exécution d'une règle obligatoire par l'emploi à dessein d'un moyen efficace, qui rend ce résultat inattaquable sur le terrain du droit positif. La fraude procède de la réunion de trois éléments à savoir une règle obligatoire, l'intention de l'éluder et l'emploi à cette fin d'un moyen adéquat. Voir Jacques GHESTIN et Gilles GOUBEAUX, Traité de droit civil, introduction générale, LGDJ, Paris, PP. 630 et suivants.

${ }^{526}$ La théorie de l'abus de droit, et celle de la fraude constituent des instruments par lesquels la mise en œuvre des droits est sauvegardée. Voir GHESTIN (Jacques) et GOUBEAUX (Gilles), Traité de droit civil introduction, Op. cit. PP.574-575 et 622 et suivants.

${ }^{527}$ Selon le texte, la bonne foi est toujours présumée et c'est à celui qui allègue la mauvaise foi de la prouver.

${ }^{528}$ La prise à partie permettait en cas de dénit de justice, de dol, de concussion ou de faute lourde professionnelle d'agir en responsabilité civile contre un magistrat de l'ordre judiciaire. Voir en cela l'article 217 du code CPCCA ivoirien

529 Selon le Professeur Bernard BOULOC, l'exigence tirée du droit de défense constitue aujourd'hui la pierre angulaire des procédures juridictionnelles. Voir Bernard BOULOC, «Apparence d'hydrocarbures et présomption d'innocence ", in DMF, n661, juillet août 2005, PP.589-595. Voir aussi AKPA (Mélèdje Henri), Principes fondamentaux de célérité des droits de la défense et le CPCCA, Thèse soutenue le 22 juillet 1986, p.
} 
Autant la reconnaissance internationale du jugement dépend de la diligence du demandeur et de l'État contractant, autant elle est subordonnée au défaut de recours de la part du défendeur.

\section{Le défaut de recours judiciaire du défendeur à l'action}

La condition tirée du défaut de recours judiciaire est prévue tant par la convention de 1969 sur la responsabilité civile que par la Convention de 1971 sur la création du Fonds. L'article 10 alinéa 1 de la convention de 1969 sur la responsabilité civile dit que tout jugement d'un tribunal compétent qui est exécutoire dans l'État d'origine où il ne peut plus faire l'objet d'un recours ordinaire ${ }^{530}$, est reconnu dans tout autre État contractant. L'article 8 de la Convention FIPOL 1971 subordonne également la reconnaissance du jugement rendu au défaut de recours contre celui-ci. A cet effet, le texte déclare que tout jugement rendu contre le Fonds par un tribunal compétent et qui dans l'État d'origine est devenu exécutoire et ne peut plus faire l'objet d'un recours ordinaire est reconnu exécutoire dans tout État contractant sous réserve des conditions de l'article 10 de la convention sur la responsabilité.

Les voies de recours en ce qu'elles participent de la garantie d'une bonne justice, leur exigence en tant que condition de la reconnaissance du jugement ne souffrirait d'aucune contestation. Cependant, il est à redouter que leur exercice constitue une porte ouverte au dilatoire de nature à bloquer le processus d'indemnisation rapide des victimes. Car il est possible que les défendeurs vont soulever de façon fantaisiste des voies de recours à l'effet sinon d'échapper à la décision qui les condamne, au moins en retarder l'exécution. Aux termes de l'article 10 alinéa 2 in fine de la convention CLC 1969, les procédures exigées dans ledit État ne sauraient autoriser une révision au fond. Or justement à propos des effets liés aux voies de recours ordinaires, les articles 158 nouveaux alinéa 1 et $177 \mathrm{du}$ CPCCA ivoirien disposent respectivement que l'opposition suspend l'exécution de la décision, si celle-ci n'a pas été ordonnée nonobstant opposition. L'appel a pour effet de remettre la cause ${ }^{531}$ en l'état où elle se trouvait avant la décision entreprise $^{532}$.

\footnotetext{
326, où l'auteur déclare que seule la contradiction est le noyau dur d'une protection réelle des parties dans le procès.

Tirant la conséquence de l'importance du droit éde la défense en matière la procédure judiciaire, l'article 120CPCCA ivoirien en fait un moyen de défense pour toute personne contre laquelle un procès est engagé. Alors, elle peut exiger que lui soient communiquées les pièces sur lesquelles la partie adverse entend fonder sa demande ou sa défense.

Les voies de recours sont des moyens mis à la disposition des plaideurs pour leur permettre d'obtenir un nouvel examen du procès ou de faire valoir des irrégularités observées dans le déroulement de la procédure.

530 Les voies de recours ordinaires sont l'appel et l'opposition. L'appel permet d'obtenir la reformation ou l'annulation d'une décision rendue en premier ressort. Quant à l'opposition, c'est une procédure ouverte au plaideur contre lequel une décision a été rendue par défaut.

${ }^{531}$ La notion de cause intervient pour fixer les éléments de la demande en justice : la règle de droit invoquée par le demandeur, les faits invoqués dans la prétention, l'ensemble des faits juridiquement qualifiés. Elle intervient aussi pour vérifier si le litige n'a pas été déjà jugé. Au sens large, la cause est la contestation dont est saisi le juge. Ainsi, la cause s'identifie au procès et se distingue du litige qui reste un conflit de prétention
} 
Ainsi, si le jugement est par exemple rendu par les juridictions ivoiriennes ces voies de recours constitueraient des empêchements à l'indemnisation rapides des victimes. Dès lors, si le système international de responsabilité tient véritablement à garantir une réparation rapide et équitable des victimes, il serait impérieux que l'on purge le jugement rendu de toutes voies de recours ordinaires exclusivement au profit des créanciers de l'indemnisation des victimes des dommages de pollution par les hydrocarbures effectivement subis par les victimes. Reconnu tant par l'État du tribunal saisi de l'affaire que par les autres États parties à la convention, le jugement rendu doit pouvoir être exécuté.

Or à l'analyse, l'exécution du jugement rendu est menacée d'impasse au détriment des victimes des marées noires.

\section{B - $\quad$ L'exécution du jugement menacée d'impasse au préjudice des victimes}

Les victimes de dommages par pollution ont intérêt dans la reconnaissance par le juge de la légitimité de leurs prétentions. ${ }^{533}$ Mieux, les créanciers de l'indemnisation attachent surtout du prix à la force exécutoire du jugement pour véritablement en obtenir l'application effective. Le rédacteur de l'instrument international de responsabilité civile a-t-il garanti l'exécution du jugement rendu et reconnu ? Il ressort de l'analyse du droit maritime international que l'efficacité de l'exécution du jugement semble être subordonnée aussi bien à la volonté des États contractants (1) qu'en ce qui concerne le cas général des débiteurs contre qui est dirigée l'action en indemnisation des dommages par pollution (2).

\section{La subordination de l'exécution du jugement au bon vouloir des États parties}

Le mécanisme international d'exécution du jugement rendu laisse apparaitre que chaque État partie à la Convention joue un rôle de catalyseur dans la mise en œuvre de la décision rendue. En ce sens qu'il est tenu d'exécuter ou faire exécuter celle-ci. C’est ce sentiment que semble nous inspirer notamment la convention de 1969 sur la responsabilité civile en ses articles 9 alinéa $3 ; 10$ alinéa 2 et 11 alinéa 2.

D’abord, selon l'article 9 alinéa 3 de la Convention précitée, après la constitution du fonds par le propriétaire d'un navire qui a causé des dommages par pollution, conformément à l'article 5 de la Convention, les tribunaux de l'État où le fonds de

dépourvu de formalisme tant que ne se produit pas l'élévation du contentieux. Voir GUILLIEN (Raymond) et VINCENT (Jean), Lexique des termes juridiques, Paris 2003,14è éd, Précité, p.90.

${ }^{532}$ En outre, les voies de recours ont normalement un effet dévolutif en ce sens que le litige dans sa complexité de fait et de droit est porté devant le juge saisi du recours, le premier juge sur opposition, le juge du second degré sur appel.

${ }^{533}$ Selon l'article 1er alinéa 1 du CPCCA ivoirien, toute personne physique ou morale peut agir devant les juridictions de Côte d'Ivoire en vue d'obtenir la reconnaissance, la protection ou la sanction de son droit. 
limitation est constitué sont seuls compétents pour statuer sur toutes les questions de répartition et de distribution des fonds de limitation.

Ensuite, quant à l'article 10 alinéa 2 précité, il indique clairement que tout jugement qui est reconnu exécutoire dans chaque État contractant est exécutoire dans chaque État contractant dès que les procédures exigées dans ledit État ont été remplies ${ }^{534}$. Enfin, l'article 11 alinéa 2 fait des recommandations à tout État contractant en ces termes : " tout jugement qui est reconnu dans tout autre État contractant est exécutoire dans chaque État contractant dès que les procédures exigées ont été suivies ...».

En ce qui concerne les navires appartenant à un État contractant et utilisés à des fins commerciales chaque État est passible de poursuite devant les juridictions de cet ou de ces États contractants et renonce à toute défense dont il pourrait se prévaloir en sa qualité d'État souverain. Ainsi donc, le droit maritime international n'a pas manqué de faire des recommandations aux États parties à la convention internationale sur la responsabilité civile à l'effet de garantir au jugement rendu une exécution.

Toutefois, force est de reconnaître qu'il existe des incohérences de sorte que l'on peut craindre de réelles difficultés dans la mise en œuvre effective du jugement. En effet, la question de la liquidation ${ }^{535} \mathrm{du}$ fonds de limitation n'est pas véritablement élucidée. Quel est l'organe de liquidation du fonds indépendamment du cadre général du tribunal saisi de la demande d'indemnisation ? Quelle en est la procédure ? N'y a-t-il pas un ordre de préférence dans la répartition et la distribution du fonds de limitation? Si le Fonds est insuffisant, doit-il être augmenté par le propriétaire?

Par ailleurs, la convention semble subordonner l'exécution du jugement à des procédures exigées dans chaque État contractant. Aussi, demandons-nous de savoir si le droit international se préoccupe véritablement de l'indemnisation rapide des victimes.

Dans cette optique, supposons qu'une décision rendue dans un État tiers doit être exécutée en Côte d'Ivoire. Se fondant sur l'article 10 alinéas 2 de la convention CLC 69, la force exécutoire de cette décision rendue par la juridiction étrangère devrait être octroyée par l'autorité judiciaire ivoirienne à travers la procédure d'exequatur ${ }^{536}$.

Selon l'article 345 du CPCCA ivoirien, les décisions judiciaires, contentieuses ou gracieuses rendues dans un pays étranger ne peuvent donner lieu à aucune exécution forcée ou à aucune publicité sur le territoire de la république qu'après y avoir été déclarées exécutoires sous réserve des dispositions particulières résultant des

\footnotetext{
534 Voir aussi l'article 8 de la convention de 1992 portant création du Fonds international d'indemnisation.

${ }^{535} \mathrm{La}$ liquidation est l'ensembles des opérations préliminaires au partage d'une indivision qu'elle qu'en soit l'origine. Elle consiste à payer le passif sur les éléments d'actifs, à convertir en argent liquide tout partie des éléments afin que le partage puisse être effectué.

536 L'exequatur est une ordonnance rendue par le président du tribunal pour rendre exécutoire une décision arbitrale ou une sentence prononcée par une juridiction étrangère. Voir GUILLIEN et Jean VINCENT, lexique des termes juridiques Op.cit., p.156.
} 
conventions internationales ${ }^{537}$. Nous pensons que cette procédure longue et incertaine ralentirait le soulagement des victimes.

Par ailleurs, il conviendrait de prendre des dispositions pour tirer la conséquence des poursuites dont ferait l'objet l'État propriétaire du navire pollueur exploité à des fins commerciales. A ce titre, des dispositions doivent être prises de sorte que l'État exécute effectivement les sanctions prononcées contre lui. Car en pareille circonstance un État serait tenté de vouloir échapper à l'exécution du jugement en vertu de ses prérogatives de puissance publique, notamment lorsqu'il interprète le refus d'appliquer la décision qui le frappe comme un acte de gouvernement ou un acte politique dont la décision finale appartiendrait exclusivement à son gouvernement au sens de l'arrêt Laffitte du $1^{\text {er }}$ mai $1822^{538}$.

Or l'exécution des décisions de justice se révèle également comme le reflet de la légalité et de la justice. En cela, Philippe BOISSON fait observer que l'immunité accordée à un État au nom de l'égalité souveraine des États et le souci de protéger leur indépendance fonctionnelle par le droit international empêche la mise en œuvre de sa responsabilité devant les juridictions d'un autre État. Mais il précise que la règle de l'immunité ne joue en principe qu'à l'égard des actes de puissance publique et non pour ceux de gestion privée $^{539}$.

En effet, l'État a également l'obligation de prêter le concours de la force publique à l'exécution des décisions de justice sous peine de commettre une illégalité et d'engager sa responsabilité. Cela est affirmé par le conseil d'État dans l'affaire Couiteas du 3 novembre $1923^{540}$. Le rôle de l'État est d'autant plus redoutable qu'en se fondant sur la disposition de l'article 347 point 6 du CPCCA, les tribunaux ivoiriens ont toujours exigé que le jugement étranger n'apparaisse contraire à l'ordre public en vigueur en Côte d'Ivoire ${ }^{54}$.

De telles dispositions de la loi nationale du juge saisi du litige ou lex fori sont de nature à receler des difficultés dans l'application de la loi et à fortiori de la décision rendue à

\footnotetext{
537 C'est dire que nos recommandations si elles sont prises en compte en la matière l'emporteraient sur la loi nationale.

A propos des conditions de l'exequatur voir les articles 346 à 347 du CPCCA Ivoirien.

${ }^{538}$ Dans l'affaire Laffitte, le C.E. a rejeté le recours du banquier Laffitte qui demandait le paiement d'arrérages d'une rente que lui avait cédé la princesse Borghèse membre de la famille Bonaparte au motif que «la réclamation du sieur Laffitte tient à une question politique dont la décision appartient exclusivement au gouvernement». Voir l'affaire dans Rec. 1821, 1825, 202. Etant entendu que la théorie de l'acte de gouvernement est abandonnée dès le 19 Février 1875 par l'arrêt Prince Napoléon 1853. Voir M. Long - P. Weil, G. Braibant, Gaja 8ème édition Paris 1984, P.15 et suivants.

${ }^{539}$ BOISSON Ph., Politiques et droit de la sécurité maritime, Paris, Bureau Veritas, 1998, P. 475.

${ }^{540}$ Le justiciable nanti d'une sentence dûment revêtue de la formule exécutoire est en droit de compter sur la force publique pour l'exécution du titre qui lui a été ainsi délivré. Voir Gaja, op. cit,.45.

${ }^{541}$ Ainsi une décision rendue en France et dont le contenu a été jugé contraire à l'ordre public ivoirien n'a pu recevoir l'exequatur en Côte d'Ivoire. Voir juridiction présidentielle, TPIA, n4267 du 20 novembre 1995.
} 
l'étranger. C'est ce qui fait dire au Professeur Christian SCAPEL que le caractère international du droit maritime est source d'insécurité du transport maritime. En effet, il fait remarquer que très souvent, l'inefficacité de la règle de droit est due à la multiplicité des frontières et au refus des États parfois complaisants de se conformer à la sanction ou à toute mesure de prévention au nom de leur souveraineté. Ce qui est indiscutablement un élément d'insécurité juridiques ${ }^{542}$.

Au regard donc de ces risques graves de difficultés d'exécution du jugement étranger liées à la souveraineté des États, nous plaidons avec Christian GAVALDA qu'il soit pris en compte expressément le renforcement des commissions rogatoires internationales dans les normes sur la responsabilité civile pour les dommages de pollutions accidentelles par hydrocarbures. En faisant une telle proposition, nous n'avons nullement la prétention de dire que cette institution est une panacée. Mais nous disons que la coopération judiciaire internationale se présenterait comme un réel moyen pour surmonter le problème de l'impasse que rencontre l'exécution effective de certains procès à caractère international ${ }^{543}$.

Autant l'État contractant doit créer les conditions d'une indemnisation rapide des victimes à travers un mécanisme d'exécution du jugement rendu qui le frappe directement, autant, il doit prêter son concours pour que ses ressortissants armateurs dont la responsabilité est établie puisse se sentir obligés de réparer les dommages causés par leurs faits.

\section{L'exécution incertaine du jugement par le débiteur de l'indemnisation}

L'efficacité du système international de responsabilité civile en matière de l'exécution du jugement est toute aussi à examiner au niveau des autres parties succombantes à savoir le propriétaire du navire, l'assureur et le Fonds international d'indemnisation. La Convention créant le Fonds international d'indemnisation pour dommages par pollution prescrit le caractère solidaire de l'obligation d'exécuter un jugement rendu à la charge du propriétaire et du Fonds. Ce qui d'ailleurs peut être comparé à un couteau à double tranchant. Car cette disposition peut être jugée à la fois défavorable et favorable pour les victimes.

En effet, le caractère défavorable procède de la combinaison notamment des articles 4 et 7 de la Convention créant le Fonds international d'indemnisation. De ces textes, se dégagent les précisions qui suivent : le Fonds est exonéré de toute obligation notamment si le demandeur ne peut pas prouver que le dommage est dû à un évènement mettant en cause un ou plusieurs navires. Dans ce même esprit, l'article 6 alinéa 2 de la convention

\footnotetext{
542 Voir, Christian SCAPEL, L'insécurité maritime : L'exemple de la pollution par les hydrocarbures, in, Le droit face à l'exigence contemporaine de sécurité, op.cit., pp. 221- 222.

${ }^{543}$ Voir Christian GAVALDA, Les commissions rogatoires internationales en matière civile et commerciale, in Revue critique de droit international privé, Paris, 1964, pp. 15-39. L'auteur soutient en substance que l'intensification des rapports internationaux a entraîné l'augmentation de la collaboration entre les magistrats d'un État et ceux d'un autre État pour exercer leur fonction juridictionnelle.
} 
de 1992 sur la création du Fonds déclare que le Fonds est de toute manière exonéré dans la mesure où le propriétaire a pu l'être.

La disposition sus indiquée paraît tout aussi favorable, à l'inverse de ce qui précède. Ce qu'il faut retenir comme idée force, est que le propriétaire du navire pollueur et le Fonds supportent solidairement les obligations d'indemniser les victimes du fait des dommages causés par le premier. De sorte que si le propriétaire est condamné à indemniser les victimes, la responsabilité financière incombe également au Fonds ${ }^{544}$.

Ainsi, les protocoles d'amendement de 1992 des conventions sur la responsabilité civile et portant création du Fonds d'indemnisation définissent les modes de liquidation des indemnisations qui incombent d'une part au propriétaire du navire et d'autre part au Fonds international d'indemnisation.

En effet, conformément au protocole de 1992 sur la responsabilité civile, le propriétaire du navire reconnu coupable devra payer 3 millions de DTS pour un navire dont la jauge ne dépasse pas 5 milles unités. Pour celui dont la jauge dépasse ce nombre d'unités, pour chaque unité de jauge supplémentaire, 420 de DTS en sus du montant de 3 millions de DTS. Etant entendu que le montant total alloué ne pourra pas excéder 59,7 millions de DTS.

La victime du dommage par pollution devra surmonter d'autres obstacles à l'exercice de l'action en indemnisation. A l'évidence, les règles classiques de l'établissement de la responsabilité civile des pollueurs s'avèrent peu dissuasives.

Section 2: Le caractère peu dissuasif des règles classiques de l'établissement de la responsabilité civile des pollueurs

L'analyse des règles de réparation civile permet de relever des entraves relatives à l'indemnisation rapide des victimes de marées noires (Paragraphe1) et aux modalités de détection des pollutions marines par hydrocarbures et leur force probante (Paragraphe2).

\section{Paragraphe 1: Les entraves à l'indemnisation rapide des victimes de pollution marine}

Ces entraves sont de deux ordres : les unes ont trait aux difficultés énormes liées à l'établissement de la preuve des actes de pollution marine mettant en cause un ou

\footnotetext{
${ }^{544}$ Etant donné que le Fonds de 1971 a pour mission de verser des indemnités aux victimes de dommages dus à une pollution par les hydrocarbures qui ne sont pas pleinement indemnisées en vertu de la convention de 1969 sur la responsabilité civile. Voir OMI, Fonds international d'indemnisation de 1971 pour les dommages dus à la pollution par les hydrocarbures, Manuel sur les demandes d'indemnisation, juin 1988, pp.8-9.
} 
plusieurs navires (A) et les autres résultent des difficultés relatives au lien de causalité (B).

\section{A - Les difficultés liées à l'établissement de la preuve des préjudices imputables au propriétaire du navire}

Selon l'article 3 alinéa 4 de la Convention de 1969 sur la responsabilité civile, le propriétaire du navire est responsable de tous dommages par pollution. Que faut-il entendre par «tous dommages par pollution ${ }^{545}$ »? A la vérité, la responsabilité du propriétaire résulte des préjudices causés au milieu marin ainsi que des coûts de la dépollution des mers et des zones côtières affectées ${ }^{546}$. Les activités des transports maritimes d'hydrocarbures peuvent présenter des préjudices matériels et des économiques (1), ainsi que des préjudices écologiques (2) d'une envergure considérable.

\section{Les préjudices matériels et économiques}

Le déversement du pétrole peut avoir des répercussions sur les communautés riveraines et en particulier sur les pays en développement dont l'économie et la survie dépendent très souvent des ressources de la mer $^{547}$.

Cette catégorie de dommages est qualifiée de «dommages de pollution». C'est à dire des dommages "subis par des patrimoines identifiables et particuliers" ainsi que les personnes elles-mêmes. ${ }^{548}$

En effet, les dommages de pollution peuvent revêtir deux modalités, à savoir le préjudice corporel et le préjudice économique. Le préjudice corporel correspond à une atteinte physique à la personne. Il s'agit des maladies causées par la pollution.

Quant aux préjudices économiques, ils s'analysent en termes de manque à gagner. Il s'agit donc aussi de préjudices matériels. En d'autres termes l’on évoque le préjudice économique lorsque l'activité en cause a porté éteinte à "un patrimoine identifiable et particulier».

Le manque à gagner résulte d'un ralentissement des activités liées à la pêche, les dégâts subits par l'aquaculture, le déclin des activités touristiques ainsi que les coûts du nettoyage peuvent donner lieu à des demandes d'indemnisation contre le propriétaire

\footnotetext{
545 Voir aussi l'article 1alinéa 6 de la convention CLC 1969.

${ }^{546}$ C'est bien le phénomène de la pollution auquel il est fait allusion. C'est-à-dire la contamination ou la modification directe ou indirecte de l'environnement provoquée par tout acte susceptible d'altérer le milieu de vie de l'homme et des autres espèces vivantes, de nuire à la santé, à la sécurité, au bien être de l'homme, de la flore et de la faune ou aux biens collectifs et individuels. Voir l'article ler de la loi portant code ivoirien de l'environnement.

${ }^{547}$ SRITASTAVA (S.P.), Stratégie pour la protection du milieu marin, Grande-Bretagne, juillet 1988 p 6.

548 AKPOUE (Brou), Le droit privé de l'environnement, Thèse de droit privé , soutenue publiquement à l'Université de la Rochelle le 31 janvier 2009, pp. 11-12
} 
$\mathrm{du}$ navire ${ }^{549}$. Une jurisprudence française abondante fait état de réparation des dommages consécutifs à des pollutions de rivières ${ }^{550}$, privation d'agrément du fait de la pollution d'un étang, manque à gagner des restaurateurs riverains de la Seine et désertée par leur clientèle du fait du déversement d'égouts ${ }^{551}$.

La pollution des régions côtières revêt un caractère alarmant. En effet, les marées noires contribuent à la dégradation d'un milieu naturel en lui-même précieux. Lequel milieu dont la préservation conditionne la santé publique des populations et le maintien d'activités économiques. La pollution des eaux côtières met en péril la pêche artisanale et industrielle. Car les frayères côtières deviennent inutilisables par la gent aquatique ${ }^{552}$. Les marées noires sont un véritable cauchemar pour les pollutions d'une région donnée et au-delà, pour l'ensemble du pays du fait des pollutions qu'elles provoquent et qui ont un impact global au triple plan, sanitaire et économique ${ }^{533}$.

Par ailleurs, la responsabilité du propriétaire de navire peut également résulter de la dégradation de l'environnement. Cela équivaut à des dommages écologiques

\section{Les dommages écologiques}

Les dommages écologiques correspondent à toute atteinte portée aux espèces animales et végétales, au paysage et aux milieux naturels ainsi qu'au cadre de vie et à la qualité de vie.

A la question de savoir les formes que peuvent revêtir les dommages écologiques, Monsieur AKPOUE en distingue deux sortes. Ce sont les dommages écologiques purs et les dommages de pollution ${ }^{54}$.

Paraphrasant le mot de M. PRIEUR, il a été possible de définir les dommages écologiques purs comme: "les dommages subis par le milieu naturel dans ses éléments

\footnotetext{
549 Et bien souvent, les coûts à prévoir pour remédier à un évènement de pollution par les hydrocarbures ne sont pas forcement proportionnels à la quantité de produits déversés. Par exemple : l'évènement du Tanio qui avait provoqué le déversement de quelques 13000 tonnes de fuel lourd, le coût final du nettoyage et des dommages a été estimé à pus de 60 millions de dollars. L'importance de cette catastrophe s'étant située au $2 \mathrm{e}$ rang après celle de l'Amoco Cadiz au cours de laquelle plus de 200000 tonnes d'hydrocarbure ont été déversées. Voir, SRITASTAVA (S.P.), Stratégie pour la protection du milieu marin, Op. cit., p 7. Voir aussi, OMI, Identification et protection des zones spéciales et des zones maritimes particulièrement vulnérables 15 Avril, MEPC 53/8/2, 2005 p.6

${ }^{550}$ Privation de jouissance pendant «le temps nécessaire à la reconstitution du cheptel piscicole ».

${ }^{551}$ CE 14 juin 1907 ville de Paris C/Talon, in Recueil Lebon, 1907 p. 565

${ }^{552}$ L'ostréiculture et la conchyliculture sont également gravement menacées. Voir DESPAX (Michel) Observations sous l'Arrêt de cass. crim. 18 juin 1969, JCP 1970 - 16530 - 16531.

${ }^{553}$ Voir GNAMIEN (G.D.), «Vers la hausse du prix du poisson », in quotidien Inter $\mathrm{N}^{\circ} 2377$ du lundi 10 et mardi 11 Avril 2006 p.12.

554 AKPOUE (Brou), Le droit privé de l'environnement, Thèse de droit privé , soutenue publiquement à l'Université de la Rochelle le 31 janvier 2009, p.10
} 
inappropriés et inappropriables affectant l'équilibre écologique en tant que patrimoine collectif ${ }^{555}$.

Cette forme de d'atteinte peut se révéler irréversible. C'est le cas des oiseaux de mer et des poissons qui meurent à la suite de déversement accidentelle d'hydrocarbures. Ceuxci disparaissant de la sorte, et se trouvent irremplaçables.

La dégradation de l'environnement pose le problème crucial de l'évaluation ${ }^{556}$ des dommages issus d'une pollution par hydrocarbures, l'évaluation des dommages dits écologiques. C'est à dire qu'à priori, nous allons assister à des dommages sans réparation. Ce qui à l'évidence nous semble curieux. A notre avis, s'il y a bien des dommages réparables qui doivent engager la responsabilité de leur auteur, c'est bien les dommages écologiques au regard des conséquences graves au milieu naturel marin et aux zones côtières. En effet, les marées noires favorisent la mort de différentes espèces animales, contaminant les produits de la pêche qui deviennent impropres à la consommation. Ce qui rend la pêche infructueuse de sorte que les armateurs pêcheurs voient leur production baisser et le ralentissement des activités du secteur de la pêche ${ }^{557}$. Ces différents phénomènes ont menacé la Côte d'Ivoire du 27 au 28 mars 2006. Cette marée noire est consécutive à un accident survenu dans les eaux territoriales ivoiriennes sur la plate forme pétrolière au large de Grand-Lahou ${ }^{58}$.

En sus de ces difficultés, la victime doit faire la preuve du lien de causalité entre les préjudices et l'activité du pollueur.

\section{B - $\quad$ Les difficultés relatives au lien de causalité entre les dommages et l'activité des pollueurs}

Il se pose la question de savoir si la victime des dommages par pollution est tenue d'établir la relation de cause à effet entre ceux-ci et un évènement de pollution imputable à un armateur précis? Dans le silence du droit maritime international, certains écrits semblent aller dans le sens d'une réponse affirmative ${ }^{559}$.

\footnotetext{
555 PRIEUR (Michel), Droit de l'environnement, in AKPOUE (Brou), Op. cit., p10

556 L'indemnisation due au titre de la dégradation de l'environnement n'a été admise en droit positif que de manière exceptionnelle. Voir en ce sens REMOND GOUILLOUD (Martine), "Pollution des mers ", in Jurisclasseur fascicule $1292 \mathrm{n}^{\circ} 50,1995$, p. 15.

557 Voir notre voie, $\mathrm{n}^{\circ} 2363$ du mercredi 13 avril 2006 P14 sous la plume de Robert Krassault, Pénurie de poisson sur le marché et Franck Souhone, Les armateurs stationnent tous leurs bateaux, 2000 travailleurs au chômage, in Inter $\mathrm{N}^{\circ} 2378$ du mercredi 12 Avril 2006 p 12.

${ }^{558}$ D'importantes quantités d'hydrocarbures évaluées à plus de $5000 \mathrm{~m} 3$ déversées accidentellement par un pétrolier de la société canadienne Canadian Natural Ressources (CNR) qui exploite le champ pétrolier « espoir » ont pollué les côtes ivoiriennes. In Frat Mat Nº12423 du lundi 23 avril $200641^{\circ}$ année p. 7

${ }^{559}$ Voir par exemple OMI, Manuel sur les demandes d'indemnisation, Fonds international sur les demandes d'indemnisation de 1971 pour les dommages dus à la pollution par les hydrocarbures, juin 1988 P.17. Voir aussi, Christophe PRIOU, Transport par eau, la commission d'enquête sur l'application des mesures préconisées en matière de transport maritime des produits dangereux ou polluants et l'évaluation de leur efficacité juillet 2003, p. 16.
} 
Dans ce cas, il semble que le problème est lié à l'établissement de la preuve du lien de causalité entre l'activité polluante et le dommage écologique. C'est-à-dire le lien de cause à effet entre le dommage environnemental et le fait du pollueur.

Dans la pratique cet exercice qui consiste à établir lien de causalité entre la faute et le préjudice subi peut s'avérer une source de réelles difficultés pour les victimes ${ }^{560}$.

Nous remarquerons à ce propos que s'il est aisément possible d'identifier l'auteur d'une pollution accidentelle massive par hydrocarbures, il demeure en revanche difficile de déterminer les auteurs des rejets opérationnels. A ce sujet, un rapport préparé par le US Academy of Sciences en 1990 pour l'OMI établissait que 568.800 tonnes d'hydrocarbures s'étaient déversées en mer durant l'année 1989. De cette quantité déversée, seuls 114.000 tonnes d'hydrocarbures étaient le résultat de déversement accidentel $^{561}$.

La difficulté que nous voulons faire ressortir à travers cette analyse est celle qui tient à la quasi impossibilité matérielle pour les victimes d'établir le lien de causalité entre les rejets effectués en mer et les dégâts causés aux activités économiques exercées aux bords des mers, aux aires protégées et au patrimoine aquatique. Par exemple, en Afrique, singulièrement au Nigeria, même si ces affaires ne concernent pas à proprement parler la pollution marine par les hydrocarbures, elles ont mis en évidence l'obstacle que constitue pour les victimes l'établissement du lien de causalité («causal connection») avant toute indemnisation des préjudices subis à celles-ci. Ces affaires concernent l'exploitation pétrolière offshore. La teneur des décisions rendues par la cour suprême du Nigeria en est une parfaite illustration ${ }^{562}$. La décision finale de la juridiction supérieure nigériane a été défavorable aux victimes pour défaut d'établissement du lien de causalités63.

En Côte d'Ivoire également la cour suprême a eu à juger dans le même sens. En effet, dans l'arrêt n0001 de 2001, SDV contre TRABEX et CAMAT, la haute juridiction a

\footnotetext{
560 Cf. DOUSSAN (I.), «Environnement et ressources naturelles », J.-CL.rur.fasc.nº705,spéc.nº 200 ; M.L.DEMEESTER, in AKPOUE Brou, Droit privé de l'environnement, Op. cit., pp.131-132

${ }^{561}$ KRISTAKIS (Théodore), et IMPERIALI(Claude), L'exemple du contrôle exercé par l'OMI dans le domaine de la pollution marine, IMPERIALI (Claude) (dir.), L'effectivité $d u$ droit international de l'environnement: contrôle de la mise en ceuvre des conventions internationales, Paris, Economica, 1998, p.157.

${ }^{562}$ Voir, EBEKU (S.A. Kaniye),judicial attitude to redress for Oil-related Environnemental Damage in Nigeria, RECIEL, volume 12, Oxford, Blackwell Publishing, 2003, P203.

563 "We are unable to agree with the learned trial judge that the evidence of an expert is not absolutely necessary to prove damage to be caused by vibrations radiating from seismic operations taking place within a reasonable distance from the property damaged. These are phenomena beyond the knowledge of the unscientific and untrained in seismology and civil engineering"

En substance, la Cour Suprême fait remarquer que l'établissement du lien de causalité entre les préjudices subis par la victime et les opérations sismiques incriminées devrait être effectué seulement par des experts. Le fait pour la victime de ne pas avoir observé cette exigence équivaut pour elle à ne pas rapporter la preuve du lien de causalité ; que par suite, la victime ne se verra pas allouer les dommages intérêts demandés. Voir TIEBLEY Yves Didier, thèse précitée, p.264
} 
décidé que le fait dommageable imputable à la SDV ayant entraîné les avaries à la marchandise a crée entre le destinataire et l'aconier un lien de droit ${ }^{564}$.

Quels sont donc les moyens de preuve dont disposerait l'un ou l'autre, le propriétaire du navire pour se disculper, et du côté des victimes, comment ces dernières peuvent-elles établir que le navire suspect est véritablement responsable de la réalisation des dommages sans buter sur des problèmes insurmontables de preuve?

Cette question trouve sa réponse dans les modalités de preuve des dommages dus aux pollutions par hydrocarbures et leur force probatoire. Ces obstacles ne sont-ils pas de nature à rendre illusoire l'indemnisation des victimes ou d'éventuelles poursuites judiciaires contre les pollueurs surtout au niveau des pays de l'Afrique de l'ouest et du centre à court de moyens financiers et matériels? Ces interrogations trouvent une part de réponse dans l'établissement des modalités de preuve des pollutions par hydrocarbures et leur force probante en justice.

\section{Paragraphe 2: Les modalités de détection des pollutions marines par hydrocarbures et leur force probante}

Au regard des questions soulevées plus haut, il semble pertinent d'affirmer avec Michel ROUSSEAU que l'accumulation des indices de pollutions par hydrocarbures semble un gage de succès d'un procès relatif aux dommages causés à l'environnement ${ }^{565}$, aux victimes humaines, économiques, ainsi qu'à l'État et ses démembrements. Dès lors, tout mode de preuve semble admis pourvu que l'on situe avec exactitude les responsabilités civiles $^{566}$. Ainsi, peuvent avoir valeur probante, les moyens généraux fondés sur la comparaison des échantillons d'hydrocarbures tels que ${ }^{567}$ les procès verbaux de constat, les rapports d'expertise, les inspections de l'Administration en charge de la sécurité maritime, les procès verbaux ou certificat douaniers (A) ainsi que d'autres moyens techniques ou scientifiques de pointe (B).

\footnotetext{
564 Voir également en ce sens, l'arrêt de la cour suprême ivoirienne, arrêt n³90 de 2006, Sté SCAC Delmas Vieljeux contre Sté Armement Blanchard. Dans sa décision, la cour a cassé la décision de la cour d'appel au motif qu'elle ne relève aucune circonstance précise de nature à ce que le fait dommageable pour lequel la responsabilité de la Sté SCAC était recherchée avait pour auteur le navire "Romain Delmas", alors que d'autres rapports d'enquête administrative et d'expertise régulières versés au dossier remettaient totalement en cause les témoignages et les conclusions des rapports sur lesquels elle fondait sa décision. Ceux-ci ne permettent pas d'établir avec certitude le lien de causalité entre la faute du cargo "Romain Delmas » et les dommages subis par le sardinier.

565 ROUSSEAU (Michel), "Difficulté d'établir la responsabilité civile de l'entreprise en matière de l'environnement », in, Semaine juridique, Paris, 15 avril 1999, p.21.

566 Voir LE COUVIOUR (Karine), «Récent développement normatif et judiciaire de la répression des rejets polluants des navires, chronique d'une pollution marine ordinaire annoncée ", in JCP du 11 juin $2003, \mathrm{n}^{\circ} 24 \mathrm{P}$ 1082. Voir les articles 54 à 56 CPCCA ivoirien. Voir aussi, Emmanuel VERGE et Roger de SEGOGNE, «Preuve », in Dalloz, 1964, nº 73 p 775.

${ }^{567}$ Dans tous les modes de transport, cinq documents peuvent avoir valeur probante, à savoir les réserves, les procès verbaux de constat, l'expertise, les procès verbaux douaniers et un état différentiel.
} 


\section{A - Les méthodes manuelles fondées sur la comparaison des échantillons d’hydrocarbures}

Ces moyens sont constitués de procès verbal de constat (1) et du rapport d'expertise (2).

\section{Le procès-verbal de constat}

Les infractions relatives au déversement illicite par les navires peuvent être établies par procès verbal de constat ${ }^{568}$. Par analogie à ce qui a cours dans le monde du transport de marchandises, lors de la livraison effective de la marchandise au destinataire, le procès verbal de constat devrait servir à la vérification du registre des hydrocarbures lors des opérations de chargement et de déchargement des hydrocarbures.

En effet, les procès verbaux de constat ont la particularité d'être établis en la présence d'un expert amiable ou judiciaire à qui l'on confie la mission de rédiger un rapport d'expertise avant et pendant les opérations de déchargement. De sorte que l'on puisse établir avec certitude que la cargaison que vous déchargez quelque part est la même que vous avez pris au départ. Ainsi, à l'instar de Yannick Vicaire, membre de Greenpeace France, nous préconisons la rigueur dans la rédaction des documents administratifs faits à propos des cargaisons d'hydrocarbures ${ }^{569}$. En tout état de cause, la plupart des méthodes mises au point jusqu'à présent pour identifier la source des hydrocarbures déversées en mer sont fondées sur des techniques permettant d'effectuer des analyses comparées entre les échantillons d'hydrocarbures prélevés lors d'un déversement d'hydrocarbures en mer et un échantillon prélevé à bord d'un navire que l'on soupçonne d'avoir effectué le rejet ${ }^{570}$.

L'inspection de l'Administration en charge de la sécurité maritime et les procès verbaux ou certificats douaniers sont deux moyens qui retiendront particulièrement notre attention. A cet effet, par exemple le certificat établi par la douane servira non seulement de preuve légale pour la perception de l'impôt sur les importations, mais aussi des preuves suffisantes pour situer des responsabilités des déversements illicites des hydrocarbures.

En effet, la valeur d'un tel document ne fait pas de doute. Car il est établi par une autorité administrative qui de surcroît est extérieure aux parties en conflit ${ }^{571}$.

Il existe en Côte d'Ivoire, une réglementation relative à l'inspection des navires se trouvant dans les eaux maritimes ivoiriennes. Cette inspection est du ressort des services tels que la direction des affaires maritimes et portuaires (DGAMP), le service de la

\footnotetext{
${ }^{568}$ Acte de procédure établi par un officier public et relatant des constatations ou des dépositions. Cet acte a un caractère authentique. En matière pénale, il fait foi jusqu'à preuve du contraire. Voir GUILLIEN (Raymond) et VINCENT (Jean), Lexique des termes juridiques, 14ième édition 2003, p. 462.

${ }^{569}$ Voir l'affaire déchets toxiques en Côte d'Ivoire, interview accordée par Yannick Vicaire, dans Fraternité Matin, $\mathrm{n}^{\circ} 12553$ du 9 au 10 septembre 2006, P. 7.

${ }^{570}$ Voir OMI, Rapport du colloque sur la prévention de pollution des mers par les navires, Londres $1976, \mathrm{n}^{\circ} 26$ p.71.

${ }^{571}$ Dans tous les modes de transport en Côte d'Ivoire, un procès verbal est dressé par la douane en présence du transporteur qui doit assister toujours au chargement et déchargement des cargaisons.
} 
police de la navigation, la douane, le service de santé, le port autonome d'Abidjan; les sapeurs pompiers, le service des inspections aux conditions environnementales. Ces services interviennent successivement dans la cabine du capitaine du navire pour contrôler la conformité du navire avec les règles sur la navigabilité. C'est à dire vérifier si le navire répond aux conditions de navigation ${ }^{572}$.

Dans ce même ordre d'idées, il ne faut pas oublier de mentionner le registre des hydrocarbures et le journal de la navigation. Le registre des hydrocarbures est un document de bord où sont consignés tous les mouvements d'hydrocarbures à bord et depuis la terre. Quant au journal la navigation, il permet de relever à une certaine position précise la présence d'hydrocarbures. Il permet donc de réaliser la traçabilité avec un navire ${ }^{573}$.

C'est le lieu de nous interroger de savoir comment le navire "Probo Koala " a pu donc échapper à tout cet arsenal de contrôle lors du déchargement de sa cargaison mortelle et surtout qu'il ait pu quitter le port d'Abidjan sans être arraisonné ou immobilisé par les autorités publiques chargées de la sécurité maritime?

D'autant plus qu'il serait possible aux autorités ivoiriennes de demander un rapport d'expertise.

\section{Le rapport d'expertise 574}

Parmi tous les modes de preuve, l'expertise est le moyen le plus utilisé parce que plus fiable. En ce sens, qu'elle est toujours effectuée par des hommes rompus à la connaissance et à l'évaluation des dommages. La CAA l'illustre à propos. Elle a statué entre autre à propos du rapport d'expertise cargaison, que celle-ci a été faite contradictoirement, ne révélant aucun vice susceptible de conduire à l'écarter, qu'il y a lieu de l'homologuer ${ }^{575}$.

Pour Michel Rousseau, l'apport d'un expert spécialiste qui fera toutes les analyses recherchées et investigations et emploiera tous les moyens même très modernes pour

\footnotetext{
572 Voir compte rendu de l'entretien avec Mr ZOUZOUA, Service prévention des risques et inspections des navires, CIAPOL, MINEEF 15 juin 2006 à 10 heures.

${ }_{573}$ Au sens de l'arrêt de la cour de cassation criminelle française du 13 mars 2007, in Lexinter.net, Jurisprudence 2005à2009, Pollution marine et preuve. Il s'agissait d'un navire-citerne étranger d'une jauge brute supérieure ou égale de 500 tonneaux qui rejetait des hydrocarbures dans les eaux territoriales françaises. Les fonctionnaires signalèrent à leur interlocuteur qu'il procédait à un rejet d'hydrocarbures et qu'ils allaient rédiger un procès verbal de constatation des pollutions maritime.

${ }^{574}$ Procédure de recours à un technicien consistant à demander à un spécialiste dans les cas où le recours à des constatations ou à une consultation ne permettrait pas d'obtenir les renseignements nécessaires, d'éclairer le tribunal sur certains aspects du procès nécessitant l'avis d'un homme d'art. Voir GUILLIEN (Raymond) et VINCENT (Jean), Lexique des termes juridiques, Op.cit., P 264. Voir dans ce sens, l'article 65 alinéa 1 du CPCCA ivoirien.

575 Voir CAA, arrêt $n^{\circ} 157$ du 14 février 2003, Sté Delmas SA contre Sté Africaine d'Assurance et de Réassurance en Côte d'Ivoire ou SAFARIV-CI.
} 
donner des conclusions permettant souvent d'arriver à un degré de précision n'est pas négligeable ${ }^{576}$. L'expertise est un moyen par excellence de l'établissement de la preuve des dommages et par delà, la responsabilité de son auteur. C'est une phase importante de la procédure judiciaire ${ }^{577}$. De toutes les façons, quand il s'agit d'expliquer techniquement l'origine d'un dommage qui n'est pas évident, la justice ne recours qu'aux avis des experts. C'est un moyen très utilisé en Côte d'Ivoire ${ }^{58}$, tout comme la méthode de l'enquête ${ }^{579}$.

L'expertise revêt trois formes à savoir l'expertise judiciaire, l'expertise amiable et l'expertise officieuse ${ }^{580}$. L'expertise judiciaire est ordonnée par le président du tribunal sur requête de l'une des parties intéressée à la solution du litige. Cependant, l'une des parties peut récuser l'expert ordonné pour cause grave susceptible de mettre en doute son impartialité dans les cinq jours à compter de la date où cette partie a eu connaissance de la désignation. L'acte de nomination de l'expert doit préciser sa mission et le délai imparti pour le dépôt de son rapport.

L'expertise amiable est au contraire faite en dehors de toute décision judiciaire, en commun accord des parties ou même sur la présence des parties régulièrement convoquées. Quant à l'expertise officieuse, elle est réalisée par l'une des parties et ne nécessite pas le commun accord des parties pour le choix des experts. Ce mode peut être contesté par la partie adverse qui pourra requérir une contre expertise. Mais en général, la partie convoquée vient s'y joindre. Ce qui lui confère la nature d'expertise amiable.

Peut-on assimiler tout rapport comme par exemple le constat d'huissier à une expertise ? Comme le dit son nom, l'expertise doit être faite par un expert. Dès lors que le rapport n'est pas réalisé par un professionnel du domaine considéré, tout rapport ne sera pas considéré comme un rapport d'expert. Donc l'huissier qui est un officier ministériel chargé d'accomplir des actes extra judiciaires, son rapport n'est pas une expertise. Cependant, un constat d'huissier est recevable quand il s'agit d'effectuer sur place toute constatation et même des prélèvements aux fins d'analyses ${ }^{581}$.

Quelle est véritablement la portée du rapport de l'expert? Une fois que l'expert détermine l'origine des dommages, son rôle s'achève. Il ne lui appartient pas de

\footnotetext{
576 Voir ROUSSEAU (Michel), «Difficulté d'établir la responsabilité civile de l'entreprise en matière d'environnement », JCP 1999, $\mathrm{n}^{\circ} 1$, P.22

577 Voir article 65 à 76 CPCCA ivoirien.

578 Selon l'article 65 du CPCCA ivoirien, l'expertise ne peut porter que sur des questions purement techniques. Il n'est commis qu'un seul expert, à moins que le juge n'estime nécessaire d'en désigner trois.

579 Articles 77 à 82 CPCCA. Aux termes de l'article 77 précité en son alinéal, s'il y a lieu d'entendre des témoins, le juge chargé de la mise en état autorise les parties qui invoquent leurs témoignages à les faire comparaître devant lui aux jours et heures qu'il fixe.

580 Voir VERGE (Emmanuel), De SEGOGNE (Roger), "Preuve », Dalloz 1964, 2ième édition n 164 et265, P786.

581 Voir en ce sens, ROUSSEAU (Michel), «Difficulté à établir la responsabilité civile de l'entreprise en matière d'environnement précité », in Semaine juridique, 1999; n 1 p 22.
} 
déterminer les responsabilités. Cela revient au juge qui décidera selon sa conviction ou non de l'effet qui s'y attache ${ }^{582}$.

La plupart des méthodes ci-dessus étudiées sont d'une efficacité limitée. car elles sont mécaniques et impliquent le contact direct avec les substances. Or, les déversements effectués notamment en haute mer ne sont pas identifiables avant que le contrevenant prenne la fuite ${ }^{583}$.

En revanche, il est d'autres techniques scientifiques de détection des sources d'hydrocarbures.

\section{B - Les méthodes non manuelles de détection des échantillons d'hydrocarbures}

L'examen des méthodes non manuelles de détection des échantillons d'hydrocarbures nous amène à étudier les moyens usités en général (1) et de mettre en exergue le cas spécifique du CIAPOL en Côte d'Ivoire (2).

\section{Les moyens usités en général}

Après avoir énuméré les moyens usités en général (a), il conviendra d'exposer la valeur probante de ceux-ci (b).

\section{a. L'énumération des moyens}

Les moyens usités en général sont composés des méthodes scientifiques (i) et technologiques de détection des déversements illicites d'hydrocarbures en mer (ii). Les premiers cités sont constitués notamment de la télédétection, le marquage du pétrole à l'ADN en vue de l'amélioration de la traçabilité des hydrocarbures avec un navire, le système de surveillance et de contrôle des rejets d'hydrocarbures composé du détecteur à réponse ultra rapide, les appareils de laboratoire et le rayon lumineux. Quant aux moyens spécifiquement technologiques, nous citerons les images satellitaires ou l'observation aéromaritime par hélicoptère des pollutions par hydrocarbures.

\section{i. Les méthodes scientifiques de détection d'hydrocarbures}

Le marquage des résidus d'hydrocarbures à bord des navires citernes est une méthode suédoise. Elle permet d'identifier directement un navire qui a déversé des hydrocarbures

\footnotetext{
582 Aux termes de l'article 75 du CPCCA ivoirien, l'avis de l'expert ne lie pas le tribunal.

${ }^{583}$ Voir OMI, Rapport du colloque sur la prévention de la pollution des mers par les navires. Londres, 1976, P 71. Voir aussi LE COUVIOUR (Karine), « Chronique d'une pollution marine ordinaire annoncée », in JCP, 11 juin 2003, n²4, p.1083.
} 
en mer. Selon cette méthode, chaque navire peut être marqué séparément par une substance qui lui est spécifiquement réservée ${ }^{584}$.

Quant à l'estimation de la quantité des sludges, cette méthode repose sur le croisement de trois études officielles effectuées par cinq méthodes différentes aboutissant au résultat selon lequel les rejets d'hydrocarbures d'un type sont compris entre 0,7 millions de tonnes et 1,3 millions de tonnes ${ }^{585}$. A propos de la description de la méthode de calcul, les auteurs indiquent en substance que sur la base d'échantillons prélevés dans différents compartiments de la colonne d'eau, la concentration d'hydrocarbures a été établie entre 10 et 40 microgrammes/litre en méditerranée. En actualisant cette estimation avec l'augmentation du trafic maritime, la quantité totale d'hydrocarbures concentrée dans l'eau serait comprise aujourd'hui entre 0,7 et 1,3 millions de tonnes pour la méditerranée $e^{586}$.

\section{ii. L'observation aéromaritime des hydrocarbures}

Les avions de la patrouille maritime des douanes, de la gendarmerie et de la marine nationale tels que les avions Falcon 50 et les appareils Dassault en France par exemple permettent la détection des pollutions en mer. Ces appareils effectuent des vols de surveillance, recherchent les pollueurs potentiels qui vident les cuves de leurs bateaux dans l'océan au lieu de faire la queue dans les ports pour les déverser dans une station prévue à cet effet. Les observations visuelles corroborées par diverses photographies prises par hélicoptère assurent une surveillance aéro-maritime et une surveillance maritime de routine ${ }^{587}$.

L'action des douanes dans la lutte contre les pollutions maritimes a été jugée indéniable. En France par exemple, depuis 1988, la douane apporte une contribution forte dans la lutte contre la pollution maritime par hydrocarbures. Elle s'est fait une spécialité de la télédétection par voie aérienne grâce à ses avions POLMAR. Ces avions, dotés d'équipements techniques particuliers, ont pour mission de détecter et de constater les pollutions maritimes causées par des rejets illicites des navires afin de faire sanctionner les responsables devant les tribunaux.

Ils ont également vocation à intervenir lors d'accidents majeurs, en assurant la surveillance des nappes de pollutions et le guidage des moyens nautiques spécialisés, en charge de la récupération, ce qui a été le cas notamment lors des naufrages des pétroliers ERIKA et PRESTIGE. Par ailleurs, l'expert national "pollution maritime" de la douane,

\footnotetext{
584 Voir OMI, les exposés X1 à X7 à propos des mesures à prendre pour le contrôle, la détection ainsi que pour le rassemblement des données, In Rapport du colloque sur la prévention de la pollution des mers par les navires, Londres, 1976, pp.67 - 71.

585 Voir l'article de Elisa-Noemie et Frédéric Castallemet, « 20 Prestige souilleront la méditerranée cette année ", in Rapport sur la pollution marine par hydrocarbures et les dégazages sauvages en méditerranée, Paris 2003, pp. 4 - 6.

${ }^{586}$ Voir en ce sens ROUSSEAU (Michel), « Difficulté à établir la responsabilité civile de l'entreprise en matière d'environnement précité» Semaine juridique, 1999, $\mathrm{n}^{\circ} 1, \mathrm{p} .22$.

587 Voir cass. Crim 13 mars 2007 in Lexinter, Jurisprudence 2005 à 2009, Pollution marine et preuve, du 1106-2009.
} 
mène une action d'information et de sensibilisation des divers acteurs nationaux impliqués dans la lutte contre les rejets illicites en mer de produits polluants. Il a apporté son assistance technique à la justice dans le cadre de jugements d'affaires de rejets illicites.

L'action de la douane s'est confirmée au niveau européen avec la participation à « SuperCEPCO », opération de lutte contre les rejets illicites impliquant 8 pays de l'Europe du Nord, la Commission européenne et l'agence européenne de sécurité maritime (AESM).

Depuis plusieurs années, la douane utilise les deux avions spécialisés de télédétection des pollutions par hydrocarbures, les avions POLMAR, dont dispose la France. En 2008, l'action des avions des douanes a permis au plan national d'identifier 203 pollutions ( $56 \%$ des observations nationales) et donné lieu à la rédaction de 8 procès verbaux (sur un total national de 11), lorsque les navires à l'origine de rejets illicites ont été identifiés. Pour ce qui concerne la façade maritime Atlantique, les aéronefs des douanes basés à Lann-Bihoué et Bordeaux Mérignac ont observés 51 pollutions marines et établis 4 procès-verbaux à l'encontre de navires pollueurs.

Afin de renforcer ses capacités d'intervention contre les rejets illicites polluants, dont l'accumulation est tout aussi dommageable pour l'environnement que les graves pollutions causées par les naufrages répétés de ces dernières années, la douane a engagé le renouvellement de ses moyens de télédétection.

Un nouvel appareil Polmar III a été récemment mis en service. Il est basé à LannBihoué, au plus près des côtes exposées aux pollutions (Atlantique et Manche/Mer du Nord). Cet appareil est doté d'équipements de télédétection plus performants. Plus légers de $200 \mathrm{~kg}$, ils accroissent son autonomie.

Les moyens de détection aéromaritime des hydrocarbures déversés dans le milieu marin présentent un intérêt indéniable.

b. La valeur probante des moyens d'observation aéromaritime des pollutions maritimes Une étude a mis en évidence la valeur probante des observations aéromaritimes faites avec hélicoptère ${ }^{588}$. Elle indique qu'en cas d'accident, l'observation aérienne est le seul moyen d'avoir une idée claire de la réalités ${ }^{59}$. Elle constitue le premier maillon d'une chaîne de décisions essentielles. A propos du profil de vol, les hydrocarbures ont

\footnotetext{
588 Voir CEDRE, Guide opérationnel : Observation aérienne des pollutions pétrolières, octobre 2009, Voir Cosse (Christian), "Télédétection" et Le Roux (Anne) "L'apport des images satellitales", in, Centre Régional Méditerranéen pour l'Intervention d'Urgence contre la Pollution Marine Accidentelle, Rapport de Stage national de formation sur l'observation aérienne des pollutions, Salé, Maroc, 15-17 Décembre 2009, Janvier 2010, 62 pp.38-39.

${ }^{589}$ Autrement, en l'absence de moyens aériens il faut parfois se contenter d'observations à partir d'un navire, d'une falaise côtière ou d'une plate-forme d'exploration ou de production en mer. Dans ce cas, il sera difficile de bien discerner les contours de la nappe et les épaisseurs d’huile et de maîtriser l'orientation de la lumière.
} 
tendance à s'étaler en bandes parallèles au vent. Il faut prospecter la zone à couvrir en volant travers au vent pour augmenter les possibilités de détection.

Les documents photographiques et vidéos sont des éléments de preuve pour la répression des rejets illicites. Idéalement, toutes les informations nécessaires peuvent être fournies par trois vues complémentaires : une vue détaillée de la nappe, une vue d'ensemble du navire et de la nappe montrant que les hydrocarbures proviennent d'un navire particulier, une vue détaillée du navire permettant de l'identifier (couleur de la coque, des cheminées, nom ...). En pratique, on prendra une série de photos montrant le navire et son sillage pollué, l'étendue du sillage (sans discontinuité), le nom du navire et les alentours (en particulier, si possible, d'autres navires présentant des sillages " propres» pour comparaison sur le même cliché) pour bien montrer que c'est le navire en question qui est en train de polluer.

Dans la mesure du possible, les observations réalisées à partir d'un avion non spécialisé (ex : patrouille maritime) seront confirmées grâce à une reconnaissance par hélicoptère (observation plus fine) ou en faisant appel à un avion équipé d'un système de télédétection spécialisé. A titre d'illustration, il conviendrait d'indiquer à propos de la catastrophe de l'Erika qu'Avant de se casser en deux, l'Erika a perdu du fioul qui est arrivé à la côte sans avoir été observé en mer, faute de recherches spécifiquement orientées vers le repérage de ces pertes non signalées par le capitaine du navire ${ }^{590}$.

A cet effet, en l'absence, à l'heure actuelle, de texte fixant, au niveau marocain, les attributions de chacune des administrations dans les opérations de surveillance et répression des rejets illicites, il a été décidé d'ouvrir une formation aux trois corps des Forces Royales Air, à savoir la Marine Royale, la Division Aéronavale et la Gendarmerie Royale, susceptibles, a priori, de mener des opération de surveillance aéromaritime et d'établir un procès verbal de constatation de pollution ${ }^{591}$.

Cette opération peut malheureusement se révéler dangereuse. C'est pourquoi dans le cas d'une reconnaissance en hélicoptère, plusieurs préconisations devront être respectées. L'approche du lieu de déversement doit se faire perpendiculairement au vent ou vent arrière, à une altitude qui ne soit pas inférieure à 50 mètres, l'hélicoptère n'évoluant pas en zones dangereuses. Le personnel de l'hélicoptère devra être muni de masques respiratoires, d'un explosimètre et accessoirement d'un toximètre pour détecter la présence de vapeurs toxiques dans l'air. L'hélicoptère en vol stationnaire au-dessus de la nappe inflammable ne descendra pas à une altitude inférieure à 20 mètres dans tous les cas, 30 mètres dans le cas d'un déversement important de produit très inflammable. A ce propos, Anne Le Roux, n'a pas manqué dans son étude, d'insister principalement que l'observation depuis l'espace aérien des hydrocarbures déversés en mer est certes

\footnotetext{
590 Voir CEDRE, Guide opérationnel : Observation aérienne des pollutions pétrolières, octobre 2009, pp.8 et ss. 591 Centre Régional Méditerranéen pour l'Intervention d'Urgence contre la Pollution Marine Accidentelle, Rapport de Sage national de formation sur l'observation aérienne des pollutions, Salé, Maroc, 15-17 Décembre 2009, Janvier 2010, p.4.
} 
déterminante pour la mise en place d'une stratégie de répression des actes de pollution illicites, mais elle présente un danger potentiel pour les observateurs aériens ${ }^{592}$.

S'agissant des analyses effectuées à partir des photos par satellite civil d'observation au sol, des auteurs révèlent que les images aériennes effectuées par la patrouille policière ou douanière de l'agence spatiale européenne à Rome donnent une idée de l'intensité des rejets délibérés en méditerranée.

Christian Cosse a présenté les principaux capteurs utilisables pour la détection de pollutions par hydrocarbures en mer, et notamment ceux équipant les avions de surveillance aéromaritime en France : SLAR (Side-Looking Airborne Radar), scanners Infrarouge et Ultraviolet, radiomètre micro-ondes. Il a présenté des exemples d'images acquises à partir de ces capteurs et a indiqué les contraintes, potentialités et limites de chaque équipement. De son côté, Anne Le Roux a présenté le type d'images acquises par les capteurs (radars) embarqués sur certains satellites, l'exploitation qui pouvait en être faite, les potentialités et limites de cette technique et les progrès récents et envisageables, notamment en termes de coopération européenne et internationale ${ }^{593}$.

Les équipements technologiques ci dessus étudiés, contrastent avec les moyens rudimentaires employés dans le cadre spécifique du CIAPOL en Côte d'Ivoire.

\section{Le cas spécifique du CIAPOL en Côte d'Ivoire}

Nos enquêtes effectuées au BNEDT révèlent notamment que le CIAPOL est la seule structure qui a en charge la surveillance du territoire et la gestion des pollutions accidentelles de la mer, des zones lagunaires et côtières. En effet, au titre des missions du CIAPOL, le décret n91-662 du 9 octobre 1991 prévoit en son article 4 que le CIAPOL a pour mission :

" - l'analyse systématique des eaux naturelles (marines, lagunaires, fluviales, souterraines) des déchets (solides, liquides et gazeux) et des résidus, l'évaluation des pollutions et nuisances...

- La surveillance continue du milieu marin et lagunaire ainsi, que des zones côtières à des patrouilles régulières

- La lutte contre les pollutions de ces milieux...»

\footnotetext{
${ }^{592}$ Le Roux (Anne), "Le comportement et la dérive des hydrocarbures déversés en mer », In Centre Régional Méditerranéen pour l'Intervention d'Urgence contre la Pollution Marine Accidentelle, Rapport de Stage national de formation sur l'observation aérienne des pollutions, Salé, Maroc, 15-17 Décembre 2009, Janvier 2010, p.4

593 Voir COSSE (Christian), "Télédétection» et Le Roux (Anne ) "L'apport des images satellitaires », in Centre Régional Méditerranéen pour l'Intervention d'Urgence contre la Pollution Marine Accidentelle, Rapport de Stage national de formation sur l'observation aérienne des pollutions, Salé, Maroc, 15-17 Décembre 2009, Janvier 2010, pp.7-8. Voir aussi en ce sens CEDRE, Guide opérationnel: Observation aérienne des pollutions pétrolières, octobre 2009, p.43.
} 
- La mise en cuvre du plan d'intervention d'urgence contre les pollutions accidentelles en mer, en lagunes ou dans les zones côtières, dénommé plan POLLUMAR».

A cet effet, l'article 4 dudit décret portant organisation du plan POLLUMAR, à propos de la préparation de la lutte contre les pollutions des eaux déclare que le ministre chargé de l'environnement est responsable de la coordination des actions de prévention et de lutte contre la pollution des milieux récepteurs marins et lagunaires. Il est chargé d'informer toute personne participant au plan POLLUMAR sur les questions de pollution par les hydrocarbures et autres substances nocives. Il réunit une documentation aussi complète que possible concernant notamment les produits polluants et leurs effets, les matérielles et dispositifs techniques et juridiques de prévention et de lutte contre les pollutions ${ }^{594}$.

A l'analyse, le CIAPOL manque malheureusement d'efficacité en matière de la lutte contre les pollutions. Car il ne dispose pas de moyens de surveillance adéquats. Or il est sensé avec le plan pollumar faire face à toutes sortes de catastrophes. En outre, le Fonds national de l'environnement prévu à cet effet manque de financement ${ }^{595}$. L'Administration publique ivoirienne chargée de gérer et/ou protéger le milieu marin est protéiforme. Cette Administration se répartit en une pluralité de départements ministériels eux-mêmes ayant sous leur tutelle ou leur direction une diversité d'organes techniques ${ }^{596}$.

A cet effet, monsieur GUILY Benoît a préconisé qu'il soit mis sur pied un comité inter ministériel et réquisitionner toutes les structures telles que la SIR, le CIAPOL, le BNETD, le port autonome d'Abidjan en collaboration avec les structures de l'État aux fins d'intervenir efficacement en situation critique de pollution accidentelle dans les eaux ivoiriennes.

Ces propositions seraient un gage de sécurité maritime en général et en particulier un facteur d'indemnisation des victimes des dommages de pollution par hydrocarbures. A

594 Pour la réalisation de ses missions le CIAPOL comprend trois sous directions à savoir : le Laboratoire Central de l'Environnement (LCE), la Compagnie d'Intervention Contre les Pollutions du Milieu Marin et Lagunaire (CIPOMAR) chargée entre autre de la mise en œuvre du plan POLLUMAR et la Sous Direction des Affaires administratives et financières. En cela, la législation ivoirienne en la matière implique les moyens des structures privées dans la lutte contre les pollutions accidentelles des eaux ivoiriennes appelée "plan d'entreprise" prévu aux articles 7, 8 et 11 du décret de janvier 1998 portant organisation du plan POLLUMAR.

${ }_{595}$ C'est la substance de notre entretien avec monsieur GUILY Benoît ingénieur des travaux publics au BNETD et de monsieur N'DOUMI, Ingénieur au Centre de cartographie et de télédétection du 2 mars 2007. Cela est également confirmé par notre entretien avec ZOUZOUA Edmond, chef du service de prévention des risques et d'inspection des navires au CIAPOL/MINEEF du 15 juin 2006. Les personnalités citées sont membres de l'Administration ivoirienne.

596 Il s'agit notamment du Ministère des infrastructures économiques et du Ministère de l'économie et des finances qui, tous deux, assurent la tutelle des ports autonomes d'Abidjan et de San Pedro ; du Ministère de l'intérieur qui, de concert avec le Ministère de l'environnement, des eaux et forêts, intervient dans la mise en oeuvre du Plan POLLUMAR. Voir TIEBLEY Yves Didier, Thèse précitée, pp.49-51. 
côté de la palette des moyens de détection et de contrôle des rejets illicites d'hydrocarbures ci- dessus étudiés, nous recommandons à l'endroit des pays en développement, le renforcement de la patrouille des gardes-côtes en permanence. Il faut exiger aux navires, l'installation des dispositifs de détection et de contrôle instantané des rejets d'hydrocarbures en mer à bord des navires. Mais, étant donné que ceux-ci peuvent sombrer en même temps que leur cargaison, il serait donc conseillé la technique du marquage des résidus d'hydrocarbures à l'échelon mondial et en particulier pour les eaux maritimes des pays africains en raison de l'incapacité de ceux-ci à faire face à eux seuls aux dommages de pollution. Et ce, à l'effet de déterminer assez rapidement à qui imputer le déversement des hydrocarbures.

Au-delà de ces moyens de détection des hydrocarbures étudiés, force est de reconnaître que les côtes ivoiriennes en particulier et celles des pays en développement africains ${ }^{577}$ en général sont peu surveillées contre les déversements illicites d'hydrocarbures effectués par les firmes de transport d'hydrocarbures. En ce sens que la surveillance physique par les gardes- côte donne une sous estimation des dommages écologiques en raison du caractère rudimentaire des moyens employés.

En plus des règles d'ordre procédural relatives à l'action en responsabilité civile, le droit maritime international recèle des faiblesses au niveau des règles relatives à l'étendue de la responsabilité civile du propriétaire du navire.

\footnotetext{
${ }^{597}$ Au niveau africain, le professeur Maurice KAMTO souligne, à juste titre d'ailleurs, que « l'incohérence des institutions classiques ...vient de l'absence de coordination dans un contexte de pluralisme structurel accentué. Il en résulte, d'une part, un manque de vision globale des problèmes et une absence d'articulation des solutions, d'autre part, une dispersion des moyens de fonctionnement, la dilution du pouvoir de décision et donc une certaine inertie de l'administration face à des problèmes qui appellent des réactions rapides ». KAMTO (Maurice), «Droit de l'environnement en Afrique, cité par TIEBLEY Yves Didier, Thèse précitée, p.51
} 



\section{CHAPITRE 2: LES FAIBLESSES DU SYSTEME INTERNATIONAL D'INDEMNISATION DECOULANT DE L'ETENDUE DE LA RESPONSABILITE CIVILE DU PROPRIETAIRE DU NAVIRE}

Le droit maritime international offre au transporteur maritime d'hydrocarbures des moyens de défense pour dégager sa responsabilité. En effet, en contrepartie ${ }^{598}$ de la responsabilité «de plein droit ${ }^{599}$ ", la responsabilité encourue par le propriétaire du navire est assortie de nombreux cas d'exonération et de limitations financières dans son étendue ${ }^{600}$. En général, la limitation de responsabilité a pour fonction de rationaliser une dette. Ainsi, l'entrepreneur de transport maritime d'hydrocarbures a pour souci premier de mesurer les risques afférents aux opérations qu'il traite, de les prévenir et si besoin s'en prémunir ${ }^{601}$.

La règle du plafonnement de la responsabilité financière de l'armateur pétrolier ne metelle pas en mal la sécurité maritime ? Il ressort de l'analyse du système international en vigueur que les acteurs du transport d'hydrocarbures sont à l'abri des recours des victimes des dommages dus aux marées noires ${ }^{602}$.

Le système actuel à savoir la Convention de Bruxelles de 1992 sur la responsabilité civile est donc en phase avec la conception de certains auteurs ${ }^{603}$ qui font valoir que le régime

598 Contrairement à la tradition maritime suivant laquelle il ne peut être en mer de responsabilité que fondée sur la faute en raison du risque de toute opération maritime.

599 Expression empruntée au Professeur Martine REMOND-GOUILLOUD, "Pollution des mers », in Jurisclasseur, volume 7 fascicule $n^{\circ} 1292$, Op. cit. , $\mathrm{n}^{\circ} 13$, p. 6, à notre avis il est plus commode de parler de responsabilité présumée du propriétaire du navire pollueur.

600 Voir à propos de la limitation de l'étendue de la responsabilité du propriétaire, les dispositions des articles 3, 5 et 7 de la convention CLC 1969 et l'article 2 de son protocole de 1992 la modifiant en son article 5. La convention FIPOL en son article 4 alinéa 2 et 4 . Voir également en ce sens, Rapport de la commission d'enquête sur l'application des mesures préconisées en matière de sécurité du transport maritime des produits dangereux ou polluants et l'évaluation de leur efficacité, juillet 2003 P 88. La priorité du mécanisme international reste l'indemnisation des victimes peu importe les causes réelles du sinistre à savoir le comportement et la conscience des personnes qui sont déterminants pour une meilleure préservation de l'environnement.

601 En la matière il est donc difficile d'appliquer l'article 1149 du code civil qui pose le principe de la réparation intégrale lorsque la perte subie et le gain manqué peuvent être mesurés à l'avance et avec certitude.

${ }_{602}$ La faiblesse du régime actuel sous l'égide de l'OMI, même celui issu du protocole de 1992 révisant la convention sur la responsabilité civile et ceux de FIPOL, est mise en évidence par l'accident de l'Erika et du prestige où l'indemnisation n'est pas suffisamment efficace, ni ne contribue pas à améliorer la sécurité des transports maritimes.

603 Le professeur Pierre BONASSIES distingue cependant quatre niveaux différents de réparation à savoir la convention de 1992 sur la responsabilité civile, la convention de 1992 portant création du Fonds international d'indemnisation des dommages par pollution. Ces deux premiers niveaux de réparation constituent le fonctionnement normal du mécanisme de responsabilité et d'indemnisation instauré par les conventions de 1992. Au delà de celles-ci, les victimes peuvent s'adresser aux juges nationaux pour obtenir une indemnisation complémentaire. Le troisième niveau est constitué lorsque le propriétaire ne peut plus bénéficier de la limitation de responsabilité. Et enfin, les victimes peuvent s'adresser à des protagonistes qui ne sont pas concernés par le mécanisme international. Voir BONASSIES P., Après Erika : les quatre niveaux de réparation des dommages résultant d'une pollution marine par hydrocarbures, Revue de droit commercial maritime, aérien et des transports, octobre- novembre- décembre, vol 4, 2000, pp. 140-145. 
d'indemnisation ne devrait pas avoir d'autres finalités que d'indemniser correctement les victimes et ne devrait pas chercher seulement à responsabiliser les acteurs du transport maritime en les incitant à recourir à une flotte de qualitétét.

Ainsi, la réparation des dommages comme pour tout autre mode transport ${ }^{65}$ est plafonnée par la loi en vigueur. Ce plafond est même impératif et les clauses contraires semblent être interdites ${ }^{606}$. Ainsi donc, la réparation qui pourrait être allouée à la suite des dommages par pollutions dues aux hydrocarbures se trouve atténuée de deux manières. Dans certains cas, la responsabilité de l'armateur pétrolier n'ouvre pas droit à une réparation intégrale du préjudice. Ce plafonnement de responsabilité est un acte de promotion implicite des actes de pollution (Section 1). Et dans d'autres cas, la responsabilité bien que certaine, peut tomber complètement. C'est cela l'hypothèse des exonérations de responsabilité, apparaissant comme une entrave à l'indemnisation effective des victimes (Section 2).

\section{Section 1: La promotion implicite des actes de pollution due à l'institution du "plafonnement ${ }^{607}$ de responsabilité civile}

Le système international d'indemnisation se compose de deux conventions internationales. Il s'agit d'abord de la Convention de Bruxelles du 29 novembre 1969 portant sur la responsabilité civile pour les dommages dus à la pollution par les hydrocarbures telle que modifiée par le Protocole du 27 novembre 1992 (ou Convention CLC 1992); ensuite de la Convention de Bruxelles du 18 décembre 1971 portant création d'un Fonds international d'indemnisation pour les dommages dus à la pollution par les hydrocarbures telle que modifiée par le Protocole du 27 novembre 1992 (Convention FIPOL 1992).

Le droit maritime international présente des insuffisances. En ce sens qu'il fait la promotion de manière implicite des actes de pollution par les hydrocarbures. Ces

\footnotetext{
604 Voir notamment l’article de Sandrine SPAETER, les firmes face à leur responsabilité environnementale, Revue problèmes économiques, 24 novembre 2004, bimensuel n² 2.863, pp. 62 et 63.

${ }^{605}$ Voir par exemple les articles 18 et 19 de l'AUCTMR

${ }^{606}$ Aux termes de l'article 5 alinéa 1 de la Convention CLC 1969, le montant de $2.000 \mathrm{f}$ total limitant la responsabilité du propriétaire par tonnage du navire ne peut en aucun cas excéder 210.000 .000 de francs. Et l'article 2 du protocole de 1992 indique que le montant total par évènement est de 133 unités de compte par tonneau de jauge du navire, ne peut en aucun cas excéder 14.000 .000 d'unité de compte.

${ }^{607} \mathrm{Il}$ s'agit de l'une des institutions traditionnelles les plus spécifiques du droit maritime. Depuis le Moyen âge, un principe repris en droit français par l'Ordonnance de la Marine Marchande de 1681, permettait à l'armateur d'abandonner le navire et le fret à ses créanciers maritimes même si le navire a fait naufrage dans les abysses océaniques. La règle reprise à l'article $216 \mathrm{du}$ code de commerce français de 1841 disposait que tout propriétaire du navire est civilement responsable des faits du capitaine et tenu des engagements contractés par ce dernier. Il peut dans tous les cas s'affranchir des obligations ci-dessus par l'abandon du navire et du fret. Puis la limitation en valeur va se substituer à l'abandon en nature. Depuis 1957, l'armateur peut opposer à ses créanciers un fonds de limitation dont le montant est calculé proportionnellement au tonnage du navire. Voir en ce sens, SCAPEL (Christian), «L'insécurité maritime : L'exemple de la pollution par les hydrocarbures », in Le droit face à l'exigence contemporaine de sécurité, op. cit., p.140
} 
insuffisances se constatent aussi bien au niveau de la convention CLC1992 (Paragraphe1) qu'au niveau des la Convention FIPOL 1971(Paragraphe2).

\section{Paragraphe 1: Les insuffisances de la Convention CLC 1992}

Les victimes de pollution par hydrocarbures ne peuvent prétendre en vertu des conventions de Bruxelles sur la responsabilité civile, à une indemnisation intégrale. Le propriétaire n'est débiteur d'une obligation de réparer qu'à hauteur d'un plafond pré déterminé. Peu importe l'ampleur réelle des dommages subis ${ }^{608}$.

Cette situation préjudiciable aux victimes est le résultat de deux sortes de limitations à savoir la limitation du plafond de responsabilité civile du pollueur (A) et de la renonciation des victimes à leur droit de poursuite judiciaire par d'autres voies contre le propriétaire (B).

\section{A - La limitation financière de la responsabilité civile du propriétaire du navire}

La limitation financière de la responsabilité civile du propriétaire du navire traduit un encouragement implicite des actes de pollution (1) et viole le principe du pollueurpayeur (2).

\section{L'encouragement implicite des actes de pollution}

Il est possible de faire des critiques à l'endroit du système de plafonnement de responsabilité. En ce sens qu'à l'analyse, la Convention CLC apparaît comme un encouragement implicite des actes de pollution.

En effet, comment le propriétaire qui a constitué un fonds de garantie ou qui souscrit à une police d'assurance équivalente au plafond de sa responsabilité civile éventuelle se préoccuperait-il de prendre les mesures préventives en vue d'éviter sinon de minimiser autant que possible les risques d'accidents maritimes sources de marées noires. À ce sujet, certains auteurs ont pu écrire:

'The limits on liability have been critically attacked in economic analyses of law where it has been argued that a financial limit on the exposure to liability of an injurer may dilute

\footnotetext{
${ }^{608}$ Pour justifier cet état de fait, des auteurs comme SABRINA Robert indiquent que la limitation de responsabilité est le corollaire du caractère objectif de cette même responsabilité qui a pour fondement une activité licité et nécessaire au besoin de la communauté. Voir aussi en ce sens Martin ARRIBAS J.J., La réparation des dommages catastrophiques: comparaison des solutions existantes dans les conventions internationales, in LEBEN (Ch.) et CARON (D.), " Les aspects internationaux des catastrophes naturelles et industrielles », Académie de droit international de la Haye, Martinus Nijhoff, 2001, p. 705.
} 
the incentives for prevention. According to some scholars, limits on liability lead to a "deresponsibilization" of the industry involved'609.

Ces auteurs font remarquer que les limites de responsabilité civile sont fortement critiquées dans les analyses économiques du droit de la responsabilité civile. Celles-ci considèrent que les limites de responsabilité accordées au pollueur anéantissent l'effet dissuasif recherché à travers la condamnation de celui-ci à payer des dommages-intérêts aux victimes.

L'affaire de l'Erika illustre parfaitement cet état de chose. En effet, le propriétaire du navire pollueur - la société Tevere Shipping - a vu sa responsabilité civile être écartée dès lors qu'il a constitué un fonds de garantie de 84 millions de FF auprès du Tribunal de commerce de Nantes alors que l'étendue des dommages subis par les victimes était évaluée à 6 milliards de FF par un cabinet d'expertise sollicité par les collectivités locales sinistrées $^{610}$.

Cet état de fait conduit Monsieur TIEBLEY Yves Didier à faire l'observation suivante : quelle serait alors la motivation du propriétaire d'un navire sous-norme à respecter les prescriptions conventionnelles - en l'occurrence celles de l'Annexe I à la Convention MARPOL 73/78 - s'il sait d'avance les dommages intérêts qui lui seraient imputables ? Surtout lorsque les dommages intérêts sont négligeables au regard des bénéfices escomptés de l'exploitation de ce navire sous-norme ? Visiblement, aucune motivation ne l'inciterait à se mettre en règle vis-à-vis de la Convention MARPOL 73/78 ${ }^{611}$.

Par ailleurs, la limitation financière de responsabilité viole le principe du pollueur payeur.

\section{La violation du principe du pollueur-payeur}

Le principe du pollueur-payeur signifie que celui dont l'acticité cause une dégradation de l'environnement doit en assurer la réparation. Ce Principe exprimé pour la première

609 FAURE (Michael) et WANG (Hui), « The International Regimes for the Compensation of Oil Pollution Damage: Are they effective? », RECIEL, Vol.12, n³, Oxford, Blackwell Publishing, 2003, p.249. Ces mêmes auteurs relèvent dans un autre article: 'If the liability therefore is limited to a certain amount, the potential injurer will consider the accident as one with a magnitude capped at the limited amount. Hence, he will not spend the care necessary to reduce the total accident costs. Obviously, the amount of care spent by the potential injurer will be lower and a problem of underdeterrence will arise'. FAURE (Michael) et WANG (Hui), «Financial caps for oil pollution damage: A historical mistake? », Marine Policy, n³2, 2008, p.600, cite par TIEBLEY Yves Didier, Thèse précitée, p.268.

610 Rapport MAZARD et GUERARD (Janvier 2001), commandé par l'Association Interrégionale Ouest Littorale Solidaire regroupant les différentes régions atlantiques victimes de cette catastrophe. Cf. NDENDÉ (Martin), " Regard sur les procédures d'indemnisation des victimes de la catastrophe de l'Erika ", Annuaire de Droit Maritime et Océanique, 2002, p.98, cité par TIEBLEY Yves Didier, thèse précitée, p.269.

611 Ibidem 
fois par l'OCDE dans une recommandation du 28 mai 1972, est devenu un instrument de lutte contre la pollution ${ }^{612}$.

La limitation de responsabilité viole le principe du pollueur-payeur, particulièrement sa fonction curative qui se manifeste à travers la responsabilité civile du pollueur. Admettre la non indemnisation intégrale des victimes de marées noires revient à faire supporter par celles-ci une bonne partie, pour ne pas dire la plus grande partie, des coûts des dommages auxquels elles n'ont pas contribué à la réalisation.

Il s'agit indéniablement d'une négation du droit à la propriété tel que prévu par l'article $15^{613}$ de la Constitution ivoirienne du ler août 2000. Les écarts énormes qui existent entre les plafonds de responsabilité civile du propriétaire de navire et les estimations des coûts des dommages affaiblissent considérablement la portée du principe d'indemnisation contenu dans les dispositions pertinentes de la Convention CLC. La limitation de responsabilité ne permet pas de produire un effet dissuasif à l'égard des propriétaires de navire sous-norme.

Nous partageons l'avis selon lequel l'assurance obligatoire souscrite par le propriétaire du navire ne devrait couvrir celui-ci qu'à hauteur du plafond conventionnel défini. En revanche, les dommages non couverts par l'assurance seraient supportés par le propriétaire (aussi bien nominal que véritable) du navire pollueur ${ }^{614}$. Ce faisant, les pollueurs potentiels seraient incités à appliquer beaucoup plus minutieusement les mesures de sécurité applicables aux pétroliers.

Les insuffisances du droit international se constatent aussi à travers la privation du droit de poursuite judiciaire contre le propriétaire par d'autres voies.

\section{B - La privation des victimes de leur droit de poursuite judiciaire par d'autres voies contre le propriétaire}

La privation des victimes de leur droit de poursuite judiciaire par d'autres voies contre le propriétaire se constate dans l'impact de la limitation de responsabilité sur la protection

${ }^{612}$ Ainsi que le disait Martine REMOND-GOUILLOUD:«celui qui pollue doit payer».Cf. REMPONDGOUILLOUD (Martine), Du droit de détruire, Essai sur le droit de l'environnement, PUF, 1989, spéc. 162, in AKPOUE (Brou), Le droit privé de l'environnement, 0p. cit., p.142-143

${ }^{613}$ Selon le texte susvisé, le droit de propriété est garanti à tous. Nul ne doit être privé de sa propriété si ce n'est pour cause d'utilité publique et sous la condition d'une juste et préalable indemnisation.

Le droit à la propriété est aussi défendu par l'articleler du CPCCA ivoirien en ces termes: "Toute personne physique ou morale, peut agir devant les juridictions de la république de Côte d'Ivoire, en vue d'obtenir la reconnaissance, la protection ou la sanction de son droit.

Toute personne, physique ou morale, peut dans tous les cas, être appelée devant ces juridictions à l'effet de défendre à une action dirigée contre elle."

${ }^{614}$ FAURE (Michael) et WANG (Hui), « The International Regimes for the Compensation of Oil Pollution Damage: Are they effective? ", op.cit, p.249; FAURE (Michael) et WANG (Hui), "Compensation for Oil Pollution Damage: China versus the International Regime », Asia Pacific Journal of Environmental Law, Vol.9, Issue 1,2005, p.33. 
des droits d'action des victimes. En effet, la limitation de responsabilité semble déroger au principe de "l'indivisibilité du patrimoine» qui prévaut en droit commun. En ce sens, qu'elle apparait comme un moyen de recours implicite à l'institution de la "fortune de mer» (1). Il en résulte une faveur accordée à l'industrie pétrolière (2).

\section{Le recours implicite à l'institution de la "fortune de mer»}

Le dépôt d'un fonds de garantie ou d'une assurance obligatoire apparait comme un moyen de recours implicite à l'institution de la "fortune de mer " ${ }^{615}$. Car les victimes qui demandent réparation sur le fondement des articles III alinéa 1 et V alinéa 1 de la Convention CLC 1969 renoncent par la même occasion à toute poursuite judiciaire tendant à obtenir réparation sur d'autres biens du propriétaire (article VI alinéal $a$ et $b$ ). Bien plus, l'article III $₫ 4$ tel que modifié par le Protocole 1992 interdit quasiment le recours des victimes contre les personnes autres que le propriétaire (nominal) du navire ${ }^{616}$.

Cette restriction est très critiquable dans la mesure où, souvent, les propriétaires nominaux des navires pollueurs sont insolvables. En revanche, les propriétaires effectifs beaucoup plus solvables seraient à l'abri des poursuites éventuelles des victimes ${ }^{617}$. Il est donc évident que les articles VI $\$ 1 a$ ) et $b$ ) et III $\$ 4$ limitent l'accès des victimes à la justice. Ce faisant, ces articles contreviennent aux dispositions pertinentes précitées de la Constitution ivoirienne du ler août 2000 qui prévoient respectvement en ses articles 15

\footnotetext{
615 L'expression de droit maritime consacrant l'existence d'un patrimoine d'affectation, suivant lequel les armateurs des navires peuvent limiter leur responsabilité à l'égard de leurs contractants ou des tiers si les dommages se produisent à bord ou en rapport avec la navigation. Cf. GUILLIEN (Raymond), VINCENT (Jean), Lexique des termes juridique, Op.cit., p. 282

Le patrimoine d'affectation que représente la fortune de mer s'oppose au concept de l'unité du patrimoine consacré par l'article 2092 du code civil français aux termes desquels, "quiconque s'est obligé personnellement, est ténu de remplir son engagement sur tous ses biens mobiliers et immobiliers, présents et à venir. " Ce texte confère en principe au créancier ce que l'on appelle le droit de gage général sur tous les biens qui composent le patrimoine du débiteur, au moment où il exerce ses poursuites pour les vendre et se faire payer sur le prix. Voir en ce sens, WEILL (Alex), TERRE (François), Doit des obligations, Dalloz, $4^{\text {ème édition , 1986, p.860 }}$ ${ }^{616}$ L'article III alinéa 4 dispose : "Aucune demande de réparation de dommage de pollution ne peut être formée contre le propriétaire autrement que sur la base de la présente Convention. Sous réserve du paragraphe 5 du présent article, aucune demande de réparation de dommage par pollution, qu'elle soit ou non fondée sur la présente Convention, ne peut être introduite contre : a) les préposés ou mandataires du propriétaire ou les membres de l'équipage; b) le pilote ou toute autre personne qui, sans être membre de l'équipage, s'acquitte de services pour le navire; c) tout affréteur (sous quelque appellation que ce soit, y compris un affréteur coque nue), armateur ou armateur-gérant $d u$ navire ; d) toute personne accomplissant des opérations de sauvetage avec l'accord du propriétaire ou sur les instructions d'une autorité publique compétente ; e) toute personne prenant des mesures de sauvetage; f) tous préposés ou mandataires des personnes aux alinéas c), d) et e); à moins que le dommage ne résulte de leur fait ou de leur omission personnels, commis avec l'intention de provoquer un tel dommage, ou commis témérairement et avec conscience qu'un tel dommage en résulterait probablement ".

617 L'affaire de l'Amoco-Cadiz illustre parfaitement cette situation. Cf. NDENDÉ (Martin), « L'affaire de l'Amoco-Cadiz ...Quatorze ans de bataille juridique », Collection Espaces et Ressources Maritimes, Editions Pédone, Janvier $1992, \mathrm{n}^{\circ} 6$.
} 
et 20 que : «le droit de propriété est garanti à tous ...»et «toute personne a droit à un libre et égal accès à la justice."

Il en résulte une faveur accordée à l'industrie pétrolière.

\section{Une faveur accordée à l'industrie pétrolière}

Au regard de ce qui précède, Monsieur TIEBLEY Yves Didier fait remarquer que la limitation de responsabilité telle que pratiquée actuellement se caractérise par son aspect non dissuasif. Selon l'auteur, il ne serait pas du tout exagéré de penser que la Convention CLC 1969 fait la part belle à l'industrie pétrolière au détriment des victimes de marées noires ${ }^{618}$. Ce qui est de nature à mettre en mal l'idéal qui a animé les rédacteurs de la Convention FIPOL 1992 à savoir l'idemnisation satisfaisante des victimes.

Par ailleurs, en se référant à certaines affaires d'indemnisation des victimes de marées noires, l'ambivalence de la Convention CLC 1992 se constate également au niveau des limites de la Convention FIPOL 1992 et de la Convention supplémentaire de 2003.

\section{Paragraphe 2: Les limites de la Convention FIPOL 1992 et de la Convention complémentaire de 2003 modifiant le protocole de 1992}

Les lacunes du droit maritime international envisages en l'espèce sont de deux ordres. Celles qui découlent des faiblesses de certaines dispositions de la Convention FIPOL de 1992 (A) et celles de la Convention complémentaire de 2003 modifiant le Protocole de 1992 (B).

\section{A - Les faiblesses des dispositions de la Convention FIPOL 1992 tirées des délais de prescription aux cas de dommages diffus et différés}

Les faiblesses qui attirent particulièrement notre attention sont relatives des délais de prescription de l'action en réparations des dommages écologiques issus de la Convention FIPOL de 1992.

Selon l'article $6 \$ 1$ de la Convention FIPOL 1992: "les droits à indemnisation ...s'éteignent à défaut d'action en justice intentée...dans les trois ans qui suivent la date à laquelle le dommage est survenu. Néanmoins, aucune action en justice ne peut être intentée après un délai de six ans à compter de la date à laquelle s'est produit l'évènement ayant causé le dommage ».

${ }^{618}$ Voir TIEBLEY Yves Didier, Thèse précitée, p.270. 
En effet, les délais de prescription sont inadaptés au regard des caractères diffus et différés des dommages écologiques.

Les dommages écologiques sont diffus. Car les dommages de pollution par hydrocarbures sont du type d'événements qui peut donner lieu à une pluralité d'auteurs potentiels du dommage écologique, parmi lesquels il faut trouver le débiteur de la réparation. En pratique, il est possible que la détermination du débiteur de l'indemnisation prenne du temps. Il n'y a pas de doute que ces difficultés aient un impact défavorable sur l'action en réparation des dommages, à exercer selon la Convention FIPOL ${ }^{619}$.

Les délais de prescription des dommages différés sont tout aussi défavorables aux victimes. Dans la mesure où dans ce cas d'espèce, le droit maritime international fait fi des dommages différés que viendraient à subir celles-ci à l'expiration des délais conventionnels précités.

Cette éventualité n'est pas une vue de l'esprit. En effet, il est établi qu'un accident maritime peut continuer à générer une pollution préjudiciable au milieu environnant plus d'une décennie après qu'il se soit produit. C'est le cas du naufrage du pétrolier Exxon Valdez. En effet, près de quinze ans après la catastrophe, le pétrole de l'Exxon Valdez a continué à polluer les plages du golfe du Prince William en Alaska, menaçant un certain nombre d'espèces marines. Il est vrai que les dommages causés par cette pollution différée sont surtout d'ordre écologique mais il n'est pas à exclure qu'elle se mue en dommage environnemental, lorsqu'elle atteindra des biens appropriés, évaluables en termes monétaires.

Il est aussi possible que la pollution différée à laquelle nous faisons allusion intervienne sur le territoire d'un État tiers à la Convention FIPOL, comme par exemple les ÉtatsUnis d'Amérique. Mais il n'empêche qu'elle constitue un cas d'école intéressant. D'ailleurs, le cas Exxon Valdez n'est pas un cas isolé dans la mesure où le Prestige (naufragé le 13 novembre 2002 au large de la Galice en Espagne) a pu produire, lui aussi, une marée noire différée avec un impact plus notable sur les biens des populations riveraines.

Cette éventualité n'a d'ailleurs pas échappé à la population riveraine espagnole qui s'en inquiétait malgré les propos rassurants de leurs autorités. Il est clair que la réparation de cette nouvelle forme de marées noires ne saurait être imputée au propriétaire du navire englouti dès lors que celui-ci s'est exonéré de toute responsabilité civile en constituant le fonds de garantie exigé par l'article VII de Convention CLC.

\footnotetext{
619 Dans cette optique, un auteur a pu écrire: "En ce qui concerne le dommage diffus, il décrit la situation où il existe une multitude de sources, de sorte qu'il devient difficile d'identifier le responsable de la nuisance. " Cf. AKPOUE (Brou), Le droit privé de l'environnement, Thèse unique de droit privé, Université de la Rochelle, 31janvier 2009, pp. 132-133
} 
Dans une telle hypothèse, la victime devrait être indemnisée sur le fondement de l'article 4 alinéa 1 de la Convention FIPOL ${ }^{62}$.Il conviendrait donc d'admettre que la prescription ne court pas contre celui qui ne peut agir ${ }^{621}$. Cette forme de réclamation originale devrait être circonscrite aux victimes de marées noires différées afin de prévenir les recours intempestifs des victimes ordinaires forcloses. La détermination du type de marée noire ne devrait pas être laissée à l'entière discrétion du Fonds. Il serait avantageux que les victimes insatisfaites puissent déférer la décision du Fonds à la censure des juridictions compétentes du lieu où est survenu le dommage.

La Convention supplémentaire de 2003 n'est pas non plus en reste des insuffisances.

\section{B - Des faiblesses persistantes de la Convention complémentaire de 2003 modifiant le protocole de 1992}

A ce stade de notre analyse, nos critiques à l'endroit du système d'indemnisation CLC69, FIPOL71 et les Protocoles d'amendement y relatifs restent également valables en dépit du relèvement des barèmes des indemnités. Notamment en ce qui concerne l'idée même, du plafonnement de l'indemnisation (1), et de la problématique de la ratification des nouvelles conventions qui abrogent les Conventions précitées par les États en développement (2).

\section{La persistante idée du plafonnement de responsabilité}

Des ajustements sont donc souhaités au titre du relèvement significatif des plafonds d'indemnisation. En effet, comparativement à la Oil Pollution Act 1990 américaine, les plafonds de limitation de responsabilité prévus par le système international de responsabilité s'avère très bas. Selon l'OPA, la loi américaine, la responsabilité du «civilement responsable» propriétaire, exploitant ou affréteur d'un navire pollueur de plus de 3000 tonnes est calculée sur la base de 1200 Dollars par tonne, avec un seuil minimum de 10 millions de dollars US. A titre de comparaison, nous nous referons à la limite de responsabilité selon l'OPA dans l'affaire de l'Exxon Valdez.

La limite de responsabilité pour n'importe quelle partie responsable du Exxon est de 114.202. 800,40 de Dollars US (95 169 tonnes multipliées par 1200 dollars par tonnes). A cet effet, un auteur rendant compte de l'ampleur de la réparation effectuée par la société Exxon écrit :

«Ce litige est sur le point de se conclure prochainement par une transaction historique entre la société Exxon, le ministère de la justice et l'Alaska. Dans cette transaction, Exxon reconnaît sa responsabilité pénale et accepte de payer une amende de 100

\footnotetext{
${ }^{620}$ Le Fonds est tenu d'indemniser toute personne ayant subi un dommage par pollution si cette personne n'a pas été en mesure d'obtenir une indemnisation équitable ...parce que la Convention (CLC) ne prévoit aucune responsabilité pour les dommages en question.

621 Selon l'adage «contra non valentem agere non currit proscriptio».
} 
millions de dollars, la plus importante jamais prononcée aux États-Unis. Exxon qui a déjà payé plus de 2 milliards de dollars pour le nettoyage, accepte de payer jusqu'à 1 milliard de dollar de plus selon un échéancier fixé ...Exxon accepte aussi de payer encore 100 millions de dollars si des problèmes environnementaux significatifs apparaissent au delà des 10 années à venir. Cet accord n'affecte pas directement les quelques 300 litiges privés contre Exxon ${ }^{622} »$.

Ces montants sont sans commune mesure avec la limitation de responsabilité ayant cours sous le régime international dans l'affaire de l'Amoco Cadiz où seulement 77 millions de FF étaient payés aux victimes. Ces montants traduisent la volonté des autorités américaines de parvenir à un dédommagement aussi satisfaisant que possible des victimes des marées noires.

En 2006, le montant des plafonnements fut relevé confortement à la Loi de 2006 sur la garde côtière et le transport maritime. En outre, la méthode de calcul applicable aux pétroliers a changé. En effet, le plafonnement de responsabilité applicable à un pétrolier à simple coque sera plus élevé que celui d'un pétrolier à double coque de la même catégorie ${ }^{623}$. Par ailleurs, la loi américaine exige la garantie financière au civilement responsable pour prouver qu'il jouit d'une garantie financière équivalente aux plafonds de responsabilité imposés par l'OPA. Sans oublier que la limitation de responsabilité sous le régime de l'OPA n'est pas automatique. Pour bénéficier de la limitation de responsabilité, le civilement responsable doit satisfaire à certaines conditions notamment la collaboration avec le gouvernement fédéral, l'obligation de rapport et de conformité. ${ }^{624}$

Sous le regime international de responsabilité civile, le propriétaire de la cargaison à savoir la compagnie pétrolière, quant à lui, doit simplement verser un fonds. C'est-à-dire

622 SMITH Jr. (Turner T.), «Les déversements de pétrole en mer aux États-Unis : l'Exxon Valdez et au-delà, » in SFDE, le dommage écologique en droit interne, communautaire et comparé, Actes du colloque organisé les 21 et 22 mars 1991 à la faculté de droit, d'économie et de gestion de l'Université de Nice Sophia-Antipolis, Paris, Economica, 1992, pp.203- 209.

623 Cf.United States Coast Guard, Consumer Price Index Adjustments of Oil Pollution Act of 1990 Limits of Liability-Vessels and Deepwater Port, Federal Register Vol.74, Nº125,1 july 2009, pp.31357-31369, citée par WANG Hui et Michael FAURE, « Responsabilité civile et réparation des pollutions marines, Leçon à tirer des déversements provenant des plateformes pétrolière », in Oil, Gas and Energie law Intelligence, Vol. 8, septembre 2008, p.3. A titre d'exemple, pour un pétrolier à simple coque supérieur à $3000 \mathrm{tjb}$, le plafonnement de responsabilité sous le régime de la loi de 2006 visée plus haut est de 3000 dollars US par tjb ou 22.000.000 dollars US. Ce qui est remarquable est que cette Loi inclut en plus des pétroliers à simple coque, les pétroliers disposant de citernes latérales ou d'espaces de double fond. En plus le montant limite de responsabilité est toujours plus élevé de deux montants comparés. En 2009, la Coast Guard a effectué le premier ajustement de l'index à la consommation. Il a procédé au relèvement des plafonds de responsabilité le faisant passer de 1.900 à 2.100 dollars US pour les pétroliers à double coque et de 3.000 à 3200 dollars US pour les pétroliers à coque simple.

624 La Loi américaine susvisée s'intitule « Coast Guard and Maritime Transportation Act of 2006 ». Cette loi a été promulguée le 11 juillet 2006.Voir WANG ( Hui) et FAURE (Michael), « Responsabilité civile et réparation des pollutions marines, Leçons à tirer des déversements provenant des plateformes pétrolières ", in Oil, Gas and Energie law Intelligence, Vol. 8, septembre 2008, pp.3-4 et 8. 
une contribution en fonction de la quantité d'hydrocarbures importée. Comme on le voit, ces contributions sont en définitive payées par les consommateurs finaux. Ce système conduit à faire supporter la charge de la catastrophe aux riverains et aux collectivités nationales. Puisque, c'est en réalité le consommateur qui supporte le poids du financement du Fonds assuré au moyen des taxes perçues sur le volume de pétrole transporté par voie maritime. Quant à l'armateur et l'affréteur ils sont quittes puisqu'ils ont souscrit un contrat d'assurance pour l'un, cotisé à un Fonds pour l'autre.

Par ailleurs, il est un argument selon lequel l'indemnisation doit être limitée, car une réparation illimitée signifierait la disparition $\mathrm{du}$ transport maritime des hydrocarbures ${ }^{625}$. Pour le Professeur VIALARD, cet argument est trompeur. Selon lui, si tel était vraiment le cas, aucun armateur ne transporterait pas un seul baril de pétrole aux USA. Puisque les plafonds d'indemnisation y sont très élevés comme le décrit nos développements qui précèdent. Pourtant, nul ne peut se passer du marché américain. Le Professeur FAURE Michael rapporte en ce sens qu'une étude menée en 2003 a identifié 16 États qui imposent la responsabilité illimitée en cas de marées noires ${ }^{626}$.

L'indifférence totale des pays en développement à ratifier les Conventions internationales de droit maritime reste aussi à critiquer.

\section{La problématique de la ratification des Conventions internationales par les pays africains}

Toutes les propositions ci-dessus indiquées doivent inspirer les décideurs africains, à l'effet de ratifier les Conventions internationales existantes. Car à défaut d'obtenir l'application de l'OPA 90 des États Unis qui est une loi purement nationale ${ }^{627}$. Au moins il est souhaitable d'appartenir au système international de la responsabilité civile issu des conventions internationales d'indemnisation du droit maritime ${ }^{628}$ et leurs différents protocoles d'amendements respectifs en cours.

Cela peut tout de même se révéler comme une opportunité d'être couvert par la solidarité internationale en situation de catastrophe due à la marée noire. C’est aussi une

\footnotetext{
625 Cette doctrine est contredite par le Professeur VIALARD « Faut-il réformer le régime de l'indemnisation des dommages de pollution par les hydrocarbure? », in DMF mai 2003, p. 435.

${ }^{626}$ Cf. Etkin, D., A Worldwide Review of Maine Oil Spill Fines and Penalties, Environmental Reseacsh Consulting, 2003, p.22, cite par FAURE (Michael), “ responsabilité civile et réparation des pollutions marines, Leçon à tirer des déversements provenant des plateformes pétrolières, op. cit., p.8.

${ }^{627}$ Selon l'OPA, la responsabilité du « civilement raisonnable » propriétaire exploitant ou affréteur d'un navire polluant de plus de 3.000 tonnes est calculée sur la base de 1.200 dollars par tonnes avec un seuil minimum de 10 millions de dollars us. Ainsi, dans l'affaire Exxon Valdez, la limite de responsabilité pour n'importe quelle partie responsable est de 114002 800, 40 Dollars us. (95.169 tonnes multipliées par 1.200 Dollars par tonnes).

${ }^{628}$ Comparativement à la OPA 90, les montants prévus par ces conventions sont bas. Cela est notable dans l'affaire de l'Amoco-cadiz où le montant de l'indemnisation a été fixé à 70 millions de FF. Ce qui traduit la volonté des États-Unis à un dédommagement aussi satisfaisant que possible des victimes des marées noires. D'où leur refus de ratifier les conventions internationales CLC et FIPOL jugeant trop bas les plafonds de responsabilité prévus.
} 
opportunité pour régler le problème de vide législatif souvent très préjudiciable en cas de situation critique de marées noires de grande envergure. Les pays industrialisés quant à eux, propriétaires des pétroliers et les plus gros contributeurs aux FIPOL ont pour la plupart ratifié les nouvelles conventions de 1992 et de 2003 précitées, aujourd'hui en vigueur. Pendant ce temps, la plupart des pays africains de l'OMAOC ne restent couverts que par les vieilles Conventions CLC69 et FIPOL 71 très dépassées aujourd'hui ${ }^{629}$.

Le système de l'exonération de responsabilité civile du propriétaire est de nature à rendre à néant l'idée même de l'indemnisation des victimes des marées noires.

\section{Section 2: Les entraves à l'indemnisation effective des victimes découlant des exonérations légales de responsabilité civile}

La victime du dommage par pollution dû au déversement d'hydrocarbures bénéficie de la facilité de mettre en jeu de la responsabilité du propriétaire du navire. En effet, pour obtenir réparation, il lui suffira de prouver que le dommage est la conséquence de l'évènement incriminé pour obtenir la responsabilité de celui-ci qui lui a occasionné des dommages $^{630}$. En contrepartie, de ce régime favorable à la victime, le transporteur bénéficie au titre de l'étendue de responsabilité en plus des limitations financières, des exonérations lui permettant de dégager sa responsabilité.

En effet, le transporteur peut voir sa responsabilité complètement tomber s'il établit que le dommage est dû à une cause qui ne lui est pas imputable ${ }^{631}$. Les causes d'exonérations sont énumérées limitativement ${ }^{632}$ par la convention CLC respectivement en ses articles 3 alinéa 2, 4 alinéa 2 et $5 / 3^{\text {ème }}$ de la convention FIPOL 71. L'analyse combinée des conventions, nous autorise à entrevoir des causes générales (Section1) et des causes spéciales (Section2) qui exonèrent aussi bien l'exploitant du navire pétrolier que le Fonds international d'indemnisation ${ }^{633}$.

\footnotetext{
629 Voir STANZEL (K.) (conseiller technique FIPOL), Les évolutions récentes du régime international CLCFIPOL, Pollutions accidentelles des eaux, Impact des Evolutions juridiques et Réglementaires, 14ème journée d'information du CEDRE, mars 2009, États Membres ( non paginé).

${ }^{630}$ Il n'aura qu'à démontrer le lien de causalité entre les dommages et l'évènement incriminé. Car la mise en jeu de la responsabilité du transporteur n'exige pas cumulativement les trois conditions de l'article 1382 du code civil. Voir dans ce sens MERCADAL (Barthélemy), Droit de transport terrestre et aérien, Précis Dalloz, $\mathrm{n}^{\circ} 223,1973$, p. 124.

${ }^{631}$ Voir l'arrêt de la cour de cassation française du 3 novembre 1966, in D.M.F, 1966, 466. Cela veut dire que la responsabilité qui pèse sur le propriétaire du navire n'est pas une responsabilité "objective ", car celle-ci ne laisserait aucune échappatoire au propriétaire. Ce n'est pas non plus une présomption de faute. Voir René RODIERE, Traité général de Droit maritime, Paris, DALLOZ, n519, 1976, P.660. Voir aussi en ce sens, SRITASTAVA (S.P), «Stratégie pour la protection du milieu marin », Grande Bretagne, juillet 1988, p.16.

${ }^{632}$ A titre d'illustration, voir l'article 3 alinéas 4 et 5 de la convention CLC 1969.

${ }^{633}$ Néanmoins ainsi que le fait remarquer Thomas A. Mensah, cette exonération n'est pas automatique. Car le propriétaire doit prouver que l'évènement en question n'est pas la cause du dommage. Cf. Mensah A., Civil Liability and Compensation for Vessel-Source Pollution of the Marin environment and the United Nations Convention of the Law of the Sea 1982. Cité par SABRINA Robert, l'Erika: Responsabilité pour un désastre écologique, op. cit., pp. 33-34.
} 


\section{Paragraphe 1: Les causes générales d'exonération de responsabilité civile du propriétaire}

L'article 3 de la convention CLC apparaît comme la synthèse de toutes les causes d'exonération. Il en est de même pour l'article 4 alinéa 2 et l'article 5 de la convention FIPOL qui font tomber la responsabilité du Fonds ${ }^{634}$.

En effet, le texte précité en son alinéa premier dispose que le propriétaire est libéré s’il établit que le dommage par pollution est dû alternativement à un acte de guerre et assimilé aux faits du tiers (A) et à la force majeure (B).

\section{A - Les cas alternatifs du fait du tiers, des actes de guerre ou assimilés}

Aux termes de l'article 3 de la convention CLC 1969, le propriétaire n'est pas responsable s'il prouve que le dommage par pollution résulte d'un acte de guerre, d'une guerre civile, ou d'une insurrection. Il ne l'est pas d'avantage lorsque le dommage résulte en totalité du fait qu'un tiers a délibérément agi ou omis d'agir dans l'intention de causer un dommage ( 1) ainsi que d'autre situations voisines(2).

\section{Le fait du tiers ou assimilé}

Que faut-il entendre par «un tiers »? Le préposé du propriétaire du navire est-il un tiers? Ou encore sont-ce les personnes extérieures aux navires qui sont visées? Dans l'exemple du préposé, nous estimons qu'un employé du propriétaire qui provoque intentionnellement ou non l'écoulement en ouvrant les vannes ne saurait être considéré comme un tiers. Car s'agissant de la responsabilité délictuelle, le commettant, propriétaire du navire est responsable de ses préposés agissant dans l'exercice de leur fonction $^{635}$.

Dès lors, souhaiterions nous que les législations internationales prennent le soin de préciser la notion de «tiers». Aussi pour notre part, suggérons-nous à l'instar du Doyen René RODIERE qu'en l'espèce, l'on fasse allusion à l'intervention active ou passive des personnes absolument étrangères au propriétaire du navire. Pour le professeur Martine REMOND GOUILLOUD, ce qui serait visé en l'espèce c'est l'hypothèse d'un «acte terroriste ${ }^{636}$, telle que la piraterie susceptible d'être à notre sens source de pollution accidentelle en raison de la violence employée non seulement par les pirates mais aussi par les moyens militaires pour secourir les otages et les cargaisons. En effet, la montée

\footnotetext{
634 Étant entendu que le FIPOL ne protège pas les victimes au sens propre. C'est plutôt la responsabilité civile de l'armateur qui est garantie, Voir en ce sens, D.S. 1982, Chron.15, p. 194.

${ }^{635}$ Voir l'article 1384 alinéa 1 du code civil français. Voir aussi l'article $1797 \mathrm{du}$ code civil français, l'entrepreneur répond du fait des personnes qu'il emploie.

636 Voir RODIERE (René), Traité général de droit maritime, pollution des mers, Paris, édition Dalloz, $\mathrm{n}^{\circ} 1292$, , $\mathrm{n}^{\circ} 13,1976$, p. 661.
} 
en puissance des pirateries ${ }^{637}$ professionnelles en haute mer ou dans des zones de mouillage est préjudiciable pour la sécurité maritime en général et surtout dessert les intérêts des pays du tiers monde. En ce sens que cette forme de brigandage maritime pourrait être exploitée par les armateurs pour dégager leur responsabilité. Et cela est d'autant plus plausible qu'entre autres raisons, la piraterie est le résultat de l'incapacité de certains pays pour la plupart du tiers monde à gérer la sûreté de leurs eaux territoriales ${ }^{638}$.

Il existe des situations voisines aux causes générales d'exonération de responsabilité civile du propriétaire tirées du fait des tiers et des actes de guerre ou assimilés.

\section{Les situations voisines}

Avec l'hypothèse de la piraterie, les propriétaires des navires bénéficieront là, à coup sûr d'un moyen de défense supplémentaire ${ }^{639}$. Et ce, lorsque l'opérateur maritime de transport d'hydrocarbures interprèterait ces événements comme le fait des populations locales victimes des dommages de pollution pétrolière ou encore comme la défaillance de l'État côtier.

Une telle allégation mériterait d'être rejetée dans une certaine mesure où nous savons aussi que le développement de la piraterie moderne est aussi la conséquence des conditions de navigation maritime défectueuses que l'industrie du transport maritime

\footnotetext{
${ }^{637}$ Selon le dictionnaire de la terminologie du droit international, Paris, Sirey, 1960, p.755, la piraterie constitue un brigandage maritime. Le fait de courir les mers sans commission d'aucun État en commettant à des fins privées des actes de violence contre les personnes et les biens, mettant en danger la sécurité générale, considérée en conséquence comme un crime du droit des gens dont la répression appartient à tout État, quel que soit le pavillon abordé par le pirate. Aux termes de l'article 15 de la convention de Genève du 29 avril 1958 sur la haute mer, constitue la piraterie :

1- tout acte illégitime de violence, de détention ou toute déprédation commis pour des buts personnels par l'équipage ou les passagers d'un navire privé ou d'un aéronef privé et dirigé en haute mer contre un autre navire ou aéronef, ou contre des personnes ou des biens à leur bord, contre un navire ou aéronef, des personnes ou des biens dans un lieu ne relevant de la juridiction d'aucun État.

2- tous actes de participation volontaire à l'utilisation d'un navire ou d'un aéronef, lorsque celui qui les commet a connaissance des faits conférant à ce navire ou à cet aéronef le caractère d'un navire ou d'un aéronef pirate.

3- toute action ayant pour but d'inciter à commettre des actes définis aux alinéas 1 ou 2 , ou entreprise avec l'intention de les faciliter.

${ }^{638}$ Les pirates d'aujourd'hui sévissent essentiellement dans les régions d'Asie du Sud et d'Asie du SUD-EST( dans la mer de Chine méridionale), le long des côtes de l'Amériques du sud, du golfe d'Aden, de la mer rouge, mais aussi et surtout celle de Somalie, dans le golfe de Guinée et dans la mer de Caraïbe.

Selon le Bureau maritime international, plus de 4000 actes de piraterie ont été enregistrés durant les vingt dernières années. Un rapport de la RAND Corporation estime le nombre d'attaques et de la tentative d'attaques à 209 durant la période de 1994 à 1999 et à 2463 entre 2000 et fin 2006, soit une augmentation exponentielle de ces pratiques depuis le début de XXIe siècle. Voir http://fr.wiki/pirates-moderne, du 24-1108.

${ }^{639}$ Cela est d'autant plus déplorable que les armateurs bénéficient déjà formellement d’une panoplie de causes d'exonération de sa responsabilité civile à savoir la force majeure, l'action ou la négligence d'un gouvernement, et le fait de la victime.
} 
gagnerait à corriger. En effet, très souvent, les équipages sont peu nombreux et non armés. Une vingtaine d'hommes sur un navire de 15 mètres. En outre les navires marchands se déplacent à des vitesses faibles entre 30 et $40 \mathrm{~km} / \mathrm{h}^{640}$.

C’est dans cet ordre d'idées qu'ayant compris les nouveaux enjeux sécuritaires dans l'environnement des transports maritimes internationaux, l'OMI a crée le code ISPS (code international pour la sûreté des navires et des installations portuaires) à la suite des attentats de septembre 2001, le 12 décembre 2002 par la résolution de la conférence des gouvernements contractants à la convention internationale pour la sauvegarde de la vie humaine en mer (SOLAS 1974) ${ }^{641}$.

Dans la plupart des cas, les pirates ne s'intéressent pas à la marchandise transportée, mais plutôt aux affaires personnelles de l'équipage et au contenu du coffre fort, qui peut contenir d'importantes quantités de monnaie destinée à payer le personnel et les taxes portuaires. Il arrive aussi, que les pirates se débarrassent de l'équipage et conduisent le navire dans un port afin de vendre la cargaison et dans de rares cas de transformer son identité et de le revendre.

Par ailleurs, à supposer qu'à la suite d'une difficulté mécanique du navire à priori non directement liée à la cargaison, se produise des risques de pollution consécutive aux opérations d'assistance notamment les risque de chavirement, de cassure ou d'explosion voire le risque de ne pas trouver un port qui accepte d'accueillir un navire endommagé ou encore d'abordage entre le pétrolier en détresse et le navire qui lui apporte une assistance. Dans une telle hypothèse, une jurisprudence de la cour de cassation française prend le soin de faire le départ entre le contrat de remorquage et celui d'assistance. Pour la cour, le contrat d'assistance ou de sauvetage concerne les opérations engagées lorsque le navire est en danger de se perdre et que la remise à flot ne peut se faire par délestage d'une partie de sa cargaison. En cela elle se fonde sur la loi française du 29 avril $1916^{642}$.

Pour sa part, à l'occasion du colloque de Marseille sur la responsabilité en matière d'assistance à des pétroliers, le commandant L.A. Gaillard, directeur de la société des remorqueurs du port autonome de Marseille décrit les différends moments d'opération d'assistance à un pétrolier comme suit:"fixation du navire par remorqueur, encrages ou lestage complémentaire, mise en place des équipements anti-pollution (barrage), transfert de la cargaison, remorquage final dans un port ${ }^{643}$."Si au cours de cet accident donc, des

\footnotetext{
${ }^{640}$ Voir http://fr.wiki/pirates-moderne, du 24-11-08.

${ }^{641}$ Pour l'histoire et le fonctionnement du code ISPS, voir http//Serch.llive.com/results.aspx? $\mathrm{q}=$ code+ISPSform=QBRE, du 25-11-08. En tout état de cause, la norme ISPS oblige les navires à se doter de système d'alerte satellitaire et à créer à l'intérieur du bateau des zones de refuge fermées, à respecter des procédures de discrétion et de veille. Toujours en guise de solution, il est des sociétés privées qui proposent une offre de prestation de sécurité aux armateurs et des États européens et la Chine qui ont décidé d'escorter leurs navires marchands qui naviguent dans les zones réputées sensibles à la piraterie.

${ }^{642}$ Voir, Cass. Ch. Civile, section com., 25 octobre 1961, in DMF, 1962, pp.11-12.

Selon la cour, l'intervention de « le Gard » au profit du pétrolier "Regina » ne peut être considéré comme un contrat de sauvetage, mais comme un contrat de remorquage.

${ }^{643}$ Voir, DMF janvier 1976, n³25, p. 10.
} 
quantités d'hydrocarbures se déversent à la mer, faut-il légitimement invoquer le fait du tiers pour dégager la responsabilité du propriétaire du navire pétrolier?

Nous pensons que dans ce cas d'espèce, l'exonération de la responsabilité de l'armateur ou de l'affréteur serait absurde. Elle ne se justifierait pas. En ce sens que les opérations engagées de la sorte visent à prévenir ou à limiter un dommage de pollution ${ }^{644}$. En plus, une solution contraire serait préjudiciable aux victimes ${ }^{645}$. La force majeure est une autre cause de l'exonération de la responsabilité de l'opérateur maritime.

\section{B - $\quad$ La force majeure}

L'article 3 alinéa 1 de la convention CLC 69 dispose également que le propriétaire n'est pas responsable s'il prouve que le dommage par pollution résulte d'un "phénomène naturel de caractère exceptionnel, inévitable et irrésistible». Nous pensons que c'est la force majeure qui s'entrevoit dans ces dispositions de la convention CLC 69 précitée. Le juge semble en général donner une conception restreinte à la notion de la force majeure (1). Il en résulte des effets bénéfiques au profit des victimes (2).

\section{La conception restreinte du juge de la notion de force majeure}

La force majeure est un évènement imprévisible et insurmontable. A propos de la notion de la force majeure, la TGI de Paris dans son jugement du 15 juin 1984 l'a définie comme un évènement que le transporteur n'a pu ni prévoir, ni éviter dans sa cause comme dans ses effets, malgré les soins, l'attention et la diligence qu'il a porté à l'exécution de ses obligations légales ou contractuelle ${ }^{646}$.

A propos de la notion de force majeure, la jurisprudence se montre très rigoureuse en matière de la preuve. Elle refuse d'exclure toute faute du débiteur susceptible d'avoir concouru à la réalisation de l'évènement dommageable ${ }^{647}$. Ainsi, la cour de cassation dans un arrêt du 10 novembre $1983^{648}$ a refusé la force majeure au transporteur non seulement pour vol mais également pour les dommages résultant de l'incendie. L'incendie ayant pour cause originelle une imprudence du transporteur. De même, pendant la seconde guerre mondiale, la compagnie du chemin de fer a été déclarée

\footnotetext{
644 Ces opérations qualifiées de «mesure de sauvegarde " participent de la lutte contre la pollution des mers. Voir en cela PRIOU (Christoph), Rapport de la commission d'enquête sur l'application des mesures préconisées en matière de sécurité du transport maritime, 10 juillet, 2003, pp 1616 et suivants.

645 Ce qui confirme notre opinion, étant entendu que l'auteur des opérations de sauvegarde ferait partie des victimes au sens de l'article 1 alinéa 6 de la CLC 69 qui définit également "le dommage par pollution", notamment comme le coût des mesures de sauvegarde et toute perte subie lors des opérations de réduction et de limitation des dommages.

${ }^{646}$ Tribunal de grande instance de Paris, 15 juin 1984, gaz du palais 1984, sommaire 449.

${ }^{647}$ Cassation 9 janvier 1984 D.P. 1984-1- p. 454.

${ }^{648}$ C. Rouen, 10 novembre 1983 B.T 1984 p. 5280.
} 
irrecevable à exciper de la force majeure pour les marchandises détruites par les bombardements postérieurement à l'expiration des délais de transport ${ }^{649}$.

Par ailleurs, pour constituer la force majeure, l'évènement doit-il être extérieur à la personne ou à l'entreprise qui l'invoque ? Dans l'affirmative, on doit interdire de considérer par exemple la grève même subite du personnel d'un armateur (propriétaire) comme un cas de force majeure. Cela a été jugé dans un arrêt du 4 décembre 1981 par la cour de cassation qui a refusé au transporteur maritime le bénéfice de la force majeure. L'équipage de celui-ci avait obligé le commandant (du navire) à mouiller le navire de façon à interdire l'accès au port de Havre ${ }^{650}$. Ainsi d'après un jugement rendu par le tribunal de Sète et confirmé par la cour de Montpellier le 24 juillet $1950^{651}$ l'exonération tirée de la fortune de mer peut-être écartée lorsqu'il est prouvé que le transporteur a accompli une manœuvre maladroite ou préméditée des vannes, qui aurait permis une fuite du liquide à la mer et que, d'autre part, une intercommunication des citernes se serait établie par suite de la fermeture défectueuse des vannes ou une retiraison clandestine par le plan d'eau du port mal surveillé.

Encore plus, le fait du tiers peut-il s'assimiler à la force majeure? Selon la jurisprudence, le fait du tiers n'est assimilé à la force majeure que s'il en présente les caractères fondamentaux ${ }^{652}$.

La conception restreinte de la force majeure est source d'effets bénéfiques.

\section{Les effets de la conception restreinte donnée par le juge}

La solution adoptée par la jurisprudence tend de plus en plus à limiter l'influence de la force majeure dans le domaine des transports ${ }^{653}$. Ainsi a-t-il été jugé en droit maritime dans l'affaire de Lamoricière que lorsqu'un bâtiment a déjà essuyé sans dommage une tempête aussi violente que celle qui est à l'origine du sinistre, le transporteur n'est pas en droit d'invoquer la force majeure, étant donné que l'évènement n'est ni insurmontable, ni imprévisible ${ }^{654}$.

Nous partageons la conception de la jurisprudence. Le transporteur maritime devrait donc répondre de tous ces évènements naturels. Car le navire ne se définit-il pas dans la tradition du droit maritime par son aptitude à affronter les épreuves de la mer ? A titre d'exemple, en matière de transport aérien, transposable, la cour de Grenoble dans

\footnotetext{
${ }^{649}$ Cassation 16 mai 1949, 3 janvier 1950 BT. 1949-50.

${ }^{650}$ Cass. ch. Mixte,4 décembre 1981, D. 1982, p. .365.

651 DMF 1951, p. 6.

${ }^{652}$ Le fait du tiers ne constitue un cas d'exonération pour le transporteur que s'il ne pouvait être ni prévu, ni empêché. Cependant, dans une décision en date du 9 janvier 1987, la cour de cassation française a jugé néanmoins qu'il est des cas où le fait du tiers ne relève pas de la force majeure notamment lorsque l'accident est survenu dans des circonstances banales. Voir C Aix - Provence 9 juillet 1987 B.T 1987 p. 156.

${ }^{653}$ Voir, De JUGLARD (Michel) et CHASSERIAUX (Jean), « Droit maritime et droit aérien », in RTDC 1952, p. 604.

654 Aix, 5 janvier 1949, S. 1949. 2. 121.
} 
l'affaire Robin Arlaud, a considéré que les évènements atmosphériques qui peuvent pour les autres transporteurs constituer des causes extérieures, ne sauraient jouer ce rôle pour les transports aériens ${ }^{655}$. Il existe d'autres situations parfois invocables comme constitutives de force majeure, mais qui n'en relèvent pas forcement notamment en cas de malaise du conducteur (commandant de bord ou capitaine). ${ }^{656}$

Il ressort de toutes ces remarques que la force majeure s'apprécie au cas par cas en fonction des circonstances de fait, et que celui qui s'en prévaut ne doit pas avoir commis de faute ayant facilité la réalisation de l'évènement dommageable. Cette conception de la jurisprudence sur la notion de la force majeure est d'un secours appréciable en particulier pour les victimes et pour la sécurité maritime en général. Ainsi, comme le démontre notre analyse, des situations pourraient abusivement être invoquées par un propriétaire pour dégager sa responsabilité. La rigueur de la jurisprudence mérite d'être suivie à l'effet de réduire au maximum les échappatoires des propriétaires des pétroliers pollueurs.

En cela, imaginons un commandant ou capitaine du navire qui agissant dans l'exercice de ses fonctions décide de faire voile malgré les mauvaises conditions météorologiques ou encore indépendamment du défaut des conditions de navigabilité du navire. Un tel transporteur ne peut légitimement bénéficier de la force majeure. Il va de soi, que ce comportement n'exonère pas le propriétaire du navire en cas d'accident ayant causé des dommages par pollution. C'est ainsi que, les circonstances du naufrage de l'Erika n'ont pas suffit pour retenir la force majeure. En effet, l'Erika a entrepris son voyage par temps de tempête avec une forte houle et des creux de 8 à 9 mètres. Ces contraintes naturelles même si elles ont été un facteur aggravant par ailleurs habituelles, n'ont pas constitué selon SABRINA un phénomène naturel de caractère exceptionnel, inévitable et irrésistible ${ }^{657}$.

En sus des causes que nous avons qualifiées de générales, il en est d'autres qui apparaissent comme des causes spéciales d'exonérations ${ }^{658}$.

\section{Paragraphe 2: Les causes spéciales d'exonération de responsabilité civile du propriétaire}

Ces exonérations résultent des articles 3 alinéa 2 c) et alinéa 3 de la CLC 69 ainsi que des articles 4 alinéa 3 a) et article 5 alinéa 3 de la convention FIPOL $71^{659}$. Il ressort de

\footnotetext{
${ }^{655}$ Voir, Cour Grenoble 25 mars 1925, in D. 1925. II. 137.

${ }^{656} \mathrm{La}$ cour de cassation a jugé que la déficience physique du chauffeur, du transporteur ne pouvait constituer pour un opérateur la cause étrangère de nature à l'exonérer de sa responsabilité de gardien du véhicule. Voir, Cass. 4 novembre 1965, B.T, 1966, p.60.

657 Voir SABRINA (Robert), L'Erika : responsabilité pour un désastre écologique, op. cit., pp.33-34.

658 Ces causes semblent dans leur ensemble être inhérentes aux victimes de pollution par les hydrocarbures : D’où le caractère paradoxal desdits cas exceptés.

${ }^{659}$ Voir l'article 6 alinéas 2 et 3 du protocole de 1992, qui modifie la convention de 1971 portant création du Fonds.
} 
l'analyse du système desdites conventions, deux catégories d'exonération. Ce sont l'action ou négligence d'un gouvernement (A) et la faute ou l'action de la victime (B) qui valent l'exonération de la responsabilité aussi bien du propriétaire, que celle du Fonds international d'indemnisation.

\section{A - Action ou négligence d'un gouvernement}

La cause d'exonération tirée de l'action ou la négligence d'un gouvernement devrait servir à responsabiliser les États en développement à investir dans la lutte contre les pollutions marines (1) et inciter à impliquer les structures publiques et privées dans la politique de lutte contre les pollutions marines (2).

\section{La responsabilisation des pays en développement à investir dans la lutte contre les pollutions marines}

L'action ou la négligence d'un gouvernement en tant que cause valant libération du propriétaire est prévue par l'article 3 alinéa 2 c) de la convention CLC 69. Le texte déclare que le propriétaire n'est pas responsable s'il prouve que le dommage par la pollution résulte en totalité de la négligence ou d'une autre action préjudiciable d'un gouvernement ou autre autorité responsable de l'entretien des feux ou autres aides à la navigation dans l'exercice de cette fonction.

Comment convient-il d'entendre cette disposition? Nous estimons qu'en l'espèce, le propriétaire doit démontrer pour s'exonérer de sa responsabilité que la négligence ou la défaillance en cause a constitué la cause exclusive du dommage.

En effet, l'expression " en totalité » exclut du domaine du texte toutes les hypothèses où l'acte en cause a simplement contribué à sa survenance tel le bombardement d'un navire pollueur comme l'a fait le gouvernement britannique lors de l'affaire du Torrey Canyon en $1967^{660}$.

Les causes d'exonération de responsabilité civile tirées de l'action ou la négligence d'un gouvernant doit interpeller les autorités des États maritimes en général et en particuliers ceux des pays en développement. En effet, compte tenu de la position de la Côte d'Ivoire en tant que pays producteur de pétrole ${ }^{661}$, « la probabilité de la survenance d'accidents

\footnotetext{
660 Selon le Professeur Martine Remond Gouilloud, cet exemple d'exonération a donné lieu à interprétation judiciaire en Suède.: le Tsesis, navire soviétique s'était échoué dans les eaux suédoises en 1977, son armateur revendiqua et obtint son exonération du fait que les cartes marines suédoises en usage n'était pas à jour. La cour suprême de Suède, acceptant de considérer les cartes marines comme aides à la navigation lui donna gain de cause. De même dans un cas similaire du José MARTI appartenant au même armateur et échoué dans les mêmes eaux en 1981, une solution différente devrait intervenir bien que le navire se fût échoué sur un récif non mentionné par les cartes du fait que l'accident était en partie imputable à une faute du pilote. Voir REMOND GOUILLOUD (Martine), in jurisclasseur volume 7, pollution des mers, Op. cit. , p.6.

${ }_{661}$ Voir l'article de GBANGBO (Jean Louis), Hydrocarbures, vers le pétrole ivoirien ? Où l'auteur fait état de ce qu'en 2006, la production pétrolière de la Côte d'Ivoire est montée à 80.000 barils par jour contre 21.000 en
} 
comme celui de la CNR tend à devenir vraisemblable et n'est plus à négliger ${ }^{662}$. Ainsi la Côte d'Ivoire qui a le devoir de protéger son environnement marin et la santé de la population, doit renforcer ses capacités de lutte, des plans détaillés de prévention des pollutions des mers. A la vérité, il ressort de nos différents entretiens avec des autorités du CIAPOL que le plan POLLUMAR existe. Mais il n'existe pas suffisamment de plan de prévention des pollutions. Et ce, mis à part, le canal de Vridi ${ }^{663}$, il n'existe pas de carte de vulnérabilité participant des aides à la navigation. A cet effet, à propos du Port autonome d'Abidjan (République de Côtr d'voire) les inquiétudes d'un technicien portuaire ivoirien sont édifiantes: «Les dimensions des ouvrages d'accostage commencent à devenir inadaptées aux nouvelles caractéristiques des navires mis en service par les principaux armements désservant nos côtes... " ${ }^{664}$

En fait, la carte de vulnérabilité est un moyen qui permet aux services de lutte contre la pollution d'intervenir efficacement (promptement). Avec l'accident du navire canadien qui a déversé les hydrocarbures au large de Jacqueville, l'on s'est aperçu que ce n'était pas une vue d'esprit. Cela devrait faire prendre conscience du caractère indispensable des politiques de prévention des pollutions par les hydrocarbures. De sortes que les gouvernements mettent tout en œuvre aux fins non seulement de renforcer les infrastructures portuaires mais aussi de ratifier les conventions internationales qui existent en la matière telles que l'OPRC, la CLC, le FIPOL ainsi que les différents protocoles d'amendement de ces conventions.

L'urgence est telle que l'armateur étranger dont le navire polluerait à titre d'exemple les eaux maritimes ivoiriennes trouverait dans le défaut d'infrastructures d'aides à la navigation, une cause d'exonération de sa responsabilité pour les dommages causés. Tandis que l'armateur ivoirien ne bénéficierait pas des mêmes dispositions relatives à l'exonération de responsabilité. Ainsi, au regard de l'article 192 de la convention des Nations Unies sur le droit de la mer du 10 décembre $1982^{665}$, la liberté de la mer qui est le privilège des États, s'accompagne également de l'obligation pour eux de faire respecter l'ensemble de la réglementation internationale régissant cet espace par les opérateurs privés individuels qui relèvent de leur juridiction ou non. Or le plus souvent, les

juillet 2005. Aujourd'hui, la Côte d'Ivoire compte 28 blocs pétroliers, in Inter $n^{\circ} 2613$ du vendredi 26 janvier 2007 p. 10 .

${ }^{662}$ Ainsi que le déclarait le Ministre des Mines et de l'énergie, le vendredi 7 avril 2006 lors de l'audience qu'il a accordé à M Jean François Lévy, expert consultant de l'OMI. Voir compte rendu de la mission de M J F Lévy, $\mathrm{n}^{\circ} 9$, du 5 au 7 avril 2006 en Côte d'Ivoire. Avril 2006, p. 4

${ }^{663}$ C'est le canal de Vridi creusé en 1906 et ouvert le 23 juillet 1950 où se trouvent trois quais à savoir le quai SIR, le quai PETROCI et le quai TEXACO, qui conduit à la zone portuaire. Le canal de Vridi représente pour la Côte d'Ivoire un enjeu éminemment économique car il permet à la zone portuaire de s'ouvrir sur l'océan. Voir Jeune Afrique n0 137, novembre 1990, p.3240.

${ }^{664}$ Cf. l'interview accordée au quotidien le nouveau navire par Dr DJEDJE Gnakalé, Consultant e portuaire international, $\mathrm{n}^{\circ} 233$ du mercredi 6 au mardi 12 juillet 2011, pp.9-11.

${ }^{665}$ Voir en ce sens également l'article 235 de la même convention qui constitue en la matière le traité cadre de l'action des États en matière de protection de l'environnement marin. En ce qu'elle pose les grands principes du droit de la mer et prévoit une répartition des compétences entre les États afin que la protection du milieu marin soit au mieux respectée. Et ce, sur la base du Principe 21 de la déclaration de Stockholm. 
désastres écologiques dus à la pollution par hydrocarbures mettent en évidence les insuffisances des États quant au respect de leurs obligations préventives.

La cause d'exonération de la responsabilité du propriétaire du navire pollueur relative à l'action ou de la négligence d'un gouvernant devrait inciter les pays en développement à tout faire pour créer des infrastructures portuaires. De sorte à éviter de tomber sous le coup des textes instigués par les pays industrialisés ${ }^{666}$ propriétaire de la quasi-totalité des pétroliers du monde. Car à l'analyse ceux-ci cherchent à se protéger contre toutes demandes d'indemnisation consécutives aux dommages par pollution causés aux victimes.

Faut-il continuer, de croire que l'on ne peut rien entreprendre en raison des difficultés de sous développement? Faut-il continuer de tout attendre des organismes internationaux telle que l'OMI pour rendre fonctionnel les plans d'urgences de prévention et de lutte contre les pollutions marines, comme le plan POLLUMAR ${ }^{667}$ ?

L'implication de toutes les structures pétrolières dans la lutte contre les pollutions pétrolières s'imposent.

\section{La nécessité d'impliquer toutes les structures publiques et privées dans la politique de lutte contre les pollutions marines}

Nous pensons qu'au niveau de chaque pays, il suffit de faire un minimum d'effort. On n'a pas besoin d'avoir des équipements de pointe, lourds pour prévenir et lutter efficacement contre les risques de pollution par hydrocarbures. Le CIAPOL et les structures privés disposent du minimum qu'il convient d'organiser de rentabiliser et de coordonner ${ }^{668}$.

Il faut d'une part mettre sur pied une franche politique de collaboration entre les différentes structures publiques de gestion des accidents marins notamment la DGAMP, le CIAPOL, les ministères du transport et de l'environnement, et la SIR et d'autre part celles-ci avec les entreprises pétrolières privées afin de lutter efficacement contre les sinistres. A titre d'exemple, lors du naufrage de l'Erika, l'administration française a été la cible de nombreuses critiques quant à sont manque d'efficacité dans le déploiement des

\footnotetext{
${ }^{666}$ Ceux-ci disposent des infrastructures portuaires de pointe. Alors qu'en la matière, les pays en développement comme la Côte d'Ivoire sont viscéralement sous équipés, sans armements.

667 Il ressort de notre entretien avec monsieur HOBA Honorat, coordonnateur régional de la coopération technique en Afrique de l'ouest et du centre, que depuis 2002, l'OMI en la matière a désormais une mission de prévention des déversements d'hydrocarbures. Elle n'apporte plus d'assistance technique, ni financière. A preuve, lors du déversement d'hydrocarbure (accident) l'OMI n'a donné que des adresses d'organismes compétents pour $\mathrm{y}$ faciliter l'accès.

668 Il ressort de notre enquête que le P.A.A et la SIR disposent des moyens de lutte contre les pollutions accidentelles en mer et d'un plan de lutte interne appelé POI. Il est souhaitable que tous ces plans de lutte des entreprises de la communauté portuaire soient intégrés au plan pollunar et les vulgariser auprès des différents partenaires. Voir en ce sens, le compte rendu du consultant de l'OMI en Côte d'Ivoire, avril 2006, op.cit., p.2
} 
plans POLMAR-terre et POLMAR-mer ${ }^{669}$, l'impréparation à terre, le manque de moyen, l'incapacité à encadrer le travail du nettoyage des plages, à laisser développer une impression de manque de maîtrise des évènements ${ }^{670}$.

Comme on le voit, il est des cas où l'État du port peut voir sa responsabilité engagée visà-vis de l'armateur. En effet, dans une affaire en date du 21 juin 1961, le conseil d'État français a jugé que l'administration est responsable des avaries souffertes par un navire le «Cap Cepet» qui a heurté les enrochements se trouvant à l'extrémité d'un port dans lequel il devrait accoster. Et ce, par suite de l'extinction du fanal qui est situé dans le prolongement de la jetée. Dès lors que ce feu servait à guider les navires au cours de leurs manœuvres et que l'administration n'établit pas que cet ouvrage était en bon état d'entretien normal ${ }^{671}$.

En cela, il convient donc de réviser, codifier et vulgariser les textes régissant les rapports entre les différents établissements concernés de l'État ivoirien et les industries pétrolières que sont notamment CHEUVRON, TEXACO, SHELL, CNR en ce qui concerne la protection de l'environnement en matière des pollutions maritimes provenant des déversements d'hydrocarbures. Dans cette même optique, il faut créer ou corriger le circuit de communication afin que l'information arrive au bon endroit à l'effet d'éviter des malentendus préjudiciables à l'environnement.

S’il y a un autre cas d'exonération de la responsabilité très défavorable à la victime, c'est bien la faute ou la négligence de celle-ci. En ce que cette cause est de nature à libérer non seulement le propriétaire, mais aussi le Fonds ${ }^{672}$.

\section{B - $\quad$ La faute ou négligence de la victime}

La notion de l'action ou la négligence de la victime, en tant que cause d'exonération de la responsabilité du propriétaire apparaît d'abord à nos yeux comme nécessaire à préciser (1). Ensuite, il conviendrait d'en dégager les effets préjudiciables à la victime (2).

\footnotetext{
669 Voir MULLER (M.)., La prévention des risques et les conditions de réparation des dommages dus aux pollutions marines, in Avis du Conseil Economique et Social, les causes et conséquences du naufrage de l'Erika, Paris, Journaux officiels, mars 2000, p.17.

${ }^{670}$ Dans l'affaire de l'Amoco Cadiz, les défendeurs avaient mis en cause la responsabilité des pouvoirs publics français pour manque de diligence dans l'organisation de la lutte contre la marée noire. Les tribunaux Américains avaient rejeté cette responsabilité.

${ }^{671}$ C.E., 21 juin 1961, in DMF 1962, 14-16. Dans ce cas d'espèce le conseil d'État a rejeté les allégations de l'administration fondée sur la force majeure et la faute du capitaine. Selon la haute juridiction, il y a absence de force majeure dans la mesure où dans les circonstances de l'espèce, l'état de la mer ne présentait pas le caractère d'une tempête d'une violence exceptionnelle constituant un cas de force majeure. Absence de faute du capitaine du navire endommagé, car il n'y avait aucune restriction particulière par gros temps, par les règlements à l'accès de nuit dans le port, et le capitaine à fait appel au pilote qu'il n'a pu prendre à bord à raison de l'état de la mer.

${ }^{672}$ Voir l'article 6 alinéa 3 de la convention de 1992 portant création du Fonds.
} 


\section{La notion de "négligence de la victime"}

Aux termes de l'article 6 alinéa 3 du protocole de 1992 modifiant la convention de 1971 portant création du Fonds, si le propriétaire prouve que le dommage par pollution résulte en totalité ou en partie, soit du fait que la personne qui l'a subi a agit ou omis d'agir dans l'intention de causer un dommage, soit encore si elle a fait preuve de négligence, le Fonds peut être exonéré de tout ou partie de son obligation d'indemniser cette personne. Toutefois, cette exonération du Fonds ne s'applique pas aux mesures de sauvegardes ${ }^{673}$.

Conformément à l'article 3 alinéa 3 du protocole de 1992 sur la responsabilité civile, le propriétaire n'est pas responsable s'il prouve que le dommage par pollution résulte en totalité ou en partie, soit du fait que la personne qui l'a subi a agi ou omis d'agir dans l'intention de causer un dommage, soit de la négligence de cette personne. Le propriétaire peut être exonéré de tout ou partie de la responsabilité envers ladite personne.

$\mathrm{Au}$ regard donc de la combinaison des conventions ci-dessus mentionnées, la faute ou négligence intentionnelle ou non de la victime peut la priver de son droit à la réparation des dommages soufferts.

Que faut-il entendre par l'expression "l'action ou la négligence de la victime »? En tant que victime des pollutions et tiers par rapport à l'opération du transport d'hydrocarbures comment le demandeur peut-il se voir opposer une telle cause d'exonération ${ }^{674}$ ? Tant il est vrai qu'à l'évidence le propriétaire ne peut répondre d'un fait qui lui est étranger, ${ }^{675}$ il n'en demeure pas moins surprenant et embarrassant que l'on rencontre ce type de cause d'exonération de responsabilité du propriétaire du navire en matière des dommages de pollution par hydrocarbures causés aux victimes jugées collatérales. A défaut de voir reformer cette disposition ${ }^{676}$, au moins il conviendrait de clarifier l'expression "faute de la victime».

\footnotetext{
${ }^{673}$ Voir aussi PRIOU (Christophe), Rapport sur les mesures préconisées en matière de sécurité du transport maritime, 10 juillet 2003, pp 12 et 13 .

674 L'on peut bien comprendre l'expression « action ou la négligence » de l'expéditeur ou du destinataire de la marchandise notamment en matière de transport terrestre, où selon le professeur Brou Kouakou la notion de faute de l'ayant droit de la marchandise est plus intellectuelle que physique: elle peut consister à une fausse déclaration ou une identification incorrecte du destinataire, le choix d'un véhicule inadapté ou encore le fait de n'avoir pas attiré l'attention du transporteur sur une particularité non apparente de la marchandise ou encore l'absence ou l'irrégularité d'un document nécessaire au dédouanement. Voir KOUAKOU (Brou), "Contrat de transport de marchandise par route ", in Penant, $n^{\circ} 845$, octobre- décembre 2003, P. 426.

${ }^{675}$ La cour de cassation française l'a jugé dans un arrêt du 3 février 1948, in Bulletin des Transports, 1909, P. 121.

${ }^{676}$ Car c'est normal qu'en cas de faute de la victime de réduire son indemnisation, à l'effet de l'inciter à contribuer à la prévention et à la réduction des pollutions. Voir en ce sens, FAURE Michael, Deterrence, Insirability and Compensation in Environmental Liability, Future Developements in the European Union, European Centre of Tort and Insurance Law (BECTIL), Springer, 2003,p.19, cite par WANG Hui et Michael FAURE, Responsabilité civile et réparation des pollutions marines, Leçons à tirer des déversements provenant des plateformes pétrolières, p.10
} 
Cet état de fait risque d'être exploité par le débiteur de la réparation pour s'opposer au payement.

\section{Les effets préjudiciables de la négligence à la victime}

Pour être libératoire, est-il nécessaire que la faute de la victime soit en rapport direct et exclusif avec le dommage ? Il ressort des conventions susvisées que la responsabilité du propriétaire du navire en la matière, est entièrement effacée ou réduite. En d'autres termes, la faute intentionnelle ou non de la victime peut priver celle-ci de son droit à la réparation des dommages subis ${ }^{677}$.

La négligence en cause peut avoir simplement contribué à la survenance du dommage sans en avoir été la cause exclusive et l'indemnisation de la victime peut se trouver supprimée ou simplement réduite $\mathrm{e}^{678}$.

En raison du caractère abstrait et ambigu de l'expression "action ou négligence de la victime qui a agi ou omis d'agir dans l'intention de causer des dommages " nous en redoutons des abus de la part des propriétaires des navires et les risques liés au large pouvoir d'appréciation du juge saisi. En tout état de cause, il conviendrait que les faits imputables à la victime qu'invoqueraient le propriétaire et le Fonds pour dégager leur responsabilité ne pourraient qu'être matériels ou positifs.

A titre d'exemple, le propriétaire ou le Fonds pourrait être exonéré de sa responsabilité $s^{\prime}$ il prouve que les dommages résultent des actes de sabotage ou encore de piraterie ${ }^{679}$ pratiqués par les victimes sur les pétroliers ou sur les installations portuaires de navigation ${ }^{60}$. Hormis ces hypothèses nous pensons qu'à la vérité, les dispositions des conventions internationales relatives à la faute de la victime sont embarrassantes et peu évidentes. Il reste à savoir si cette disposition est une sorte d'allusion faite à la défaillance des gouvernements à doter leurs ports d'installations de navigation, à l'effet d'étendre la liste des causes d'exonération de la responsabilité des propriétaires et du Fonds ${ }^{681}$. De

\footnotetext{
${ }^{677}$ Dans ce cas la responsabilité du propriétaire est entièrement effacée ou réduite, alors que dans les autres cas elle est complètement écartée.

678 Voir en ce sens, REMOND-GOUILLOUD (Martine), « Pollution des mers ", Jurisclasseur, volume 7, fascicule $1292 \mathrm{n}^{\circ}$ 13, P. 6. Voir aussi, René RODIERE, Traité général de droit maritime, Dalloz, $\mathrm{n}^{\circ}$ 519, 1976, p 661

${ }^{679}$ Un crime consistant pour toute personne se trouvant à bord d'un aéronef en vol, d'un navire en mer ou de tout autre moyen de transport collectif, à s'emparer ou à en exercer le contrôle par violence ou menace de violence. Voir GUINCHARD (Raymond) et VINCENT (Jean), Lexique des termes juridiques, Paris , Dalloz, 2003, p. 411.

${ }^{680}$ Les actes de sabotage pratiqués par les populations contre les installations pétrolières au Congo ou au Nigeria entraînant souvent des explosions et incendies illustraient bien ce phénomène.

${ }^{681}$ Voir en ce sens REMOND-GOUILLOUD (Martine), "Amoco Cadiz: Remarques sur un prototype ", in IFREMER, objectifs mer : les institutions face aux nouvelles données de la présence en mer, Colloque de Paris, Brest, IFREMER, 1983, p. 201.
} 
sorte à échapper à leurs obligations de réparer les dommages subis par les victimes ou demandeurs à l'indemnisation.

\section{CONCLUSION DE LA DEUXIEME PARTIE}

Il résulte de l'étude qui précède que l'efficacité du droit maritime international est contrariée par la persistance des entraves.

En effet, la persistance des entraves découle d'une part, des mécanismes juridiques de prévention et de lutte contre les marées noires et d'autre part des règles d'indemnisation des victimes des marées noires.

Le droit maritime international comporte des insuffisances au titre des normes préventives et de lutte opérationnelle contre les marées noires. L'ampleur des insuffisances est illustrée par les difficultés d'application des instruments juridiques internationaux. Par exemple, en droit spécifiquement ivoirien, des incohérences sont à noter au niveau du plan Pollumar ivoirien. Celui-ci éprouve des difficultés liées principalement au manque de moyens matériels et de ressources financières suffisantes pour prévenir ou lutter contre les pollutions marines effectives.

En outre, les normes répressives en vigueur manquent de fermeté à l'égard des pollueurs du fait de manque de moyens techniques ou d'équipements nécessaires à la détection des actes de pollution dans les eaux relevant de ses zones maritimes.

Au plan de l'Afrique de l'Ouest et de Centre, une réelle politique des plans d'intervention d'urgence intégrés contre les situations critiques tarde à être effective.

A l'analyse le système international d'indemnisation des victimes des marées noires recèlent des limites. Celles-ci découlent non seulement de la procédure relative à l'action en responsabilité civile contre le propriétaire du navire, mais aussi de l'étendue de la responsabilité civile du propriétaire du navire. La procédure est caractérisée par le recours exclusif au règlement judiciaire contentieux et par le manque de dissuasion suffisante à l'égard des pollueurs des milieux marins par hydrocarbures. Ce manque de dissuasion est favorisé par l'application de certaines règles classiques de responsabilité civile à propos de la preuve des préjudices et du lien de causalité entre les préjudices et un événement de pollution marines sources des dommages subis par la victime.

Par ailleurs, concernant l'étendue de la responsabilité civile du propriétaire, l'on peut également observer des faiblesses du système international d'indemnisation. Car il fait la promotion implicite des actes de pollution, du fait de l'institution de la limitation financière de la responsabilité civile du propriétaire du navire. En outre, l'indemnisation effective des victimes des marées noires se heure à l'existence du principe de l'exonération légale de responsabilité civile du propriétaire du navire. En effet, celui- ci 
se voit reconnaître la possibilité de dégager sa responsabilité en alléguant que l'évènement source des dommages par pollution ne lui est pas imputable. La disparition de la responsabilité civile du propriétaire du navire, a pour corollaire la non réparation des dommages causés.

Comme on le voit, le régime international d'indemnisation peut se révéler être défavorable à l'indemnisation concrète des victimes des marées noires. 


\section{CONCLUSION GENERALE}

Les instruments juridiques internationaux relatifs au transport maritime d'hydrocarbures garantissent-ils la protection des milieux marins et des populations contre les effets désastreux des marées noires ? Leur efficacité n'est-elle pas contrariée par la persistance des entraves?

Cette question peut paraître absurde si l'on se fie aux objectifs louables que s'est assigné en principe la communauté internationale en adoptant les instruments juridiques internationaux pour réglementer le transport maritime des hydrocarbures. Ces instruments traduisent la prise de conscience du danger du phénomène des marées noires pour l'homme, les collectivités publiques, les activités économiques et pour l'environnement.

En effet, l'existence des normes internationales régissant le transport maritime des hydrocarbures est indéniable. Il existe un système de prévention et de lutte curative contre le phénomène des marées noires. En ce qui concerne la prévention des marées noires, il existe au plan universel et même régional notamment européen et américain, non seulement des règles relatives à la construction des navires pétroliers, mais aussi de réglementation des rejets polluants d'hydrocarbures en termes de leur prévention et de répression pénale des infractions aux normes préventives.

Par ailleurs, au niveau de lutte curative contre le phénomène des marées noires, il est prévu des mécanismes juridiques internationaux d'intervention contre les marées noires et des règles dissuasives en matière d'indemnisation des victimes des dommages de pollution par hydrocarbures. Il est donc des normes de lutte opérationnelle contre les marées noires au plan universel, voire européen et africain.

S'agissant du régime international d'indemnisation pour les dommages dus à la pollution par les hydrocarbures, il fournit aux victimes des marées noires, depuis le Protocole de 2003 à la Convention de 1992 portant création du Fonds, une indemnisation complémentaire supérieure au montant d'indemnisation disponible. Dans cette optique, il ne faut pas manquer de citer l'existence d'un certain nombre de garanties d'indemnisation des victimes. Il s'agit notamment de l'institution des principes de la canalisation de responsabilité, de l'assurance obligatoire, ainsi que de la possibilité de la déchéance du droit à la limitation financière et à l'exonération de la responsabilité civile du propriétaire du navire.

Cependant, une analyse minutieuse des textes juridiques internationaux, combinée avec la pratique, révèle des insuffisances qui l'affaiblissent en fin de compte. En dépit de la volonté de l'OMI de prémunir les milieux marins et les régions lagunaires et côtières contre les contaminations dues aux déversements accidentels d'hydrocarbures, le phénomène persiste. Au point où l'on serait tenté de douter de sa capacité à éradiquer le phénomène des marées noires. Ce doute pourrait s'expliquer par les nombreuses atténuations qui assortissent le principe international d'interdiction des marées noires. 
En ce qui concerne les dispositions pénales de lutte contre les marées noires, elles se singularisent par le divorce entre la théorie et la réalité. En effet, les normes pénales sensées être dissuasives au regard de l'analyse économique de la règle de droit se révèle être appliquées de manière laxiste. Toutes ces failles rendent inefficaces les mesures préventives de lutte contre les marées noires. Cette situation semble révéler le privilège accordé aux compagnies pétrolières ou la tolérance observée à l'égard des transporteurs maritimes et des industries pétrolières au détriment de la sécurité maritime.

Par ailleurs, les États en développements manquent d'équipements et d'infrastructures fiables pour se conformer aux exigences des Conventions internationales de droit maritime dont ils sont parties. Il en résulte une disparité entre les pays dits puissances maritimes et les pays en développement, devant l'exigence de la sécurité maritime.

Il y a donc une impérieuse nécessité de rééquilibrer les mesures préventives en faveur de l'environnement marin en reconduisant en la matière la théorie du risque profit. Théorie selon laquelle c'est à celui qui tire profit d'une activité de supporter les conséquences dommageables que celle-ci cause.

En dépit du relèvement substantiel de l'indemnisation des victimes particulièrement depuis 2003, nous déplorons les mécanismes tirés des règles relatives aux exonérations et aux limitations financières de responsabilité. Cette situation s'apparente au droit implicite de polluer reconnu aux compagnies opérant dans le secteur du transport maritime des hydrocarbures vu que le droit civil ne permet pas, par essence, d'obtenir une indemnisation intégrale de la victime. Une indemnisation intégrale signifierait que la situation de la victime serait la même avant et après l'accident, une fois les dommages et intérêts octroyés à celle-ci. Or, il est bien établi que le Droit civil a un but « correctif ».

Autrement dit, les dommages et intérêts alloués à des victimes ne pourront en aucun cas excéder les préjudices subis. Le mécanisme qui s'applique au dommage de pollution par les hydrocarbures remplit difficilement toutes les fonctions du régime de responsabilité qui sont l'indemnisation prompte et adéquate des dommages, le partage équitable de responsabilité et réduction des risques des dommages futurs. En effet, le mécanisme international permet une indemnisation rapide, mais ne tend pas à faire rendre compte des actes de responsabilité réels. Aussi, dirions-nous que ce système est adapté à des dommages de pollutions de faible ampleur. Dès lors, qu'il est question d'une multitude de responsabilités dans un naufrage qui a pris les proportions d'une véritable catastrophe écologique, économique et sociale, ce mécanisme ne répond plus parfaitement à ses objectifs. 
De même, la procédure judiciaire instaurée nous semble présenter de véritables embûches dans le processus d'indemnisation des victimes ${ }^{682}$. Pour poursuivre le responsable, il faudra prouver de façon précise le lien de causalité. C'est-à-dire montrer que le rejet polluant a contribué à la réalisation des dommages. Or, nous savons que ceux-ci sont souvent diffuse et différés et exigent des expertises scientifiques longues et coûteuses. S'il est facile de reconnaître que telle pollution affecte l'eau, l'air ou la faune, il est difficile d'établir la mesure dans laquelle le préjudice affecte un tiers par ricochet ${ }^{683}$.

Le mécanisme soulève de vives protestations contre les affréteurs qui par leur contribution au FIPOL "achètent leur responsabilité» selon les dires pertinents de Alexandre MOUTARDIER, collaborateur du cabinet d'avocats Huglo \& Lepage, le 21 août 2002.

Par ailleurs, l'élargissement de l'assiette des préjudices indemnisables par la prise en compte des dommages écologiques est très récent. En effet, c'est au moyen de la Convention complémentaire de 2003 que de tels dommages sont pris en compte. Mais les tribunaux se sont de tout temps montrés réticents à indemniser les dommages écologiques. Auparavant seuls les éléments qui révèlent une nature économique, c'est-àdire qui sont évaluables en terme monétaire qui sont indemnisés. Par contre, les aspects touchant aux échanges biologiques entre les différents éléments altérés de la nature ne sont pas de tout temps pris en compte dans la fixation des dommages et intérêts.

Dans le pire des cas, elles instituent une permission de polluer dès lors que le pollueur est financièrement capable de dédommager les victimes de pollution. Par ailleurs, en ce qui concerne la lutte au moyen des plans d'intervention d'urgence internationaux ou ivoiriens, il nous a été donné de constater l'inadéquation entre les objectifs ambitieux assignés à ses plans et l'insuffisance des moyens dégagés à cet effet. Le comble est que les ressources limitées des États pris individuellement ne les ont pas conduit à mettre ensemble leurs compétences dans le cadre des plans d'urgence intégrés. Au niveau national, le constat est amer: très peu d'États ont élaboré des plans d'intervention d'urgence. Encore faut-il que les ressources financières existent à l'effet d'accomplir leur mission. ${ }^{64}$

Il y a lieu d'aller donc au delà du mécanisme international de responsabilité en recherchant par d'autres moyens, les responsables en cause à l'instar des victimes de l'Erika qui se sont adressées à la justice française pour tenter d'atteindre les degrés

\footnotetext{
${ }^{682}$ Le Professeur Michel DESPAX fait remarquer que c'est à un véritable «steeple-chase » juridique que doit se prêter celui qui engage une action en réparation. DESPAX (Michel), "La pollution des eaux et ses problèmes juridiques », Librairies techniques, 1968, p. 791, in Michel PRIEUR, op.cit., p.734.

683 Et pourtant, selon Michel DESPAX, l'écologie nous enseigne qu'êtres et choses forment un tout complexe, difficilement sécables et que le phénomène d'interdépendance constitue une dimension fondamentale de l'univers. Voir DESPAX (Michel), in JCP, 1970, I, 2359.

${ }_{684}$ À l'horizon 1995, le Congo et la Côte-d'Ivoire étaient les seules parties contractantes à la convention d'Abidjan du 23 mars 1981 à avoir élaboré des plans d'intervention d'urgence nationaux. Voir à ce sujet KAMTO (Maurice), Droit de l'environnement en Afrique, EDICEF/AUPELF, 1996, P.276.
} 
supérieurs de réparation et de mettre en exergue les responsabilités de l'ensemble des opérateurs privés. Le système de responsabilité et d'indemnisation de droit privé ne s'est pas révélé satisfaisant dans le règlement du contentieux consécutif à la pollution des côtes françaises. Destiné à instaurer un équilibre entre les intervenants au transport maritime, un partage de fardeau de la réparation et dans le but d'unification des règles en matière de responsabilité civile enfin de devenir le lieu exclusif du règlement des demandes d'indemnisation.

Aussi souhaiterions-nous des aménagements au niveau du système juridique international de sécurité maritime introduit dans les pays en développement de l'OMAOC singulièrement, en matière du transport d'hydrocarbures. Ces ajustements juridiques souhaités toucheraient aussi bien les aspects préventifs que le volet de la responsabilité civile dudit système. Ce qui permettrait de rehausser son efficacité, en termes de dissuasion les pollueurs. Car ceux-ci ne se préoccupent souvent que de leurs profits financiers au mépris de protection de l'environnement et de la santé des populations.

En ce qui concerne les ajustements à caractère préventif des instruments juridiques, ils portent sur l'amélioration des mesures de lutte et de la limitation des pollutions pétrolières. À cela, il faudrait ajouter, l'inadéquation de la règle de la liberté des mers que l'on tend involontairement à appliquer surtout lors des opérations de lutte opérationnelle contre les marées noires. A l'analyse, cette règle est source de conséquences préjudiciables à l'intervention de l'État côtier sinistré contre les marées noires.

Aussi s'avère-t-il nécessaire d'intensifier la coopération à l'endroit des pays en développement, en termes d'assistance technique, de formation et d'équipement. Ceci motiverait les États à ratifier les conventions internationales de droit maritime et réduirait la disparité des États parties aux conventions internationales de droit maritime au regard de la nécessité de la sécurité maritime. Ce soutien serait aussi un moyen d'amélioration des plans régionaux de lutte contre les pollutions pétrolières, initiés par les pays en développement africains.

En ce qui concerne le système répressif, il est caractérisé par la plus grande souplesse. La répression des actes de pollution est toujours confiée à chaque État au niveau de son droit interne. L'on peut redouter la complaisance des autorités étatiques à appliquer les textes de loi pertinents au regard du caractère international par essence des contentieux liés aux marées noires. Il convient de durcir le système répressif.

Dans le même ordre d'idées, il serait judicieux d'encourager les pays africains à rendre effective et intensifier la politique de coopération intégrée en matière de protection de l'environnement marin et côtier. Ce qui leur permettrait d'améliorer les plans d'intervention d'urgence nécessaires à la maîtrise et à la réduction matérielle des conséquences néfastes des marées noires. 
En dépit de la situation de difficulté économique des pays africains, ceux-ci devraient savoir qu'en attendant l'appui de la communauté internationale, le rehaussement de la lutte contre les pollutions marines accidentelles dépend d'abord d'eux-mêmes. À ce titre, il conviendrait d'impliquer les structures privées et des collectivités territoriales côtières dans les mécanismes opérationnelles de lutte contre les marées noires. Les autorités compétentes ouest et centre africains, en général, et les autorités ivoiriennes, en particulier, pourraient s'investir à les en persuader. À ce sujet, ils pourraient constituer des entités additionnelles de lutte contre les pollutions accidentelles en vue de pallier, dans la mesure du possible, les moyens humains et matérielles insuffisants de l'État.

Nous plaidons pour que le principe de la liberté des mers qui est la caractéristique du droit maritime classique, soit fortement édulcoré dans le cas du transport des hydrocarbures. Cela permettrait à l'État victime de pollutions marines d'engager ses opérations de lutte de façon inconditionnée contre la situation critique.

En outre, la répression des actes de pollution en haute mer ne devrait pas être l'apanage exclusif de l'État du pavillon, mais des efforts conjugués de celui-ci et de l'État côtier sinistré.

Nous recommandons le principe de l'interdiction générale des déversements de pétrole. Ce qui aurait pour conséquence la suppression des nombreuses exonérations d'infractions à la Convention internationale de prévention des pollutions marine par hydrocarbures. Cette option renforcerait la sécurité maritime par sa fermeté à l'égard les pollueurs.

En sus des adaptations susmentionnées, d'autres innovations pourraient être apportées au droit maritime relatif au transport d'hydrocarbures tel qu'appliqué en Côte d'Ivoire. Il s'agira pour le juge africain et ivoirien en particulier d'éviter des écueils préjudiciables à l'indemnisation des victimes des marées noires. À ce titre, il pourrait s'inspirer du juge français et américain notamment dans les affaires Amoco Cadiz et Erika. D’abord, dans l'arrêt rendu par la cour d'appel de Chicago le 24 janvier 1992, dans l'affaire Amoco Cadiz, le juge a interprété de façon large la notion de propriétaire de navire pollueur. Il est allé au delà de la définition contenue dans la Convention CLC 1969 en adoptant une conception extensive de la notion de "propriétaire du navire». De ce fait, il a retenu la responsabilité civile de la Standard Oil, propriétaire effectif et solvable du navire pollueur, au lieu de celle de l'Amoco Transport, une société intercalaire et non solvable, comme l'aurait voulu la Convention CLC 1969.

Cette interprétation hardie, favorable aux victimes est également perceptible dans le jugement du 18 janvier 2008 rendu au pénal par le tribunal de grande instance de Paris dans l'affaire de l'Erika.

Par ailleurs, la définition extensive de la notion de "déchets» de la jurisprudence constante de la Cour européenne des communautés européennes nous semble appropriée. Cette conception pourrait influencer la définition restrictive des dommages 
indemnisables tels que prévus par le système international. L'approche du juge européen au sujet des dommages de pollution indemnisables pourrait être un outil supplémentaire auquel pourrait recourir le juge national pour contourner le principe de la canalisation de responsabilité qui prévaut dans le système international. Ce qui permettrait une indemnisation beaucoup plus substantielle des victimes des marées noires.

Dans cette optique, nous plaidons pour la responsabilité solidaire de tous ceux qui interviennent dans l'opération de transport à quelque niveau que se soit. En outre, nous souhaitons des ajustements au titre des conditions d'exercice de l'action en responsabilité pour dommage de pollution par hydrocarbures. Il s'agit notamment de la preuve des dommages de pollution par hydrocarbures, des délais de l'action en responsabilité et surtout du lien de causalité entre les dommages subis et l'activité du pollueur. Il conviendrait d'aménager les textes internationaux de sorte à renverser, sinon à alléger le fardeau de la preuve et du lien de causalité des dommages qui pèsent sur la victime. Concernant les délais de l'action en indemnisation des victimes, une rallonge de ce délai nous semble judicieux au regard des risques avérés de dommages différés. En outre, il faut créer deux délais à savoir celui de la réclamation et de l'action proprement dite.

En vue de rendre la sanction civile plus dissuasive, il convient d'apporter des aménagements au niveau de l'étendue de la responsabilité civile des pollueurs. Pour ce faire, il faudrait renforcer les sanctions découlant des cas de déchéances légales du droit à la limitation et à l'exonération de responsabilité à défaut de supprimer les institutions de limitation et d'exonération de responsabilité civile du pollueur. Ainsi, le législateur ivoirien pourrait s'inspirer de la Loi américaine qui s'intitule Coast Guard and Maritime Transportation Act of 2006. Conformément à cette loi de 2006, le montant des plafonds d'indemnisation fut relevé de deux montants comparés. En 2009, il a été procédé au relèvement des plafonds de responsabilité les faisant passer de 1.900 à 2.100 dollars US pour les pétroliers à double coque et de 3000 à 3.200 dollars US pour les pétroliers à coque simple. En outre, la méthode de calcul ne se fie pas au tonnage du navire, mais tient aussi compte de sa capacité à se conformer aux mesures préventives du point de vue de sa construction et de son équipement.

En outre, il faudrait instaurer des "dommages intérêts punitifs » dont les montants équivaudraient au double voire au triple des dommages causés aux victimes, surtout lorsque ceux-ci sont causés intentionnellement ou résultent d'une négligence grave. En outre il conviendrait d'instituer et mettre en application le principe pollueur payeur, ainsi que des taxes ou une garantie financière obligatoire à la charge des navires fréquentant les eaux des États côtiers africains.

La Côte d'Ivoire pourrait bénéficier d'une indemnisation substantielle des victimes de marées noires d'origine accidentelle en ratifiant les deux protocoles aux Conventions CLC 1969 et FIPOL 1971. Il s'agit d'abord du protocole de 1992 portant création d'un Fonds international d'indemnisation pour les dommages de pollution par 
hydrocarbures. Mais cette suggestion pourrait paraître insuffisante, au regard des plafonds d'indemnisation insuffisants révélés par les affaires Erika et Prestige. Dans ce cas, nous maintiendrons notre proposition en considération de l'augmentation substantielle dont est l'objet le Fonds international d'indemnisation conformément au protocole de 2003 à la Convention de 1992 précité. L'adhésion des pays africains comme la Côte d'Ivoire aux Conventions précitées éviterait aux victimes de marées noires de se retrouver devant une impasse due à l'ineffectivité des Conventions initiales CLC 1969 et FIPOL 1971. Car celles-ci sont, à l'heure actuelle, des coquilles vides. Etant donné qu'elles ne couvrent plus des sinistres depuis le 24 mai 2002: les États développés, principales puissances maritimes et principaux contributeurs n'y sont plus parties après leur adhésion aux protocoles de 1992 et surtout à la Convention supplémentaire de $2003^{685}$.

Il serait prétentieux de soutenir que la mise en œuvre des propositions susmentionnées, à elles seules suffira à résorber les problèmes toujours récurrents des marées noires dans le monde et particulièrement en Afrique. Ces ajustements souhaités constituent une ébauche de solutions qui contribuera indéniablement au rehaussement des textes internationaux de droit maritime en terme de l'amélioration de la protection des milieux marins et de la santé des populations côtières contre les désastres liés aux marées noires.

Ainsi que le disait le Professeur COULIBALY Climanlo Jérôme, il est vrai que " tout juriste est la proie d'un complexe: le complexe de justinien, que tout juriste qui pense juridiquement, cache dans son cour un justinien qui sommeille, que tout juriste porte en lui l'âme d'un législateur ${ }^{686}$. Mais nous n'avons nullement la prétention d'élaborer ici le projet des reformes des normes et règles de prévention des pollutions et de responsabilité civile pour les dommages de pollution dus au transport maritime d'hydrocarbures. Une telle œuvre dépasse largement le cadre de notre étude. Il nous a suffit cependant, de fournir quelques indications susceptibles d'aider les rédacteurs de la réforme éventuelle à l'entreprendre.

Car «Il ne s'agit plus seulement de lutter contre un danger survenu, il faut préserver le milieu marin dans son essence à raison de son importance pour l'équilibre écologique de la planète ${ }^{687}$. En effet, nous, génération d'aujourd'hui, même si la mer est réputée libre et sans maître, avons-nous le droit de laisser l'univers maritime sans droit?

\footnotetext{
${ }^{685}$ Voir en ce sens, www.ejustice.foguvbe, p.3, du 22/11/ 2010 à 14 heures.

${ }^{686}$ COULIBALY Climanlo Jérôme, Les intermédiaires du transport maritime international de marchandises en droit ivoirien, Thèse précitée, p. 477.

${ }^{687}$ Voir E. LANGAVANT, Droit de la mer, Op.,cit., p.127.
} 



\section{ANNEXES}

- Convention internationale de 1973 pour la prévention de la pollution par les navires (Conclue à Londres le 2 novembre 1973) ;

- Protocole de 1978 relatif à la Convention internationale de 1973 pour la prévention de la pollution par les navires;

- Convention internationale sur les normes de formation des gens de mer, de délivrance de brevets et de veille, 1978.

- Convention relative à la coopération en matière de protection et de mise en valeur du milieu marin et des zones côtières de la région de l'Afrique de l'ouest et du centre ;

- Convention de 2006 du travail maritime ;

- Loi n96-766 du 03 octobre portant code de l'environnement en Côte d'Ivoire ; 


\title{
CONVENTION INTERNATIONALE DE 1973 POUR LA PRÉVENTION DE LA POLLUTION PAR LES NAVIRES (CONCLUE À LONDRES LE 2 NOVEMBRE 1973)
}

\author{
Les Parties à la Convention,
}

Conscientes de la nécessité de protéger l'environnement en général et le milieu marin en particulier,

Reconnaissant que les déversements délibérés, par négligence ou accidentels, d'hydrocarbures et autres substances nuisibles par les navires constituent une source grave de pollution,

Reconnaissant également l'importance de la Convention internationale de 1954 pour la prévention de la pollution des eaux de la mer par les hydrocarbures, premier instrument multilatéral à avoir eu pour objectif essentiel la protection de l'environnement, et sensibles à la contribution marquante que cette Convention a apportée à la préservation des mers et des littoraux contre la pollution,

Désireuses de mettre fin à la pollution intentionnelle du milieu marin par les hydrocarbures et autres substances nuisibles et de réduire au maximum les rejets accidentels de ce type de substances,

Estimant que le meilleur moyen de réaliser cet objectif est d'établir des règles de portée universelle et qui ne se limitent pas à la pollution par les hydrocarbures, sont convenues de ce qui suit :

\section{Art. 1 : Obligations générales découlant de la Convention}

1. Les Parties à la Convention s'engagent à donner effet aux dispositions de la présente Convention, ainsi qu'aux dispositions de celles des Annexes 6 par lesquelles elles sont liées, afin de prévenir la pollution du milieu marin par le rejet de substances nuisibles ou d'effluents contenant de telles substances en infraction aux dispositions de la Convention.

2. Sauf disposition expresse contraire, toute référence à la présente Convention constitue en même temps une référence à ses Protocoles et aux Annexes.

\section{Art. 2 : Définitions}

Aux fins de la présente Convention, sauf disposition expresse contraire :

1. «Règles» désigne les règles figurant en annexe à la présente Convention.

2. «Substance nuisible» désigne toute substance dont l'introduction dans la mer est susceptible de mettre en danger la santé de l'homme, de nuire aux ressources biologiques, à la faune et à la flore marines, de porter atteinte à l'agrément des sites ou de gêner toute autre utilisation légitime de la mer, et notamment toute substance soumise à un contrôle en vertu de la présente Convention.

3. a) «Rejet», lorsqu'il se rapporte aux substances nuisibles ou aux effluents contenant de telles substances, désigne tout déversement provenant d'un navire, quelle qu'en soit la cause, et comprend tout écoulement, évacuation, épanchement, fuite, déchargement par pompage, émanation ou vidange.

b) «Rejet» ne couvre pas :

i) l'immersion au sens de la Convention sur la prévention de la pollution des mers résultant de l'immersion de déchets faite à Londres le 29 décembre 19727; ni

ii) les déversements de substances nuisibles qui résultent directement de l'exploration, de l'exploitation et du traitement connexe au large des côtes des ressources minérales du fond des mers et des océans; ni

iii) les déversements de substances nuisibles effectués aux fins de recherches scientifiques légitimes visant à réduire ou à combattre la pollution.

4. «Navire» désigne un bâtiment exploité en milieu marin de quelque type que ce soit et englobe les hydroptères, les aéroglisseurs, les engins submersibles, les engins flottants et les plates-formes fixes ou flottantes.

5. «Autorité» désigne le Gouvernement de l'État qui exerce son autorité sur le navire. Dans le cas d'un navire autorisé à battre le pavillon d'un État, l'Autorité est le Gouvernement de cet État. Dans le cas des platesformes fixes ou flottantes affectées à l'exploration et à l'exploitation du fond des mers et du sous-sol 
adjacent aux côtes sur lesquelles l'État riverain a des droits souverains aux fins de l'exploration et de l'exploitation de leurs ressources naturelles, l'Autorité est le Gouvernement de l'État riverain intéressé.

6. «Evénement» désigne un incident qui entraîne ou est susceptible d'entrainer le rejet à la mer d'une substance nuisible ou d'un effluent contenant une telle substance.

7. «Organisation» désigne l’Organisation intergouvernementale consultative de la navigation maritime.

\section{Art. 3 : Champ d'application}

1. La présente Convention s'applique :

a) aux navires autorisés à battre le pavillon d'une Partie à la Convention; et

b) aux navires qui ne sont pas autorisés à battre le pavillon d'une Partie mais qui sont exploités sous l'autorité d'une telle Partie.

2. Aucune disposition du présent article ne saurait être interprétée comme portant atteinte aux droits souverains des Parties sur le fond des mers et sur le sous-sol adjacent aux côtes aux fins d'exploration et d'exploitation des ressources naturelles ou comme étendant ces droits, conformément au droit international.

3. La présente Convention ne s'applique ni aux navires de guerre ou navires de guerre auxiliaires ni aux autres navires appartenant à un État ou exploités par cet État tant que celui-ci les utilise exclusivement à des fins Gouvernementales et non commerciales. Cependant, chaque Partie doit s'assurer, en prenant des mesures appropriées qui ne compromettent pas les opérations ou la capacité opérationnelle des navires de ce type lui appartenant ou exploités par elle, que ceux-ci agissent d'une manière compatible avec la présente Convention, pour autant que cela soit raisonnable dans la pratique.

\section{Art. 4 : Infractions}

1. Toute violation des dispositions de la présente Convention est sanctionnée par la législation de l'Autorité dont dépend le navire en cause, quel que soit l'endroit où l'infraction se produit. Si l'Autorité est informée d'une telle infraction et est convaincue qu'il existe des preuves suffisantes pour lui permettre d'engager des poursuites pour l'infraction présumée, elle engage ces poursuites le plus tôt possible conformément à sa législation.

2. Toute violation des dispositions de la présente Convention commise dans la juridiction d'une Partie à la Convention est sanctionnée par la législation de cette Partie. Chaque fois qu'une telle infraction se produit, la Partie doit :

a) soit engager des poursuites conformément à sa législation ;

b) soit fournir à l'Autorité dont dépend le navire les preuves qui peuvent être en sa possession pour démontrer qu'il y a eu infraction.

3. Lorsque des informations ou des preuves relatives à une infraction à la Convention par un navire sont fournies à l'Autorité dont dépend le navire, cette Autorité informe rapidement l'État qui lui a fourni les renseignements ou les preuves et l'Organisation des mesures prises.

4. Les sanctions prévues par la législation des Parties en application du présent article doivent être, par leur rigueur, de nature à décourager les contrevenants éventuels, et d'une sévérité égale quel que soit l'endroit où l'infraction a été commise.

\section{Art. 5 : Certificats et règles spéciales concernant l'inspection du navire}

1. Sous réserve des dispositions du paragraphe 2 du présent article, les Certificats délivrés sous l'autorité d'une Partie à la Convention conformément aux dispositions des règles sont acceptés par les autres Parties contractantes et considérés, à toutes les fins visées par la présente Convention, comme ayant la même validité qu'un Certificat délivré par elles-mêmes.

2. Tout navire qui est tenu de posséder un Certificat délivré conformément aux dispositions des règles est soumis, dans les ports ou les terminaux au large relevant de la juridiction d'une autre Partie, à une inspection effectuée par des fonctionnaires dûment autorisés à cet effet par ladite Partie. Toute inspection de cet ordre a pour seul objet de vérifier la présence à bord d'un Certificat en cours de validité, sauf si cette Partie a des raisons précises de penser que les caractéristiques du navire ou de son équipement diffèrent sensiblement de celles qui sont portées sur le Certificat. Dans ce cas, ou s'il n'y a pas à bord du navire de Certificat en cours de validité, l'État qui effectue l'inspection prend les mesures nécessaires pour empêcher le navire d'appareiller avant qu'il puisse le faire sans danger excessif pour le milieu marin. Toutefois, ladite 
Partie peut autoriser le navire à quitter le port ou le terminal au large pour se rendre au chantier de réparation approprié le plus proche.

3. Si une Partie refuse à un navire étranger l'accès d'un port ou d'un terminal au large qui relève de sa juridiction, ou si elle procède à une intervention quelconque à l'encontre de ce navire en arguant du fait que le navire n'est pas conforme aux dispositions de la présente Convention, la Partie avise immédiatement le Consul ou le représentant diplomatique de la Partie dont le navire est autorisé à battre le pavillon, ou, en cas d'impossibilité, l'Autorité dont relève le navire intéressé. Avant de signifier un tel refus et avant de procéder à une telle intervention, la Partie demande à consulter l'Autorité dont relève le navire. L'Autorité est également avisée lorsqu'un navire ne possède pas à son bord de Certificat en cours de validité conforme aux dispositions des règles.

4. Les Parties appliquent aux navires des États qui ne sont pas Parties à la Convention les prescriptions de la présente Convention dans la mesure où cela est nécessaire pour ne pas faire bénéficier ces navires de conditions plus favorables.

\section{Art. 6 : Recherche des infractions et mise en oeuvre des dispositions de la Convention}

1. Les Parties à la Convention coopèrent à la recherche des infractions et à la mise en oeuvre des dispositions de la présente Convention en utilisant tous les moyens pratiques appropriés de recherche et de surveillance continue du milieu ainsi que des méthodes satisfaisantes de transmission des renseignements et de rassemblement des preuves.

2. Tout navire auquel la présente Convention s'applique peut être soumis, dans tout port ou terminal au large d'une Partie, à l'inspection de fonctionnaires désignés ou autorisés par ladite Partie, en vue de vérifier s'il a rejeté des substances nuisibles en infraction aux dispositions des règles. Au cas où l'inspection fait apparaître une infraction aux dispositions de la Convention, le compte rendu en est communiqué à l'Autorité pour que celle-ci prenne des mesures appropriées.

3. Toute Partie fournit à l'Autorité la preuve, si elle existe, que ce navire a rejeté des substances nuisibles ou des effluents contenant de telles substances en infraction aux dispositions des règles. Dans toute la mesure du possible, cette infraction est portée à la connaissance du capitaine du navire par l'autorité compétente de cette Partie.

4. Dès réception de cette preuve, l'Autorité examine l'affaire et peut demander à l'autre Partie de lui fournir sur l'infraction des éléments de fait plus complets ou plus concluants. Si l'Autorité estime que la preuve est suffisante pour lui permettre d'intenter une action, elle intente une action dès que possible et conformément à sa législation. L'Autorité informe rapidement la Partie qui lui a signalé l'infraction présumée, ainsi que l'Organisation, des poursuites engagées.

5. Une Partie peut inspecter tout navire, auquel la présente Convention s'applique, qui fait escale dans un port ou un terminal au large relevant de sa juridiction lorsqu'une autre Partie lui demande de procéder à cette enquête en fournissant suffisamment de preuves que le navire a rejeté dans un lieu quelconque des substances nuisibles ou des effluents contenant de telles substances. Il est rendu compte de l'enquête à la Partie qui l'a demandée ainsi qu'à l'Autorité, afin que des mesures appropriées soient prises conformément aux dispositions de la présente Convention.

\section{Art. 7 : Retards causés indûment aux navires}

1. Il convient d'éviter, dans toute la mesure du possible, que les mesures prises en application de l'article 4, 5 ou 6 de la présente Convention ne retiennent ou ne retardent indûment le navire.

2. Tout navire qui a été retenu ou retardé indûment par suite de l'application de l'article 4, 5 ou 6 de la présente Convention a droit à réparation pour les pertes ou dommages subis.

\section{Art. 8 : Rapports sur les événements entraînant ou pouvant entraîner le rejet de substances nuisibles}

1. En cas d'événement, il est fait rapport sans retard et, dans toute la mesure du possible, conformé-ment aux dispositions du Protocole I de la présente Convention.

2. Chaque Partie à la Convention doit :

a) prendre les dispositions nécessaires pour qu'un fonctionnaire ou un organisme compétent reçoive et analyse tous les rapports sur les événements et

b) notifie à l'Organisation les détails complets de ces dispositions, pour diffusion aux autres Parties et États membres de l'Organisation.

3. Chaque fois qu'une Partie reçoit un rapport en vertu des dispositions du présent article, ladite Partie le transmet sans retard à: 
a) l'Autorité dont relève le navire en cause; et

b) tout autre État susceptible d'être touché par l'événement.

4. Toute Partie à la Convention fait donner à ses navires et aéronefs chargés de l'inspection des mers et aux services compétents des instructions les invitant à signaler à ses autorités tout événement mentionné au Protocole I de la présente Convention. Si elle le juge bon, elle fait également rapport à l'Organisation et à toute autre Partie intéressée.

\section{Art. 9 : Autres traités et interprétation}

1. Lors de son entrée en vigueur la présente Convention remplace la Convention internationale de 1954 pour la prévention de la pollution des eaux de la mer par les hydrocarbures, modifiée, à l'égard des Parties à cette Convention.

2. Aucune disposition de la présente Convention ne préjuge la codification et l'élaboration du droit de la mer par la Conférence des Nations Unies sur le droit de la mer convoquée en vertu de la résolution $2750 \mathrm{C}$ (XXV) de l'Assemblée générale des Nations Unies, ni les revendications et positions juridiques présentes ou futures de tout État touchant le droit de la mer et la nature et l'étendue de la juridiction de l'État riverain et de l'État du pavillon.

3. Dans la présente Convention, le terme «juridiction» s'interprète conformément au droit international en vigueur lors de l'application ou de l'interprétation de la présente Convention.

\section{Art. 10 : Règlement des différends}

Tout différend entre deux ou plusieurs Parties à la Convention relatif à l'interprétation ou à l'application de la présente Convention, qui n'a pu être réglé par voie de négociation entre les Parties en cause est, sauf décision contraire des Parties, soumis à l'arbitrage à la requête de l'une des Parties, dans les conditions prévues au Protocole II de la présente Convention.

\section{Art. 11 : Communication de renseignements}

1. Les Parties à la Convention s'engagent à communiquer à l'Organisation :

a) le texte des lois, ordonnances, décrets, règlements et autres instruments promulgués sur les diverses questions qui entrent dans le champ d'application de la présente Convention ;

b) la liste des organismes non Gouvernementaux habilités à agir en leur nom pour tout ce qui touche à la conception, à la construction et à l'équipement des navires transportant des substances nuisibles conformément aux dispositions des règles ;

c) un nombre suffisant de modèles des certificats qu'elles délivrent en application de dispositions des règles;

d) une liste des installations de réception précisant leur emplacement, leur capacité, les installations disponibles et autres caractéristiques ;

e) tous les rapports officiels ou résumés de ces rapports qui exposent les résultats de l'application de la présente Convention; et

f) un rapport annuel qui présente, sous une forme normalisée par l'Organisation, les statistiques relatives aux sanctions effectivement infligées pour les infractions à la présente Convention.

2. L'Organisation informe les Parties de toute communication reçue en vertu du présent article et diffuse à toutes les Parties les informations qui lui ont été communiquées, au titre des alinéas b) à f) du paragraphe 1 du présent article.

\section{Art. 12 : Accidents survenus aux navires}

1. Chaque Autorité s'engage à effectuer une enquête au sujet de tout accident survenu à l'un quelconque de ses navires soumis aux dispositions des règles, lorsque cet accident a eu, pour le milieu marin, des conséquences néfastes très importantes.

2. Chaque Partie à la Convention s'engage à fournir à l'Organisation des renseignements sur les résultats de cette enquête lorsqu'elle estime que ceux-ci peuvent aider à déterminer les modifications qu'il serait souhaitable d'apporter à la présente Convention.

Art. 13 : Signature, ratification, acceptation, approbation et adhésion

1. La présente Convention reste ouverte à la signature, au siège de l'Organisation, du 15 janvier 1974 au 31 décembre 1974, et reste ensuite ouverte à l'adhésion. Les États peuvent devenir Parties à la présente Convention par :

a) signature sans réserve quant à la ratification, l'acceptation ou l'approbation; ou 
b) signature sous réserve de ratification, d'acceptation ou d'approbation, suivie de ratification, d'acceptation ou d'approbation; ou

c) adhésion.

2. La ratification, l'acceptation, l'approbation ou l'adhésion s'effectuent par le dépôt d'un instrument à cet effet auprès du Secrétaire général de l'Organisation.

3. Le Secrétaire général de l'Organisation informe tous les États ayant signé la présente Convention ou y ayant adhéré de toute signature ou du dépôt de tout nouvel instrument de ratification, d'acceptation, d'approbation ou d'adhésion et de la date de ce dépôt.

\section{Art. $14:$ Annexes facultatives}

1. Un État peut, lorsqu'il signe, ratifie, accepte ou approuve la présente Convention ou y adhère, déclarer qu'il n'accepte pas l'une quelconque ou l'ensemble des Annexes III, IV et V (ci-après dénommées «Annexes facultatives») de la présente Convention. Sous réserve de ce qui précède, les Parties à la Convention sont liées par l'une quelconque des Annexes dans son intégralité.

2. Un État qui a déclaré qu'il n'était pas lié à une Annexe facultative peut à tout moment accepter cette Annexe en déposant auprès de l'Organisation un instrument du type visé au paragraphe 2 de l'article 13.

3. Un État qui fait une déclaration en vertu du paragraphe 1 du présent article au sujet d'une Annexe facultative, et qui n'accepte pas cette Annexe par la suite conformément au paragraphe 2 du présent article n'assume aucune obligation et n'a le droit de se prévaloir d'aucun bénéfice découlant de la Convention en ce qui concerne les questions relevant de cette Annexe; dans la présente Convention, toutes les références aux Parties ne constituent pas de référence à cet État en ce qui concerne les questions qui relèvent de cette Annexe.

4. L'Organisation informe les États qui ont signé le présente Convention ou qui y ont adhéré de toute déclaration faite en vertu du présent article ainsi que de la réception de tout instrument déposé conformément aux dispositions du paragraphe 2 du présent article.

\section{Art. 15 : Entrée en vigueur}

1. La présente Convention entre en vigueur douze mois après la date à laquelle au moins 15 États dont les flottes marchandes représentent au total au moins 50 pour cent du tonnage brut de la flotte mondiale des navires de commerce sont devenus Parties à cette Convention conformément aux dispositions de l'article 13.

2. Une annexe facultative entre en vigueur douze mois après la date à laquelle les conditions énoncées au paragraphe 1 du présent article ont été remplies pour cette Annexe.

3. L'Organisation informe les États qui ont signé la présente Convention ou qui y ont adhéré de la date de son entrée en vigueur et de la date à laquelle une Annexe facultative entre en vigueur conformément aux dispositions du paragraphe 2 du présent article.

4. Pour les États qui ont déposé un instrument de ratification, d'acceptation, d'approbation de la Convention ou d'une Annexe facultative quelconque ou d'adhésion à celles-ci après que les conditions régissant leur entrée en vigueur ont été remplies mais avant leur entrée en vigueur, la ratification, l'acceptation, l'approbation ou l'adhésion prend effet au moment de l'entrée en vigueur de la Convention ou de l'Annexe facultative ou trois mois après la date de dépôt de l'instrument, si cette dernière date est postérieure.

5. Pour les États qui ont déposé un instrument de ratification, d'acceptation, d'approbation de la Convention ou d'une Annexe facultative, ou d'adhésion à celles-ci après leur entrée en vigueur, la Convention ou l'Annexe facultative prend effet trois mois après la date du dépôt de l'instrument.

6. Tout instrument de ratification, d'acceptation, d'approbation ou d'adhésion déposé après la date à laquelle ont été remplies toutes les conditions prévues à l'article 16 pour l'entrée en vigueur d'un amendement à la présente Convention ou à une Annexe facultative s'applique au texte modifié de la Convention ou de l'Annexe facultative.

\section{Art. 16 : Amendements}

1. La présente Convention peut être amendée par l'une quelconque des procédures définies dans les paragraphes ci-après.

2. Amendements après examen par l'Organisa-tion :

a) tout amendement proposé par une Partie à la Convention est soumis à l'Organisation et diffusé par son Secrétaire général à tous les Membres de l'Organisation et à toutes les Parties six mois au moins avant son examen ; 
b) tout amendement proposé et diffusé suivant la procédure ci-dessus est soumis par l'Organisation à un organe compétent pour examen ;

c) les Parties à la Convention, qu'elles soient ou non Membres de l'Organisation, sont autorisées à participer aux travaux de l'organe compétent ;

d) les amendements sont adoptés à la majorité des deux tiers des seules Parties à la Convention, présentes et votantes;

e) s'ils sont adoptés conformément à l'alinéa d) ci-dessus, les amendements sont communiqués par l'Organisation à toutes les Parties à la Convention aux fins d'acceptation ; f) un amendement est réputé avoir été accepté dans les conditions suivantes :

i) un amendement à un article de la Convention est réputé avoir été accepté à la date à laquelle il a été accepté par les deux tiers des Parties dont les flottes marchandes représentent au total 50 pour cent au moins du tonnage brut de la flotte mondiale des navires de commerce;

ii) un amendement à une Annexe de la Convention est réputé avoir été accepté conformément à la procédure définie au paragraphe f) iii) à moins que, au moment de son adoption, l'organe compétent ne décide que l'amendement est réputé avoir été accepté à la date à laquelle il a été accepté par les deux tiers des Parties dont les flottes marchandes représentent au total 50 pour cent au moins du tonnage brut de la flotte mondiale des navires de commerce; néanmoins, à tout moment avant l'entrée en vigueur d'un amendement à une Annexe, une Partie peut notifier au Secrétaire général de l'Organisation que l'amendement n'entrera en vigueur à son égard qu'après avoir été expressément approuvé par elle ;

iii) un amendement à un appendice d'une Annexe de la Convention est réputé avoir été accepté à l'expiration d'un délai qui est fixé par l'organe compétent lors de son adoption mais qui ne doit pas être inférieur à dix mois, à moins qu'une objection n'ait été communiquée à l'Organisation pendant cette période par un tiers au moins des Parties ou par des Parties dont les flottes marchandes représentent au total au moins 50 pour cent du tonnage brut de la flotte mondiale des navires de commerce, celle des deux conditions qui est remplie la première étant prise en considération ;

iv) un amendement au Protocole I de la Convention est soumis aux mêmes procédures que les amendements aux Annexes de la Convention, conformément au paragraphe f) ii) ou f) iii) ci-dessus ;

v) un amendement au Protocole II de la Convention est soumis aux mêmes procédures que les amendements à un article de la Convention conformément au paragraphe fi) ci-dessus ;

g) l'entrée en vigueur de l'amendement intervient dans les conditions suivantes :

i) s'il s'agit d'un amendement à un article de la Convention, au Protocole II, ou au Protocole I ou à une Annexe de la Convention qui n'est pas accepté conformément à la procédure définie à l'alinéa f) iii), l'amendement accepté conformément aux dispositions qui précèdent entre en vigueur six mois après la date de son acceptation à l'égard des Parties qui ont déclaré l'avoir accepté ;

ii) s'il s'agit d'un amendement au Protocole I, à un appendice d'une Annexe ou à une Annexe de la Convention qui est accepté conformément à la procédure définie à l'alinéa f) iii), l'amendement réputé accepté dans les conditions qui précèdent entre en vigueur six mois après son acceptation pour toutes les Parties contractantes, à l'exception de celles qui, avant cette date, ont fait une déclaration aux termes de laquelle elles ne l'acceptent pas ou une déclaration conformément au paragraphe f) ii), aux termes de laquelle leur approbation est nécessaire.

3. Amendement par une conférence :

a) à la demande d'une Partie appuyée par un tiers au moins des Parties, l'Organisation convoque une conférence des Parties à la Convention pour examiner les amendements à la présente Convention;

b) tout amendement adopté par cette conférence à la majorité des deux tiers des Parties présentes et votantes est communiqué par le Secrétaire général de l'Organisation à toutes les Parties en vue d'obtenir leur acceptation ;

c) à moins que la conférence n'en décide autrement, l'amendement est réputé accepté et entre en vigueur selon les procédures prévues à cet effet au paragraphe 2, alinéas f) et g) ci-dessus.

4. a) Dans le cas d'un amendement à une Annexe facultative, l'expression «Partie à la Convention» doit être interprétée dans le présent article comme désignant une Partie liée par ladite Annexe.

b) Toute Partie qui a refusé d'accepter un amendement à une Annexe est traitée comme non-Partie aux seules fins de l'application de cet amendement.

5. L'adoption et l'entrée en vigueur d'une nouvelle Annexe sont soumises aux mêmes procédures que celles qui régissent l'adoption et l'entrée en vigueur d'un amendement à un article de la Convention.

6. Sauf disposition expresse contraire, tout amendement à la présente Convention fait en application du présent article et ayant trait à la structure des navires n'est applicable qu'aux navires dont le contrat de 
construction est signé, ou, en l'absence d'un tel contrat, dont la quille est posée à la date d'entrée en vigueur de l'amendement ou postérieurement à cette date.

7. Tout amendement à un Protocole ou à une Annexe doit porter sur le fond de ce Protocole ou de cette Annexe et doit être compatible avec les dispositions des articles de la présente Convention.

8. Le Secrétaire général de l'Organisation informe toutes les Parties de tout amendement qui entre en vigueur en vertu du présent article ainsi que de la date à laquelle chacun des amendements entre en vigueur.

9. Toute déclaration ou objection relative à un amendement communiquée en vertu du présent article doit être notifiée par écrit au Secrétaire général de l'Organisation. Celui-ci informe toutes les Parties à la Convention de cette notification et de sa date de réception.

\section{Art. 17 : Promotion de la coopération technique}

Les Parties à la Convention doivent, en consultation avec l'Organisation et d'autres organismes internationaux, avec le concours et en coordination avec le Directeur exécutif du Programme des Nations Unies pour l'environnement, promouvoir l'aide à apporter aux Parties qui demandent une assistance technique en vue :

a) de former du personnel scientifique et technique ;

b) de se procurer l'équipement et les installations de réception et de surveillance appropriés,

c) de faciliter l'adoption d'autres mesures et dispositions visant à prévenir ou à atténuer la pollution du milieu marin par les navires; et

d) d'encourager la recherche ;

de préférence à l'intérieur des pays intéressés, de façon à favoriser la réalisation des buts et des objectifs de la présente Convention.

\section{Art. 18 : Dénonciation}

1. La présente Convention ou toute Annexe facultative peut être dénoncée par l'une quelconque des Parties à la Convention à tout moment après l'expiration d'une période de cinq ans à compter de la date à laquelle la Convention ou une telle Annexe entre en vigueur à l'égard de cette Partie.

2. La dénonciation s'effectue au moyen d'une notification écrite adressée au Secrétaire général de l'Organisation, qui communique la teneur et la date de réception de cette notification ainsi que la date à laquelle la dénonciation prend effet à toutes les autres Parties.

3. La dénonciation prend effet douze mois après la date à laquelle le Secrétaire général de l'Organisation en a reçu notification ou à l'expiration de tout autre délai plus important énoncé dans la notification.

\section{Art. 19 : Dépôt et enregistrement}

1. La présente Convention est déposée auprès du Secrétaire général de l'Organisation qui en adresse des copies certifiées conformes à tous les États qui ont signé la Convention ainsi qu’à tous les États qui y adhèrent.

2. Dès l'entrée en vigueur de la présente Convention, son texte est transmis par le Secrétaire général de l'Organisation au Secrétaire général de l'Organisation des Nations Unies pour y être enregistré et publié conformément à l'Article 102 de la Charte des Nations Unies.

\section{Art. 20 : Langues}

La présente Convention est établie en un seul exemplaire en langues anglaise, espagnole, française et russe, chaque texte faisant également foi. Il en est fait des traductions officielles en langues allemande, arabe, italienne et japonaise qui sont déposées avec l'exemplaire original revêtu des signatures.

En foi de quoi, les soussignés, dûment autorisés à cet effet par leurs Gouvernements, ont apposé leur signature à la présente Convention.

Fait à Londres ce deux novembre mil neuf cent soixante-treize.

(Suivent les signatures) 


\title{
PROTOCOLE DE 1978 RELATIF À LA CONVENTION INTERNATIONALE DE 1973 POUR LA PRÉVENTION DE LA POLLUTION PAR LES NAVIRES
}

\author{
(Conclu à Londres le 17 février 1978 \\ Approuvé par l'Assemblée fédérale le 9 mars 1987) \\ Les Parties au présent Protocole,
}

Reconnaissant que la Convention internationale de 1973 pour la prévention de la pollution par les navires peut contribuer de manière appréciable à la protection du milieu marin contre la pollution par les navires,

Reconnaissant également la nécessité d'améliorer encore la prévention de la pollution des mers par les navires, notamment par les pétroliers, ainsi que la lutte contre cette pollution,

Reconnaissant en outre la nécessité de mettre en oeuvre les règles relatives à la prévention de la pollution par les hydrocarbures qui figurent à l'Annexe I de cette Convention aussi rapidement et de manière aussi étendue que possible,

Considérant toutefois qu'il est nécessaire d'ajourner l'application de l'Annexe II de cette Convention jusqu'au moment où certains problèmes d'ordre technique auront été résolus de façon satisfaisante,

Estimant que le meilleur moyen de réaliser ces objectifs est de conclure un Protocole relatif à la Convention internationale de 1973 pour la prévention de la pollution par les navires,

sont convenues de ce qui suit:

\section{Art. I : Obligations générales}

1. Les Parties au présent Protocole s'engagent à donner effet aux dispositions :

a) du présent Protocole et de son Annexe2 qui fait partie intégrante du présent Protocole; et

b) de la Convention internationale de 1973 pour la prévention de la pollution par les navires (ci-après dénommée «la Convention»), sous réserve des modifications et adjonctions énoncées dans le présent Protocole.

2. La Convention et le présent Protocole seront considérés et interprétés comme un seul et même instrument.

3. Toute référence au présent Protocole constitue en même temps une référence à son Annexe.

\section{Art. II : Mise en oeuvre de l'Annexe II de la Convention}

1. Nonobstant les dispositions du paragraphe 1 de l'article 14 de la Convention, les Parties au présent Protocole conviennent qu'elles ne seront pas liées par les dispositions de l'Annexe II de la Convention pendant une période de trois années à compter de la date d'entrée en vigueur du présent Protocole ou pendant une période plus longue qui serait décidée à la majorité des deux tiers des Parties au présent Protocole présentes et votantes au sein du Comité de la protection du milieu marin (ci-après dénommé «le Comité») de l'Organisation3 interGouvernementale consultative de la navigation maritime (ci-après dénommée «l'Organisation»).

2. Au cours de la période stipulée au paragraphe 1 du présent article, les Parties au présent Protocole ne sont ni astreintes ni habilitées à se prévaloir de privilèges au titre de la Convention en ce qui concerne des questions liées à l'Annexe II de la Convention et toute référence faite aux Parties dans la Convention n'inclut pas les Parties au présent Protocole lorsqu'il s'agit de questions visées par ladite annexe.

\section{Art. III : Communication de renseignements}

Remplacer le texte de l'alinéa b) du paragraphe 1) de l'article 11 de la Convention par le suivant :

b) la liste des inspecteurs désignés ou des organismes reconnus qui sont autorisés à agir pour leur compte dans l'application des mesures concernant la conception, la construction, l'armement et l'exploita-tion des navires transportant des substances nuisibles conformément aux dispositions des règles, en vue de sa diffusion aux Parties qui la porteront à la connaissance de leurs fonctionnaires. L'Autorité doit donc notifier à 
l'Organisation les responsabilités spécifiques confiées aux inspecteurs désignés ou aux organismes reconnus et les conditions de l'autorité qui leur a été déléguée.»

\section{Art. IV : Signature, ratification, acceptation, approbation et adhésion}

1. Le présent Protocole est ouvert à la signature, au siège de l'Organisation, du $1^{\text {er }}$ juin 1978 au 31 mai 1979 et reste ensuite ouvert à l'adhésion. Les États peuvent devenir Parties au présent Protocole par :

a) signature sans réserve quant à la ratification, l'acceptation ou l'approbation; ou

b) signature sous réserve de ratification, d'acceptation ou d'approbation, suivie de ratification, d'acceptation ou d'approbation; ou

c) adhésion.

2. La ratification, l'acceptation, l'approbation ou l'adhésion s'effectuent par le dépôt d'un instrument à cet effet auprès du Secrétaire général de l'Organisation.

\section{Art. V : Entrée en vigueur}

1. Le présent Protocole entre en vigueur douze mois après la date à laquelle au moins quinze États dont les flottes marchandes représentent au total au moins cinquante pour cent du tonnage brut de la flotte mondiale des navires de commerce sont devenus Parties à ce Protocole conformément aux dispositions de son article IV.

2. Tout instrument de ratification, d'acceptation, d'approbation ou d'adhésion déposé après la date d'entrée en vigueur du présent Protocole prend effet trois mois après la date du dépôt.

3. Tout instrument de ratification, d'acceptation, d'approbation ou d'adhésion déposé après la date à laquelle un amendement au présent Protocole est réputé avoir été accepté conformément aux dispositions de l'article 16 de la Convention s'applique au Protocole dans sa forme modifiée.

\section{Art. VI : Amendements}

Les procédures définies à l'article 16 de la Convention pour les amendements aux articles, à une Annexe et à un appendice à une Annexe de la Convention s'appliquent respectivement aux amendements aux articles, à l'Annexe et à un appendice à l'Annexe du présent Protocole.

\section{Art. VII : Dénonciation}

1. Le présent Protocole peut être dénoncé par l'une quelconque des Parties au présent Protocole à tout moment après l'expiration d'une période de cinq ans à compter de la date à laquelle le présent Protocole entre en vigueur à l'égard de cette Partie.

2. La dénonciation s'effectue par le dépôt d'un instrument de dénonciation auprès du Secrétaire général de l'Organisation.

3. La dénonciation prend effet douze mois après la date à laquelle le Secrétaire général de l'Organisation en a reçu notification, ou à l'expiration de tout autre délai plus long spécifié dans la notification.

\section{Art. VIII : Dépositaire}

1. Le présent Protocole est déposé auprès du Secrétaire général de l'Organisation (ci-après dénommé «le Dépositaire»).

2. Le Dépositaire :

a) informe tous les États qui ont signé le présent Protocole ou qui y adhèrent :

i) de toute signature nouvelle ou de tout dépôt d'instrument nouveau de ratification, d'acceptation, d'approbation ou d'adhésion et de la date de cette signature ou de ce dépôt;

ii) de la date d'entrée en vigueur du présent Protocole ;

iii) de tout dépôt d'instrument dénonçant le présent Protocole, de la date à laquelle cet instrument a été reçu et de la date à laquelle la dénonciation prend effet ;

iv) de toute décision prise en application du paragraphe 1 de l'article II du présent Protocole ;

b) transmet des copies certifiées conformes du présent Protocole à tous les États signataires de ce protocole et à tous les États qui y adhèrent.

3. Dès l'entrée en vigueur du présent Protocole, le Dépositaire en transmet une copie certifiée conforme au Secrétariat de l'Organisation des Nations Unies en vue de son enregistrement et de sa publication conformément à l'Article 102 de la Charte des Nations Unies. 
Art. IX : Langues

Le présent Protocole est établi en un seul exemplaire original en langues anglaise, espagnole, française et russe, chaque texte faisant également foi. Il en est fait des traductions officielles en langues allemande, arabe, italienne et japonaise qui sont déposées avec l'exemplaire original revêtu des signatures.

En foi de quoi, les soussignés, dûment autorisés à cet effet par leurs Gouvernements respectifs, ont apposé leur signature au présent Protocole.

Fait à Londres ce dix-sept février mil neuf cent soixante-dix-huit.

(Suivent les signatures) 


\section{CONVENTION INTERNATIONALE DE 1978 SUR LES NORMES DE FORMATION DES GENS DE MER, DE DELIVRANCE DES BREVETS ET DE VEILLE}

\section{Les Parties à la présente Convention,}

désireuses d'améliorer la sauvegarde de la vie humaine et des biens en mer et la protection du milieu marin en établissant d'un commun accord des normes internationales de formation des gens de mer, de délivrance des brevets et de veille, considérant que le meilleur moyen d'atteindre ce but est de conclure une convention internationale sur les normes de formation des gens de mer, de délivrance des brevets et de veille, sont convenues de ce qui suit:

Art. I Obligations générales découlant de la Convention

Art. II Définitions

Art. III Champ d'application

Art. IV Communication de renseignements

Art. V Autres traités et interprétation

Art. VI Brevets

Art. VII Dispositions transitoires

Art. VIII Dispenses

Art. IX Equivalences

Art. X Contrôle

Art. XI Promotion de la coopération technique

Art. XII Amendements

Art. XIII Signature, ratification, acceptation, approbation et adhésion

Art. XIV Entrée en vigueur

Art. XV Dénonciation

Art. XVI Dépôt et enregistrement

Art. XVII Langues Champ d'application de la convention le 28 octobre 2004

\section{Article I Obligations générales découlant de la Convention}

1. Les Parties s'engagent à donner effet aux dispositions de la Convention et de son Annexe ${ }^{1}$, qui fait partie intégrante de la Convention. Toute référence à la Convention constitue en même temps une référence à l'Annexe.

2. Les Parties s'engagent à promulguer toutes lois et tous décrets, ordres et règlements et à prendre toutes autres mesures nécessaires pour donner à la Convention son plein et entier effet, afin de garantir que, du point de vue de la sauvegarde de la vie humaine et des biens en mer ainsi que de la protection du milieu marin, les gens de mer à bord des navires ont les qualifications et l'aptitude correspondant à leurs fonctions.

\section{Article II Définitions}

Aux fins de la Convention, sauf disposition expresse contraire:

a) le terme «Partie» désigne un Etat à l'égard duquel la Convention est entrée en vigueur;

b) le terme «Administration» désigne le Gouvernement de la Partie dont le navire est autorisé à battre le pavillon;

c) le terme «brevet» désigne un document valide, quelle que soit son appellation, délivré par l'Administration ou avec l'autorisation de cette dernière, ou reconnu par l'Administration, et habilitant le titulaire à remplir les fonctions énoncées dans ledit document ou autorisées par les règlements nationaux;

d) le terme «breveté» signifie ayant obtenu un brevet dans les conditions requises;

e) le terme "Organisation» désigne l'Organisation intergouvernementale consultative de la navigation maritime1 (OMCI);

f) l'expression «Secrétaire général» désigne le Secrétaire général de l'Organisation,

g) l'expression «navire de mer» désigne un navire autre que les navires qui naviguent exclusivement dans les eaux intérieures ou dans des eaux situées à l'intérieur ou au proche voisinage d'eaux abritées ou de zones où s'appliquent les règlements portuaires,

h) l'expression «navire de pêche» désigne un navire utilisé pour la capture du poisson, des baleines, des phoques, des morses ou autres ressources vivantes de la mer; 
i) l'expression «Règlements des radiocommunications» désigne les Règlements des radiocommunications annexés ou considérés comme annexés à la plus récente Convention internationale des télécommunications en vigueur à un moment donné.

${ }^{1}$ Depuis le 22 mai 1982, l'Organisation porte le nom d'«Organisation Maritime Internationale».

\section{Article III Champ d'application}

La Convention s'applique aux gens de mer servant à bord des navires de mer qui sont autorisés à battre le pavillon d'une Partie, à l'exception de ceux qui servent à bord:

a) des navires de guerre, navires de guerre auxiliaires ou autres navires appartenant à un Etat ou exploités par cet Etat tant que celui-ci les utilise exclusivement à des fins gouvernementales et non commerciales; toutefois, chaque Partie doit s'assurer, en prenant des mesures appropriées qui ne compromettent pas les opérations ou la capacité opérationnelle des navires de ce type lui appartenant ou exploités par elle, que les personnes servant à bord de ces navires répondent aux prescriptions de la Convention, pour autant que cela soit raisonnable dans la pratique;

b) des navires de pêche;

c) des yachts de plaisance ne se livrant à aucun trafic commercial;

d) des navires en bois de construction primitive.

\section{Article IV Communication de renseignements}

1. Les Parties communiquent le plus rapidement possible au Secrétaire général:

a) le texte des lois, décrets, ordres, règlements et instruments promulgués sur les différentes questions qui entrent dans le champ d'application de la Convention;

b) tous les détails, le cas échéant, sur le programme et la durée des études, ainsi que sur les examens et autres conditions qu'elles prévoient à l'échelon national pour la délivrance de chaque brevet conformément à la Convention;

c) un nombre suffisant de modèles des brevets délivrés conformément à la Convention.

2. Le Secrétaire général informe toutes les Parties de toute communication reçue en vertu de l'al. a) du par. 1) et en particulier, il leur diffuse sur demande, aux fins des art. IX et X, les renseignements qui lui ont été communiqués au titre des al. b) et c) du par. 1).

\section{Article V Autres traités et interprétation}

1. Tous les traités, conventions et arrangements antérieurs qui se rapportent aux normes de formation des gens de mer, de délivrance des brevets et de veille et qui sont en vigueur entre les Parties conservent leur plein et entier effet, pendant la durée qui leur est assignée, en ce qui concerne:

a) les gens de mer auxquels la présente Convention ne s'applique pas;

b) les gens de mers auxquels la présente Convention s'applique, pour ce qui est des points qui n'y font pas l'objet de prescriptions expresses.

2. Toutefois, dans la mesure où de tels traités, conventions ou arrangements sont en conflit avec les prescriptions de la Convention, les Parties revoient les engagements qu'elles ont contractés en vertu desdits traités, conventions et arrangements afin d'éviter tout conflit entre ces engagements et les obligations découlant de la Convention.

3. Tous les points qui ne font pas l'objet de prescriptions expresses dans la convention restent soumis à la législation des Parties.

4. Aucune disposition de la Convention ne préjuge la codification et l'élaboration du droit de la mer par la Conférence des Nations Unies sur le droit de la mer convoquée en vertu de la résolution $2750 \mathrm{C}$ (XXV) de l'Assemblée générale des Nations Unies, ni les revendications et positions juridiques présentes ou futures de tout Etat touchant le droit de la mer et la nature et l'étendue de la juridiction de l'Etat côtier et de l'Etat du pavillon.

\section{Article VI Brevets}

1. Des brevets sont délivrés aux candidats aux fonctions de capitaine, d'officier, de matelot ou de mécanicien qui, à la satisfaction de l'Administration, remplissent les conditions requises en matière de service, d'âge, d'aptitude physique, de formation, de qualifications et d'examens conformément aux dispositions appropriées de l'Annexe de la Convention. 
2. Les brevets de capitaine et d'officier délivrés conformément aux dispositions du présent article sont visés, par l'Administration qui les délivre, de la manière prescrite à la règle I/2 de l'Annexe. Si la langue utilisée n'est pas l'anglais, une traduction dans cette langue doit être jointe.

\section{Article VII Dispositions transitoires}

1. Un brevet d'aptitude ou une attestation de service portant sur une fonction pour laquelle la Convention exige un brevet, qui a été délivré avant l'entrée en vigueur de la Convention à l'égard d'une Partie en conformité de la législation de cette Partie ou des Règlements des radiocommunications, est reconnu comme habilitant son titulaire à exercer ladite fonction après l'entrée en vigueur de la Convention à l'égard de ladite Partie.

2. Après l'entrée en vigueur de la convention à l'égard d'une Partie, son Administration peut continuer à délivrer des brevets d'aptitude conformément à la pratique établie, pendant une période n'excédant pas cinq ans. Ces brevets sont réputés valides aux fins de la Convention. Au cours de cette période transitoire, il n'est délivré de tels brevets qu'aux gens de mer qui ont commencé leur service en mer avant l'entrée en vigueur de la Convention à l'égard de la Partie considérée dans le service spécialisé du navire auquel ces brevets se rapportaient. L'Administration veille à ce que tous les autres candidats à un brevet passent des examens et obtiennent leurs brevets conformément aux dispositions de la Convention.

3. Une Partie peut, dans un délai de deux ans à compter de l'entrée en vigueur de la Convention à son égard, délivrer une attestation de service aux gens de mer qui ne possèdent pas un brevet approprié en vertu de la Convention, ni un brevet d'aptitude délivré en vertu de la législation de ladite Partie avant l'entrée en vigueur de la Convention à l'égard de cette Partie, mais qui:

a) ont occupé les fonctions pour lesquelles ils cherchent à obtenir une attestation de service pendant au moins trois années en mer au cours des sept années précédant l'entrée en vigueur de la Convention à l'égard de cette Partie;

b) ont fourni une preuve attestant qu'ils se sont acquittés de ces fonctions de façon satisfaisante;

c) ont prouvé à l'Administration leur aptitude physique, notamment en ce qui concerne leur acuité visuelle et auditive, compte tenu de leur âge au moment où ils présentent leur demande.

Aux fins de la Convention, une attestation de service délivrée en application du présent paragraphe est considérée comme l'équivalent d'un brevet délivré conformément aux dispositions de la Convention.

\section{Article VIII Dispenses}

1. Dans des circonstances d'extrême nécessité, les Administrations peuvent, si elles estiment qu'il n'en découle aucun danger pour les personnes, les biens ou l'environnement, délivrer une dispense afin de permettre à un marin donné de servir à bord d'un navire donné pendant une période donnée ne dépassant pas six mois dans des fonctions pour lesquelles il ne détient pas le brevet approprié, à condition d'être convaincues que le titulaire de la dispense possède des qualifications suffisantes pour occuper le poste vacant d'une manière offrant toute sécurité. Cette dispense n'est accordée pour le poste d'officier radioélectricien ou d'opérateur radiotéléphoniste que dans les circonstances prévues par les dispositions pertinentes des Règlements des radiocommunications. Toutefois, une dispense ne doit pas être accordée pour les fonctions de capitaine ou de chef mécanicien, sauf en cas de force majeure et seulement pendant une période aussi courte que possible.

2. Toute dispense accordée pour un poste ne doit l'être qu'à une personne possédant le brevet requis pour occuper le poste immédiatement au-dessous. Lorsque, pour le poste au-dessous, aucun brevet n'est requis au titre de la Convention, une dispense peut être accordée à une personne dont les qualifications et l'expérience sont, de l'avis de l'Administration, d'un niveau équivalant nettement à celui qui est requis pour le poste à pourvoir, à condition que cette personne soit invitée, si elle ne détient pas de brevet approprié, à passer un test accepté par l'Administration pour démontrer qu'une telle dispense peut lui être accordée en toute sécurité. En outre, les Administrations doivent s'assurer que le poste en question sera occupé dès que possible par le titulaire d'un brevet approprié.

3. Les Parties envoient au Secrétaire général, dès que possible après le $1^{\text {er }}$ janvier de chaque année, un rapport donnant des renseignements sur le nombre total de dispenses délivrées pendant l'année à des navires de mer au titre de chacune des fonctions pour lesquelles un brevet est requis, ainsi que des renseignements sur le nombre de ces navires ayant une jauge brute supérieure et inférieure à 1600 tonneaux. 


\section{Article IX Equivalences}

1. Les dispositions de la Convention n'interdisent pas à une Administration de conserver ou d'adopter d'autres méthodes d'instruction et d'entraînement, y compris celles qui comportent un service en mer et une organisation de bord spécialement adaptés aux progrès techniques et à des types particuliers de navires et de services, à condition que le niveau du service en mer, des connaissances et de l'efficacité atteint en matière de navigation et de maniement technique du navire et de la cargaison assure un degré de sécurité en mer et ait des effets, en ce qui concerne la prévention de la pollution, au moins équivalents à ceux des prescriptions de la Convention.

2. Des détails sur ces méthodes sont communiqués dès que possible au Secrétaire général qui renseigne toutes les Parties à ce sujet.

\section{Article X Contrôle}

1. Les navires, à l'exception des navires exclus par l'article III, sont soumis dans les ports d'une Partie à des contrôles effectués par des fonctionnaires dûment autorisés par cette Partie, afin de vérifier que tous les gens de mer servant à bord qui sont tenus d'être titulaires d'un brevet au titre de la Convention sont détenteurs dudit brevet ou d'une dispense appropriée. Un brevet est accepté à moins qu'il n'y ait de bonnes raisons de penser qu'il a été obtenu de façon frauduleuse ou que le détenteur du brevet n'est pas la personne à qui ce dernier a été initialement délivré.

2. Dans les cas où il constate des carences au titre des dispositions du par. 1) ou des procédures indiquées dans la règle I/4 intitulée «Procédure de contrôle», le fonctionnaire chargé du contrôle en informe immédiatement par écrit le capitaine du navire et le consul ou, en son absence, le représentant diplomatique le plus proche ou l'autorité maritime de l'Etat dont le navire est autorisé à battre le pavillon afin que des mesures appropriées soient prises. Cette notification fait état de façon détaillée des carences qui ont été constatées et des raisons pour lesquelles la Partie considère que ces carences présentent un danger pour les personnes, les biens ou l'environnement.

3. Lorsqu'un contrôle est exercé au titre du par. 1), si, compte tenu des dimensions et du type du navire, ainsi que de la longueur et de la nature du voyage, il n'est pas remédié aux carences mentionnées au par. 3 de la règle $\mathrm{I} / 4$ et s'il apparaît qu'il en résulte un danger pour les personnes, les biens ou l'environnement, la Partie qui exerce le contrôle prend les mesures nécessaires pour que le navire n'appareille pas avant qu'il soit satisfait à ces prescriptions dans la mesure suffisante pour supprimer le danger. Il est rendu compte rapidement au Secrétaire général des faits concernant les mesures prises.

4. Lorsqu'un contrôle est exercé en vertu du présent article, tous les efforts possibles sont faits pour éviter qu'un navire ne soit inutilement retenu ou retardé. Si un navire est inutilement retenu ou retardé, il a droit à une indemnisation pour toute perte ou tout dommage en résultant.

5. Le présent article est appliqué de sorte que les navires battant le pavillon d'une Partie non contractante ne bénéficient pas d'un traitement plus favorable que celui réservé aux navires battant pavillon d'une Partie.

\section{Article XI Promotion de la coopération technique}

1. Les Parties à la Convention doivent, en consultation avec l'Organisation et avec son appui, promouvoir l'aide à apporter aux Parties qui demandent une assistance technique pour:

a) former du personnel administratif et technique;

b) créer des établissements pour la formation des gens de mer;

c) se procurer des équipements et des installations pour les établissements de formation;

d) mettre au point des programmes de formation appropriés, comprenant une formation pratique à bord de navires de mer; et

e) faciliter l'adoption d'autres mesures et dispositions susceptibles d'améliorer les qualifications des gens de mer;

de préférence à l'échelon national, sous-régional ou régional, de façon à favoriser la réalisation des objectifs de la Convention, compte tenu des besoins particuliers des pays en développement à cet égard.

2. Pour sa part, l'Organisation poursuit ses efforts dans le sens indiqué ci-dessus, de façon appropriée, en consultation ou en association avec d'autres organisations internationales, notamment l'Organisation internationale du travail.

\section{Article XII Amendements}

1. La Convention peut être modifiée par l'une ou l'autre des procédures ci-après:

a) amendements après examen par l'Organisation: 
i) tout amendement proposé par une Partie est soumis au Secrétaire général et diffusé par celui-ci à tous les Membres de l'Organisation, à toutes les Parties et au Directeur général du Bureau international du travail six mois au moins avant son examen;

ii) tout amendement ainsi proposé et diffusé est soumis au Comité de la sécurité maritime de l'Organisation pour examen;

iii) les Parties, qu'elles soient ou non Membres de l'Organisation, sont autorisées à participer aux délibérations du Comité de la sécurité maritime aux fins de l'examen et de l'adoption des amendements;

iv) les amendements sont adoptés à la majorité des deux tiers des Parties présentes et votantes au sein du Comité de la sécurité maritime élargi conformément à l'al. a) iii) (ci-après dénommé «Comité de la sécurité maritime élargi»), à condition qu'un tiers au moins des Parties soit présent au moment du vote;

v) les amendements ainsi adoptés sont communiqués par le Secrétaire général à toutes les Parties, aux fins d'acceptation;

vi) un amendement à un article est réputé avoir été accepté à la date à laquelle il a été accepté par les deux tiers des Parties;

vii) un amendement à l'Annexe est réputé avoir été accepté:

1. à l'expiration d'une période de deux ans à compter de la date à laquelle il est communiqué aux Parties pour acceptation; ou

2. à l'expiration de toute autre période, qui ne pourra toutefois être inférieure à un an, s'il en est décidé ainsi au moment de son adoption par une majorité des deux tiers des Parties présentes et votantes au sein du Comité de la sécurité maritime élargi;

toutefois, l'amendement est réputé ne pas avoir été accepté si, pendant la période ainsi spécifiée, plus d'un tiers des Parties, ou des Parties dont les flottes marchandes représentent au total 50 p. 100 au moins du tonnage brut de la flotte mondiale des navires de commerce d'une jauge brute égale ou supérieure à 100 tonneaux, notifient au Secrétaire général qu'elles élèvent une objection contre cet amendement;

viii) un amendement à un article entre en vigueur, à l'égard des Parties qui l'ont accepté, six mois après

la date à laquelle il est réputé avoir été accepté, et il entre en vigueur, à l'égard de chaque Partie qui l'accepte après cette date, six mois après son acceptation par cette Partie;

ix) un amendement à l'Annexe entre en vigueur à l'égard de toutes les Parties, à l'exception de celles qui ont élevé une objection contre ledit amendement conformément à l'al. a) vii) et qui n'ont pas retiré cette objection, six mois après la date à laquelle il est réputé avoir été accepté. Avant la date fixée pour l'entrée en vigueur d'un amendement, toute Partie peut notifier au Secrétaire général qu'elle se dispense de donner effet à l'amendement pendant une période qui ne dépasse pas un an à compter de la date de son entrée en vigueur, ou pendant une période plus longue si la majorité des deux tiers des Parties présentes et votantes au sein du Comité de la sécurité maritime élargi en décide ainsi au moment de l'adoption de l'amendement;

b) amendement par une conférence:

i) à la demande d'une Partie appuyée par un tiers au moins des Parties, l'Organisation convoque, en association ou en consultation avec le Directeur général du Bureau international du travail, une conférence des Parties pour examiner les amendements à la Convention;

ii) tout amendement adopté par cette conférence à la majorité des deux tiers des Parties présentes et votantes est communiqué par le Secrétaire général à toutes les Parties aux fins d'acceptation;

iii) à moins que la conférence n'en décide autrement, l'amendement est réputé avoir été accepté et entre en vigueur selon les procédures prévues respectivement aux al. a) vi) et a) viii) ou aux al. a) vii) et a) ix), à condition que les références au Comité de la sécurité maritime élargi contenues dans ces alinéas soient considérées comme des références à la conférence.

2. Toute déclaration d'acceptation ou d'objection relative à un amendement ou toute notification communiquée en vertu de l'al. a) ix) du par. 1) doivent être adressées par écrit au Secrétaire général. Celuici informe toutes les Parties de cette communication et de la date à laquelle il l'a reçue.

3. Le Secrétaire général informe toutes les Parties de tout amendement qui entre en vigueur, ainsi que la date à laquelle cet amendement entre en vigueur.

\section{Article XIII}

\section{Signature, ratification, acceptation, approbation et adhésion}

1. La Convention reste ouverte à la signature, au siège de l'Organisation du $1^{\text {er }}$ décembre 1978 au 30 novembre 1979, et reste ensuite ouverte à l'adhésion. Tout Etat peut devenir Partie par:

a) signature sans réserve quant à la ratification, l'acceptation ou l'approbation; ou 
b) signature sous réserve de ratification, d'acceptation ou d'approbation, suivie de ratification, d'acceptation ou d'approbation; ou

c) adhésion.

2. La ratification, l'acceptation, l'approbation ou l'adhésion s'effectuent par le dépôt d'un instrument à cet effet auprès du Secrétaire général.

3. Le Secrétaire général informe tous les Etats ayant signé la Convention ou y ayant adhéré et le Directeur général du Bureau international du travail de toute signature ou du dépôt de tout instrument de ratification, d'acceptation, d'approbation ou d'adhésion et de la date de ce dépôt.

\section{Article XIV Entrée en vigueur}

1. La Convention entre en vigueur douze mois après la date à laquelle au moins vingt-cinq Etats dont les flottes marchandes représentent au total au moins 50 p. 100 du tonnage brut de la flotte mondiale des navires de commerce d'une jauge brute égale ou supérieure à 100 tonneaux ont, soit signé cette convention sans réserve quant à la ratification, l'acceptation ou l'approbation, soit déposé les instruments requis de ratification, d'acceptation, d'approbation ou d'adhésion, conformément aux dispositions de l'art. XIII.

2. Le Secrétaire général informe tous les Etats qui ont signé la Convention ou qui y ont adhéré de la date de son entrée en vigueur.

3. Tout instrument de ratification, d'acceptation, d'approbation ou d'adhésion déposé au cours des douze mois mentionnés au par. 1) prend effet au moment de l'entrée en vigueur de la Convention ou trois mois après la date de dépôt de l'instrument, si cette dernière est postérieure.

4. Tout instrument de ratification, d'acceptation, d'approbation ou d'adhésion déposé après la date d'entrée en vigueur de la Convention prend effet trois mois après la date du dépôt.

5. Tout instrument de ratification, d'acceptation, d'approbation ou d'adhésion déposé après la date à laquelle un amendement est réputé avoir été accepté conformément à l'art. XII s'applique à la Convention dans sa forme modifiée.

\section{Article XV Dénonciation}

1. La Convention peut être dénoncée par l'une quelconque des Parties à tout moment après l'expiration d'une période de cinq ans à compter de la date à laquelle la Convention est entrée en vigueur pour cette Partie.

2. La dénonciation s'effectue au moyen d'une notification écrite adressée au Secrétaire général, qui communique la teneur et la date de réception de cette notification ainsi que la date à laquelle la dénonciation prend effet à toutes les autres Parties et au Directeur général du Bureau international du travail.

3. La dénonciation prend effet douze mois après la date à laquelle le Secrétaire général en a reçu notification, ou à l'expiration de tout autre délai plus important énoncé dans la notification.

\section{Article XVI Dépôt et enregistrement}

1. La Convention est déposée auprès du Secrétaire général, qui en adresse des copies certifiées conformes à tous les Etats qui ont signé la Convention ou qui y adhérent.

2. Dès l'entrée en vigueur de la Convention, son texte est transmis par le Secrétaire général au Secrétaire général de l'Organisation des Nations Unies pour être enregistré et publié conformément à l'art. 102 de la Charte des Nations Unies. 


\section{CONVENTION RELATIVE À LA COOPÉRATION EN MATIÈRE DE PROTECTION ET DE MISE EN VALEUR DU MILIEU MARIN ET DES ZONES CÔTIËRES DE LA RÉGION DE L'AFRIQUE DE L'OUEST ET DU CENTRE}

Date d'adoption: 23 mars 1981

Lieu d'adoption : Abidjan, Côte d'Ivoire

Date d'entrée en vigueur : 05 août 1984

Secrétariat : Centre d'activité du Programme pour les océans et les zones côtières PNUE PO Box 30552 Nairobi, KENYA

Les Parties contractantes,

Conscientes de la valeur que le milieu marin et les zones côtières de la région de l'Afrique de l'Ouest et du Centre présentent du point de vue économique et social et du point de vue de la santé,

Pleinement conscientes du devoir qui leur incombe de préserver leur patrimoine naturel dans l'intérêt des générations présentes et futures,

Reconnaissant la menace que la pollution et le fait que l'environnement ne soit pas pris en compte dans le processus de développement font peser sur le milieu marin et les zones côtières, leur équilibre écologique, leurs ressources et leurs utilisations légitimes,

Appréciant pleinement la nécessité devant laquelle elles se trouvent de coopérer afin de pouvoir maintenir grâce à une approche

coordonnée et globale, un rythme de développement soutenu sans nuire à l'environnement,

Appréciant aussi pleinement la nécessité d'adopter, du fait du manque de renseignements scientifiques sur la pollution des mers dans la région de l'Afrique de l'Ouest et du Centre, un programme de recherche, de surveillance et d'évaluation soigneusement planifié,

Notant qu'en dépit des progrès réalisés, les conventions internationales relatives à la pollution des mers ne couvrent pas toutes les sources de pollution des mers, ni tous les aspects de cette pollution et ne répondent pas pleinement aux besoins particuliers de la région de l'Afrique de l'Ouest et du Centre,

Sont convenues de ce qui suit :

\section{Article premier : Champ d'application géographique}

La présente Convention s'applique au milieu marin, aux zones côtières et aux eaux intérieures connexes relevant de la juridiction des États de la région de l'Afrique de l'Ouest et du Centre, de la Mauritanie à la Namibie comprise, qui sont devenus Parties contractantes à la présente Convention dans les conditions prévues à l'article 27 et au paragraphe 1 de l'article 28 (la zone correspondante étant appelée ci-après "zone d'application de la Convention").

\section{Article 2 : Définitions}

Aux fins de la présente Convention :

1. Par "pollution", il faut entendre l'introduction directe ou indirecte, par l'homme, de substances ou d'énergie dans le milieu marin, les zones côtières et eaux intérieures connexes, lorsqu'elle a des effets nuisibles tels que dommages aux ressources biologiques, risques pour la santé de l'homme, entraves aux activités maritimes, y compris la pêche, altération de la qualité de l'eau de mer du point de vue de son utilisation et dégradation des valeurs d'agrément.

2. Par "Organisation", il faut entendre l'organisme désigné pour assurer le secrétariat de la Convention et des protocoles y relatifs, conformément à l'article 16 de la présente Convention.

\section{Article 3 : Dispositions générales}

1. Les Parties contractantes peuvent conclure des accords bilatéraux ou multilatéraux, y compris des accords régionaux ou sous-régionaux, en vue d'assurer la protection du milieu marin et des zones côtières de la région de l'Afrique de l'Ouest et du Centre, sous réserve que ces accords soient compatibles avec la présente Convention et conformes au droit international.

Copie de ces accords sera déposée auprès de l'Organisation et, par son entremise, communi-quée à toutes les Parties contractantes. 
2. Aucune disposition de la présente Convention ou des protocoles y relatifs ne peut être interprétée comme portant atteinte aux obligations assumées par une Partie contrac-tante en vertu d'accords conclus antérieure-ment.

3. Aucune disposition de la présente Convention ne porte atteinte à la codification ni à l'élaboration du droit de la mer par la Conférence des Nations Unies sur le droit de la mer convoquée en application de la résolution $2750 \mathrm{C}$ (XXV) de l'Assemblée générale des Nations Unies, ni aux revendications ou aux positions juridiques présentes ou futures de toute Partie contractante touchant la nature et l'étendue de sa juridiction maritime.

\section{Article 4 : Obligations générales}

1. Les Parties contractantes, agissant individuellement ou conjointement, selon le cas, prennent toutes les mesures appropriées, conformément aux dispositions de la présente Convention et de ses protocoles en vigueur auxquels elles sont parties, pour prévenir, réduire, combattre et maitriser la pollution dans la zone d'application de la Convention et pour assurer une gestion rationnelle des ressources naturelles du point de vue de l'environnement, en utilisant à cette fin les meilleurs moyens dont elles disposent, compte tenu de leurs possibilités.

2. Les Parties contractantes coopèrent en vue d'élaborer et d'adopter, outre le Protocole relatif à la coopération en matière de lutte contre la pollution en cas de situation critique ouvert à la signature en même temps que la présente Convention, d'autres protocoles prescrivant des mesures, des procédures et des normes convenues en vue de prévenir, réduire, combattre et maîtriser la pollution, quelle qu'en soit la source, ou de promouvoir la gestion de l'environnement, conformément aux objectifs de la présente Convention.

3. Au niveau national, les Parties contractantes adoptent des lois et règlements garantissant la bonne exécution des obligations visées par la présente Convention et s'efforcent d'harmoniser leurs politiques nationales dans ce domaine.

4. Les Parties contractantes coopèrent avec les organisations internationales, régionales et sous-régionales compétentes en vue d'élaborer et d'adopter des pratiques, des procédures et des mesures recommandées pour prévenir, réduire, combattre et maîtriser la pollution, quelle qu'en soit la source, conformément aux objectifs de la présente Convention et des protocoles y relatifs, et en vue de s'aider mutuellement à s'acquitter de leurs obligations en vertu de la Convention et des protocoles y relatifs.

5. En prenant des mesures pour prévenir, réduire, combattre et maîtriser la pollution dans la zone d'application de la Convention ou promouvoir la gestion de l'environnement, les Parties contractantes agissent de manière à ne pas transférer, directement ou indirectement, le préjudice ou les risques d'une zone dans une autre ou à ne pas remplacer un type de pollution par un autre.

\section{Article 5 : Pollution par les navires}

Les Parties contractantes prennent toutes les mesures appropriées, conformément au droit international, pour prévenir, réduire, combattre et maîtriser dans la zone d'application de la Convention la pollution causée par les rejets normaux ou accidentels des navires, et assurent l'application effective, dans ladite zone, des règles et normes généralement admises au niveau international en matière de lutte contre ce type de pollution.

\section{Article 6 : Pollution due aux opérations d'immersion effectuées par les navires et aéronefs}

Les Parties contractantes prennent toutes les mesures appropriées pour prévenir, réduire, combattre et maitriser la pollution de la zone d'application de la Convention causée par les opérations d'immersion effectuées par les navires et les aéronefs, et assurent l'application effective, dans ladite zone, des règles et normes généralement admises au niveau international en matière de lutte contre ce type de pollution.

\section{Article 7 : Pollution d'origine tellurique}

Les Parties contractantes prennent toutes les mesures appropriées pour prévenir, réduire, combattre et maitriser la pollution de la zone d'application de la Convention due aux déversements par les fleuves, les estuaires, les établissements côtiers et les émissaires ou aux opérations d'immersion effectuées sur les côtes, ou émanant de toute autre source située sur leur territoire.

\section{Article 8 : Pollution résultant d'activités liées à l'exploration et à l'exploitation du fond de la mer et de son sous-sol}

Les Parties contractantes prennent toutes les mesures appropriées pour prévenir, réduire, combattre et maitriser la pollution résultant directement ou indirectement d'activités d'exploration et d'exploitation du 
fond de la mer et de son sous-sol entreprises dans le cadre de leur juridiction, ainsi que d'îles artificielles, d'installations et d'ouvrages relevant de leur juridiction.

\section{Article 9 : Pollution d'origine atmosphé-rique ou transatmosphérique}

Les Parties contractantes prennent toutes les mesures appropriées pour prévenir, réduire, combattre et maitriser la pollution d'origine atmosphérique ou transatmosphérique dans la zone d'application de la Convention.

\section{Article 10 : Érosion côtière}

Les Parties contractantes prennent toutes les mesures appropriées pour prévenir, réduire, combattre et maitriser, dans la zone d'application de la Convention, l'érosion côtière due aux activités de l'homme, telles que la récupération des terres et les activités de génie civil sur la côte.

\section{Article 11 : Zones spécialement protégées}

Les Parties contractantes prennent, individuel-lement ou conjointement, selon le cas, toutes les mesures appropriées pour protéger et préserver les écosystèmes singuliers ou fragiles ainsi que l'habitat des espèces et autres formes de vie marine appauvries, menacées ou en voie de disparition. A cet effet, les Parties contractantes s'efforcent d'établir des zones protégées, notamment des parcs et des réserves, et d'interdire ou de réglementer toute activité de nature à avoir des effets néfastes sur les espèces, les écosystèmes ou les processus biologiques de ces zones.

\section{Article 12 : Coopération en matière de lutte contre la pollution en cas de situation critique}

1. Les Parties contractantes coopèrent pour prendre toutes les mesures nécessaires en cas de situation critique génératrice de pollution dans la zone d'application de la Convention, quelle que soit la cause de cette situation critique, et pour réduire ou éliminer les dommages qui en résultent.

2. Toute Partie contractante ayant connaissance d'une situation critique génératrice de pollution dans la zone d'application de la Convention en informe sans délai l'Organisation et, par l'intermédiaire de cette Organisation ou directement, toute autre Partie contractante qui risque d'être touchée par cette situation critique.

\section{Article 13 : Évaluation de l'impact sur l'environnement}

1. Dans le cadre de leurs politiques de gestion de l'environnement, les Parties contractantes élaborent des directives techniques et autres en vue de faciliter la planification de leurs projets de développement de manière à réduire au maximum l'impact néfaste que ces projets pourraient avoir sur la zone d'application de la Convention.

2. Chaque Partie contractante s'efforce de prévoir, dans le cadre de toute activité de planification entraînant l'exécution de projets sur son territoire, notamment dans les zones côtières, une évaluation de limpact potentiel de ces projets sur l'environnement qui peut entraîner une pollution importante dans la zone d'application de la Convention ou y provoquer des transformations considérables et néfastes.

3. Les Parties contractantes mettent au point, en consultation avec l'Organisation, des procédures en vue de diffuser des renseigne-ments sur l'évaluation des activités visées au paragraphe 2 du présent article.

\section{Article 14 : Coopération scientifique et technique}

1. Les Parties contractantes coopèrent, avec l'aide des organisations internationales et régionales compétentes, dans les domaines de la recherche scientifique, de la surveillance et de l'évaluation de la pollution dans la zone d'application de la Convention, et échangent des données et des renseignements scientifi-ques aux fins de la Convention et des protoco-les y relatifs.

2. En outre, les Parties contractantes élaborent et coordonnent des programmes nationaux de recherche et de surveillance pour tous les types de pollution observés dans la zone d'application de la Convention et mettent en place, en collaboration avec les organisations internationales et régionales compétentes, un réseau régional de centres et d'instituts nationaux de recherche, de façon à obtenir des résultats compatibles. Les Parties contractantes s'efforcent de participer à des arrangements internationaux concernant la recherche et la surveillance en matière de pollution dans les zones situées au-delà des limites de leur juridiction nationale.

3. Les Parties contractantes coopèrent, directement ou par l'intermédiaire des organi-sations internationales ou régionales compétentes, à l'élaboration de programmes d'assistance technique et autre dans des 
domaines liés à la pollution du milieu marin et à la gestion rationnelle de l'environnement dans la zone d'application de la Convention.

\section{Article 15 : Responsabilité et réparation des dommages}

Les Parties contractantes coopèrent en vue d'élaborer et d'adopter des règles et des procédures appropriées concernant la détermi-nation des responsabilités et la réparation ou l'indemnisation rapide et adéquate des dommages résultant de la pollution dans la zone d'application de la Convention.

\section{Article 16 : Arrangements institutionnels}

1. Les Parties contractantes désignent le Programme des Nations Unies pour l'environ-nement pour assurer les fonctions de secrétariat ci-après :

i) Préparer et convoquer les réunions des Parties contractantes et les conférences prévues aux articles 17 et 18 ;

ii) Communiquer aux Parties contractantes les notifications, rapports et autres renseignements reçus en conformité des articles 3,12 et 22 ;

iii) Accomplir les fonctions qui lui sont confiées en vertu des protocoles à la présente Convention ;

iv) Examiner les demandes de renseignements et les informations émanant des Parties contractantes et consulter lesdites Parties sur les questions relatives à la présente Conven-tion, à ses protocoles et à ses annexes ;

v) Coordonner l'exécution des activités de coopération convenues aux réunions des Parties contractantes et aux conférences visées à l'article 17 ;

vi) Établir tels arrangements administratifs qui peuvent se révéler nécessaires à l'exécution efficace des fonctions de secrétariat.

2. Chaque Partie contractante désigne une autorité nationale compétente qui est chargée de la coordination des efforts nationaux de mise en oeuvre de la présente Convention et des protocoles y relatifs. Ladite autorité nationale sert d'organe de liaison entre la Partie contractante et l'Organisation.

\section{Article 17 : Réunions des Parties contractantes}

1. Les Parties contractantes tiennent une réunion ordinaire tous les deux ans et, chaque fois qu'elles le jugent nécessaire, des réunions extraordinaires à la demande de l'Organisation ou à la demande d'une Partie contractante, appuyée par au moins trois autres Parties contractantes.

2. Les réunions des Parties contractantes ont pour objet de veiller à l'application de la présente Convention et des protocoles y relatifs et, en particulier :

i) D'étudier les rapports soumis par les Parties contractantes conformément à l'article 22;

ii) D'adopter, de réviser et d'amender, le cas échéant, conformément aux dispositions de l'article 20, les annexes à la présente Convention et aux protocoles y relatifs ;

iii) De faire des recommandations concernant l'adoption de protocoles additionnels ou d'amendements à la présente Convention ou aux protocoles y relatifs, conformément aux dispositions des articles 18 et 19 ;

iv) De constituer, le cas échéant, des groupes de travail pour examiner toutes questions en rapport avec la présente Convention ainsi que les protocoles et les annexes y relatifs ;

v) De faire le bilan de la pollution dans la zone d'application de la Convention ;

vi) D'étudier et d'adopter des décisions concernant les activités de coopération à entreprendre dans le cadre de la présente Convention et des protocoles y relatifs, y compris leurs incidences financières et institutionnelles;

vii) D'étudier et de mettre en oeuvre toute mesure supplémentaire requise, le cas échéant, pour atteindre les objectifs de la présente Convention et des protocoles y relatifs.

\section{Article 18 : Adoption de protocoles additionnels}

1. Les Parties contractantes, au cours d'une conférence de plénipotentiaires, peuvent adopter des protocoles additionnels à la présente Convention, conformément au paragraphe 2 de l'article 4.

2. Une conférence de plénipotentiaires en vue de l'adoption de protocoles additionnels est convoquée par l'Organisation si les deux tiers au moins des Parties contractantes en font la demande.

3. En attendant l'entrée en vigueur de la présente Convention, l'Organisation peut, après avoir consulté les signatures de la présente Convention, convoquer une conférence de plénipotentiaires en vue de l'adoption de proto-coles additionnels. 


\section{Article 19 : Amendements à la Convention et aux protocoles}

1. Toute Partie contractante à la présente Convention peut proposer des amendements à la Convention ou à l'un quelconque des protocoles.

Les textes des projets d'amendements à la présente Convention ou à l'un de ses protocoles sont communiqués aux Parties contractantes par l'Organisation six mois avant qu'ils ne soient soumis à l'examen de la réunion ordinaire des Parties contractantes.

2. Les amendements sont adoptés à la majorité des deux tiers des Parties contractantes et entrent en vigueur douze mois après leur approbation.

\section{Article 20 : Annexes et amendements aux annexes}

1. Les annexes à la présente Convention ou à l'un quelconque des protocoles font partie intégrante de la Convention ou du protocole.

2. Sauf disposition contraire de l'un quelcon-que des protocoles, la procédure prévue à l'article 19 s'applique à l'adoption et à l'entrée en vigueur de tout amendement aux annexes de la présente Convention ou de l'un quelconque des protocoles.

3. L'adoption et l'entrée en vigueur d'une nouvelle annexe à la présente Convention ou à l'un quelconque des protocoles sont soumises aux mêmes procédures que l'adoption et l'entrée en vigueur d'un amendement à une annexe conformément aux dispositions du paragraphe 2 du présent article; toutefois, si cela implique un amendement à la Convention ou au protocole visé, la nouvelle annexe n'entre en vigueur qu'après amendement de la Convention ou du protocole.

\section{Article 21 : Règlement intérieur et règles financières}

1. Les Parties contractantes adoptent un règlement intérieur pour les réunions et conférences visées aux articles 17 et 18 ci-dessus.

2. Les Parties contractantes adoptent des règles financières, préparées en consultation avec l'Organisation, pour déterminer notamment leur participation financière.

\section{Article 22 : Rapports}

Les Parties contractantes adressent à l'Organisation des rapports sur les mesures adoptées en application de la présente Conven-tion et des protocoles auxquels elles sont parties, la forme et la fréquence de ces rapports étant déterminées lors des réunions des Parties contractantes.

\section{Article 23 : Contrôle de l'application}

Les Parties contractantes s'engagent à coopérer pour élaborer des procédures leur permettant de veiller à l'application de la présente Con-vention et des protocoles y relatifs.

\section{Article 24 : Règlement des différends}

1. Si un différend surgit entre des Parties contractantes à propos de l'interprétation ou de l'application de la présente Convention ou des protocoles y relatifs, ces Parties s'efforcent de le régler par voie de négociation ou par tout autre moyen pacifique de leur choix.

2. Si les Parties concernées ne peuvent régler leur différend par les moyens mentionnés au paragraphe précédent, le différend est soumis à l'arbitrage dans des conditions fixées par les Parties contractantes dans une annexe à la présente Convention.

\section{Article 25 : Relation entre la Convention et les Protocoles}

1. Aucun État ne peut devenir Partie contractante à la présente Convention s'il ne devient en même temps partie à un protocole au moins. Aucun État ne peut devenir partie contractante à un protocole s'il n'est pas, ou ne devient pas en même temps, Partie contrac-tante à la présente Convention.

2. Tout protocole à la présente Convention n'engage que les Parties contractantes à ce pro-tocole.

Seules les Parties contractantes à un protocole peuvent prendre les décisions relatives audit protocole pour l'application des articles 17, 19 et 20 de la présente Convention.

\section{Article 26 : Signature}

La présente Convention et le Protocole relatif à la coopération en matière de lutte contre la pollution en cas de situation critique seront ouverts à Abidjan du 23 mars au 22 juin 1981 à la signature des États côtiers et insulaires, de la Mauritanie à la Namibie comprise. 


\section{Article 27 : Ratification, acceptation et approbation}

La présente Convention et tout protocole y relatif seront soumis à ratification, acceptation ou approbation. Les instruments de ratification, d'acceptation ou d'approbation seront déposés auprès du Gouvernement de la Côte d'Ivoire, qui assumera les fonctions de Dépositaire.

\section{Article 28 : Adhésion}

1. À partir du 23 juin 1981, la présente Convention et le Protocole relatif à la coopération en matière de lutte contre la pollution en cas de situation critique seront ouverts à l'adhésion des États visés à l'article 26.

2. Après l'entrée en vigueur de la présente Convention et de tout protocole y relatif, tout État africain non visé à l'article 26 pourra y adhérer.

3. La présente Convention et tout protocole y relatif restent également ouverts après leur entrée en vigueur à l'adhésion de tout autre État sous réserve d'approbation préalable par les trois quarts des États visés à l'article 26 qui sont devenus Parties contractantes.

4. Les instruments d'adhésion seront déposés auprès du Dépositaire.

\section{Article 29 : Entrée en vigueur}

1. La présente Convention et le premier des protocoles entrent en vigueur à la même date, conformément aux dispositions du paragraphe 2 ci-dessous.

2. La Convention et tout protocole entrent en vigueur le soixantième jour à compter de la date du dépôt d'au moins six instruments de ratification, d'acceptation ou d'approbation de cette Convention et du protocole, ou d'adhésion à ceux-ci par les parties visées à l'article 26.

3. Par la suite, la présente Convention et tout protocole entrent en vigueur à l'égard de tout État visé à l'article 26 , le soixantième jour après le dépôt de l'instrument de ratification, d'acceptation, d'approbation ou d'adhésion.

\section{Article 30 : Dénonciation}

1. A tout moment après l'expiration d'un délai de cinq ans à compter de la date d'entrée en vigueur de la présente Convention, toute Partie contractante pourra dénoncer la Convention en donnant par écrit une notification à cet effet.

2. Sauf disposition contraire de l'un quelconque des protocoles à la présente Convention, toute Partie contractante pourra, à tout moment après l'expiration d'un délai de cinq ans à compter de la date d'entrée en vigueur de ce protocole, dénoncer le protocole en donnant par écrit une notification à cet effet.

3. La dénonciation prendra effet quatre-vingt-dix jours après la date à laquelle elle aura été reçue par le Dépositaire.

4. Toute Partie contractante qui dénonce la présente Convention sera considérée comme ayant également dénoncé tout protocole auquel elle était partie.

Toute Partie contractante qui, à la suite de sa dénonciation d'un protocole, n'est plus partie à aucun des protocoles à la présente Convention sera considérée comme ayant également dénoncé la présente Convention.

\section{Article 31 : Fonctions du dépositaire}

1. Le Dépositaire notifie aux Parties contractantes, à toute autre partie visée à l'article 26, ainsi qu'à l'Organisation :

i) La signature de la présente Convention et de tout protocole y relatif et le dépôt des instruments de ratification, d'acceptation, d'approbation ou d'adhésion, effectués confor-mément aux dispositions des articles 26,27 et 28 ;

ii) La date à laquelle la Convention et tout protocole entreront en vigueur conformément aux dispositions de l'article 29;

iii) Les notifications de dénonciation faites conformément aux dispositions de l'article 30 ;

iv) Les amendements adoptés en ce qui concerne la Convention et tout protocole, leur acceptation par les Parties contractantes et la date d'entrée en vigueur de ces amendements conformément aux dispositions de l'article 19;

v) L'adoption de nouvelles annexes et des amendements à toute annexe conformément aux dispositions de l'article 20.

2. L'original de la présente Convention et de tout protocole y relatif sera déposé auprès du Dépositaire, le Gouvernement de la Côte d'Ivoire, qui en adressera des copies certifiées conformes aux Parties 
contractantes, à l'Organisation de l'Unité Africaine, à l'Organi-sation et au Secrétaire général de l'Organisation des Nations Unies pour enregistrement et publication conformément à l'Article 102 de la Charte des Nations Unies.

En foi de quoi les soussignés, dûment autorisés par leurs Gouvernements respectifs, ont signé la présente Convention.

Fait à Abidjan, le vingt-trois mars mil neuf cent quatre-vingt-un, en un seul exemplaire en langues anglaise, espagnole et française, les trois textes faisant également foi. 


\section{PROTOCOLE RELATIF À LA COOPÉRATION EN MATIÈRE DE LUTTE CONTRE LA POLLUTION EN CAS DE SITUATION CRITIQUE}

Article premier : Aux fins du présent Protocole :

1. On entend par "autorité nationale compétente" l'autorité désignée par le Gouvernement d'une Partie contractante, conformément au paragraphe 2 de l'article 16 de la Convention relative à la coopération en matière de protection et de mise en valeur du milieu marin et des zones côtières de la région de l'Afrique de l'Ouest et du Centre, et responsable :

a) De la lutte et des autres opérations engagées en cas de situation critique pour le milieu marin ;

b) De la réception et de la coordination des rapports relatifs à certaines situations critiques pour le milieu marin ;

c) De la coordination des activités relatives aux situations critiques pour le milieu marin en général au sein de son propre Gouvernement et avec les autres Parties contractantes.

2. L'expression "situation critique pour le milieu marin" désigne tout incident, événement ou situation, quelle qu'en soit la cause, ayant pour conséquence une pollution importante ou une menace imminente de pollution importante du milieu marin et des zones côtières par des hydrocarbures ou d'autres substances nuisibles, et en particulier les collisions, échouements et autres incidents survenant à des navires, y compris les navires-citernes, les éruptions sur les sites de production pétrolière et la présence d'hydrocarbures ou d'autres substances nuisibles due à des défaillances d'installations industrielles.

3. L'expression "plan d'intervention d'urgence en cas de situation critique pour le milieu marin" désigne un plan, élaboré sur une base nationale, bilatérale ou multilatérale, pour lutter contre la pollution et les autres atteintes au milieu marin et aux zones côtières, ou la menace de situations de ce genre, résultant d'accidents ou d'autres événements imprévus.

4. L'expression "opérations pour faire face aux situations critiques pour le milieu marin" désigne toute activité visant à prévenir, réduire, combattre et maitriser la pollution provoquée par les hydrocarbures ou d'autres substances nuisibles, ou la menace d'une telle pollution à la suite d'une situation critique pour le milieu marin, y compris le nettoyage des nappes de pétrole et la récupération ou le sauvetage de colis, de conteneurs, de citernes mobiles, de camions-citernes ou de wagons-citernes.

5. On entend par "intérêts connexes" les intérêts d'une Partie contractante qui sont directement ou indirectement affectés ou menacés par une situation critique pour le milieu marin, entre autres :

a) Les activités maritimes, côtières, portuaires ou d'estuaires, y compris les activités de pêches ;

b) L'attrait historique et touristique de la zone considérée ;

c) La santé et le bien-être des habitants de la zone touchée, y compris la conservation des ressources vivantes de la mer, de la faune et de la flore sauvage et la protection des parcs et réserves marins et côtiers.

6. Le terme "Convention" désigne la Convention relative à la coopération en matière de protection et de mise en valeur du milieu marin et des zones côtières de la région de l'Afrique de l'Ouest et du Centre.

7. On entend par "Organisation" l'organisme désigné à l'article 16 de la Convention pour exercer les fonctions de secrétariat pour la Convention.

Article 2 : La zone d'application du présent Protocole (ci-après appelée "zone du Protocole") est la même que la zone de la Convention telle qu'elle est définie dans l'article premier de la Convention.

Article 3 : Le présent Protocole s'applique aux situations existantes ou potentielles critiques pour le milieu marin qui constituent une menace de pollution importante pour la zone du Protocole et les intérêts connexes des Parties contractantes.

Article 4 : Les Parties contractantes s'engagent à coopérer pour toutes les questions relatives à l'adoption de mesures nécessaires et efficaces de protection de leurs côtes respectives et des intérêts connexes contre les dangers et les effets de la pollution résultant de situations critiques pour le milieu marin.

Article 5 : Chaque Partie contractante fournit aux autres Parties contractantes et à l'Organisation des renseignements sur:

a) Son autorité nationale compétente;

b) Ses lois, règlements et autres instruments juridiques se rapportant d'une manière générale aux questions traitées dans le présent Protocole, y compris celles qui ont trait à l'organisation et au fonctionnement de 
l'autorité nationale compétente, dans la mesure où cette organisation et ce fonctionnement sont liés aux questions traitées dans le présent Protocole;

c) Ses plans nationaux d'intervention d'urgence en cas de situation critique pour le milieu marin.

Article 6 : Les Parties contractantes échangent, par l'entremise de l'Organisation ou directement, des renseignements sur les programmes de recherche-développement, y compris les résultats obtenus quant aux moyens de lutter contre la pollution par les hydrocarbures et autres substances nuisibles, et sur l'expérience acquise dans la lutte contre cette pollution.

Article 7 :

1. Chaque Partie contractante s'engage à demander aux capitaines de navires battant son pavillon et aux pilotes des aéronefs immatriculés sur son territoire, ainsi qu'aux personnes responsables d'ouvrages opérant au large des côtes sous sa juridiction, de signaler à toute Partie contractante, par les voies les plus rapides et les plus appropriées compte tenu des circonstances, et conformément à l'annexe au présent Protocole :

a) Tous les accidents causant ou pouvant causer une pollution des eaux de la mer par les hydrocarbures ou d'autres substances nuisibles;

b) La présence, les caractéristiques et l'étendue des nappes d'hydrocarbures ou d'autres substances nuisibles repérées en mer et de nature à constituer une menace grave et imminente pour le milieu marin, les côtes ou les intérêts connexes d'une ou de plusieurs Parties contractantes.

2. Toute Partie contractante recevant un rapport présenté en application du paragraphe 1 ci-dessus informe dans les meilleurs délais l'Organisation et, soit par l'intermédiaire de celle-ci, soit directement, l'autorité nationale compétente de toute Partie contractante susceptible d'être touchée par la situation critique pour le milieu marin.

Article 8 :

1. Toute Partie contractante ayant besoin d'assistance pour faire face à une situation critique pour le milieu marin, notamment pour la récupération ou le sauvetage de colis, conteneurs, citernes mobiles, camionsciternes ou wagons-citernes, peut demander le concours de toute autre Partie contractante. La demande d'assistance est adressée en premier lieu aux autres Parties contractantes dont les côtes et les intérêts connexes sont susceptibles d'être touchés par la situation critique en cause. Les Parties contractantes auxquelles une demande est adressée en application du présent paragraphe s'engagent à faire tout leur possible pour fournir l'assistance demandée.

2. L'assistance visée au paragraphe 1 du présent article peut consister à :

a) Fournir du personnel, des produits et des équipements, et en assurer le renforcement;

b) Fournir des moyens de surveillance et de contrôle, et en assurer le renforcement ;

c) Mettre à disposition des sites pour l'évacuation des substances polluantes; ou

d) Faciliter le mouvement de personnes, d'équipements et de produits à destination ou à partir du territoire des Parties contractantes ou transitant par ce territoire.

3. Toute Partie contractante qui demande une assistance en application du paragraphe 1 du présent article fait rapport aux autres Parties contractantes et à l'Organisation sur les résultats de sa demande.

4. Les Parties contractantes s'engagent à étudier dès que possible et selon les moyens dont elles disposent la répartition des tâches à entreprendre pour faire face aux situations critiques pour le milieu marin dans la zone du Protocole.

5. Chaque Partie contractante s'engage à informer les autres Parties contractantes et l'Organisation des mesures prises pour faire face à des situations critiques pour le milieu marin dans les cas où les autres Parties contractantes ne sont pas appelées à l'aide.

Article 9:

1. Les Parties contractantes s'efforcent de maintenir et de promouvoir, soit individuellement soit par voie de coopération bilatérale ou multilatérale, des plans et des moyens d'intervention d'urgence en cas de situation critique pour le milieu marin, pour lutter contre la pollution par les hydrocarbures et autres substances nuisibles. Ces moyens comprennent en particulier des équipements, navires, aéronefs et personnels préparés aux opérations en cas de situation critique.

2. Les Parties contractantes coopèrent pour mettre au point des instructions et procédures permanentes que devront suivre les autorités nationales compétentes chargées de recevoir et de transmettre les rapports sur la pollution par des hydrocarbures et autres substances nuisibles présentés en application de l'article $7 \mathrm{du}$ 
présent Protocole. Cette coopération vise à assurer rapidement et régulièrement la réception, la transmission et la diffusion de ces rapports.

\section{Article 10 :}

1. Chaque Partie contractante agit conformé-ment aux principes ci-après dans la conduite des opérations menées sous son autorité pour faire face aux situations critiques pour le milieu marin :

a) Évaluer la nature et l'ampleur de la situation critique et transmettre les résultats de cette évaluation à toute autre Partie contractante intéressée ;

b) Déterminer les mesures nécessaires et appropriées qu'il convient de prendre pour faire face à la situation critique, en consultant s'il y a lieu d'autres Parties contractantes ;

c) Établir les rapports et demandes d'assistance nécessaires conformément aux articles 7 et 8 du présent Protocole; et

d) Prendre des mesures appropriées et concrètes pour prévenir, réduire, combattre et maîtriser les effets de la pollution, y compris la surveillance et le contrôle de la situation critique.

2. Dans l'exécution des opérations entreprises en application du présent Protocole pour faire face à une situation critique pour le milieu marin, les Parties contractantes doivent :

a) Agir conformément aux principes du droit international et aux conventions internationales applicables aux interventions en cas de situation critique pour le milieu marin; et

b) Signaler à l'Organisation ces interventions en cas de situation critique pour le milieu marin.

\section{Article 11 :}

1. Des réunions ordinaires des Parties contrac-tantes au présent Protocole ont lieu en même temps que les réunions ordinaires des Parties contractantes à la Convention tenues confor-mément à l'article 17 de la Convention.

Les Parties contractantes au présent Protocole peuvent aussi tenir des réunions extraordi-naires dans les conditions prévues à l'article 17 de la Convention.

2. Les réunions des Parties contractantes au présent Protocole ont notamment pour objet :

a) De veiller à l'application du présent Protocole et d'examiner l'efficacité des mesures adoptées et l'opportunité de prendre d'autres mesures, en particulier sous forme d'annexes ;

b) De réviser et d'amender, le cas échéant, toute annexe au présent protocole ;

c) De remplir, en tant que de besoin, toutes autres fonctions en application du présent Protocole.

\section{Article 12 :}

1. Les dispositions de la Convention relatives aux protocoles s'appliquent au présent Protocole.

2. Le règlement intérieur et les règles financières adoptés conformément à l'article 21 de la Convention s'appliquent au présent Protocole, à moins que les Parties contractantes audit Protocole n'en décident autrement.

En foi de quoi les soussignés, dûment autorisés par leurs Gouvernements respectifs, ont signé le présent Protocole.

Fait à Abidjan, le vingt-trois mars mil neuf cent quatre-vingt-un, en un seul exemplaire en langues anglaise, espagnole et française, les trois textes faisant également foi. 


\section{MLC Convention du travail maritime, 2006}

Convention du travail maritime, 2006 (Note: Date d'entrée en vigueur: 00:00:0000)

Lieu:Genève

Date d'adoption:07:02:2006

Session de la Conférence: 94

Sujet: Gens de mer

Cette convention a été adoptée après 1985 et est considérée à jour.

La Conférence générale de l'Organisation internationale du Travail,

Convoquée à Genève par le Conseil d'administration du Bureau international du Travail, et s'y étant réunie le 7 février 2006 en sa quatre-vingt-quatorzième session;

Désireuse de créer un instrument unique et cohérent qui intègre autant que possible toutes les normes à jour contenues dans les actuelles conventions et recommandations internationales du travail maritime ainsi que les principes fondamentaux énoncés dans d'autres conventions internationales du travail, notamment:

- la convention (no 29) sur le travail forcé, 1930;

- la convention (no 87) sur la liberté syndicale et la protection du droit syndical, 1948;

- la convention (no 98) sur le droit d'organisation et de négociation collective, 1949;

- la convention (no 100) sur l'égalité de rémunération, 1951;

- la convention (no 105) sur l'abolition du travail forcé, 1957;

- la convention (no 111) concernant la discrimination (emploi et profession), 1958;

- la convention (no 138) sur l'âge minimum, 1973;

- la convention (no 182) sur les pires formes de travail des enfants, 1999;

Consciente que l'Organisation a pour mandat fondamental de promouvoir des conditions de travail décentes;

Rappelant la Déclaration de l'OIT relative aux principes et droits fondamentaux au travail, 1998;

Consciente également que les gens de mer peuvent se prévaloir des dispositions d'autres instruments de l'OIT et doivent jouir des libertés et droits fondamentaux reconnus à toutes les personnes;

Considérant que les activités du secteur maritime se déploient dans le monde entier et que les gens de mer doivent par conséquent bénéficier d'une protection particulière;

Tenant compte également des normes internationales sur la sécurité des navires, la sécurité et la sûreté des personnes et la qualité de la gestion des na-vires édictées dans la Convention internationale de 1974 pour la sauvegarde de la vie humaine en mer, telle que modifiée, et dans la Convention de 1972 sur le règlement international pour prévenir les abordages en mer, telle que modifiée, ainsi que des prescriptions relatives à la formation et aux compétences requises des gens de mer qui figurent dans la Convention internationale de 1978 sur les normes de formation des gens de mer, de délivrance des brevets et de veille, telle que modifiée;

Rappelant que la Convention des Nations Unies de 1982 sur le droit de la mer établit un cadre juridique général régissant l'ensemble des activités sur les mers et les océans, qu'elle revêt une importance stratégique comme base de l'ac-tion et de la coopération nationales, régionales et mondiales dans le secteur maritime et que son intégrité doit être préservée;

Rappelant l'article 94 de la Convention des Nations Unies de 1982 sur le droit de la mer qui définit les devoirs et les obligations incombant à l'Etat du pa-villon notamment en ce qui concerne les conditions de travail, les effectifs et les questions sociales à bord des navires qui battent son pavillon;

Rappelant le paragraphe 8 de l'article 19 de la Constitution de l'Organisa-tion internationale du Travail qui dispose que l'adoption d'une convention ou d'une recommandation par la Conférence ou la ratification d'une convention par un Membre ne devront en aucun cas être considérées comme affectant toute loi, toute sentence, toute coutume ou tout accord qui assurent des conditions plus favorables aux travailleurs intéressés que celles prévues par la convention ou la recommandation;

Déterminée à faire en sorte que ce nouvel instrument soit conçu de manière à recueillir la plus large acceptation possible par les gouvernements, les armateurs et les gens de mer attachés aux principes du travail décent, qu'il soit facile à mettre à jour et qu'il puisse être appliqué et respecté de manière effective;

Après avoir décidé d'adopter diverses propositions relatives à l'élabora-tion d'un tel instrument, question qui constitue le seul point à l'ordre du jour de la session;

Après avoir décidé que ces propositions prendraient la forme d'une convention internationale,

adopte, ce vingt-troisième jour de février deux mille six, la convention ci-après, qui sera dénommée Convention du travail maritime, 2006. 
Obligations générales

\section{Article I}

1. 1. Tout Membre qui ratifie la présente convention s'engage à donner plein effet à ses dispositions conformément aux prescriptions de l'article VI afin de garantir le droit de tous les gens de mer à un emploi décent.

2. Les Membres coopèrent entre eux pour assurer l'application effective et le plein respect de la présente convention.

Définitions et champ d'application

\section{Article II}

1. Aux fins de la présente convention, et sauf stipulation contraire dans une disposition particulière, l'expression:

a) autorité compétente désigne le ministre, le service gouvernemental ou toute autre autorité habilitée à édicter des règlements, des arrêtés ou autres instructions ayant force obligatoire dans le domaine visé par la disposition en question et à les faire appliquer;

b) déclaration de conformité du travail maritime désigne la déclaration visée dans la règle 5.1.3;

c) jauge brute désigne la jauge brute d'un navire mesurée conformément aux dispositions pertinentes de l'annexe I à la Convention internationale de 1969 sur le jaugeage des navires ou de toute autre convention l'ayant remplacée. Pour les navires visés par les dispositions transitoires de jaugeage adoptées par l'Organisation maritime internationale, la jauge brute est celle qui est indiquée dans la rubrique OBSERVATIONS du Certificat international de jaugeage des navires (1969);

d) certificat de travail maritime désigne le certificat visé dans la règle 5.1.3;

e) prescriptions de la présente convention renvoie aux prescriptions des articles, des règles et de la partie $\mathrm{A}$ du code qui font partie de la présente convention;

f) gens de mer ou marin désigne les personnes employées ou engagées ou travaillant à quelque titre que ce soit à bord d'un navire auquel la présente convention s'applique;

g) contrat d'engagement maritime renvoie à la fois au contrat de travail du marin et au rôle d'équipage;

h) service de recrutement et de placement des gens de mer désigne toute personne, société, institution, agence ou autre organisation du secteur public ou du secteur privé s'occupant du recrutement de gens de mer pour le compte d'armateurs ou de leur placement auprès d'armateurs;

i) navire désigne tout bâtiment ne naviguant pas exclusivement dans les eaux intérieures ou dans des eaux situées à l'intérieur ou au proche voisinage d'eaux abritées ou de zones où s'applique une réglementation portuaire;

j) armateur désigne le propriétaire du navire ou toute autre entité ou personne, telle que le gérant, l'agent ou l'affréteur coque nue, à laquelle le propriétaire a confié la responsabilité de l'exploitation du navire et qui, en assumant cette responsabilité, a accepté de se charger des tâches et obligations incombant aux armateurs aux termes de la présente convention, indépendamment du fait que d'autres entités ou personnes s'acquittent en son nom de certaines de ces tâches ou responsabilités.

2. Sauf disposition contraire expresse, la présente convention s'applique à tous les gens de mer.

3. Si, aux fins de la présente convention, l'appartenance d'une catégorie de personnes aux gens de mer soulève un doute, la question est tranchée par l'autorité compétente de chacun des Membres après consultation des organisations d'armateurs et de gens de mer intéressées.

4. Sauf disposition contraire expresse, la présente convention s'applique à tous les navires appartenant à des entités publiques ou privées normalement affectés à des activités commerciales, à l'exception des navires affectés à la pêche ou à une activité analogue et des navires de construction traditionnelle tels que les boutres et les jonques. La présente convention ne s'applique ni aux navires de guerre ni aux navires de guerre auxiliaires.

5. En cas de doute sur l'applicabilité de la présente convention à un navire ou à une catégorie de navires, la question est tranchée par l'autorité compétente de chacun des Membres après consultation des organisations d'armateurs et de gens de mer intéressées.

6. Lorsque l'autorité compétente décide qu'il ne serait pas raisonnable ou possible au moment présent d'appliquer certains éléments particuliers du code visé à l'ar-ticle VI, paragraphe 1, à un navire ou à certaines catégories de navires battant le pa-villon du Membre, les dispositions pertinentes dudit code ne s'appliqueront pas, dès lors que la question visée est régie différemment par la législation nationale, des 
conventions collectives ou d'autres mesures. L'autorité compétente ne pourra en décider ainsi qu'en consultation avec les organisations d'armateurs et de gens de mer intéressées, et seulement pour des navires d'une jauge brute inférieure à 200 qui n'effec-tuent pas de voyages internationaux.

7. Toute décision prise par un Membre en application des paragraphes 3,5 ou 6 doit être communiquée au Directeur général du Bureau international du Travail qui en informera les Membres de l'Organisation.

8. Sauf disposition contraire expresse, toute référence à la «convention» vise également les règles et le code.

Droits et principes fondamentaux

\section{Article III}

Tout Membre vérifie que les dispositions de sa législation respectent, dans le contexte de la présente convention, les droits fondamentaux suivants:

a) la liberté d'association et la reconnaissance effective du droit de négociation collective;

b) l'élimination de toute forme de travail forcé ou obligatoire;

c) l'abolition effective du travail des enfants;

d) l'élimination de la discrimination en matière d'emploi et de profession.

Droits en matière d'emploi et droits sociaux des gens de mer

\section{Article IV}

1. Tous les gens de mer ont droit à un lieu de travail sûr et sans danger où les normes de sécurité sont respectées.

2. Tous les gens de mer ont droit à des conditions d'emploi équitables.

3. Tous les gens de mer ont droit à des conditions de travail et de vie décentes à bord des navires.

4. Tous les gens de mer ont droit à la protection de la santé, aux soins médicaux, à des mesures de bien-être et aux autres formes de protection sociale.

5. Tout Membre veille, dans les limites de sa juridiction, à ce que les droits en matière d'emploi et les droits sociaux des gens de mer, tels qu'énoncés dans les paragraphes qui précèdent, soient pleinement respectés conformément aux prescriptions de la présente convention. Sauf disposition contraire de celle-ci, le respect de ces droits peut être assuré par la législation nationale, les conventions collectives applicables, la pratique ou d'autres mesures.

Responsabilité d'appliquer et de faire respecter les dispositions

\section{Article V}

1. Tout Membre applique et fait respecter la législation ou les autres mesures qu'il a adoptées afin de s'acquitter des obligations contractées aux termes de la présente convention en ce qui concerne les navires et les gens de mer relevant de sa juridiction.

2. Tout Membre exerce effectivement sa juridiction et son contrôle sur les na-vires battant son pavillon en se dotant d'un système propre à assurer le respect des prescriptions de la présente convention, notamment par des inspections régulières, des rapports, des mesures de suivi et l'engagement de poursuites conformément à la législation applicable.

3. Tout Membre veille à ce que les navires battant son pavillon soient en possession d'un certificat de travail maritime et d'une déclaration de conformité du travail maritime, comme le prescrit la présente convention.

4. Tout navire auquel la présente convention s'applique peut, conformément au droit international, faire l'objet de la part d'un Membre autre que l'Etat du pavillon, lorsqu'il se trouve dans l'un de ses ports, d'une inspection visant à vérifier que ce navire respecte les prescriptions de la présente convention. 5. Tout Membre exerce effectivement sa juridiction et son contrôle sur les services de recrutement et de placement des gens de mer éventuellement établis sur son territoire.

6. Tout Membre interdit les violations des prescriptions de la présente convention et doit, conformément au droit international, établir des sanctions ou exiger l'adoption de mesures correctives en vertu de sa législation, de manière à décourager toute violation.

7. Tout Membre s'acquitte des responsabilités contractées aux termes de la présente convention en faisant en sorte que les navires battant le pavillon de tout Etat ne l'ayant pas ratifiée ne bénéficient pas d'un traitement plus favorable que ceux battant le pavillon de tout Etat l'ayant ratifiée. 
Règles et parties A et B du code

\section{Article VI}

1. Les règles et les dispositions de la partie $\mathrm{A}$ du code ont force obligatoire. Les dispositions de la partie $\mathrm{B}$ du code n'ont pas force obligatoire.

2. Tout Membre s'engage à respecter les droits et principes énoncés dans les règles et à appliquer chacune d'entre elles de la manière indiquée dans les dispositions correspondantes de la partie A du code. En outre, il doit dûment envisager de s'acquit-ter de ses obligations de la manière prescrite dans la partie B du code.

3. Un Membre qui n'est pas en mesure de mettre en uvre les droits et principes de la manière indiquée dans la partie A du code peut, sauf disposition contraire expresse de la présente convention, en appliquer les prescriptions par la voie de dispositions législatives, réglementaires ou autres qui sont équivalentes dans l'ensemble aux dispositions de la partie A.

4. Aux seules fins des dispositions du paragraphe 3 du présent article, une loi, un règlement, une convention collective ou toute autre mesure d'application est considéré comme équivalent dans l'ensemble dans le contexte de la présente convention si le Membre vérifie que:

a) il favorise la pleine réalisation de l'objectif et du but général de la disposition ou des dispositions concernées de la partie A du code;

b) il donne effet à la disposition ou aux dispositions concernées de la partie A du code.

Consultations avec les organisations d'armateurs et de gens de mer

\section{Article VII}

Les dérogations, exemptions et autres applications souples de la présente convention nécessitant, aux termes de celle-ci, la consultation des organisations d'ar-mateurs et de gens de mer ne peuvent être décidées par un Membre, en l'absence de telles organisations représentatives sur son territoire, qu'après consultation avec la commission visée à l'article XIII.

\section{Entrée en vigueur}

\section{Article VIII}

1. Les ratifications formelles de la présente convention sont communiquées au Directeur général du Bureau international du Travail aux fins d'enregistrement.

2. La présente convention ne lie que les Membres de l'Organisation internationale du Travail dont la ratification a été enregistrée par le Directeur général.

3. La convention entrera en vigueur douze mois après que la ratification d'au moins 30 Membres représentant au total au moins 33 pour cent de la jauge brute de la flotte marchande mondiale aura été enregistrée.

4. Par la suite, cette convention entrera en vigueur pour chaque Membre douze mois après la date de l'enregistrement de sa ratification.

Dénonciation

\section{Article IX}

1. Un Membre ayant ratifié la présente convention peut la dénoncer à l'expira-tion d'une période de dix ans à compter de la date de la mise en vigueur initiale de la convention, par un acte communiqué au Directeur général du Bureau international du Travail aux fins d'enregistrement. La dénonciation ne prend effet qu'une année après avoir été enregistrée.

2. Tout Membre qui, dans l'année après la période de dix années mentionnée au paragraphe 1 du présent article, ne se prévaut pas de la faculté de dénonciation prévue sera lié pour une nouvelle période de dix ans et pourra, par la suite, dénoncer la présente convention à l'expiration de chaque nouvelle période de dix années dans les conditions prévues au présent article. Effet de l entrée en vigueur

\section{Article X}

La présente convention porte révision des conventions suivantes:

Convention ( $\left.\mathrm{n}^{\circ} 7\right)$ sur l'âge minimum (travail maritime), 1920

Convention ( $\left.n^{\circ} 8\right)$ sur les indemnités de chômage (naufrage), 1920

Convention ( $n^{\circ}$ 9) sur le placement des marins, 1920 
Convention ( $\left.\mathrm{n}^{\circ} 16\right)$ sur l'examen médical des jeunes gens (travail maritime), 1921

Convention ( $\left.\mathrm{n}^{\circ} 22\right)$ sur le contrat d'engagement des marins, 1926

Convention ( $\left.\mathrm{n}^{\circ} 23\right)$ sur le rapatriement des marins, 1926

Convention ( $\left.n^{\circ} 53\right)$ sur les brevets de capacité des officiers, 1936

Convention ( $\left.n^{\circ} 54\right)$ des congés payés des marins, 1936

Convention ( $\left.n^{\circ} 55\right)$ sur les obligations de l'armateur en cas de maladie ou d'accident des gens de mer, 1936

Convention ( $\left.n^{\circ} 56\right)$ sur l'assurance-maladie des gens de mer, 1936

Convention ( $n^{\circ}$ 57) sur la durée du travail à bord et les effectifs, 1936

Convention ( $n^{\circ} 58$ ) (révisée) sur l'âge minimum (travail maritime), 1936

Convention ( $n^{\circ} 68$ ) sur l'alimentation et le service de table (équipage des navires), 1946

Convention ( $n^{\circ} 69$ ) sur le diplôme de capacité des cuisiniers de navire, 1946

Convention ( $\left.n^{\circ} 70\right)$ sur la sécurité sociale des gens de mer, 1946

Convention ( $\left.n^{\circ} 72\right)$ des congés payés des marins, 1946

Convention ( $n^{\circ} 73$ ) sur l'examen médical des gens de mer, 1946

Convention ( $\left.n^{\circ} 74\right)$ sur les certificats de capacité de matelot qualifié, 1946

Convention ( $\left.\mathrm{n}^{\circ} 75\right)$ sur le logement des équipages, 1946

Convention ( $\left.\mathrm{n}^{\circ} 76\right)$ sur les salaires, la durée du travail à bord et les effectifs, 1946

Convention ( ${ }^{\circ}$ 91) sur les congés payés des marins (révisée), 1949

Convention ( $\left.n^{\circ} 92\right)$ sur le logement des équipages (révisée), 1949

Convention ( $\mathrm{n}^{\circ}$ 93) sur les salaires, la durée du travail à bord et les effectifs (révisée), 1949

Convention ( $\left.n^{\circ} 109\right)$ sur les salaires, la durée du travail à bord et les effectifs (révisée), 1958

Convention ( $n^{\circ} 133$ ) sur le logement des équipages (dispositions complémentaires), 1970

Convention ( $\left.\mathrm{n}^{\circ} 134\right)$ sur la prévention des accidents (gens de mer), 1970

Convention ( $\mathrm{n}^{\circ} 145$ ) sur la continuité de l'emploi (gens de mer), 1976

Convention ( $\left.n^{\circ} 146\right)$ sur les congés payés annuels (gens de mer), 1976

Convention ( $\mathrm{n}^{\circ} 147$ ) sur la marine marchande (normes minima), 1976

Protocole de 1996 relatif à la convention ( $n^{\circ}$ 147) sur la marine marchande (normes minima), 1976

Convention ( $n^{\circ} 163$ ) sur le bien-être des gens de mer, 1987

Convention ( $\left.\mathrm{n}^{\circ} 164\right)$ sur la protection de la santé et les soins médicaux (gens de mer), 1987

Convention ( $\left.n^{\circ} 165\right)$ sur la sécurité sociale des gens de mer (révisée), 1987

Convention ( $\left.n^{\circ} 166\right)$ sur le rapatriement des marins (révisée), 1987

Convention ( ${ }^{\circ}$ 178) sur l'inspection du travail (gens de mer), 1996

Convention ( $n^{\circ} 179$ ) sur le recrutement et le placement des gens de mer, 1996

Convention ( $\left.n^{\circ} 180\right)$ sur la durée du travail des gens de mer et les effectifs des navires, 1996.

Fonctions de dépositaire

\section{Article XI}

1. Le Directeur général du Bureau international du Travail notifiera à tous les Membres de l'Organisation internationale du Travail l'enregistrement de toute ratification, acceptation et dénonciation qui lui seront communiquées en vertu de la présente convention.

2. Quand les conditions énoncées au paragraphe 3 de l'article VIII auront été remplies, le Directeur général appellera l'attention des Membres de l'Organisation sur la date à laquelle la présente convention entrera en vigueur.

\section{Article XII}

Le Directeur général du Bureau international du Travail communiquera au Secrétaire général de l'Organisation des Nations Unies, aux fins d'enregistrement conformément à l'article 102 de la Charte des Nations Unies, des renseignements complets sur toute ratification, acceptation et dénonciation enregistrée en vertu de la présente convention. 
Commission tripartite spéciale

\section{Article XIII}

1. Le Conseil d'administration du Bureau international du Travail suit en permanence l'application de la présente convention par le truchement d'une commission créée par lui et dotée d'une compétence spéciale dans le domaine des normes du travail maritime.

2. Pour traiter des questions relevant de la présente convention, cette commission est composée de deux représentants désignés par le gouvernement de chacun des Membres ayant ratifié la présente convention et des représentants des armateurs et des gens de mer désignés par le Conseil d'administration après consultation de la Commission paritaire maritime.

3. Les représentants gouvernementaux des Membres n'ayant pas encore ratifié la présente convention peuvent participer aux travaux de la commission mais sans droit de vote sur les questions relevant de la convention. Le Conseil d'administration peut inviter d'autres organisations ou entités à se faire représenter à la commission par des observateurs.

4. Les droits de vote des représentants des armateurs et des représentants des gens de mer à la commission sont pondérés de façon à garantir que chacun de ces deux groupes possède la moitié des droits de vote dont dispose l'ensemble des gouvernements représentés à la réunion et autorisés à voter.

Amendement à la présente convention

\section{Article XIV}

1. La Conférence générale de l'Organisation internationale du Travail peut adopter des amendements à toute disposition de la présente convention dans le cadre de l'article 19 de la Constitution de l'Organisation internationale du Travail et des règles et procédures de l'Organisation relatives à l'adoption des conventions. Des amendements au code peuvent également être adoptés conformément aux procédures prescrites à l'article XV.

2. Le texte desdits amendements est communiqué pour ratification aux Membres dont les instruments de ratification de la présente convention ont été enregistrés avant leur adoption.

3. Le texte de la convention modifiée est communiqué aux autres Membres de l'Organisation pour ratification conformément à l'article 19 de la Constitution.

4. Un amendement est réputé avoir été accepté à la date à laquelle ont été enregistrés les instruments de ratification de cet amendement ou, selon le cas, les instruments de ratification de la convention modifiée d'au moins 30 Membres représentant au total au moins 33 pour cent de la jauge brute de la flotte marchande mondiale.

5. Un amendement adopté dans le cadre de l'article 19 de la Constitution n'a force obligatoire que pour les Membres de l'Organisation dont la ratification a été enregistrée par le Directeur général du Bureau international du Travail. 6. Pour les Membres visés au paragraphe $2 \mathrm{du}$ présent article, un amendement entre en vigueur douze mois après la date d'acceptation visée au paragraphe 4 du présent article, ou douze mois après la date d'enregistrement de leur instrument de ratification, si cette date est postérieure.

7. Sous réserve des dispositions du paragraphe 9, pour les Membres visés au paragraphe 3 du présent article, la convention modifiée entre en vigueur douze mois après la date d'acceptation visée au paragraphe 4 du présent article, ou douze mois après la date d'enregistrement de leur instrument de ratification, si cette date est postérieure.

8. Pour les Membres dont la ratification de la convention a été enregistrée avant l'adoption d'un amendement mais qui n'ont pas ratifié celui-ci, la présente convention demeure en vigueur sans l'amendement en question.

9. Tout Membre dont l'instrument de ratification de la présente convention est enregistré après l'adoption de l'amendement mais avant la date visée au paragraphe 4 du présent article peut préciser, dans une déclaration jointe audit instument, qu'il ratifie la convention mais non l'amendement. Si l'instrument de ratification est accompagné d'une telle déclaration, la convention entre en vigueur pour le Membre concerné douze mois après la date d'enregistrement de l'instrument de ratification. Si celui-ci n'est pas accompagné d'une déclaration ou s'il est enregistré à la date ou après la date visée au paragraphe 4, la convention entre en vigueur pour le Membre concerné douze mois après cette date; dès l'entrée en vigueur de la convention modifiée conformément au paragraphe 7 du présent article, l'amendement a force obligatoire pour le Membre concerné, sauf disposition contraire dudit amendement. 


\section{Article XV}

1. Le code peut être amendé soit selon la procédure énoncée à l'article XIV, soit, sauf disposition contraire expresse, selon la procédure décrite dans le présent article.

2. Un amendement au code peut être proposé au Directeur général du Bureau international du Travail par le gouvernement d'un Membre de l'Organisation, par le groupe des représentants des armateurs ou par le groupe des représentants des gens de mer nommés à la commission visée à l'article XIII. Un amendement proposé par un gouvernement doit avoir été proposé ou être appuyé par au moins cinq gouvernements de Membres ayant ratifié la convention ou par le groupe des représentants des armateurs ou des gens de mer susvisés.

3. Après avoir vérifié que la proposition d'amendement remplit les conditions établies au paragraphe 2 du présent article, le Directeur général la communique sans tarder, avec toute observation ou suggestion jugée opportune, à l'ensemble des Membres de l'Organisation en les invitant à lui faire connaître leurs observations ou suggestions sur cette proposition dans un délai de six mois ou dans le délai, compris entre trois et neuf mois, fixé par le Conseil d'administration.

4. A l'expiration du délai visé au paragraphe 3 du présent article, la proposition, accompagnée d'un résumé des observations ou suggestions faites selon le même paragraphe, est transmise à la commission pour examen dans le cadre d'une réunion. Un amendement est réputé adopté:

a) si la moitié au moins des gouvernements des Membres ayant ratifié la présente convention sont représentés à la réunion au cours de laquelle la proposition est examinée;

b) si une majorité d'au moins deux tiers des membres de la commission votent en faveur de l'amendement; et

c) si cette majorité rassemble au moins la moitié des voix des membres gouvernementaux, la moitié des voix des représentants des armateurs et la moitié des voix des représentants des gens de mer inscrits à la réunion lorsque la proposition est mise aux voix.

5. Un amendement adopté conformément aux dispositions du paragraphe 4 du présent article est présenté à la session suivante de la Conférence pour approbation. Pour être approuvé, il doit recueillir la majorité des deux tiers des voix des délégués présents. Si cette majorité n'est pas atteinte, l'amendement est renvoyé devant la commission pour que celle-ci le réexamine, si elle le souhaite.

6. Le Directeur général notifie les amendements approuvés par la Conférence à chacun des Membres dont l'instrument de ratification de la présente convention a été enregistré avant la date de cette approbation. Ces Membres sont désignés ci-après comme les «Membres ayant déjà ratifié la convention». La notification qu'ils reçoivent fait référence au présent article et un délai leur est imparti pour exprimer formellement leur désaccord. Ce délai est de deux ans à compter de la date de notification sauf si, lorsqu'elle approuve l'amendement, la Conférence fixe un délai différent qui doit être au minimum d'une année. Une copie de la notification est communiquée pour information aux autres Membres de l'Organisation.

7. Un amendement approuvé par la Conférence est réputé avoir été accepté sauf si, avant la fin du délai prescrit, plus de 40 pour cent des Membres ayant ratifié la convention et représentant 40 pour cent au moins de la jauge brute de la flotte marchande mondiale des Membres ayant ratifié la convention expriment formellement leur désaccord auprès du Directeur général.

8. Un amendement réputé avoir été accepté entre en vigueur six mois après la fin du délai fixé pour tous les Membres ayant déjà ratifié la convention, sauf ceux ayant exprimé formellement leur désaccord conformément aux dispositions du paragraphe 7 du présent article et n'ayant pas retiré ce désaccord conformément aux dispositions du paragraphe 11. Toutefois:

a) avant la fin du délai fixé, tout Membre ayant déjà ratifié la convention peut informer le Directeur général qu'il ne sera lié par l'amendement que lorsqu'il aura notifié expressément son acceptation;

b) avant la date d'entrée en vigueur de l'amendement, tout Membre ayant déjà ratifié la convention peut informer le Directeur général qu'il n'appliquera pas cet amendement pendant une période déterminée.

9. Un amendement faisant l'objet de la notification mentionnée au paragraphe 8 a) du présent article entre en vigueur pour le Membre ayant notifié son acceptation six mois après la date à laquelle il a informé le Directeur général qu'il accepte l'amen-dement ou à la date à laquelle l'amendement entre en vigueur pour la première fois, si celle-ci est postérieure.

10. La période visée au paragraphe $8 \mathrm{~b}$ ) du présent article ne devra pas dépasser une année à compter de la date d'entrée en vigueur de l'amendement ou se prolonger au-delà de la période plus longue prescrite par la Conférence au moment où elle a approuvé l'amendement. 
11. Un Membre ayant exprimé formellement son désaccord sur un amendement donné peut le retirer à tout moment. Si la notification de ce retrait parvient au Directeur général après l'entrée en vigueur dudit amendement, celui-ci entre en vigueur pour le Membre six mois après la date à laquelle ladite notification a été enregistrée.

12. Une fois qu'un amendement est entré en vigueur, la convention ne peut être ratifiée que sous sa forme modifiée.

13. Dans la mesure où un certificat de travail maritime porte sur des questions couvertes par un amendement à la convention qui est entré en vigueur:

a) un Membre ayant accepté cet amendement n'est pas tenu d'étendre le bénéfice de la convention en ce qui concerne les certificats de travail maritime délivrés à des navires battant le pavillon d'un autre Membre qui:

i) a exprimé formellement, selon le paragraphe 7 du présent article, un désaccord avec l'amendement et ne l'a pas retiré; ou

ii) a notifié, selon le paragraphe 8 a) du présent article, que son acceptation est subordonnée à une notification ultérieure expresse de sa part et n'a pas accepté l'amendement;

b) un Membre ayant accepté l'amendement étend le bénéfice de la convention en ce qui concerne les certificats délivrés à des navires battant le pavillon d'un autre Membre qui a notifié, selon le paragraphe 8 b) du présent article, qu'il n'appli-quera pas l'amendement pendant une période déterminée conformément au paragraphe $10 \mathrm{du}$ présent article.

Textes faisant foi

\section{Article XVI}

Les versions française et anglaise du texte de la présente convention font également foi.

Note explicative sur les règles et le code de la convention du travail maritime

1. La présente note ne fait pas partie de la convention du travail maritime. Elle vise seulement à en faciliter la lecture.

2. La convention se compose de trois parties distinctes mais reliées entre elles, à savoir les articles, les règles et le code.

3. Les articles et les règles énoncent les droits et principes fondamentaux ainsi que les obligations fondamentales des Membres ayant ratifié la convention. Ils ne peuvent être modifiés que par la Conférence sur le fondement de l'article 19 de la Constitution de l'Organisation internationale du Travail (voir article XIV de la convention).

4. Le code indique comment les règles doivent être appliquées. Il se compose d'une partie $\mathrm{A}$ (normes obligatoires) et d'une partie B (principes directeurs non obligatoires). Le code peut être modifié suivant la procédure simplifiée décrite à l'article XV de la convention. Etant donné qu'il contient des indications détaillées sur la manière dont les dispositions doivent être appliquées, les modifications qui lui seront éventuellement apportées ne devront pas réduire la portée générale des articles et des règles.

5. Les dispositions des règles et du code sont regroupées sous les cinq titres suivants:

Titre 1: Conditions minimales requises pour le travail des gens de mer à bord des navires

Titre 2: Conditions d'emploi

Titre 3: Logement, loisirs, alimentation et service de table

Titre 4: Protection de la santé, soins médicaux, bien-être et protection en matière de sécurité sociale

Titre 5: Conformité et mise en application des dispositions

6. Chaque titre contient des groupes de dispositions ayant trait à un droit ou à un principe (ou à une mesure de mise en application pour le titre 5), avec une numérotation correspondante. Ainsi, le premier groupe du titre 1 comprend la règle 1.1, la norme A1.1 et le principe directeur B1.1 (concernant l'âge minimum).

7. La convention a trois objectifs sous-jacents:

a) établir (dans les articles et règles) un ensemble solide de droits et de principes;

b) laisser aux Membres (grâce aux dispositions du code) une grande souplesse dans la manière dont ils mettent en oeuvre ces principes et droits;

c) veiller (via le titre 5) à ce que les principes et les droits soient correctement respectés et mis en application.

8. La souplesse d'application résulte essentiellement de deux éléments: le premier est la faculté donnée à chaque Membre, si nécessaire (article VI, paragr. 3), de donner effet aux prescriptions détaillées de la partie A du code en mettant en uvre des mesures équivalentes dans l'ensemble (telles que définies à l'article VI, paragr. 4). 
9. Le second élément de souplesse réside dans les prescriptions obligatoires d'un grand nombre des dispositions de la partie A qui sont énoncées d'une façon plus générale, ce qui laisse une plus grande latitude quant aux mesures précises devant être prises au niveau national. Dans ces cas-là, des orientations pour la mise en uvre sont données dans la partie B, non obligatoire, du code. Ainsi, les Membres ayant ratifié la convention peuvent vérifier le type de mesures qui peuvent être attendues d'eux en vertu de l'obligation générale énoncée dans la partie $\mathrm{A}$, ainsi que les mesures qui ne seraient pas nécessairement exigées. Par exemple, la norme A4.1 prescrit que tous les navires doivent permettre un accès rapide aux médicaments nécessaires pour les soins médicaux à bord des navires (paragr. 1 b)) et que «tout navire dispose d'une pharmacie de bord» (paragr. 4 a)). Pour s'acquitter en toute bonne foi de cette obligation, il ne suffit manifestement pas d'avoir une pharmacie à bord de chaque navire. Une indication plus précise de ce qui est nécessaire pour garantir que le contenu de la pharmacie sera correctement stocké, utilisé et entretenu figure dans le principe directeur B4.1.1 (paragr. 4).

10. Les Membres ayant ratifié la convention ne sont pas liés par les principes directeurs indiqués et, comme il est précisé dans le titre 5 à propos du contrôle par l'Etat du port, les inspections ne viseront que les prescriptions pertinentes (articles, règles et normes de la partie A). Toutefois, les Membres sont tenus, aux termes du paragraphe 2 de l'article VI, de dûment envisager de s'acquitter des obligations qui leur incombent au titre de la partie $\mathrm{A}$ du code de la manière indiquée dans la partie $\mathrm{B}$. Après avoir dûment étudié les principes directeurs correspondants, ils peuvent décider de prendre des dispositions différentes pour le stockage, l'utilisation et l'entretien du contenu de la pharmacie, pour prendre l'exemple déjà cité. Ceci est acceptable. Toutefois, s'ils suivent les principes directeurs de la partie B, les Membres concernés, de même que les organes du BIT chargés de contrôler l'application des conventions internationales du travail, peuvent s'assurer sans plus ample examen que les dispositions prises par les Membres montrent qu'ils se sont acquittés de manière adéquate des obligations énoncées dans la partie A.

Les règles et le code

Titre 1. Conditions minimales requises pour le travail des gens de mer à bord d'un navire

\section{Règle}

Règle 1.1 - Age minimum

Objet: assurer qu'aucune personne n'ayant pas l'âge minimum ne travaille à bord d'un navire

1. 1. Aucune personne d'un âge inférieur à l'âge minimum ne peut être employée ou engagée ou travailler à bord d'un navire.

2. L'âge minimum au moment de l'entrée en vigueur initiale de la présente convention est de 16 ans.

3. Un âge minimum supérieur est exigé dans les cas spécifiés dans le code.

\section{Norme}

Norme A1.1 - Age minimum

1. L'emploi ou l'engagement ou le travail à bord d'un navire de toute personne de moins de 16 ans est interdit.

2. Le travail de nuit par un marin de moins de 18 ans est interdit. Aux fins de la présente norme, le terme «nuit» est défini conformément à la législation et à la pratique nationales. Il couvre une période de neuf heures consécutives au moins, commençant au plus tard à minuit et se terminant au plus tôt à 5 heures du matin.

3. Une dérogation à la stricte observation de la restriction concernant le travail de nuit peut être décidée par l'autorité compétente quand:

a) la formation effective des gens de mer concernés dans le cadre de programmes et plans d'études établis pourrait en être compromise; ou

b) la nature particulière de la tâche ou un programme de formation agréé exige que les gens de mer visés par la dérogation travaillent la nuit et l'autorité décide, après consultation des organisations d'armateurs et de gens de mer intéressées, que ce travail ne portera pas préjudice à leur santé ou à leur bien-être.

4. L'emploi ou l'engagement ou le travail des gens de mer de moins de 18 ans est interdit lorsque le travail est susceptible de compromettre leur santé ou leur sécurité. Les types de travail en question seront déterminés par la législation nationale ou par l'autorité compétente, après consultation des organisations d'armateurs et de gens de mer intéressées, conformément aux normes internationales applicables.

\section{Principe directeur}

Principe directeur B1.1 - Age minimum 
1. Lorsqu'ils établissent des règlements relatifs aux conditions de travail et de vie, les Membres devraient accorder une attention particulière aux besoins des jeunes de moins de 18 ans.

Règle

Règle 1.2 - Certificat médical

Objet: assurer que tous les gens de mer sont médicalement aptes à exercer leurs fonctions en mer

1. Aucun marin ne peut travailler à bord d'un navire s'il ne produit pas un certificat médical attestant qu'il est médicalement apte à exercer ses fonctions.

2. Des exceptions ne sont possibles que dans les cas spécifiés dans le code.

\section{Norme}

Norme A1.2 - Certificat médical

1. L'autorité compétente exige qu'avant de commencer à servir à bord d'un navire les gens de mer soient en possession d'un certificat médical valide attestant qu'ils sont médicalement aptes aux fonctions qu'ils accompliront en mer.

2. Pour que les certificats médicaux rendent compte fidèlement de l'état de santé des gens de mer eu égard aux fonctions qu'ils ont à exercer, l'autorité compétente détermine, après consultation des organisations d'armateurs et de gens de mer intéressées, et compte dûment tenu des directives internationales applicables mentionnées dans la partie B du code, la nature de l'examen médical et du certificat correspondant.

3. La présente norme s'applique sans préjudice de la Convention internationale de 1978 sur les normes de formation des gens de mer, de délivrance des brevets et de veille, telle que modifiée (STCW). Un certificat médical délivré conformément aux prescriptions de la STCW est accepté par l'autorité compétente aux fins de la règle 1.2. Un certificat médical conforme en substance à ces prescriptions, dans le cas des gens de mer qui ne sont pas couverts par la STCW, est également accepté.

4. Le certificat médical est délivré par un médecin dûment qualifié ou, dans le cas d'un certificat concernant uniquement la vue, par une personne reconnue par l'autorité compétente comme étant qualifiée pour délivrer de tels certificats. Les médecins doivent disposer d'une entière indépendance professionnelle en ce qui concerne les procédures d'examen médical.

5. En cas de refus de délivrance d'un certificat ou de limitation imposée à l'ap-titude au travail en termes notamment de durée, de domaine d'activité ou de zone géographique, les gens de mer peuvent se faire examiner à nouveau par un autre médecin ou par un arbitre médical indépendants.

6. Le certificat médical indique notamment que:

a) l'ouie et la vue de l'intéressé, ainsi que la perception des couleurs s'il s'agit d'une personne devant être employée à des tâches pour lesquelles l'aptitude au travail risque d'être diminuée par le daltonisme, sont toutes satisfaisantes;

b) l'intéressé n'est atteint d'aucun problème médical qui risque d'être aggravé par le service en mer, de le rendre inapte à ce service ou de mettre en danger la santé d'autres personnes à bord.

7. A moins qu'une période plus courte ne soit prescrite en raison de la nature des fonctions que l'intéressé aura à exécuter ou en vertu de la STCW:

a) un certificat médical reste valide pendant deux ans au maximum à moins que le marin n'ait moins de 18 ans, auquel cas la durée maximale de validité sera d'un an;

b) un certificat se rapportant à la perception des couleurs reste valide pendant six ans au maximum.

8. Dans les cas d'urgence, l'autorité compétente peut autoriser un marin à travailler sans certificat médical valide jusqu'au prochain port d'escale où il pourra se faire délivrer un certificat médical par un médecin qualifié, à condition que:

a) la durée de validité de cette autorisation ne dépasse pas trois mois;

b) l'intéressé soit en possession d'un certificat médical d'une date récente périmé.

9. Si la période de validité d'un certificat expire au cours d'un voyage, le certificat reste valide jusqu'au prochain port d'escale où le marin pourra se faire délivrer un certificat médical par un médecin qualifié, à condition que cette période n'excède pas trois mois.

10. Les certificats médicaux des gens de mer travaillant à bord des navires effectuant normalement des voyages internationaux doivent au minimum être fournis en anglais.

\section{Principe directeur}

Principe directeur B1.2 - Certificat médical

Principe directeur B1.2.1 - Directives internationales 
1. L'autorité compétente, les médecins, les examinateurs, les armateurs, les représentants des gens de mer et toutes les autres personnes intéressées par la conduite des visites médicales destinées à déterminer l'aptitude physique des futurs gens de mer et des gens de mer en activité devraient suivre les Directives relatives à la conduite des examens médicaux d'aptitude précédant l'embarquement et des examens médicaux périodiques des gens de mer BIT/OMS, y compris toute version ultérieure, et toutes autres directives internationales applicables publiées par l'Organisation internationale du Travail, l'Organisation maritime internationale ou l'Organisation mondiale de la santé.

\section{Règle}

Règle 1.3 - Formation et qualifications

Objet: assurer que les gens de mer sont formés ou qualifiés pour exercer leurs fonctions à bord des navires

1. Pour travailler à bord d'un navire, un marin doit avoir suivi une formation, être titulaire d'un certificat de capacité ou être qualifié à un autre titre pour exercer ses fonctions.

2. Les gens de mer ne doivent être autorisés à travailler à bord d'un navire que s'ils ont suivi avec succès une formation à la sécurité individuelle à bord des navires.

3. Les formations et brevets conformes aux instruments ayant force obligatoire adoptés par l'Organisation maritime internationale sont considérés comme répondant aux prescriptions des paragraphes 1 et 2 de la présente règle.

4. Tout Membre qui, au moment où il ratifie la présente convention, est lié par les dispositions de la convention (no 74) sur les certificats de capacité de matelot qualifié, 1946, doit continuer à s'acquitter des obligations découlant de cet instrument, sauf si des dispositions à caractère contraignant portant sur la question ont été adoptées par l'Organisation maritime internationale et sont entrées en vigueur, ou jusqu'à ce que tel soit le cas, ou jusqu'à ce que cinq ans se soient écoulés depuis l'entrée en vigueur de la présente convention conformément au paragraphe 3 de l'article VIII, la date la plus rapprochée étant retenue.

Règle 1.4 - Recrutement et placement

Objet: assurer que les gens de mer ont accès à un système efficient et bien réglementé de recrutement et de placement des gens de mer

1. 1. Tous les gens de mer doivent pouvoir avoir accès à un système efficient, adéquat et transparent pour trouver sans frais un emploi à bord d'un navire.

2. 2. Les services de recrutement et de placement des gens de mer opérant sur le territoire d'un Membre doivent se conformer aux normes énoncées dans le code.

3. Tout Membre exige, en ce qui concerne les gens de mer qui travaillent à bord de navires battant son pavillon, que les armateurs qui utilisent des services de recrutement et de placement des gens de mer établis dans des pays ou territoires auxquels la présente convention ne s'applique pas s'assurent que ces services se conforment aux prescriptions énoncées dans le code.

\section{Norme}

Norme A1.4 - Recrutement et placement

1. Tout Membre qui a mis en place un service public de recrutement et de placement des gens de mer veille à ce que ce service soit géré dans les règles de façon à protéger et promouvoir les droits des gens de mer en matière d'emploi tels qu'ils sont énoncés dans la présente convention.

2. Lorsque des services privés de recrutement et de placement des gens de mer dont l'objet principal est le recrutement et le placement des gens de mer ou qui recrutent et placent un nombre non négligeable de gens de mer opèrent sur le territoire d'un Membre, ils ne peuvent exercer leur activité qu'en vertu d'un système normalisé de licence ou d'agrément ou d'une autre forme de réglementation. Un tel système ne peut être établi, modifié ou remplacé qu'après consultation des organisations d'armateurs et de gens de mer intéressées. En cas de doute sur la question de savoir si la présente convention s'applique à un service privé de recrutement et de placement donné, la question doit être tranchée par l'autorité compétente de chaque Membre après consultation des organisations d'armateurs et de gens de mer intéressées. Il convient de ne pas encourager une prolifération excessive de ces services privés de recrutement et de placement.

3. Les dispositions du paragraphe 2 de la présente norme s'appliquent aussi, dans la mesure où l'autorité compétente, en consultation avec les organisations d'ar-mateurs et de gens de mer intéressées, estime qu'elles sont adaptées, dans le cas des services de recrutement et de placement assurés par une organisation de gens de mer sur le territoire d'un Membre pour fournir des gens de mer qui sont ressortissants du Membre à des navires qui battent son pavillon. Les services visés par ce paragraphe sont ceux qui remplissent les conditions suivantes: 
a) le service de recrutement et de placement est géré conformément à une convention collective conclue entre cette organisation et un armateur;

b) tant l'organisation des gens de mer que l'armateur sont établis sur le territoire du Membre;

c) le Membre dispose d'une législation nationale ou d'une procédure pour autoriser ou enregistrer la convention collective qui permet l'exploitation du service de recrutement et de placement;

d) le service de recrutement et de placement est géré dans les règles et des mesures comparables à celles prévues au paragraphe 5 de la présente norme existent pour protéger et promouvoir les droits des gens de mer en matière d'emploi.

4. Rien dans la présente norme ou dans la règle 1.4 n'a pour effet:

a) d'empêcher un Membre d'assurer un service public gratuit de recrutement et de placement des gens de mer dans le cadre d'une politique visant à répondre aux besoins des gens de mer et des armateurs, que ce service fasse partie du service public de l'emploi ouvert à l'ensemble des travailleurs et des employeurs ou qu'il agisse en coordination avec ce dernier;

b) d'imposer à un Membre l'obligation d'établir sur son territoire un système de gestion des services privés de recrutement et de placement des gens de mer.

5. Tout Membre adoptant le système mentionné au paragraphe 2 de la présente norme doit au minimum, par voie de législation ou par d'autres mesures:

a) interdire aux services de recrutement et de placement des gens de mer d'avoir recours à des moyens, mécanismes ou listes pour empêcher ou dissuader les gens de mer d'obtenir un emploi pour lequel ils possèdent les qualifications requises;

b) interdire que des honoraires ou autres frais soient facturés aux gens de mer, directement ou indirectement, en tout ou en partie, pour le recrutement, le placement ou l'obtention d'un emploi, en dehors du coût que les gens de mer doivent assumer pour obtenir un certificat médical national obligatoire, le livret professionnel national et un passeport ou autre document personnel de voyage similaire, sauf le coût des visas qui doit être à la charge de l'armateur;

c) s'assurer que les services de recrutement et de placement des gens de mer opérant sur son territoire:

i) tiennent à disposition, aux fins d'inspection par l'autorité compétente, un registre à jour de tous les gens de mer recrutés ou placés par leur intermédiaire;

ii) s'assurent que, préalablement à l'engagement ou au cours du processus d'engagement, les gens de mer sont informés des droits et obligations énoncés dans leur contrat d'engagement et que les dispositions nécessaires sont prises pour que les gens de mer puissent examiner leur contrat d'engage-ment avant et après leur signature et pour qu'un exemplaire du contrat leur soit remis;

iii) vérifient que les gens de mer recrutés ou placés par leur intermédiaire possèdent les qualifications requises et détiennent les documents nécessaires pour l'emploi considéré, et que les contrats d'engagement maritime sont conformes à la législation et à toute convention collective incluse dans le contrat;

iv) s'assurent, dans la mesure où cela est réalisable, que l'armateur a les moyens d'éviter que les gens de mer ne soient abandonnés dans un port étranger;

v) examinent toute plainte concernant leurs activités et y répondent et avisent l'autorité compétente des plaintes pour lesquelles aucune solution n'a été trouvée;

vi) mettent en place un système de protection, sous la forme d'une assurance ou d'une mesure équivalente appropriée, pour indemniser les gens de mer ayant subi des pertes pécuniaires du fait que le service de recrutement et de placement ou l'armateur en vertu du contrat d'engagement maritime n'a pas rempli ses obligations à leur égard.

6. L'autorité compétente supervise et contrôle étroitement tous les services de recrutement et de placement des gens de mer opérant sur le territoire du Membre concerné. Les licences ou agréments ou autres autorisations permettant de gérer un service privé sur le territoire sont accordés ou renouvelés seulement après vérification que le service de recrutement et de placement concerné remplit les conditions prévues par la législation nationale.

7. L'autorité compétente s'assure que des mécanismes et procédures appropriés existent en vue d'enquêter, si nécessaire, au sujet des plaintes relatives aux activités des services de recrutement et de placement des gens de mer, avec le concours, lorsqu'il y a lieu, des représentants des armateurs et des gens de mer.

8. Tout Membre doit, dans la mesure du possible, informer ses ressortissants des problèmes qui peuvent résulter d'un engagement sur un navire battant le pavillon d'un Etat qui n'a pas ratifié la présente convention, tant qu'il n'est pas établi que des normes équivalentes à celles fixées par cette convention sont appliquées. Les mesures prises à cet effet par le Membre qui a ratifié la convention ne devront pas être en 
contradiction avec le principe de la libre circulation des travailleurs stipulé par les traités auxquels les deux Etats concernés peuvent être parties.

9. Tout Membre doit exiger que les armateurs de navires battant son pavillon qui utilisent des services de recrutement et de placement des gens de mer établis dans des pays ou territoires auxquels la présente convention ne s'applique pas s'assurent, dans la mesure du possible, que ces services respectent les prescriptions de la présente norme.

10. Rien dans la présente norme n'a pour effet de réduire les obligations et responsabilités des armateurs ou d'un Membre en ce qui concerne les navires battant son pavillon.

\section{Principe directeur}

Principe directeur B1.4 - Recrutement et placement

Principe directeur B1.4.1 - Directives organisationnelles et opérationnelles

1. En exécutant ses obligations en vertu du paragraphe 1 de la norme A1.4, l'autorité compétente devrait envisager de:

a) prendre les mesures nécessaires pour promouvoir une coopération efficace entre les services de recrutement et de placement des gens de mer, qu'ils soient publics ou privés;

b) prendre en compte, avec la participation des armateurs, des gens de mer et des établissements de formation concernés, les besoins du secteur maritime, aux niveaux national et international, lors de l'élaboration des programmes de formation des gens de mer qui, à bord, ont des responsabilités dans la sécurité de la navigation et la prévention de la pollution;

c) prendre des dispositions appropriées en vue de la coopération des organisations représentatives des armateurs et des gens de mer à l'organisation et au fonctionnement des services publics de recrutement et de placement des gens de mer, là où ils existent;

d) déterminer, compte dûment tenu du respect de la vie privée et de la nécessité de protéger la confidentialité, les conditions dans lesquelles les données personnelles sur les gens de mer peuvent être traitées par les services de recrutement et de placement des gens de mer, y compris la collecte, la conservation, le recoupement et la communication de ces données à des tiers;

e) disposer d'un mécanisme de collecte et d'analyse des informations pertinentes sur le marché du travail maritime, notamment sur l'offre actuelle et prévisible de gens de mer embarqués, classés par âge, sexe, grade et qualifications, ainsi que sur les besoins du secteur, la collecte de données sur l'âge ou le sexe n'étant admissible qu'à des fins statistiques ou si elles sont utilisées dans le cadre d'un programme visant à prévenir toute discrimination fondée sur l'âge ou le sexe;

f) veiller à ce que le personnel responsable de la supervision des services publics et privés de recrutement et de placement des gens de mer qui, à bord, ont des responsabilités dans la sécurité de la navigation et la prévention de la pollution soit convenablement formé, en ayant acquis notamment une expérience reconnue du service en mer, et à ce qu'il possède une connaissance appropriée du secteur maritime, y compris les instruments internationaux maritimes sur la formation, les certificats de capacité et les normes du travail;

g) prescrire des normes opérationnelles et adopter des codes de conduite et des pratiques éthiques pour les services de recrutement et de placement des gens de mer;

h) exercer un contrôle du système de licence ou d'agrément dans le cadre d'un système de normes de qualité.

2. Lors de la mise en place du système mentionné au paragraphe 2 de la norme A1.4, tout Membre devrait envisager d'exiger des services de recrutement et de placement des gens de mer établis sur son territoire qu'ils mettent au point et qu'ils maintiennent des pratiques de fonctionnement vérifiables. Ces pratiques de fonctionnement pour les services privés de recrutement et de placement des gens de mer et, dans la mesure où elles sont applicables, pour les services publics de recrutement et de placement des gens de mer devraient porter sur les points suivants:

a) les examens médicaux, les documents d'identité des gens de mer et toutes autres formalités auxquelles ceux-ci doivent satisfaire pour obtenir un emploi;

b) la tenue, dans le respect de la vie privée et de la confidentialité, de registres complets et détaillés des gens de mer couverts par leur système de recrutement et de placement, lesquels devraient au moins inclure les informations suivantes: i) les qualifications des gens de mer; ii) leurs états de service; iii) les données personnelles pertinentes pour l'emploi; iv) les données médicales pertinentes pour l'emploi;

c) la tenue à jour de listes des navires auxquels les services de recrutement et de placement fournissent des gens de mer et l'assurance qu'il existe un moyen de contacter ces services à tout moment en cas d'urgence; 
d) les procédures propres à assurer que les services de recrutement et de placement des gens de mer ou leur personnel n'exploitent pas les gens de mer lorsqu'il s'agit d'obtenir un engagement à bord de tel ou tel navire ou dans telle ou telle compagnie;

e) les procédures propres à parer aux risques d'exploitation des gens de mer pouvant résulter de la remise d'avances sur salaire ou de toute autre transaction financière conclue entre l'armateur et les gens de mer et traitée par les services de recrutement et de placement;

f) la nécessité de faire connaître clairement les frais que les gens de mer devront éventuellement prendre à leur charge lors du recrutement;

g) la nécessité de veiller à ce que les gens de mer soient informés de toutes conditions particulières applicables au travail pour lequel ils vont être engagés, ainsi que des politiques adoptées par l'armateur en ce qui concerne leur emploi;

h) les procédures établies pour traiter les cas d'incompétence ou d'indiscipline conformément aux principes d'équité, à la législation et à la pratique nationales et, le cas échéant, aux conventions collectives;

i) les procédures propres à assurer, dans la mesure où cela est réalisable, que tous les certificats et documents obligatoires présentés par les gens de mer pour obtenir un emploi sont à jour et n'ont pas été obtenus frauduleusement, et que les références professionnelles sont vérifiées;

j) les procédures propres à assurer que les demandes d'informations ou de conseils formulées par les proches des gens de mer lorsque les gens de mer sont à bord sont traitées sans délai, avec bienveillance et sans frais;

k) la vérification que les conditions de travail à bord des navires sur lesquels des gens de mer sont placés sont conformes aux conventions collectives applicables conclues entre un armateur et une organisation représentative des gens de mer, et, par principe, la mise à disposition de gens de mer aux seuls armateurs qui offrent des conditions d'emploi conformes à la législation ou aux conventions collectives applicables.

3. La coopération internationale entre les Membres et les organisations intéressées pourrait être encouragée, notamment en ce qui concerne:

a) l'échange systématique d'informations sur le secteur et le marché du travail maritimes, sur une base bilatérale, régionale et multilatérale;

b) l'échange d'informations sur la législation du travail maritime;

c) l'harmonisation des politiques, des méthodes de travail et de la législation régissant le recrutement et le placement des gens de mer;

d) l'amélioration des procédures et des conditions de recrutement et de placement des gens de mer sur le plan international;

e) la planification de la main-d'oeuvre, compte tenu de l'offre et de la demande de gens de mer et des besoins du secteur maritime.

Titre 2. Conditions d'emploi

\section{Règle}

Règle 2.1 - Contrat d'engagement maritime

Objet: assurer aux gens de mer un contrat d'engagement maritime équitable

1. Les conditions d'emploi d'un marin sont définies ou mentionnées dans un contrat rédigé en termes clairs, ayant force obligatoire, et doivent être conformes aux normes énoncées dans le code.

2. Le contrat d'engagement maritime doit être approuvé par le marin dans des conditions telles que l'intéressé a le loisir d'en examiner les clauses et conditions, de demander conseil à cet égard et de les accepter librement avant de signer.

3. Dans la mesure où la législation et la pratique du Membre le permettent, le contrat d'engagement maritime s'entend comme incluant les conventions collectives applicables.

\section{Norme}

Norme A2.1 - Contrat d'engagement maritime

1. Tout Membre adopte une législation exigeant que les navires qui battent son pavillon respectent les prescriptions suivantes:

a) à bord des navires battant son pavillon, les gens de mer doivent être en possession d'un contrat d'engagement maritime signé par le marin et l'armateur ou son représentant, ou, lorsqu'ils ne sont pas salariés, d'un document attestant l'exis-tence d'un arrangement contractuel ou assimilable, leur garantissant des conditions de travail et de vie décentes à bord ainsi que l'exige la présente convention; 
b) les gens de mer signant un contrat d'engagement maritime doivent pouvoir examiner le document en question et demander conseil avant de le signer et disposer de toute autre facilité propre à assurer qu'ils se lient librement en étant dûment informés de leurs droits et responsabilités;

c) l'armateur et le marin détiennent l'un et l'autre un original signé du contrat d'en-gagement maritime;

d) des mesures sont prises pour que les gens de mer, y compris le capitaine du navire, puissent obtenir à bord, sans difficulté, des informations précises sur les conditions de leur emploi, et pour que les fonctionnaires de l'autorité compétente, y compris dans les ports où le navire fait escale, puissent aussi accéder à ces informations, y compris la copie du contrat d'engagement maritime;

e) tout marin reçoit un document mentionnant ses états de service à bord du navire.

2. Lorsque le contrat d'engagement maritime est constitué pour tout ou partie par une convention collective, un exemplaire de cette convention est tenu à disposition à bord. Lorsque le contrat d'engagement maritime et les conventions collectives applicables ne sont pas en anglais, les documents suivants sont tenus à disposition en anglais, sauf sur les navires affectés seulement à des trajets domestiques:

a) un exemplaire d'un contrat type;

b) les parties de la convention collective qui donnent lieu à une inspection par l'Etat du port conformément aux dispositions de la règle 5.2 de la présente convention.

3. Le document mentionné au paragraphe 1 e) de la présente norme ne contient aucune appréciation de la qualité du travail du marin et aucune indication de son salaire. La législation nationale détermine la forme de ce document, les mentions qui y figurent et la manière dont elles sont consignées.

4. Tout Membre doit adopter une législation indiquant les mentions à inclure dans tous les contrats d'engagement maritime régis par le droit national. Le contrat d'engagement maritime comprend dans tous les cas les indications suivantes:

a) le nom complet du marin, sa date de naissance ou son âge, ainsi que son lieu de naissance;

b) le nom et l'adresse de l'armateur;

c) le lieu et la date de la conclusion du contrat d'engagement maritime;

d) la fonction à laquelle le marin doit être affecté;

e) le montant du salaire du marin ou la formule éventuellement utilisée pour le calculer;

f) le congé payé annuel ou la formule éventuellement utilisée pour le calculer;

g) le terme du contrat et les conditions de sa cessation, notamment:

i) si le contrat est conclu pour une durée indéterminée, les conditions dans lesquelles chaque partie pourra le dénoncer ainsi que le délai de préavis, qui ne doit pas être plus court pour l'armateur que pour le marin;

ii) si le contrat est conclu pour une durée déterminée, la date d'expiration; iii) si le contrat est conclu pour un voyage, le port de destination et le délai à l'ex-piration duquel l'engagement du marin cesse après l'arrivée à destination;

h) les prestations en matière de protection de la santé et de sécurité sociale qui doivent être assurées au marin par l'armateur;

i) le droit du marin à un rapatriement;

j) la référence à la convention collective, s'il y a lieu;

k) toutes autres mentions que la législation nationale pourrait imposer.

5. Tout Membre adopte une législation établissant les durées minimales du préavis qui est donné par les gens de mer et par les armateurs pour la cessation anticipée du contrat d'engagement maritime. Ces délais de préavis sont fixés après consultation des organisations d'armateurs et de gens de mer intéressés et ne sont pas inférieurs à sept jours.

6. Un préavis d'une durée inférieure au minimum peut être donné dans les circonstances reconnues par la législation nationale ou par les conventions collectives applicables comme justifiant la cessation du contrat d'engagement avec un préavis plus court ou sans préavis. En déterminant ces circonstances, le Membre s'assure que la nécessité pour le marin de résilier, sans pénalité, le contrat d'engagement avec un préavis plus court ou sans préavis, pour des raisons humanitaires ou pour d'autres motifs d'ur-gence, est prise en considération.

\section{Principe directeur}

Principe directeur B2.1 - Contrat d'engagement maritime

Principe directeur B2.1.1 - Etats de service

1. S'agissant des informations devant figurer dans les états de service visés au paragraphe 1 e) de la norme A2.1, tout Membre devrait veiller à ce que le document en question contienne suffisamment 
d'informations, accompagnées de leur traduction en anglais, pour faciliter l'accès à un autre emploi ou pour satisfaire aux conditions de service en mer requises à des fins d'avancement ou de promotion. Un livret de débarquement peut satisfaire aux prescriptions du paragraphe 1 e) de cette norme.

\section{Règle}

Règle 2.2 - Salaires

Objet: assurer aux gens de mer la rétribution de leurs services

1. Tous les gens de mer doivent être rétribués pour leur travail régulièrement et intégralement conformément à leur contrat d'engagement.

\section{Norme}

Norme A2.2 - Salaires

1. Tout Membre exige que les sommes dues aux gens de mer travaillant à bord des navires battant son pavillon soient versées à des intervalles n'excédant pas un mois et conformément aux dispositions des conventions collectives applicables.

2. Les gens de mer reçoivent un relevé mensuel des montants qui leur sont dus et de ceux qui leur ont été versés, sur lequel devront figurer les salaires, les paiements supplémentaires et le taux de change appliqué si les versements ont été effectués dans une monnaie ou à un taux distincts de ceux qui avaient été convenus.

3. Tout Membre exige de l'armateur qu'il prenne des mesures, telles que celles qui sont mentionnées au paragraphe 4 de la présente norme, pour donner aux gens de mer la possibilité de faire parvenir une partie ou l'intégralité de leurs rémunérations à leurs familles, aux personnes à leur charge ou à leurs ayants droit.

4. Les mesures à prendre pour assurer que les gens de mer pourront faire parvenir leurs rémunérations à leurs familles sont notamment les suivantes:

a) un système permettant aux gens de mer de demander, au moment de prendre leurs fonctions ou en cours d'emploi, qu'une partie de leurs salaires soit régulièrement versée à leurs familles, par virement bancaire ou par des moyens analogues;

b) l'obligation que ces virements soient effectués en temps voulu et directement à la personne ou aux personnes désignées par les gens de mer.

5. Tout frais retenu pour le service visé aux paragraphes 3 et 4 de la présente norme doit être d'un montant raisonnable et, sauf dispositions contraires, le taux de change appliqué devra, conformément à la législation nationale, correspondre au taux courant du marché ou au taux officiel publié et ne pas être défavorable au marin.

6. Tout Membre qui adopte des lois ou règlements régissant les salaires des gens de mer doit dûment envisager d'appliquer les principes directeurs énoncés dans la partie B du code.

\section{Principe directeur}

Principe directeur B2.2 - Salaires

Principe directeur B2.2.1 - Définitions particulières

1. Aux fins du présent principe directeur:

a) matelot qualifié désigne tout marin qui est jugé posséder la compétence professionnelle nécessaire pour remplir toute tâche dont l'exécution peut être exigée d'un matelot affecté au service du pont, autre que les tâches du personnel d'en-cadrement ou spécialisé, ou tout marin défini comme tel par la législation ou la pratique nationale ou en vertu d'une convention collective;

b) salaire ou solde de base désigne la rémunération perçue, quels qu'en soient les éléments, pour une durée normale du travail, ce qui exclut le paiement des heures supplémentaires, les primes ou gratifications, allocations, congés payés et autres émoluments complémentaires;

c) salaire forfaitaire désigne un salaire composé du salaire de base et d'autres prestations liées au salaire; le salaire forfaitaire peut inclure la rémunération de toutes les heures supplémentaires effectuées et toutes autres prestations liées au salaire, ou il peut n'inclure que certaines prestations dans le cas d'un forfait partiel;

d) durée du travail désigne le temps durant lequel les gens de mer sont tenus de travailler pour le navire;

e) heures supplémentaires désigne les heures de travail effectuées en sus de la durée normale du travail.

Principe directeur B2.2.2 - Calcul et paiement

1. Pour les gens de mer qui reçoivent une rémunération séparée pour les heures supplémentaires effectuées:

a) la durée normale du travail à la mer et au port ne devrait pas, aux fins du calcul du salaire, être supérieure

à huit heures par jour; 
b) aux fins du calcul des heures supplémentaires, la durée normale du travail par semaine, rémunérée par le salaire ou la solde de base, devrait être fixée par la législation nationale, pour autant qu'elle n'est pas fixée par des conventions collectives; elle ne devrait pas être supérieure à 48 heures; les conventions collectives peuvent prévoir un traitement différent mais non moins favorable;

c) le taux ou les taux de rémunération des heures supplémentaires, qui devraient dans tous les cas être supérieurs d'au moins 25 pour cent au taux horaire du salaire ou de la solde de base, devraient être prescrits par la législation nationale ou par convention collective, selon le cas;

d) le capitaine, ou une personne désignée par lui, devrait tenir un registre de toutes les heures supplémentaires effectuées; ce registre devrait être émargé par le marin à intervalles ne dépassant pas un mois.

2. Pour les gens de mer dont le salaire est intégralement ou partiellement forfaitaire:

a) le contrat d'engagement maritime devrait spécifier clairement, s'il y a lieu, le nombre d'heures de travail censées être effectuées par le marin pour la rémunération prévue, ainsi que toutes allocations supplémentaires qui pourraient lui être dues en sus du salaire forfaitaire et dans quels cas;

b) lorsque des heures supplémentaires sont payables pour des heures de travail effectuées en sus des heures couvertes par le salaire forfaitaire, le taux horaire devrait être supérieur d'au moins 25 pour cent au taux horaire de base correspondant à la durée normale du travail telle que définie au paragraphe 1 du présent principe directeur; le même principe devrait être appliqué aux heures supplémentaires couvertes par le salaire forfaitaire;

c) pour la partie du salaire intégralement ou partiellement forfaitaire qui correspond à la durée normale du travail, telle que définie au paragraphe 1 a) du présent principe directeur, la rémunération ne devrait pas être inférieure au salaire minimum applicable;

d) pour les gens de mer dont le salaire est partiellement forfaitaire, des registres de toutes les heures supplémentaires effectuées devraient être tenus et émargés comme prévu au paragraphe $1 \mathrm{~d}$ ) du présent principe directeur. 3. La législation nationale ou les conventions collectives pourraient prévoir que les heures supplémentaires ou le travail effectué le jour de repos hebdomadaire ou les jours fériés seront compensés par une période au moins équivalente d'exemption de service et de présence à bord ou par un congé supplémentaire en lieu et place d'une rémunération ou par toute autre compensation qu'elles pourraient prévoir.

4. La législation nationale adoptée après consultation des organisations représentatives des armateurs et des gens de mer ou, selon le cas, les conventions collectives devraient tenir compte des principes suivants:

a) le principe d'une rémunération égale pour un travail de valeur égale devrait être appliqué à tous les gens de mer travaillant sur le même navire, sans discrimination fondée sur la race, la couleur, le sexe, la religion, les opinions politiques, l'ascendance nationale ou l'origine sociale;

b) le contrat d'engagement maritime spécifiant le montant ou le taux des salaires devrait être disponible à bord; il faudrait tenir à la disposition du marin des informations sur le montant des salaires ou leurs taux en lui remettant au moins une copie signée de l'information correspondante dans une langue qu'il comprenne, ou en plaçant une copie du contrat à un endroit accessible à l'équipage, ou par tout autre moyen approprié;

c) les salaires devraient être payés dans une monnaie ayant cours légal, le cas échéant par virement bancaire, chèque bancaire ou postal ou ordre de paiement;

d) à la fin de l'engagement, toute rémunération restant due devrait être payée sans délai indu;

e) des sanctions adéquates ou d'autres mesures appropriées devraient être prises par l'autorité compétente à l'encontre de tout armateur qui retarderait indûment ou n'effectuerait pas le paiement de toute rémunération due;

f) les salaires devraient être versés directement sur le compte bancaire désigné par le marin, sauf s'il a demandé par écrit qu'il en soit autrement;

g) sous réserve des dispositions de l'alinéa $h$ ) du présent paragraphe, l'armateur ne devrait restreindre d'aucune manière la liberté du marin de disposer de son salaire;

h) les retenues sur salaires ne devraient être autorisées que si:

i) cela est expressément prévu par la législation nationale ou une convention collective applicable et le marin a été informé, de la façon que l'autorité compétente considère comme la plus appropriée, des conditions dans lesquelles ces retenues sont opérées;

ii) elles ne dépassent pas au total la limite éventuellement établie par la législation nationale, les conventions collectives ou les décisions judiciaires;

i) aucune retenue ne devrait être effectuée sur la rémunération du marin pour l'ob-tention ou la conservation d'un emploi; 
j) il devrait être interdit d'infliger aux gens de mer des amendes autres que celles autorisées par la législation nationale, les conventions collectives ou d'autres dispositions;

k) l'autorité compétente devrait être habilitée à inspecter les magasins et services disponibles à bord afin de s'assurer qu'ils pratiquent des prix justes et raisonnables dans l'intérêt des gens de mer concernés;

1) les créances des travailleurs relatives à leurs salaires et autres sommes dues au titre de leur emploi, dans la mesure où elles ne sont pas garanties conformément à la Convention internationale de 1993 sur les privilèges et hypothèques maritimes, devraient être protégées par un privilège, conformément à la convention (no 173) sur la protection des créances des travailleurs en cas d'insolvabilité de leur employeur, 1992.

5. Tout Membre devrait, après consultation des organisations représentatives des armateurs et des gens de mer, instituer des procédures pour instruire les plaintes relatives à toutes questions couvertes par le présent principe directeur.

Principe directeur B2.2.3 - Salaires minima

1. 1. Sans préjudice du principe de la libre négociation collective, tout Membre devrait établir, après consultation des organisations représentatives des armateurs et des gens de mer, des procédures de fixation des salaires minima pour les gens de mer. Les organisations représentatives des armateurs et des gens de mer devraient participer au fonctionnement de ces procédures.

2. En établissant de telles procédures et en fixant les salaires minima, il faudrait tenir dûment compte des normes internationales du travail relatives aux salaires minima ainsi que des principes suivants:

a) le niveau des salaires minima devrait tenir compte de la nature de l'emploi maritime, des effectifs des navires et de la durée normale du travail des gens de mer; b) le niveau des salaires minima devrait être ajusté à l'évolution du coût de la vie et des besoins des gens de mer.

3. L'autorité compétente devrait s'assurer:

a) au moyen d'un système de contrôle et de sanctions, que les salaires versés ne sont pas inférieurs aux taux établis;

b) que tout marin qui a été rémunéré à un taux inférieur au taux minimum peut recouvrer, par une procédure judiciaire ou autre, accélérée et peu onéreuse, la somme qui lui reste due.

Principe directeur B2.2.4 - Montant mensuel minimum du salaire ou de la solde de base des matelots qualifiés

1. Le salaire ou la solde de base pour un mois civil de service d'un matelot qualifié ne devrait pas être inférieur au montant établi périodiquement par la Commission paritaire maritime ou par un autre organe autorisé à le faire par le Conseil d'adminis-tration du Bureau international du Travail. Sur décision du Conseil d'administration, le Directeur général notifiera toute révision du montant ainsi établi aux Membres de l'Organisation.

2. Rien dans le présent principe directeur ne devrait être interprété comme affectant les accords entre les armateurs, ou leurs organisations, et les organisations de gens de mer en ce qui concerne la réglementation des conditions minimales d'emploi, sous réserve que ces conditions soient reconnues par l'autorité compétente.

\section{Règle}

Règle 2.3 - Durée du travail ou du repos

Objet: assurer aux gens de mer une durée de travail ou de repos réglementée

1. Tout Membre veille à ce que la durée du travail ou du repos des gens de mer soit réglementée.

2. Tout Membre fixe un nombre maximal d'heures de travail ou un nombre minimal d'heures de repos sur une période donnée conformément aux dispositions du code.

\section{Norme}

Norme A2.3 - Durée du travail ou du repos

1. Aux fins de la présente norme:

a) heures de travail désigne le temps durant lequel le marin est tenu d'effectuer un travail pour le navire;

b) heures de repos désigne le temps qui n'est pas compris dans la durée du travail; cette expression n'inclut pas les interruptions de courte durée.

2. Dans les limites indiquées aux paragraphes 5 à 8 de la présente norme, tout Membre fixe soit le nombre maximal d'heures de travail qui ne doit pas être dépassé durant une période donnée, soit le nombre minimal d'heures de repos qui doit être accordé durant une période donnée. 
3. Tout Membre reconnait que la norme de durée du travail pour les gens de mer, comme pour les autres travailleurs, est de huit heures, avec un jour de repos par semaine, plus le repos correspondant aux jours fériés. Cependant, rien n'empêche un Membre d'adopter des dispositions visant à autoriser ou à enregistrer une convention collective qui fixe les horaires normaux de travail des gens de mer sur une base qui ne soit pas moins favorable que ladite norme. 4. Pour définir les normes nationales, tout Membre prend en compte les dangers qu'entraîne une fatigue excessive des gens de mer, notamment de ceux dont les tâches ont une incidence sur la sécurité de la navigation et sur la sûreté et la sécurité de l'exploitation du navire.

5. Les limites des heures de travail ou de repos sont établies comme suit:

a) le nombre maximal d'heures de travail ne doit pas dépasser:

i) 14 heures par période de 24 heures;

ii) 72 heures par période de sept jours;

ou

b) le nombre minimal d'heures de repos ne doit pas être inférieur à:

i) 10 heures par période de 24 heures;

ii) 77 heures par période de sept jours.

6. Les heures de repos ne peuvent être scindées en plus de deux périodes, dont l'une d'une durée d'au moins six heures, et l'intervalle entre deux périodes consécutives de repos ne doit pas dépasser 14 heures.

7. Les rassemblements, les exercices d'incendie et d'évacuation et les exercices prescrits par la législation nationale et par les instruments internationaux doivent se dérouler de manière à éviter le plus possible de perturber les périodes de repos et à ne pas provoquer de fatigue.

8. Lorsqu'un marin est sur appel, par exemple lorsqu'un local de machines est sans présence humaine, il bénéficie d'une période de repos compensatoire adéquate si la durée normale de son repos est perturbée par des appels.

9. S'il n'existe ni convention collective ni sentence arbitrale ou si l'autorité compétente décide que les dispositions de la convention collective ou de la sentence arbitrale sont insuffisantes en ce qui concerne les paragraphes 7 et 8 de la présente norme, l'autorité compétente fixe les dispositions visant à assurer aux gens de mer un repos suffisant.

10. Tout Membre exige que soit affiché à un endroit facilement accessible un tableau précisant l'organisation du travail à bord, qui doit indiquer pour chaque fonction au moins:

a) le programme du service à la mer et au port;

b) le nombre maximal d'heures de travail ou le nombre minimal d'heures de repos prescrit par la législation nationale ou les conventions collectives applicables.

11. Le tableau visé au paragraphe 10 de la présente norme est établi selon un modèle normalisé dans la ou les langues de travail du navire ainsi qu'en anglais.

12. Tout Membre exige que des registres des heures quotidiennes de travail ou de repos des gens de mer soient tenus pour qu'il soit possible de veiller au respect des paragraphes 5 à 11 de la présente norme. Ces registres suivent un modèle normalisé établi par l'autorité compétente compte tenu des directives disponibles de l'Organisa-tion internationale du Travail ou tout modèle normalisé établi par l'Organisation. Ils sont dans les langues indiquées au paragraphe 11 de la présente norme. Le marin reçoit un exemplaire des inscriptions aux registres le concernant, qui doit être émargé par le capitaine, ou par une personne autorisée par ce dernier, ainsi que par le marin.

13. Rien dans les paragraphes 5 et 6 de la présente norme n'empêche un Membre d'adopter une législation nationale ou une procédure permettant à l'autorité compétente d'autoriser ou d'enregistrer des conventions collectives prévoyant des dérogations aux limites fixées. Ces dérogations doivent, dans la mesure du possible, être conformes aux dispositions de la présente norme mais peuvent tenir compte de périodes de congé plus fréquentes ou plus longues, ou de l'octroi de congés compensatoires aux gens de mer de quart ou aux gens de mer travaillant à bord de navires affectés à des voyages de courte durée.

14. Rien dans la présente norme n'affecte le droit du capitaine d'un navire d'exiger d'un marin les heures de travail nécessaires pour assurer la sécurité immédiate du navire, des personnes à bord ou de la cargaison ou pour porter secours à d'autres navires ou aux personnes en détresse en mer. Le cas échéant, le capitaine pourra suspendre les horaires normaux de travail ou de repos et exiger qu'un marin accomplisse les heures de travail nécessaires jusqu'au retour à une situation normale. Dès que cela est réalisable après le retour à une situation normale, le capitaine doit faire en sorte que tout marin ayant effectué un travail alors qu'il était en période de repos selon l'ho-raire normal bénéficie d'une période de repos adéquate. 


\section{Principe directeur}

Principe directeur B2.3 - Durée du travail ou du repos

Principe directeur B2.3.1 - Jeunes gens de mer

1. En mer comme au port, les dispositions ci-après devraient s'appliquer à tous les jeunes gens de mer de moins de 18 ans:

a) l'horaire de travail ne devrait pas excéder huit heures par jour ni 40 heures par semaine et les intéressés ne devraient effectuer d'heures supplémentaires que lorsque cela est inévitable pour des raisons de sécurité;

b) une pause suffisante devrait être accordée pour chacun des repas et une pause d'au moins une heure devrait être assurée pour prendre le repas principal; c) un repos de 15 minutes intervenant aussitôt que possible après la fin d'une période de travail de deux heures devrait être assuré.

2. A titre exceptionnel, les dispositions du paragraphe 1 du présent principe directeur pourront ne pas être appliquées lorsque:

a) il n'est pas possible de les concilier avec le service de quart des jeunes gens de mer à la passerelle, aux machines ou au service général ou lorsque le travail organisé par équipe ne le permet pas;

b) la formation effective des jeunes gens de mer, selon des programmes et plans d'études établis, pourrait en être compromise.

3. De telles exceptions devraient être enregistrées, avec indication des motifs, et signées par le capitaine.

4. Le paragraphe 1 du présent principe directeur ne dispense pas les jeunes gens de mer de l'obligation générale, faite à l'ensemble des gens de mer, de travailler dans toute situation d'urgence, conformément aux dispositions du paragraphe 14 de la norme A2.3.

\section{Règle}

Règle 2.4 - Droit à un congé

Objet: assurer aux gens de mer un congé approprié

1. 1. Tout Membre exige que les gens de mer employés sur des navires battant son pavillon aient droit à un congé annuel rémunéré dans les conditions voulues, conformément aux dispositions du code.

2. Des permissions à terre sont accordées aux gens de mer dans un souci de santé et de bien-être, pour autant qu'elles soient compatibles avec les exigences pratiques de leur fonction.

\section{Norme}

Norme A2.4 - Droit à un congé

1. Tout Membre adopte une législation qui détermine les normes minimales de congé annuel applicables aux gens de mer engagés sur des navires battant son pavillon, en tenant dûment compte des besoins particuliers des gens de mer en matière de congé.

2. Sous réserve des dispositions de toute convention collective ou législation prévoyant un mode de calcul approprié tenant compte des besoins particuliers des gens de mer à cet égard, les congés payés annuels sont calculés sur la base d'un minimum de 2,5 jours civils par mois d'emploi. Le mode de calcul de la période de service est fixé par l'autorité compétente ou l'organisme approprié dans chaque pays. Les absences au travail justifiées ne sont pas comptées comme congé annuel.

3. Tout accord portant sur la renonciation au droit au congé payé annuel minimum défini dans la présente norme, sauf dans les cas prévus par l'autorité compétente, est interdit.

\section{Principe directeur}

Principe directeur B2.4 - Droit à un congé

Principe directeur B2.4.1 - Calcul des droits

1. Dans les conditions déterminées par l'autorité compétente ou par l'organisme approprié dans chaque pays, toute période de service effectuée en dehors du contrat d'engagement maritime devrait être comptée dans la période de service.

2. Dans les conditions déterminées par l'autorité compétente ou fixées dans une convention collective applicable, les absences au travail pour participer à un cours agrée de formation professionnelle maritime ou pour des motifs tels qu'une maladie ou un accident, ou pour cause de maternité, devraient être comptées dans la période de service.

3. Le niveau de rémunération pendant le congé annuel devrait être celui de la rémunération normale du marin telle qu'établie par la législation nationale ou le contrat d'engagement maritime applicable. Dans le cas des gens de mer employés pour des périodes de moins d'une année ou en cas de cessation de la relation de travail, la rémunération du congé devrait être calculée au prorata. 
4. Ne devraient pas être comptés dans le congé payé annuel:

a) les jours fériés officiels et coutumiers reconnus comme tels dans l'Etat du pa-villon, qu'ils se situent ou non dans la période de congé payé annuel;

b) les périodes d'incapacité de travail résultant de maladies ou d'accidents, ou pour cause de maternité, dans les conditions déterminées par l'autorité compétente ou par l'organisme approprié dans chaque pays;

c) les permissions à terre temporaires accordées aux gens de mer pendant le contrat d'engagement;

d) les congés compensatoires de toute nature, dans les conditions déterminées par l'autorité compétente ou par l'organisme approprié dans chaque pays.

Principe directeur B2.4.2 - Prise du congé annuel

1. L'époque à laquelle le congé sera pris devrait être déterminée par l'armateur après consultation et, dans la mesure du possible, avec l'accord des gens de mer intéressés ou de leurs représentants, à moins qu'elle ne soit fixée par voie réglementaire, par convention collective, par sentence arbitrale ou de toute autre manière conforme à la pratique nationale.

2. Les gens de mer devraient en principe avoir le droit de prendre leur congé annuel à l'endroit où ils ont des attaches effectives, c'est-à-dire en général au lieu vers lequel ils ont le droit d'être rapatriés. Les gens de mer ne devraient pas être tenus, sans leur consentement, de prendre le congé annuel qui leur est dû à un endroit autre, sauf en application des dispositions du contrat d'engagement maritime ou de la législation nationale.

3. Les gens de mer qui sont obligés de prendre leur congé annuel alors qu'ils se trouvent à un endroit autre que le lieu autorisé au paragraphe 2 du présent principe directeur devraient avoir droit au transport gratuit jusqu'au lieu le plus proche de leur domicile, qu'il s'agisse du lieu d'engagement ou du lieu de recrutement; leurs frais d'entretien et les autres frais en rapport direct avec ce voyage devraient être à la charge de l'armateur, et le temps de voyage ne devrait pas être déduit du congé payé annuel qui leur est dû.

4. Les gens de mer en congé annuel ne devraient être rappelés que dans les cas d'extrême urgence et avec leur accord.

Principe directeur B2.4.3 - Fractionnement et cumul

1. Le fractionnement du congé payé annuel ou le cumul du congé acquis au cours d'une année avec un congé ultérieur peut être autorisé par l'autorité compétente ou par l'organisme approprié dans chaque pays.

2. Sous réserve des dispositions du paragraphe 1 du présent principe directeur, et à moins qu'il n'en soit convenu autrement par un accord liant l'armateur et les gens de mer intéressés, le congé payé annuel recommandé dans le présent principe directeur devrait consister en une période ininterrompue.

Principe directeur B2.4.4 - Jeunes gens de mer

1. Des mesures particulières devraient être envisagées pour tout marin de moins de 18 ans qui a servi pendant six mois, ou toute autre durée inférieure en application d'une convention collective ou d'un contrat d'engagement maritime, sans congé à bord d'un navire allant à l'étranger, qui n'est pas retourné dans le pays où il a son domicile durant cette période et n'y retournera pas durant les trois mois de voyage suivants. Ces mesures pourraient consister à lui donner le droit d'être rapatrié, sans frais pour lui-même, au lieu de son engagement d'origine dans le pays de son domicile afin qu'il puisse prendre les congés accumulés pendant le voyage.

\section{Règle}

Règle 2.5 - Rapatriement

Objet: assurer aux gens de mer la possibilité de rentrer chez eux

1. Les gens de mer ont le droit d'être rapatriés sans frais pour eux-mêmes dans les cas et dans les conditions spécifiés dans le code.

2. Tout Membre exige des navires battant son pavillon qu'ils fournissent une garantie financière en vue d'assurer que les gens de mer sont dûment rapatriés, conformément au code.

\section{Norme}

Norme A2.5 - Rapatriement

1. Tout Membre veille à ce que les gens de mer embarqués sur des navires battant son pavillon aient le droit d'être rapatriés dans les cas suivants:

a) lorsque le contrat d'engagement maritime expire alors que les intéressés se trouvent à l'étranger; 
b) lorsque le contrat d'engagement maritime est dénoncé: i) par l'armateur; ou ii) par le marin pour des raisons justifiées;

c) lorsque le marin n'est plus en mesure d'exercer les fonctions prévues par le contrat d'engagement maritime ou qu'il n'est pas possible de lui demander de les exercer compte tenu de circonstances particulières.

2. Tout Membre veille à ce que des dispositions appropriées soient prévues dans sa législation ou d'autres mesures ou dans les conventions collectives, prescrivant:

a) les cas dans lesquels les gens de mer ont le droit d'être rapatriés, conformément au paragraphe 1 b) et c) de la présente norme;

b) la durée maximale des périodes d'embarquement au terme desquelles les gens de mer ont droit au rapatriement; ces périodes doivent être inférieures à douze mois;

c) le détail des droits devant être octroyés par l'armateur en matière de rapatriement, y compris les destinations du rapatriement, le mode de transport, les dépenses devant être prises en charge et autres dispositions qu'il lui incombe de prendre.

3. Tout Membre doit interdire à l'armateur d'exiger du marin, au début de son emploi, une avance en vue de couvrir les frais de son rapatriement et, également, de recouvrer auprès du marin les frais de rapatriement sur son salaire ou ses autres droits, sauf si l'intéressé a été reconnu, conformément à la législation nationale, à d'autres dispositions ou aux conventions collectives applicables, coupable d'un manquement grave aux obligations de son emploi.

4. La législation nationale ne doit pas faire obstacle au droit de l'armateur de recouvrer le coût du rapatriement au titre d'arrangements contractuels avec des tiers.

5. Si un armateur omet de prendre des dispositions pour le rapatriement d'un marin qui y a droit ou d'en assumer les frais:

a) l'autorité compétente de l'Etat du pavillon organise le rapatriement du marin; si elle omet de le faire, l'Etat à partir du territoire duquel le marin doit être rapatrié ou l'Etat dont il est ressortissant peuvent organiser le rapatriement et en recouvrer les frais auprès de l'Etat du pavillon;

b) l'Etat du pavillon pourra recouvrer auprès de l'armateur les frais encourus pour le rapatriement du marin; c) les frais de rapatriement ne doivent en aucun cas être à la charge du marin, sauf dans les conditions prévues au paragraphe 3 de la présente norme.

6. En tenant compte des instruments internationaux applicables, y compris la Convention internationale de 1999 sur la saisie conservatoire des navires, un Membre qui a payé le coût du rapatriement conformément aux dispositions du code peut immobiliser les navires de l'armateur concerné, ou demander leur immobilisation, jusqu'à ce que le remboursement soit effectué conformément aux dispositions du paragraphe 5 de la présente norme.

7. Tout Membre facilite le rapatriement des gens de mer qui servent sur des na-vires faisant escale dans ses ports ou traversant ses eaux territoriales ou intérieures, ainsi que leur remplacement à bord.

8. En particulier, un Membre ne doit pas refuser à un marin le droit d'être rapatrié du fait de la situation financière d'un armateur ou au motif que celui-ci est dans l'impossibilité ou refuse de remplacer l'intéressé.

9. Tout Membre exige que, sur les navires battant son pavillon, une copie des dispositions nationales applicables au rapatriement soit détenue et mise à la disposition des gens de mer, dans la langue qui convient.

\section{Principe directeur}

Principe directeur B2.5 - Rapatriement

Principe directeur B2.5.1 - Conditions des droits au rapatriement

1. Tout marin devrait avoir le droit d'être rapatrié:

a) dans le cas prévu au paragraphe 1 a) de la norme A2.5, à la fin de la période de préavis donné conformément aux dispositions du contrat d'engagement maritime;

b) dans les cas prévus au paragraphe 1 b) et c) de la norme A2.5:

i) en cas de maladie ou d'accident ou pour une autre raison d'ordre médical qui exige le rapatriement du marin quand il est reconnu médicalement en< état de voyager;

ii) en cas de naufrage;

iii) quand l'armateur n'est plus en mesure de remplir ses obligations légales ou contractuelles d'employeur vis-à-vis du marin pour cause d'insolvabilité, de vente du navire, de changement d'immatriculation du navire, ou pour toute autre raison analogue; 
iv) quand un navire fait route vers une zone de guerre, telle que définie par la législation nationale ou le contrat d'engagement maritime, où le marin n'accepte pas de se rendre;

v) en cas de cessation ou de suspension de l'emploi du marin conformément à une sentence arbitrale ou à une convention collective, ou en cas de cessation de l'emploi pour toute autre raison similaire.

2. Pour fixer les durées maximales des périodes d'embarquement au terme desquelles le marin a droit au rapatriement, conformément au présent code, il faudrait tenir compte des facteurs qui affectent le milieu de travail du marin. Tout Membre devrait, dans toute la mesure possible, s'efforcer de réduire ces durées en fonction des changements et évolutions de la technologie et pourrait s'inspirer des recommandations de la Commission paritaire maritime en la matière.

3. En application de la norme A2.5, les frais à la charge de l'armateur en cas de rapatriement devraient inclure au moins:

a) le voyage jusqu'à la destination choisie pour le rapatriement, conformément au paragraphe 6 du présent principe directeur;

b) le logement et la nourriture du marin depuis le moment où il quitte le navire jusqu'à son arrivée à la destination de rapatriement;

c) la rémunération et les indemnités depuis le moment où le marin quitte le navire jusqu'à son arrivée à la destination de rapatriement si cela est prévu par la législation nationale ou par les conventions collectives;

d) le transport de 30 kilogrammes de bagages personnels du marin jusqu'à la destination de rapatriement;

e) le traitement médical, si nécessaire, en attendant que l'état de santé du marin lui permette de voyager jusqu'à sa destination de rapatriement.

4. Le temps passé dans l'attente du rapatriement et la durée du voyage ne devraient pas être déduits des congés payés que le marin a acquis.

5. L'armateur devrait continuer de supporter les frais de rapatriement jusqu'à ce que le marin soit débarqué à une destination fixée conformément au présent code, ou jusqu'à ce qu'il obtienne un emploi convenable à bord d'un navire se rendant à l'une de ces destinations.

6. Tout Membre devrait prévoir que l'armateur aura la responsabilité d'organi-ser le rapatriement par des moyens appropriés et rapides. Le transport aérien devrait être le mode normal de transport. Le Membre devrait prescrire les destinations vers lesquelles les gens de mer peuvent être rapatriés. Ces destinations devraient comprendre les pays avec lesquels les gens de mer seront réputés avoir des attaches effectives, $\mathrm{y}$ compris:

a) le lieu où le marin a accepté de s'engager;

b) le lieu stipulé par convention collective;

c) le pays de résidence du marin;

d) tout autre lieu convenu entre les parties au moment de l'engagement.

7. Le marin devrait avoir le droit de choisir, parmi les destinations prescrites, le lieu vers lequel il doit être rapatrié.

8. Le droit au rapatriement peut expirer si le marin intéressé ne le revendique pas dans un délai raisonnable défini par la législation nationale ou les conventions collectives.

Principe directeur B2.5.2 - Mise en uvre par les Membres

1. Toute l'assistance pratique possible devrait être apportée au marin resté dans un port étranger en attendant son rapatriement et, lorsqu'il tarde à être rapatrié, l'autorité compétente du port étranger devrait veiller à ce que le représentant consulaire ou le représentant local de l'Etat du pavillon et de l'Etat dont le marin est ressortissant ou de l'Etat où il réside en soient informés immédiatement.

2. Tout Membre devrait en particulier s'assurer que des arrangements satisfaisants existent:

a) pour que tout marin employé sur un navire battant pavillon d'un pays étranger soit rapatrié lorsqu'il est débarqué dans un port étranger pour une cause dont il n'est pas responsable:

i) soit vers le port d'engagement;

ii) soit vers un port de l'Etat dont il est ressortissant ou de l'Etat où il réside, selon le cas;

iii) soit vers tout autre port fixé par accord entre l'intéressé et le capitaine ou l'armateur, avec l'approbation de l'autorité compétente ou sous réserve d'autres garanties appropriées;

b) pour que tout marin employé sur un navire battant pavillon d'un pays étranger reçoive des soins médicaux et des prestations d'entretien lorsqu'il est débarqué dans un port étranger en raison d'une maladie ou d'un accident survenus, sans faute intentionnelle de sa part, au service du navire.

3. S'il apparaît qu'après avoir servi sur un navire pendant au moins quatre mois au cours de son premier voyage à l'étranger un marin de moins de 18 ans n'est pas apte à la vie en mer, il devrait avoir la possibilité 
d'être rapatrié, sans frais pour lui-même, du premier port de relâche qui s'y prête dans lequel se trouvent des services consulaires de l'Etat du pavillon du navire ou de l'Etat dont le jeune marin est ressortissant ou de l'Etat où il réside. Le rapatriement effectué dans les conditions ci-dessus ainsi que ses raisons devraient être notifiés aux autorités qui ont délivré le document ayant permis au jeune marin d'embarquer.

\section{Règle}

Règle 2.6 - Indemnisation des gens de mer en cas de perte du navire ou de naufrage

Objet: assurer que les gens de mer seront indemnisés en cas de perte du navire ou de naufrage

1. Les gens de mer ont droit à une indemnisation adéquate en cas de lésion, perte ou chômage découlant de la perte du navire ou du naufrage.

\section{Norme}

Norme A2.6 - Indemnisation des gens de mer en cas de perte du navire ou de naufrage

1. Tout Membre prend des dispositions pour que, en cas de perte du navire ou de naufrage, l'armateur paie à chaque marin à bord une indemnité pour faire face au chômage résultant de la perte ou du naufrage.

2. Les dispositions du paragraphe 1 de la présente norme sont sans préjudice des autres droits que les gens de mer peuvent avoir en vertu de la législation nationale du Membre concerné en cas de pertes ou de lésions découlant de la perte du navire ou du naufrage.

\section{Principe directeur}

Principe directeur B2.6 - Indemnisation des gens de mer en cas de perte du navire ou de naufrage

Principe directeur B2.6.1 - Calcul de l'indemnité de chômage

1. L'indemnité due pour le chômage résultant de la perte du navire ou du naufrage devrait être payée pour tous les jours de la période effective de chômage du marin au taux du salaire payable en vertu du contrat d'engagement, mais le montant total de l'indemnité payable à chaque marin pourra être limité à deux mois de salaire.

2. Tout Membre devrait veiller à ce que les gens de mer puissent avoir recours, pour le recouvrement de ces indemnités, aux mêmes procédures légales que pour le recouvrement des arriérés de salaires gagnés pendant le service.

\section{Règle}

Règle 2.7 - Effectifs

Objet: faire en sorte que les gens de mer travaillent à bord de navires dotés d'effectifs suffisants pour assurer la sécurité, l'efficience et la sûreté de l'exploitation des navires

1. Tout Membre exige que tous les navires battant son pavillon soient dotés d'un nombre suffisant de gens de mer employés à bord pour assurer la sécurité et l'ef-ficience de l'exploitation du navire, l'attention nécessaire étant accordée à la sûreté, quelles que soient les circonstances, compte tenu du souci d'éviter une trop grande fatigue aux gens de mer ainsi que de la nature et des conditions particulières du voyage.

\section{Norme}

Norme A2.7 - Effectifs

1. Tout Membre exige que tous les navires battant son pavillon aient à bord des effectifs suffisants pour assurer la sécurité et l'efficience de l'exploitation des navires, l'attention nécessaire étant accordée à la sûreté. Tout navire doit avoir à bord un équipage suffisant, en nombre et en qualité, pour assurer la sécurité et la sûreté du navire et de son personnel, quelles que soient les conditions d'exploitation, conformément au document spécifiant les effectifs minima de sécurité ou à tout autre document équivalent établi par l'autorité compétente, et pour satisfaire aux normes de la présente convention.

2. Pour déterminer, approuver ou réviser les effectifs d'un navire, l'autorité compétente tient compte de la nécessité d'éviter ou de restreindre une durée du travail excessive afin d'assurer un repos suffisant et de limiter la fatigue, ainsi que des principes énoncés à ce sujet dans les instruments internationaux applicables, notamment ceux de l'Organisation maritime internationale.

3. Lorsqu'elle détermine les effectifs, l'autorité compétente tient compte de toutes les prescriptions de la règle 3.2 et de la norme A3.2 concernant l'alimentation et le service de table.

\section{Principe directeur}

Principe directeur B2.7 - Effectifs 
Principe directeur B2.7.1 - Règlement des différends

1. Tout Membre devrait instituer ou vérifier qu'il existe un mécanisme efficace pour instruire et régler les plaintes ou différends relatifs aux effectifs d'un navire.

2. Des représentants des organisations d'armateurs et de gens de mer devraient participer, avec ou sans d'autres personnes ou autorités, au fonctionnement de ce mécanisme.

\section{Règle}

Règle 2.8 - Développement des carrières et des aptitudes professionnelles et possibilités d'emploi des gens de mer<

Objet: promouvoir le développement des carrières et des aptitudes professionnelles ainsi que les possibilités d'emploi des gens de mer

1. Tout Membre doit avoir des politiques nationales visant à promouvoir l'em-ploi dans le secteur maritime et à encourager l'organisation des carrières et le développement des aptitudes professionnelles ainsi que

l'amélioration des possibilités d'emploi des gens de mer domiciliés sur son territoire.

\section{Norme}

Norme A2.8 - Développement des carrières et des aptitudes professionnelles et possibilités d'emploi des gens de mer

1. Tout Membre doit avoir des politiques nationales propres à encourager le développement des carrières et des aptitudes professionnelles ainsi que les possibilités d'emploi des gens de mer, afin que le secteur maritime soit pourvu d'une main-d'oeuvre stable et compétente.

2. Les politiques visées au paragraphe 1 de la présente norme ont pour but d'aider les gens de mer à renforcer leurs compétences, leurs qualifications et leurs possibilités d'emploi.

3. Tout Membre, après consultation des organisations d'armateurs et de gens de mer intéressées, fixe des objectifs clairs en matière d'orientation, d'éducation et de formation professionnelles des gens de mer dont les fonctions à bord du navire ont essentiellement trait à la sécurité de l'exploitation et de la navigation du navire, y compris en matière de formation continue.

\section{Principe directeur}

Principe directeur B2.8 - Développement des carrières et des aptitudes professionnelles et possibilités d'emploi des gens de mer

Principe directeur B2.8.1 - Mesures tendant à promouvoir le développement des carrières et des aptitudes professionnelles ainsi que les possibilités d'emploi des gens de mer

1. Les mesures à prendre pour atteindre les objectifs énoncés dans la norme A2.8 pourraient notamment être les suivantes:

a) des accords sur le développement des carrières et la formation conclus avec un armateur ou une organisation d'armateurs;

b) des dispositions visant à promouvoir l'emploi grâce à l'établissement et à la tenue de registres ou de listes, par catégorie, de gens de mer qualifiés;

c) la promotion de possibilités, à bord et à terre, de perfectionnement professionnel des gens de mer afin de développer leurs aptitudes professionnelles et de les doter de compétences transférables, en vue de leur permettre de trouver un travail décent et de le garder, d'améliorer les perspectives d'emploi de chacun et de s'adapter aux évolutions de la technologie et des conditions du marché du travail dans le secteur maritime.

Principe directeur B2.8.2 - Registre des gens de mer

1. Lorsque des registres ou des listes régissent l'emploi des gens de mer, ces registres et ces listes devraient comprendre toutes les catégories professionnelles de gens de mer selon des modalités déterminées par la législation ou la pratique nationales ou les conventions collectives.

2. Les gens de mer inscrits sur un tel registre ou une telle liste devraient avoir priorité d'engagement pour la navigation.

3. Les gens de mer inscrits sur un tel registre ou une telle liste devraient se tenir prêts à travailler selon des modalités que la législation ou la pratique nationales ou les conventions collectives détermineront.

4. Dans la mesure où la législation nationale le permet, l'effectif des registres et des listes des gens de mer devrait être révisé périodiquement afin de le fixer à un niveau correspondant aux besoins du secteur maritime. 
5. Lorsqu'une réduction de l'effectif d'un tel registre ou d'une telle liste devient nécessaire, toutes mesures utiles devraient être prises en vue d'en prévenir ou d'en atténuer les effets préjudiciables aux gens de mer, compte tenu de la situation économique et sociale du pays.

Titre 3. Logement, loisirs, alimentation et service de table

\section{Règle}

Règle 3.1 - Logement et loisirs

Objet: assurer que les gens de mer disposent à bord d'un logement et de lieux de loisirs décents

1. Tout Membre veille à ce que les navires battant son pavillon fournissent et entretiennent pour les gens de mer travaillant et vivant à bord un logement et des lieux de loisirs décents afin de promouvoir leur santé et leur bien-être.

2. Les prescriptions du code mettant en uvre la présente règle qui ont trait à la construction et à l'équipement des navires ne s'appliquent qu'aux navires construits à la date ou après la date d'entrée en vigueur de la présente convention pour le Membre concerné. Pour les navires construits avant cette date, les prescriptions relatives à la construction et à l'équipement des navires énoncées dans la convention (no 92) sur le logement des équipages (révisée), 1949, et la convention (no 133) sur le logement des équipages (dispositions complémentaires), 1970, continueront à s'appliquer, dans la mesure où elles étaient applicables avant cette date en vertu de la législation ou de la pratique du Membre concerné. Un navire est réputé avoir été construit à la date à laquelle sa quille a été posée ou lorsque sa construction se trouve à un stade équivalent.

3. Sauf disposition contraire expresse, toute prescription résultant d'un amen-dement au code concernant le logement des gens de mer et les lieux de loisirs ne s'ap-pliquera qu'aux navires construits à la date ou après la date à laquelle l'amendement prendra effet pour le Membre concerné.

\section{Norme}

Norme A3.1 - Logement et loisirs

1. Tout Membre adopte une législation exigeant que les navires battant son pavillon:

a) respectent les normes minimales nécessaires pour garantir que les logements mis à la disposition des gens de mer travaillant ou vivant à bord soient sûrs, décents et conformes aux dispositions pertinentes de la présente norme;

b) soient soumis à des inspections visant à assurer le respect initial et permanent de ces normes.

2. Pour l'élaboration et l'application de la législation relative à la présente norme, l'autorité compétente, après consultation des organisations d'armateurs et de gens de mer intéressées:

a) tient compte de la règle 4.3 et des dispositions correspondantes du code qui concernent la protection de la santé et de la sécurité ainsi que la prévention des accidents à la lumière des besoins spécifiques des gens de mer qui vivent et travaillent à bord des navires;

b) envisage dûment de suivre les principes directeurs énoncés dans la partie B du code.

3. Les inspections prescrites par la règle 5.1.4 ont lieu: a) lors de la première immatriculation du navire ou lors d'une nouvelle immatriculation; b) en cas de modification substantielle du logement des gens de mer à bord du navire.

4. L'autorité compétente veille avec un soin particulier à l'application des prescriptions de la présente convention concernant:

a) la taille des cabines et autres espaces de logement;

b) le chauffage et la ventilation;

c) le bruit et les vibrations ainsi que les autres facteurs ambiants;

d) les installations sanitaires;

e) l'éclairage;

f) l'infirmerie.

5. L'autorité compétente de tout Membre veille à ce que les navires battant le pavillon de ce Membre observent, en ce qui concerne les installations de logement et les lieux de loisirs à bord, les normes minimales qui sont prévues aux paragraphes 6 à 17 de la présente norme.

6. En ce qui concerne les prescriptions générales relatives aux logements: a) dans tous les locaux destinés au logement des gens de mer, la hauteur de l'espace libre doit être suffisante; elle ne doit pas être inférieure à 203 centimètres dans les locaux destinés au logement des gens de mer afin d'assurer une entière aisance de mouvement; l'autorité compétente peut autoriser une réduction, dans certaines limites, de la hauteur de l'espace libre dans tout ou partie de l'espace de ces locaux si elle juge que cette réduction: 
i) est raisonnable;

ii) ne nuit pas au confort des gens de mer;

b) les logements doivent être convenablement isolés;

c) sur les navires autres que les navires à passagers, tels que définis à la règle 2 e) et $\mathrm{f}$ ) de la Convention internationale de 1974 pour la sauvegarde de la vie humaine en mer, telle que modifiée (Convention SOLAS), les cabines doivent être situées au-dessus de la ligne de charge, au milieu ou à l'arrière du navire, sauf dans des cas exceptionnels où elles peuvent être situées à l'avant du navire, parce qu'un autre emplacement ne serait pas envisageable compte tenu du type du navire, de ses dimensions ou du service auquel il est destiné mais en aucun cas au-delà de la cloison d'abordage;

d) sur les navires à passagers, et sur les navires spéciaux construits conformément aux dispositions du Recueil de règles de sécurité applicables aux navires spéciaux de l'OMI, 1983, et de ses versions ultérieures (dénommés ci-après «navires spéciaux»), l'autorité compétente peut, sous réserve que des dispositions satisfaisantes soient prises pour l'éclairage et la ventilation, permettre que les cabines soient installées audessous de la ligne de charge mais en aucun cas juste au-dessous des coursives de service;

e) les cabines ne doivent pas ouvrir directement sur les compartiments affectés à la cargaison, la salle des machines, les cuisines, les magasins, les séchoirs ou les installations sanitaires communes; les parties des cloisons séparant ces locaux des cabines, ainsi que les cloisons extérieures, doivent être convenablement construites en acier ou en tout autre matériau approuvé et être imperméables à l'eau et aux gaz;

f) les matériaux utilisés pour construire les cloisons intérieures, les panneaux et les revêtements, les sols et les raccordements doivent être adaptés à leur usage et propres à garantir un environnement sans danger pour la santé;

g) les logements doivent être bien éclairés et des dispositifs suffisants doivent être prévus pour l'écoulement des eaux;

h) les installations prévues pour le logement, les loisirs et le service de table doivent être conformes aux prescriptions de la règle 4.3 et aux dispositions correspondantes du code qui ont trait à la protection de la santé et de la sécurité ainsi qu'à la prévention des accidents pour ce qui concerne la prévention du risque d'expo-sition à des niveaux nocifs de bruit et de vibrations et à d'autres facteurs ambiants ainsi qu'aux substances chimiques à bord des navires et pour garantir aux gens de mer un milieu de travail et un cadre de vie acceptables à bord.

7. En ce qui concerne la ventilation et le chauffage:

a) les cabines et les réfectoires doivent être convenablement ventilés;

b) tous les navires, hormis ceux qui naviguent régulièrement dans des zones où le cli< mat tempéré ne l'exige pas, doivent être équipés d'un système de climatisation des logements des gens de mer, du local radio et de tout poste central de commande des machines;

c) l'aération de toutes les installations sanitaires doit se faire par communication directe avec l'air libre, indépendamment de toute autre partie des logements; d) une installation de chauffage satisfaisante doit fournir la chaleur voulue, sauf à bord des navires qui naviguent exclusivement sous des climats tropicaux.

8. En ce qui concerne les prescriptions pour l'éclairage, sous réserve des aménagements particuliers éventuellement autorisés à bord des navires à passagers, les ca-bines et les réfectoires doivent être éclairés par la lumière naturelle et pourvus d'un éclairage artificiel adéquat.

9. Lorsque des cabines sont nécessaires à bord des navires, elles doivent répondre aux prescriptions suivantes:

a) sur les navires autres que les navires à passagers, chaque marin doit disposer d'une cabine individuelle; dans le cas des navires d'une jauge brute inférieure à 3000 ou des navires spéciaux, l'autorité compétente peut, après consultation des organisations d'armateurs et de gens de mer intéressées, autoriser des dérogations à cette prescription;

b) des cabines séparées doivent être mises à la disposition des hommes et des femmes;

c) les cabines doivent être d'une taille convenable et aménagées de manière à assurer un confort raisonnable et à en faciliter la bonne tenue;

d) chaque marin doit disposer en toute circonstance de sa propre couchette;

e) les dimensions intérieures des couchettes ne doivent pas être inférieures à 198 centimètres sur 80 centimètres;

f) la superficie par occupant des cabines des gens de mer à une seule couchette ne doit pas être inférieure à:

i) 4,5 mètres carrés sur les navires d'une jauge brute inférieure à 3000 ;

ii) 5,5 mètres carrés sur les navires d'une jauge brute égale ou supérieure à 3000 mais inférieure à 10000 ;

iii) 7 mètres carrés sur les navires d'une jauge brute égale ou supérieure à 10000 ; 
g) cependant, pour permettre l'aménagement de cabines à une seule couchette à bord des navires d'une jauge brute inférieure à 3000 , des navires à passagers et des navires spéciaux, l'autorité compétente peut autoriser une superficie plus réduite;

h) sur les navires d'une jauge brute inférieure à 3000 autres que les navires à passagers et les navires spéciaux, les cabines peuvent être occupées par deux marins au maximum. La superficie de ces cabines ne doit pas être inférieure à 7 mètres carrés;

i) à bord des navires à passagers et des navires spéciaux, la superficie des cabines des gens de mer qui n'exercent pas les fonctions d'officier ne doit pas être inférieure à:

i) 7,5 mètres carrés pour les cabines de deux personnes;

ii) 11,5 mètres carrés pour les cabines de trois personnes;

iii) 14,5 mètres carrés pour les cabines de quatre personnes;

j) sur les navires spéciaux, les cabines peuvent être occupées par plus de quatre personnes. La superficie par occupant de ces cabines ne doit pas être inférieure à 3,6 mètres carrés;

k) sur les navires autres que les navires à passagers et les navires spéciaux, la superficie par occupant des cabines destinées aux gens de mer qui exercent les fonctions d'officier, lorsque ceux-ci ne disposent pas d'un salon particulier ou d'un bureau, ne doit pas être inférieure à:

i) 7,5 mètres carrés sur les navires d'une jauge brute inférieure à 3000 ;

ii) 8,5 mètres carrés sur les navires d'une jauge brute égale ou supérieure à 3000 mais inférieure à 10000 ;

iii) 10 mètres carrés sur les navires d'une jauge brute égale ou supérieure à 10000 ;

1) sur les navires à passagers et les navires spéciaux, la superficie par occupant des cabines destinées aux gens de mer qui exercent les fonctions d'officier, lorsque ceux-ci ne disposent pas d'un salon particulier ou d'un bureau, ne doit pas être inférieure à 7,5 mètres carrés pour les officiers subalternes et à 8,5 mètres carrés pour les officiers supérieurs. On entend par officiers subalternes les officiers au niveau opérationnel et par officiers supérieurs les officiers chargés de la gestion;

$\mathrm{m}$ ) le capitaine, le chef mécanicien et le second capitaine doivent disposer d'une pièce contiguë à leur cabine qui leur servira de salon particulier ou de bureau ou d'un espace équivalent. L'autorité compétente peut exempter de cette obligation les navires d'une jauge brute inférieure à 3000 après consultation des organisations d'armateurs et de gens de mer intéressées;

n) pour chaque occupant, le mobilier doit comprendre une armoire à vêtements d'une contenance minimale de 475 litres et un tiroir ou un espace équivalent d'au moins 56 litres. Si le tiroir est incorporé dans l'armoire, le volume minimal combiné de celle-ci doit être de 500 litres. Elle doit être pourvue d'une étagère et son utilisateur doit pouvoir la fermer à clé afin de préserver sa vie privée;

o) chaque cabine doit être pourvue d'une table ou d'un bureau, de modèle fixe, rabattable ou à coulisse, et de sièges confortables suivant les besoins.

10. En ce qui concerne les prescriptions pour les réfectoires:

a) les réfectoires doivent être séparés des cabines et situés aussi près que possible de la cuisine. L'autorité compétente peut, après consultation des organisations d'armateurs et de gens de mer intéressées, exempter de cette obligation les navires d'une jauge brute inférieure à 3000 ;

b) les réfectoires doivent être d'une taille et d'un confort suffisants et être convenablement meublés et aménagés, y compris en ce qui concerne la possibilité de se procurer des boissons en tout temps, compte tenu du nombre de gens de mer susceptibles de les utiliser à un moment donné. Des réfectoires séparés ou communs sont prévus s'il y a lieu.

11. En ce qui concerne les prescriptions pour les installations sanitaires:

a) tous les gens de mer doivent avoir commodément accès à des installations sanitaires à bord répondant à des normes minimales de santé et d'hygiène et à des normes raisonnables de confort, des installations séparées étant prévues pour les hommes et pour les femmes;

b) il doit y avoir des installations sanitaires aisément accessibles de la passerelle de navigation et de la salle des machines ou situées près du poste de commande de cette salle; l'autorité compétente peut exempter les navires d'une jauge brute inférieure à 3000 de cette obligation après consultation des organisations d'armateurs et de gens de mer intéressées;

c) à bord de tout navire, il y a lieu de prévoir en un endroit approprié au minimum des toilettes, un lavabo et une baignoire ou une douche, ou les deux, pour chaque groupe de six personnes ou moins qui ne disposent pas d'installations personnelles;

d) sauf sur les navires à passagers, chaque cabine doit être équipée d'un lavabo alimenté en eau douce courante, chaude et froide, sauf lorsqu'il en existe un dans le cabinet de toilette attenant; 
e) à bord des navires à passagers effectuant normalement des voyages d'une durée ne dépassant pas quatre heures, l'autorité compétente peut envisager des dispositions spéciales ou une réduction du nombre d'installations sanitaires requises;

f) tous les points d'eau affectés aux soins de propreté doivent être alimentés en eau douce courante, chaude et froide.

12. En ce qui concerne les prescriptions pour l'infirmerie, tout navire embarquant 15 marins ou plus et affecté à un voyage d'une durée de plus de trois jours dispose d'une infirmerie distincte réservée à des fins exclusivement médicales. L'autorité compétente peut accorder des dérogations à cette disposition en ce qui concerne les navires affectés à la navigation côtière. Lors de l'approbation de l'infirmerie, l'autorité compétente doit s'assurer qu'elle est facile d'accès par tous les temps et que ses occupants sont confortablement logés et peuvent recevoir rapidement les soins nécessaires.

13. Des installations de blanchisserie convenablement situées et aménagées doivent être prévues.

14. A bord de tous les navires, les gens de mer doivent pouvoir avoir accès en dehors de leurs heures de service à un ou plusieurs emplacements sur un pont découvert; cet espace doit avoir une superficie suffisante, compte tenu des dimensions du navire et du nombre de gens de mer à bord.

15. Tous les navires doivent disposer de bureaux séparés ou d'un bureau commun au navire pour le service du pont et pour celui des machines; l'autorité compétente peut exempter de cette obligation les navires d'une jauge brute inférieure à 3000 après consultation des organisations d'armateurs et de gens de mer intéressées.

16. Les navires touchant régulièrement des ports infestés de moustiques doivent être équipés en conséquence selon les prescriptions de l'autorité compétente.

17. Des installations, commodités et services de loisirs appropriés, adaptés aux besoins particuliers des gens de mer qui doivent vivre et travailler à bord des navires, sont mis à la disposition de tous les gens de mer à bord, en tenant compte des dispositions de la règle 4.3 et des dispositions correspondantes du code qui ont trait à la protection de la santé et de la sécurité et à la prévention des accidents.

18. L'autorité compétente doit exiger que des inspections fréquentes soient menées à bord des navires par le capitaine ou sous son autorité, de façon à ce que le logement des gens de mer soit maintenu en bon état d'entretien et de propreté et offre des conditions d'habitabilité décentes. Les résultats de chaque inspection sont consignés par écrit et sont disponibles pour consultation.

19. Dans le cas des navires où il y a lieu de tenir compte, sans qu'il en résulte de discrimination, des intérêts des gens de mer ayant des pratiques religieuses et sociales différentes et distinctes, l'autorité compétente peut, après consultation des organisations d'armateurs et de gens de mer intéressées, autoriser des dérogations, appliquées équitablement, aux dispositions de la présente norme, à condition qu'il n'en résulte pas une situation qui, dans l'ensemble, serait moins favorable que celle qui aurait découlé de l'application de ladite norme.

20. Tout Membre peut, après consultation des organisations d'armateurs et de gens de mer intéressées, exempter des prescriptions des dispositions de la présente norme énumérées ci-dessous les navires d'une jauge brute inférieure à 200 lorsque cela est raisonnable, en tenant compte de la taille du navire et du nombre de personnes à bord:

a) paragraphes 7 b), 11 d) et 13; b) paragraphe $9 \mathrm{f}$ ) et h) à l), uniquement en ce qui concerne la superficie.

21. Des dérogations aux prescriptions de la présente norme ne seront possibles que dans les cas expressément prévus dans ladite norme et seulement dans des circonstances particulières où des motifs solides peuvent être invoqués pour les justifier et sous réserve de protéger la santé et la sécurité des gens de mer.

\section{Principe directeur}

Principe directeur B3.1 - Logement et loisirs

Principe directeur B3.1.1 - Conception et construction

1. Les cloisons extérieures des cabines et des réfectoires devraient assurer une isolation adéquate. Les encaissements des machines, ainsi que les cloisons qui limitent les cuisines ou les autres locaux dégageant de la chaleur, devraient être convenablement calorifugés lorsque cette chaleur pourrait incommoder dans les logements et les coursives adjacents. Des dispositions devraient également être prises pour assurer une protection contre les effets de la chaleur dégagée par les canalisations de vapeur ou d'eau chaude, ou les deux.

2. Les cabines, les réfectoires, les salles de récréation et les coursives situées à l'intérieur du logement de l'équipage devraient être convenablement isolés de façon à éviter toute condensation ou toute chaleur excessive. 
3. Les cloisons et les plafonds devraient être faits d'un matériau dont la surface puisse aisément être maintenue en état de propreté. Il faudrait éviter tout type de construction susceptible d'abriter de la vermine.

4. Les cloisons et plafonds des cabines et réfectoires devraient pouvoir être maintenus aisément en état de propreté et devraient être d'une couleur claire, résistante et non toxique.

5. Les matériaux et le mode de construction des revêtements de pont dans tout local affecté au logement des gens de mer devraient être approuvés; ces revêtements devraient être antidérapants et imperméables à l'humidité, et leur maintien en état de propreté devrait être aisé.

6. Lorsque les revêtements de pont sont en matière composite, le raccordement avec les parois devrait être profilé de manière à éviter les fentes.

Principe directeur B3.1.2 - Ventilation

1. Le système de ventilation des cabines et des réfectoires devrait être réglable de façon à maintenir l'air dans des conditions satisfaisantes et à en assurer une circulation suffisante par tous les temps et sous tous les climats.

2. Les systèmes de climatisation, qu'ils soient de type individuel ou central, devraient être conçus de façon:

a) à maintenir l'atmosphère à une température et à un degré d'humidité relative satisfaisants par rapport aux conditions atmosphériques extérieures, à assurer un renouvellement d'air suffisant dans tous les locaux climatisés, à tenir compte des caractéristiques particulières de l'exploitation en mer et à ne pas produire de vibrations ou de bruits excessifs;

b) à faciliter l'entretien et la désinfection afin de prévenir ou contrôler la propagation des maladies.

3. La force motrice nécessaire pour faire fonctionner le système de climatisation et les autres systèmes de ventilation prévus aux paragraphes ci-dessus du présent principe directeur devrait être disponible pendant tout le temps où les gens de mer habitent ou travaillent à bord et quand les circonstances l'exigent. Toutefois, il n'est pas nécessaire d'utiliser à cette fin une source d'énergie de secours.

Principe directeur B3.1.3 - Chauffage

1. L'installation de chauffage du logement des gens de mer devrait fonctionner pendant tout le temps où les gens de mer habitent ou travaillent à bord et quand les circonstances l'exigent.

2. A bord de tout navire où doit exister une installation de chauffage, celui-ci devrait être assuré par l'eau chaude, l'air chaud, l'électricité, la vapeur ou un moyen équivalent. Toutefois, dans la zone réservée au logement, la vapeur ne devrait pas être utilisée pour la transmission de la chaleur. L'installation de chauffage devrait être en mesure de maintenir dans le logement des gens de mer la température à un niveau satisfaisant dans les conditions normales de temps et de climat que le navire est susceptible de rencontrer en cours de navigation. L'autorité compétente devrait prescrire les conditions à réaliser.

3. Les radiateurs et autres appareils de chauffage devraient être placés et, si nécessaire, protégés de manière à éviter le risque d'incendie et à ne pas constituer une source de danger ou d'incommodité pour les occupants des locaux.

Principe directeur B3.1.4 - Eclairage

1. Tout navire devrait être pourvu d'une installation permettant d'éclairer à l'électricité le logement des gens de mer. S'il n'existe pas à bord deux sources indépendantes de production d'électricité, un éclairage supplémentaire de secours devrait être fourni au moyen de lampes ou d'appareils d'éclairage de modèle approprié.

2. Dans les cabines, une lampe de lecture électrique devrait être placée à la tête de chaque couchette.

3. Des normes appropriées d'éclairage naturel et artificiel devraient être établies par l'autorité compétente.

Principe directeur B3.1.5 - Cabines

1. Les couchettes devraient être aménagées de manière à assurer le plus grand confort possible au marin et au partenaire qui l'accompagne éventuellement.

2. Lorsque cela est raisonnable et réalisable, compte tenu des dimensions du navire, de l'activité à laquelle il est affecté et de son agencement, les cabines devraient être conçues et équipées avec un cabinet de toilette comportant des toilettes, afin d'as-surer un confort raisonnable à leurs occupants et d'en faciliter la bonne tenue.

3. Pour autant que cela est réalisable, les cabines devraient être réparties de façon à séparer les quarts et à éviter que des personnes qui travaillent le jour et des personnes assurant les quarts ne partagent une même cabine.

4. Les membres du personnel de maistrance ne devraient pas être logés plus de deux par cabine. 
5. Pour autant que cela est réalisable, il faudrait envisager de faire bénéficier le second mécanicien de la disposition figurant au paragraphe $9 \mathrm{~m}$ ) de la norme A3.1.5.

6. L'espace occupé par les couchettes, les armoires, les commodes et les sièges devrait être compris dans le calcul de la superficie. Les espaces exigus ou de forme irrégulière qui n'augmentent pas effectivement l'espace disponible pour circuler et qui ne peuvent être utilisés pour y placer des meubles ne devraient pas être compris dans ce calcul.

7. La superposition de plus de deux couchettes devrait être interdite. Dans le cas où des couchettes sont placées le long de la muraille du navire, il devrait être interdit de superposer des couchettes à l'endroit où un hublot est situé au-dessus d'une couchette.

8. Lorsque des couchettes sont superposées, la couchette inférieure ne devrait pas être placée à moins de 30 centimètres du plancher; la couchette supérieure devrait être disposée à mi-hauteur environ entre le fond de la couchette inférieure et le dessous des barrots de plafond.

9. Le cadre d'une couchette et, le cas échéant, la planche de roulis devraient être d'un matériau approuvé, dur, lisse et non susceptible de se corroder ou d'abriter de la vermine.

10. Les cadres tubulaires éventuellement utilisés pour la construction des couchettes devraient être totalement fermés et ne pas comporter de perforations qui pourraient offrir un accès à la vermine.

11. Chaque couchette devrait être pourvue d'un matelas confortable avec sommier ou d'un matelas-sommier combiné. Le matelas et son rembourrage devraient être d'une matière approuvée. Il ne faudrait pas utiliser pour le rembourrage des matelas une matière de nature à abriter de la vermine.

12. Lorsque des couchettes sont superposées, un fond imperméable à la poussière devrait être fixé en dessous du sommier à ressorts de la couchette supérieure.

13. Le mobilier devrait être construit en un matériau lisse et dur, non susceptible de se déformer ou de se corroder.

14. Les hublots des cabines devraient être garnis de rideaux ou d'un équivalent.

15. Chaque cabine devrait être pourvue d'un miroir, de petits placards pour les articles de toilette, d'une étagère à livres et d'un nombre suffisant de patères.

Principe directeur B3.1.6 - Réfectoires

1. Les réfectoires peuvent être communs ou séparés. La décision en la matière devrait être prise après consultation des représentants des gens de mer et des armateurs et sous réserve de l'approbation de l'autorité compétente. Il faudrait tenir compte de facteurs tels que les dimensions du navire et les diverses caractéristiques culturelles, religieuses ou sociales des gens de mer.

2. Dans le cas où des réfectoires distincts doivent être installés pour les gens de mer, des réfectoires distincts devraient être prévus pour:

a) le capitaine et les officiers; b) le personnel de maistrance et autres gens de mer.

3. A bord des navires autres que les navires à passagers, la superficie des réfectoires à l'usage des gens de mer ne devrait pas être inférieure à 1,5 mètre carré par place assise prévue.

4. A bord de tous les navires, les réfectoires devraient être pourvus de tables et de sièges appropriés, fixes ou amovibles, en nombre suffisant pour le plus grand nombre de gens de mer susceptibles de les utiliser en même temps.

5. Les installations suivantes devraient être utilisables à tout moment lorsque les gens de mer sont à bord:

a) un réfrigérateur d'un accès commode et d'une capacité suffisante pour le nombre de personnes utilisant le ou les réfectoires;

b) des installations permettant de disposer de boissons chaudes; c) des installations de distribution d'eau fraîche.

6. Une installation convenable pour le lavage des ustensiles de table ainsi que des placards suffisants pour y ranger ces ustensiles devraient être prévus lorsque les offices qui peuvent exister ne sont pas directement accessibles des réfectoires.

7. Le dessus des tables et des sièges devrait être d'une matière résistant à l'humidité.

Principe directeur B3.1.7 - Installations sanitaires

1. Les lavabos et les baignoires devraient être de dimensions suffisantes et d'un matériau approuvé, à surface lisse, non susceptible de se fissurer, de s'écailler ou de se corroder.

2. Toutes les toilettes devraient être d'un modèle approuvé et pourvues d'une chasse d'eau puissante ou d'un autre moyen d'évacuation adéquat, tel qu'un système d'aspiration, en état constant de fonctionnement et à commande individuelle. 
3. Les installations sanitaires destinées à être utilisées par plusieurs personnes devraient être conformes à ce qui suit:

a) les revêtements de sol devraient être d'un matériau durable approuvé, imperméable à l'humidité; ils devraient être pourvus d'un système efficace d'écoule-ment des eaux;

b) les parois devraient être en acier ou en tout autre matériau approuvé et être étanches sur une hauteur d'au moins 23 centimètres à partir du plancher;

c) les locaux devraient être suffisamment éclairés, chauffés et aérés;

d) les toilettes devraient être situées en un endroit aisément accessible des cabines et des points d'eau affectés aux soins de propreté, mais elles devraient en être séparées; elles ne devraient pas donner directement sur les cabines ni sur un passage qui constituerait seulement un accès entre cabines et toilettes; toutefois, cette dernière disposition ne devrait pas s'appliquer aux toilettes situées entre deux cabines dont le nombre total d'occupants ne dépasse pas quatre;

e) lorsque plusieurs toilettes sont installées dans un même local, elles devraient être suffisamment encloses pour assurer l'intimité.

4. Le matériel mis à la disposition des gens de mer pour la lessive devrait comprendre:

a) des machines à laver;

b) des machines à sécher le linge ou des locaux de séchage convenablement chauffés et ventilés;

c) des fers à repasser et des planches à repasser ou des appareils équivalents.

Principe directeur B3.1.8 - Infirmerie

1. L'infirmerie devrait être conçue de manière à faciliter les consultations et l'administration des premiers soins ainsi qu'à contribuer à prévenir la propagation des maladies infectieuses.

2. L'entrée, les couchettes, l'éclairage, la ventilation, le chauffage et l'installa-tion d'eau devraient être aménagés de manière à assurer le confort et à faciliter le traitement des occupants.

3. Le nombre de couchettes à installer dans l'infirmerie devrait être prescrit par l'autorité compétente.

4. Les occupants de l'infirmerie devraient disposer, pour leur usage exclusif, d'installations sanitaires qui fassent partie de l'infirmerie elle-même ou soient situées à proximité immédiate de celle-ci. Ces installations sanitaires devraient comprendre au minimum des toilettes, un lavabo, une baignoire ou une douche.

Principe directeur B3.1.9 - Autres installations

1. Lorsque des installations séparées sont prévues pour permettre au personnel du service des machines de se changer, celles-ci devraient être:

a) situées à l'extérieur de la salle des machines, mais aisément accessibles de celleci;

b) équipées d'armoires individuelles, ainsi que de baignoires ou de douches, ou des deux, et de lavabos, alimentés en eau douce courante, chaude et froide.

Principe directeur B3.1.10 - Articles de literie, ustensiles de table et articles divers

1. Tout Membre devrait envisager d'appliquer les principes suivants:

a) des articles de literie et des ustensiles de table en bon état de propreté devraient être fournis par l'armateur à tous les gens de mer, qui les utiliseront à bord pendant qu'ils seront au service du navire et qui, aux dates spécifiées par le capitaine et lorsqu'ils cesseront d'être au service du navire, devront les rendre;

b) la literie devrait être de bonne qualité. Les assiettes, les gobelets et autres ustensiles de table devraient être d'une matière approuvée et se prêtant à un nettoyage facile;

c) des serviettes de toilette, du savon et du papier hygiénique devraient être fournis par l'armateur à tous les gens de mer.

Principe directeur B3.1.11 - Installations de loisirs et dispositions concernant le courrier et les visites à bord des navires

1. Il faudrait réexaminer fréquemment les installations et services de loisirs afin d'assurer qu'ils soient adaptés aux besoins des gens de mer, compte tenu de l'évolution de la technique et des conditions d'exploitation et de toute autre nouveauté dans le secteur des transports maritimes.

2. Les installations de loisirs devraient au minimum être équipées d'une bibliothèque et des moyens nécessaires pour lire et pour écrire et, si possible, de jeu.

3. Lors de l'établissement des plans concernant les installations de loisirs, l'autorité compétente devrait envisager l'installation d'une cantine.

4. Lorsque cela est réalisable, il faudrait aussi envisager de fournir gratuitement aux gens de mer: 
a) un fumoir;

b) la possibilité de regarder la télévision et d'écouter la radio;

c) la possibilité de regarder des films, dont le stock devrait être suffisant pour la durée du voyage et, le cas échéant, être renouvelé à des intervalles raisonnables;

d) des articles de sport, y compris du matériel de culture physique, des jeux de table et des jeux de pont;

e) lorsque cela est approprié, des moyens de pratiquer la natation;

f) une bibliothèque contenant des ouvrages de caractère professionnel et autre, en quantité suffisante pour la durée du voyage, et dont le stock devrait être renouvelé à des intervalles raisonnables;

g) des moyens de réaliser des travaux d'artisanat pour se détendre;

h) des appareils électroniques tels que radios, télévisions, magnétoscopes, lecteurs de CD/DVD, ordinateurs, logiciels, magnétophones à cassettes;

i) s'il y a lieu, des bars pour les gens de mer, à moins que cela ne soit contraire aux habitudes nationales, religieuses ou sociales;

j) un accès raisonnable à des communications téléphoniques avec la terre ainsi qu'à des services de messagerie électronique et à Internet, s'il y a lieu, le cas échéant pour un tarif raisonnable.

5. Tout devrait être mis en uvre pour que le courrier des gens de mer soit acheminé dans les conditions les plus sûres et les plus rapides possible. Des efforts devraient aussi être envisagés pour éviter que les gens de mer n'aient à payer des frais supplémentaires lorsque le courrier leur est réexpédié par suite de circonstances indépendantes de leur volonté.

6. Des mesures devraient être envisagées pour garantir, sous réserve de la législation nationale ou internationale applicable, que, chaque fois que cela est possible et raisonnable, les gens de mer obtiennent rapidement l'autorisation de recevoir leur partenaire ou leurs parents et amis à bord de leur navire à titre de visiteurs quand celuici se trouve au port. Ces mesures devraient tenir compte des autorisations requises à des fins de sûreté.

7. La possibilité d'autoriser les gens de mer à être accompagnés de leur partenaire de temps à autre lors d'un voyage devrait être prise en considération, lorsque cela est possible et raisonnable. Les partenaires devraient être munis d'une assurance adéquate couvrant les risques d'accident et de maladie; l'armateur devrait accorder aux gens de mer tout son concours pour contracter cette assurance.

Principe directeur B3.1.12 - Prévention du bruit et des vibrations

1. Les installations pour le logement, les loisirs et le service de table devraient être situées aussi loin que possible des machines, du compartiment de l'appareil à gouverner, des treuils du pont, des installations de ventilation, de chauffage et de climatisation, ainsi que des autres machines et appareils bruyants.

2. Des matériaux insonorisants ou d'autres matériaux adaptés absorbant le bruit devraient être utilisés pour la construction et la finition des parois, des plafonds et des ponts à l'intérieur des espaces bruyants, ainsi que des portes automatiques pro-pres à assurer une isolation phonique des locaux abritant des machines.

3. La salle des machines et les autres locaux abritant des machines devraient être dotés, lorsque cela est réalisable, de postes centraux de commande insonorisés à l'usage du personnel de la salle des machines. Les postes de travail tels que l'atelier devraient être isolés, dans la mesure du possible, pour éviter le bruit général de la salle des machines, et des mesures devraient être prises pour réduire le bruit du fonctionnement des machines.

4. Les niveaux de bruit autorisés dans les postes de travail et les locaux d'habi-tation devraient être conformes aux directives internationales de l'OIT relatives aux niveaux d'exposition, y compris celles figurant dans le recueil de directives pratiques du BIT intitulé Les facteurs ambiants sur le lieu de travail, 2001, et, le cas échéant, aux normes de protection particulières recommandées par l'Organisation maritime internationale, ainsi qu'à tout texte modificatif ou complémentaire ultérieur relatif aux niveaux de bruit acceptables à bord des navires. Un exemplaire des instruments applicables, en anglais ou dans la langue de travail du navire, devrait être conservé à bord et être à la disposition des gens de mer.

5. Le logement, les lieux de loisirs et le service de table ne devraient pas être exposés à des vibrations excessives.

\section{Règle}

Règle 3.2 - Alimentation et service de table

Objet: assurer aux gens de mer une alimentation de bonne qualité, y compris l'eau potable, servie dans des conditions d'hygiène réglementées 
1. Tout Membre doit veiller à ce que les navires qui battent son pavillon transportent à bord et fournissent de la nourriture et de l'eau potable d'une qualité appropriée, dont la valeur nutritionnelle et la quantité répondent aux besoins des personnes à bord, en tenant compte de leurs appartenances culturelles et religieuses différentes.

2. Les gens de mer à bord d'un navire sont nourris gratuitement jusqu'à la fin de leur engagement.

3. Les gens de mer employés comme cuisiniers de navire chargés de la préparation des repas doivent posséder la formation et les qualifications requises pour ce poste.

\section{Norme}

Norme A3.2 - Alimentation et service de table

1. Tout Membre doit adopter une législation ou d'autres mesures visant à garantir des normes minimales en ce qui concerne la quantité et la qualité de l'alimenta-tion et de l'eau potable ainsi que des normes relatives au service de table pour les repas servis aux gens de mer à bord des navires qui battent son pavillon et doit, par des activités éducatives, faire connaître les normes visées au présent paragraphe et en promouvoir l'application.

2. Tout Membre veille à ce que les navires qui battent son pavillon observent les normes minimales suivantes: a) un approvisionnement suffisant en vivres et en eau potable, d'une valeur nutritive, d'une qualité et d'une variété satisfaisantes, compte tenu du nombre de gens de mer à bord, de leur religion et de leurs habitudes culturelles en matière alimentaire ainsi que de la durée et de la nature du voyage;

b) un aménagement et un équipement du service de cuisine et de table qui permettent de fournir aux gens de mer des repas convenables, variés et nutritifs, préparés et servis dans des conditions d'hygiène satisfaisantes;

c) un personnel de cuisine et de table convenablement formé ou ayant reçu l'ins-truction nécessaire.

3. Les armateurs veillent à ce que les gens de mer engagés comme cuisinier de navire soient formés, qualifiés et reconnus compétents pour le poste conformément aux dispositions de la législation du Membre concerné.

4. Les prescriptions visées au paragraphe 3 de la présente norme incluent la nécessité de suivre avec succès un cours de formation agréé ou reconnu par l'autorité compétente, portant sur l'aptitude pratique à faire la cuisine, l'hygiène personnelle et l'hygiène alimentaire, le stockage des vivres, la gestion des stocks, et la protection de l'environnement et la santé et la sécurité dans le service de cuisine et de table.

5. A bord des navires opérant avec un effectif prescrit de moins de dix personnes qui, en raison de la taille de l'équipage ou du mode d'exploitation, peuvent ne pas être tenus par l'autorité compétente d'avoir à bord un cuisinier pleinement qualifié, quiconque prépare la nourriture dans la cuisine doit avoir reçu une formation ou une instruction dans des domaines incluant l'hygiène alimentaire et personnelle ainsi que la manipulation et le stockage des aliments à bord.

6. Dans des circonstances d'extrême nécessité, l'autorité compétente peut délivrer une dispense autorisant un cuisinier qui n'est pas pleinement qualifié à servir sur un navire donné et pour une période déterminée, jusqu'au port d'escale approprié suivant ou pour une période ne dépassant pas un mois, à condition que la personne à qui la dispense est accordée ait reçu une formation ou une instruction dans des domaines incluant l'hygiène alimentaire et personnelle ainsi que la manipulation et le stockage des aliments à bord.

7. Conformément aux procédures prévues au titre 5 en matière de conformité continue des dispositions, l'autorité compétente exige que des inspections documentées fréquentes soient menées à bord des navires, par le capitaine ou sous son autorité, dans les domaines suivants:

a) l'approvisionnement en vivres et en eau potable;

b) tous locaux et équipements utilisés pour le stockage et la manipulation des vivres et de l'eau potable;

c) la cuisine et toute autre installation utilisée pour la préparation et le service des repas.

\section{Principe directeur}

8. Aucun marin de moins de 18 ans ne doit être employé ou engagé ou travailler comme cuisinier de navire.

Principe directeur B3.2 - Alimentation et service de table

Principe directeur B3.2.1 - Inspection, éducation, recherche et publication

1. En coopération avec d'autres agences et organisations compétentes, l'auto-rité compétente devrait recueillir des informations à jour sur la nutrition et sur les méthodes d'achat, de stockage et de conservation des vivres, ainsi que sur la façon de préparer et de servir les repas, compte tenu des spécificités du service de table à bord d'un navire. Ces informations devraient être mises gratuitement ou à un coût raisonnable à la disposition des fabricants et des commerçants spécialisés dans la fourniture de vivres ou de matériel de cuisine et de table pour les navires, des capitaines, maîtres d'hôtel et cuisiniers de navire, et des 
organisations d'armateurs et de gens de mer intéressées. A cette fin, il faudrait utiliser des moyens appropriés de diffusion, tels que manuels, brochures, affiches, graphiques ou annonces dans des périodiques professionnels.

2. L'autorité compétente devrait faire des recommandations en vue d'éviter le gaspillage de vivres, de faciliter le maintien d'un niveau adéquat d'hygiène et d'assurer une organisation du travail optimale.

3. En coopération avec des agences et des organisations compétentes, l'autorité compétente devrait élaborer du matériel didactique et diffuser des informations à bord concernant les méthodes propres à assurer une alimentation et un service de table satisfaisants.

4. L'autorité compétente devrait coopérer étroitement avec les organisations d'armateurs et de gens de mer intéressées et avec les autorités nationales ou locales qui s'occupent des questions d'alimentation et de santé; elle pourra en cas de besoin recourir aux services de ces autorités.

Principe directeur B3.2.2 - Cuisiniers de navire

1. Ne devraient obtenir un certificat de capacité comme cuisinier de navire que les gens de mer qui remplissent les conditions suivantes:

a) avoir servi en mer pendant une période minimum fixée par l'autorité compétente et qui peut varier en fonction des qualifications ou de l'expérience pertinentes des intéressés;

b) avoir réussi l'examen prescrit par l'autorité compétente ou un examen équivalent à l'issue d'un cours de formation agréé pour les cuisiniers.

2. L'examen prescrit peut être organisé et le certificat délivré soit directement par l'autorité compétente, soit, sous le contrôle de celle-ci, par une école de cuisine agréée.

3. L'autorité compétente devrait prévoir la reconnaissance, le cas échéant, des certificats de capacité de cuisinier de navire délivrés par des Membres ayant ratifié la présente convention ou la convention ( $n^{\circ}$ 69) sur le diplôme de capacité des cuisiniers de navire, 1946, ou par toute autre institution agréée.

Titre 4. Protection de la santé, soins médicaux, bien-être et protection en matière de sécurité sociale

\section{Règle}

Règle 4.1 - Soins médicaux à bord des navires et à terre

Objet: protéger la santé des gens de mer et leur assurer un accès rapide à des soins médicaux à bord et à terre

1. Tout Membre s'assure que tous les gens de mer qui travaillent sur des navires battant son pavillon sont couverts par des mesures appropriées pour la protection de leur santé et ont accès à des soins médicaux rapides et adéquats pendant la durée de leur service à bord.

2. La protection et les soins visés au paragraphe 1 de la présente règle sont en principe assurés gratuitement aux gens de mer.

3. Tout Membre s'assure que les gens de mer travaillant à bord de navires qui se trouvent sur son territoire ont accès à ses installations médicales à terre s'ils requièrent des soins médicaux immédiats.

4. Les dispositions énoncées dans le code concernant la protection de la santé et les soins médicaux à bord comportent des normes relatives à des mesures visant à assurer aux gens de mer une protection de la santé et des soins médicaux aussi comparables que possible à ceux dont bénéficient en général les travailleurs à terre.

\section{Norme}

Norme A4.1 - Soins médicaux à bord des navires et à terre

1. Pour protéger la santé des gens de mer travaillant à bord d'un navire battant son pavillon et leur assurer des soins médicaux qui comprennent les soins dentaires essentiels, tout Membre s'assure que soient adoptées des mesures qui:

a) garantissent l'application aux gens de mer de toutes les dispositions générales relatives à la protection de la santé au travail et aux soins médicaux qui concernent leur service, ainsi que de toutes les dispositions spéciales spécifiques au travail à bord d'un navire;

b) garantissent aux gens de mer une protection de la santé et des soins médicaux aussi comparables que possible à ceux dont bénéficient en général les travailleurs à terre, y compris un accès rapide aux médicaments, au matériel médical et aux services de diagnostic et de traitement nécessaires, ainsi qu'à l'information et aux connaissances médicales;

c) accordent aux gens de mer le droit de consulter sans délai un médecin ou un dentiste qualifié dans les ports d'escale, lorsque cela est réalisable; 
d) garantissent que, dans une mesure conforme à la législation et à la pratique du Membre, les services de soins médicaux et de protection de la santé soient fournis sans frais pour eux-mêmes aux gens de mer à bord ou débarqués dans un port étranger;

e) ne se limitent pas au traitement des gens de mer malades ou blessés mais comprennent également des mesures de caractère préventif, notamment l'élabora-tion de programmes de promotion de la santé et d'éducation sanitaire.

2. L'autorité compétente adopte un modèle type de rapport médical à l'usage des capitaines et du personnel médical compétent à terre et à bord. Ce rapport a un caractère confidentiel et sert exclusivement à faciliter le traitement des gens de mer.

3. Tout Membre adopte une législation établissant, pour les soins médicaux et hospitaliers à bord des navires qui battent son pavillon, des prescriptions concernant les installations, les équipements et la formation.

4. La législation nationale exige au minimum le respect des prescriptions suivantes:

a) tout navire dispose d'une pharmacie de bord, de matériel médical et d'un guide médical, dont les spécifications sont prescrites par l'autorité compétente et qui sont inspectés régulièrement par elle. Les prescriptions nationales doivent tenir compte du type de navire, du nombre de personnes à bord, de la nature, de la destination et de la durée des voyages ainsi que des normes médicales recommandées sur le plan national et international;

b) tout navire ayant à son bord 100 personnes ou plus et effectuant normalement des voyages internationaux de plus de trois jours doit disposer d'un médecin qualifié chargé des soins médicaux. La législation nationale détermine également, compte tenu notamment de facteurs comme la durée, la nature et les conditions du voyage et le nombre des gens de mer, quels autres navires doivent disposer d'un médecin à bord;

c) les navires n'ayant pas de médecin à bord doivent compter au moins un marin chargé des soins médicaux et de l'administration des médicaments dans le cadre de ses fonctions normales ou un marin apte à administrer les premiers secours. Les gens de mer chargés d'assurer les soins médicaux à bord et qui ne sont pas médecins doivent avoir suivi avec succès une formation aux soins médicaux qui soit conforme aux dispositions de la Convention internationale de 1978 sur les normes de formation des gens de mer, de délivrance des brevets et de veille, telle que modifiée (STCW). Les gens de mer chargés d'administrer les premiers secours doivent avoir suivi avec succès une formation aux premiers secours, conforme aux dispositions de la STCW. La législation nationale précise le niveau de formation exigé compte tenu notamment de facteurs comme la durée, la nature et les conditions des voyages, ainsi que le nombre de gens de mer à bord;

d) l'autorité compétente prend les mesures voulues pour que des consultations médicales par radio ou par satellite, y compris des conseils de spécialistes, soient possibles pour les navires en mer, à toute heure. Ces consultations médicales, y compris la transmission par radio ou par satellite de messages médicaux entre un navire et les personnes à terre donnant des conseils, sont assurées gratuitement à tous les navires, quel que soit leur pavillon.

\section{Principe directeur}

Principe directeur B4.1 - Soins médicaux à bord des navires et à terre

Principe directeur B4.1.1 - Fourniture de soins médicaux

1. Pour les navires qui ne sont pas tenus de disposer d'un médecin à bord, l'autorité compétente, en déterminant le niveau de formation aux soins médicaux nécessaire, devrait exiger que:

a) les navires pouvant d'ordinaire avoir accès dans les huit heures à des soins médicaux qualifiés et à des équipements médicaux comptent au moins dans leur équipage un marin ayant reçu la formation agréée en soins médicaux de premiers secours requise par la STCW, qui lui permette de prendre immédiatement des mesures efficaces en cas d'accident ou de maladie susceptible de survenir à bord et de faire bon usage des conseils médicaux transmis par radio ou par satellite;

b) tous les autres navires disposent d'au moins un marin ayant reçu la formation agréée en soins médicaux exigée par la STCW, comprenant une formation pratique et une formation à des techniques de soins d'urgence comme la thérapie intraveineuse, qui doit permettre aux intéressés de participer efficacement à des programmes coordonnés d'assistance médicale aux navires en mer et d'assurer aux malades et aux blessés un niveau de soins médicaux satisfaisant au cours de la période pendant laquelle ils sont susceptibles de rester à bord.

2. Les formations visées au paragraphe 1 du présent principe directeur devraient être fondées sur le contenu des éditions les plus récentes du Guide médical international de bord, du Guide des soins médicaux 
d'urgence à donner en cas d'accidents dus à des marchandises dangereuses, du Document destiné à servir de guide - Guide international de formation maritime, et de la partie médicale du Code international des signaux ainsi que des guides nationaux analogues.

3. Les personnes visées au paragraphe 1 du présent principe directeur et tous les autres gens de mer désignés par l'autorité compétente devraient suivre, approximativement tous les cinq ans, des cours de perfectionnement leur permettant d'entretenir et d'accroitre leurs connaissances et leurs compétences et de se tenir au courant des nouveautés.

4. La pharmacie de bord et son contenu ainsi que le matériel médical et le guide médical à conserver à bord devraient être correctement entretenus et inspectés à des intervalles réguliers, ne dépassant pas douze mois, par des personnes responsables désignées par l'autorité compétente, qui devraient contrôler les étiquettes, les dates de péremption, les conditions de conservation et les indications d'emploi de tous les médicaments et s'assurer du fonctionnement conforme de tous les équipements. Lors de l'adoption ou de la révision du guide médical de bord en usage dans le pays, pour déterminer le contenu de la pharmacie de bord et le matériel médical à conserver à bord, l'autorité compétente devrait tenir compte des recommandations internationales dans ce domaine, y compris de l'édition la plus récente du Guide médical international de bord ainsi que des autres guides mentionnés au paragraphe 2 .

5. Lorsqu'une cargaison classée dangereuse ne figure pas dans l'édition la plus récente du Guide des soins médicaux d'urgence à donner en cas d'accidents dus à des marchandises dangereuses, l'information nécessaire sur la nature des substances, les risques encourus, les équipements de protection individuelle à utiliser, les procédures médicales appropriées et les antidotes spécifiques devrait être communiquée aux gens de mer. Les antidotes spécifiques et les équipements de protection individuelle devraient se trouver à bord lorsque des marchandises dangereuses sont transportées. Cette information devrait être intégrée dans les politiques et programmes de sécurité et de santé au travail exposés dans la règle 4.3 et dans les dispositions correspondantes du code.

6. Tous les navires devraient avoir à bord une liste complète et à jour des stations de radio par l'intermédiaire desquelles des consultations médicales peuvent être obtenues et, s'ils sont équipés d'un système de communication par satellite, ils devraient avoir à bord une liste complète et à jour des stations côtières par l'intermé-diaire desquelles les consultations médicales peuvent être obtenues. Les gens de mer chargés des soins médicaux ou des premiers secours à bord devraient être préparés à l'utilisation du guide médical de bord et de la partie médicale de l'édition la plus récente du Code international des signaux, afin de pouvoir comprendre le type d'infor-mations nécessaires au médecin consulté ainsi que les conseils qu'ils en reçoivent.

Principe directeur B4.1.2 - Modèle de rapport médical

1. Le modèle de rapport médical pour les gens de mer prescrit dans la partie A du code devrait être conçu de manière à faciliter les échanges d'informations médicales et assimilées concernant les gens de mer entre le navire et la terre en cas de maladie ou d'accident.

Principe directeur B4.1.3 - Soins médicaux à terre

1. Les services médicaux à terre prévus pour le traitement des gens de mer devraient être adéquats, et les médecins, dentistes et autres membres du personnel médical devraient être dûment qualifiés.

2. Des mesures devraient être prises pour que les gens de mer, dans les ports, puissent:

a) recevoir un traitement ambulatoire en cas de maladie ou d'accident;

b) être hospitalisés au besoin;

c) recevoir un traitement dentaire, surtout en cas d'urgence.

3. Des mesures appropriées devraient être prises pour faciliter le traitement des gens de mer malades. En particulier, les gens de mer devraient être promptement ad-mis dans les cliniques et les hôpitaux à terre, sans difficulté et sans distinction de nationalité ou de confession, et, dans toute la mesure possible, des dispositions devraient être prises pour assurer, lorsque cela est nécessaire, la continuité du traitement complétant l'action des services sanitaires qui leur sont ouverts.

Principe directeur B4.1.4 - Assistance médicale aux autres navires et coopération internationale

1. Tout Membre devrait dûment envisager de participer à la coopération internationale en matière d'assistance, de programmes et de recherches dans les domaines de la protection de la santé et des soins médicaux. Cette coopération pourrait viser à: 
a) développer et coordonner les efforts de recherche et de sauvetage et organiser une aide et une évacuation médicales rapides en mer, en cas de maladie ou d'ac-cident grave à bord d'un navire, grâce notamment à des systèmes de signalement périodique de la position des navires, à des centres de coordination des opérations de sauvetage et à des services d'urgence par hélicoptère, conformément à la Convention internationale de 1979 sur la recherche et le sauvetage maritimes, ainsi qu'au Manuel international de recherche et de sauvetage aéronautiques et maritimes (IAMSAR);

b) utiliser de façon optimale tout navire ayant à bord un médecin ainsi que les navires prépositionnés en mer pouvant fournir des services hospitaliers et des moyens de sauvetage;

c) établir et tenir à jour une liste internationale de médecins et d'établissements médicaux disponibles à travers le monde pour assurer des soins médicaux d'urgence aux gens de mer;

d) débarquer les gens de mer à terre en vue d'un traitement d'urgence;

e) rapatrier les gens de mer hospitalisés à l'étranger dès que cela est réalisable, conformément à l'avis médical des médecins traitant le cas, en tenant compte des souhaits et des besoins du marin;

f) prendre des dispositions visant à apporter une assistance personnelle aux gens de mer pendant leur rapatriement, conformément à l'avis médical des médecins traitant le cas, en tenant compte des souhaits et des besoins du marin;

g) s'efforcer d'établir des centres sanitaires pour les gens de mer, qui seraient chargés de:

i) mener des recherches sur l'état de santé, les traitements médicaux et les soins de santé préventifs des gens de mer;

ii) former le personnel médical et le personnel de santé à la médecine maritime;

h) collecter et évaluer les statistiques sur les accidents du travail, les maladies professionnelles et les décès de gens de mer et les intégrer dans le système national de statistiques sur les accidents du travail et les maladies professionnelles couvrant d'autres catégories de travailleurs, en les harmonisant avec ce système;

i) organiser des échanges internationaux d'informations techniques, de matériel pédagogique et de personnel enseignant ainsi que des cours de formation, des séminaires et des groupes de travail internationaux;

j) assurer à tous les gens de mer des services de santé et des services médicaux, curatifs et préventifs, qui leur soient spécialement destinés dans les ports ou mettre à leur disposition des services généraux médicaux, de santé et de rééducation;

k) prendre les dispositions nécessaires en vue de rapatrier, dès que cela est possible, le corps ou les cendres des gens de mer décédés, conformément aux souhaits de leurs parents les plus proches.

2. La coopération internationale dans le domaine de la protection de la santé et des soins médicaux des gens de mer devrait se fonder sur des accords bilatéraux ou multilatéraux ou des consultations entre Membres.

Principe directeur B4.1.5 - Personnes à la charge des gens de mer

1. Tout Membre devrait adopter des mesures propres à assurer aux personnes à la charge des gens de mer ayant leur domicile sur son territoire des soins médicaux appropriés et suffisants, en attendant la création d'un service de soins médicaux ouvert aux travailleurs en général et aux personnes à leur charge quand de tels services n'existent pas, et informer le Bureau international du Travail des mesures prises à cet effet.

\section{Règle}

Règle 4.2 - Responsabilité des armateurs

Objet: assurer la protection des gens de mer contre les conséquences financières d'une maladie, d'un accident ou d'un décès survenant en relation avec leur emploi

1. Tout Membre veille à ce que des mesures prises conformément au code soient appliquées à bord des navires qui battent son pavillon pour assurer aux gens de mer travaillant à bord de ces navires le droit à une assistance et à un soutien matériel de la part de l'armateur pour faire face aux conséquences financières des maladies, accidents ou décès survenant pendant leur service dans le cadre d'un contrat d'engagement maritime ou résultant de leur emploi dans le cadre de ce contrat.

2. La présente règle est sans préjudice des autres moyens de droit dont le marin pourrait disposer.

\section{Norme}

Norme A4.2 - Responsabilité des armateurs

1. Tout Membre adopte une législation disposant que les armateurs des navires battant son pavillon sont responsables de la protection de la santé et des soins médicaux de tous les gens de mer travaillant à bord de ces navires, conformément aux normes minimales suivantes: 
a) les armateurs doivent prendre à leur charge le coût pour les gens de mer travaillant à bord de leurs navires de toute maladie et tout accident survenant entre la date stipulée pour le commencement du service et la date à laquelle ils sont censés avoir été dûment rapatriés ou résultant de leur emploi entre ces deux dates;

b) les armateurs doivent prendre à leur charge une couverture financière pour garantir une indemnisation en cas de décès ou d'incapacité de longue durée des gens de mer résultant d'un accident du travail, d'une maladie professionnelle ou d'un risque professionnel, telle que prévue par la législation nationale, le contrat d'engagement maritime ou une convention collective;

c) les frais médicaux, y compris le traitement médical et la fourniture des médicaments et autres moyens thérapeutiques, sont à la charge de l'armateur, ainsi que la nourriture et le logement du marin malade ou blessé hors de son domicile jusqu'à sa guérison ou jusqu'à la constatation du caractère permanent de la maladie ou de l'incapacité;

d) les frais d'inhumation, si le décès survient à bord ou s'il se produit à terre pendant la période de l'engagement, sont à la charge de l'armateur.

2. La législation nationale peut limiter la responsabilité de l'armateur en matière de prise en charge des soins médicaux, de la nourriture ou du logement à une période qui ne pourra être inférieure à 16 semaines à partir du jour de l'accident ou du début de la maladie.

3. Lorsque la maladie ou l'accident entraîne une incapacité de travail, l'arma-teur verse:

a) la totalité du salaire tant que le malade ou le blessé demeure à bord ou jusqu'à ce qu'il ait été rapatrié conformément à la présente convention;

b) la totalité ou une partie du salaire, selon ce que prévoient la législation nationale ou les conventions collectives, à partir du rapatriement ou du débarquement du marin jusqu'à sa guérison ou, si l'éventualité se présente plus tôt, jusqu'à ce qu'il ait droit à des prestations en espèces au titre de la législation du Membre concerné.

4. La législation nationale peut limiter l'obligation de l'armateur de verser à un marin débarqué tout ou partie de son salaire à une période qui ne peut être inférieure à 16 semaines à partir du jour de l'accident ou du début de la maladie.

5. La législation nationale peut exempter l'armateur de toute responsabilité pour:

a) un accident qui n'est pas survenu au service du navire;

b) un accident ou une maladie imputable à une faute intentionnelle du marin ma-lade, blessé ou décédé;

c) une maladie ou une infirmité dissimulée volontairement au moment de l'engage-ment.

6. Dès lors que la responsabilité en est assumée par les autorités publiques, la législation nationale peut exempter l'armateur de l'obligation d'acquitter les frais des soins médicaux, du logement et de la nourriture, ainsi que de l'inhumation.

7. L'armateur, ou ses représentants, doivent prendre des mesures afin de sauvegarder les biens laissés à bord par les gens de mer malades, blessés ou décédés et pour les faire parvenir à eux-mêmes ou à leurs parents les plus proches.

\section{Principe directeur}

Principe directeur B4.2 - Responsabilité de l'armateur

1. Le paiement de la totalité du salaire, prévu par le paragraphe 3 a) de la norme A4.2, peut exclure les primes.

2. La législation nationale peut prévoir que l'armateur cesse d'être tenu de prendre en charge les frais d'un marin malade ou blessé dès que celui-ci peut bénéficier de prestations médicales dans le cadre d'un régime d'assurance maladie ou d'assurance accident obligatoire ou d'indemnisation des travailleurs accidentés.

3. La législation nationale peut prévoir le remboursement par une institution d'assurance des frais d'inhumation supportés par l'armateur, lorsque le système d'as-surance sociale ou de réparation comporte une prestation en ce qui concerne le marin décédé.

\section{Règle}

Règle 4.3 - Protection de la santé et de la sécurité et prévention des accidents

Objet: faire en sorte que le milieu de travail des gens de mer à bord des navires contribue à leur santé et à leur sécurité au travail

1. Tout Membre veille à ce que les gens de mer travaillant à bord des navires qui battent son pavillon bénéficient d'un système de protection de la santé au travail et à ce qu'ils vivent, travaillent et se forment à bord des navires dans un environnement sûr et sain. 
2. Tout membre, après consultation des organisations représentatives des armateurs et des gens de mer et en tenant compte des codes, directives et normes applicables recommandées par les organisations internationales, les administrations nationales et les organismes du secteur maritime, élabore et promulgue des directives nationales relatives à la gestion de la sécurité et de la santé au travail à bord des navires battant son pavillon.

3. Tout Membre adopte une législation et d'autres mesures au sujet des questions précisées dans le code, en tenant compte des instruments internationaux applicables, et fixe les normes relatives à la protection de la sécurité et de la santé au travail et à la prévention des accidents à bord des navires battant son pavillon.

\section{Norme}

Norme A4.3 - Protection de la santé et de la sécurité et prévention des accidents

1. La législation et les autres mesures à adopter conformément au paragraphe 3 de la règle 4.3 couvrent les sujets suivants:

a) l'adoption et l'application effective ainsi que la promotion de politiques et programmes de sécurité et de santé au travail à bord des navires qui battent le pa-villon du Membre, y compris l'évaluation des risques et la formation et l'instruc-tion des gens de mer;

b) les précautions raisonnables afin de prévenir les accidents du travail et les lésions et maladies professionnelles à bord des navires, y compris les mesures visant à réduire et à prévenir les risques d'exposition à des niveaux nocifs de facteurs ambiants et de produits chimiques, ainsi que les risques de lésion ou de maladie pouvant résulter de l'utilisation de l'équipement et des machines à bord des navires;

c) des programmes à bord visant la prévention des accidents du travail et des lésions et maladies professionnelles, ainsi qu'une amélioration constante de la protection de la sécurité et de la santé au travail, avec la participation des représentants des gens de mer et de toutes autres personnes intéressées à leur mise en uvre, en tenant compte des mesures de prévention, y compris le contrôle de la conception et les mesures d'ingénierie, le remplacement des processus et procédures applicables aux tâches collectives et individuelles et l'utilisation de l'équipement de protection individuelle;

d) les prescriptions relatives à l'inspection, à la notification et à la correction des situations dangereuses ainsi qu'à l'enquête sur les accidents du travail survenus à bord et à leur notification.

2. Les dispositions prévues au paragraphe 1 de la présente norme doivent: a) tenir compte des instruments internationaux applicables relatifs à la protection de la sécurité et de la santé au travail en général, ainsi qu'aux risques particuliers, et traiter de tous les aspects de la prévention des accidents du travail et des lésions et maladies professionnelles qui sont susceptibles de s'appliquer au travail des gens de mer, et particulièrement de ceux qui sont propres à l'exercice du métier de marin; b) indiquer clairement l'obligation qu'ont les armateurs, les gens de mer et les autres personnes intéressées de se conformer aux normes applicables ainsi qu'aux politiques et programmes applicables au navire en matière de sécurité et santé au travail, une attention particulière étant accordée à la santé et à la sécurité des gens de mer de moins de 18 ans; c) indiquer les fonctions du capitaine ou de la personne désignée par lui, ou des deux, pour assumer la responsabilité particulière de la mise en uvre et du respect de la politique et du programme du navire en matière de sécurité et de santé au travail; d) indiquer l'autorité dont sont investis les gens de mer du navire qui ont été nommés ou élus en tant que délégués à la sécurité aux fins de participer aux réunions du comité de sécurité du navire. Un tel comité doit être établi sur les bateaux à bord desquels se trouvent cinq marins ou plus.

3. La législation et les autres mesures visées au paragraphe 3 de la règle 4.3 sont régulièrement examinées en consultation avec les représentants des organisations d'armateurs et de gens de mer et, si nécessaire, révisées compte tenu de l'évolution de la technologie et de la recherche, afin de faciliter une amélioration constante des politiques et programmes en matière de sécurité et de santé au travail et d'assurer un milieu de travail sans danger aux gens de mer employés à bord des navires qui battent le pavillon du Membre.

4. Le respect des prescriptions des instruments internationaux applicables qui portent sur les niveaux acceptables d'exposition aux risques professionnels à bord des navires et sur l'élaboration et l'application des politiques et programmes des navires en matière de sécurité et de santé au travail est réputé équivaloir au respect des prescriptions de la présente convention.

5. L'autorité compétente veille à ce que: a) les accidents du travail et les lésions et maladies professionnelles soient dûment déclarés, en tenant compte des orientations fournies par l'Organisation internationale du Travail au sujet de la notification et de l'enregistrement des accidents du travail et des maladies professionnelles; b) des statistiques complètes de ces accidents et maladies soient tenues, analysées et 
publiées et, s'il y a lieu, suivies par des recherches sur les tendancs générales et les risques identifiés; c) les accidents du travail fassent l'objet d'une enquête.

6. Les déclarations et enquêtes relatives aux questions de sécurité et de santé au travail sont de nature à garantir la protection des données personnelles des gens de mer et tiennent compte des orientations fournies par l'Organisation internationale du Travail à ce sujet.

7. L'autorité compétente coopère avec les organisations d'armateurs et de gens de mer afin de prendre des mesures pour informer tous les gens de mer des risques particuliers rencontrés à bord des navires sur lesquels ils travaillent, par exemple par l'af-fichage d'avis officiels exposant les instructions à ce sujet.

8. L'autorité compétente exige des armateurs, lorsqu'ils évaluent les risques dans le cadre de la gestion de la sécurité et de la santé au travail, qu'ils se réfèrent aux informations statistiques appropriées émanant de leurs navires et aux statistiques générales fournies par l'autorité compétente.

\section{Principe directeur}

Principe directeur B4.3 - Protection de la santé et de la sécurité et prévention des accidents

Principe directeur B4.3.1 - Dispositions concernant les accidents du travail et les lésions et maladies professionnelles

1. Les dispositions visées à la norme A4.3 devraient tenir compte du recueil de directives pratiques du BIT intitulé Prévention des accidents à bord des navires en mer et dans les ports, 1996, et de ses versions ultérieures, ainsi que des autres normes et directives connexes de l'Organisation internationale du Travail, et des autres normes, directives et recueils pratiques internationaux concernant la protection de la sécurité et de la santé au travail, y compris les niveaux d'exposition qui y figurent.

2. L'autorité compétente devrait veiller à ce que les directives nationales relatives à la gestion de la sécurité et de la santé au travail portent en particulier sur les points suivants:

a) dispositions générales et dispositions de base;

b) caractéristiques structurelles du navire, y compris les moyens d'accès et les risques liés à l'amiante;

c) machines;

d) effets des températures extrêmement basses ou extrêmement élevées de toute surface avec laquelle les gens de mer peuvent être en contact;

e) effets du bruit auxquels sont soumis les gens de mer dans les postes de travail et les logements à bord;

f) effets des vibrations auxquels sont soumis les gens de mer dans les postes de travail et les logements à bord;

g) effets des facteurs ambiants autres que ceux visés aux alinéas e) et f) auxquels sont soumis les gens de mer dans les postes de travail et les logements à bord, y compris la fumée du tabac;

h) mesures spéciales de sécurité sur le pont et au-dessous;

i) matériel de chargement et de déchargement;

j) prévention et extinction des incendies;

k) ancres, chaînes et câbles;

1) cargaisons dangereuses et lest;

$\mathrm{m})$ équipement de protection individuelle des gens de mer;

n) travail dans des espaces confinés;

o) effets physiques et mentaux de la fatigue;

p) effets de la dépendance envers les drogues et l'alcool;

q) protection et prévention relatives au VIH/SIDA;

r) réponse aux urgences et aux accidents.

3. L'évaluation des risques et la réduction de l'exposition en ce qui concerne les points auxquels se réfère le paragraphe 2 du présent principe directeur devraient tenir compte des effets physiques, y compris ceux résultant de la manutention de charges, du bruit et des vibrations, des effets chimiques et biologiques et des effets mentaux sur la santé au travail, des effets de la fatigue sur la santé physique et mentale, et des accidents du travail. Les mesures nécessaires devraient tenir dûment compte du principe de prévention selon lequel, entre autres choses, la lutte contre les risques à la source, l'adaptation des tâches à l'individu, particulièrement en ce qui concerne la conception des lieux de travail, et le remplacement de ce qui est dangereux par des éléments exempts de danger ou moins dangereux, doivent primer sur l'utilisation d'équipement de protection individuelle pour les gens de mer.

4. Par ailleurs, l'autorité compétente devrait veiller à ce qu'il soit tenu compte des conséquences pour la santé et la sécurité, particulièrement dans les domaines suivants:

a) réponse aux urgences et aux accidents; 
b) effets de la dépendance envers les drogues et l'alcool;

c) protection et prévention relatives au VIH/SIDA.

Principe directeur B4.3.2 - Exposition au bruit

1. L'autorité compétente, conjointement avec les organes internationaux compétents et les représentants des organisations d'armateurs et de gens de mer intéressées, devrait examiner de façon continue la question du bruit à bord des navires en vue d'améliorer la protection des gens de mer, dans toute la mesure possible, contre les effets nocifs de l'exposition au bruit.

2. L'examen visé au paragraphe 1 du présent principe directeur devrait tenir compte des effets nocifs de l'exposition à un bruit excessif sur l'ouie, la santé et le confort des gens de mer, ainsi que des mesures à prescrire ou à recommander pour réduire le bruit à bord des navires en vue de protéger les gens de mer. Les mesures à envisager devraient inclure les suivantes:

a) informer les gens de mer des dangers qu'une exposition prolongée à des niveaux de bruit élevés comporte pour l'ouïe et la santé et leur apprendre à se servir du matériel de protection contre le bruit;

b) fournir aux gens de mer lorsque c'est nécessaire un équipement de protection de l'ouie homologué;

c) évaluer les risques et réduire l'exposition au bruit dans toutes les installations prévues pour le logement, les loisirs et le service de table, ainsi que dans la salle des machines et les autres locaux abritant des machines.

Principe directeur B4.3.3 - Exposition aux vibrations

1. L'autorité compétente, conjointement avec les organismes internationaux compétents et les représentants des organisations d'armateurs et de gens de mer intéressées, et en tenant compte, s'il y a lieu, des normes internationales pertinentes, devrait examiner de façon continue la question des vibrations à bord des navires en vue d'améliorer la protection des gens de mer, dans toute la mesure possible, contre les effets nocifs de ces vibrations.

2. L'examen visé au paragraphe 1 du présent principe directeur devrait inclure les effets de l'exposition à des vibrations excessives sur la santé et le confort des gens de mer, ainsi que les mesures à prescrire ou à recommander pour réduire les vibrations à bord des navires en vue de protéger les gens de mer. Les mesures à envisager devraient inclure les suivantes:

a) informer les gens de mer des dangers qu'une exposition prolongée à des vibrations comporte pour leur santé;

b) fournir aux gens de mer lorsque c'est nécessaire un équipement de protection individuelle homologué;

c) évaluer les risques et réduire l'exposition aux vibrations dans toutes les installations prévues pour le logement, les loisirs et le service de table en adoptant des mesures conformes aux orientations fournies par le recueil de directives pratiques du BIT intitulé Les facteurs ambiants sur le lieu de travail, 2001, et ses révisions ultérieures, en tenant compte des différences existant entre l'exposition dans ces installations et aux postes de travail.

Principe directeur B4.3.4 - Obligations de l'armateur

1. 1. Toute obligation incombant à l'armateur de fournir du matériel de protection ou d'autres dispositifs de prévention des accidents devrait être assortie, en général, de dispositions en vertu desquelles les gens de mer sont tenus d'utiliser ces dispositifs et d'observer les mesures de prévention des accidents et de protection de la santé qui les concernent.

2. Il faudrait aussi tenir compte des articles 7 et 11 de la convention ( $\left.n^{\circ} 119\right)$ sur la protection des machines, 1963, et des dispositions correspondantes de la recommandation $\left(\mathrm{n}^{\circ} 118\right)$ sur la protection des machines, 1963, qui disposent qu'il incombe, d'une part, à l'employeur de veiller à ce que les machines soient munies de dispositifs de protection appropriés et à ce qu'aucune machine ne soit utilisée sans ces dispositifs et, d'autre part, au travailleur de ne pas utiliser une machine si les dispositifs de protection dont elle est pourvue ne sont pas en place, et de ne pas rendre inopérants ces dispositifs.

Principe directeur B4.3.5 - Déclaration des accidents du travail et compilation des statistiques

1. Tous les accidents du travail et les maladies professionnelles devraient être signalés pour faire l'objet d'enquêtes et pour que des statistiques détaillées soient établies, analysées et publiées, en tenant compte de la protection des données personnelles des gens de mer concernés. Les rapports ne devraient pas être limités aux cas d'accidents et de maladies mortels ni aux accidents impliquant le navire. 
2. Les statistiques visées au paragraphe $1 \mathrm{du}$ présent principe directeur devraient porter sur le nombre, la nature, les causes et les conséquences des accidents, des lésions et des maladies professionnels et préciser, le cas échéant, dans quel service du navire l'accident s'est produit, le type d'accident et s'il est survenu en mer ou dans un port.

3. Tout Membre devrait tenir dûment compte de tout système ou modèle international d'enregistrement des accidents des gens de mer éventuellement établi par l'Organisation internationale du Travail.

Principe directeur B4.3.6 - Enquêtes

1. 1. L'autorité compétente devrait entreprendre une enquête sur les causes et les circonstances de tous les accidents du travail et de toutes les lésions et maladies professionnelles entraînant des pertes de vies humaines ou de graves lésions corporelles, ainsi que sur tous autres cas spécifiés par la législation nationale.

2. Il faudrait envisager d'inclure les points suivants parmi ceux qui pourraient faire l'objet d'une enquête:

a) le milieu de travail, par exemple les surfaces de travail, la disposition des machines, les moyens d'accès, l'éclairage et les méthodes de travail;

b) la fréquence par groupe d'âge des accidents du travail et des lésions et des maladies professionnelles;

c) les problèmes physiologiques ou psychologiques spéciaux posés par le séjour à bord des navires;

d) les problèmes résultant de la tension physique à bord des navires, en particulier lorsqu'elle est la conséquence de l'accroissement de la charge de travail;

e) les problèmes et les conséquences résultant des progrès techniques, ainsi que de leur influence sur la composition des équipages;

f) les problèmes résultant de défaillances humaines.

Principe directeur B4.3.7 - Programmes nationaux de protection et de prévention

1. Afin de disposer d'une base fiable pour l'adoption de mesures visant à promouvoir la protection de la sécurité et de la santé au travail et la prévention des accidents du travail et des lésions et des maladies professionnelles qui sont dus aux risques propres au travail maritime, il faudrait entreprendre des recherches sur les tendances générales ainsi que sur les risques révélés par les statistiques.

2. La mise en uvre des programmes de protection et de prévention pour la promotion de la sécurité et de la santé au travail devrait être organisée de telle sorte que l'autorité compétente, les armateurs et les gens de mer ou leurs représentants et les autres organismes intéressés puissent y jouer un rôle actif, y compris par des moyens comme l'organisation de sessions d'information et l'adoption de directives sur les niveaux d'exposition maxima aux facteurs ambiants potentiellement nocifs et aux autres risques ou les résultats d'une évaluation systématique des risques. En particulier, il faudrait créer des commissions mixtes, nationales ou locales, chargées de la prévention et de la protection de la sécurité et de la santé au travail ou des groupes de travail ad hoc et des comités à bord, au sein desquels les organisations d'armateurs et de gens de mer intéressées seraient représentées. 3. Lorsque ces activités sont menées au niveau de la compagnie, il conviendrait d'envisager la représentation des gens de mer dans tout comité de sécurité à bord des navires de l'armateur en question.

Principe directeur B4.3.8 - Contenu des programmes de protection et de prévention

1. Il faudrait envisager d'inclure les fonctions suivantes parmi les fonctions attribuées aux commissions et autres organismes visés au paragraphe 2 du principe directeur B4.3.7:

a) l'élaboration de directives et de politiques nationales relatives aux systèmes de gestion de la sécurité et de la santé au travail et de dispositions, de règles et de manuels relatifs à la prévention des accidents;

b) l'organisation d'une formation et de programmes relatifs à la protection en matière de sécurité et de santé au travail et à la prévention des accidents;

c) l'organisation d'une information publique en matière de protection de la sécurité et de la santé au travail et de prévention des accidents, en particulier au moyen de films, d'affiches, d'avis et de brochures;

d) la distribution de documentation et la diffusion d'informations relatives à la protection en matière de sécurité et de santé au travail et à la prévention des accidents, de façon à atteindre les gens de mer à bord des navires.

2. Les règles ou recommandations adoptées par les autorités ou organismes nationaux ou par les organisations internationales intéressées devraient être prises en considération pour la préparation des textes relatifs aux mesures de protection en matière de sécurité et de santé au travail et de prévention des accidents ou l'élaboration des pratiques recommandées. 
3. Lors de l'élaboration des programmes de protection en matière de sécurité et de santé au travail et de prévention des accidents, tout Membre devrait tenir dûment compte de tout recueil de directives pratiques concernant la sécurité et la santé des gens de mer éventuellement publié par l'Organisation internationale du Travail.

Principe directeur B4.3.9 - Formation relative à la protection en matière de sécurité et de santé au travail et à la prévention des accidents du travail

1. Les programmes relatifs à la formation visée au paragraphe 1 a) de la norme A4.3 devraient être périodiquement revus et mis à jour pour tenir compte de l'évolu-tion des types de navires et de leurs dimensions ainsi que des changements intervenus dans le matériel utilisé, dans l'organisation des équipages, dans les nationalités, dans les langues et dans les méthodes de travail à bord.

2. L'information publique relative à la protection en matière de sécurité et de santé au travail et à la prévention des accidents devrait être continue. Elle pourrait revêtir les formes suivantes:

a) matériel éducatif audiovisuel, tel que films, à utiliser dans les centres de formation professionnelle des gens de mer et, si possible, présenté à bord des navires;

b) affiches apposées à bord des navires;

c) insertion, dans les périodiques lus par les gens de mer, d'articles sur les risques professionnels maritimes et sur les mesures de protection en matière de sécurité et de santé au travail et de prévention des accidents;

d) campagnes spéciales utilisant divers moyens d'information pour instruire les gens de mer, y compris des campagnes sur les méthodes de travail sûres.

3. L'information publique visée au paragraphe 2 du présent principe directeur devrait tenir compte des nationalités, langues et cultures différentes des gens de mer à bord d'un navire.

Principe directeur B4.3.10 - Education des jeunes gens de mer en matière de sécurité et de santé

1. Les règlements sur la sécurité et la santé devraient se référer aux dispositions générales concernant les examens médicaux, avant l'entrée en fonction et en cours d'emploi, ainsi que la prévention des accidents et la protection de la santé au travail, qui sont applicables aux activités des gens de mer. Ces règlements devraient préciser en outre les mesures propres à réduire au minimum les risques professionnels auxquels sont exposés les jeunes gens de mer dans l'exercice de leurs fonctions.

2. Les règlements devraient établir des restrictions empêchant que des jeunes gens de mer dont les aptitudes correspondantes ne seraient pas pleinement reconnues par l'autorité compétente exécutent sans contrôle ni instruction appropriés certains types de travaux comportant un risque particulier d'accident ou d'atteinte à leur santé ou à leur développement physique ou exigeant un degré particulier de maturité, d'ex-périence ou d'aptitude. L'autorité compétente pourrait prendre en considération, en particulier, les tâches comportant:

a) le levage, le déplacement ou le transport de charges ou d'objets lourds;

b) le travail à l'intérieur des chaudières, des réservoirs et des caissons étanches;

c) l'exposition à des bruits ou à des vibrations atteignant des niveaux nocifs;

d) la conduite d'engins de levage ou d'autres équipements ou outils à moteur ou la communication par signes avec les conducteurs d'équipements de ce genre;

e) la manipulation de câbles d'amarrage ou de remorquage ou des apparaux de mouillage;

f) le gréement;

g) le travail dans la mâture ou sur le pont par gros temps;

h) le quart de nuit;

i) l'entretien de l'équipement électrique;

j) le contact avec des matières potentiellement dangereuses ou avec des agents physiques nocifs, tels que des substances dangereuses ou toxiques, et l'exposition à des rayonnements ionisants;

k) le nettoyage des appareils de cuisine;

1) la manipulation ou la responsabilité des embarcations annexes.

3. Des mesures pratiques devraient être prises par l'autorité compétente ou par un organisme approprié pour attirer l'attention des jeunes gens de mer sur l'informa-tion concernant la prévention des accidents et la protection de leur santé à bord des navires. Ces mesures pourraient inclure des cours et des campagnes d'information officielles de prévention des accidents à l'intention des jeunes, ainsi qu'une instruction et une surveillance professionnelles des jeunes gens de mer.

4. Les programmes d'éducation et de formation des jeunes gens de mer, tant à terre qu'à bord, devraient prévoir un enseignement sur les dangers que l'abus d'alcool, de drogues et d'autres substances 
potentiellement nocives peut avoir sur leur santé et leur bien-être, ainsi que sur les risques et problèmes posés par le VIH/SIDA et les autres activités dangereuses pour la santé.

Principe directeur B4.3.11 - Coopération internationale

1. Les Membres, au besoin avec l'assistance d'organismes intergouvernementaux et d'autres organisations internationales, devraient s'efforcer conjointement de parvenir à la plus grande uniformité possible de l'action visant à protéger la sécurité et la santé au travail et à prévenir les accidents.

2. Lors de l'élaboration de programmes de promotion de la protection en matière de sécurité et de santé au travail et de la prévention des accidents du travail conformément aux dispositions de la norme A4.3, tout Membre devrait tenir dûment compte des recueils de directives pratiques publiés par l'Organisation internationale du Travail, ainsi que des normes appropriées des organisations internationales.

3. Les Membres devraient tenir compte de la nécessité d'une coopération internationale en vue de la promotion continue d'activités relatives à la protection en matière de sécurité et de santé au travail et à la prévention des accidents du travail. Cette coopération pourrait revêtir les formes suivantes:

a) accords bilatéraux ou multilatéraux visant à uniformiser les normes et les dispositifs de protection en matière de sécurité et de santé au travail et de prévention des accidents;

b) échanges de renseignements sur les risques particuliers auxquels sont exposés les gens de mer et sur les moyens de promouvoir la sécurité et la santé au travail et de prévenir les accidents;

c) assistance en matière d'essais de matériel et d'inspection, conformément aux dispositions nationales de l'Etat du pavillon;

d) collaboration pour l'établissement et la diffusion des dispositions, des règles ou des manuels relatifs à la protection en matière de sécurité et de santé au travail et à la prévention des accidents;

e) collaboration pour la production et l'utilisation du matériel de formation; f) mise en commun des moyens matériels ou assistance mutuelle pour la formation des gens de mer dans le domaine de la protection en matière de sécurité et de santé au travail, de la prévention des accidents et des méthodes de travail sûres.

\section{Règle}

Règle 4.4 - Accès à des installations de bien-être à terre

Objet: assurer aux gens de mer qui travaillent à bord d'un navire l'accès à des installations et services à terre afin d'assurer leur santé et leur bien-être

1. 1. Tout Membre veille à ce que les installations de bien-être à terre, s'il en existe, soient aisément accessibles. Il doit aussi promouvoir la mise en place d'installa-tions de bien-être, telles que celles qui sont énumérées dans le code, dans des ports déterminés en vue d'assurer aux gens de mer des navires se trouvant dans ces ports l'accès à des installations et services de bien-être adéquats.

2. Les responsabilités du Membre concernant les installations à terre telles que les installations et services culturels, de bien-être, de loisirs et d'information, sont énoncées dans le code.

\section{Norme}

Norme A4.4 - Accès à des installations de bien-être à terre

1. Tout Membre doit exiger que les installations de bien-être existant sur son territoire puissent être utilisées par tous les gens de mer, quels que soient leur nationalité, leur race, leur couleur, leur sexe, leur religion, leurs opinions politiques ou leur origine sociale et quel que soit l'Etat du pavillon du navire à bord duquel ils sont employés ou engagés, ou travaillent.

2. Tout Membre doit promouvoir la mise en place d'installations de bien-être dans les ports appropriés du pays et déterminer, après consultation des organisations d'armateurs et de gens de mer intéressées, quels sont les ports appropriés.

3. Tout Membre doit favoriser la création de conseils du bien-être chargés d'examiner régulièrement les installations et services de bien-être afin de veiller à ce qu'ils soient adaptés eu égard aux changements des besoins des gens de mer résultant de l'évolution de la technique, de l'exploitation ou de toute autre nouveauté dans le secteur des transports maritimes.

\section{Principe directeur}

Principe directeur B4.4 - Accès à des installations de bien-être à terre

Principe directeur B4.4.1 - Responsabilités des Membres

1. Tout Membre devrait: 
a) prendre des mesures pour que des installations et services de bien-être adéquats soient fournis aux gens de mer dans des ports d'escale déterminés et qu'une protection adéquate leur soit assurée dans l'exercice de leur profession;

b) tenir compte, dans la mise en uvre de ces mesures, des besoins particuliers des gens de mer en matière de sécurité, de santé et de loisirs, surtout à l'étranger et à leur arrivée dans des zones de guerre.

2. Les dispositions prises pour le contrôle des installations et services de bienêtre devraient prévoir la participation des organisations représentatives des armateurs et des gens de mer intéressées.

3. Tout Membre devrait prendre des mesures visant à accélérer la libre circulation, entre les navires, les organisations centrales d'approvisionnement et les institutions de bien-être, de tout le matériel nécessaire, tel que films, livres, journaux et équipement sportif, à l'usage des gens de mer, tant à bord de leur navire que dans les centres à terre.

4. Les Membres devraient coopérer entre eux en vue de promouvoir le bienêtre des gens de mer, en mer et dans les ports. Cette coopération devrait comprendre les mesures suivantes:

a) des consultations entre autorités compétentes en vue d'offrir des installations et services de bien-être aux gens de mer, dans les ports et à bord des navires, ou de les améliorer;

b) des accords sur la mise en commun de ressources et la fourniture conjointe d'ins-tallations de bien-être dans les grands ports de façon à éviter les doubles emplois inutiles;

c) l'organisation de compétitions sportives internationales et l'encouragement des gens de mer à participer à des activités sportives; d) l'organisation de séminaires internationaux sur la question du bien-être des gens de mer, en mer et dans les ports.

Principe directeur B4.4.2 - Installations et services de bien-être dans les ports

1. Tout Membre devrait offrir les installations et services de bien-être nécessaires dans des ports appropriés du pays ou veiller à ce qu'ils soient offerts.

2. Les installations et services de bien-être devraient être fournis, conformément aux conditions et à la pratique nationales, par une ou plusieurs des institutions suivantes:

a) les pouvoirs publics;

b) les organisations d'armateurs et de gens de mer intéressées, en vertu des conventions collectives ou d'autres dispositions arrêtées d'un commun accord; c) des organisations bénévoles.

3. Les installations nécessaires de bien-être et de loisirs devraient être créées ou développées dans les ports. Elles devraient comprendre:

a) des salles de réunion et de détente, selon les besoins;

b) des installations de sport et autres installations de plein air, notamment pour des compétitions; c) des installations pédagogiques;

d) le cas échéant, des installations permettant de pratiquer la religion et d'obtenir des conseils personnels.

4. Ces installations peuvent être fournies en mettant à la disposition des gens de mer, selon leurs besoins, les installations destinées à un usage plus général.

5. Lorsqu'un grand nombre de gens de mer de différentes nationalités ont besoin, dans un port déterminé, de certaines installations telles qu'hôtels, clubs ou installations sportives, les autorités ou les institutions compétentes de leurs pays d'origine et des Etats du pavillon ainsi que les associations internationales intéressées devraient procéder à des consultations et coopérer entre elles, de même qu'avec les autorités et les organes compétents du pays dans lequel le port est situé, en vue de mettre leurs res-sources en commun et d'éviter les doubles emplois inutiles.

6. Il devrait y avoir des hôtels ou foyers adaptés aux besoins des gens de mer, là où cela est nécessaire. Ils devraient offrir des services équivalant à ceux d'un hôtel de bonne classe et devraient, autant que possible, être bien situés et ne pas se trouver à proximité immédiate des installations portuaires. Ces hôtels ou foyers devraient être soumis à un contrôle approprié, les prix devraient être raisonnables et, lorsque cela est nécessaire et réalisable, des dispositions devraient être prises pour permettre de loger les familles des gens de mer.

7. Ces installations devraient être ouvertes à tous les gens de mer sans distinction de nationalité, de race, de couleur, de sexe, de religion, d'opinion politique ou d'origine sociale et quel que soit l'Etat du pavillon du navire à bord duquel ils sont employés ou engagés ou travaillent. Sans contrevenir de quelque manière que ce soit à ce principe, il pourrait être nécessaire, dans certains ports, de prévoir plusieurs types d'installations d'un niveau comparable mais adaptées aux coutumes et aux besoins des différents groupes de gens de mer. 
8. Des dispositions devraient être prises pour que, dans la mesure où cela est nécessaire, du personnel qualifié soit employé à plein temps, en plus d'éventuels agents bénévoles, pour la gestion des installations et services de bien-être des gens de mer.

Principe directeur B4.4.3 - Conseils du bien-être

1. Il conviendrait de créer des conseils de bien-être, selon le cas au niveau du port ou au niveau régional ou national. Leurs fonctions devraient être notamment:

a) de s'assurer que les installations de bien-être sont toujours adéquates et de déterminer s'il convient d'en créer d'autres ou de supprimer celles qui sont sousutilisées;

b) d'aider et de conseiller ceux à qui il incombe de fournir des installations de bienêtre et d'assurer une coordination entre eux.

2. Les conseils de bien-être devraient compter parmi leurs membres des représentants des organisations d'armateurs et de gens de mer, de l'autorité compétente et, le cas échéant, d'organisations bénévoles et d'organismes sociaux.

3. Selon les circonstances, les consuls des Etats maritimes et les représentants locaux des organismes de bienêtre étrangers devraient être associés, conformément à la législation nationale, aux travaux des conseils de bien-être portuaires, régionaux ou nationaux.

Principe directeur B4.4.4 - Financement des installations de bien-être

1. Conformément aux conditions et à la pratique nationales, un appui financier aux installations de bien-être dans les ports devrait provenir d'une ou de plusieurs des sources suivantes:

a) subventions publiques;

b) taxes ou autres droits spéciaux acquittés par les milieux maritimes;

c) contributions volontaires versées par les armateurs, les gens de mer ou leurs organisations;

d) contributions volontaires d'autres sources.

2. Lorsque des impôts, taxes et autres droits spéciaux sont prévus afin de financer les services de bien-être, ils ne devraient être employés qu'aux fins pour lesquelles ils sont levés.

Principe directeur B4.4.5 - Diffusion d'informations et mesures de facilitation

1. Les gens de mer devraient recevoir des informations sur tous les moyens à la disposition du public dans les ports d'escale, notamment les moyens de transport, les services de bien-être, les services récréatifs et éducatifs et les lieux de culte, ainsi que sur ceux qui leur sont spécialement destinés.

2. Des moyens de transport adéquats à prix modique devraient être disponibles à tout moment raisonnable lorsque cela est nécessaire pour permettre aux gens de mer de se rendre en ville à partir d'endroits d'accès facile dans la zone portuaire.

3. Les autorités compétentes devraient prendre les mesures nécessaires pour faire connaître aux armateurs ainsi qu'aux gens de mer arrivant dans un port toute loi ou coutume spéciale dont la violation pourrait mettre leur liberté en danger.

4. Les autorités compétentes devraient doter les zones portuaires et les routes d'accès aux ports d'un éclairage suffisant et de panneaux indicateurs et y faire effectuer des patrouilles régulières en vue d'assurer la protection des gens de mer.

Principe directeur B4.4.6 - Gens de mer dans un port étranger

1. En vue de protéger les gens de mer qui se trouvent dans un port étranger, il conviendrait de prendre des mesures tendant à faciliter:

a) l'accès au consul de l'Etat dont ils sont ressortissants ou de l'Etat où ils résident;

b) une coopération efficace entre les consuls et les autorités locales ou nationales.

2. Le cas des gens de mer incarcérés ou consignés dans un port étranger doit être traité rapidement, conformément à la procédure légale, et les intéressés doivent bénéficier de la protection consulaire appropriée.

3. Lorsqu'un marin est incarcéré ou consigné, pour quelque raison que ce soit, sur le territoire d'un Membre, l'autorité compétente devrait, si le marin le demande, en informer immédiatement l'Etat du pavillon ainsi que l'Etat dont le marin est ressortissant. L'autorité compétente devrait rapidement informer le marin de son droit de présenter une telle demande. L'Etat dont le marin est ressortissant devrait informer rapidement la famille du marin. L'autorité compétente devrait autoriser les agents consulaires de ces Etats à voir immédiatement le marin et à lui rendre visite régulièrement par la suite aussi longtemps qu'il sera incarcéré. 
4. Tout Membre devrait, chaque fois que cela est nécessaire, prendre des mesures pour protéger les gens de mer des agressions et autres actes illégaux lorsque le navire se trouve dans ses eaux territoriales et en particulier aux abords des ports.

5. Les responsables dans les ports et à bord des navires devraient faire tout leur possible pour permettre aux gens de mer d'aller à terre au plus tôt après l'arrivée du navire au port.

\section{Règle}

Règle 4.5 - Sécurité sociale

Objet: assurer l'adoption de mesures visant à faire bénéficier les gens de mer de la sécurité sociale

1. Tout Membre veille à ce que tous les gens de mer et, dans la mesure prévue par sa législation nationale, les personnes à leur charge bénéficient d'une protection de sécurité sociale conforme au code, sans préjudice, toutefois, des conditions plus favorables prévues au paragraphe 8 de l'article 19 de la Constitution.

2. Tout Membre s'engage à prendre des mesures, en fonction de sa situation nationale, à titre individuel comme dans le cadre de la coopération internationale, pour atteindre progressivement une protection de sécurité sociale complète pour les gens de mer.

3. Tout Membre veille à ce que les gens de mer qui sont soumis à sa législation en matière de sécurité sociale et, dans la mesure prévue par sa législation nationale, les personnes à leur charge soient admis à bénéficier d'une protection de sécurité sociale qui ne soit pas moins favorable que celle dont jouissent les travailleurs employés à terre.

\section{Norme}

Norme A4.5 - Sécurité sociale

1. Les branches à prendre en considération pour atteindre progressivement la protection complète de sécurité sociale prévue à la règle 4.5 sont les soins médicaux,

les indemnités de maladie, les prestations de chômage, les prestations de vieillesse, les prestations en cas d'accident du travail ou de maladie professionnelle, les prestations familiales, les prestations de maternité, les prestations d'invalidité et les prestations de survivants, qui complètent la protection prévue par les règles 4.1, concernant les soins médicaux, et 4.2, concernant la responsabilité des armateurs, ainsi que par d'autres titres de la présente convention.

2. Lors de la ratification, la protection assurée par tout Membre conformément au paragraphe 1 de la règle 4.5 doit inclure au moins trois des neuf branches énumérées au paragraphe 1 de la présente norme.

3. Tout Membre prend des mesures, en fonction de sa situation nationale, pour assurer la protection de sécurité sociale complémentaire prévue au paragraphe 1 de la présente norme à tous les gens de mer résidant habituellement sur son territoire. Cette responsabilité peut être mise en uvre, par exemple, au moyen d'accords bilatéraux ou multilatéraux en la matière ou de systèmes fondés sur des cotisations. La protection ainsi garantie ne doit pas être moins favorable que celle dont jouissent les personnes travaillant à terre qui résident sur le territoire du Membre en question.

4. Nonobstant l'attribution des responsabilités indiquée au paragraphe 3 de la présente norme, les Membres peuvent établir, par des accords bilatéraux ou multilatéraux, ou par des dispositions adoptées dans le cadre des organisations régionales d'in-tégration économique, d'autres règles relatives à la législation de la sécurité sociale applicable aux gens de mer.

5. Les responsabilités de tout Membre concernant les gens de mer à bord des navires qui battent son pavillon comprennent celles qui sont prévues par les règles 4.1 et 4.2 et par les dispositions correspondantes du code ainsi que celles qui sont inhérentes à ses obligations générales en vertu du droit international.

6. Tout Membre doit examiner les diverses modalités selon lesquelles, en l'ab-sence d'une couverture suffisante dans les branches mentionnées au paragraphe 1 de la présente norme, des prestations comparables seront offertes aux gens de mer, conformément à la législation et à la pratique nationales.

7. La protection visée au paragraphe 1 de la règle 4.5 peut, selon le cas, être prévue par la législation, des régimes privés, des conventions collectives ou une combinaison de ces moyens.

8. Dans la mesure compatible avec leur législation et leur pratique nationales, les Membres coopèrent, par voie d'accord bilatéraux ou multilatéraux ou d'autres arrangements, pour garantir le maintien des droits relatifs à la sécurité sociale, qu'ils soient assurés par des systèmes contributifs ou non contributifs, acquis ou en cours d'acquisition par les gens de mer, indépendamment de leur lieu de résidence.

9. Tout Membre définit des procédures équitables et efficaces pour le règlement des différends.

10. Tout Membre, lors de la ratification, précise les branches pour lesquelles la protection est assurée, conformément au paragraphe 2 de la présente norme. Lorsqu'il assurera par la suite la couverture d'une ou 
de plusieurs des autres branches énumérées au paragraphe 1 de la présente norme, il en informera le Directeur général du Bureau international du Travail, lequel tiendra un registre de ces avis, qu'il mettra à la disposition de toutes les parties intéressées.

11. Les rapports soumis au Bureau international du Travail en vertu de l'article 22 de la Constitution doivent également contenir des informations sur les mesures prises conformément au paragraphe 2 de la règle 4.5 pour étendre la protection à d'autres branches.

\section{Principe directeur}

Principe directeur B4.5 - Sécurité sociale

1. La protection assurée lors de la ratification, conformément au paragraphe 2 de la norme A4.5, devrait porter au minimum sur les soins médicaux, les indemnités de maladie et les prestations en cas d'accident du travail ou de maladie professionnelle.

2. Dans les cas mentionnés au paragraphe 6 de la norme A4.5, des prestations comparables pourront être fournies par voie d'assurance, d'accords bilatéraux ou multilatéraux ou d'autres moyens appropriés, en tenant compte des dispositions des conventions collectives applicables. Lorsque de telles mesures sont adoptées, les gens de mer auxquels elles s'appliquent devraient être informés des modalités selon lesquelles la protection assurée par les diverses branches de la sécurité sociale sera fournie.

3. Lorsque les gens de mer relèvent de plus d'une législation nationale en matière de sécurité sociale, les Membres concernés devraient coopérer en vue de déterminer par accord mutuel celle des législations qui s'appliquera, en tenant compte de facteurs comme le type et le niveau de protection plus favorables aux gens de mer intéressés, ainsi que la préférence de ceux-ci.

4. Les procédures à définir en vertu du paragraphe 9 de la norme A4.5 devraient être conçues de manière à couvrir tous les différends relatifs aux réclamations des gens de mer intéressés, quelle que soit la manière dont la couverture est assurée.

5. Tout Membre ayant des gens de mer nationaux ou des gens de mer non nationaux, ou les deux, employés à bord des navires battant son pavillon devrait offrir la protection de sécurité sociale prévue par la présente convention, telle qu'applicable, et devrait réexaminer périodiquement les branches de la protection de sécurité sociale visée au paragraphe 1 de la norme A4.5 en vue d'identifier toute autre branche utile aux gens de mer concernés.

6. Le contrat d'engagement maritime devrait préciser les modalités selon lesquelles la protection des différentes branches de la sécurité sociale sera assurée à l'in-téressé par l'armateur et contenir toute autre information utile dont dispose celui-ci, comme les déductions obligatoires du salaire du marin et les cotisations de l'armateur qui peuvent être exigées, conformément aux prescriptions des organismes autorisés spécifiés dans le cadre des régimes nationaux de sécurité sociale applicables.

7. Lorsqu'il exerce effectivement sa juridiction dans le domaine des questions sociales, le Membre dont le navire bat pavillon devrait s'assurer que les obligations des armateurs en matière de protection de sécurité sociale sont respectées, notamment en ce qui concerne le versement des cotisations aux régimes de sécurité sociale.

Titre 5. Conformité et mise en application des dispositions

1. Les règles qui figurent sous ce titre précisent la responsabilité de tout Membre quant au plein respect et à l'application des principes et droits définis dans les articles de la présente convention ainsi que des obligations spécifiques mentionnées sous ses titres 1, 2, 3 et 4 .

2. Les paragraphes 3 et 4 de l'article VI, qui autorisent la mise en uvre des dispositions de la partie A du code par des dispositions équivalentes dans l'ensemble, ne s'appliquent pas à la partie A du code relevant du présent titre.

3. Conformément au paragraphe 2 de l'article VI, tout Membre doit s'acquitter des responsabilités qui lui incombent en application des règles de la manière indiquée dans les normes correspondantes de la partie $\mathrm{A}$ du code en tenant dûment compte des principes directeurs correspondants de la partie B du code.

4. Les dispositions du présent titre sont mises en uvre en tenant compte du fait que les gens de mer et les armateurs, comme toute autre personne, sont égaux devant la loi et ont droit à une protection juridique égale; ils ont accès sans faire l'objet de discrimination aux cours, tribunaux ou autres mécanismes de règlement des différends. Les dispositions du présent titre ne portent pas attribution de compétence matérielle ou territoriale. 


\section{Règle}

Règle 5.1 - Responsabilités de l'Etat du pavillon

Objet: assurer que tout Membre s'acquitte des responsabilités qui lui incombent en vertu de la présente convention à l'égard des navires qui battent son pavillon

Règle 5.1.1 - Principes généraux

1. Il incombe à tout Membre de veiller à ce que ses obligations en vertu de la présente convention soient mises en uvre à bord des navires battant son pavillon.

2. Tout Membre établit un système efficace d'inspection et de certification des conditions du travail maritime, conformément aux règles 5.1.3 et 5.1.4, en vue d'assurer que les conditions de travail et de vie des gens de mer sont et demeurent conformes aux normes de la présente convention à bord des navires battant son pavillon.

3. Aux fins de l'instauration d'un système efficace d'inspection et de certification des conditions du travail maritime, un Membre peut, le cas échéant, habiliter des institutions publiques ou d'autres organismes, y compris ceux d'un autre Membre, si celui-ci y consent, dont il reconnaît la compétence et l'indépendance pour réaliser des inspections ou délivrer des certificats, ou les deux. Dans tous les cas, le Membre conserve la pleine responsabilité de l'inspection et de la certification des conditions de travail et de vie des gens de mer intéressés à bord des navires battant son pavillon.

4. Le certificat de travail maritime, complété par une déclaration de conformité du travail maritime, atteste, sauf preuve contraire, que le navire a été dûment inspecté par l'Etat du pavillon et que les prescriptions de la présente convention concernant les conditions de travail et de vie des gens de mer ont été suivies dans la mesure certifiée.

5. Des informations sur le système mentionné au paragraphe 2 de la présente règle, y compris la méthode utilisée pour évaluer son efficacité, doivent figurer dans les rapports soumis par le Membre au Bureau international du Travail en vertu de l'article 22 de la Constitution.

\section{Norme}

Norme A5.1.1 - Principes généraux

1. 1. Tout Membre définit des objectifs et des normes précis pour l'administration de ses systèmes d'inspection et de certification, ainsi que des procédures générales appropriées pour évaluer dans quelle mesure ces objectifs sont atteints et ces normes respectées.

2. Tout Membre exige qu'un exemplaire de la présente convention soit tenu à disposition à bord de tous les navires battant son pavillon.

\section{Principe directeur}

Principe directeur B5.1.1 - Principes généraux

1. L'autorité compétente devrait prendre les dispositions nécessaires pour favoriser une coopération efficace entre les institutions publiques et les autres organismes auxquels se réfèrent les règles 5.1.1 et 5.1.2 et qui sont intéressés par les conditions de travail et de vie des gens de mer à bord des navires.

2. En vue d'assurer plus efficacement la coopération entre les inspecteurs et les armateurs, les gens de mer et leurs organisations respectives, et afin de maintenir ou d'améliorer les conditions de travail et de vie des gens de mer, l'autorité compétente devrait consulter à intervalles réguliers les représentants desdites organisations quant aux meilleurs moyens d'atteindre ces objectifs. Les modalités de ces consultations devraient être déterminées par l'autorité compétente après consultation des organisations d'armateurs et de gens de mer.

\section{Règle}

Règle 5.1.2 - Habilitation des organismes reconnus

1. L'autorité compétente doit avoir établi que les institutions publiques ou autres organismes mentionnés au paragraphe 3 de la règle 5.1.1 (les «organismes reconnus»), sont conformes aux prescriptions du code quant à leur compétence et à leur indépendance. Les fonctions d'inspection ou de certification que les organismes recon-nus pourront être autorisés à assurer doivent relever des activités pour lesquelles le code dit expressément qu'elles seront réalisées par l'autorité compétente ou un organisme reconnu.

2. Les rapports mentionnés au paragraphe 5 de la règle 5.1 .1 doivent contenir des informations relatives à tout organisme reconnu, à la portée des pouvoirs qui lui sont conférés et aux dispositions prises par le Membre pour assurer que les activités autorisées sont menées à bien de façon complète et efficace. 


\section{Norme}

Norme A5.1.2 - Habilitation des organismes reconnus

1. Aux fins de l'habilitation visée au paragraphe 1 de la règle 5.1.2, l'autorité compétente doit examiner la compétence et l'indépendance de l'organisme intéressé et établir que celui-ci a démontré que, dans la mesure nécessaire à l'exercice des activités visées par l'habilitation:

a) il possède l'expertise correspondant aux aspects pertinents de la présente convention ainsi qu'une connaissance suffisante de l'exploitation des navires, y compris les conditions minimales requises pour le travail à bord d'un navire, les conditions d'emploi, le logement et les loisirs, l'alimentation et le service de table, la prévention des accidents, la protection de la santé, les soins médicaux, le bien-être et la protection en matière de sécurité sociale;

b) il est en mesure de maintenir et d'actualiser les compétences de son personnel;

c) il a une connaissance suffisante des prescriptions de la présente convention ainsi que de la législation nationale applicable et des instruments internationaux pertinents;

d) sa taille, sa structure, son expérience et ses moyens correspondent au type et à la portée de l'habilitation.

2. Toute habilitation accordée en matière d'inspection doit au moins autoriser l'organisme reconnu à exiger la correction des défauts qu'il aura constatés quant aux conditions de travail et de vie des gens de mer et à effectuer des inspections dans ce domaine si l'Etat du port le lui demande.

3. Tout Membre doit établir:

a) un système propre à assurer l'adéquation des tâches réalisées par les organismes reconnus, y compris des informations sur l'ensemble des dispositions applicables de la législation nationale et des instruments internationaux pertinents;

b) des procédures de communication avec ces organismes et de contrôle de leur action.

4. Tout Membre fournit au Bureau international du Travail la liste des organismes reconnus qu'il a habilités à agir en son nom et doit tenir cette liste à jour. La liste doit indiquer les fonctions que les organismes reconnus sont habilités à assumer. Le Bureau tiendra cette liste à la disposition du public.

\section{Principe directeur}

Principe directeur B5.1.2 - Habilitation des organismes reconnus

1. L'organisme demandant à être reconnu devrait démontrer qu'il a la compétence et la capacité nécessaires, sur le plan technique et administratif et en matière de gestion, pour assurer la prestation d'un service de qualité dans les délais prescrits.

2. Aux fins de l'évaluation des moyens dont dispose un organisme donné, l'auto-rité compétente devrait vérifier que celui-ci:

a) dispose d'un personnel technique, de gestion et d'appui adéquat;

b) dispose, pour fournir les services requis, de professionnels qualifiés en nombre suffisant et répartis de sorte à assurer une couverture géographique satisfaisante;

c) a démontré sa capacité à fournir des services de qualité dans les délais prescrits;

d) est indépendant et capable de rendre compte de son action.

3. L'autorité compétente devrait conclure un accord écrit avec tout organisme qu'elle reconnait en vue d'une habilitation. Cet accord devrait notamment porter sur les aspects suivants:

a) champ d'application;

b) objet;

c) conditions générales;

d) exécution des fonctions visées par l'habilitation;

e) base juridique des fonctions visées par l'habilitation;

f) communication de rapports à l'autorité compétente;

g) notification de l'habilitation par l'autorité compétente à l'organisme reconnu;

h) contrôle par l'autorité compétente des activités déléguées à l'organisme reconnu.

4. Tout Membre devrait exiger des organismes reconnus qu'ils élaborent un système pour la qualification du personnel employé comme inspecteurs de sorte à assurer la mise à jour régulière de leurs connaissances et compétences.

5. Tout Membre devrait exiger des organismes reconnus qu'ils tiennent des registres de leurs services de sorte à pouvoir établir qu'ils ont agi conformément aux normes applicables pour les aspects couverts par ces services. 
6. Lors de l'élaboration des procédures de contrôle mentionnées au paragraphe $3 \mathrm{~b}$ ) de la norme A5.1.2, tout Membre devrait tenir compte des Directives pour l'habilitation des organismes agissant au nom de l'administration adoptées dans le cadre de l'Organisation maritime internationale. MLC_

\section{Règle}

Règle 5.1.3 - Certificat de travail maritime et déclaration de conformité du travail maritime

1. La présente règle s'applique aux navires:

a) d'une jauge brute égale ou supérieure à 500, effectuant des voyages internationaux;

b) d'une jauge brute égale ou supérieure à 500, battant le pavillon d'un Membre et opérant à partir d'un port ou entre deux ports d'un autre pays.

Aux fins de la présente règle, «voyage international» désigne un voyage d'un pays à un port d'un autre pays.

2. La présente règle s'applique également à tout navire qui bat le pavillon d'un Membre et qui n'est pas couvert par le paragraphe 1 de la présente règle, sur demande de l'armateur au Membre concerné.

3. Tout Membre doit exiger des navires battant son pavillon qu'ils conservent et tiennent à jour un certificat de travail maritime certifiant que les conditions de travail et de vie des gens de mer à bord, y compris les mesures visant à assurer la conformité continue des dispositions adoptées qui doivent être mentionnées dans la déclaration de conformité du travail maritime dont il est question au paragraphe 4 de la présente règle, ont fait l'objet d'une inspection et répondent aux prescriptions de la législation nationale ou autres dispositions visant l'application de la présente convention.

4. Tout Membre doit exiger des navires battant son pavillon qu'ils conservent et tiennent à jour une déclaration de conformité du travail maritime mentionnant les prescriptions nationales visant l'application de la présente convention en ce qui concerne les conditions de travail et de vie des gens de mer et énonçant les mesures adoptées par l'armateur pour assurer le respect de ces prescriptions sur le navire ou les navires concernés.

5. Le certificat de travail maritime et la déclaration de conformité du travail maritime doivent être conformes au modèle prescrit par le code.

6. Lorsque l'autorité compétente du Membre ou un organisme reconnu dûment habilité à cet effet a vérifié par une inspection qu'un navire battant le pavillon du Membre respecte ou continue de respecter les normes de la présente convention, elle doit délivrer ou renouveler le certificat de travail maritime correspondant, et le consigner dans un fichier accessible au public.

7. Des prescriptions détaillées concernant le certificat de travail maritime et la déclaration de conformité du travail maritime, y compris une liste des points devant faire l'objet d'une inspection et être approuvés, sont énoncées dans la partie $\mathrm{A}$ du code.

\section{Norme}

Norme A5.1.3 - Certificat de travail maritime et déclaration de conformité du travail maritime

1. Le certificat de travail maritime est délivré au navire, pour une durée n'excé-dant pas cinq ans, par l'autorité compétente ou par un organisme reconnu dûment habilité à cet effet. La liste des points qui doivent être inspectés et jugés conformes à la législation nationale ou autres dispositions visant l'application des prescriptions de la présente convention pour ce qui touche aux conditions de travail et de vie des gens de mer à bord avant qu'un certificat de travail maritime puisse être délivré figure à l'annexe A5-I.

2. La validité du certificat de travail maritime est subordonnée à la réalisation d'une inspection intermédiaire, effectuée par l'autorité compétente ou par un organisme reconnu dûment habilité à cet effet, qui a pour objet de vérifier que les prescriptions nationales visant l'application de la présente convention sont toujours respectées. Si une seule inspection intermédiaire est effectuée alors que le certificat a une durée de validité de cinq ans, cette inspection doit avoir lieu entre le deuxième et le troisième anniversaire de la date d'établissement du certificat. La date anniversaire s'entend du jour et du mois de chaque année qui correspondent à la date d'expiration du certificat de travail maritime. L'inspection intermédiaire doit être tout aussi étendue et approfondie que les inspections effectuées en vue du renouvellement du certificat. Le certificat sera visé à l'issue d'une inspection intermédiaire favorable.

3. Nonobstant le paragraphe 1 de la présente norme, lorsque l'inspection effectuée aux fins d'un renouvellement a eu lieu dans les trois mois précédant l'échéance du certificat en cours, le nouveau certificat de travail maritime est valide à partir de la date à laquelle l'inspection en question a été effectuée, pour une durée n'excédant pas cinq ans à partir de la date d'échéance du certificat en cours. 
4. Lorsque l'inspection effectuée aux fins d'un renouvellement a eu lieu plus de trois mois avant la date d'échéance du certificat en cours, le nouveau certificat de travail maritime est valide pour une durée n'excédant pas cinq ans à partir de la date à laquelle l'inspection en question a eu lieu.

5. Le certificat de travail maritime peut être délivré à titre provisoire:

a) aux nouveaux navires, à la livraison;

b) lorsqu'un navire change de pavillon;

c) lorsqu'un armateur prend à son compte l'exploitation d'un navire qui est nouveau pour cet armateur.

6. Un certificat de travail maritime ne peut être délivré à titre provisoire que pour une durée n'excédant pas six mois par l'autorité compétente ou un organisme reconnu dûment habilité à cet effet.

7. Un certificat de travail maritime provisoire n'est délivré qu'une fois qu'il a été établi que:

a) le navire a été inspecté, dans la mesure où cela est raisonnablement possible, au regard des prescriptions énumérées à l'annexe A5-I, en tenant compte de la vérification des éléments visés aux alinéas b), c) et d) du présent paragraphe;

b) l'armateur a démontré à l'autorité compétente ou à l'organisme reconnu que des procédures adéquates sont mises en uvre à bord en vue d'assurer le respect des dispositions de la présente convention;

c) le capitaine connaît les prescriptions de la présente convention et les obligations en matière de mise en uvre;

d) les informations requises ont été présentées à l'autorité compétente ou à l'orga-nisme reconnu en vue de l'établissement d'une déclaration de conformité du travail maritime.

8. La délivrance du certificat de travail maritime à durée de validité ordinaire est subordonnée à la réalisation, avant la date d'échéance du certificat provisoire, d'une inspection complète telle que prévue au paragraphe 1 de la présente norme. Aucun nouveau certificat provisoire ne sera délivré après la période initiale de six mois mentionnée au paragraphe 6 de la présente norme. La délivrance d'une déclaration de conformité du travail maritime n'est pas requise pendant la durée de validité du certificat provisoire.

9. Le certificat de travail maritime, le certificat de travail maritime provisoire et la déclaration de conformité du travail maritime seront établis conformément aux modèles présentés à l'annexe A5-II.

10. La déclaration de conformité du travail maritime sera annexée au certificat de travail maritime. Elle comprend deux parties:

a) la partie I est établie par l'autorité compétente, qui:

i) indique la liste des points qui doivent être inspectés en application du paragraphe 1 de la présente norme;

ii) indique les prescriptions nationales donnant effet aux dispositions pertinentes de la présente convention en renvoyant aux dispositions applicables de la législation nationale et en donnant, dans la mesure nécessaire, des informations concises sur les points importants des prescriptions nationales;

iii) fait référence aux prescriptions de la législation nationale relatives à certaines catégories de na-vires;

iv) mentionne toute disposition équivalente dans l'ensemble adoptée en vertu du paragraphe 3 de l'article VI; v) indique clairement toute dérogation octroyée par l'autorité compétente en vertu du titre 3;

b) la partie II est établie par l'armateur et énonce les mesures adoptées pour assurer une conformité continue avec les prescriptions nationales entre deux inspections ainsi que les mesures proposées pour assurer une amélioration continue.

L'autorité compétente ou l'organisme reconnu dûment habilité à cet effet certifie la partie II et délivre la déclaration de conformité du travail maritime.

11. Le résultat de toutes les inspections ou autres vérifications effectuées ultérieurement sur le navire et tous défauts importants relevés au cours de ces vérifications sont consignés, de même que la date du constat qu'il a été remédié aux défauts. Ces informations, accompagnées d'une traduction en anglais lorsqu'elles ne sont pas consignées dans cette langue, sont soit transcrites sur la déclaration de conformité du travail maritime, soit annexées à ce document, soit tenues à la disposition des gens de mer, des inspecteurs de l'Etat du pavillon, des fonctionnaires autorisés de l'Etat du port et des représentants des armateurs et des gens de mer par d'autres moyens, conformément à la législation nationale.

12. Un exemplaire valide et à jour du certificat de travail maritime et de la déclaration de conformité du travail maritime, et leur traduction en anglais lorsque l'ori-ginal n'est pas dans cette langue, doit être conservé à bord et une copie doit être affichée bien en vue à un endroit accessible aux gens de mer. Copie de ces documents est communiquée aux gens de mer, inspecteurs de l'Etat du pavillon, fonctionnaires autorisés de l'Etat du port ou représentants des armateurs et des gens de mer qui en feront la demande, conformément à la législation nationale. 
13. L'obligation relative à la production d'une traduction en anglais, mention-née aux paragraphes 11 et 12 de la présente norme, ne concerne pas un navire n'effec-tuant pas un voyage international.

14. Tout certificat établi en application des paragraphes 1 ou 5 de la présente norme perd sa validité:

a) si les inspections prescrites ne sont pas effectuées dans les délais fixés au paragraphe 2 de la présente norme;

b) si le certificat n'est pas visé conformément au paragraphe 2 de la présente norme;

c) s'il y a changement du pavillon du navire;

d) lorsqu'un armateur cesse d'assumer la responsabilité de l'exploitation d'un navire;

e) lorsque des modifications importantes ont été apportées à la structure ou aux équipements visés au titre 3 .

15. Dans le cas mentionné au paragraphe $14 \mathrm{c}$ ), d) ou e) de la présente norme, le nouveau certificat n'est délivré que si l'autorité compétente ou l'organisme reconnu qui le délivre est pleinement convaincu que le navire est conforme aux prescriptions de la présente norme.

16. Un certificat de travail maritime est retiré par l'autorité compétente ou l'or-ganisme reconnu dûment habilité à cet effet par l'Etat du pavillon s'il est avéré que le navire en question ne respecte pas les prescriptions de la présente convention et qu'aucune mesure corrective prescrite n'a été prise.

17. Lorsqu'un retrait de certificat de travail maritime est envisagé conformément au paragraphe 16 de la présente norme, l'autorité compétente ou l'organisme reconnu tient compte de la gravité ou de la fréquence des manquements.

\section{Principe directeur}

Principe directeur B5.1.3 - Certificat de travail maritime et déclaration de conformité du travail maritime

1. L'énoncé des prescriptions nationales figurant dans la partie I de la déclaration de conformité du travail maritime devrait inclure ou être accompagné de références aux dispositions législatives régissant les conditions de travail et de vie des gens de mer pour chacune des prescriptions énumérées à l'annexe A5-I. Lorsque la législation nationale reprend précisément les prescriptions énoncées dans la présente convention, il suffira d'y faire référence. Lorsqu'une disposition de la présente convention est mise en uvre par des dispositions équivalentes dans l'ensemble, conformément au paragraphe 3 de l'ar-ticle VI, elle devrait être identifiée et une explication concise devrait être fournie. Lorsqu'une dérogation est octroyée par l'autorité compétente en vertu du titre 3, la disposition ou les dispositions en question devraient être clairement indiquées.

2. Les mesures mentionnées dans la partie II de la déclaration de conformité du travail maritime, établie par l'armateur, devraient notamment indiquer en quelles occasions la conformité continue avec certaines prescriptions nationales sera vérifiée, les personnes devant procéder à la vérification, les registres devant être tenus ainsi que les procédures devant être suivies si un défaut de conformité est constaté. La partie II peut se présenter sous des formes diverses. Elle pourra renvoyer à une documentation plus générale portant sur les politiques et procédures relatives à d'autres aspects du secteur maritime, comme les documents requis par le Code international de la gestion de la sécurité (Code ISM) ou les informations requises en application de la règle 5 du chapitre XI-1 de la Convention SOLAS, qui porte sur la fiche synoptique continue des navires.

3. Les mesures pour assurer une conformité continue devraient se référer notamment aux prescriptions internationales générales faisant obligation à l'armateur et au capitaine de se tenir informés des derniers progrès réalisés en matière technologique et scientifique en ce qui concerne l'aménagement des lieux de travail, compte tenu des dangers inhérents au travail des gens de mer, et d'informer en conséquence les représentants des gens de mer, garantissant ainsi un meilleur niveau de protection des conditions de travail et de vie des gens de mer à bord.

4. Il importe par-dessus tout que la déclaration de conformité du travail maritime soit libellée en termes clairs choisis en vue d'aider tous les intéressés, notamment les inspecteurs de l'Etat du pavillon, les fonctionnaires autorisés de l'Etat du port et les gens de mer, à vérifier que les prescriptions sont bien mises en uvre.

5. L'annexe B5-I présente un exemple des informations pouvant figurer dans la déclaration de conformité du travail maritime.

6. Lorsqu'un navire change de pavillon comme indiqué au paragraphe $14 \mathrm{c}$ ) de la norme A5.1.3 et que les deux Etats concernés ont ratifié la présente convention, l'Etat dont le navire était autorisé à battre pavillon précédemment devrait, dans les meilleurs délais, communiquer à l'autorité compétente de l'autre Membre copie du certificat de travail maritime et de la déclaration de conformité du travail maritime conservés à 
bord du navire avant le changement de pavillon et, le cas échéant, copie des rapports d'inspection pertinents si l'autorité compétente en fait la demande dans les trois mois suivant la date du changement du pavillon.

\section{Règle}

Règle 5.1.4 - Inspection et mise en application

1. Tout Membre vérifie, par un système efficace et coordonné d'inspections périodiques, de surveillance et d'autres mesures de contrôle, que les navires qui battent son pavillon respectent les prescriptions de la présente convention telles qu'elles sont mises en uvre par la législation nationale.

2. La partie A du code contient des prescriptions détaillées au sujet du système d'inspection et de mise en application mentionné au paragraphe 1 de la présente règle.

\section{Norme}

Norme A5.1.4 - Inspection et mise en application

1. Tout Membre dispose d'un système d'inspection des conditions faites aux gens de mer à bord des navires battant son pavillon, notamment pour vérifier que les mesures relatives aux conditions de travail et de vie énoncées dans la déclaration de conformité du travail maritime, le cas échéant, sont suivies et que les prescriptions de la présente convention sont respectées.

2. L'autorité compétente désigne des inspecteurs qualifiés en nombre suffisant pour assumer les responsabilités qui lui incombent en application du paragraphe 1 de la présente norme. Lorsque des organismes reconnus sont habilités à mener à bien des inspections, le Membre exige que les personnes affectées à cette activité disposent des qualifications requises à cet effet et donne aux intéressés l'autorité juridique nécessaire pour exercer leurs fonctions.

3. Les dispositions nécessaires sont prises pour assurer que les inspecteurs ont la formation, les compétences, les attributions, les pouvoirs, le statut et l'indépendance nécessaires ou souhaitables pour pouvoir effectuer la vérification et assurer la conformité visées au paragraphe 1 de la présente norme.

4. Les inspections sont effectuées à des intervalles conformes aux prescriptions de la norme A5.1.3, le cas échéant. Ces intervalles ne doivent en aucun cas excéder trois ans.

5. Si un Membre reçoit une plainte qui ne lui apparaît pas manifestement infondée ou acquiert la preuve qu'un navire battant son pavillon ne se conforme pas aux prescriptions de la présente convention ou qu'il y a de sérieux manquements dans l'ap-plication des mesures énoncées dans la déclaration de conformité du travail maritime, il prend les dispositions nécessaires pour enquêter sur la question et s'assurer que des mesures sont prises pour remédier aux manquements constatés.

6. Tout Membre formule des règles adaptées et en assure l'application effective en vue de garantir aux inspecteurs un statut et des conditions de service propres à les rendre indépendants de tout changement de gouvernement et de toute influence extérieure indue.

7. Les inspecteurs, ayant reçu des instructions claires quant aux tâches à accomplir et munis des pouvoirs appropriés, sont autorisés:

a) à monter à bord des navires battant le pavillon du Membre;

b) à procéder à tous examens, contrôles ou enquêtes qu'ils jugent nécessaires pour s'assurer que les normes sont strictement respectées;

c) à exiger qu'il soit remédié à tout manquement et à interdire à un navire de quitter le port jusqu'à ce que les mesures nécessaires aient été prises lorsqu'ils ont des raisons de croire que les manquements constituent une infraction grave aux prescriptions de la présente convention, y compris les droits des gens de mer, ou représentent un grave danger pour la sécurité, la santé ou la sûreté des gens de mer.

8. Toute mesure prise en vertu du paragraphe $7 \mathrm{c}$ ) de la présente norme doit pouvoir faire l'objet d'un recours devant l'autorité judiciaire ou administrative.

9. Les inspecteurs ont la faculté de donner des conseils au lieu d'intenter ou de recommander des poursuites lorsqu'il n'y a pas une infraction manifeste aux prescriptions de la présente convention qui met en danger la sécurité, la santé ou la sûreté des gens de mer concernés et qu'il n'existe pas d'antécédents d'infractions analogues.

10. Les inspecteurs tiennent confidentielle la source de toute plainte ou réclamation alléguant qu'il existe un danger ou des manquements de nature à compromettre les conditions de travail et de vie des gens de mer, ou qu'il y a violation des dispositions législatives, et s'abstiennent de révéler à l'armateur ou à son représentant ou à l'exploitant du navire qu'il a été procédé à une inspection à la suite d'une telle plainte ou réclamation. 
11. Les inspecteurs ne doivent pas se voir confier des tâches en nombre ou d'une nature tels qu'elles soient susceptibles de nuire à une inspection efficace ou de porter préjudice à leur autorité ou à leur impartialité vis-à-vis des armateurs, des gens de mer ou de toute autre partie intéressée. Les inspecteurs doivent notamment:

a) avoir l'interdiction de posséder un intérêt quelconque, direct ou indirect, dans les activités qu'ils sont appelés à contrôler;

b) être tenus, sous peine de sanctions ou de mesures disciplinaires appropriées, de ne pas révéler, même après avoir cessé leurs fonctions, les secrets commerciaux ou les procédés d'exploitation confidentiels ou les informations de nature personnelle dont ils pourraient avoir eu connaissance dans l'exercice de leurs fonctions.

12. Les inspecteurs, pour toute inspection effectuée, soumettent un rapport à l'autorité compétente. Une copie de ce rapport, en langue anglaise ou dans la langue de travail du navire, est remise au capitaine et une autre est affichée sur le tableau d'af-fichage du navire pour l'information des gens de mer et communiquée à leurs représentants, sur demande.

13. L'autorité compétente tient des registres des inspections des conditions faites aux gens de mer à bord des navires battant le pavillon du Membre dont elle relève. Elle publie un rapport annuel sur les activités d'inspection dans un délai raisonnable ne dépassant pas six mois à partir de la fin de l'année.

14. Dans le cas d'une enquête faisant suite à un incident majeur, le rapport est soumis à l'autorité compétente dès que possible et au plus tard un mois après la conclusion de l'enquête.

15. Lorsqu'il est procédé à une inspection ou lorsque des mesures sont prises conformément aux dispositions de la présente norme, tous les efforts raisonnables sont faits pour éviter que le navire ne soit indûment retenu ou retardé.

16. Des indemnités sont versées conformément à la législation nationale pour tout préjudice ou perte résultant de l'exercice illicite des pouvoirs des inspecteurs. La charge de la preuve incombe dans chaque cas au plaignant.

17. Des sanctions appropriées et d'autres mesures correctives sont prévues et effectivement appliquées par tout Membre en cas d'infraction aux prescriptions de la présente convention, y compris les droits des gens de mer, et d'entrave à l'exercice des fonctions des inspecteurs.

\section{Principe directeur}

Principe directeur B5.1.4 - Inspection et mise en application

1. L'autorité compétente et tout autre service ou autorité responsable de tout ou partie de l'inspection des conditions de travail et de vie des gens de mer devraient disposer des ressources nécessaires pour pouvoir remplir leurs fonctions. En particulier:

a) tout Membre devrait prendre les mesures nécessaires pour que les inspecteurs puissent disposer, en tant que de besoin, de l'assistance d'experts et de techniciens dûment qualifiés dans l'accomplissement de leur travail;

b) les inspecteurs devraient disposer de locaux convenablement situés ainsi que de moyens matériels et de transport adéquats pour pouvoir s'acquitter de manière efficace de leurs tâches.

2. L'autorité compétente devrait élaborer une politique en matière de conformité et de mise en application en vue de garantir une certaine cohérence et de guider les activités d'inspection et de mise en application relatives à la présente convention. L'énoncé de cette politique devrait être communiqué à tous les inspecteurs et aux représentants de la loi concernés et tenu à la disposition du public ainsi que des armateurs et des gens de mer.

3. L'autorité compétente devrait instituer des procédures simples lui permettant d'être saisie de façon confidentielle de toute information relative à des infractions éventuelles aux prescriptions de la présente convention, y compris les droits des gens de mer, soumise par les gens de mer directement ou par l'intermédiaire de leurs représentants et faire en sorte que les inspecteurs puissent enquêter sans délai à ce sujet, y compris:

a) en habilitant le capitaine, les gens de mer ou les représentants de ces derniers à demander une inspection lorsqu'ils le jugent nécessaire;

b) en fournissant aux armateurs et aux gens de mer ainsi qu'aux organisations intéressées des informations et conseils techniques au sujet des moyens les plus efficaces de donner effet aux prescriptions de la présente convention et d' uvrer à une amélioration continue des conditions faites aux gens de mer à bord des navires.

4. Les inspecteurs devraient être pleinement formés et suffisamment nombreux pour pouvoir s'acquitter efficacement de leurs tâches compte dûment tenu des éléments suivants: 
a) l'importance des tâches leur incombant, en particulier le nombre, la nature et la taille des navires soumis à l'inspection ainsi que le nombre et la complexité des dispositions légales à appliquer;

b) les ressources mises à la disposition des inspecteurs;

c) les conditions pratiques dans lesquelles l'inspection doit être effectuée pour être efficace.

5. Sous réserve des conditions établies par la législation nationale pour le recrutement dans le service public, les inspecteurs devraient posséder des qualifications et une formation adéquate pour exercer leurs fonctions et, autant que possible, avoir une formation maritime ou une expérience de marin. Ils devraient posséder une connaissance adéquate des conditions de travail et de vie des gens de mer ainsi que de la langue anglaise.

6. Des mesures devraient être prises pour assurer aux inspecteurs un perfectionnement approprié en cours d'emploi.

7. Tous les inspecteurs devraient connaitre précisément les circonstances dans lesquelles il y a lieu de procéder à une inspection, l'étendue de l'inspection à effectuer dans les différentes circonstances visées et la méthode générale d'inspection.

8. Les inspecteurs, munis des pouvoirs nécessaires en application de la loi nationale, devraient au moins être autorisés:

a) à monter à bord des navires librement et à l'improviste. Cependant, au moment d'engager l'inspection du navire, les inspecteurs devraient informer de leur présence le capitaine ou la personne assumant le commandement et, selon le cas, les gens de mer ou leurs représentants;

b) à interroger le capitaine, les gens de mer ou toute autre personne, y compris l'ar-mateur ou son représentant, sur toute question concernant l'application des prescriptions de la législation, en présence de tout témoin que la personne peut avoir demandé;

c) à exiger communication de tous les livres, journaux de bord, registres, certificats ou autres documents ou informations ayant directement trait à l'objet de l'ins-pection en vue de vérifier que la législation nationale assurant la mise en uvre de la présente convention est respectée;

d) à s'assurer de l'affichage des avis requis par la législation nationale mettant en uvre la présente convention;

e) à prélever et à emporter, aux fins d'analyse, des échantillons de produits, de marchandises, d'eau potable, de vivres, de matériaux et de substances utilisés ou manipulés;

f) à la suite d'une inspection, à porter immédiatement à l'attention de l'armateur, de l'exploitant du navire ou du capitaine les manquements pouvant porter préjudice à la santé et à la sécurité des personnes à bord;

g) à alerter l'autorité compétente et, s'il y a lieu, l'organisme reconnu sur tous manquements ou abus que la législation en vigueur ne prend pas spécifiquement en compte et à les saisir de propositions pour l'amélioration de cette législation;

h) à aviser l'autorité compétente de tout accident du travail ou maladie professionnelle affectant des gens de mer dans les cas et selon la manière prescrits par la législation.

9. Lorsqu'un échantillon est prélevé ou emporté conformément au paragraphe 8 e) du présent principe directeur, l'armateur ou son représentant et, selon le cas, un marin devraient assister à l'opération ou en être avisés. La quantité de l'échantillon devrait être dûment consignée par l'inspecteur.

10. Le rapport annuel publié par l'autorité compétente de tout Membre en ce qui concerne les navires battant le pavillon de ce Membre devrait inclure:

a) une liste des lois et des règlements en vigueur relatifs aux conditions de travail et de vie des gens de mer, ainsi que tous les amendements devenus applicables pendant l'année;

b) des informations détaillées sur l'organisation du système d'inspection;

c) des statistiques des navires ou autres locaux assujettis à l'inspection et des navires ou autres locaux effectivement inspectés;

d) des statistiques de l'ensemble des gens de mer assujettis à la législation nationale;

e) des statistiques et des informations sur les violations de la législation, les sanctions infligées et les cas où des navires ont été immobilisés;

f) des statistiques des accidents du travail et des maladies professionnelles affectant des gens de mer et ayant fait l'objet d'une déclaration.

\section{Règle}

Règle 5.1.5 - Procédures de plainte à bord 
1. Tout Membre exige qu'il existe à bord des navires battant son pavillon des procédures permettant un règlement juste, efficace et rapide de toute plainte présentée par un marin alléguant une infraction aux prescriptions de la présente convention, y compris les droits des gens de mer.

2. Tout Membre interdit et sanctionne toute forme de victimisation d'un marin ayant porté plainte.

3. Les dispositions de la présente règle et des sections correspondantes du code sont sans préjudice du droit du marin de chercher réparation par tout moyen légal lui paraissant approprié.

\section{Norme}

Norme A5.1.5 - Procédures de plainte à bord

1. Sans préjudice d'une portée plus large que la législation ou les conventions collectives nationales pourront préciser, les gens de mer pourront avoir recours aux procédures à bord pour porter plainte sur toute question constituant selon eux une infraction aux prescriptions de la présente convention, y compris les droits des gens de mer.

2. Tout Membre veille à ce que la législation prévoie l'établissement de procédures de plainte à bord appropriées en vue de satisfaire aux prescriptions de la règle 5.1.5. Ces procédures doivent viser à ce que le litige à l'origine de la plainte soit régléau niveau le plus bas possible. Cependant, dans tous les cas, les gens de mer ont le droit de porter plainte directement auprès du capitaine et, s'ils le jugent nécessaire, auprès d'autorités extérieures appropriées.

3. Les gens de mer ont le droit d'être accompagnés ou représentés pendant la procédure de plainte à bord et des mesures seront prévues pour prévenir la victimisation de gens de mer ayant porté plainte. Le terme victimisation désigne tout acte malveillant, quel qu'en soit l'auteur, à l'encontre d'un marin ayant présenté une plainte qui n'est pas manifestement abusive ni calomnieuse.

4. Tous les gens de mer doivent recevoir, outre un exemplaire de leur contrat d'engagement maritime, un document décrivant les procédures de plainte en vigueur à bord du navire. Le document doit mentionner notamment les coordonnées de l'auto-rité compétente dans l'Etat du pavillon et, si ce n'est pas le même, dans le pays de résidence des gens de mer, ainsi que le nom d'une ou de plusieurs personnes se trouvant à bord qui seraient susceptibles, à titre confidentiel, de les conseiller de manière impartiale quant à leur plainte et de les aider de toute autre manière à mettre en uvre la procédure de plainte qui leur est ouverte tandis qu'ils sont à bord.

\section{Principe directeur}

Principe directeur B5.1.5 - Procédures de plainte à bord

1. Sous réserve de toutes dispositions pertinentes d'une convention collective applicable, l'autorité compétente devrait, en étroite consultation avec les organisations d'armateurs et de gens de mer, établir un modèle en vue de l'établissement de procédures équitables, rapides et étayées par des documents pour le traitement des plaintes à bord des navires battant le pavillon du Membre concerné. Les éléments suivants devraient être pris en compte lors de l'établissement de ces procédures:

a) de nombreuses plaintes peuvent viser précisément les personnes à qui elles doivent être soumises, voire le capitaine du navire. En tout état de cause, les gens de mer devraient aussi pouvoir se plaindre directement au capitaine ou auprès d'instances extérieures;

b) afin d'éviter toute victimisation des gens de mer ayant présenté une plainte relative à des questions relevant de la présente convention, les procédures devraient encourager la désignation à bord du navire d'une personne à même de conseiller les gens de mer sur les procédures auxquelles ils peuvent avoir recours et, si le marin auteur de la plainte le lui demande, d'assister à tout entretien ou audience se rapportant au motif du litige.

2. Les procédures examinées pendant les consultations visées au paragraphe 1 du présent principe directeur devraient au minimum prévoir ce qui suit:

a) les plaintes devraient être soumises au chef de service du marin qui porte plainte ou à son responsable hiérarchique;

b) le chef de service ou le responsable hiérarchique du marin devrait s'efforcer de régler le problème dans un délai prescrit, adapté à la gravité de l'objet du litige;

c) si le chef de service ou le responsable hiérarchique ne parvient pas à régler le litige à la satisfaction du marin, celui-ci peut en référer au capitaine, qui devrait s'occuper personnellement de la question;

d) les gens de mer devraient en tout temps avoir le droit d'être accompagnés et représentés par un autre marin de leur choix à bord du navire concerné; 
e) les plaintes et les décisions auxquelles elles ont donné lieu devraient être enregistrées et copie devrait en être remise aux gens de mer concernés;

f) si une plainte ne peut être réglée à bord, elle devrait être soumise à terre à l'arma-teur, qui devrait disposer d'un délai suffisant pour régler le problème, s'il y a lieu en consultation avec les gens de mer concernés ou toute personne qu'ils peuvent nommer pour les représenter;

g) dans tous les cas, les gens de mer devraient avoir le droit d'adresser leur plainte directement au capitaine et à l'armateur ainsi qu'aux autorités compétentes.

\section{Règle}

Règle 5.1.6 - Accidents maritimes

1. Tout Membre diligente une enquête officielle sur tout accident maritime grave ayant entrâ̂né blessure ou perte de vie humaine qui implique un navire battant son pa-villon. Le rapport final de cette enquête est en principe rendu public.

2. Les Membres doivent coopérer en vue de faciliter les enquêtes sur les accidents maritimes graves visés au paragraphe 1 de la présente règle.

\section{Norme}

Norme A5.1.6 - Accidents maritimes

(Pas de dispositions)

\section{Principe directeur}

Principe directeur B5.1.6 - Accidents maritimes

(Pas de dispositions)

\section{Règle}

Règle 5.2 - Responsabilités de l'Etat du port

Objet: permettre à tout Membre d'assumer les responsabilités qui lui incombent en vertu de la présente convention en ce qui concerne la coopération internationale nécessaire pour assurer la mise en uvre et le respect des normes de la convention à bord de navires étrangers

Règle 5.2.1 - Inspections dans le port

1. Chaque navire étranger faisant escale, dans le cours normal de son activité ou pour une raison inhérente à son exploitation, dans le port d'un Membre est susceptible d'être inspecté, conformément aux dispositions du paragraphe 4 de l'article $\mathrm{V}$, pour vérifier la conformité aux prescriptions de la présente convention relatives aux conditions de travail et de vie des gens de mer à bord du navire, y compris les droits des gens de mer.

2. Tout Membre accepte le certificat de travail maritime et la déclaration de conformité du travail maritime exigés par la règle 5.1.3 comme attestant, sauf preuve contraire, la conformité aux prescriptions de la présente convention, y compris les droits des gens de mer. En conséquence, sauf dans les cas précisés dans le code, l'ins-pection dans ses ports est limitée à un contrôle du certificat et de la déclaration.

3. Les inspections dans les ports sont effectuées par des fonctionnaires autorisés, conformément aux dispositions du code et des autres accords internationaux applicables régissant les inspections menées sur le territoire du Membre au titre du contrôle des navires par l'Etat du port. Ces inspections se limitent à vérifier que les aspects examinés sont conformes aux prescriptions applicables des articles et des règles de la présente convention ainsi que de la seule partie A du code.

4. Les inspections effectuées en application de la présente règle se fondent sur un système efficace d'inspection et de surveillance relevant de l'Etat du port et propre à contribuer à assurer que les conditions de travail et de vie des gens de mer à bord des navires relâchant dans le port du Membre intéressé sont conformes aux prescriptions de la présente convention, y compris les droits des gens de mer.

5. Des informations relatives au système visé au paragraphe 4 de la présente règle, y compris la méthode utilisée pour évaluer son efficacité, figurent dans les rapports soumis par les Membres en application de l'article 22 de la Constitution.

\section{Norme}

Norme A5.2.1 - Inspections dans le port 
1. Lorsqu'un fonctionnaire autorisé, s'étant présenté à bord pour effectuer une inspection et ayant demandé, le cas échéant, le certificat de travail maritime et la déclaration de conformité du travail maritime, constate que:

a) les documents requis ne sont pas présentés ou ne sont pas tenus à jour, ou le sont de façon mensongère, ou que les documents présentés ne contiennent pas les informations exigées par la présente convention ou ne sont pas valables pour une autre raison; ou

b) il existe de solides raisons de croire que les conditions de travail et de vie à bord du navire ne sont pas conformes aux prescriptions de la présente convention; ou

c) il existe des motifs raisonnables de penser que le navire a changé de pavillon dans le but d'échapper à l'obligation de se conformer aux dispositions de la présente convention; ou

d) une plainte a été déposée au motif que certaines conditions de travail et de vie à bord du navire ne sont pas conformes aux prescriptions de la présente convention;

une inspection plus approfondie peut être effectuée afin de vérifier les conditions de travail et de vie à bord du navire. Une telle inspection sera en tout état de cause effectuée lorsque les conditions de travail et de vie dont il est jugé ou allégué qu'elles ne sont pas conformes pourraient constituer un réel danger pour la sécurité, la santé ou la sûreté des gens de mer, ou lorsque le fonctionnaire autorisé a des raisons de croire que tout manquement constitue une infraction grave aux prescriptions de la présente convention, $y$ compris les droits des gens de mer.

2. Lorsqu'une inspection plus approfondie est effectuée sur un navire étranger dans le port d'un Membre par des fonctionnaires autorisés dans les circonstances indiquées au paragraphe $1 \mathrm{a}$ ), b) ou c) de la présente norme, elle porte, en principe, sur les points énumérés à l'annexe A5-III.

3. Lorsqu'une plainte est déposée en vertu du paragraphe $1 \mathrm{~d}$ ) de la présente norme, l'inspection doit se limiter en général à l'objet de la plainte, à moins que la plainte ou son instruction ne fournisse de solides raisons de procéder à une inspection approfondie, conformément au paragraphe $1 \mathrm{~b}$ ) de la présente norme. Aux fins du paragraphe $1 \mathrm{~d}$ ) de la présente norme, il faut entendre par "plainte» toute information soumise par un marin, un organisme professionnel, une association, un syndicat ou, de manière générale, toute personne ayant un intérêt à la sécurité du navire, y compris sous l'aspect des risques pour la sécurité ou la santé des gens de mer à bord.

4. Lorsque, à la suite d'une inspection plus détaillée, il est constaté que les conditions de travail et de vie à bord du navire ne sont pas conformes aux prescriptions de la présente convention, le fonctionnaire autorisé doit immédiatement porter à la connaissance du capitaine du navire les manquements constatés et les délais dans lesquels il doit y être remédié. Au cas où le fonctionnaire autorisé considère que les manquements constatés sont importants, ou si ces manquements ont un rapport avec une plainte déposée en vertu du paragraphe 3 de la présente norme, le fonctionnaire autorisé les porte à la connaissance des organisations d'armateurs et de gens de mer présentes sur le territoire du Membre où l'inspection est effectuée, et il peut:

a) informer un représentant de l'Etat du pavillon;

b) communiquer les informations pertinentes aux autorités compétentes du port d'escale suivant.

5. Le Membre sur le territoire duquel l'inspection est effectuée a le droit d'adresser au Directeur général du Bureau international du Travail une copie du rapport d'inspection accompagnée, le cas échéant, de la réponse communiquée dans le délai prescrit par les autorités compétentes de l'Etat du pavillon, afin que soit prise toute mesure pouvant être considérée comme appropriée et utile pour s'assurer que cette information est consignée et qu'elle est portée à la connaissance des parties susceptibles d'utiliser les moyens de recours pertinents.

6. Au cas où, après une inspection plus approfondie de la part du fonctionnaire autorisé, il est constaté que le navire n'est pas conforme aux prescriptions de la présente convention et que:

a) les conditions à bord présentent un danger évident pour la sécurité, la santé ou la sûreté des gens de mer; ou

b) la non-conformité constitue une infraction grave ou répétée aux prescriptions de la présente convention, y compris les droits des gens de mer, le fonctionnaire autorisé prend des mesures pour assurer que le navire ne prendra pas la mer tant que les non-conformités visées aux alinéas a) ou b) du présent paragraphe n'auront pas été rectifiées, ou encore tant qu'il n'aura pas accepté un plan visant à les rectifier et ne sera pas convaincu que le plan sera mis en uvre rapidement. Si le navire est interdit d'appareiller, le fonctionnaire autorisé en informe sans délai l'Etat du pa-villon et invite un de ses représentants à être présent, si possible, et demande une réponse de l'Etat du pavillon dans le délai prescrit. Le fonctionnaire autorisé informe également, sans délai, les organisations d'armateurs et de gens de mer appropriées de l'Etat du port où a eu lieu l'inspection. 
7. Tout Membre veille à ce que ses fonctionnaires autorisés reçoivent des orientations, du type indiqué dans la partie B du code, concernant la nature des circonstances qui justifient l'immobilisation d'un navire en vertu du paragraphe 6 de la présente norme.

8. Dans l'exercice des responsabilités qui lui incombent en vertu de la présente norme, tout Membre évite, dans toute la mesure possible, d'immobiliser ou de retarder indûment un navire. S'il est établi qu'un navire a été indûment immobilisé ou retardé, des dommages et intérêts sont payés pour toute perte ou tout préjudice subi. La charge de la preuve incombe dans chaque cas au plaignant.

\section{Principe directeur}

Principe directeur B5.2.1 - Inspection dans le port

1. L'autorité compétente devrait élaborer une politique d'inspection à l'inten-tion des fonctionnaires autorisés qui procèdent à des inspections en vertu de la règle 5.2.1. Cette politique devrait viser à assurer une certaine cohérence et à guider parailleurs les activités d'inspection et de mise en application liées aux prescriptions de la présente convention, y compris les droits des gens de mer. L'énoncé de cette politique devrait être communiqué à tous les fonctionnaires autorisés et tenu à la disposition du public ainsi que des armateurs et des gens de mer.

2. Aux fins de l'élaboration d'une politique relative aux circonstances justifiant l'immobilisation d'un navire en vertu du paragraphe 6 de la norme A5.2.1, l'autorité compétente devrait tenir compte que, en ce qui concerne les infractions visées au paragraphe 6 b) de la norme A5.2.1, la gravité de la violation peut être due à la nature du manquement en question. Cela s'applique particulièrement aux cas de violation des droits et principes fondamentaux ou des droits en matière d'emploi et des droits sociaux des gens de mer tels qu'établis par les articles III et IV. Par exemple, l'emploi d'une personne d'un âge inférieur à l'âge prescrit devrait être considéré comme une infraction grave, même si cela ne concerne qu'une seule personne à bord. Dans d'autres cas, le nombre de manquements différents constatés au cours d'une inspection donnée devrait être pris en compte: par exemple, il faudrait éventuellement plusieurs manquements concernant le logement ou l'alimentation et le service de table qui ne menacent pas la sécurité ou la santé pour que cela soit considéré comme constitutif d'une infraction grave.

3. Les Membres devraient, autant que possible, coopérer les uns avec les autres pour l'adoption de directives relatives aux politiques d'inspection, reconnues au niveau international, notamment en ce qui concerne les circonstances justifiant l'immo-bilisation d'un navire.

\section{Règle}

Règle 5.2.2 - Procédures de traitement à terre des plaintes des gens de mer

1. Tout Membre veille à ce que les gens de mer se trouvant à bord de navires faisant escale dans un port situé sur son territoire qui font état d'une infraction à des prescriptions de la convention, y compris les droits des gens de mer, aient le droit de déposer une plainte pour y remédier de façon rapide et concrète.

\section{Norme}

Norme A5.2.2 - Procédures de traitement à terre des plaintes des gens de mer

1. Une plainte d'un marin alléguant une infraction aux prescriptions de la présente convention, y compris les droits des gens de mer, peut être déposée auprès d'un fonctionnaire autorisé au port où le navire fait escale. Dans ce cas, ledit fonctionnaire doit entreprendre une enquête initiale.

2. Dans les cas appropriés, eu égard à la nature de la plainte, l'enquête initiale doit vérifier si les procédures de plaintes à bord prévues à la règle 5.1 .5 ont été envisagées. Le fonctionnaire autorisé peut également mener une inspection plus détaillée conformément à la norme A5.2.1.

3. Le fonctionnaire autorisé doit, dans les cas appropriés, encourager le règlement de la plainte à bord du navire.

4. Si l'enquête ou l'inspection menée au titre de la présente norme révèle la non-conformité avec le paragraphe 6 de la norme A5.2.1, les dispositions de ce paragraphe sont appliquées.

5. Lorsque les dispositions du paragraphe 4 de la présente norme ne s'appli-quent pas et que la plainte n'a pas été réglée à bord du navire, le fonctionnaire autorisé doit sans délai en aviser l'Etat du pavillon, en cherchant à obtenir, dans un délai pres-crit, des conseils et un plan de mesures correctives.

6. Lorsque la plainte n'a pas été réglée malgré les mesures prises conformément au paragraphe 5 de la présente norme, l'Etat du port doit communiquer une copie du rapport établi par le fonctionnaire autorisé au Directeur général. Le rapport doit être accompagné de toute réponse reçue dans les délais prescrits de la part de l'autorité compétente de l'Etat du pavillon. Les organisations d'armateurs et de gens de mer 
appropriées de l'Etat du port sont également informées. En outre, des statistiques et des informations concernant les plaintes réglées doivent être régulièrement communiquées par l'Etat du port au Directeur général. Ces deux communications sont faites afin que, sur la base d'une action appropriée et rapide, un registre de ces informations soit tenu et porté à la connaissance des parties, y compris les organisations d'armateurs et de gens de mer qui sont susceptibles d'utiliser les moyens de recours pertinents.

7. Des mesures appropriées doivent être prises pour garantir la confidentialité des plaintes déposées par les gens de mer.

\section{Principe directeur}

Principe directeur B5.2.2 - Procédures de traitement à terre des plaintes des gens de mer

1. Lorsqu'une plainte visée à la norme A5.2.2 est traitée par un fonctionnaire autorisé, celui-ci devrait déterminer dans un premier temps s'il s'agit d'une plainte de nature générale qui concerne tous les gens de mer à bord du navire ou une catégorie d'entre eux, ou d'une plainte relative au cas particulier du marin concerné.

2. Si la plainte est de nature générale, le recours à une inspection plus détaillée, conformément à la norme A5.2.1, devrait être envisagé.

3. Si la plainte concerne un cas particulier, il convient de prendre connaissance de l'issue des procédures d'examen de la plainte éventuellement menées à bord du navire pour son règlement. Si de telles procédures n'ont pas été envisagées, le fonctionnaire autorisé devrait encourager le plaignant à avoir recours à toutes procédures disponibles à bord du navire. De bonnes raisons doivent exister pour justifier l'examen d'une plainte avant que toute procédure de plainte à bord du navire ait été envisagée. Celles-ci incluent l'inadéquation ou la lenteur des procédures internes ou encore la crainte du plaignant de subir des représailles pour avoir déposé une plainte.

4. Dans toute enquête relative à une plainte, le fonctionnaire autorisé devrait donner au capitaine, à l'armateur et à toute personne impliquée dans la plainte la possibilité de faire connaître leurs vues.

5. Le fonctionnaire autorisé peut s'abstenir d'intervenir davantage dans le règlement de la plainte dans le cas où l'Etat du pavillon, répondant à la notification de l'Etat du port conformément au paragraphe 5 de la norme A5.2.2, démontre qu'il est en mesure de traiter la question et dispose de procédures adéquates à cette fin, et qu'il a présenté un plan d'action acceptable.

\section{Règle}

Règle 5.3 - Responsabilités du fournisseur de main-d'oeuvre

Objet: assurer que tout Membre s'acquitte des responsabilités qui lui incombent en vertu de la présente convention en ce qui concerne le recrutement et le placement des gens de mer ainsi que leur protection sociale 1. Sans préjudice du principe de sa responsabilité en ce qui concerne les conditions de travail et de vie des gens de mer à bord des navires battant son pavillon, tout Membre a également la responsabilité de veiller à l'application des prescriptions de la présente convention relatives au recrutement, au placement et à la protection en matière de sécurité sociale des gens de mer qui sont ses nationaux, ou des résidents, ou encore des personnes domiciliées sur son territoire, dans la mesure où cette responsabilité est prévue dans la présente convention.

2. Des précisions détaillées pour la mise en uvre du paragraphe 1 de la présente règle figurent dans le code.

3. Tout Membre met en place un système efficace d'inspection et de surveillance pour s'acquitter de ses responsabilités en tant que fournisseur de main-d'oeuvre en vertu de la présente convention.

4. Des informations relatives au système mentionné au paragraphe 3 de la présente règle, y compris la méthode utilisée pour évaluer son efficacité, devront figurer dans les rapports soumis par les Membres en application de l'article 22 de la Constitution.

\section{Norme}

Norme A5.3 - Responsabilités du fournisseur de main-d'oeuvre

1. Tout Membre assure le respect des prescriptions de la présente convention applicables à l'administration et aux activités des services de recrutement et de placement des gens de mer établis sur son territoire au moyen d'un système d'inspection et de surveillance et par des procédures légales en cas d'infraction aux dispositions en matière de licence et autres prescriptions prévues dans la norme A1.4.

\section{Principe directeur}

Principe directeur B5.3 - Responsabilités du fournisseur de main-d'oeuvre 
1. Les services privés de recrutement et de placement des gens de mer établis sur le territoire du Membre et fournissant les services d'un marin à un armateur, où qu'ils se trouvent, devraient être tenus de s'engager à veiller au respect par l'armateur des termes des contrats d'engagement maritime conclus avec les gens de mer.

Annexe A5-I

Conditions de travail et de vie des gens de mer devant être inspectées et approuvées par 1 Etat du pavillon avant la certification d un navire conformément à la norme A5.1.3, paragraphe 1:

Age minimum

Certificat médical

Qualifications des gens de mer

Contrats d engagement maritime

Recours à tout service de recrutement et de placement privé sous licence ou agréé ou réglementé

Durée du travail ou du repos

Effectifs du navire

Logement

Installations de loisirs à bord

Alimentation et service de table

Santé et sécurité et prévention des accidents

Soins médicaux à bord

Procédures de plainte à bord

Paiement des salaires

Annexe A5-II (format PDF 204KB)

Annexe A5-III

Eléments généraux sujets à un contrôle détaillé par un fonctionnaire autorisé de 1 Etat du port effectuant une inspection au titre de la norme A5.2.1:

Age minimum

Certificat médical

Qualifications des gens de mer

Contrats d engagement maritime

Recours à tout service de recrutement et de placement privé sous licence ou agréé ou réglementé

Durée du travail ou du repos

Effectifs du navire

Logement

Installations de loisirs à bord

Alimentation et service de table

Santé et sécurité et prévention des accidents

Soins médicaux à bord

Procédures de plainte à bord

Paiement des salaires 


\section{LOI No96-766 DU 3 OCTOBRE 1996 PORTANT CODE DE L'ENVIRONNEMENT RÉPUBLIQUE DE CÔTE D'IVOIRE}

L'Assemblée Nationale a adopté,

Le Président de la République promulgue la loi dont la teneur suit :

TITRE PREMIER

DÉFINITIONS, OBJECTIFS ET DOMAINE D'APPLICATION

\section{CHAPITRE PREMIER : Définitions}

Article premier : Aux termes de la présente loi :

L'environnement est l'ensemble des éléments physiques, chimiques, biologiques et des facteurs socioéconomiques, moraux, et intellectuels susceptibles d'avoir un effet direct ou indirect, immédiat ou à terme sur le développement du milieu, des êtres vivants et des activités humaines.

L'environnement humain concerne l'aménagement du territoire et du cadre de vie.

L'environnement naturel comprend :

- Le sol et le sous-sol,

- Les ressources en eau,

- L'air,

- La diversité biologique,

- Les paysages, sites et monuments ...

Les ressources en eau comprennent les eaux intérieures, de surface et les eaux souterraines.

L'air est la couche atmosphérique dont la modification physique, chimique ou autre peut porter atteinte 'a la santé des êtres vivants, aux écosystèmes et à l'environnement en général.

Le paysage est une portion de territoire dont les divers éléments forment un ensemble pittoresque par la disposition de ses composantes ou les contours de ses formes ou l'effet de ses couleurs.

Le site est une portion de paysage particularisée par sa situation géographique et/ou son histoire.

Le monument naturel est un élément ou un groupe d'éléments dus à la nature tels que rochers, arbres, sources, bouleversements du sol, accidents géologiques ou autres qui, séparément ou ensemble, forment un panorama digne d'attention.

L'écosystème est un ensemble structuré qui englobe en une seule et même unité fonctionnelle le biotope et la biocénose.

Un biotope est l'aire géographique où l'ensemble des facteurs physiques et chimiques de l'environnement reste sensiblement constant.

L'écologie est l'étude des milieux où vivent, se reproduisent et meurent des êtres vivants ainsi que des rapports de ces êtres avec le milieu et leur protection contre la pollution.

La diversité biologique est la variabilité des organismes vivants de toute origine, y compris, entre autres, les écosystèmes terrestres, marins et autres écosystèmes aquatiques et les complexes écologiques dont il fait partie ; cela comprend la diversité au sein des espèces et entre espèces ainsi que celle des écosystèmes. 
La pollution est la contamination ou la modification directe ou indirecte de l'environnement provoquée par tout acte susceptible :

- D’altérer le milieu de vie de l'homme et des autres espèces vivantes;

- De nuire à la santé, à la sécurité et au bien-être de l'homme, de la flore et de la faune ou aux biens collectifs et individuels.

La pollution des eaux est l'introduction dans le milieu aquatique de toute substance susceptible de modifier les caractéristiques physique, chimique et/ou biologique de l'eau et de créer des risques pour la santé de l'homme, de nuire à la faune et à la flore terrestres et aquatiques, de porter atteinte à l'agrément des sites ou de gêner toute autre utilisation normale des eaux.

La pollution atmosphérique ou pollution de l'air est l'émission volontaire ou accidentelle dans la couche atmosphérique de gaz, de fumée, ou de substances de nature à créer des nuisances pour les êtres vivants, à compromettre leur santé ou la sécurité publique ou à nuire à la production agricole, à la conservation des édifices ou au caractère des sites et paysages.

La pollution transfrontière est la pollution qui a son origine dans un pays et dont les effets se propagent dans d'autres pays.

Les aires protégées sont des zones spécialement consacrées à la préservation de la diversité biologique et des ressources naturelles qui y sont associées.

Les zones maritimes comprennent les eaux archipélagiques, la mer territoriale, la zone économique exclusive, le plateau continental ainsi que le rivage de la mer, les fonds marins et le sous-sol correspondant.

L'établissement humain comprend l'ensemble des agglomérations urbaines et rurales, des infrastructures et équipements dont elles doivent disposer pour assurer à leurs habitants un cadre de vie agréable et une existence saine, harmonieuse et équilibrée.

Les hydrocarbures sont des substances énergétiques, fluides (liquides ou gazeuses).

La nuisance est toute atteinte à la santé des êtres vivants, de leur fait, par l'émission de bruits, d'odeurs, etc.

Les déchets sont des produits solides, liquides ou gazeux, résultant des activités des ménages ou d'un processus de fabrication ou tout bien meuble ou immeuble abandonné ou qui menace en ruine.

Les déchets dangereux sont des produits solides, liquides ou gazeux, qui présentent une menace sérieuse ou des risques particuliers pour la santé, la sécurité des êtres vivants et la qualité de l'environnement.

Les matières fertilisantes sont les engrais, les amendements et tout produit dont l'emploi, contribue à améliorer la production agricole.

Les risques naturels sont les catastrophes et calamités naturelles qui peuvent avoir des effets imprévisibles sur l'environnement et la santé.

L'accident majeur est défini comme un événement tel qu'une émission de substances dangereuses, un incendie, une explosion résultant d'un développement incontrôlé d'une activité industrielle, agricole ou domestique.

Les plans d'urgence se définissent comme l'organisation rapide et rationnelle, sous la responsabilité d'une autorité déterminée, des moyens de tout nature pour faire face à une situation d'une extrême gravité.

Les feux de brousse sont des feux allumés volontairement ou non, quelle qu'en soit l'ampleur, causant des dommages à l'homme à ses biens, à la flore et à la faune. 
La désertification désigne la dégradation des terres dans les zones arides, semi-arides ou subhumides sèches par suite de divers facteurs, parmi lesquels les variations climatiques et les activités humaines.

La pêche consiste en la capture, l'extraction ou la récolte de poissons, cétacés, chéloniens végétaux, planctons ou d'animaux vertébrés ou invertébrés vivant partiellement ou complètement dans le milieu aquatique.

La chasse consiste en tout acte tendant à :

- Blesser ou tuer pour s'approprier ou non de tout ou partie de sa dépouille, un animal en liberté ou dans son milieu naturel au sens des textes législatifs et réglementaires en vigueur;

- Détruire les oeufs des oiseaux ou des reptiles.

La capture consiste en tout acte tendant à :

Priver de sa liberté un animal sauvage ;

- $\quad$ Récolter ou retirer hors de leur lieu naturel d'éclosion, les oeufs des oiseaux ou des reptiles.

L'étude d'impact environnemental est un rapport dévaluation de l'impact probable d'une activité envisagée sur l'environnement.

Le Bureau d'Études d'Impact environnemental est un service à la disposition de l'autorité nationale compétente chargé d'examiner les études d'impact.

L'audit environnemental est une procédure d'évaluation et de contrôle des actions de protection et de l'environnement.

L'autorité nationale compétente peut être une entité unique ou un groupement d'entités dont les compétences sont définies par décret.

L'Association de Défense de l'Environnement est la convention par laquelle deux ou plusieurs personnes mettent en commun leurs connaissances ou leurs activités dans un but autre que de partager des bénéfices en vue de concourir à la défense de l'environnement.

\section{CHAPITRE II : Objectifs}

Article 2 : Le présent Code vise à :

- Protéger les sols, sous-sols, sites, paysages, monuments nationaux, les formations végétales, la faune et la flore et particulièrement les domaines classés, les parcs nationaux et réserves existantes ;

- Établir les principes fondamentaux destinés à gérer, à protéger l'environnement contre toutes les formes de dégradation afin de valoriser les ressources naturelles, de lutter contre toutes sortes de pollutions et nuisances;

- Améliorer les conditions de vie des différents types de populations dans le respect de l'équilibre avec le milieu ambiant ;

- Créer les conditions d'une utilisation rationnelle et durable des ressources naturelles pour les générations présentes et futures;

- Garantir à tous les citoyens, un cadre de vie écologiquement sain et équilibré ;

- Veiller à la restauration des milieux endommagés.

\section{CHAPITRE III : Domaine d'application}

Article 3 : La présente loi ne fait pas obstacle à l'application des dispositions législatives et réglementaires concernant l'urbanisme et les constructions, la santé, l'hygiène, la sécurité et la tranquillité publique, la protection des écosystèmes et d'une manière générale à l'exercice des pouvoirs de Police.

Article 4 : La présente loi ne s'applique pas aux activités militaires et aux situations de guerre. 
Cette exclusion ne dispense pas les auteurs de telles activités de prendre en compte les préoccupations de protection de l'environnement.

Article 5 : la présente loi s'applique à toutes les formes de pollution, telles que définies à l'article premier du présent Code et susceptibles de provoquer une altération de la composition et de la consistance de la couche atmosphérique avec des conséquences dommageables pour la santé des êtres vivants, la production, les biens et l'équilibre des écosystèmes.

Article 6 : Sont soumis aux dispositions de la présente loi :

- Les installations classées telles que définies dans leur nomenclature: les usines, dépôts, mines, chantiers, carrières, stockages souterrains ou en surface, magasins et ateliers;

- Les installations exploitées ou détenues par toute personne physique ou morale, publique ou privée, qui peuvent présenter des dangers ou des inconvénients, soit pour la commodité, soit pour la santé, la sécurité et la salubrité publique ;

- Les déversements, écoulements, rejets, dépôts susceptibles de provoquer ou d'accroître la dégradation du milieu récepteur.

Article 7 : Sont visés, aux termes de la présente loi, les différents types d'énergie suivants :

- L'énergie solaire;

- L'énergie de biomasse ;

- L'énergie éolienne;

- L'énergie géothermique;

- L'énergie hydro-électrique;

- L'énergie thermique ;

- L'énergie nucléaire.

Article 8 : Aux termes de la présente loi, sont visées les substances ou combinaisons de substances fabriquées ou à l'état naturel susceptibles, en raison de leur caractère toxique, radioactif, corrosif ou nocif, de constituer un danger pour la santé des personnes, la conservation des sols et sous-sols, des eaux, de la faune et de la flore, de l'environnement en général, lorsqu'elles sont utilisées ou évacuées dans le milieu naturel.

Article 9 : Est visée par la présente loi, l'utilisation de techniques publicitaires agressives ;

Nul ne peut faire de la publicité sur un immeuble sans l'autorisation du propriétaire ou des autorités compétentes dans les conditions fixées par décret.

\section{TITRE II L'ENVIRONNEMENT}

\section{CHAPITRE I : L'environnement naturel}

Section 1 : Le sol et le sous-sol

Article 10 : Le sol et le sous-sol constituent des ressources naturelles à préserver de toutes formes de dégradation et dont il importe de promouvoir l'utilisation durable.

L'usage du sol et du sous-sol doit être fait en respectant les intérêts collectifs attachés à leur préservation.

À ce titre, le droit de propriété doit être exercé sans qu'il nuise à l'intérêt général. Les statuts du sol doivent établir les droits et obligations du titulaire vis-à-vis d'une protection du sol.

Article 11 : Les sols doivent être affectés à des usages conformes à leur vocation. L'utilisation d'espaces pour des usages non réversibles doit être limitée et la plus rationnelle possible. 
Article 12 : Tout projet d'aménagement et d'exploitation du sol à des fins agricoles, industrielles ou urbaines, tout projet de recherche ou d'exploitation des matières premières du sous-sol sont soumis à autorisation préalable dans les conditions fixées par décret.

Section 2 : Les ressources en eau et les eaux maritimes

Article 13 : Les points de prélèvement de l'eau destinée à la consommation humaine doivent être entourés d'un périmètre de protection prévu à l'article 51 du présent Code.

Toute activité susceptible de nuire à la qualité des eaux est interdite ou peut être réglementée à l'intérieur des périmètres de protection.

Article 14 : La gestion de l'eau peut être concédée.

Le concessionnaire est responsable de la qualité de l'eau distribuée conformément aux normes en vigueur.

Article 15 : Les occupants d'un bassin versant et/ou les utilisateurs de l'eau peuvent se constituer en association pour la protection du milieu.

Section 3 : La diversité biologique

Article 16: L'introduction, l'importation et l'exportation de toute espèce animale ou végétale sont soumises à autorisation préalable dans les conditions fixées par décret.

Article 17 : En dehors de la chasse traditionnelle ou des cas prévus par les articles 99 et 103 du Code pénal relatifs à la légitime défense et à l'état de nécessité, toutes formes de chasse sont soumises à l'obtention d'un permis de chasse.

Article 18 : Toutes les formes de pêche relèvent de l'autorité nationale compétente :

- La pêche artisanale doit être exercée dans le respect de la réglementation en tenant compte d'une bonne gestion de l'environnement ;

- La pêche industrielle requiert pour son exercice, l'obtention d'une licence délivrée par l'autorité administrative compétente.

Article 19 : La vente, l'échange, la commercialisation de la viande de chasse sont réglementés.

Section 4 : L'air

Article 20 : Les immeubles, les installations classées, les véhicules et engins à moteur, les activités industrielles, commerciales, artisanales ou agricoles, détenus par toute personne physique ou morale doivent être conçus et exploités conformément aux normes techniques en matière de préservation de l'atmosphère.

\section{CHAPITRE II : L'environnement humain}

Article 21 : Les plans d'aménagement du territoire, les schémas directeurs, les plans d'urbanisme et autres documents d'urbanisme doivent prendre en compte les impératifs de protection de l'environnement dans le choix, l'emplacement et la réalisation des zones d'activité économique, industrielle, de résidence et de loisirs.

Article 22 : L'autorité compétente, aux termes des règlements en vigueur, peut refuser le permis de construire si les constructions sont de nature à porter atteinte au caractère ou à l'intégrité des lieux avoisinants.

Article 23 : Aucun travail public ou privé dans le périmètre auquel s'applique un plan ne peut être réalisé que s'il n'est compatible avec ce dernier, et s'il ne prend en considération les dispositions d'ordre environnemental, prévues par les textes en vigueur. 
Article 24 : Les travaux de construction d'ouvrages publics tels que routes, barrages, peuvent être soumis à étude d'impact environnemental.

Article 25 : Les caractéristiques des eaux résiduaires rejetées doivent permettre aux milieux récepteurs de satisfaire aux objectifs qui leur sont assignés. Le déversement des eaux résiduaires dans le réseau d'assainissement public ne doit nuire ni à la conservation des ouvrages, ni à la gestion de ces réseaux.

Article 26 : Tous les déchets, notamment les déchets hospitaliers et dangereux doivent être collectés, traités et éliminés de manière écologiquement rationnelle afin de prévenir, supprimer ou réduire leurs effets nocifs sur la santé de l'homme, sur les ressources naturelles, sur la faune et la flore et sur la qualité de l'environnement.

Article 27 : L'enfouissement dans le sol et le sous-sol de déchets non toxiques ne peut être opéré qu'après autorisation et sous réserve du respect des prescriptions techniques et règles particulières définies par décret.

Article 28 : L'élimination des déchets doit respecter les normes en vigueur et être conçue de manière à faciliter leur valorisation.

À cette fin, il est fait obligation aux structures concernées de :

- Développer et divulguer la connaissance des techniques appropriées ;

- Conclure des contrats organisant la réutilisation des déchets ;

- Réglementer les modes de fabrication.

Article 29: Tous les engins doivent être munis d'un avertisseur sonore conforme à un type homologué par les services compétents et ne doivent pas émettre de bruit susceptible de causer une gêne aux usagers de la route et aux riverains.

Article 30 : En agglomération, l'usage des avertisseurs sonores n'est autorisé qu'en cas de besoin absolu pour donner des avertissements nécessaires aux autres usagers de la route.

La nuit, les signaux sonores ne doivent être utilisés qu'en cas de nécessité absolue.

Article 31 : Lorsque l'urgence le justifie, l'autorité compétente peut prendre toutes les mesures appropriées pour faire cesser immédiatement toute émission de bruits susceptibles de nuire à la santé des êtres vivants, de constituer une gêne excessive et insupportable pour le voisinage ou d'endommager les biens.

Article 32 : Les feux précoces ou les feux allumés en vue de renouvellement des pâturages, de débroussaillement de cultures ou dans le cadre de l'aménagement des zones pastorales, forestières ou savanicoles, des parcs nationaux et des réserves fauniques font l'objet de réglementation de la part de l'autorité administrative compétente.

\section{TITRE III PRINCIPES GÉNÉRAUX}

Article 33 : Toute personne a le droit fondamental de vivre dans un environnement sain et équilibré. Il a aussi le devoir de contribuer individuellement ou collectivement à la sauvegarde du patrimoine naturel.

À cette fin, lorsqu'un tribunal statue sur une demande, il prend notamment en considération, l'état des connaissances scientifiques, les solutions adoptées par les autres pays et les dispositions des instruments internationaux.

Article 34 : La politique nationale de protection de l'environnement incombe à l'État.

L'État peut élaborer des plans d'actions environnementales avec les collectivités locales ou toute autre structure. 
Article 35 : Lors de la planification et de l'exécution d'actes pouvant avoir un impact important sur l'environnement, les autorités publiques et les particuliers se conforment aux principes suivants :

\subsection{Principe de précaution}

Lors de la planification ou de l'exécution de toute action, des mesures préliminaires sont prises de manière à éviter ou à réduire tout risque ou tout danger pour l'environnement.

Toute personne dont les activités sont susceptibles d'avoir un impact important sur l'environnement doit, avant d'agir prendre en considération les intérêts d'autrui ainsi que la nécessité de protéger l'environnement.

Si, à la lumière de l'expérience ou des connaissances scientifiques, une action est jugée susceptible de causer un risque ou un danger pour l'environnement, cette action n'est entreprise qu'après évaluation préalable indiquant qu'elle n'aura pas d'impact préjudiciable à l'environnement.

\subsection{Substitution}

Si à une action susceptible d'avoir un impact préjudiciable à l'environnement, peut être substituée une autre action qui présente un risque ou un danger moindre, cette dernière action est choisie même si elle entraîne des coûts plus élevés en rapport avec les valeurs à protéger.

\subsection{Préservation de la diversité biologique}

Toute action doit éviter d'avoir un effet préjudiciable notable sur la diversité biologique

\subsection{Non-dégradation des ressources naturelles}

Pour réaliser un développement durable, il y a lieu d'éviter de porter atteinte aux ressources naturelles tels que l'eau, l'air et les sols qui, en tout état de cause font partie intégrante du processus de développement et ne doivent pas être prises en considération isolément. Les effets irréversibles sur les terres doivent être évités dans toute la mesure du possible.

\subsection{Principe "Pollueur-payeur»}

Toute personne physique ou morale dont les comportements et les activités causent ou sont susceptibles de causer des dommages à l'environnement, est soumise à une taxe et/ou à une redevance. Elle assume, en outre, toutes les mesures de remise en état.

\subsection{Information et participation}

Toute personne a le droit d'être informée de l'état de l'environnement et de participer aux procédures préalables à la prise de décisions susceptibles d'avoir des effets préjudiciables à l'environnement.

\subsection{Coopération}

Les autorités publiques, les institutions internationales, les associations et les particuliers concourent à protéger l'environnement à tous les niveaux possibles.

\section{TITRE IV LES OBLIGATIONS DE L'ÉTAT ET DES COLLECTIVITÉS LOCALES}

\section{CHAPITRE PREMIER : Dispositions générales}

Article 36 : L'État est propriétaire des gisements et des accumulations naturelles d'hydrocarbures existant en Côte d'Ivoire, y compris sur le plateau continental.

Article 37 : Les cours d'eau, les lagunes, les lacs naturels, les nappes phréatiques, les sources, les bassins versants et les zones maritimes sont du domaine public.

Article 38 : Les immeubles, établissements agricoles, industriels, commerciaux ou artisanaux, véhicules ou autres objets mobiliers possédés, exploités ou détenus par toute personne physique ou morale, privée ou 
publique, devront être construits, exploités ou utilisés de manière à satisfaire aux normes techniques en vigueur ou édictées en application de la présente loi.

Article 39 : Tout projet important susceptible d'avoir un impact sur l'environnement doit faire l'objet d'une étude d'impact préalable. Il en est de même pour les programmes, plans et politiques pouvant affecter l'environnement. Un décret en précisera la liste complète.

Tout projet fait l'objet d'un contrôle et d'un suivi pour vérifier la pertinence des prévisions et adopter les mesures correctives nécessaires.

Article 40 : L'Étude d'Impact environnemental (EIE) comporte au minimum :

- Une description de l'activité proposée ;

- Une description de l'environnement susceptible d'être affecté y compris les renseignements spécifiques nécessaires pour identifier ou évaluer les effets de l'activité proposée sur l'environnement ;

- Une liste des produits utilisés le cas échéant ;

- Une description des solutions alternatives le cas échéant ;

- Une évaluation des effets probables ou potentiels de l'activité proposée et des autres solutions possibles sur l'environnement, y compris les effets directs, indirects, cumulatifs à court, moyen et long termes ;

- L'identification et la description des mesures visant à atténuer les effets de l'activité proposée et les autres solutions possibles sur l'environnement et une évaluation de ces mesures;

- Une indication des lacunes en matière de connaissance et des incertitudes rencontrées dans la mise au point de l'activité nécessaire ;

- Une indication sur les risques pour l'environnement d'un État voisin dus à l'activité proposée ou aux autres solutions possibles;

- Un bref résumé de l'information fournie au titre des rubriques précédentes;

- La définition des modalités de contrôle et de suivi réguliers des indicateurs environnementaux avant (état initial), pendant le chantier, durant l'exploitation de l'ouvrage ou de l'aménagement et le cas échéant, après la fin de l'exploitation (remise en état ou réaménagement des lieux);

- Une estimation financière des mesures préconisées pour prévenir, réduire ou compenser les effets négatifs du projet sur l'environnement des mesures de suivi et contrôle réguliers d'indicateurs environnementaux pertinents.

Article 41 : L'examen des études d'impact environnemental par le Bureau d'Étude d'Impact environnemental, donnera lieu au versement d'une taxe au Fonds National de l'Environnement dont l'assiette sera précisée par décret.

Article 42 : Sur proposition de l'autorité nationale compétente, le Conseil des ministres établit et révise par décret la liste des travaux, activités, documents de planification pour lesquels les autorités publiques ne pourront, sous peine de nullité, prendre aucune décision, approbation ou autorisation sans disposer d'une étude d'impact environnemental leur permettant d'en apprécier les conséquences directes ou indirectes pour l'environnement.

Article 43 : Sont soumises à autorisation, les installations qui présentent des dangers ou inconvénients visés à l'article 6 du présent Code.

Elles ne peuvent être ouvertes sans une autorisation préalable délivrée dans les conditions fixées par décret sur demande de l'exploitant.

Sont soumises à déclaration, les installations qui, bien que ne présentant pas de tels dangers ou inconvénients, doivent néanmoins respecter les prescriptions générales dictées par l'autorité compétente en vue d'assurer la protection des intérêts visés à l'article 6. Les installations soumises à autorisation, qui génèrent des risques majeurs (incendies, explosions, émanations toxiques, etc.), font l'objet d'une réglementation spécifique visant notamment à maîtriser l'urbanisation dans leur environnement immédiat.

Article 44 : Sont soumises à permis ou à licence, la pêche industrielle, la chasse et la capture. 
Article 45 : L'inspection des installations classées est assurée par des agents assermentés ayant la qualité d'officier de Police judiciaire dans l'exercice de leur fonction.

Article 46 : Les installations classées visées à l'article 6 sont assujetties à une taxe de contrôle et d'inspection, versée au Fonds National de l'Environnement.

Article 47 : Les installations de l'État affectées à la défense nationale, sont soumises à des règles particulières.

Article 48 : Toutes les installations classées existantes bénéficient d'un délai de 2 ans à compter de la promulgation de la présente loi pour se conformer à ses dispositions et à ses textes d'application.

Article 49 : Il est instauré des normes appropriées pour la protection de l'environnement.

Il est créé un label pour les produits de consommation les plus respectueux de l'environnement.

Des normes sont également exigées pour les produits importés.

Article 50 : Les entreprises ou ouvrages, sources de pollutions importantes seront soumis à un audit écologique par des experts agréés, aux frais de leurs promoteurs. Les conditions de cet audit sont précisées par décret. Les résultats de l'audit écologique sont transmis à l'autorité nationale compétente.

Article 51 : Il est institué des périmètres de protection en vue de la conservation ou de la restauration des :

- Écosystèmes ;

- Forêts, boisements, espèces et espaces protégés ;

- Monuments, sites et paysages ;

- Systèmes hydrauliques et de la qualité des eaux

Espaces littoraux ...

Article 52 : L'autorité nationale compétente peut à l'intérieur des périmètres visés à l'article 49 :

- Interdire, limiter ou réglementer les activités incompatibles avec les objectifs assignés à la zone ;

- Mettre en oeuvre des programmes de restauration du milieu naturel ou des monuments ;

- Approuver tout plan d'aménagement ou d'action définissant les moyens d'atteindre les objectifs assignés à la zone.

Article 53 : La protection, la valorisation et la conservation du patrimoine culturel et architectural font partie intégrante de la politique nationale de protection et de la mise en valeur de l'environnement.

Article 54 : Il est dressé, une liste de sites et monuments protégés qui précise les mesures à prendre pour la protection du patrimoine architectural, historique et culturel sur tout le territoire national.

Cette liste est révisée tous les cinq ans.

\section{CHAPITRE III : Obligations de l'État et des Collectivités locales}

\section{Section $1:$ Les obligations de l'État}

Article 55 : L'État s'engage à :

- Faire de l'environnement et de sa protection une politique globale et intégrée ;

- Prendre toutes les dispositions appropriées pour assurer ou faire assurer le respect des obligations découlant des conventions et accords internationaux auxquels il est partie ;

- Interdire toute activité menée sous son contrôle ou dans les limites de sa juridiction, susceptible d'entraîner une dégradation de l'environnement dans un autre État ou dans des régions ne relevant d'aucune juridiction nationale ; 
- Euvrer en toute coopération avec les autres États pour prendre les mesures contre la pollution transfrontière.

Article 56 : L'État détermine la politique nationale de l'environnement et veille à sa mise en oeuvre.

Il assure, par des mesures idoines, la protection, la conservation et la gestion de l'environnement. Toutefois, Les occupants d'un bassin versant et/ou les utilisateurs de l'eau peuvent se constituer en association pour la protection du milieu.

Il réglemente l'établissement d'accès aux digues et aux déversements d'égouts dans les milieux récepteurs.

Il interdit et réglemente l'exercice d'activités susceptibles de constituer, d'une manière ou d'une autre, une menace pour l'environnement, l'intégrité et le fonctionnement des écosystèmes.

Article 57 : L'État détermine :

- La création d'un réseau de réserves biologiques en proportion avec l'usage des sols ;

- Les mesures de lutte contre l'érosion ;

- Les mesures de lutte contre la pollution du sol par des substances chimiques, les engrais, les produits phytosanitaires et autres dont l'usage est admis ;

- Les mesures de prévention des pollutions diffuses affectant le sol et les mesures concrètes de restauration des sols endommagés;

- Les périmètres de protection des points de prélèvement de l'eau destinée à la consommation humaine ;

- Les seuils critiques des polluants atmosphériques;

- Les espaces alloués aux zones industrielles.

Article 58 : L’État dresse une liste :

- Des espèces animales et végétales qui doivent être partiellement, intégralement ou spécialement protégées en raison, de leur rôle dans les écosystèmes, de leur rareté, de leur valeur esthétique, de la menace qui pèse sur leurs populations et enfin l'intérêt économique, culturel et scientifique qu'elles représentent ;

- Des sites et monuments protégés en précisant les mesures à prendre pour la protection du patrimoine architectural, historique et culturel national ;

- Des établissements, édifices et monuments qui, bien que non classés ou inscrits sur lesquels l'affichage est interdit.

Cette liste est revue et corrigée tous les cinq ans.

Article 59 : L'État assure la gestion de l'eau en préservant la qualité de ses sources, en évitant le gaspillage et en accroissant la disponibilité.

Article 60 : L'État établit des normes conçues de manière à faciliter la valorisation des déchets.

À cette fin, il est fait obligation aux structures concernées :

- De développer et de divulguer la connaissance des techniques appropriées ;

- De conclure des contrats organisant la réutilisation des déchets;

- De réglementer les modes de fabrication et d'utilisation de certains matériaux ou produits, afin de faciliter la récupération des éléments de leur composition.

Article 61 : L'État s'engage à :

- Promouvoir l'utilisation des énergies renouvelables ou non ;

- Lutter contre toute forme de gaspillage des énergies ;

- Lutter contre le gaspillage de toutes les sources d'énergie notamment les ressources ligneuses.

Article 62 : Tout projet de texte relatif à l'environnement est soumis à l'avis et à l'observation de l'autorité nationale compétente. 
L'Autorité Nationale Compétente dispose d'un délai d'un mois à compter de la transmission du projet pour donner suite. Le silence de ladite autorité vaut, aux termes du délai, approbation. Toute divergence entre l'auteur d'un projet et l'autorité nationale compétente est tranchée par le Conseil des ministres.

Article 63 : L'État prend les mesures adéquates pour introduire l'éducation, la formation et la sensibilisation environnementale dans les programmes d'enseignement à tous les niveaux. Il peut donner son agrément aux associations de défense de l'environnement et leur attribuer des subventions.

Article 64 : Dans sa politique nationale de gestion de l'environnement, l'État de Côte d'Ivoire intègre la Coopération internationale.

Article 65 : L'autorité nationale compétente coordonne les mécanismes nationaux de mise en oeuvre et de suivi des Conventions et Accords internationaux relatifs à l'Environnement.

\section{Section 2 : Les obligations des Collectivités locales}

Article 66 : Les communes sont responsables de la collecte et de l'élimination des déchets ménagers. Cette action peut être entreprise en liaison avec les départements et les régions ou avec des groupes publics ou privés habilités à cet effet.

Elles ont l'obligation d'élaborer des schémas de collecte et de traitement des déchets ménagers avec le concours des services techniques des structures compétentes.

Elles assurent également l'élimination d'autres déchets qu'elles peuvent, eu égard à leurs caractéristiques et aux quantités produites, contrôler ou traiter.

Article 67 : Les Collectivités locales sont tenues d'avoir :

- Un plan de gestion de l'environnement;

- Une ou plusieurs décharges contrôlées d'ordures ménagères.

Elles veillent à enrayer tous les dépôts sauvages.

Elles instituent une taxe de salubrité.

Section 3 : Les obligations communes à l'État et aux Collectivités locales

Article 68 : Il incombe à l'État et aux Collectivités locales et aux concessionnaires d'assurer, dans le respect des prescriptions environnementales, l'exploitation rationnelle des gisements et accumulations naturelles d'hydrocarbures liquides ou gazeux existant en Côte d'Ivoire y compris sur le plateau continental.

Article 69 : L'État et les Collectivités doivent veiller à la création, au maintien et à l'entretien d'espaces verts.

Article 70 : La gestion des eaux usées relève de la compétence de l'État, des Collectivités locales et de toutes autres structures susceptibles de produire des effluents de nature à porter atteinte à l'environnement.

Elle peut faire l'objet d'une concession.

Article 71 : L'État, les régions, les départements et les Collectivités locales s'engagent à élaborer des programmes d'action et des plans d'urgence dans tous les domaines en vue de protéger l'environnement.

Article 72 : L'éducation, la formation et la sensibilisation environnementales incombent à l'État, aux Collectivités locales et aux associations de défense.

Article 73 : Les Établissements et Institutions publics ou privés ayant en charge l'enseignement, la recherche et l'information, sont tenus dans le cadre de leurs compétences respectives :

- De sensibiliser aux problèmes d'Environnement par des programmes adaptés ; 
- D'intégrer dans leurs activités, des programmes permettant d'assurer une meilleure connaissance de l'Environnement.

Section 2 : Les institutions

Article 74 : Pour l'application de la présente loi, il est créé :

- Un Réseau de Réserves biologiques en proportion avec l'intensification de l'exploitation des sols;

- Un Observatoire de la Qualité de l'Air ;

- Une Agence Nationale de l'Environnement (ANDE), Établissement public de catégorie particulière doté de la personnalité morale et de l'autonomie financière ;

- Un Fonds national de l'environnement (FNDE);

- Une bourse de déchets ;

Par ailleurs, le juge des référés est compétent pour constater ou faire cesser immédiatement une pollution ou toute forme de dégradation de l'environnement.

La procédure d'urgence prévue aux articles 221 à 230 du Code de procédure civile, commerciale et administrative est applicable.

\section{TITRE IV DISPOSITIONS PRÉVENTIVES ET DISPOSITIONS PÉNALES}

\section{CHAPITRE I : Dispositions préventives}

Article 75 : Sont interdits :

- Les déversements, les rejets de tous corps solides, de toutes substances liquides, gazeuses, dans les cours et les plans d'eau et leurs abords ;

- Toute activité susceptible de nuire à la qualité de l'air et des eaux tant de surface que souterraines.

Article 76 : Il est interdit de rejeter dans les zones maritimes et lagunaires, toutes substances, susceptibles de :

- Détruire les sites et monuments présentant un intérêt scientifique, culturel, touristique ou historique ;

- Détruire la faune et la flore ;

- Constituer un danger pour la santé des êtres vivants ;

- Porter atteinte à la valeur esthétique et touristique de la lagune, de la mer et du littoral.

Article 77 : Il est interdit de rejeter dans les eaux maritimes et lagunaires sous juridiction ivoirienne :

- Des eaux usées, à moins de les avoir préalablement traitées conformément aux normes en vigueur ;

- Des déchets de toutes sortes non préalablement traités et nuisibles.

Article 78 : Il est interdit de détenir ou d'abandonner des déchets susceptibles de :

- Favoriser le développement d'animaux vecteurs de maladies ;

- Provoquer des dommages aux personnes et aux biens.

Article 79 : Sont interdits :

- Tous déversements, écoulements, rejets ou dépôts de toutes natures susceptibles de provoquer ou d'accroître la pollution des eaux continentales, lagunaires et maritimes dans les limites territoriales;

- Toute exploitation illégale, dégradante et/ou non réglementée ;

Toute émission dans l'atmosphère de gaz toxique, fumée, suie, poussière ou toutes autres substances chimiques non conformes à la réglementation en vigueur.

Article 80 : Conformément aux dispositions spéciales des Conventions internationales ratifiées par la Côte d'Ivoire, sont interdits, les déversements, les immersions et incinérations dans les eaux maritimes sous juridiction ivoirienne de substances de toutes natures susceptibles de :

- De porter atteinte à la santé publique et aux ressources maritimes biologiques ;

- De nuire aux activités maritimes y compris la navigation et la pêche ;

- D’altérer la qualité des eaux maritimes ; 
- De dégrader les valeurs d'agrément et le potentiel touristique de la mer et du littoral.

Article 81 : Sont interdits :

- L'importation non autorisée des déchets sur le territoire national ;

- Les dépôts de déchets sur le domaine public non autorisé, y compris le domaine public maritime tel que défini par les textes en vigueur ;

- L'immersion, l'incinération, ou l'élimination par quelque procédé que ce soit, des déchets dans les eaux continentales, lagunaires et maritimes, sous juridiction ivoirienne.

Article 82 : Sont interdits sur le territoire national, tous actes relatifs à l'achat, à la vente, à l'importation, à l'exportation et au transit des substances ou combinaisons de substances visées à l'article 8 de la présente loi.

Article 83 : Sont interdites, si elles n'ont pas fait l'objet d'une homologation et/ou si elles ne bénéficient pas d'une autorisation provisoire de vente, d'importation, d'exportation, délivrée par les autorités compétentes, toute importation, exportation, détention en vue de la vente ou de la mise en vente, de distribution même à titre gratuit de l'une quelconque des matières fertilisantes définies à l'article premier de la présente loi.

Article 84 : L'usage de l'avertisseur sonore est interdit dans les agglomérations et aux environs des hôpitaux et des écoles sauf en cas de nécessité absolue et dans ce cas, il doit être bref et modéré.

De même, sont interdites les émissions de bruits, de lumières et d'odeurs susceptibles de nuire à la santé des êtres vivants ou de constituer une gêne excessive et insupportable pour le voisinage ou d'endommager des biens.

Article 85 : Tout affichage est interdit sur :

- Les immeubles classés monuments historiques ou inscrits ;

- Les monuments naturels et dans les sites classés, inscrits ou protégés ;

- Les monuments, sites et les constructions dont la liste est établie par les autorités compétentes, bénéficiant d'une protection spéciale ;

- Les panneaux de signalisation routière.

Article 86 : Sont interdits :

- L'usage d'explosifs, de drogues, de produits chimiques ou appâts dans les eaux, de nature à enivrer le poisson ou à le détruire ;

- L'emploi de drogues, de produits chimiques ou appâts de nature à détruire le gibier et/ou le rendre impropre à la consommation ;

- Les feux de brousse non contrôlés.

Article 87 : Il est interdit de :

- Tuer, blesser ou capturer les animaux appartenant aux espèces protégées ;

- Détruire ou endommager les habitats, les larves et les jeunes espèces protégées ;

- Faire périr, endommager les végétaux protégés, en cueillir tout ou partie ;

- Transporter ou mettre en vente tout ou partie d'un animal ou d'un végétal protégé ;

- Procéder à l'abattage d'arbres dans les forêts classées, aires protégées et parcs nationaux.

\section{CHAPITRE II : Dispositions pénales}

Article 88 : Toute personne morale ou physique, qui omet de faire une étude d'impact environnemental prescrite par l'autorité compétente et préalable à tout projet susceptible d'avoir des effets nuisibles sur l'environnement, est passible de suspension d'activité ou de fermeture d'établissement sans préjudice des mesures de réparation aux dommages causés à l'environnement, aux personnes et aux biens.

La falsification d'une étude d'impact environnemental et/ou sa non-conformité sont punies des mêmes peines. 
Article 89 : Est puni d'un emprisonnement de deux mois à deux ans et d'une amende de 5.000.000 de francs, quiconque procède ou fait procéder à l'abattage d'arbres ou d'animaux dans les forêts classées, les aires protégées et les parcs nationaux.

Les complices sont punis par des mêmes peines.

Article 90 : Est punie d'une amende de 10.000.000 de francs à 100.000.000 de francs et d'un emprisonnement de six mois à deux ans ou de l'une de ces deux peines seulement, toute destruction de site ou monument classé.

Article 91 : Est puni d'un emprisonnement de un à six mois et d'une amende de 1.000 .000 de francs à 5.000.000 de francs ou de l'une de ces deux peines seulement tout responsable d'un établissement faisant obstacle à l'exercice des fonctions des agents chargés de l'inspection des installations classées.

En cas de récidive, il sera procédé à la fermeture temporaire de l'établissement.

Article 92 : Est passible d'une amende de 5.000.000 de francs à 50.000.000 de francs sans préjudice d'une suspension temporaire des activités, ou d'une fermeture de l'établissement, tout établissement qui ne se sera pas mis en conformité avec les dispositions de la présente loi dans les deux ans de sa promulgation.

Article 93 : Quiconque poursuit l'exploitation d'une installation classée sans se conformer à la mise en demeure d'avoir à respecter les prescriptions techniques déterminées, sera puni d'une peine d'emprisonnement d'un mois à un an et d'une amende de 200.000 francs à 2.000 .000 de francs.

Article 94 : Quiconque poursuit l'exploitation d'une installation classée frappée de fermeture, de suspension ou d'interdiction est puni de deux mois à deux ans d'emprisonnement et de 50.000.000 de francs à 100.000.000 de francs ou de l'une de ces deux peines seulement.

Article 95 : Est puni d'une amende de 1.000 .000 de francs à 2.500 .000 de francs et d'un emprisonnement de six mois à deux ans ou de l'une de ces deux peines seulement quiconque se livre de façon illicite à des travaux de recherche ou d'exploitation des hydrocarbures.

Article 96 : Est passible d'une amende de 100.000.000 de francs à 500.000.000 de francs quiconque effectue des rejets interdits ou, sans autorisation, des rejets soumis à autorisation préalable ainsi que défini aux articles 74 à 86 du présent Code dans les conditions fixées par décret ou ne se conforme pas aux conditions déterminées par son autorisation.

Article 97 : Est puni d'une amende de 2.000.000 de francs à 50.000.000 de francs et d'un emprisonnement de deux mois à deux ans ou de l'une de ces deux peines seulement, toute personne ayant pollué les eaux continentales par des déversements, écoulements, rejets et dépôts de substances de toute nature susceptible de provoquer ou d'accroître la pollution des eaux et/ou des eaux maritimes dans les limites territoriales.

En cas de récidive, la peine est portée au double. Le coupable peut être condamné à curer les lieux pollués. L'autorité nationale compétente peut, en cas de négligence, refus ou résistance, y procéder ou y faire procéder aux frais et dépens de l'intéressé.

Article 98 : Est puni d'une amende de 100.000.000 de francs à 1.000.000.000 de francs et d'un emprisonnement de un à cinq ans ou de l'une des deux peines seulement sans préjudice des sanctions administratives en vigueur, quiconque, nonobstant les dispositions spéciales des Conventions internationales, procède à des déversements, immersion et incinération dans les eaux maritimes sous juridiction ivoirienne, des substances de toutes natures, susceptibles :

- De porter atteinte à la santé publique et aux ressources maritimes biologiques ;

- De nuire aux activités maritimes y compris la navigation et la pêche ;

- D’altérer la qualité des eaux maritimes ;

- De dégrader les valeurs d'agrément et le potentiel touristique de la mer et du littoral. 
L'Administration maritime peut arraisonner tout navire surpris en flagrant délit de déversement de contaminants, y compris les hydrocarbures en mer.

En cas de récidive, l'amende est portée au double et l'Administration se réserve le droit de procéder à la saisie des biens.

Article 99 : Est passible d'un emprisonnement de 1 à 5 ans et d'une amende de 5.000 .000 de francs à 100.000.000 de francs quiconque :

- Dépose des déchets dans le domaine public maritime national ;

- Importe sans autorisation des déchets sur le territoire national ;

- Immerge, incinère ou élimine par quelque procédé que ce soit des déchets dans les eaux continentales, lagunaires et/ou maritimes sous juridiction ivoirienne.

Article 100 : Est punie d'une amende de 1.000 .000 de francs à 30.000 .000 de francs et d'un emprisonnement de trois à vingt-quatre mois ou l'une de ces deux peines seulement, toute entreprise agréé procédant à des dépôts sauvages.

L'autorisation d'exercer toute activité de collecte de déchets sur le territoire nation peut être suspendue pour une période d'au moins deux ans.

Article 101 : Quiconque procède ou fait procéder à l'achat, à la vente, à l'importation, au transit, au stockage, à l'enfouissement ou au déversement sur le territoire national de déchets dangereux ou signe un accord pour l'autorisation de telles activités est puni d'un emprisonnement de 10 à 20 ans et d'une amende de 500.000 .000 de francs à 5.000 .000 .000 de francs.

La juridiction ayant prononcé la peine peut :

- Ordonner la saisie de tout moyen ayant servi à la commission de l'infraction ;

- Ordonner la saisie et l'élimination des déchets aux frais et dépens des propriétaires desdits déchets.

Article 102 : Est puni d'une amende de 1.000 francs à 5.000 francs celui qui dépose, abandonne, jette des ordures déchets, matériaux, ou versé des eaux usées domestiques en un lieu public ou privé sauf si le dépôt a lieu à un emplacement désigné à cet effet par l'Autorité compétente.

Sont punis d'une amende de 1.000 francs à 10.000 francs ou astreints qu nettoyage, ceux qui auront pollué par des déchets humains un bien public ou privé sauf si ces emplacements sont désignés à cet effet par l'autorité compétente.

Article 103 : Est passible d'une amende de 10.000 francs à 5.000 .000 de francs quiconque :

- Fait usage dans les agglomérations et aux environs des hôpitaux et des écoles, d'avertisseurs sonores en dehors des cas de danger immédiat ;

- Fait usage intempestif et sans nécessité absolue, en dehors des agglomérations, d'avertisseurs sonores;

- Fait usage, sans nécessité absolue d'avertisseurs sonores dans la nuit ;

- Émet des bruits susceptibles de causer une gêne aux usagers de la route et aux riverains ;

- Utilise des engins à moteur munis d'avertisseurs sonores non conformes au type homologué par les services compétents ;

- Émet des bruits susceptibles de nuire à la santé des êtres vivants, de constituer une gêne excessive et insupportable pour le voisinage ou d'endommager des biens.

Article 104 : Est puni d'une amende de 50.000 francs à 5.000 .000 de francs et d'un emprisonnement de trois mois au maximum quiconque fait :

- De la publicité sur un immeuble sans l'autorisation du propriétaire et des autorités compétentes;

- De l'affichage et graffitis sur des immeubles classés inscrits ou classés monuments historiques, sur des monuments naturels et dans les sites inscrits ou protégés.

Article 105 : Les circonstances atténuantes et le sursis ne sont pas applicables aux infractions prévues par le présent Code relatives aux déchets dangereux. 
Article 106 : La tentative et la complicité des infractions prévues par le présent Code sont punissables des mêmes peines que l'infraction elle-même.

Article 107 : Les infractions sont constatées sur procès-verbal par les agents assermentés de l'autorité nationale compétente.

Article 108 : L'Administration chargée de l'Environnement peut transiger en toute circonstance et à tout moment de la procédure avant toute décision au fond.

La demande transaction est soumise à l'autorité nationale compétente qui fixe en cas d'acceptation, le montant de celle-ci.

Article 109 : La poursuite des infractions relevant du présent Code obéit aux règles définies par le Code de Procédure pénale.

Article 110 : Les collectivités locales, les associations de l'environnement régulièrement déclarées ou toutes personnes doivent saisir l'Autorité Nationale Compétente pour tout recours devant les juridictions et/ou exercer les droits reconnus à la partie civile en ce qui concerne les faits constituant une infraction relevant de la présente loi et portant un préjudice direct ou indirect aux intérêts collectifs ou individuels.

\section{TITRE VI DISPOSITIONS FINALES}

Article 111 : Les modalités d'application des dispositions de la présente loi feront l'objet de décrets.

Article 112 : La présente loi abroge toutes les dispositions antérieures contraires.

Article 113 : La présente loi sera enregistrée et publiée au Journal Officiel de la République de Côte d'Ivoire et exécutée comme loi de l'État.

Fait à Abidjan, le 3 octobre 1996 



\section{SUMMARY}

Preventive and curative fight against oil spills through International Maritime Law is an undeniable fact nowadays. The law system of prevention of oil spills regulates the construction of ships and emissions of hydrocarbons. It establishes the double hull principle and the requirement of on shore reception facilities. At the regional level, precisely in America and Europe, the emphasis is put on the fight against substandard ships and the prohibition of such ships. Concerning polluting discharges of oil, MARPOL 73/78 prohibits them and entrusts contracting States to repress violations to its pertinent provisions. As for the STCW 1995, it focuses on the safety of the ship as to terms of control and training of crew.

Curative international legal instruments dealing with oil spills, particularly those set at the African, European and U.S. level reveal themselves under operational measures and compensation rules for victims of oil spills. Concerning fight against oil spills, International Law grants coastal states and flag states competence to intervene against marine pollution that occurs in their internal waters, territorial sea and their Economic Exclusive Zone (EEZ).

Rules of compensation have evolved favourably to victims. This evolution is perceivable through the institution of a strict liability of the polluting ship owner. In addition, the Supplementary Convention of 2003 expands the base of compensable damage and enhance substantially the compensation amounts awarded to oil spills victims. Compensation of oil spills victims is guaranteed by the principle of the channelling of liability to the shipowner and the institution of a compulsory insurance. Finally, victims take advantage of the disqualification, under certain circumstances, to capping and exemption from liability of the shipowner.

However, the current legislative effort is thwarted by the persistence of obstacles to the effectiveness of International Maritime Law. Deficiencies are perceivable at the prevention of marine pollution level, as well as operational measures against oil spills. The difficulties in applying international legal instruments manifest themselves in Africa by the lack of integrated emergency response plans against marine pollution. Côte d'Ivoire, particularly the Plan Pollumar, suffers from a lack of material and financial resources that would permit to fight efficiently against marine pollution. In addition, repressive rules against marine pollution are ineffective due to the lack of appropriate means to detect acts of pollution.

In the analysis, the rules of compensation for oil spills victims contain shortcomings. The indemnification procedure is characterized by choosing exclusively judicial settlement of disputes arising among victims and shipowner. Compensation rules are sufficiently underdeterrent against polluters in comparison with classic rules of evidence of oil pollution damages and the causal link between these damages and the polluter ship activity. It is obvious that International Maritime Law implicitly encourages acts of pollution by establishing systems of capping and exemption of the shipowner liability. This regime is likely to hinder a satisfactory compensation of oil spills victims. 



\section{CURRICULUM VITAE}

Date and place of birth: July 20th, 1971 in Divo (Republic of Côte d'Ivoire).

Pre-university education completed in September 1990 with the obtainment of the Bachelor Degree at the Charles de Gaulle Grammar School, in Bouaké (Republic of Côte d'Ivoire).

Degree: Master Degree in Private Law obtained in November 2004 at the University of Cocody (Republic of Côte d'Ivoire; West Africa) ${ }^{688}$.

Professional practice after completion of the Master Degree (essentially in private universities):

- Teaching of Private Law

Tutoring ${ }^{69}$ (TD) in various Law Faculties, precisely in :

- the Faculty of Politics, Law and Administrative Sciences of the University of Cocody (Abidjan) (2004-2008);

- the Law Faculty of the West Africa Catholic University (Abidjan) (2005-2008);

- the Law Faculty of the United Methodist University - Côte d'Ivoire (2010 till now);

- Lecturer in Business Law at the British Institute of Management and Trade (Abidjan);

- Lecturer in Business Law at the INSTEC (Abidjan);

- Consultant at the International Counsel and Strategy ${ }^{690}$ (CSI) School in Abidjan.

\section{Company Activities}

Associate in a Law office in Abidjan;

Director of studies at the 'ESIAB' institute ${ }^{691}$ in Abidjan;

Legal Counsel to the "African Development Fund" (Fadev) in Abidjan;

Counseling and Legal Assistance in an Audit and Consulting firm, named ACA in Abidjan $^{692}$.

\footnotetext{
688 With an average of 12 out of 20 (third-class honours).

689 In French, these courses are named 'Travaux dirigés'.

${ }^{690}$ In french : Conseil et Stratégie Internationale (CSI).

691 A Graduate School of International Insurance and Banking.

692 ACA : Audit et Conseil en Afrique.
} 